\title{
Fleischmann,
}

Die Descendenztheorie 


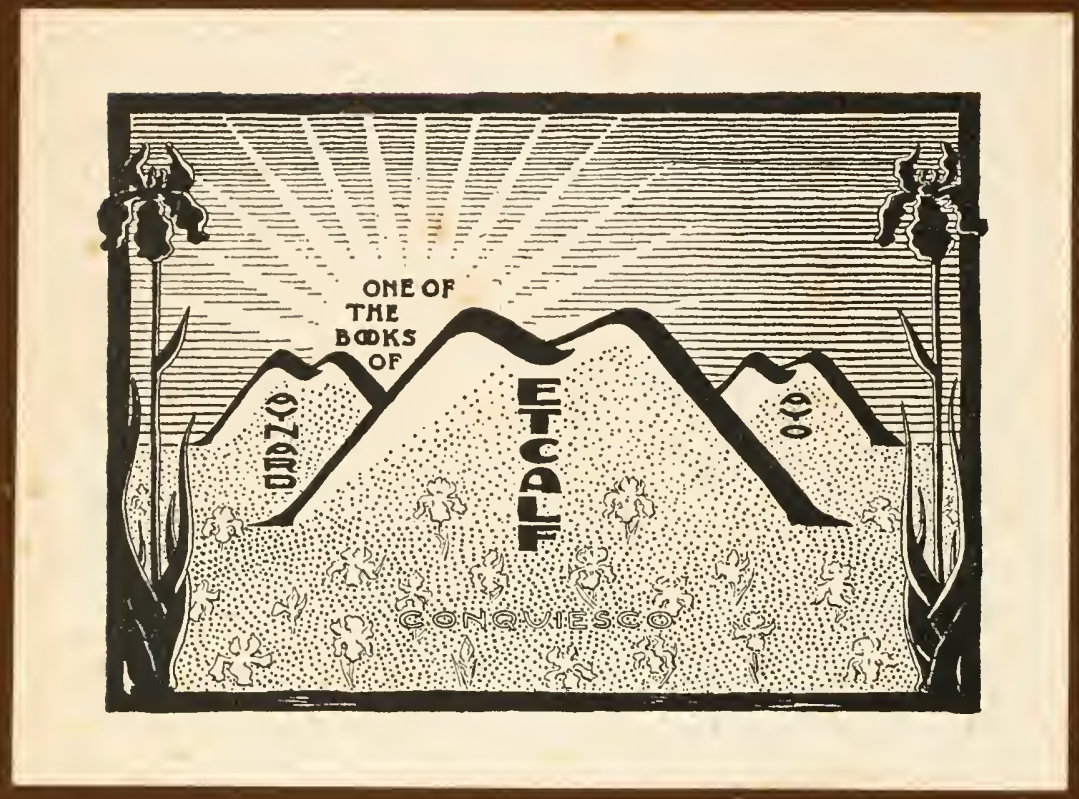




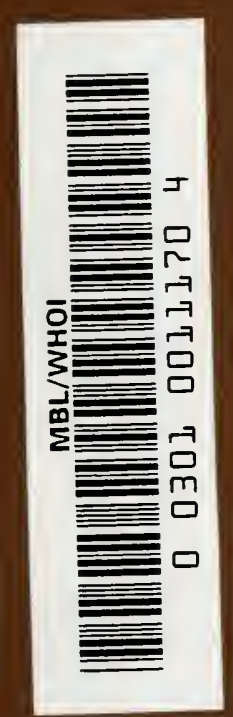





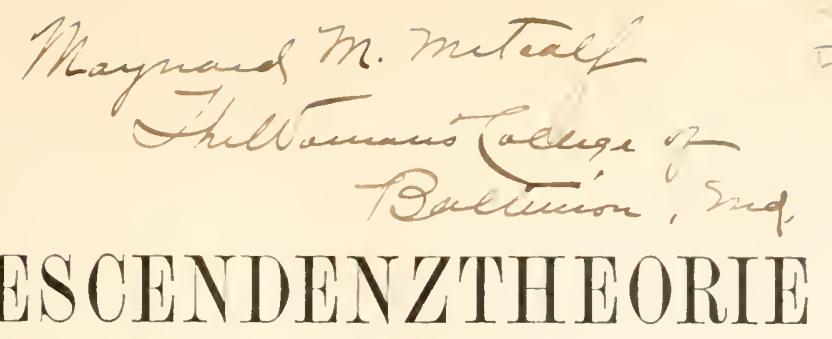

\title{
GEIELTERSTÄNDLICHE TORLESLYGEN
}

ÜBER DEN AUF- IND NIEDERGANG EINER NATURWISSENSCHAFTLICHEX HYPOTHESE

\section{GEHALTEN VOR}

STUDIERENDEN ALLER FAKULTÄTEN

$$
\text { rox }
$$

\section{Dr. ALBERT FLEISCHMANN}

O. Ö. PROFESSOR DER ZOOLOGIE UND VERGLEICHEXDEN ANATOMIE LN ERLANGEN

\author{
MIT 124 TEXTABBILDUNGEN
}

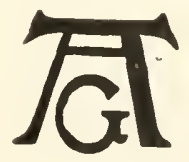

LEIPZIG

TERLAG VON ARTHUR GEORGI 
Druck von C. Grumbach in Leipzig. 


\section{Torwort.}

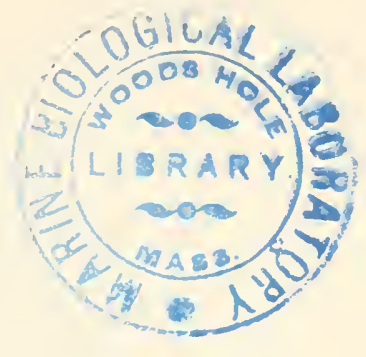

Vor Jahresfrist habe ich vor einem größeren Hörerkreise einen Cyklus von Vorlesungen iiber den gegenwärtigen Stand der Descendenztheorie gehalten. Von verschiedenen Seiten aufgefordert, lasse ich dieselben im Druck erscheinen und hoffe so für meinen Teil auch litterarisch beizutragen, dass die falschen Ansichten ron dem wissenschaftlichen Werte dieser Theorie zerstört werden. Ohnehin sind die sachlichen und logischen Gründe, welche Einige der Jüngeren unter den Zoologen bestimmen, die Richtigkeit der verführerischen Lehre zu bezweifeln, seit längerem nicht mehr in zusammenfassender Form vorgeführt worden. Mögen diese Vorlesungen die Lücke ausfüllen und die Sicherheit eines Standpunktes erweisen, welchen man bisher nur mit Achselzucken zu betrachten sich berechtigt fühlte!

Das Anrecht auf eine Meinungsäußerung in dieser Frage glaube ich mir persönlich um so mehr zusprechen zu dürfen, als ich lange Jahre zu den „begeisterten Jüngern" der Entwickelungslehre zählte und eine "Reihe von Arbeiten über Entwickelungsgeschichte geschrieben habe, die ganz auf dem Boden der Descendenztheorio stehen."1) Allein je mehr ich mich in die vermeintlichen Beweisgründe derselben vertiefte und durch Spezialuntersuchungen positive Anhaltspunkte für die Stammesverwandtschaft der Tiere zu gewinuen suchte, um so klarer stellte sich mir die Erkenntnis heraus, dass jene Theorie eben doch mehr nur ein bestrickender, Ergebnisse und Aufklärung vortäuschender Roman sei, als eine auf positiven Grundlagen aufgebaute Lehre.

Die Wandlung meiner Ansicht, welche ich zuerst durch eine öffentliche Vorlesung im Winter 1891/92 bekannte und später in meinem Lehrbuche der Zoologie ${ }^{2}$ ) vertrat, hat bei Vielen im descendenz-theoretischen Lager Staunen und Unwillen hervorgerufen. Insbesondere hat E. Haeckel meine Stellungnahme verdonnert und zugleich mit folgenden Sätzen schmählichen Verdacht auf mich zu lenken versucht $\left.{ }^{3}\right)$ :

1) E. Haeckel, Jenaische Zeitschrift. 1898. Bd. 31. S. 470.

2) Wiesbaden, C. W. Kreidel, 1898.

3) E. Haeckel, Aufsteigende und absteigende Zoologie. Jenaische Zeitschrift 1898. Bd, 31. Seite 470 . 
„Dr. Fleischmann war spezieller Schiiler und Assistent des ausgezeichneten Zoologen Selenka und vertrat seine Stelle in Erlangen mehrere Jahre wiihrend dessen ausgedehnten Reisen; nachdem Selenka seine Professur vor zwei Jahren niedergelegt hatte, scheint Fleischmann jetzt definitiv zu seinem Nachfolger bestimmt zu sein. Tielleicht steht die inzwischen erfolgte, Bekehrung' damit in ur'sächlichem Zusammenhang? Jedenfalls würde dann der dringende, noch im Vorjahre ausgesprochene Herzenswunsch des bayrischen Landtags erfüllt, dass die Naturwissenschaft endlich umkehre, und dass man als ihre Vertreter keine ,Darwinisten' mehr anstelle. Da an allen anderen Universitïten die Entwickelungslehre für Zoologie wie fiir Botanik die Grundlage bildet, so wird dann das rechtgläubige Erlangen um so strahlender als kindliche Vertreterin des naiven "Schöpfungsglaubens' in dieser Wissenschaft glänzen, unbefleckt von skeptischer Spekulation und kausaler Erkenntnis."

Woher nahm der Mann, dem meine Persönlichkeit völlig unbekannt ist, das Recht, die Reinheit meines wissenschaftlichen Urteils zu bezweifeln? Doch wohl nur aus der Verranntheit in den Glauben an die allein selig machende Kraft seiner theoretischen Dogmen, in der er sich zu sagen erlaubt, wer hier nicht folge, den könnten bloß äußere, unlautere Gründe zurückhalten. Dass es aber Leute giebt, welche deshalb nicht folgen, weil sie kritischer und besonnener sind als andere und weil sie die lediglich der iiberreizten Phantasie entsprungenen Sätze wohl unterscheiden von wissenschaftlich erwiesenen Lehren, scheint E. Haeckel weniger fasslich.

Wenn ich der Darwin-Haeckel'schen Hypothese über die Stammesverwandtschaft und die Entstehung der Tierarten nicht beipflichte, will ich nicht das gerade Gegenteil derselben lehren. Meiu Ziel ist kein anderes als festzulegen, dass wir die Frage als jenseits des Gebietes exakter Analyse stehend zu erachten und die Unzulässigkeit der stammesgeschichtlichen Hypothese für jedermann offenkundig zu halten haben. Der Naturforscher kann exakt bloß über diejenigen Organismen und Erscheinungen reden, welche er wirklich beobachtet. Die Individuen der jetzt lebenden, die Reste der verstorbenen und fossilen Tierarten bilden für den Zoologen Quelle und Objekt der wissenschaftlichen Arbeit. Dasselbe ist als gegeben hinzunehmen und kann ebenso wenig genetisch erklärt werden, als der Physiker die Entstehung der mechanischen Gesetze und der Chemiker die Bildung der Elemente erklären will. Sobald der Naturforscher von längst rerflossenen Geschehnissen, wie der Ent- 
stehung der Tierarten spricht, denen weder er noch ein anderer Augenzeuge beigewohnt hat, verlässt er eigentlich sein Fachgebiet. Damit soll die Reflexion über solche Probleme keineswegs als unberechtigt bezeichnet werden; der Menschengeist wird fort und fort uiber die Grenzen der greifbaren und sichtbaren Wirklichkeit hinaus drängen und der Lösung der Welträtsel durch Hypotbesen näher zu kommen suchen. Aber im Gegensatze zur modernen Überschätzung der Descendenzhypothese will ich laut davor warnen, dieselbe als gesicherte Voraussetzung weiterer wissenschaftlicher Arbeit anzusehen, damit nicht länger noch aus der falschen Prämisse gänzlich unhaltbare Schlïsse abgeleitet werden.

Der Vorwurf Haeckel's, ich sei ... rom krassen Darwinistischen Unglauben zum frommen Glauben an die unabhängige Erschaffung der einzelnen unveränderten Arten bekehrt worden", berührt mich nicht. Er ist ein dialektischer Kniff zur Bekämpfung eines Gegners, den sachlich zu widerlegen man sich die Mühe sparen möchte, und ungehörig in der Diskussion wissenschaftlich gerechter Männer, welche die Stichhaltigkeit ihrer Meinung nur nach dem Gewicht der sachlichen Grïnde werden erproben wollen.

Eine große Gefahr meines Widerspruches sieht Haeckel darin, dass „alle Gegner unserer modernen Entwickelungslehre - vor allem die orthodoxen Theologen und die teleologischen Philosophen mein Lehrbuch als eine gründliche Widerlegung der Darwin'schen Irrlehren begrüßen würden". Haeckel's schiefe Auffassung der Streitpunkte (rergl. S. 34-37) tritt in diesem Satze klar zu Tage. Er hat sich immer so geberdet, als sei die Billigung der Descendeuztheorie ein untrïgliches Zeichen liberaler Gesinnung und hat die Tritik seines Idols besonders wegen des Frohlockens verabscheut, mit relchem seine politischen Gegner die sachliche Opposition betrachten werden. Da das gleiche Bedenken auch ron anderen Anhängern der stammesgeschichtlichen Schule geteilt wird, erkläre ich auf das bestimmteste, dass ich die Berechtigung des Entwickelungsgedankens lediglich auf dem sachlichen Gebiete meines Faches geprüft habe, unbekümmert um alle Konsequenzen. Nach meiner Überzeugung hat der Fachmann, besonders derjenige, dem die — Gott sei Dank noch unabhängige Stellung des Universitïtsprofessors beschieden ist, die moralische Pflicht, das Resultat seines Nachdenkens ohne Rücksicht auf jede außerwissenschaftliche Folgerung darzulegen. Als der geschworone Zeuge ehrlichen Strebens nach Erkenntnis wird er ron keiner Erwägung berührt, welche Konsequenzen für religiöse, politische, soziale Verhältnisse daraus gezogen werden möchten. Frei ron jeglichem Parteiinteresse spreche ich auf den folgenden Bogen 
aus, was ernstlich und objektiv betriebene Studien mir als sicheres Ergebnis erscheinen lassen.

Soweit es für einen Kreis nicht fachmännisch geschulter $\mathrm{Zu}$ hörer möglich ist, habe ich in meinen Vorlesungen die Beweismittel der Descendenztheorie, welche sich auf die Ergebnisse der vergleichenden Anatomie, Paläontologie und Entwicklungsgeschichte stiitzen, einer kritischen Betrachtung unterzogen und war mir stets bewusst, dass die Darstellung mehr eine Skizze bleiben werde und nicht so eingehend sein diirfe, als ich es selbst wünschte. Erschöpfende Ausführlichkeit kann bei Vorlesungen vor einer grösseren Schar eben niemals erreicht werden, weil in der kurzen Zeit, welche der Laie für die Beschäftigung mit einem fremden Wissensgebiet aufwenden will, die liebevoll ins einzelne dringende Arbeit des Fachgelehrten nicht zu leisten ist. Ich hoffe aber durch die Besprechung ausgewählter Probleme der Stammesgeschichte die falsche popularisierende Weise vermieden zu haben, welche die Schwierigkeiten einer wissenschaftlichen Frage absichtlich übergeht. Auch bei der nachträglichen Redaktion leitete mich das bestimmte Verlangen, dass der Leser meine ohne Aufwand eines großen, gelehrten Apparates einfach stilisierten Ausführungen wirklich nachdenke.

Wenn ich vielfach Ausschnitte aus den Abhandlungen der Fachgelehrten, gewissermaßen offizielle Aktenstïcke der wissenschaftlichen Diskussion eingefügt habe, welche dem Leser einen Einblick in die Ratlosigkeit der ganzen stammesgeschichtlichen Schule gestatten, so geschah es, um dem Vorwurfe zu begegnen, als plagten mich allein unter allen Fachgenossen die skeptischen Zweifel an der herrschenden Modetheorie.

Das Stenogramm hat wenig redaktionelle Änderungen für den Druck erfahren, weil ich das in der Ursprïnglichkeit der freien Rede liegende persönliche Moment nicht verwischen wollte. Nur manche Abschnitte, die an der Hand der natïrlichen Objekte leicht ausführlich dargestellt werden können, während der gedruckte Bericht wegen des niemals auszugleichenden Mangels von Demonstrationspräparaten große Weitschweifigkeit erheischt, sind mit Rücksicht auf den Umfang des Buches stark gekiurzt worden.

Mein Lehrer und väterlicher Freund Prof. E. Selenka hat mir die Benutzung der Clichés seines im gleichen Verlage erschienenen zoologischen Taschenbuches in liebenswürdiger Weise gestattet. Ihm sei auch an dieser Stelle warmer Dank gesagt.

Erlangen, 18. Oktober 1900.

\section{A. Fleischmann.}




\section{Inhalt.}

Erstes Kapitel.

Einleitung

Zweites Kapitel.

Die Typen des Tierıeiches

Drittes Kapitel.

Der Bauplan der Gliedmaßen

Viertes Kapitel.

Fingerhand and Fischflosse

Fünftes Kapitel.

Das "Paradepferd" der Descendenztheorie

Sechstes Kapitel.

Die Stammesgeschichte der Vögel. Der Urgreifrogel . . . . . . . 88

Siebentes Kapitel.

Die Wurzeln des Säugetierstammes 106

Achtes $\mathrm{K}$ apitel.

Die Entstehung der lungenatmenden Wirbeltiere

Neuntes Kapitel.

Die Stammesgeschichte der Arthropoden . . . . . . . . . . 132

Zehntes Kapitel.

Die palaeontologische Entwicklung einer Süßwasserschnecke . . . . . 147

Elftes Kapitel.

Das eigentliche phylogenetische Problem der Mollusken. . . . . . 171

$\mathrm{Zwölftes} \mathrm{Kapitel.}$

Die Entstehung der Stachelhäuter . . . . . . . . . . . . 182

Dreizehntes Kapitel.

Das Licht der Entwicklungsgeschichte . . . . . . . . . . . 199

Vierzehntes Kapitel.

Die Ausnahmen des biogenetischen Grundgesetzes . . . . . . . . 217

Fünfzehntes Kapitel.

Der Zusammenbruch der Haeckelschen Doctrin . .

Sechzehntes Kapitel.

Der Entwicklungsgedanke und die logischen Gesetze . . . . . . . 253 



\section{Erstes Kapitel.}

\section{Einleitung.}

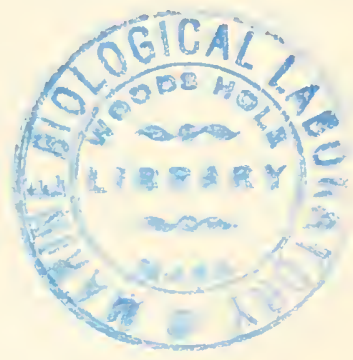

Falsche Meinungen herrschen iiber den Wert der Descendenztheorie, die auf zoologischer Basis vor vierzig Jahren neu begriindet wurde und vielen Menschen so großartig erschien, dass sie sehr rasch eine Wirkung auf andere Wissenschaften ausübte, in alle Schichten der Bevölkerung eindrang und dem letzten Drittel des scheidenden Jahrhunderts den Titel der Darwin'schen Epoche der Kulturgeschichte verlieh. Es bedarf heutzutage keiner umständlichen Beweisfïhrung, um die Herrschaft dieser Lehre zu erweisen; denn jeder von Ihnen hat es genugsam erfahren, dass überall das Bestreben herrscht, wissenschaftliche Lehrmeinungen oder Ansichten des Tageslebens durch den Hinweis auf die Werke Darwin's und seiner Schule zu begriinden.

In der That ist der Zauber, den die moderne Abstammungslehre auf jedes begeisterungsfähige Menschenkind ausübt, unbeschreiblich stark. Keine andere wissenschaftliche $\mathrm{H}_{y}$ pothese vermag in gleicher Weise alle Fäden unseres Denkens zu umfangen und uns in ihren Ideenkreis zu bannen. Das Problem von der längst verrauschten Urgeschichte unseres eigenen Geschlechtes, die Frage, wie der Mensch auf Erden entstanden, aus welchen Uranfängen er sich zum Glanze der Kultur des neunzehnten Jahrhunderts emporgeschwungen hat, taucht irgend einmal am Gedankenhorizonte jedes denkenden Mannes auf und heischt gebieterisch den Lösungsversuch. Eine bestimmte von naturwissenschaftlicher Seite erteilte Antwort wird umso gläubiger hingenommen, je mehr sie verwandte Erinnerungen aus der Kinderzeit wachruft, wo wir alle dem Reize einer längst entschwundenen Märchenwelt unterlagen und die Pracht des goldenen Zeitalters der Nenschheit fast greifbar vor unseren Augen sahen. Vollständig kann sich keiner dem Bannkreise dieser Vorstellungen entziehen; mag auch der gereifte Mann lächelnd auf die kindlichen Legenden herabblicken, die Vorliebe für sagenhafte Erzählungen haftet ihm trotzdem an. Gerade in unseren Tagen, die so gerne als das aufgeklärte nüchterne Zeitalter gepriesen werden, hat die 
Sagenwelt ihr Recht auf dem naturwissenschaftlichen Gebiete behauptet. Sie können es in vielen wissenschaftlichen Werken lesen: die höchste Aufgabe menschlicher Forschung sei die Frage nach dem, was wir nicht wissen können, nämlich nach der Vergangenheit der Mensehen- und Tiergeschlechter jenseits der geschichtlichen Morgenröte; die Frage, wie sind die organischen Wesen geworden, was sie sind, miisse den denkenden Geist mohr beschäftigen, als die Kenntnisnahme der Gegenwart.

Die moderne, von wissenschaftlichen Forschern vertretene Antwort klingt an uralte Gedankengänge an und zeigt dadurch, wie tief im menschlichen Geiste das Sehnen nach unmöglicher Erkenntnis warzelt. Auf Grund von Naturbeobachtungen, welchen die Unterstiitzung durch die vortrefflichen modernen Instrumente mangelte, hatten sich griechische Philosophen eine Antwort zurecht gelegt, die darin mit der heute geltenden Meinung übereinstimmt, dass sie von der Annahme ausgeht, die friiheren Zustände des Menschen und der Tiere auf Erden seien total andere gewesen, als die modernen, uns vertrauten Verhältnisse.

Der kühne Denker des Altertumes, Anaximandros aus Nilet, welcher einen von uns nicht genaner zu bestimmenden Stoff das Unendliche genannt - als den Urgrund aller Dinge bezeichnete, suchte die Entstehung der Tiere in folgender Weise zu erklären. Zuerst, meinte er, seien die Tiere im Wasser, welches die ganze Erdkugel umgeben habe, ent tanden. Sie seien mit einer stacheligen Rinde umgeben gewesen. Mit fortschreitendem Alter seien sie anf das Land gestiegen und hätten, indem die Rinde geborsten sei, in kurzer Zeit ihre Lebensweise geändert. Also ist die Umwandlung der Seetiere in Landbewohner offenbar gelehrt und mit höchst naiver Logik als sicher bewiesen hingestellt worden. Ebenso sind die Menschen nach seiner Ansicht aus andersartigen Tieren entstanden. Als Beweis führt Anaximander an, dass die Tiere sich rasch selbst ernähren, während der Mensch einer langen Wartung bedürfe, so dass er wohl nicht, wenn er am Anfange so hilflos beschaffen gewesen wäre, wie er jetzt geboren wird, sich hätte erhalten können. Die ersten Menschen entstanden in Fischen, wurden ernährt, und nachdem sie die Fühigkeit, sich selbst zu helfen, erworben hatten, wurden sie ausgeworfen und lebten auf dem Lande, anfangs selbst noch ähnlich einem Fische. Der Fisch wurde auch als Speise verboten, weil er zugleich Vater und Mutter der Menschen sei.

Solche in höchst naiver Form ausgesprochenen Ansichten der Alten, deren Vertreter ich jetzt nicht namhaft machen will, haben merkwürdigerweise vor unseren Augen einen grossartigen Triumph gefeiert, nachdem sie lange Jahrhunderte durch die in den heiligen 
Religionsschriften der Juden enthaltene Schöpfungsgeschichte verdrängt gewesen waren, welche ebenso naiv dic Beständigkeit der heute vorhandenen Tier- und Pflanzenarten rom Weltenanfang an berichtete und für die gesamte Lebewelt einen mit den wirklichen VerhäItnissen gänzlich unvereinbaren paradiesischen Friedenszustand vor dem Sündenfalle lehrte. Da die unerhörte Machtsteigerung der christlichen Lehre den öffentlichen $Z_{\text {wreifel an dem mosaischen }}$ Berichte lange untersagte, regte sich kein Widerspruch der gelehrten Kreise, bis durch die experimentelle Reform der Naturbeobachtung im 17. und 18. Jahrhundert der Autoritätsglaube vernichtet und die kritische Methode in der Naturwissenschaft eingebiurgert wurde.

Seit dem Jahre 1756 lassen sich hie und da einzelne Wortführer hören, welche die Ideen der griechischen Philosophen, sicher ohne Kenntnis derselben und ohne das klare Bewusstsein, in alten Gedankenfährten zu wandeln, ron neuem rerkünden. Sie fanden jedoch unter den Fachgenossen keinen Anklang, weil das Hauptinteresse der damaligen Zoologen auf die von Linné rorgezeichneten systematischen Arbeiten gerichtet war. Mehr als hundert Jahre (1748-1859) herrschte nämlich die Ansicht, dass die wichtigste Aufgabe des Zoologen darin bestehe, die lebenden Tiere zu sammeln, ihr Aussehen möglichst genau zu beschreiben und nach richtig gewählten Merkmalen in die Gruppenbegriffe des Linnéschen Systemes einzuordnen. Über diesem wissenschaftlichen Arbeitsplane stand durch Linnés Autoritüt geschützt die mosaische Lehre von der Unveränderlichkeit der Tier- und Pflanzenarten.

Die einseitig klassifizicrende Richtung hatte in der ersten Hälfte unseres Jahrhunderts eine große Ode und Eintönigkeit der zoologischen Arbeit hervorgerufen, welche ans der Litteratur jener Zeit langweilig genug spricht. Nutzlose Streitigkeiten über eine befriedigende Einteilung der großen Tiergruppen und die richtige Reihenfolge der Ordnungen, Familien und Gattungen, unerfreuliche Diskussionen über die Bedeutung eines trennenden Merkmals, über den Geltungsbereich einer systematischen Art, über den Unterschied zwischen Arten und Varietäten u. a. beanspruchen darin einen großen Raum.

Da legte Charles Darwin durch sein berühmtes Buch: Die Entstehung der Arten durch natürliche Zuchtwahl im. Jahre 1859 erfolgreichen Protest ein, indem er die bisher blok als unterscheidende Merkmale betrachteten Eigenschaften der Tiere als Schriftspuren einer uralten, von der Natur selbst aufgezeichneten Urkunde behandelte, welche über die Stammesgeschichte oder wie man auch sagt: die Phylogenie der Organismen Aufklärung verbreiten könne. In den Augen der damaligen Professoren der Zoologie 
war sein Versuch ein unerhörter Frevel und die darauf folgende Erregung der wissenschaftlichen Meinung außerordentlich stark. Denn Darwin's Beginnen bedeutete die Kriegserklärung an zwei bisher kaum bezweifelte zoologische Dogmen: 1. an das Dogma der Unveränderlichkeit der Arten; 2. an die Typentheorie.

Die letytere, von dem französischen Anatomen Cuvier begründet, lehrte, dass es im Tierreich vier sogenannte T'ypen gebe, vier große Hauptzweige der Körpergestaltung, deren Glieder nach einem gemeinsamen Bauplan modelliert zu sein scheinen, also formverwandt sind und nur durch leichte, auf die Entwickelung oder das Hinzutreten einzelner Teile gegründete Modifikationen sich unterscheiden, ohne dass an der Wesenheit des Planes etwas geändert ist, während sie von anderen Typen grundsätzlich durch unausfüllbare Spalten getrennt seien. Als solche Typen hatte Cuvier aufgestellt:

1. Die Wirbeltiere, d. h. die Fische, Amphibien, Reptilien, Vögel und Säugetiere;

2. die Weichtiere, Muscheln, Schnecken und Tintenfische;

3. die Gliedertiere, Insekten, Spinnen, Krebse, Gliederwïrmer.

4. Radiärtiere, Stachelhäuter, Eingeweidewürmer, Medusen, Polypen, Infusorien.

Darwin dagegen hehauptete in Anlehnung an den französischen Zoologen Lamark, die Organisationstypen seien nicht so scharf getrennt, wie Cuvier angenommen habe, sie seien vielmehr durch Umbildung aus einauder hervorgegangen, ihre Vertreter seien durch Blutsbande verkniipft, das ganze Tierreich selbst sei ein einheitlicher Lebensbaum, den er mit poetischem Schwunge schilderte ${ }^{1}$ ): ,Die Verwandtsehaften aller Wesen einer Klasse sind manchmal in Form eines großen Baumes dargestellt worden. Ich glaube, dieses Bild entspricht sehr der Wahrheit. Die grïnen und kmospenden Zweige stellen die jetzigen Arten und die in jedem vorangehenden Jahre entstandenen die lange Aufeinanderfolge erloschener Arten dar. In jeder Wachstumsperiode haben alle wachsenden Zweige nach allen Seiten hin anszutreiben und die umgebenden Zweige und Äste zn überwachsen und zu unterdrücken gestrebt. Die großen, in Zweige geteilten Äste waren zur Zeit, wo der Stamm noch jung war, selbst knospende Zweige gewesen. Von den vielen Zweigen, welche munter gediehen, als der Baum noch ein bloßer Busch war,

1) Ch. Darwin, Die Entstehung der Arten durch natürliche Zuchtwahl. Stuttgart 1860. p. 140. 
leben nur noch zwei oder drei, die jetzt als mächtige Aste alle anderen Verzweigungen abgeben, und so haben von den Arten, welche in lïngst rergangenen Zeiten lebten, nur sehr wenige noch lebende und abgeänderte Nachkommen. Ton der ersten Entwickelung eines Baumes an ist mancher Ast und mancher Zweig rerdort und verschwunden, und diese verlorenen Äste ron verschiedener Größe mögen jene ganzen Ordnungen, Familien und Gattungen vorstellen, welche, nur im fossilen Zustande bekannt, keine lebenden Vertreter mehr haben. Wie wir hier und da einen vereinzelten dïnnen $Z$ weig ans einer Gabelteilung tief unten am Stamme herrorkommen sehen, welcher durch Zufall begünstigt an seiner Spitze noch fortlebt, so sehen wir zuweilen ein Tier, wie das Schnabeltier, das durch seine Verwandtschaften gewissermaßen zwei große Zweige der belebten Welt miteinander rerbindet. Wie Knospen durch Wachstum neue Knospen herrorbringen und wie auch diese wieder, wenn sie kräftig sind, nach allen Seiten ausragen und viele schwächere Zweige überwachsen, so ist es, wie ich glaube, durch Zeugung mit dem großen Baume des Lebens ergangen, der mit seinen toten und gebrochenen Ästen die Erdrinde erfiillt und mit seinen herrlichen und sich noch immer weiter teilenden Verzweigungen ihre Oberfläche bekleidet."

Durch diesen Ausschnitt wollte ich Sie selbst die verführerische Wirkung erfahren lassen, welche den Schriften Darwin's anhaftet und eine ungeheure Zahl von Gelehrten in den Bannkreis der Abstammungslehre gezogen hat. Wäre Darwin selbstbewusst mit bestinmt präcisierten Behauptungen anfgetreten, etwa wie Oken sein naturphilosophisches System entwickelt hat, so hätte er sicher den grossen Einfluss auf seine Zeitgenossen nicht erlangt. Aber seine bescheidene Ausdrucksweise, die oft bis aufs Unerträgliche gesteigerte Manier, die eigene Ansicht durch eine Masse von gegenteiligen Einwänden zu bekämpfen, der Widerlegung der Gegengriinde einen großen Raum zu gönnen und schließlich der ursprïnglich ausgesprochenen Meinung beizuptlichten, regte die Leser zur Vertiefung in Einzelfragen und damit zu nener wissenschaftlicher Arbeit an.

Toll Begeisterung wandte sich eine große Zahl ron jungen und tiichtigen Forschern der Aufgabe zu, durch das rergleichende Studium der anatomischen, entwickelungsgeschichtlichen und biologischen Thatsachen die Beweise für die neue Auffassung zu sichten. Während früher nur die trennenden Momente betont worden waren, 
strebte jetzt jeder die mnterscheidenden Merkmale zwischen den weiten Tiertypen und den engeren systematischen Gruppen, z. B. zwischen Wirbeltieren und Gliederwiirmern, zwischen Vögeln und Eidechsen, zwischen dem Menschen und den Affen ihres tremnenden Wertes zu entkleiden und die zwischen diesen Gruppen bestehenden Ähnlichkeiten als besonders bedeutungsvoll zu hesprechen.

So begann die sachliche Prüfung der Darwin'schen Spekulation innerhalb des exakten Gebietes der zoologischen Fachwissenschaft und zwar nach zweierlei Richtungen: einerseits wurde die Frage untersucht, ob eine Entwicklung iiberhaupt stattgefunden habe, also ob eine wirkliche Blutsverwandtschaft zwischen den systematischen Gruppen des Tierreiches besteht, andererseits nach den Ursachen geforseht, welche für die züchtende Umbildung maßgebend gewesen sein künnten.

Ich werde in den folgenden Torlesungen nur die erste Frage behandeln, weil die Zuchtwahltheorie unter den Gebildeten niemals so großes Interesse, als die Abstammungslehre erweckt hat, und weil sie in der ursprünglichen Fassung hente von verhältnismäßig wenigen Gelehrten vertreten wird. Darwin's Erkläruugsversuch, wie durch Zuchtwahl die Umbildung der Tierarten möglich gewesen sein könne, hat bereits die Annahme zur Voraussetzung, dass alle Lebewesen blutsverwandt seien, und dass die höher Organisierten ron niederen und einfacher gebanten abstammen. Da diese Voranssetzung mir iiberhaupt nicht hinreichend begrindet erscheint, will ich die Fundamente der Abstammungslehre allein besprechen.

Zwischen den Gelehrten, welche sich seit vierzig Jahren abmühen, eine bestimmte Vorstellung über Vorgänge aus längst entschwundener '/eit zu gewinnen, machten sich bald lebhafte Meinungsverschiedenheiten geltend und spalteten das Gros der Naturforscher in zwei Parteien. Die Freunde s) der Abstammungslehre waren ïberzeugt, dass „die Grundlage der Dar'win'schen Lehre, die Descendenzhypothese, die einzige heutzutage berechtigte wissenschaftliche Annahme iiber die Entstehung der organischen Formen ist, dass demnach wissenschaftliche Diskussionen es nur noch mit der Darwin'schen Theorie selbst zu thun haben könnten, nicht aber mit deren Grundlage“. Die anderen dagegen wollten zuror schlagende Beweisgründe für die Blutsverwandtschaft der Tiere hören, ehe sie sich der. neu verkïndeten Lamark'schen Umwandlungslehre anschließen könnten. Diese Parteien sind bis heute bestehen geblieben, obgleich die Stärkezahl ihrer Mitglieder mannigfachen

1) Vergl. A. Weismann, Über die Berechtigung der Darwinschen Theorie. Akademischer Vortrag, gehalten am 8. Juli 1868 in der Aula der Universität Freiburg i. Br. Leipzig, W. Engelmann 1868. Torwort p. III, Zeile 11-15. 
Schwankungen unterworfen war. Wïhrend der Jahre 1860-1870 mochten wohl die Gegner der Lehre iiberwogen haben; dann änderte sich das Terhältnis zu Gunsten der Anhänger. Aber seit einem Jahrzehnte gewinnt es den Anschein, als sei die Zahl der direkt widersprechenden oder anch der gleichgiiltig gewordenen Gelehrten im Zunehmen begriffen. Es wäre jedoch vollkommen verkehrt, wollte man die Richtigkeit einer wissenschaftlichen Theorie schlechthin nach der Zahl ihrer Anhänger beurteilen; denn die Kulturgeschichte lehrt uns viele Beispiele kennen, dass ganze Generationen von gelehrten Männern Behauptungen für wahr gehalten und mit dem Aufgebote höchsten Scharfsinnes verteidigt haben, welche heute ein Laie als unrichtig verlacht.

Der Streit zwischen beiden Parteien ist mitunter außerordentlich heftig geworden und hat viele Feindschaft zwischen die Genossen gemeinsamer Arbeit getragen. AktenmäBig lassen sich freilich solche Torfälle schwer nachweisen, weil die kritischen Epitheta, welche wissenschaftliche Forscher den Vertretern einer anderen Ansicht zuerkennen, gliicklicherweise selten durch die Buchdruckerkunst der Nachwelt iiberliefert werden. Damit Sie selbst ermessen können, wie hochgradig die Erregung durch die theoretische Meinungsverschiedenheit gesteigert wurde, will ich Ihnen ans einem Streite, der zwischen den Professoren E. Häckel in Jena, Carl Semper in Wiirzburg, V. Hensen in Kiel, W. His in Leipzig entbrannte, einige Scenen vorführen.

W. His und A. Goette hatten es gewagt, gegen Häckel's Auffassung der Entwickelungsgeschichte zu opponieren. Deshalb bedachte sie der Sachwalter ${ }^{1}$ ) der Entwickelungstheorie mit folgender Kritik :

"Wir wïrden diese unglaubliche Roheit physiologischer und morphologischer Torstellungen für unbegreiflich halten ( - besonders bei einem Anatomen ( $\mathrm{His}$ ), der die Torlesungen von Johannes Miiller, Robert Remak, Rudolf Virchow und Albert Kölliker gehört hat -) wenn wir sie uns nicht hinreichend durch dev beherrschenden Einfluss des „.hochrerehrten“ Carl Lu dwig (Professor der Physiologie in Leipzig) erklären könnten. Dieser "grosse Physiologe“, welchem Wilhelm His "Unsere Körperform" gewidmet hat, zeichnet sich bekanntlich ebenso sehr durch seine Technik in der Kunst des Experimentierens und durch sinnreiche Erfindung physiologischer Apparate, wie durch die naive Roheit seiner allgemeinen biologischen Anschaungen und durch

1) Häckel, Ziele und Wege der heutigen Eotwicklungsgeschichte. Jenaische Zeitschrift für Naturwissenschaften. 10. Bd. 1876 . p. 34, p. 45, p. 58, p. 71. 
seine sprichwörtliche Unbekanntschaft mit dem Gesamtgebiete der Morphologie ans." -

"Wenn His die Schriften Immanuel Kant's oder auch nur cinmal die induktive Logik von Stuart Mill gesehen hätte (was ihn überhaupt ror vielen Fehlern bewahrt haben würde), so würde er anch richtigere Ansichten über den Wert der Induktions- und Deduktionsschliisse besitzen. Da ihm jedoch das Terständnis für philosophische Verstandesoperationen iiberhaupt fehlt, so erscheint auch hieriiber eine weitere Auseinandersetzung ïberfliissig." -

Über Alexander Götte, Professor der Zoologie in Straßburg, der 1875 die „Entwickelungsgeschichte der Unke als Grundlage einer rergleichenden Morphologie der Wirbeltiere" herausgegeben hatte, fällt Häckel folgendes Urteil:

"Welcher bodenlose Unsinn, welche umbegreiflichen Widersprüche in den angeführten und vielen ähnlichen Sätzen angehäuft sind, brauche ich wohl kaum ausdrücklich hervorzuheben."

„Wenn wir freilich erwägen, dass die morphologische „Vergleichung" eine philosophische Verstandesoperation ist, die um so mehr Urteil, Vorsicht und allgemeine morphologische Bildung erfordert, je verwickelter die zu vergleichenden Objekte sind; und wenn wir uns dann wieder der oben mitgeteilten göttlichen Proben Götte'scher Philosophic erinnern, dann werden wir uns über keine "Vergleichung" desselben mehr wundern. In der That haben viele Vergleichungen von Götte einen ähnlichen Wert, wie der oben von mir angezogene Vergleich des Tiereies mit einem Knallbonbon."

„Hier versagt mir die Feder! Ich hoffe, dem Leser reißt mit mir der Faden der Geduld, und er stimmt mir bei, wenn ich erkläre, dass eine gleich anspruchsvolle und simnlose Anmaßung in der Wissenschaft unerhört ist und die härteste Züchtigung vor deren öffentlichem Forum verdient! Ein völlig unklarer und unreifer Handlanger der Wissenschaft, dem jedes tiefere Verständnis für deren Ziele und Wege abgeht, wagt es, den anerkannt größten Meister derselben (Carl Ernst von Baer), auf dessen Schultern wir alle stehen, darüber zu belehren, dass er seine eigenen wichtigsten, von ihm selbst erst festgestellten Grundbegriffe nicht verstehe, und dass sie eigentlich ihr Gegenteil bedenten!"

Da die Gegner der Descendenztheorie damals häufig Louis A gassiz als die erste Autorität auf dem Gebiete der Entwickelungsgeschichte anfïhrten und behaupteten, derselbe als ,gründlichster Kenner" dieser Wissenschaft habe die "große Irrlehre" Darwin's längst gründlich widerlegt, sah sich Häckel zu einer heftigen 
Polemik ${ }^{1}$ ) gegen den bereits verstorbenen Gelehrten veranlasst, aus der ich einige Stellen herausgreife:

„Einer ernsten Widerlegung werden die populär-naturwissenschaftlichen Schriften von Agassiz in den Fachlireisen der Naturforscher nicht für würdig gehalten. Aber außerhalb der Fachkreise erfrenen sie sich einer großen Anerkennung und einer hohen wenn auch natürlich rerständnislosen - Bewunderung. Wir wïrden das völlig Unhaltbare und Sinnlose derselben hier nicht besonders hervorheben, wenn nicht die orthodoxe Kirche in Agassiz einen vorzüglichen Bundesgenossen erkannt, sich seiner Ideen bemächtigt und sie mit Erfolg zu einen neuen Aufputz ihres theistischen Phrasengebäudes benutzt hätte. Die Wirkung dieser Charlatanerie ist nicht zu unterschätzen. Man lese blob die zahlreichen Nekrologe, in welchen Agassiz im vorigen Jahre (1874) nicht bloß als einer der größten Naturforscher seiner Zeit verherrlicht, sondern anch besonders darauf hingewiesen wurde, wie derselbe die gröliten Resultate der modernen Naturwissenschaft in den schönsten Einklang mit dem Wortlaut der Bibel zu bringen gewusst und als die wahre „Natürliche Schöpfungsgeschichte" diejenige des Moses nachgewiesen hat."

"Weit entfernt daron, meinen rerehrten Spezialkollegen Moses (dessen hohe Verdienste ich stets willig anerkannt habe) wegen dieser naturwissenschaftlichen Huldigung von Agassiz zu beneiden, möchte ich mir doch in geziemender Bescheidenheit die Vermutung gestatten, dass es letzterem mit jenen und älnnlichen Sätzen wohl niemals ernst gewesen ist. Ich wenigstens sehe iberall deutlich den Pferdefub des Mephisto unter dem schwarzen Priestertalir hervorschauen, in welchen sich der schlaue Agassiz mit so viel theatralischem Anstand und dekorativem Talent einzuhüllen verstelıt. Wer die zahlreichen Schriften ron Agassiz (insbesondere die theistisch-naturphilosophischen) näher kennt und wer mit den darin kundgegebenen frommen Ideen den bekannten Lebensgang des großen wissenschaftlichen Industrieritters, seine Vorliebe für das philanthropische Institut der Sklarerei etc. zusammenhält, kann sich der Überzeugung nicht verschließen, dass derselbe im Grunde ganz andere Anschauungen besaß, als es dem nicht eingeweihten Leser seiner Werke scheinen könnte."

„Es liegt vielleicht nahe, mich noch wider ein drittes Gegnerpaar zu wenden, welches unter den zahlreichen Feinden der heutigen Entwickelungsgeschichte in das Vordertreffen sich gedrängt hat, nämlich Albert Wigand und Adolf Bastian. Indessen ge- 
stche ich, dass ich weder lust und Muße finde, den unglaublichen und wirklich gehäuften Unsinn, den diese beiden Schriftsteller der Entwickelungsgeschichte in den Weg gelegt haben, fortzuräumon. Auch ist das dicke Buch von Albert Wigand "Der Darwinismus und die Naturforschung Newtons und Cuviers" (1874), sowie desselben Autor's "Genealogie der Urzellen" (1872) bereits von dem trefflichen, um die Förderung der Descendenztheorie hochverdienten Zoologen Gustav Jäger in Stuttgart gründlich analysiert und richtig gewïrdigt worden." "1)

Wir wollen nun eine andere Scene der damaligen Diskussion betrachten! In der ersten Auflage der natürlichen Schöpfungsgeschichte hatte Häckel ein und denselben Holzstock auf einer Seite (p. 248) dreimal neben einander abdrucken lassen und die vollkommen identischen Figuren als Embryo des Hundes, des Huhnes und der Schildkröte bezeichnet. $\mathrm{His}^{2}$ ) protestierte im Interesse der wissenschaftlichen Wahrheit gegen das sonderbare Verfahren und schloss seine Kritik mit den Worten:

„Es bleibt das Verfahren von Prof. Häckel ein leichtfertiges Spiel mit Thatsachen, geführlicher noch als das früher gerügte Spiel mit Worten. Letzteres fällt der Kritik jedes verständigen Denkers anheim, jenes vermag aber nur vom speziellen Fachmann durchschaut $\mathrm{zu}$ werden, und es ist um so weniger zu verantworten, da Hïckel sich wohl des Einflusses bewusst ist, den or auf weite Trieise auszuüben vermag."

,Ich selbst bin im Glauben aufgewachsen, dass unter allen Qualifikationen eines Naturforschers Zuverlässigkeit und unbedingte Achtung vor der thatsächlichen Wahrheit die einzige ist, welche nicht entbehrt werden kann. Auch heute noch bin ich der Ansicht, dass mit Wegfall dieser einen Qualifikation alle iibrigen, und sollten sie noch so glänzend sein, erbleichen. Mögen daher andere in Herm Häckel den thätigen und rücksichtslosen Parteiführer verehren, nach meinem Urteil hat er durch die Art seiner Kampfführung selbst auf das Recht verzichtet, im Krreise ernsthafter Forscher als Ebenbürtiger mitzuzählen."

Darauf erwiderte $\mathrm{Häckel}{ }^{3}$ ):

„Dieses vernichtende Urteil von His ist allerdings für mich fürchterlich! Nun, wenn ich aus dem Kreise ernsthafter Forscher durch diesen Rhadamanthys-Spruch ausgeschlossen bin, dann wird mir wohl nichts übrig bleiben, als der Übergang in das Lager der

1) 1. c. p. 90 .

2) W. His, Unsere Körperform nnd das physiologische Problem ihrer Entstehung. Leipzig 1874, p. 171.

3) 1. c. p. 39 . 
scherzhaften Forscher, und der Versuch, der Naturwissenschaft auf meine Weise mit Humor zu dienen! ,Ein jeder dient ihr auf besondere Weise!: Warum auch nicht? Kann der erusteste Forscher beim Nachdenken über die tiefsinnigen Theorien ron $\mathrm{His}$, die ich als Höllenlappen-, Briefcouvert-, Gummischlauch-Theorie etc. bezeichnet habe, ernst bleiben? Oder kann ein kenntnisreicher und urteilsfähiger Forscher ernst bleiben angesichts des erheiternden Unsinns, der jetzt tagtäglich unter der Firma ernster Wissenschaft zur Widerlegung der Entwickelungstheorie auf den Markt gebracht wird? Man lese nur den neuen „Schöpfungsplan“, den uns Louis A gassiz noch nach seinem Tode in einem kürzlich erschienenen, ron Giebel übersetzten und eingeführten Buche offenbart hat! Man lese das geistreiche neueste Werk ron Adolf Bastian über ,Schöpfung oder Entstehung", oder die halsbrechenden Evolutionen ron Michelis in seiner heiteren „Häckelogenie", oder den gehäuften Unsinn in dem dicken Buche von Wigand: „Der Darwinismus und die Naturforschung Newtons und Cuviers". Welche reiche Quelle der Erheiterung und der vergleichend-psychologischen Gemütsergötzung!:

An Häckel's Terhalten ïbte der verstorbene Professor der Zoologie in Würzburg K. Semper sehr scharfe Kritik:

..Dass aber Häckell) wagt, Hypothesen als feststehende bewiesene Sätze vorzuführen, ein System aus ihnen aufzubauen, macht sie zu Übelgebilden, die das wirklich durch ernste Arbeit der Wissenschaft gewonnene Gut verhïllen und damit diese letztere schädigen. Aber nicht genug, dass er Ihnen Hypothesen als wahre Lehrsätze hinstellt, die Gegner seiner sogenannten Theorien als Dualisten d. h. fiir ihn als Phantasten und Dogmatiker zu bezeichnen wagt, auch die Beobachtungsthatsachen, die seinem Gebäude zu Grunde liegen oder liegen sollen, kann der Zoologe nicht mehr als Thatsachen hinnehmen."

„Die größte Stärke einer ganzen Anzahl sogenannter Theorien Häckel's liegt fast durchweg nicht in dem logischen Bau, sondern in der dogmatischen Wiederholung und häufigen Betonung ihrer äußeren Anerkennung und ihrer wissenschaftlichen Fruchtbarkeit."

V. Hensen 2 ), Professor der Physiologie in Kiel sprach sich 1892 noch deutlicher aus:

„Es wird behauptet, daß die Ideen ron Lamark und Charles Darwin, namentlich in der Weise, wie sie Häckel geformt und ausgeführt hat, jetzt die wissenschaftliche, mit Studien

1) Carl Seinper, Der Häckelismus in der Zoologie. Hamburg 1876. p. 31, ก. 28 .

2) Victor Hensen, Die Planktonexpedition u. Häckel's Darwinismus. Kiel u. Leipzig 1892. p. 5. 
iiber die Organismen beschiiftigte Welt beherrschen. Ich weiß nicht, in wie holem Grade dies der Fall ist, ja ich möchte sogar solchem Anschein gegentiber einwenden, daß diese wissenschaftliche Welt ihrem innersten Wesen nach durch nichts beherrscht wird und durch nichts beherrscht werden kann. Soweit man an Hypothesen glaubt und auf sie schwört, hört man leider auf, wissenschaftlich zu sein und wenn das wirklich heute alle Forscher thäten, so stände in dieser Richtung die Wissenschaft still, oder richtiger gesagt, es existierte nur Rechtgläubigkeit, die Wissenschaft schliefe. Meines Wissens liegt die Sache aber nicht ganz so, es halten manche mir persönlich bekannte Forscher sich völlig gegenwärtig, dass die Descendenztheorie nur Hypothesen vorlegt, denen sich eine Reihe von Thatsachen sehr gut anschmiegt; auch ist schlieBlich jeder, der auf diesem Gebiete forscht, mehr oder weniger ein Zweifler. Wenn ich nicht irre, sind sogar die juingeren Forscher auf ihren besonderen Forschungsgebieten in immer schärfer sich betonender Opposition gegen Häckel's Dogmen begriffen, was sie freilich meistens nicht hindert, auf anderem Gebiet ihnen treu und ergeben zu sein." -

„Häckel ${ }^{1}$ ) ist nicht nur Fachgelehrter in allen genaunten und einigen anderen naturwissenschaftlichen Fächern, er ist außerdem noch Theologe und hat dabei recht dentlich gezeigt, dass es doch nicht ganz gleichgiiltig ist, wie weit man sein Gebiet ausdehnt. Einen so iiblen und das Ansehen der Naturwissenschaften so schwer schädigenden Erfolg, wie ihn Häckel in dieser Richtung gehalıt hat, habe ich nicht geglaubt erwarten zu diurfen. Wie konnte aber Häckel doch die Natur der allermeisten Menschen so völlig verkennen, wie er das gethan hat, und was hatte er für alles das, was er zu zerstören bemiiht war, als Ersatz darzubieten?" „Etwas Unfruchtbareres und Öderes als sein Monismus war doch kaum zu denken! Diese Niederlage hätte er uns wohl ersparen können! „Der Erfolg dagegen, welchen Häckel als Darwinist errungen hat, ist ein desto größerer gewesen, allerdings auch dies gegen mein Erwarten, denn niemals habe ich in den beziiglichen Schriften etwas anderes erblicken können, als einen höchst interessanten und lehrreichen, sowie förderlichen Versuch der Entwickelungsgeschichte der Organismenreihen näher zu kommen. Häckel aber hat das Problem für gelöst erklärt."

„Häckel2) spielt nach wie ror leichtfertig mit der Vererbung, mit Grundgesetzen der Natur, mit Stammbäumen und EntwickelungsVorgüngen, genau wie ein "thïitiger und riicksichtsloser Parteifïhrer". Leider ist es ihm gelungen, in gewissen Zweigen der Wissenschaft

1) Hensen l. c. p. 44 .

2) Hensen 1. c. p. 64 . 
Parteien, wie in einem Parlament zu bilden, und seine Partei ist hoch getragen worden von einem autoritäts-gläubigen Laienpublikum, um welches er warb. In der Wissenschaft ist aber keine Parteiherrschaft zu dulden, sie macht zwar stark im Kampf, aber wen sollen wir denn bekämpfen? Doch nicht etwa die Natur? Sie, die niemals fälscht, sondern dem wahren Freund immer die Wahrheit redet!*

"Man sagt mir, ich erwürbe mir zu viele Feinde, wenn ich Häckel’s Partei bekämpfen wolle. - Sei es! Aber diejenigen, die fühlen können, dass ich bemüht gewesen bin, auch hier nach meinen Kräften der Wissenschaft zu dienen, werden meine Freunde sein." - _ — „Allein auf Thatsachen, auf so sorgfältig wie möglich nach Maß, Gewicht und Zahl festgestellte Thatsachen kommt es an; ihnen gegenïber verwehen alle Meinungen und Termutungen, denen diese Stiitze fehlt, wie die „Staubsäule“, welche "die Wirbelwinde auf den Straßen in die Höhe führen."

Der Gegensatz besteht noch hente in der gleiche Weise, jedoch scheint sich mir eine gewisse Klärung vorzubereiten, so dass man das Resultat einigermaßen voraussehen kann. Keinesfalls darf das Urteil eines Zeitgenossen Darwin's, des englischen Anatomen Th. Huxley als bindend betrachtet werden: „Es giebt nur eine Hypothese betreffs der Entstehung der Arten, welche wissenschaftliche Existenz hat, die Darwinische; wenn sie auch nicht strenge wahr wäre, so besitzt sie doch eine solche Annäherung an die Wahrheit, wie die Kopernikanische Theorie für die Planetenbewegung gehabt hat."

Zum Beweise dafïr brauche ich Thnen nur aus zwei modernen Schriften Belege vorzulesen. Vor 4 Jahren schloss G. Wolff') einen wissenschaftlichen Vortrag in Würzburg: „So diirfen wir wohl die Hoffnung hegen, der endgïltigen Beseitigung des Darwinismus entgegen zu gehen." Der Verfasser meint damit die Zuchtwahltheorie, nicht die Abstammungslehre, welche er nicht in den Rahmen der Diskussion gestellt hatte. Gegen die letztere war Driesch ${ }^{2}$ ) mit scharfen, aber wie mir scheint, vollkommen berechtigten Worten drei Jahre frïher aufgetreten:

„Für den denkenden Leser ist im vorigen die Verurteilung der bloßen Descendenzlehre ohne Angabe der umwandelnden Ursachen enthalten, wenigstens soweit dieselbe die Prätension erhebt, Einsicht und nicht vielmehr bloB unverstandene Thatsachen hypothetischen Charakters zu ermitteln." - - — ,Abgesehen von dem prinzipiell geringeren Werte der Geschichte gegenüber der ratio-

1) G. Wolff, Der gegenwärtige Stand des Darwinismus. Leipzig 1896.

2) Hans Driesch, Die Biologie als selbständige Grundwissenschaft. Leipzig 1893. p. 26, p. 30, 31. 
nellen Wissenschaft steht also die Biogenie (Entwickelungslehre) auch historisch genommen auf einem sehr tiefen Niveau; zwischen Wahrscheinlichkeiten rein äußerlichen Charakters (Paläontologie, Geographie) und wiister Phantasie (Typen) schwanken ihre „Stammbäume“. - - „Etwa gar auch auf die Prätensionen der widerlegten sog. Darwinschen Theorie einzugehen, wäre eine Beleidigung des Lesers. Es genïgt hier, die Titel dreier Schriften zu nennen:

Wigand, Der Darwinismus nnd die Naturforschung Newtons und Cuviers.

Nägeli, Mechanisch-physiologische Abstammungslehre.

Wolff, Beiträge zur Kritik der Darwin'schen Lehre. Biol. Centralblatt Bd. 10."

"Wann wird man einmal anfangen, diese und andere Werke zu berücksichtigen, und aufhören, in der Darwin schen ,Theorie“ ein gesichertes Gut der Wissenschaft zu erblicken?:"

Der Vorstand der biologischen Anstalt in Helgoland, Prof. Dr. R. Heinke sagte neulich: „Es ist allmählich genug philosophiert worden ïber die verschiedenen Probleme der Descendenzlehre, um bei ernster Prüfung zur Überzengung zu gelangen, dass auf diesem philosophierenden Wege nicht mehr weiterzukommen ist. Die Entdeckung neuer Thatsachen, vieler neuer Thatsachen und ihre klare Beschreibung, die Ausdehnung solcher nüchtermen Forschung auf bisher unbekannte Gebiete - das sind die wahren Mittel zum Fortschritte. 6

Aus diesen Beispielen, welche nur aus Rücksicht anf die knappe Zeit der ersten Stunde so spärlich bemessen sind, können Sie erseben, dass heutzutage unter den Naturforschern eine Einigung in Bezug auf die Abstammungs- und Zuchtwahltheorie nicht besteht, dass also alle in populären Schriften so vielfach aufgestellten Behauptungen von der einmuitigen Herrschaft der Theorie der Sachlage nicht entsprechen.

Anders aber gestaltete sich das Schicksal derselben in den Kreisen der gebildeten und ungebildeten Laien. Denn dort genügten oberflächliche Darstellungen der naturwissenschaftlichen Lehren, um die Überzeugung von der Umbildung aller Geschöpfe und ihrer aus niederer zu höherer Stufe fortschreitenden Entwickelung zu befestigen. Wir werden im Laufe unserer Betrachtungen genug Gelegenheit bekommen, die Bedeutungslosigkeit der das allgemeine Publikum bestrickenden Scheinbeweise zu erkennen. Heute will ich sie nur erinnern, welch großen Eindruck die populären Bilder aus der Geologie und Paläontologie machten, wie die philosophischen Ideen der Geschichtsschreiber von einem in der Weltgeschichte zu Tage tretenden Fortschritte, wie die Betrachtung der 
Kulturgeschichte, die Resultate der vergleichenden Sprachwissenschaft in effektroller Weise herbeigezogen wurden, um die Entwickelungstheorie einer ungehener großen Menge von Männern und Frauen plausibel zu machen.

Den tiefsten Eindruck aber machte die nach der falschen Regel der alten Scholastik aufgestellte Alternative: entweder ist das Leben auf Erden durch den übernatürlichen Eingriff eines höheren Wesens am Beginne der Welt geschaffen worden oder es hat sich einmal aus dem anorganischen Reiche auf meehanische Weise entwickelt und allmählich zu höherer Vervollkommnung emporgearbeitet. Wenu Sie die einschlägigen Schriften aus den Jahren 1860-1875 und etliche später erschionene Werke nachlesen, können Sie sich davon überzeugen, dass der durch die Descendenzlehre neuerdings wachgerufene Widerspruch gegen die mosaische Schöpfungsgeschichte eine unwiderstehliche Wirkung ausgeübt hat.

Bei der damaligen Geistesstimmung nahm eine ungeheuer große Zahl von Gebildeten ohne Zögern für die zuletzt genannte Möglichkeit Partei, weil sich dieselbe besser mit der antikirchlichen Stimmung der Zeit vereinte und als Waffe in dem Kampfe gegen die intolerante Herrschaft der Geistlichkeit benutzt werden konnte. Wäre der Kontrast gegen die von den Theologen als wichtigen Bestandteil der Glaubenslehre vorgetragene mosaische Schöpfungsgeschichte nicht häufig betont worden, so hätte die Abstammungslehre sicher nicht so viele Anhänger werben können.

Leider erhielt dadurch das wissenschaftliche Problem ein ganz falsches Gesicht, und es wurde eine rein zoologisch-botanische Frage hinausgetragen in den Tageskampf der politischen Parteien und zu einem demagogischen Kampfesmittel herabgewürdigt; denn es bleibt immer ein bedenkliches Beginnen, unfertige wissenschaftliche Ansichten vor das große Publikum zu bringen, einen Richter, bei dem sich Gefühl und Verstand notwendig durchkreuzen.

Hypothesen sind notwendige Hilfsmittel der Forschung für neu zu erhellende Gebiete der Wissenschaft, aber sie leiten wegen der unvermeidlichen Schritte auf unbekanntem Boden den Laien irre. Es zeugt von kräftigem wissenschaftlichen Leben, noue Hypothesen aufzustellen und darüber eine sachlicho Diskussion anzuregen. Diesen Kampf jedoch öffentlich führen, das Laienpublikum als richterliehe Instanz anrufen und dem einer wahren Prüfung unfähigen Volke hypothetische Lehrgebäude als dogmatische Lehrsätze mitteilen, kommt einer Täuschung des Volkes und einer Schädigung der Wissenschaft gleich.

Noch weniger berechtigt ist es, vor dem Forum der Öffentlichkeit die Autorität der Naturforschung gegenüber den religiösen 
Lehren zu erörtern; denn die Religion ist Sache des Glaubens, die Wissenschaft ist das Feld des Zweifels. Theologie und Naturwissenschaft können ebenso wenig wie Mathematik und Jurisprudenz wichtige Lehrsätze mit einander gemein haben. Eine wissenschaftliche Wahrlıeit ist nicht notwendig eine religiöse. Darwin hatte mit feinem Taktgefiihle und im Interesse der Wahrheit eine scharfe Scheidung der beiden Gebiete getroffen und das Problem von der Entstehung der Arten als ausschlielich dem zoologisch-botanischen Arbeitsgebiete zugehörig behandelt. Seine Anhänger aber haben dic dem Fortschritte und dem Frieden dienliche Scheidung verkannt und die neue Lehre geradezu als ein Kampfmittel gegen die Theologic gebraucht.

Die Folgen dieses falschen Beginnens machen sich heute in hohem Grade fiihlbar. Schon bemerken weitere Kreise, dass unter den Naturforschern große Uneinigkeit über die Abstammungslehre herrscht. Die Opposition gegen die zu dogmatischen Formeln verknöcherten Ansichten ron E. Häckel zieht die Aufmerksamkeit der allem geistigen Fortschritte feindlichen Elemente auf sich und gestiitzt anf die Streitschriften der Fachgelehrten gewinnt die orthodoxe Reaktion an Boden. Die Krise ist auBerordentlich heftig. Die darwinistisch gesinnten Forscher wollen nicht einsehen, dass in den letzten dreißig Jahren der Vorrat ihrer scheinbaren Beweise arg zusammengeschmolzen ist, während die besonnenen Gelehrten die Notwendigkeit des Riickzuges verteidigen, nachdem viele Vertreter der Naturwissenschaft mit ihren Behanptungen weit über das Fachgebiet hinausgegangen sind.

Wir stehen also gegenwärtig vor einer bedeutsamen Wendung in der Geschichte der Abstammungslehre und werden im nächsten Jahrzehnte Gelegenheit haben, alle Phasen der Krise zu erleben. Deshalb habe ich Sie an der Wende des 19. Jahrhunderts zu einer Vorlesung eingeladen, die einen Überblick sowohl iiber die Entwickelung der descendenz-theoretischen Spekulation in den letzten 40 Jahren, als auch ïber den gegenwärtigen Zustand und die Prognose für die nächsten Jahre geben soll, einzig und allein in der Absicht, Sie durch eine fachwissenschaftlich objektive Darstellung in den Stand zu setzen, sich ein selbständiges Urteil zu bilden und iiber Ihre Stellungsnahme in kiinftiger Zeit klar zu werden.

Da ich in dieser Frage eine andere Meinung hege, als die meisten meiner Kollegen, werde ich den Inhalt der populären descendenztheoretischen Werke, welche Sie zum Teil schon während der Gymnasialzeit mit Begeisterung gelesen haben, hier nicht rekapitulieren, sondern solche Thatsachen, welche ron den Anhängern der Abstammungslehre nicht gebuihrend geschildert oder 
leichthin ïberschlagen werden, eingehend darstellen und aus der dem Laienpublikum nicht rertranten zoologischen Litteratur wichtige Aktenstücke zur Illustration der Ansichten tiichtiger Vertreter und Gegner der Hypothese rorführen. Auf Grund langjähriger und sorgfältiger Prifung bin ich zur Ansicht gelangt, dass die Abstammungslehre nicht begrindet ist. Ich gehe sogar noch weiter und behaupte, die Diskussiou der Frage gehört gar nicht in den Bereich der exakten Zoologie und Botanik. Es liegt mir jedoch ferne, Sie durch dialektische Kunststiicke zum C̈bertritte auf meinen Standpunkt rerleiten zu wollen, und ich werde mich bestreben, die Ansichten der Descendenztheoretiker; soweit es eben einem Gegner möglich ist, objektir mit Ihnen auf die exakten Berreisgründe zu prïfen; denn die hohe Aufgabe des Unirersitätslehrers wird nicht erfüllt, wenn er seine Zuhörer zu blinden Parteigängern der privaten Meinung erzieht. Thm obliegt es vielmehr, seine Schüler anzuleiten. dass sie die im Leben wie in der W'issenschaft jederzeit bestehenden Gegensätze beobachten, ihre geschichtliche Notwendigkeit begreifen, ihre logische Stärke und ibre thatsächlichen Unterlagen ruhig erwïgen. Die Entscheidung, welcher Ansicht der Torzug gebiihre, bleibt dem persönlichen Ermessen des freien akademischen Bürgers iiberlassen! 


\section{Zweites Kapitel.}

\section{Die Typen des Tierreiches.}

So sehr die Vorstellung von einer fortschreitenden Entwickelung aller menschlichen Verhältnisse, des Tier- und Pflanzenreiches und des gesamten Weltalls dem Denken der meisten Menschen zusagt, so konnte sic sich doch nirgends fester einwurzeln als bei den biologischen Naturforschern, denen die Wahrheit des Satzes: лúr аøг̃ fortwährend vor die Seele geführt wird. Welche Provinz ihres Arbeitsgebietes sie auch betreten mögen, überall begegnen ihnen gewaltige Revolutionen der Körperform, die am lebenden Körper oft binnen wenig Stunden oder Tagen ablaufen und neue unerwartete Gestalten hervorzaubern. Die Beispiele der Metamorphose sind bekannte Belege dafür. Dor hässliche Wurm, welcher mühselig seinen plumpen Leib hinschleppt und mit gefräßiger Gier unsere Nutz- und Zierpflanzen entlaubt, spinnt sich ein, $u m$ sich in eine anscheinend tote Puppe zu verwandeln, welche den Winterstiirmen trotzt. Im Frühlinge entschlüpft der bramnen Hülle ein bunter, leicht beschwingter Schmetterling, der lustig in der Luft gaukelt nnd süßen Nektar aus den Blüten saugt. Tausende von ähnlicben Beispielen machen uns den Gedanken der Umbildung vertraut und veranlassen uns, auch dort, wo wir die Metamorphose nicht direkt beobachten können, eine solche für frühere Erdperioden anzunehmen. Durch allzu voreilige Generalisation scheint uns dann die Metamorphose der Tiergeschlechter als eine denknotwendige Konsequenz der individuellen Umformung. Deshalb wird der Gedanke sich in absehbarer Zeit nicht aus der Diskussion entfernen lassen, wenn auch vielleicht die nächste Generation von Forschern ihn nur als ein schönes Ideal ohne realen Inhalt, etwa wie die allgemeine Abrüstung der Völker beurteilen wird. Darw in dagegen, seine Zeitgenossen und seine später geborenen Anhänger sind von der schönen Idee bethört worden und haben ihre Geisteskraft für den aussichtslosen Versuch einer Beweisführung aufgewendet, welche nach meiner Ansicht ein ihren Wünschen nicht entsprechendes Resultat gezeitigt hat.

Ehe wir die Prüfung im einzelnen beginnen, wird es notwendig sein, Ihnen den allgemeinen Charakter des Problems, welches durch 
Darwin's Buch der zoologisehen Wissensehaft vorgelegt wurde und die Komplizierung desselben in den nachfolgenden Jalırzehnten anzuzeigen.

Wenn jemand, der mit der Mannigfaltigkeit der Geschöpfe einigermaßen vertraut ist, dem Gedanken Raum giebt, dass die höheren Tiere von niederen abstammen, dass die niederen Lebewesen durch den Kampf ums Dasein und die natürliche Zuchtwahl zu lıöherer Vollkommenheit fortgeschritten seien, so obliegt es ilmm zunächst, dic verschiedenen Klassen des Tierreiches, welche sein Denken mit den „heute sichtbaren Stufen des Entwickelungsprozesses" vergleicht, auf ihre Ähnlichkeiten und Unterschiede zu untersuchen, un die bei Stammesverwandten notwendig vorkommende Gemeinsamkeit der Form- und Charakterzüge festzustellen. Damit beginnen die Hindernisse der neuen Theorie; denn seit dem Beginne des Jahrhunderts ist es ausgemacht, dass im Tierreiche nicht ein einziges Generalmodell des Körperbaues herrscht, welches sich etwa dureh das anatomische Studium der menschlichen Leiche ergrïnden lässt.

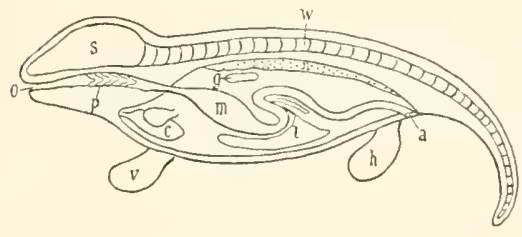

Fig. 1.

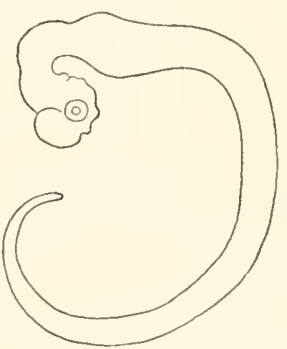

Fig. 2.

Fig. 1. Schematische Skizze des Stilplanes der Wirbeltiere. a After, $c$ Herz. $g$ Geschlechtskeimwulst, $h$ hintere Gliedmabe, $l$ Leber, $m$ Magen, $n$ Xiere, o Mund, $p$ Schlundtaschen, $s$ Schädel, $v$ rordere Gliedmaße, $w$ Wirbelsäule.

Fig. 2. Gehirn und Rückenmarkeines menschlichen Embryos. Nach His.

Gleichwie die Kunstgeschichte verschiedene Stilarten in Aufbau der Gebäude und anderen menschlichen Kunsterzeugnissen unterscheidet. kennt der Anatom Stilarten des Körperbaues, die er Formtypen oder Organisationskreise nennt. Der Bauplan eines Insekts weicht rom Bauplan des menschlichen Leibes vielleicht noch mehr ab, als ein gotischer Dom von einem chinesischen Tempel. Ich will Ihnen zunächst einige Beispiele der tierischen Stilistik vorführen:

Betrachten wir zuerst den Aufbau eines Wirbeltieres, der durch das vergleichend anatomische Studium der Fische, Amphibien, Reptilien, Vögel und Säugetiere als allgemeiner Typus abstrabicrt wurde. 
Durch den ganzen Körper (Fig. 1) zieht nahe der Rä̈ckenfläche und meist durch die Hant hindurch fühlbar eine knöcherne Stütze, die Wirbelsïule, aus zahlreichen Wirbeln zusammengefügt. In der Kopfgegend schließt sich ihr der Schädel an, eine feste Schutzkapsel fiir das Gehirn und die wichtigen Sinnesorgane des Geruches, Gesichtes und Gehöres. Die den Wirbelkörpern rückenwärts aufgesetzten ,oberen Bogen" bilden eine Reihe von Knochenarkaden, welche durch Bänder und direkte Berïhrung der Bogen selbst zu einem cylindrischen ,Kanale der Wirbelsäule" geschlossen werden, der sich direkt in die weite Schädelhöhle fortsetzt. Diesen Hohlräumen ist das Rückenmark und Gehirn als nervöses Centralorgan (Fig. 2) eingeschaltet. Dasselbe ist nicht solide - was für das Studium der anderen Organisationstypen von hoher Bedeutung ist — sondern ein Hohlgebilde, indem das Rückenmark ein sehr dickwandiges, cylindrisches, aus Nervenfasern und Nervenzellen gewebtes Rohr von engem Kraliber darstellt und rorne in der Schädelhöhle zu fünf großen, ebenfalls außerordentlich dickwandigen Gehimblasen (Vorder-, Zwischen-, Mittel-, Hinter-, Nachhirn) anschwillt. An den verschiedensten Stellen der Seitenwand von Gehirn und Rückenmark wachsen Nervenstränge heraus und dringen in alle, selbst die entferntesten Raumgebiete des Wirbeltierleibes.

Neben den oberen Bogen werden an den Wirbeln noch die Rippen gefunden, bogenartig gekriimmte Spangen, welche von den Wirbelkörpern abwärts nach der Bauchseite hängen und in der seitlichen muskulösen Körperwand eingebettet sind. Alle bisher beschricbenen Teile sind direkt nicht wahrzunehmen, weil Riickenmark und Gehirn von den Knnochenstiicken der Wirbelsäule und des Schädels und diese wieder vom Muskelfleische und der Haut verdeckt werden. Das Skelet der Wirbeltiere ist also ein inneres, in den Körper eingesenktes Knochengerüste und dient zugleich als Futteral für das noch mehr verborgene Centralnervensystem.

Unterhalb der Wirbelsäule liegt ein weiter von den Lingeweiden erfüllter Raum, die Leibeshöhle. Sie erstreckt sich nicht durch den ganzen Körper, sondern dehnt sich nur im Rumpfe aus, so dass die Kopf- und Schwanzgegend solide erscheinen. Der Darm hängt an einem zarten, Gefäße und Nerven umschliefenden Aufhängeband, dem Gekröse, von dem unterhalb der Wirbelsäule stehenden Rückengewölbe der Leibeshöhle herab. Da seine Länge die des Krörpers meist um ein Bedeutendes übertrifft, zieht er als vielfach gewundener Schlauch. Jmmer sind drei Abschnitte an ihm erkennbar: der Torder-, Mittel- und Enddarm. Die hintere Zone des Vorderdarmes ist meist erweitert als Magen ( $m$ ), und dicht hinter demselben, am Mitteldarm, münden zwei Verdauungsdrüsen, 
die kleinere lappig verzweigte Bauchspeicheldrïse und der Gallongang der mächtigen rotbramen Leber $(l)$ ein. Der IIund (o) befindet sich am Vorderende des Kopfes, der After ( $($ ) an der hinteren Grenze des Rumpfes. Charakteristisch fiir alle Wirbeltiere treten am Vorderdarme dicht hinter der Mlundhöhle seitliche Aussackungen, die Schlundtaschen (p), auf. Ihre physiologische Bedeutung und ibr Schicksal bei den verschiedenen Klassen ist jedoch so mannigfach, dass ich hier nur die Allgemeinheit des Yorkommens konstatieren kamn. Das Blut ist rot und in einem reich verzweigten, alle Organe durchziehenden Gefäßnetze eingeschlossen. Der Kreislauf des Blutes in demselben wird durch das als Saug- und Druckpumpe wirkende und deshalb in zwei Abschnitte: Torhof und Kammer geschiedene Herz (o) betrieben, welches im rordersten Winkel der Leibeshöhle unterhalb des Darmes liegt.

Die Geschlechtskeimstätten d. h. die Hoden, bezw. Eierstöcke hängen als kleine Wülste $(g)$ rom Rückengewölbe der Leibeshöhle herab. Sie besitzen intime Beziehungen zu den gleichfalls in die Gewölbewand der Leibeshöhle eingefügten paarigen Urnieren, Harnorganen, welche nur bei den Fischen und Amphibien durch die ganze Lebensdauer des Individuums Urin abscheiden und mächtig bleiben, während sie bei den drei höheren Klassen diese physiologische Rolle frübzeitig anfgeben und durch sog. Dauernieren ersetzt werden. Da ich die rerwickelten Beziehungen zwischen den Geschlechtswiilsten, den Urnieren und zwei seitlich davon ziehenden paarigen Kanälen, dem Wolffschen und Nüllerschen Gange hicr nicht darlegen kann, will ich Sie nur anf die merkwürdige Thatsache aufmerksam machen, dass bei allen Wirbeltieren die Geschlechtswïlste der Ausfiihrgänge ermangeln. Infolgedessen sind besondere

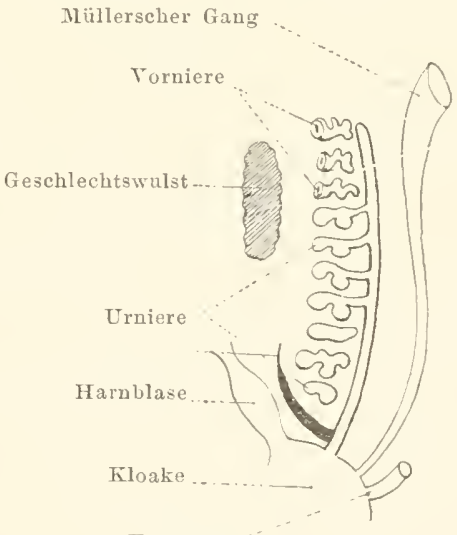

Endilarm

Fig. 3.

Schematische skizze der Beziehungen àes Geschlechtswulsteszur Urniere und dem Wolffschen und MI üllerschen Gange. (Der Wolf'sche Gang, nicht besouders bezeichnet, zieht längs der Urniere.) Bildungsvorgänge notwendig, um bei den männlichen Individuen den Wolffschen Gang mit der Ableitung des Samens, bei den weiblichen Tieren den Müllerschen Gang mit der Ausfuhr der Eier zu betrauen. Kein anderer Organisationstypus des Tierreiches zeigt Einrichtungen, welche mit diesem Stile der Geschlechtskeimstätten und deren A usfïhrgängen einigermaßenvergleichbar wären. 
Das Gleiche gilt auch, wie Sic sofort einsehen werden, für alle ïbrigen Organsysteme: Die Beschaffenheit und die rote Farbe des Blutes, Lage und Bau des Herzens, wie des gesamten Gefälisystemes, die Lage und die Wirbelgliederung des Achsenskelettes, der Besitz des Kopfschädels findet kein Analogon bei den niederen Tieren. Die Eigenart der Wirbeltiere ist vielmehr so groß, dass man ihnen sämtliche andere Lebewesen als wirbellose Tiere gegenüberstellen kamn. Sie müssen nur die Bezeichnung , wirbellose" richtig auffassen und nicht bloß an den Mangel einer knöchernen Wirbelsäule denken, sondern festhalten, dass in allen Organen des Körpers ebenso schroffe Untersehiede bestehen, wie im Skelette, weil eben zur summarischen Kennzeichnung der Sonderstellung der Wirbeltiere eine pars pro toto, eine Eigenschaft statt vieler hervorgehoben wird.

Den Leib der Insekten (Fig. 4) umgürtet eine frei zu Tage liegende, aus Chitin bestehende Panzerhülle, das äußere oder Exoskelett und schlieBt die zur Bewegung notwendigen Muskelmassen ein. Die Lagebeziehung der Stiitz- und Beweguugsorgane ist also gegeniiber den Wirbeìtieren gerade umgekehrt, und Sie

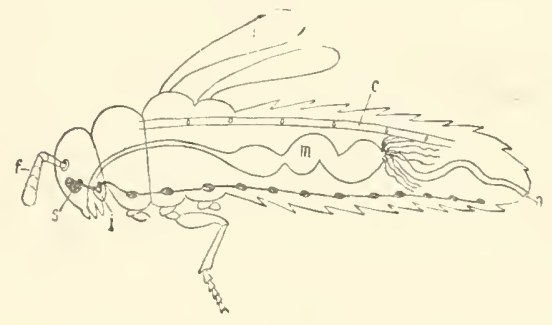

Fig. 4.

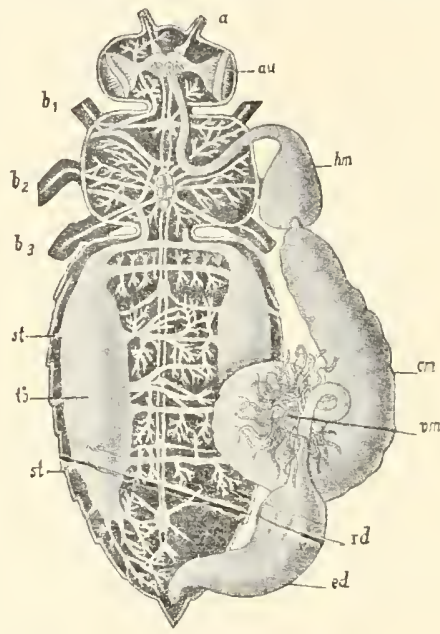

Fig. 5

Fig. 4. Schematische Skizzedes Bauplanes der Insekten. a After, $c$ Herz, $f$ Fühler, $i$ unteres Schlundgauglion, $l$ Flingel, $m$ Magen, $s$ oberes Schlundganglion.

Fig. 5. Anatomie der Honigbiene, Nach Leuckart. a Fühler, au Auge, $b_{1} b_{2} b_{3}$ Beinr. cm Chylusmagen, eq Euddarm, rl. Enddarmdrüsen, st Stigmen, tb Haupttracheenstamm, vm $\lambda$ :alpighi'sche Gefäße. Dás strickleiterförmige Nervensystem zieht in der Mittellinie der Figur.

begreifen, dass man sich nicht vor'stellen kann, die Anordnung der beiden Organsysteme sei bei irgend welchen einfachen Urinsekten derartig geändert worden, dass sie dem bei Wirbeltieren herrschenden Typus näher kamen. Wenn das äußere Hautskelett eine einfache Hülse bleibt, wie z. B. bei den Schildkiöten, so verleiht es dem Träger wohl krïftigen Schutz, aber zugleich einen hohen Grad plumper Starrheit. Die Insekten sind weit beweglicher, weil das Hautskelett in kleine, 
z. T. leicht gegen einander rerschiebbare Stiicke, ähnlich den Panzerrüstungen der mittelalterlichen Ritter zerfällt. Der Weichkörper selbst ist durch Ringfurchen der Haut in eine bestimmte Anzahl ron cylindrischen Abschnitten, den sog. Segmenten, gegliedert. Deren Oberfläche scheidet während der Larvenzeit die einzelnen Stiicke des Chitinpanzers ab.

So zeigt schon der äulere Habitus der Insekten ein ganz anderes Aussehen als irgend ein Wirbeltier. Indem etliche Segmente intimere Beziehungen zu einander erlangen, werden drei Hauptregionen des Körpers unterscheidbar. Zuvorderst steht ein linsenförmiger Abschnitt, der Kopf; dam folgen drei meist verwachsene Segmente als sog. Brust oder Thorax und eine größere Zahl (gewöhnlich 10) beweglicher Segmente als sog. Hinterleib oder Abdomen. Während das Wirbeltier auf vier Gliedmaßen gestïtzt ist, tragen drei an der Bauchseite der Brust gelenkende Beinpaare den Insektenleib. Ihre Gliederung in bewegliche Stiicke erfolgt nach eigenartigem Typus; denn jedes Bein besteht aus neun Stïcken, von denen die meisten, in Charniergelenken hängend, nur klappende Bewegungen machen können, die der Bewegung einer am Hefte befestigten Klinge eines Taschenmessers vergleichbar sind. Statt fünf Zehen stehen zwei Klauen am Ende jedes Fußes. Der Rückenfläche der Brustregion entsprossen zwei Paare von Flügeln $(l)$; das sind Organe, für welche es im ganzen Tierreiche iiberhaupt keine formverwandte Einrichtung giebt.

Die Leibeshöhle ist sehr geräumig und erstreckt sich durch den ganzen Körper. Sie höhlt also den Kopf, die Brust, den Hinterleib, ferner die Beine, die Flügel und die Fühler des Kopfes, während sie bei Wirbeltieren die Grenze des Rumpfes nicht ïberschreitet. Die Leibeshöhle ist mit Blut, einer weißen, Zcllen enthaltenden Flüssigkeit erfüllt, welches, nicht in einem Gefäßnetze eingeschlossen, kraft der Pulsationen des Herzens in ihr fluktuiert. Das Herz selbst ist anders gebaut und liegt an einer ganz andereu Stelle, als wir vorhin bei Wirbeltieren fanden. Es zieht nämlich als ein langer, ron seitlichen Öffnungen durchbohrter Schlauch (c) dicht unterhalb der Rückenwand des Hinterleibes und der Brust.

Das Nervensystem liegt dem Herzschlauche gerade gegenuiber an der Bauchwand des Körpers (Fig. 4, 5). Ihm ist die Form des dickwandigen Nervenrohres gleich Rückenmark und Gehirn nicht eigen. In jedem Segmente liegen solide paarige Hanfen von Nervenzellen und Nervenfasern, die Ganglienknoten, welche durch quer und längs streichende Nerven zu einer strickleiterähnlichen Einheit, der Bauchganglienkette, verknüpft werden. Nur im Kopfe finden sich zwei Paare von Nervenknoten ober- 
hall und unterhall, des Schlundes, die oberen und unteren Schlundganglien $(s, i)$, durch Quer- und Lüngsnerven zum sog. Schlundringe vereint. Das sind wichtige Centralorgane und ihrer physiologischen Bedeutung nach, - nicht in ihrem Baue - dem Gehirne der Wirbelticre vergleichbar. Muskeln sind an der gesamten Körperwand zerstrent, ihre Hauptmasse jedoch ist im Brustabschnitte

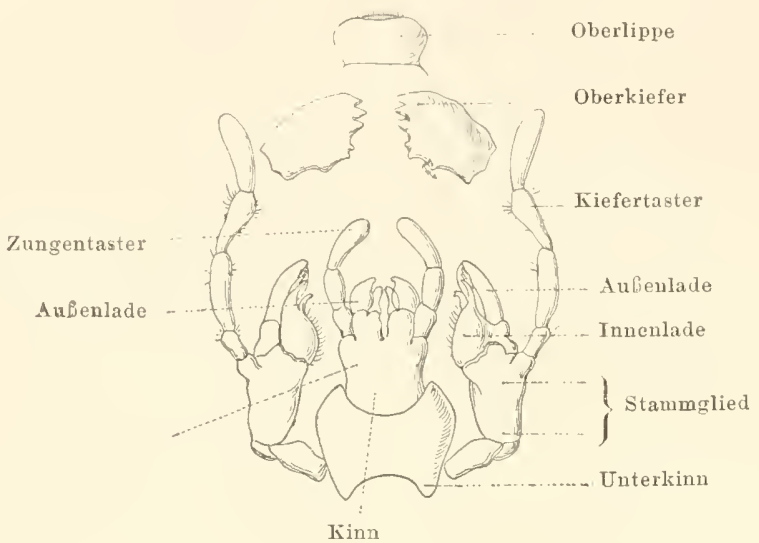

Fig. 6.

Kau werkzeugeder schabe.

zur Bewegung der Beine und Flügel konzentriert, wo sie die Leibeshöhle bis auf schmale Spalträume einengt.

Die Kauwerkzeuge (Fig. 6), bei den Wirbeltieren als hufeisen-

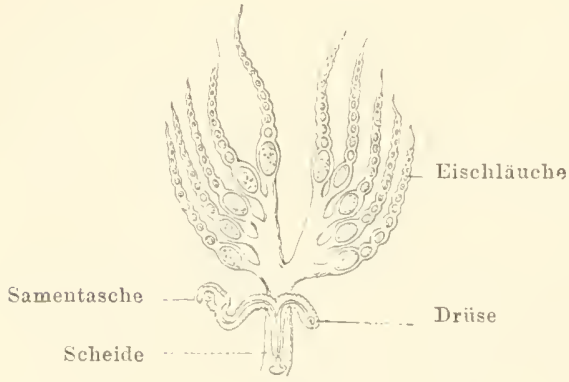

Fig. 7.

Die weiblichen Geschlechtsorgane des Flohes. Nach Stein. förmig gekrïmmte Zahnreihen auf Ober- und Unterkiefer stehend, erscheinen hier als drei Paare seitlicher und fein gegliederter Mundanhänge. Der Darm (Fig. 5) entbehrt der großen Verdaumgsdrisen, wie Leber und Bauchspeicheldriise der Wirbeltiere. Nur in der Nundhöhle münden die Ausführgänge von Speicheldrüsen. Ganz sonderbar ist das Auftreten der Malpighi'schen Gefüße, feiner, dem Enddarme anhängender Schläuche, welche, dic Ausscheidung unbrauchbarer Produkte des Stoffwechsels besorgend, ihr Sekret in don Darm 
selbst ableiten. Die Geschlechtsorgane (Fig. 7) sind mit eigenen Ausführwegen versehen, welche direkt an den Keimstätten, d. h. den Hoden und Eicrstöcken, ansetzen. Die letzteren wiederum erscheinen nicht als solide Wiilste, sondern als Büschel von feinen Hodenoder Eischläuchen.

Besonder's merkwürdig entwickeln sich dic Atomorgane, die Tracheen (Fig. 5). Von äußeren wandständigen Öffnungen, den sog. Stigmen (insgesamt 6-10 Paareu), an der Seitenwand des Körpers machsen zarte, ron einer Chitintapete ausgekleidete Schläuche, eben die Tracheen, in die Leibeshöhle und verästeln sich zu einem unglaublich feinen und zierlichen Netzwerke, das sämtliche Organe umspinnt und seine feinsten Äste in die Substanz derselben entsendet. Rhythmische Bewegungen des Hinterleibes veranlassen den Luftwechsel in den Atemröhren.

Ganz anders erscheint der Körperban der Mollusken (Fig. 8), d. h. der Muscheln, Tintenfische und Schnecken. Zunächst vermissen wir die deutliche Gliederung des weichen Leibes in scharf getrennte Hauptabschnitte, wie wir sie als Kopf, Brust und Hinterleib bei den Insekten sahen, und die äußerc Körperform ist so mannigfaltig,

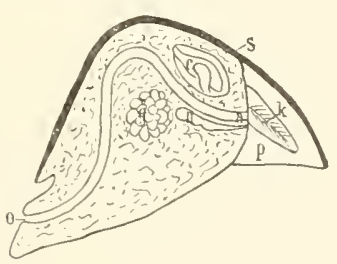

Fig. 8 .

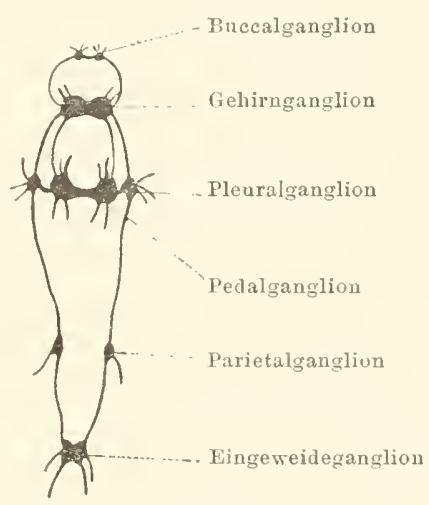

Fig. 9.

Fig. 8. Schematische Skizze des Bauplanes der Mollusken. a After, c Herz, $g$ Geschlechtskeimstätte, $k$ Kieme, $n$ Xiere, $p$ Mantelhühle, $s$ schale.

Fig. 9. Schematische Skizze des Norvensystemeseiner Schnecke.

dass sich eine allgemein giiltige Beschreibnng gar nicht geben lüsst. An der Banchseite sammeln sich mächtige Muskelmassen an und befähigen diesen Körperlappen, den sog. Fuß zur Kriech- oder Schwimmbewegung. Eine Falte der Haut springt dachförmig als sog. Mantel über den Leib heraus und begrenzt eine schmale, meist mit Wasser gefüllte Mantelhöhle ( $p$ ). die, an der hinteren Körperflïche liegend, mehr oder weniger weit an der rechten und linken Seite nach rorne dringt. Die ganze Mantelmembran 'und der größte Teil der Hautobertläche scheiden ein als Kalkschale $(s)$ erhärtendes 
Sekret ah. Die Schale dient als eine äußere, dem Chitinskelette der Insekten vergleichbare Schutzhïlle, unterscheidet sich aber wesentlich ron dem letzteren, weil sie der Gliederung entbehrt und in ihrer Formbildung so unabhängig von der anatomisehen Struktur des Tieres selbst erseheint, dass sie mit gutem Rechte das Gehäuse d. h. eine dic anatomischen Charakterziige des Tieres wenig wiederspiegelnde Wohnstätte genannt wird.

In die Mantelhöhle springen paarige Lamellen, Auswïchse des Körpers, die Kiemen ( $k$ ) vor, sie werden vom Wasser umspïlt, dienen der Atmung und sind ganz anders gebaut, als die physiologisch gleichwertigen Organe bei Insekten und Wirbeltieren.

Die Leibeshöhle durchzieht gleich wie bei den Insekten den ganzen Körper, jedoch nicht als ein weiter Raum, sondern als unregelmäßiges System von kommuniciercnden Lücken und Spalten, wie die Höhlen im Hornskelette eines Badeschwammes. Sie ist von weißem Blute erfüllt, welches, nicht in Gef:ißen eingeschlossen, durch die Spalten der Leibeshöhle getrieben wird durch die Pulsation des an der Rückenseite dicht unter der Hant im Herzhentel, einem etwas größeren Abschnitte der Leibeshöhle, liegenden Herzens $(c)$. Der Wortlaut meiner Beschreibung könnte Sie leicht rerführen, hier eine wesentliche Übereinstimmung mit dem Iusektentypus zn vermuten, welche in der That nicht vorhanden ist. Denn dort zieht das Herz als ein langer Schlauch unter der Riickendecke und sangt das Blut durch seitliche Öffinungen direkt aus der Leibeshöhle - hier gleicht das Herz einem birnförmigen Säckehen, besitzt an der rechten und linken Seite je einen sackförmigen Anhang, die Torhöfe, und diese saugen vermöge ihrer Pnlsation das Blut aus den Kiemen ein, während das Herz dasselbe in die Leibeshöhlenspalten des Körpers treibt.

Das Nerrensystem (Fig. 9) besteht ans quer und lïngs ziehenden Nervensträngen und paarigen Gauglienkuoten, welche nicht zu einer strickleiterähnlichen Gesamtheit angeordnet siud, sondern im Leibe zerstreut sind und in wesentlich geringerer Zahl (fünf Paare) als bei den Insekten (vierzehn Paare) anftreten. Längsuerven ziehen von den oberhalb der Munthöhle liegenden Gehirnganglien zu den iibrigen Nervenknoten.

Der Darm durchsetzt in Windungen die schwammige Körpermasse rom vorder- und niederständigen Mnnde (o) zum hinterständigen, höher liegenden After $(a)$. Er besitzt immer eine auBerordentlich voluminöse Verdanungsdruise, die sog. Leber. Die Harnorgane $(n)$, weite Säcke mit vielfach gefalteter Innenfläche, also durchaus verschieden von den Malpighischen Gefäßen der Insekten und den Nieren der Wirbeltiere, liegen dicht unterhalb des Enddarmes und münden mit 
gesonderten Poren nahe dem After. Die Geschlechtskeimstätten $(g)$ besitzen die Gestalt ron Säcken, nicht ron Schlanchbüscheln, an deren Innenwand die Samenzellen oder Eier reifen. Die meisten Mollnsken sind getrennt geschlechtlich, nu die Vorderkiemer und Lungenschnecken sind Zwitter mit zwitterigen Geschlechtsorganen nach einem ganz besonderen, in anderen Klassen des Tierreiches nicht wiederholten Plane.

Einen nenen Formenkreis offenbaren die Stachelhäuter, die Echinodermen, indem die wichtigen Organe nicht paarig. sondern in der FünfzahI auftreten. Der sphärisch reguläre Leib (Fig. 10) dieser Gruppe, deren Arten alle stereometrischen Varianten zwischen der Kugel, Scheibe, Walze und Kegel realisieren, wird durch ein Skelett (s)

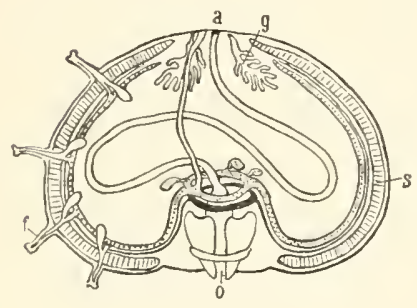

Fig. 10 .

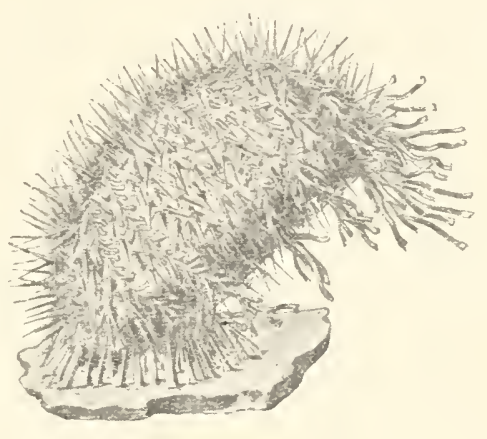

Fig. 11 .

Fig. 10. Schematische Skizze des Fauplanes der Stachelhäuter (Seeigel). a After, $f$ Wasserfübchen, g Geschlechtsorgane, o Mund, $s$ Skelett, Wassergefäle punktiert, Blutgefäljring schwarz.

Fig. 11. Ein kriechender Seeigel mit weit ausgestreckten Wasserfülchen. Nach Romanes und Ewart.

kleiner Kalkplatten gefestigt. Dasselbe ist kein AuBenskelett, wie bei den Insekten und Mollusken, sondern den tiefen Schichten der Haut eingelagert und ron den oberen Schichten derselben iiberdeckt. Über die Haut (Fig. 11) ragen fünf meridional gestellte Doppelreihen ron zarten kontraktilen, stecknadelähnlichen Schläuchen, den sog. Wasser- oder Ambulacralfiißchen $(f)$, welche sich mit ihren verdickten Endstiicken an die feste Unterlage ansaugen, wieder lösen und nach erneuter Ausstreckung und Festhaftung das Tier selbst fortbewegen. Da die Reihen der Wasserfüßchen durch fußlose Felder von einander getrennt sind, fallen an der Außenwand jedes Echinodermen zehn meridionale Zonen : fünf Ambulacralfelder und fünf Interambulacralfelder auf. Auch die Skelettplatten zeigen entsprechend den Zonen charakteristische Unter- 
schiede (Fig. 12) und andere Organe unterliegen der gleichen fünfstrahligen Präigung.

Die Leiheshöhle ist weit und geräumig, die Körperwand verhällnismäbig dünn, so dass der Leil) eines Stachelhäuters ganz gut einem sphärischen Hohlsacke rerglichen werden kann. Der Mund (o) liegt an einem, der After (a) an entgegengesetzten Pole. Nahe

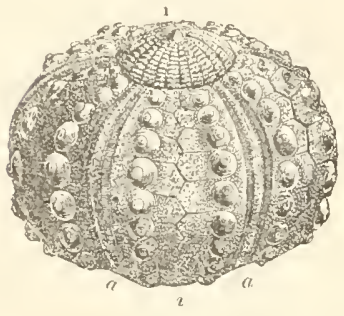

Fig. 12.

Das Kalkskejett eines Seeigels (Cidaris). a Ambulacral. felder, $i$ Interambulacralzonen, c Mundfeld.

dem Munde befindet sich innerhalb der Leibeshöhle der Ringkanal des Wassergefäßssstemes (Fig. 10 punktiert), eines allein den Echinodermen zukommenden Organsystemes. Dasselbe dient dazu. die Wasserfiißchen je nach dem Bediurfnisse mit Flüssigkeit zu füllen oder bei der Kontraktion der Fiiß3chen die ausgetriebene Fliissigkeit aufuspeichern. Deshall, gehen ron dem Ringkanale (Fig. 13) fünf meridionale Hauptstämme längs der Körperwand und entsenden kleine, mit Seitenbläschen, sog. Ampullen, besetzte Seitenzweige in die hohlen Wasserfüßchen. Tom Ringkanale zieht außerdem ein einfacher Ast, der Steinkanal, zur Hant, um dort mit einer siebförmig durchlochten "Madreporeuplatte" zn münden und Meerwasser in das sternförmige Ge-

Fübchen Ampullen der Fübchen Ambulacraler
Hauptstamm Ringkanal Steinkanal

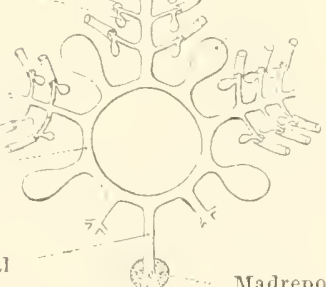

Fig. 13.

Wassergefäbsystem eınes seeigels.
Poli'scho Blasein samtgefäßnetz einzufiihren. Dem Wasserringkanale benachbart liegt ein BlutgefäBring (schwarz) mit fiinf meridionalen Seitenästen. Die Hauptmasse des Nervensystemes hildet einNervenring, der ehenfalls fünf meridionale Nerren an die Körperwand entsendet.

So ist also in ganz eigenartiger Weise fünf Organsystemen, der Bewegung, dem Sliclette, den Wasser-und BlutgefïBen und Nerren die fünfstrahlige Orduung anfgeprägt und den Echinodermen eine Sonderstellung im Tierreiche zugewiesen, da kein anderer Organisatioustypus etwas $\ddot{A} h n l i c h e s$ aufweist.

Der Darm zieht geschlnngen durch die Leibeshöhle, an eiuem 
dïmnen Bande wie bei Wirbeltieren am Gekröse aufgehängt. Er entbehrt meist größerer Driisenanhänge. Harnbereitende Organe sind mit Sicherheit nicht nachgewiesen. Die Hoden und Eierstöcke treten bei den durchweg getrennt geschlechtlichen Stachelhäutern als fiinf in meridionalen Zonen nahe dem After liegende Paare ron Säcken auf. welche direkt an der Haut ohne T'ermittelung eines Ausfiihrganges miinden.

Noch einfacher sind die Pflanzentiere, Coelenteraten, gebaut, d. h. die Polypen, Seerosen, Korallen und Quallen. Thr Kö̈rper (Fig. 14), kann einem Hohlsacke rerglichen werden, welcher mit seinem Boden festsitzt und um die Mundöffuung, einen Kranz ron beweglichen Anhängen, den Tentakehn. trägt. Eine Leibeshöhle und riele andere Organe sind überlaupt nicht differenziert. Die Mundöffnung fïhrt direkt in eine weite Magenhöhle ohne darmähnliche Fortsetzung und ohne After. Ihre Ausdehnung bestimmt meist das Tolumen des Tieres. Denn die Wand der Magenhöhle ist innig mit der Körperwand rerwachsen. Verdauungsdrïsen, Nieren, A temorgane sind nicht vorhauden. Kleinere Zellengruppen der Leibeswand entfalten teils muskulöse, teils nervöse Thätigkeit. Auch die Geschlechtszellen entstehen in der Körperwand und ge-

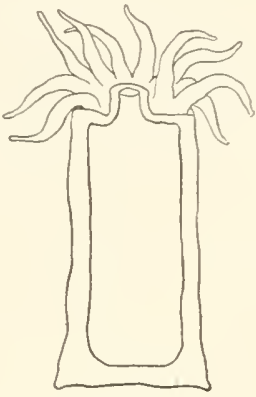

Fig. 14.

Schematische Skizze des Baulanes der Coelenteraten. langen durch Platzen derselben ins Meer. Wenn ein Skelet gebildet wird, wie bei den Leder- und Steinkorallen, so entsteht es entweder innerhalb der Leibeswand oder als Sekret der Haut.

Bei den Urtieren, Protozoen endlich verharrt der Körper fast innerhalb der Grenzen mikroskopischer Zwerghaftigkeit und entbehrt jeglicher Organbildung. Er stellt eine winzige, höchst rerschiedenartig geformte Menge lebender Substanz ror und äuBert alle Lebenserscheinungen wie ein kompliziert organisiertes Tier. Er bewegt sich, er nimmt Nahrung aut, er wirft die unbranchbaren Nahrungsbestandteile wieder ans, er scheidet die Zersetzungsprodukte seines Stoffwechsels ab, er atmet, er pflanzt sich fort - aber ohne deutlich ausgeprägte Organe. Am höchsten sind die Infusorien ausgebildet (Fig 15), deren Oberfläche mit feinsten Flimmerhaaren übersät ist. Eine schräge Rinne an einer beliebigen Körperstelle zeigt die Stelle an, wo Nahrungsstoffe in die weiche Leibesmasse aufgenommen und vor ihrem Eintritte einer Prïfung (wahrscheinlich auf ihre Zuträglichkeit) unterzogen werden. Der Leib selbst zeigt zwei Zonen, eine äußere, gleichmäBig hyaline, dünne Schicht und eine groblörnige Binnen- 
masse, in welcher der Ḱern, ein Bläschen aus färbbarer Nulileïnsubstanz, samt dem Tebenkern eingebettet ist. Beide sind die wichtigsten Teile des

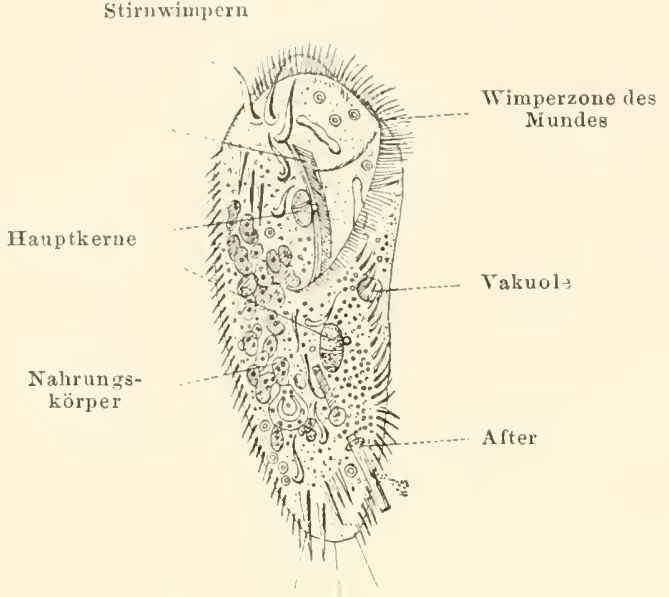

Fin. 15.

Eiu Infusorium (Stylonichia mytilus). Nach Stein. Infusorienkïrpers, denn ihr Verlust zieht unrettbar den Tod des 'Tieres nach sich.

Ich übergehe die Schilderungder anderen Stiltypen, weil die sechs Beispiele geniigen. Thuen eine Torstellung von den großen, in Wirklichkeit bestehenden Unterschieden der Organismen zu geben. Als Darwin 's Buch im Jahre 18509 erschien, war es allgemeine Ansicht der Zoologen, dass sieben stilistische Grundformen im Tierreiche herrschen, die in Verbesserung einer zuerst ron Cuvier aufGrund der Unterschiede in der allgemeinen Anordnung der Körperteile ausgesprochenen Erkenntnis angenommen wurden. Die eben an wenig Beispiclen und ganz oberflächlich charakterisierten Stileigentiimlichkeiten hatten nämlich den genialen französischen Anatomen G. Cuvier reranlasst, vier große Organisationskreise: Die Wirbeltiere, Weichtiere, Gliedertiere und Radiärtiere anfzustellen:

Der Typus der $\mathbf{W}$ irbeltiere umfasste die Säugetiere, Vögel. Reptilien, Lurche, Fische,

Der Typus der Gliedertiere die Insekten, Spinnen, Krebse, Gliederwiirmer,

Der Typus der Weichtiere die Tintenfische, Schnecken, Muscheln, Pteropoden, Brachiopoden, Cirrhopoden, Ascidien.

Unter dem Typus der Radiaten wurlen alle ïbrigen Gruppen: die Stachelhäuter, Polypen, Quallen, Eingeweidewürmer, Infusorien zusammengefasst.

Als man später die Unnatürlichkeit zweier Cuvierscher Typen erkannte und die Infusorien ganz von den Radiaten trennte, ferner den Rest der Radiaten in den Typus der Echinodermen und der Coelenteraten, sowie die Gliedertiere in die Arthropoden, Gliederfüßer d. h. Insekten, Spinnen, Krebse und in die Anneliden, 
Gliederwïmer, zerlegte, waren sieben gesonderte Organisationskreise der Tiere bekannt. In den letzten vierzig Jahren hat sich durch eingehende anatomische Forschungen die Notwendigkeit herausgestellt, noch mehr stilistische Typen zu unterscheiden, welche ich in tabellarischer Form hier aufzähle.

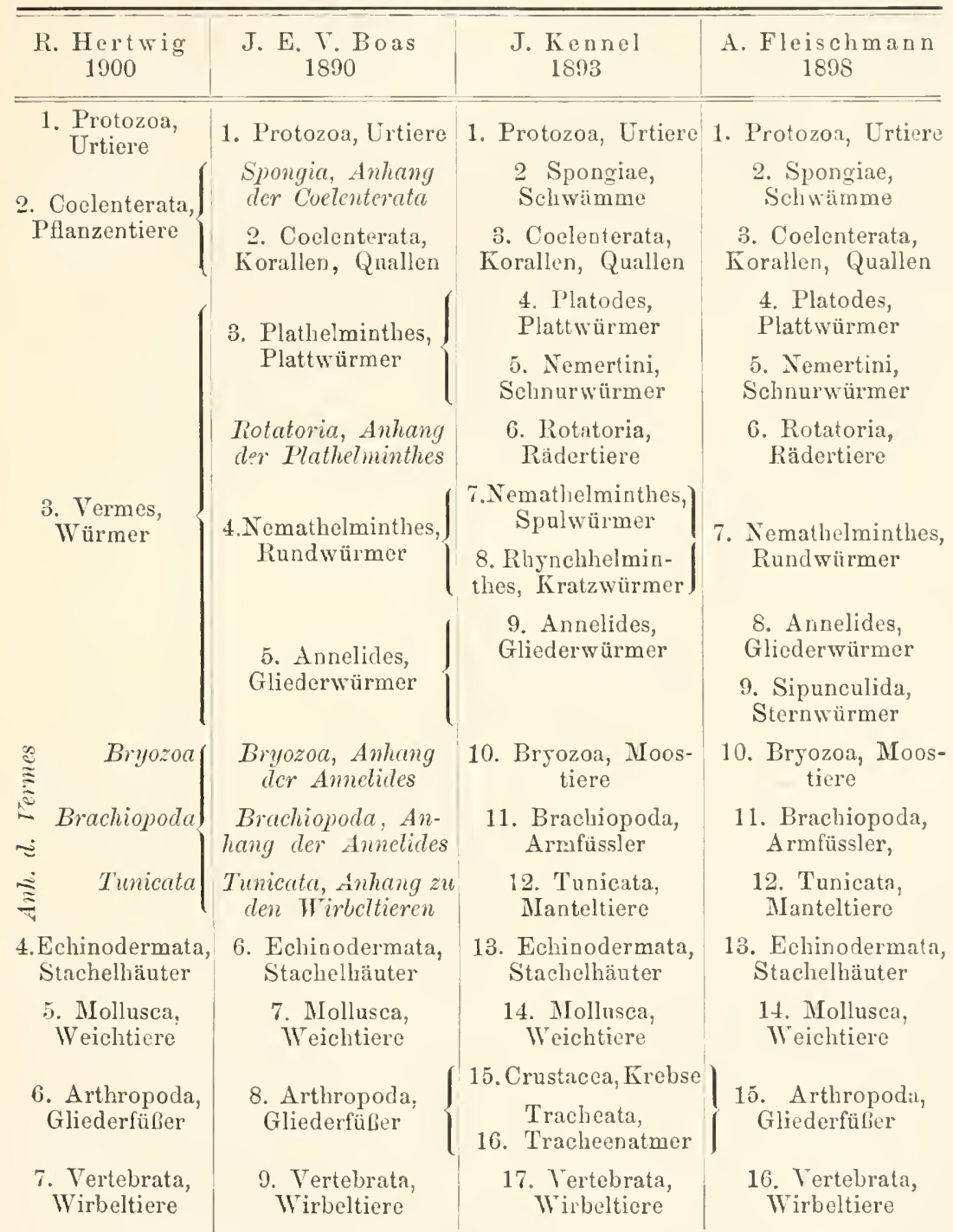


Die schärfere stilistische Trennung der Tiergruppen ist in wissenschaftlichen Abhandlungen durchgefülnt worden und hat sich ohne großes Geschrei vor der Öffentlichkeit vollzogen. Deshalb wurde die neuerliche Komplikation des Abstammungsproblems weiteren Kreisen gar nicht bekannt. Jetzt besteht aber die 'Thatsache, dass 17 Typen unterschieden sind, bei welchen die Körpergestalt, die Anordnung und die Ausbildung der einzelnen Organe in verschiedenartiger Weise erfolgt. Infolgedessen ist das Problem, welches von Darwin der zoologischen Wissenschaft rorgelegt wurde, als ein komplexes, zusammengesetztes Problem zu beurteilen. Es handelt sich nicht mehr um die verhältnismäßig einfache Frage, aus welchen Urformen die vier Curier'schen Kreise sich entwickelt haben, wir müssen vielmehr hinter jede cinzelne der Typen die Frage

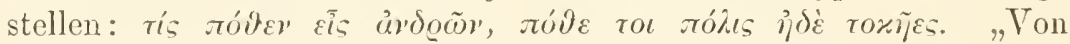
welcher Urform hast du dich entwickelt?" Der Laie unterliegt also gleich von vornherein einer großen Täuschung. Denn die Abstammungsfrage löst sich dem Eingeweihten zunächst in 17 gesonderte Probleme auf, welche gesondert untersucht werden müssen, und da ist die Zahl noch niedrig gegriffen, weil innerhalb jedes einzelnen Formenkreises wiederum ungeheuer viel Sonderprobleme auftauchen. 


\section{Drittes Kiapitel.}

\section{Der Bauplan der Gliedmassen.}

In der letzten Stunde habe ich Ihnen zu zeigen versucht, welches Problem durch das Erscheinen des Darwin'schen Werkes über die Entstehung der Arten der zoologischen Wissenschaft gestellt wurde und heute noch das allgemeine Interesse erregt. Die exakte Forschung soll ergründen, ob ïberhaupt die höheren stilistischen Typen des Tierreiches aus einfacheren Typen entstanden sind und mit der Bejahung der Frage zugleich erläutern, wie die eigenartige Organisation eines bestimmten Kreises sich in einen ganz anderen architektonischen Plan umgewandelt hat. Fermer wird Auskunft darüber verlangt, durch welche Ursachen die Umbildung eines Strukturplanes in den anderen hervorgerufen wurde. Die Schwierigkeit des Problemes tritt Ihnen lebhaft vor die Seele, wenn Sie sich nochmals der in der vorigen Stunde geschilderten Differenzen erimnern.

Bei den Wirbeltieren liegt das centrale Nervensystem in der Rückenzone des Leibes als ein Rohr, dessen solide Wand aus Nervenfasern und Ganglienzellen gewebt ist. Sein Vorderende in der Schädelregion schwillt zu den fünf großen Hirnblasen an. Bei sümtlichen übrigen Stiltypen wird diese Form des centralen Nervensystemes nicht mehr gefunden, meist tritt das letztere in Gestalt von bauchständigen Nervensträngen und segmental geordneten Ganglienknoten, wie bei den Insekten, auf oder in Gestalt von zerstreuten Ganglienzellhaufen, welche durch Nervenstränge verkniipft sind, wie bei den Mollusken.

Die Form des Herzens, seine Vorkammer und Kammer, sowie seine Lage im vordersten ventralen Winkel der Leibeshöhle stellt eine ganz unvermittelte, nur den Wirbeltieren zukommende Einrichtung dar. Solcher Beispiele ließen sich noch unendlich viele anführen.

Will die zoologische Wissenschaft die Frage lösen, von welchen Ahnen die Wirbeltiere stammen, so muss sie Zwischenformen suchen, die erläutern, wie die bauch- oder mundständigen Nervenmassen anderer Typen nach der Rückenseite verschoben und zugleich aus 
der Leibeshöhle entfernt in die solide Masse des Körpers eingelagert und von deu ganz neu erscheinenden Wirbeln umfangen wurden, wie sich das strangartige Nervensystem niederer Tiere in ein aus Ganglienzellen und Nervenfasern gewebtes Rohr umgewandelt hat, wie die Gehimblasen am vorderen Ende entstanden sind, welches die Veranlassung zur Bildung der Sinnesorgane wurde. Noch viele Hunderte von anderen Fragen sind dabei zu beantworten, um die Eintstehung des specifischen Gepräges für jeden Körperteil eines Wirbeltieres zu erklären.

Da für jede der siebzehn stilistischen Gruppen des Tierreiches die gleiche Arbeit zu leisten ist, so begreifen Sie wohl, dass das Descendenzproblem sachliche Fragen in Hülle und Füile innerhalb des Rahmens der zoologischen Fachwissenschaft aufgeworfen hat, welche mit der Schöpfungslehre der Theologen durchaus nichts zu schaffen haben. Viele von Ihnen haben bisher einer anderen Meinung gehuldigt, weil sie durch die Werke E. Haeckel's und anderer populärer Schriftsteller der Descendenzschule in falscher Weise darüber unterrichtet wurden. Daher kommt es, dass man jeden die neue Lehre nicht beifällig aufuehmenden Mann als Söldling der streng gläubigen Priesterschaft bezeichnet und ihm durch die ebenso bequeme, wie unbegründete Verdächtigung das Urteilsrecht abzusprechen glaubt.

Dieser Irrtum hat sich aus dem ersten Jahrzehnte der Darwinschen Bewegung in unsere Tage vererbt, weil die Verquickung vou zwei durchans nicht zusammengehörigen Ideenkreisen, der rein zoologischen Frage iiber die Abstammung der Tiere und der theologischen Schöpfungslehre, von Haeckel und seinen Freunden als ein Mittel angewendet wurde, um allgemeines Interesse für ihre Schriften zu erwecken.

Der Zoologe darf sich keiner Täuschung darüber hingeben, dass die sachliche Frage der Blutsverwandtschaft von Lebewesen, welche den meisten nicht einmal dem Namen nach bekannt sind, den Laien ebenso gleichgültig erscheint, wie so viele Tausend andere fachwissenschaftliche Fragen der Chemie, Mathematik, Philologie und Jurisprudenz. Was ich Ihnen neulich ïber die Architektur des Tierkörpers klar zu machen suchte, wird immer bloß den Fachmann lebhaft beschäftigen und ihn zu neuer Vertiefung anreizen. Jch glaube auch, manchem der Zuhörer nicht zu nahe zu treten, wenn ich die Vermutung äußere, er habe die Modelle und die stilistisehe Erklärung derselben wohl mit Aufmerksamkeit verfolgt, sei aber jetzt froh, dass ich die Darstellung dieser Punkte für genügend halte und auf eine breitere Ausführung verzichte. 
In dem Bestreben, die unleugbare Teilnahmslosigkeit aller' Nichtziinftler zu beseitigen, suchte Haeckel's Schule die neue zoologische Fragestellung durch den Vergleich mit dem mosaischen Schöpfungsberichte und deu Hinweis auf den Konflikt mit religiösen Ansichten interessant zu machen, ferner dadurch, dass sie aus der Fülle zoologischer Probleme die ganz untergeordnete Frage, ob der Mensch ron den Affen abstamme, als Kardinalpunkt herausgriff.

So wurde das Urteil des Publikums irre geleitet, das Problem seiner Aufrichtigkeit beraubt und die Diskussion wesentlich erschwert.

Der Fehler ist gar nicht zu entschuldigen, weil Haeckel ebenso gut wie jeder andere weiß. dass ein naturwissenschaftliches Rätsel durch die Anleihe bei theologischen Fundamentalwerken nicht gelöst werden kann. Die zoologische Wissenschaft müsste doch allgemeiner Verachtung preisgegeben werden, wenn ilıre Jünger, der eigenen Einsicht misstrauend, zu den Theologen sprechen wollten: wir haben im Buche der Natur gelesen, um die Stammesgeschichte der Tiere zu erfahren, aber keine Aufklärung gefunden, lest ihr uns aus der Bibel vor, damit wir gründliche Erkenntnis schöpfen.

Wie könnten Männer der exakten Beobachtung rekurrieren zu einem ehrwïrdigen Buche, das nimmermehr als Lehrbuch der Naturwissenschaft geschrieben wurde und andere $Z_{w}$ recke verfolgt, als Aufklärung über die modernen Probleme der Abstammungslehre zu bringen!

Fällt es niemandem ein, Belehrung über die Geographie, die Flora, die Fauna, die Geologie von Palästina uud Mesopotamien in der Bibel zu suchen, höchstens Belehrung über die dariiber bei den Zeitgenossen des Verfassers der mosaischen Bücher herrschenden Ansichten, so gedenkt auch der Zoologe nicht, seine junge Wissenschaft durch die Überlieferung der heiligen jüdischen Religionsschriften zu begründen. Trotzdem hat Haeckel den Gegnern der Descendenztheorie diese unsinnige Absicht untergeschoben, da er sie durch sachliche Gründe nicht zum Schweigen zu bringen vermochte.

Sie dürfen mir glauben, jeder will Sie uiber das wahre Verhältnis täuschen, der behauptet, die Descendenz habe auch nur eine leise Beziehung zur Religion. Das Problem ist für die Kreise der reinen Fachwissenschaft gestellt und wird durch anatomische Untersuchungen gelöst werden. Nur diejenigen Männer, die mit den Thatsachen der tierischen Anatomie, Entwicklungsgeschichte und Paläontologie genau vertraut sind, können darüber urteilen. Die lächerliche Erage, ob der mosaische Schöpfungsbericht zutrifft, kommt hierbei nicht in Betracht. Wenn ich iiber das Descendenzproblem nachdenke, kann ich natürlich auch historische Untersuchungen darüber 
anstellen, ob die Frage frïher aufgeworfen wurde, und muss dann von dem Versuche einer Antwort Kenntnis nehmen, dic im ersten Buche Mosis steht. Das kann den Naturforscher für einige Keit beschüftigen, aber indem wir die Geschichte des Problems verfolgen, sind wir doch nicht genötigt, alte einstmals von Laien geäulierte Ansichten als positive Wahrheiten hinzunehmen. Noch weniger werden wir den Kriegszustand zwisehen den Naturforschern und Theologen proklamieren, weil der exakte F'orseher das Fundament der Thatsachen jedem autoritativen Berichte rorzieht.

Nanche Naturforscher und manche Theologen mit naturwissenschaftlichen Neigungen haben gelegentlich versucht, einen Ausgleich zwischen den naturwissensehaftlichen und theologischen Glaubenssätzen zu finden, besonders seitdem vom Haeckel'schen Lager heftige Proteste gegen die fernere Aufrechterhaltung der ehristlichen Lehre erhoben worden waren. Mir scheinen die gut gemeinten Versuche erfolglos bleiben zu müssen, da die Anhänger einer bestimmten Überzẹgung sich durch einen Vermittler nicht rom Gegenteile belehren lassen. Sie scheinen mir aber auch im Prinzipe verfehlt, weil nach meiner Ansicht der Ausgleich zwischen Theologie und Naturwissenschaft überhaupt nicht zu suchen ist. Beide Fakultäten arbeiten zwar nach den gleichen logisehen Denkregeh, jedoch gehen sie ron verschiedenen Grundvoraussetzungen aus: Die Theologie glaubt, dass die heiligen Schriften die überirdische Offenlarung der Heilswahrheiten enthalten, die Naturwissenschaft dagegen will nichts für sicher ansehen, als das, was durch sinnliche Beobachtung festgestellt ist. Ein vernünftiger Mann kam nu darnach streben, die gegenseitige, durch die Zugehörigkeit zur Universitas litterarum gebotene, Toleranz der beiden, ganz versehiedene Ziele verfolgenden Wissensehaften im litterarischen und persönlichen Terkehre zu fördern und dafür zu sorgen, dass die Lehren der einen wissenschaftlichen Disziplin sagen wir der Theologie - nicht als kritischer Maßstab für naturwissenschaftliche Ergebnisse gelten und umgekehrt.

Weder beim Erscheinen vou Darwins Buche, noch heute handelt es sich um die Entscheidung, ob die Tiere ron Gott erschaffen oder anf natïrlichem Wege ohne Eingreifen einer überirdischen Macht entstanden sind. Wir haben nur zu zeigen, ob die Umbildung der Organisationstypen durch reelle Beweisstiicke sich belegen lässt; das ist zweifellos eine fachwissenschaftliche Frage, freilich in Anbetracht der Hilfsmittel und der Methode der exakten Forschung so außerordentlich kompliziert, dass ich in großen Zweifeln lin, ob sie ïberhaupt gelöst werden kann. Vorderhand ist sie noch nicht gelöst, wie die starken Meinungsversehiedeuheiten des heutigen Tages berreisen. Die Anhänger und Gegner polemisieren vor 
unseren Augen oftmals mit der gleichen Erregung, wie vor vierzig Jahren, obgleich ihr Streit eine sachliche Frage betrifft, welche die persönliche Verstimmung gar nicht rechtfertigt. Anatomische Untersuchungen werden die thatsächlichen Anhaltspunkte liefern; halten dann diese der kritischen Beurteilung stand, so wird sich der Beweis von selbst entwickeln, entweder, dass trotz der gewaltigen Unterschiede in der allgemeinen Körpergestalt, in der Terteilung, der Lage, dem Volumen, der Zahl und der Struktur der Organe, der Zeit ihres Entstehens und der Art ihrer Thätigkeit doch so viele übereinstimmende Eigenschaften bestehen, um uns den Übergang eines 'Yypus in einen anderen nicht bloß theoretisch annehmen, sondern durch die positiven Thatsachen rechtfertigen zu lassen, oder es wird sich das Gegenteil herausstellen.

Nachdem ich Ihuen gezeigt habe, dass das Abstammungsproblem eine fachzoologische Frage ist, erörtere ich kurz die Arbeitsmethoden, welche für die Lösung der Descendenzfrage in Betracht kommen. Die exakten Forscher gehen nicht von allgemeinen Sätzen aus und leiten nicht durch logische Deduktion daraus das Besondere ab. Sie fordern, dass alle Lehren auf einwandsfrei beobachteten Thatsachen begründet sind und gestatten es nicht, umgekehrt aus theoretischen Verallgemeinerungen Schliisse zu ziehen, für welche nachträglich Thatsachen als Beweise krampthaft gesucht werden. Die Folgerung aus allgemeinen Sätzen mag in manch anderer Disziplin glänzende Resultate zeitigen, in der Naturwissenschaft ist sie verpönt, so lange nicht eine sehr große ZahI von positiven Daten die Ableitung einer allgemeinen Behauptung notwendig stiitzen. Wir spotten z. B. darüber, dass vor sechzig Jahren die geistlichen und weltlichen Gerichte zu San Fernando in Chili einen Mann Namens Renoux wegen Zauberei verurteilten, weil er Raupen hatte, die sich in Schmetterlinge verwandelten. Aber dieselbe Unkenntnis herrschte vor 300 Jahren allgemein unter den Gebildeten und Gelehrten der alten Welt und ist bloß dadurch zerstreut worden, dass man die Thatsachen genau verfolgte, die Stadien der Raupen sammelte, die Veränderung des Körpers studierte und die Umwandlung in den Schmetterling durch die Beobachtung feststellte. Sicherlich wäre kein logischer DeduktionssehluB im Stande gewesen, das Resultat ebenso unanfechtbar zu erhärten.

So geht es in vielen anderen Fällen. Wenn iclı im Meere ein kleines Tier (Fig. 16) finde, von kegelförmiger Gestalt, mit Fortsätzen und Wimperschnüren, und behaupte, es sei die junge Larve eines Seeigels (Fig. 11), also eines Tieres, dessen kugeliger Leib mit Kalkstacheln und Wasserfüßchen bedeckt ist, so wird jeder verlangen, dass ich es auch beweise. Die Beweise 
wurden durch die eingehenden Beobachtungen von J. Müller vor 40 Jahren geliefert. So, wie jeder Schulknabe jetzt die Umwandlung der Raupen im Zuchtkasten verfolgt, so hat Müller die Seeigellarven beobachtet und gezeigt, dass sic

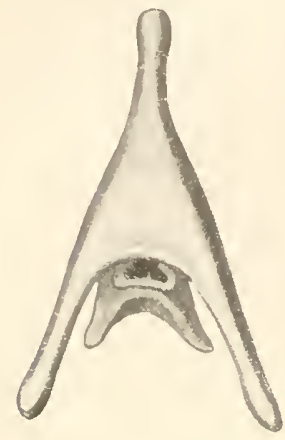

Fig. 16.

Pluteuslarveeines Seeige $1 \mathrm{~s}$. sich in einen Seeigel verwandeln, der so himmelweit von ihnen verschieden ist. Während der Seeigel durch die charakteristische Anordnung der meisten Organe nach fünfstrahligem Typus ausgezeichnet ist, erscheint die Larve bilateral symmetrisch, aber sie schreitet durch langsame Umbildung zur Organisation des Seeigels fort, wie jetzt deutlich nacligewiesen ist.

Wenn jemand sich weigern sollte, die Behauptung als richtig anzuerkennen, so bin ich im Stande, ihm die Umbildungsstadien vorzuführen und alle Zweifel zu lösen. Die Descendenztheorie, welche die Probleme der Metamorphose sämtlicher Stiltypen umfasst, muss gleichfalls so behandelt werden, indem die verbindenden Glieder zwischen den durch scharfe Grenzlinien der Organisation geschiedenen Kreisen demonstriert werden; denn die exakte Forschung soll zeigen, dass lebende Organismen die Stilgrenzen wirklich iiberschritten haben, nicht bloB, dass es unserem Verstande einleuchtend sei, sie hätten sie überschreiten können. Zu diesem Behufe müssen vermittelnde Formen, wie sie zwischen dem Raupenei und Schmetterling bekannt sind, zwischen den engeren und weiteren Gruppen des Tierreiches vorgestellt werden. Ihre Beschaffung ist fiir die Abstammungslehre unerlässliches Erfordernis, aber als Darwin's Buch erschien, waren solche Zwischenglieder nicht bekannt, überhaupt die Anatomie und Entwickelungsgeschichte der Typen zu wenig untersucht. In dieser Verlegenheit mussten einstweilen bereits bekannte Thatsachen den Fachgenossen und dem Publikum als scheinbare Beweise gelten, welche wenigstens innerhalb eines geschlossenen stilistischen Kreises die Unwandlung extremer Formen bezeugten.

Die Anatomie der Wirbeltiere bot einige bequeme Beispiele dar. Thre systematische Zusammengehörigkeit steht gauz außer Zweifel, weil die typische Anlage der meisten Körperorgane bei allen Arten der Fische, Amphibien, Reptilien, Vögel und Säugetiere übereinstimmt, trotzdem die äußere Erscheinung der fünf Klassen eine unerschöpfliche Tariation der Körpermodellierung zeigt. 
Im Körper eingebettet liegt das Kinorpel- oder Kinochenskelett, die lange Wrirbelsäule, welche aus zahlreichen Wirbeln besteht. Die Wirbel selbst lassen den cylindrischen Wirbelkörper, die oberen Bogen und die bauchwärts hängenden Rippen unterscheiden. Die oberen Bogen umspannen den Wirbelkanal, in welchem das nerröse Rückenmark geschïtzt ruht. während die Rippen in die muskulöse Leibeswand ragen und derselben neben der versteifenden Festigung einen gewissen Grad ron Beweglichkeit sichern. Am Vorderende der Wirbelsäule liegt der knöcherne Schädel. Die Leibeshöhle erstreckt sich nur über den Rumpf, nicht in die Kopf- und Schwanzregion. Der Darm zerfällt in drei Hauptabschnitte und hängt an einem breiten Band (Gekröse) ron der dorsalen Decke der Leibeshöhle. Die Hauptstämme der BlutgefäBe durchziehen in übereinstimmender Weise den Körper, stets liegt im vordersten ventralen Winkel der Leibeshöhle das Herz. Die Harn- und Geschlechtsorgane zeigen gleichen Typus. Ich könnte hundert und aber hundert allen Wirbeltieren gemeinsame Eigenschaften aufzählen. wenn ich nicht fürchten müsste, Ihre Geduld dadurch unnötiger Weise zu erschöpfen.

Dieselben waren im Jahre 1860 nicht so vollständig bekannt, wie heute, nachdem viele Spezialuntersuchungen unser Wissen anferordentlich erweitert haben. Aber ihr Torkommen spricht nicht unbedingt für die Richtigkeit der Descendenztheorie, weil sie nur Zeugnis für den gemeinsamen Bauplan der Wirbeltiere ablegen und mit sehr tiefgreifenden Unterschieden gepart sind. Um die bestehenden Gegensätze zu ermessen, brauchen Sie bloß an einen Fisch und einen Vogel zu denken, deren äußere Erscheinung und deren innerer Bau der Verschiedenheit des Aufenthaltsortes und der Lebensweise entsprechend ganz fundamentale Abweichungen ron dem allgemeinen Stilplan der Wirbeltiere zeigt. Das Gleiche gilt auch für die drei anderen Klassen: der Säuger, Reptilien und Lurche.

Lässt sich nachweisen, dass die Unterschiede einzelner Körperteile bei den Wirbeltieren graduellor, nicht wesentlicher Natur und dort, wo sie uns besonders auffallen, nur extreme Steigerungen einer, auderen Gruppen gleichfalls zukommenden Einrichtung sind, kurz gesagt, lässt sich nachweisen, daß die zunächst so fundamental geschieden erscheinenden Tierformen innerhalb der Wirbeltiergrenzen durch Ubergänge verbunden sind, so wäre es denkbar, dass anch zwischen den großen Organisationstypen eine gewisse Übereinstimmung herrscht, und die jetzt bestehenden Scheidelinien bei genauerer Analyse ihre Bedeutung teilweise verlieren.

In der ersteı Hälfte der Darwin'schen Periode erzwang der Mangel an umfassenden Untersuchungen, welche nach den eben 
charakterisierten und damals neuen Gesichtspunkteu durchgeführt gewesen wären, die bescheidene Zïgelung kühner Hoffnungen. Solche Vergleichungen, wie sie nunmehr notwendig wurden, erfordern Zeit, schon um das umfassende Untersuchungsmaterial zu sammeln und ferner, um die Vergleichung hinreichend zu vertiefen. Man war also darauf angewiesen, die bereits bekannten anatomischen Thatsachen innerhalb des Rahmens der Wirbeltiere - die Wirbellosen waren iiberhaupt ganz ungeniigend bearbeitet - in dem Sime zu prüfen, ob sich nicht aus ihnen allein ein vorläufiger Anhaltspunkt für die Umwandlung der Arten gewinnen lasse. In der That genügten einige Kapitel der vergleichenden Anatomie der neuen Geistesrichtung und wurden demgemäl; vielfach erörtert, um die Gegner zu der reformatorischen Lehre zu bekehren.

Für meine Absicht reicht es hin, ein einziges Beispiel, nämlich den einheitlichen Plan in der Verschiedenleit der Extremitäten der Wirbeltiere etwas eingehender zu besprechen. Die Gliedmaßen dieser großen, streng geschlossenen systematischen Gruppe erscheinen als äußere Anhänge des Leibes von cylindrischer, walzenïhnlicher, zwiefach winklig geknickter Form und stehen je ein Paar an der vorderen und hinteren Grenze der Rumpfgegend. Ob Sie einen Salamander, eine Schildkxöte, einen Marder ansehen, immer dienen die walzigen Gliedmaßen, den Leib über den Erdboden zu erheben, die Last des Krörpergewichtes zu stïtzen und das Tier vom Orte zu bewegen. Der gemeinsame Zweck der Bewegungsorgane hat es jedoch nicht verhindert, dass die Natur eine staunenswerte Mannigfaltigkeit derselben erzeugte und damit den besonderen Lebensbedïrfnissen der verschiedenen Wirbeltierarten Rechnung trug. Neben kurzen Stummelbeinen der Kriechtiere: Salamander, Eidechsen, Krokodile, Schildkröten, neben den niedrigen Fïssen kleiner Säuger finden wir langgestreckte grazile Säulenbeine bei guten Läufern, den Huftieren, die Beweglichkeit der Gliedmaßen steigt bei allen kletternden Arten (Affen); den Fliegern leisten sie als Luftruder vortreffliche Dienste.

Noch auffallender ist der Reichtum der Hand- und FuBformen. Um mich nicht ins Weite zu verlieren, will ich die Beispiele auf die Gruppe der Säugetiere beschränken. Die Gliedmaßen des Bären enden mit unförmlich plumpen Sohlenfiißen, aus deren Haarkleid die gekriimmten Krallen herausschauen. Die Vorderbeine des Schuppentieres tragen große sichelförmige Scharrkrallen an dem gleichmäßig cylindrischen Stamme. Beim Maulwurf ist die Hand schaufelförmig verbreitet. Die plumpen Beine des Elephanten laufen in eine stempelartige Anschwellung aus, an deren Rand wohl stumpfe Hufe, aber keine Finger sichtbar 
sind, während bei Menschen und Affen die Hand in feine zierliche Greiffinger gegliedert ist. Die schlanken Laufbeine der Huftiere endlich stehen gar mittels eines oder zweier Hufe auf dem Erdboden. Ich brauche die Beispiele nicht weiter zu häufen, um die ungeheure Abrechselung der natürlichen Handformen in Threr Erimnerung wachzurufen. Kein Laie wird durch ihren Anblick versucht, gemeinsame Gesetze des Baues zu vermuten. Die Freude der Anatomen, den einfachen gemeinsamen Bauplan für alle Gliedmaßen entdeckt zu haben, war darum sehr groß und klingt, trotzdem das stilistische Verständnis schon zu Ende des achtzehnten Jahrhunderts gereift war, in den darwinistischen Schriften der sechziger und siebenziger Jahre wieder.

Die Betrachtung der Gliedmaßen des lebenden Tieres hätte die Einsicht niemals gewonnen. Man muss die Haut, Muskeln und Bänder abpräparieren, um bei Vergleichung des Knochengeruistes die Stilverwandtschaft der Extremitäten zu entdecken. Arme und Beine zerfallen in je drei Regionen: Oberarm - Oberschenkel, Unterarm - Unterschenkel, Hand - Fuß und zeigen folgende Gliederung ihrer Skelettgrundlage (Fig. 17). In der oberen Region liegt ein einziges langes Skelettstiick (o), der Oberarmknochen, Humerus - Oberschenkelknochen, Femur; in der unteren Region folgen zwei parallele Stiicke, die Elle, Ulna (u), und die Speiche, Radius $(r)$ - das Wadenbein, Fibula, und das Schienbein, Tibia. In Hand bezw. Fuß schließen sich zunächst zwei Querreihen kleiner Knochenstückchen, die erste und zweite Reihe der Handwurzelknochen Fusswurzelknochen an. Mit Ihnen sind fünf längere Ḱnochensäulen, die Mittelhandknochen (m), Metacarpalia - Mittelfußknochen, Metatarsalia, verkniipft, welche je eine Reihe kürzerer Gliederstiicke, Phalangen der Finger - Zehen tragen. Durch die bündige Beschreibung habe ich Ihnen das Resultat der

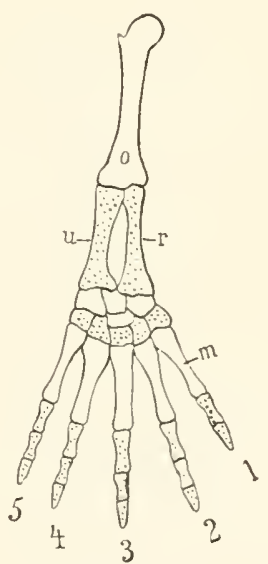

Fig. 17.

Schematische Skizze von der Zahl und Lagerung der Skelettelemente in der rechten Vordergliedma be. $m$ Mittelknochen, o Oberarm, $r$ Speiche, $u$ Elle. vergleichend-anatomischen Untersuchungen der letzten zwei Jahrhunderte vorgefuihrt. Trotz aller anffälligen und den ungeiibten Beobachter recht rerwirrenden Unterschiede sind alle, die vorderen wie hinteren Gliedmaßen nach einem gemeinsamen Plane gebaut. Derselbe ist nur in rerschiedener Weise modificiert. Aus der großen Zahl derselben greife ich wieder ein recht einfaches Beispiel 
heraus, nämlich die Terschiedenheit des Handskelettes bei den Säugern.

Jeder Taie stellt ohne weiteres fest, dass die Zahl der Finger in der Hand nicht ïberall dieselbe ist; während die Hand des Menschen (Fig. 18) und der Affen fünf frei bewegliche Finger trägt, ist die Fingerzahl anderer Arten gemindert. Zum Belege demonstriere ich Ihnen verschiedene Präparate. Beim Hunde (Fig. 19) z. B. ist der Daumen sehr klein. An der Torderpfote des lebenden Tieres sehen Sie rom ersten Finger iiberhaupt nicht mehr als ein wenig iiber die Haut vorragendes kurzes Wärzchen, am Skelette jedoch lassen sich der Mittelhand- und die Gliedknochen desselben deutlich nachweisen. Wenn auch schwach

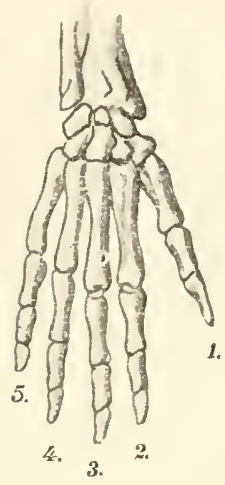

Fig. 18.

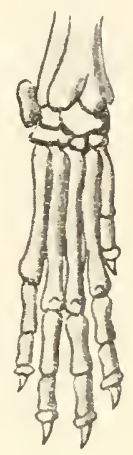

Fig. 19.

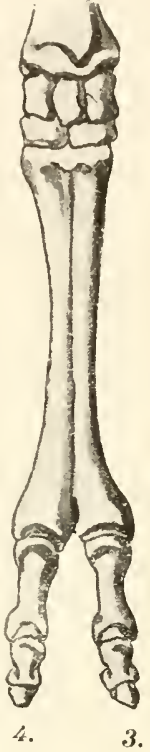

Fig. 20.

Flg. 18. Rechte Hand des Menschen. Nach Gegenbaur.

Fig. 19. Rechte Hand des Hundes. Nach Gegenbaur.

Fig, 20. Rechte Hand des Kameles. Nach Flower.

entwickelt, ist er doch vorhanden, wie an der Hand (Fig. 18) des Menschen, wo er in feiner Funktion geiibt wird.

Gehen wir weiter zu den Huftieren, so treten uns z. B. an der Hand des Kamels (Fig. 20) merkwürdige Einrichtungen entgegen. Statt der Mittelhandknochen, welche überall durch ihre Einfïgung zwischen die zweite Handwurzelreihe und die Fingerglieder erkennbar sind, findet sich ein einziger cylindrischer Knochenstab, das sog. Canonbein. An seinem unteren Rande hängen zwei Reihen von je drei Knochen, welche wir ohne weiteres als Fingerphalangen ansprechen diirfen. Nicht so leicht ist es verständlich, warum in der Mittelhand die Regel der 
fïnf wohl getrennten Mittelknochen durch die Anwesenheit eines derben Stiickes aufgehoben ist, und weiter ist die Frage zu entscheiden, welchen Fingern die beiden Reihen der Fingerglieder entsprechen, dem ersten und zweiten, oder dem zweiten und dritten. oder dem dritten und vierten Finger u. s. w.

Die Antwort ist bereits im rorigen Jahrhundert erteilt worden, als Fongeroux de Bondaroy, 1758 die Füße junger Kälher und Schafe präparierend, statt des einfachen Mittelknochens zwei getrennte, dicht an einander geschmiegte Säulenknochen fand und ihre spätere Terschmelzung feststellte. Die rergleichenden Anatomen dehuten hernach die Beobachtung anf andere Arten, Rehe, Hirsche, Antilopen u. s. w. aus und erkannten, dass in der Ordnung der Huftiere stärkere Reduktionen der Handknochen rorkommen als bei allen iibrigen Säugetieren.

Sie rerstehen den besonderen Fall ganz leicht, wenn Sie jetzt das Handskelett des Schweines (Fig. 21) betrachten, welches rier Finger, zwei starke und zwei kleinere, etwas nach riickwärts geschobene Phalangenreihen samt Mittelknochen besitzt, und sich dabei erinneren, dass wir beim Hunde bereits einen Fall kemnen gelernt haben, in welchem der Daumen schwächlich erschien. Dem Schweine fehlt der erste Finger rollständig. Die Deutung der iibrigen Finger bereitet keine Schwierigkeit, sobald Sie dieselben in ihrer natiirlichen Lage an einem vollstäudigen Schweineskelette betrachten. Nittelhand- und Gliedknochen des dritten und rierten Fingers sind kräftig; diejenigen des zweiten und fünften Fingers erscheinen als kleine Anhängsel und sind rückwärts an die hintere Seite des dritten und rierten Fingers gedrängt. Hornige Klauenschuhe umhiillen die äußersten Fingerphalangen, derbe kräftige am dritten und vierten Finger, schwächere, sog. Afterklauen bildend, am zweiteu und fünften Finger.

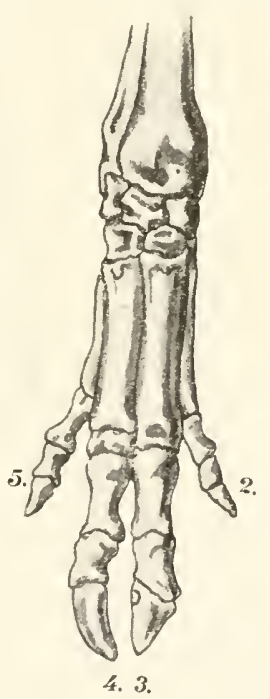

Fig. 21.

Rechte Hand des $\mathrm{Sch}$ weines. Nach Flower.

Darnach sind die zwei einzigen Phalangenreihen der Rinderhand dem dritten und vierten Finger zuzurechnen und das Canonbein als Terschmelzungsprodukt des beim Schweine getrennt bleibenden dritten und vierten Mittelkuocheus aufzufassen. Der Tergleich mit der Hand ron Hirschen und Rehen bestätigt unser Resultat. Denn hier (Fig. 22) finden wir ïber den Afterklauen winzige 
Phalangenreihen und beim Rehe sogar noch Reste der Mittelknochen des zweiten und fünften Fingers. Den Rindern und Terwandten ist also ron drei Fingern der Hand nichts übrig geblieben, als die zwei Hornschuhe der Afterklanen.

Sie merken jetzt schon, wie gut diese Beispiele in den Ideengang der Abstammungslehre passen. Die ganz extreme Handform der Wiederkäuer wird durch die Bekanntschaft mit weniger stark veränderten Beispielen ihrer Sonderstellung beraubt und dient dazu, die Gültigkeit des gemeinsamen Stilgesetzes zu bekräftigen.

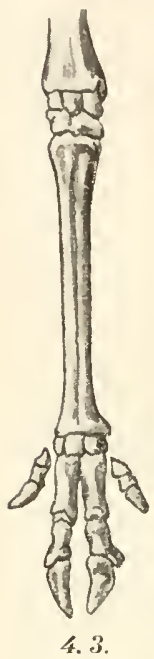

Fig. 22.

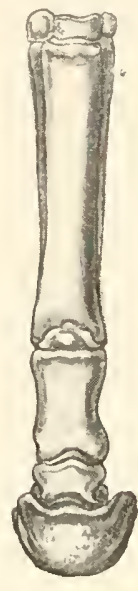

Fig. 23.

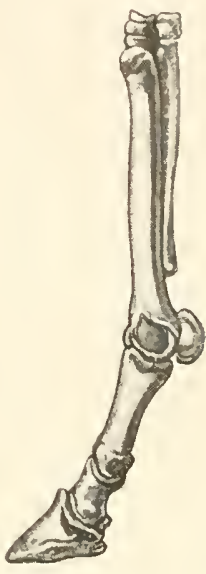

Fig. 24.

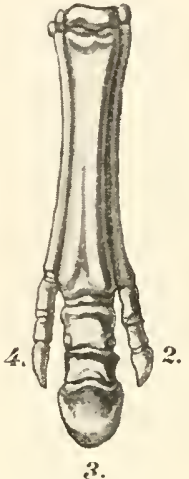

Fig. 25.

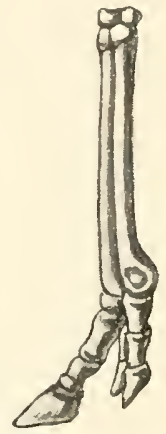

Fig. 26.

Fig. 22. Rechte Hand des Hirsches. Nach Flower.

Figg. 23, 24. Rechte Hand des Pferdes. Vorder- nnd Seitenansicht. Nach Gaudry. Figg. 25, 26. Rechte Hand von Anchitherium. Vorder- und Seitenansicht. Nach Gaudry.

Gleich erfreulich war die Analyse der Pferdehand (Fig. 23, 24), welche zuerst noch sonderbarer aussah, weil der Arm in eine einzige Phalangemreihe ausgeht. Ein kräftiger Mittelknochen stiitzt sich auf sie. Zu seinen beiden Seiten liegt je ein schmaler, spitz endender Knochenstab, die sog. Griffelbeine. In der Zone der Mittelhand angetroffen, miissen sie als Mittelknochen bezeichnet werden. Der Vergleich mit anderen Arten (Fig. 25, 26), bewies, dass sie die Reste des zweiten und vierten Hittelknochens sind. Also gehört der kräftige Mittelknochen samt den drei Phalangen dem dritten Finger an, und es sind bei den heutigen Pferden vies von den typischen fünf Fingern bis auf die Rudimente ihrer Nittelknochen gänzlich unterdriickt. 
Als sogar hier und dort lebende Exemplare ron Pferden gesehen wurden, welche neben dem einfachen Hufe zwei kleine, etwas emporgeschobene Afterhufe besaßen, jubelten die Anhänger der Abstammungslehre ïber die leiche Mühe, der Natur das Geheimnis der Schöpfung abzulauschen. Denı der dem einfingerigen Läufer unniitze Besitz ron zwei den Boden nicht beriihrenden Afterhnfen war ihnen nur durch Vererbung. durch leise Riickerinnerung an eine frïhere Periode der Geschichte des Pferdestammes erklärlich. Sie sagten, weil die Natur nichts Überfliissiges schaffe, die Organismen rielmehr ihren Bediurfnissen entprechend mit Werkzeugen ausrüiste, miisse das sporadische Anftreten der Afterklanen, sowie ihrer Ḱnochen, eine tiefere Bedeutung haben. Die naive Auslegung, dass die riickschlagende Kraft des Tererbungsgesetzes solche Erscheinungen bedinge und damit die stammesgeschichtliche Erforschung der Tierwelt ermögliche, fand damals unbedingten Glauben. Als endlich eine größere Zahl ron fossilen Tierarten durch die Paläontologen beschrieben wurde, deren Handskelett rerschiedene Grade für die Stärkung des dritten Fingers und Schwächung der übrigen Finger aufwies. wurden die Beweisakten vollständig geschlossen. Fs lagen uun mindestens zwei scheinbare Entwickelungsreihen ror, um für die Gruppe der Paarhufer die geschichtliche Ruickbildung der fünffingerigen Hand in eine zweifingerige und für die Gruppe der Unpaarhufer die Riickbildung in eine einfingerige Hand außer Zweifel zu stellen. Ja, die Spekulation trug die begeisterten Forscher bis zu der Behauptung, dass das rergleichend-anatomische Studium des Hand- und Fussskelettes die Abstammung der Säugetiere ron einer einfachen fünffingerigen kleinen Form nachgewiesen habe. Mögen Hand und Fuss rieler Arten mit fünf Fingern ausgeriistet sein orler mag der Reichtum beweglicher Endglieder bis auf zwei und eine Reihe, wie bei den Wiederkïtnern und Pferden herahsinken, oder mögen die Modifikationen der Säugerhand in ganz anderer Richtung wie bei den Walen und Fledermäusen erfolgen, deren Eigenart Sie in jedem Handbuche der vergleichenden Anatomie rerzeichnet finden, jedenfalls lässt nach der Heinung der Descenztheoretiker der gemeinsame Stilplan dieses Kürperabschnittes gar keine audere plansible Erklärung als die Abstammung ron gemeiusamen Urahnen zu.

Das Stilgesetz des Extremitätenbanes reicht iiber die Süngetierklasse hinaus. Arm und Bein der Tögel, den besonderen Lebensbedingungen in vortrefflicher Weise angepasst: der Arm samt seinem Federkleide als Luftruder dienend, das Bein zum Hiipfen, Klettern und Festhalten gebrancht, ließen denselben Grundplan erkennen und lehrten gleichzeitig einen ganz neuen Fall der Modifikation desselben. Die Gliedmaken der Reptilien und Amphibien zeigten 
sich der gleichen Regel unterthan. Deshalb schien kein Zweifel mehr erlaubt, dass die iiberraschende Einheit des anatomischen Gefüges desselben Organes bei vielen Tausenden von Tierarten durch deren direkte Blntsverwandtschaft verursacht sei, wie Darwin und seine gläubigen Schïler E. Haeckel und G. Jäger meinten. Das eine Beispiel erweckte frohe Hoffnung. Es eriibrigte für die Zukunft, andere Organe in der gleichen Weise zu prüfen. Wenn dasselbe Resultat für die Wirbelsäule, den Schädel, die Muskelu, Nerven, das Riickenmark, das Gehirn, die Sinnesorgane, für das Herz, die Lungen, den Darm u. s. w. zu Tage treten wiirde, was den Anhängern Darwin's vor der Untersuchung schon gewiss erschien, dann wäre die Stammesverwandtschaft aller Wirbeltiere bewiesen. Die Spezialuntersuchungen über die Weichteile der Wirbeltiere, welche mangels guter technischer Methoden frïher ungenügend erforscht waren, berichteten bald neue unerwartete Übereinstimmungen im Bane des Herzens, der Lungen, Nieren u. s. w.

Alle diese Befunde iibten auf das Denken der damaligen Forscher einen weitans größeren Eindruck als hente, weil jene, in der Schule der unterscheidenden Merkmale anfgewachsen, von den gemeinsamen Eigenschaften recht wenig erfahren hatten. So trug ein nebensächliches Noment zum Aufblïhen der Abstammungslehre bei. Die Siegesgewissheit steigerte sich durch nene Beispiele der stilistischen Concordanz von vorher als himmelweit verschieden beurteilten Organen und im Kraftgefühl des aufsteigenden Gedankens gaben die Autoren der sechziger und siebziger Jahre ihrer Überzengung Ausdruck: Wo die Ähnlichkeit in der Ausbildung gewisser Organe bei verschiedenen, im ,.unnatiirlichen " zoologischen Systeme Linné's weit auseinander gerissenen Gruppen gefunden wird, liegt Blutsverwandtschaft der Erscheinung zu Grunde nach dem Satze, dass die Glieder eines blutsverwandten Geschlechtes eine hochgradige Übereinstimmung auch der feinsten und kleinlichsten Ziige der Körperstruktur, ja ihrer Neigungen und Gewohnheiten zeigen. Die laute Wiederholung solcher und ähnlicher Gedanken iibertönte manche warnende Stimme klar denkender Forscher leider zum Schaden des ruhigen Fortschrittes der modernen Zoologie. Eine größere Portion von Skepsis wäre damals recht angebracht gewesen, damit viele ob der neu besprochenen Übereinstimmung die trennenden Unterschiede und das die stammesgeschichtliche Spekulation störende Gewicht derselben nicht ganz vergessen hätten.

Ich kehre wieder zum Thema meiner Betrachtung zurück, welches ich unmerklich verlassen habe, weil ich durch den absichtlichen Fehler die Abwege der stammesgeschichtlichen Schule zeigen wollte. Um Beweisgründe für die Verwandtschaft der Wirbeltier- 
arten zu finden, haben wir das geschichtliche Resultat der vergleichenden Forschung ïber das Extremitätenskelett, also das Resultat des Vergleiches fertiger Skelettformen ins Auge gefasst. Als dann die jeden unerfahrenen Mamn überraschenden Ergebnisse derselben bei den Huftieren sich hüuften, habe ich das Raisonnement der stammesgeschichtlichen Schule daran geknüpft und Sie selbst den rerlockenden Zauber solcher Denkweise empfinden lassen. Ich muss Sie also nochmals daran erimnern, dass unsere Absicht dahin zielte, neben den bestehenden Unterschieden der mannigfaltigen Arm- und Fußformen ïbereinstimmende Eigenschaften festzustellen. Das Ziel war zur Zeit der Neubelebung der Abstammungstheorie erreicht. Der einfache, ohne theoretische Beeinflussung ausgeführte Vergleich des Handskelettes sowohl, wie der ïbrigen Regionen der Gliedmaßen hatte die Herrschaft eines gemeinsamen Stilplanes für die Wirbeltiere erwiesen.

Dieses anatomische Resultat hat ungefähr den gleichen Wert wie die Erkenntnis der Stilhistoriker, dass sämtliche größere Kirchen der gothischen Periode gemeinsame Eigenschaften des Grundrisses, der Gewölbekonstruktion und des ornamentalen Schmuckes zeigen. Die descendenz-theoretische Schule aber hat das nüchterne Ergebnis anders gedeutet und aus der Konstatierung eines gemeinsamen Planes die Konsequenz gemeinsamer Ahnen gezogen. Ich kanu auch heuto für diese Folgerung die zwingende Notwendigkeit nicht einsehen und sicher werden Sie entschieden widersprechen, wenn jemand für die gothischen Hallenkirchen die ähnliche Behauptung aufstellen wollte, die gemeinsame Stilart derselben weise auf einen gemeinsamen Architekten hin. Doch trifft das Beispiel nicht vollständig, weil die gegenseitige Beeinflussung der mittelalterlichen Steinmetzschulen und ihrer wandernden Gesellen allbekannt ist.

Die Thatsache steht aber meines Erachtens außer Zweifel, dass der durchgehende Stilplan der Extremitäten bei Tierarten beobachtet wurde, welche durch viele andere Eigentümlichkeit außerordentlich stark von einander abweichen, und dass wir bisher nur einen Bruchteil des Wirbeltierkörpers untersucht haben. Aus der Ähnlichkeit eines Körperteiles folgt nicht, dass sämtliche übrigen Stücke denselben Grad der Üboreinstimmung besitzen miissen. Vergessen Sie für die Folge ja nicht, auch die stammesgeschichtliche Schule betont das, dass die anderen Organe ebenso genau zu prüfen sind, ehe der Beweis für die Blutsverwandtschaft wirklich geführt ist. Wollen wir also die Abstammung des einfingerigen Pferdes oder des zweifingerigen Rindes von fünffingerigen Ahnen gelten lassen, so müssen die Modifikationen des gesamten Skelettes und säntlicher Weichtheile in sichtbaren Stufen vorgeführt sein. 
In der Praxis, d. h. in populären Darstellungen für die Gebildeten und anch wohl in Lehrbüchern, vergessen die Descendenztheoretiker jedoch die offenkundige Unvollständigkeit des Beweismateriales und argumentieren zu gunsten ihrer Lehre, indem sie die morphologische Übereinstimmung eines einzigen Organes herausgreifen, sowie ich eben das Handskelett behandelte. Die erfreuliche Wirkung der einfachen Erkenntnis auf den Geist des ungeuibten Lesers wird dann benutzt, um bei ihm die Meinung zu erwecken, als sprïchen die anderen Organe die gleiche Sprache. Das mag im ersten Rausche einer neuen Idee nachgesehen werden, es kann späterhin, wie der heute noch anhaltende Erfolg der Lehre zeigt, dem Laien geniigen und einen jungen Mann verfuihren; denn wir wissen alle, als wir während der letzten Gymnasialjahre in $\mathrm{H}$ a eckel's Schöpfungsgeschichte ähnliche Beispiele lasen, erschien uns der Beweis für die sympathische Lehre zwingend. Den Fachgelehrten aber kann und darf das beschränkte Material nicht befriedigen. Indem er nach Vertiefung und Stärkung der Beweisgrïnde strebt, sieht er ein, dass die allgemeine Ähnlichkeit der einfingerigen Pferdehand mit der vollständigen Hand irgend eines Säugetieres. noch nicht zwingend die Blutsverwandtschaft beider fordert, weil oft die Ähnlichkeit verschiedener Tierarten in einem Organ mit den bedeutendsten Unterschieden in anderen Organen verknïpft ist. Die Feststellung der Ähnlichkeit erfordert also eine weitere Untersuchung der übrigen Organe. Die Laien halten solche Prüfung für überflïssig, sie sind zufrieden, wenn sie einen greifbaren Anhalt für eine zusagende Meinung kennen gelernt haben, und spötteln sogar über die Gründlichkeit des Fachmanns.

Sie aber werden jetzt begreifen, dass der begeisternde Eindruck, den vorhin die Kenntnisnahme des Handvergleiches auf Sie machte, die vertiefende Untersuclung nicht abschneiclen, sondern zu lebhafter Energie anfeuern muss, damit Unzulänglichkeiten der theoretischen Auffassung verhindert werden. 


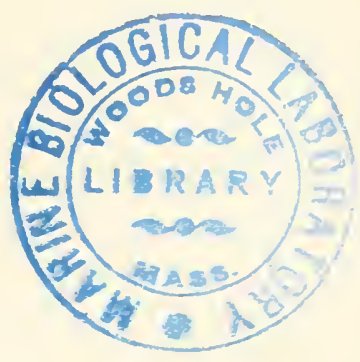

Viertes Kapitel.

\section{Fingerhand und Fischflosse.}

Durch den Versuch Darwin's, alle Tiere, welche jemals auf der Erde gelebt haben, heute leben und in fernster Zukunft leben werden, als Sprossen eines gewaltigen, die Oberfläche des Planeten iiberschattenden Stammbaumes anzusehen, wurde die zoologische Wissenschaft ror ein Problenı gestellt, das sie nicht lösen kann, trotzdem die Laien auf Grund der populären Darstellungen die Aufgabe im Bereiche der Möglichkeit liegend halten. Aber es kommt ja häufig vor, dass der mit einem bestimmten Wissensgebiete weniger vertrante Beurteiler die Schwierigkeiten einer Specialaufgabe unterschätzt und sich wundert, dass der Fachgelehrte nicht sogleich zu einer Antwort bereit ist. Das Ansehen des letzteren leidet bei der großen Nenge sogar Schadeu durch das freimuitige Bekenutnis, dass das Descendenzproblem sein wissenschaftliches Termögen iibersteigt, und es bedarf dann einer mïhsamen aufklärenden Arbeit, um den weitgehenden Optimismus des Laienpublikums auf das richtige $M[a \beta$ zuriickzufiihreu.

Die Abstammungslehre ringt zunächst mit der Unmöglichkeit, vermittelnde Zwischenglieder zwischen den durchso große Unterschiede in der Form und Anordnung der einzelnen Körperteile getrennten Formtypen des Tierreiches vorzulegen und genar zu beschreiben. Die Notwendigkeit, dieser Forderung zu genïgen, wird niemand abstreiten. Denn es steht außer Zweifel, wenn ich die Behauptung aufstelle, dass die im Neere freischwimmende und in Figur 16 abgebildete, kleine Larve sich in einen Seeigel umwandelt, so liegt mir die Pflicht der Beweisfuihrung ob. Es wäre sogar eine Beleidigung für jeden denkenden Mann, wollte ich erwarten, dass er meine Behauptung ohne Beweis annähme. In wissenschaftlichen Fragen herrschen eben die gleichen Regeln wie im praktischen Leben. Habe ich gegen jemand eine Beschuldigung erhoben, so muß ich ror Gericht die thatsächlichen Beweise für die Berechtigung meiner Behauptung rorlegen. Ebenso muß ich, wenn ich ïber den Bau oder die Entwicklung jetzt lebender Tiere eine Abhandlung reröffentliche, die meine Ansicht 
rechtfertigenden Priiparate teils durch Beschreilnung, teils durch genaue Abbikdung drelben vorführen oder direkt demonstrieren, um allen Fachkollegen die Möglichkeit zu geben, meine Anschaumnen zu kontrollieren. In jeder Frage iiber jetzt lebende Tiere muss ich so verfahren, wenn ich das Vertranen und die Achtung meiner Fachgenossen genieBen will, und gehorche damit der strengen Beweisverpflichtung jeder exakt betriebenen Wissenschaft, die allen Fachvertretern anferlegt ist, weil durch sie allein die Gewähr für die sichere Begründung mserer Lehren und für ihre gegen den Aberglauben und Autoritätsbann sieghafte Kraft gegeben wird.

Der Naturforscher, welcher die Descendenztheorie als die unabweisliche Toraussetzung der modernen - zoologischen Arbeit ansieht, muss die gleiche Terpflichtung als bindend anerkennen, und sein Bestreben, die Beweisführung für dieselbe so schlagend als möglich zu gestalten, wird ihn veranlassen, die vermittelnden Zwischenglieder, die Übergangsformen rerschiedener Organisationskreise, zu suchen.

Aber die Ausfïhrung des wohlberechtigten Versuches ist durchaus unmöglich. Wenn iiberhaupt eine Umbildung der Organismen stattgefunden hat, so geschah sie in grauer Urzeit; kein Zoologe war im stande, den Prozess selbst zu beobachten, die Zwischenglieder zu sammeln und für ein modernes Musenm zu konserrieren. Der Kampf ums Dasein, Elementarereignisse und geologische Katastrophen haben ihre Spuren vertilgt. Man kann also hentzutage einen allen Anforderungen der exakten Naturforschung entsprechenden wissenschaftlichen Beweis für die Abstammungslehre nicht mehr führen. Denn er kïnnte nur durch Demonstration der Umwandlungsformen sellsst erbracht werden. Das ganze Problem liegt darum anßerhalb des Bereiches ler exakten Naturwissenschaft, d. h. es kann nur rermittelst der kombinatorischen Phantasie unseres Denkvermögens, nicht aher durch Realitäten behandelt werden. Die meisten meiner Fachkollegen betrachten es jedoch als eine lösbare Aufgabe und glauben auch, die exakte Methode der beschreibenden Naturwissenschaften zu ihrer Lösung verwenden zu können. Da sie nicht im stande sind, die rermittelnden Zwischenformen rorzuführen, so lassen sie die neulich besprochenen scharfen Grenzen zwischen den Organisationstypen gern beiseite, ignorieren die bestehenden Unterschiede im Aufbau eines Wirbeltieres, eines Seeigels, einer Schnecke u. s, w. und suchen innerhalb eines stilistischen Kreises die zwischen den Gliedern desselben vorhandenen Differenzen geringeren Grades entweder ganz zu verwischen oder als weniger bedeutsam zn erweisen. In dem engeren Rahmen, wo der Prozess der Umbildung gleichfalls nicht zu beobachten ist, spiiren sie nach Zwischenformen teils unter den jetzt lebenden Arten, teils in den 
versteinerten Resten ausgestorbener Geschlechter und verdecken die Erfolglosigkeit der Bemiihungen gerne durch die pathetische Hoffnung, dass gliickliche Funde zur Ausfiillung der immer noch bestehenden Liicken beitragen werden.

Immerhin erscheint auf den ersten Blick das rergleichende Studium gewichtige Zeuguisse fïr den Gedanken gemeinsamer Abstammung zu liefern.' Das Hand- und FuBskelett der Wirbeltiere zeigt viele Unterschiede. Schon innerhalb einer einzigen Gruppe der Säugetiere ist die Mannigfaltiglieit der Gliedmassenbildung auBerordentlich grob. Die an ihnen zu Tage tretenden Unterschiede ließen noch vor 200 Jahren die Männer der Wissenschaft keine gemeinsamen: Eigenschaften der vorderen Extremität der Säugetiere, geschweige aller vierfïßigen Wirbeltiere rermuten. Die anatomischen Untersuchungen seit Beginn des rorigen Jahrhunderts haben uns rom Gegenteil belehrt. Es mnterliegt keinem Zweifel mehr, die so verschiedenartigen Leistungen dienenden Hände und Fïbe aller höheren Wirbeltiere sind nach einem einheitlichen Bauplan angelegt. Wer einmal daranf aufmerksam geworden ist, kann denselben in sehr rielen Fällen dentlich erkennen, jedoch sind die gemeinsamen Charaktere nicht immer so scharf ausgebildet. wie an der Figur 17. Denn die Natur führt den Plan oft ungleichmäßig aus, sie unterdriickt manche Teile, um andere dafïr zu entfalten, sie rerschmilzt Knochen der Handwurzel, drängt Knochen des L'nterarms zuriick, und rariiert die Länge des Oberarmes gar mannigfach. Aber trotz aller Modifikationen legt die anatomische Tergleichung in jedem einzelnen Ealle den einfachen, gemeiusamen Bauplan klar. Da nun der 'Typus nicht gleichmäßig durchgeführt ist, lassen sich die spezitischen Formen so ordnen, dass am Beginn der Reihe die fünffingerige Hand, am Ende der einfingerige Pferdefuß und andere stark reducierte Handformen stehen und dazwischen die rerbindenden Glieder eingeschoben sind. So erhalten wir eine durch die rergleichende Nebeneinanderstellung rerschiedener Handskelette gebildete Formenreihe oder wie man auch sagt $\mathrm{Umbildungsreihe,} \mathrm{und} \mathrm{der} \mathrm{wohl} \mathrm{unterxichtete} \mathrm{Anatom}$ Kann dieselbe durch Beispiele aus sämtlichen Gruppen der vierfïßigen Wirbeltiere rerrollständigen.

Der früher besprochene Grundplan beher'scht alle Arten der vier höheren Kilassen des Wirbeltierreiches. In der fünften Klasse jedoch, den Fischen, ist ein anderer Stiltypus für den Aufbau der Gliedmaßen geltend. Das bedeutet eine sehr bedenkliche Schwierigkeit fuir die Abstammungslehre. Sie wissen aus den populären Schriften, wenn die Wirbeltiere sich iiberhaupt ron niederen Lebewesen entwickelt haben, so müssen die Fische die Durchgangsstufen dar- 
stellen. Die Palïontologie hat deren Reste in uralten Ablagerungen von den oberen Silnrschichten an gefunden; zur Karbonzeit haben Knorpelfische die Neere unseres Planeten mit großer Individuenund Artenzahl bevölkert und in massenhaften versteinerten Resten dentliehe Spuren hinterlassen. Diese Urfische müssen die Stammeltern aller iibrigen Wirbeltiere gewesen sein, oder wenigstens denselhen sehr nahe gestanden sein, so lautet die unabweisliche Schlussfolgerung der Descendenztheorie.

Vom theoretischen Standpunkte ist gegen dieselbe nichts einzuwenden. Wir haben aber jetzt die thatsächlichen Beweise dafür zu prüfen. Wenn wir zu diesem Behufe die übrigen Wirbeltiere mit den Fischen vergleichen, um die gemeinsamen Eigenschaften aufzufinden, welche Blutsverwandte zeigen müssen, so fallen uns recht viele und scharfe Unterschiede auf. Ich will von den meisten

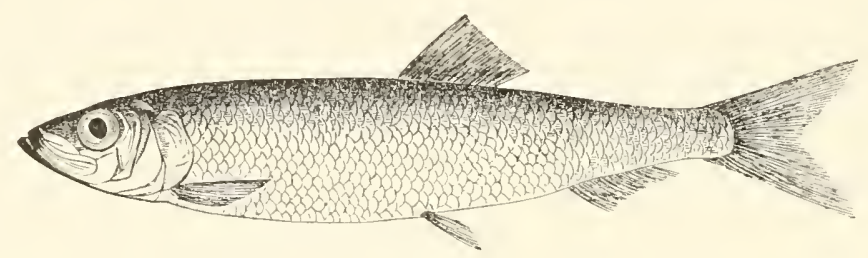

Fig. 27.

Der Laehs, Salmo salar.

derselben, vou der spezifischen Fischgestalt der in das Wasser gebannten Schwimmer, von dem Schuppenkleide, von der besonderen Art der Kiemenatmung und vielem anderen hente nicht reden, um nur ein Organ, die Gliedmaßen, zur genaueren Besprechung herauszugreifen. Die Fische bewegen sich mittels Flossen, die übrigen Wirbeltiere stehen auf fünffingerigen GliedmaBen.

Ist die Behauptung der Descendenztheorie richtig, so muss sich nachweisen lassen, in welcher Weise die parigen Flossen der $F$ ische, die Brust- und Bauchflossen, in die fünffingerige Arm- und Fußstiitze der iibrigen Wirbeltiere umgebildet ward. Hier beginnen sofort unüberwindliche Schwierigkeiten, weil die Struktur der Flosseu ganz eigenartig und kaum mit derjenigen der Gliedmaßen vergleichbar ist. Um die Darstellung dieser Verhältnisse nicht ïbermäßig zu komplizieren, werde ich Ihre Aufmerksamkeit. nur auf die Skelettbestandteile einerseits der Flossen, andererseits der fünffingerigen Gliedmaßen lenken und die Weichteile, die Bänder, die Muskeln, Nerven, Blutgefäße außer acht lassen.

Die Fischflosse zeigt einen viel größeren Reichtum an kleinen strahlig geordneten Slielettstiicken als jegliche Gliedmaße 
eines Salamanders oder Säugetieres. Trotz vielfacher, alle Erwartungen iibersteigender Mannigfaltigkeit der Flossenformen bei den 10,000 Arten der Fische sind doch gemeinsame Formbeziehungen unter ihnen erkannt, und als Grundform kann nach Gegenbaur die Flosse der Haifische gelten.

Daran fallen (Fig. 28) drei große durch straffe Bandmassen verbundene Knorpelstücke, das Pro-, Meso-, Meta-Pterygium auf, welche an der Basis der Flosse gelagert und die Verbindung zum Schultergïrtel bildend, mit zahlreichen in strahligen Reihen geordneten kleineren Knorpelstiicken besetzt sind, welche in den Flossenkörper auslaufen. Die Flossen anderer Fischgruppen bieten zwar im einzelnen viele Unterschiede, wir sind aber im stande für cine große Zahl der Fischflossen die übereinstimmende Anordnung ihrer Bestandteile, wie sie diese schematische Flosse zeigt, nachzuweisen. Darüber be-

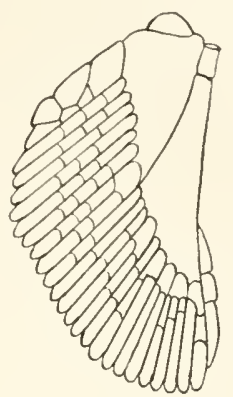

Fig. 28.

Knorpelskelett iler Brustflosse ron

Acanthias vulgaris. Nach Gegenbaur. stehen wenig Meinungsverschiedenheiten unter den Fachgelehrten.

Da die Abweichungen ron der als Norm betrachteten Flossenform uns heute nicht interessieren, stelle ich Ihnen sogleich einen anderen von der descendenztheoretischen Spekulation seit dem Erscheinen eines Aufsatzes von C. Gegenbaur $r^{1}$ viel besprochenen Formtypus, das sog. biseriale Archipterygium in der Brustllosse eines Lungenfisches, des Barramunda, Ceratodus Forsteri (Fig. 29), vor. Die kleinen Skelettelemente der lancettförmigen Flosse dieses erst vor dreißig Jahren entdeckten australischen Fisches sind so angeordnet, dass um einen Stamm, der eine Hauptreihe zahlreicher gegen die Spitze an Umfang abnehmender Knorpelplatten darstellt, zwei Längsreihen kleiner Strahlen stehen, welche die Flosse selbst

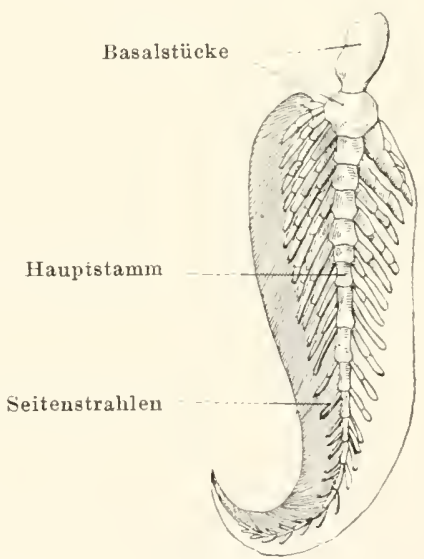

Fig. 29.

Brustflossedes Ceratodus. Nach Gegenbaur. stützen.

Der Ihnen sofort auffallende Contrast zur Flosse der Haifische

1) C. Gegenbaur, Über das Archipterygium, Jen. Zeitschr. VII, 1873. 
lïsst sich abschwächen, wenn man nur annimmt, die Strahlen der einen Seite hïtten sich vollstindig zurïckgebildet und die der anderen Seite hiitten sich teils durch Verkiirzung des Hauptstammes, teils durch Zusammenschiebung in das an der Haiflosse erscheinende Bild gruppiert. Viel gröBer erscheint aber der Gegensatz zu der fünffingerigen Extremität der übrigen Wirbeltiere. Abgesehen davon, dass die strahlige Ordnung der Knochenteile nicht dentlich ausgeprïgt ist, dass in der Fischflosse die knorpeligen Stiicke durch Bünder schicr unbeweglich verknïpft sind, während in den Gliedmaken der höheren Wirbeltiere zwischen den einzelnen Skelettstücken, die meistens verknöchern, Gelenke auftreten und der gegenseitigen Verschiebbarkeit der einzelnen Teile Gewiihr leisten, ist die Zahl der Stücke des Arm- und Beinskelettes viel geringer: Die Flosse von Ceratodus enthält mehr als hundert, die Flosse des Dornhaies ungefähr sechzig, die Gliedmaße eines höheren Wirbeltieres lıöchstens dreiundllreißig Stiicke.

Wenn Sie mich nun fragen, wie die vorschiedonen, entweder in der Klasse der Fische oder in den vier höheren Wirbeltierklassen herrschenden Formen der Extremität als stammesgeschichtliche Ent-

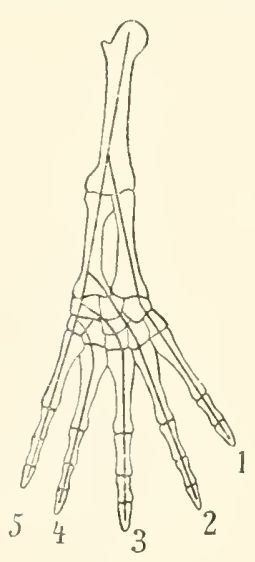

Fig. 30 .

skizze des skelettes der rechtengliedma $B$ e, in welche die Strablen nach fregenbaur eingezeichnet sinil; der Hauptstrah! zieht durch Oberarm, Elle und füften Finger. wickelungsstufen erwiesen werden, so kann ich darauf nur mit dem Referate einer Theorie antworten, welche C. Gegenbaur vor 30 Jahren aufgestellt und seither vertreten hat, obwohl strikte Beweise für seine Ansicht nicht vorliegen.

Eine ablehnende Stimmung gegen dieselbe wird bei Ihnen zunächst der direkte Augenschein crwecken, da der Vergleich des Flossen- und Gliedmaßenskelettes (Figg. 28, $29,17)$ den Mangel einer deutlich strahligen Kinochenordnung im Arm- oder Beinskelette darthut. Gerade diese topographische Beziehung ist ja charakteristisch für alle Flossenskelette und muss auch an der Hebelgliedmaße irgendwie zu sehen sein, wenn sich dieselbe aus der Flosse irgend eines unbekannten Urfisches zu höherem Typus fortschreitend entwickelt hat. Um die Schwierigkeit zu beseitigen, braucht man nach $\mathrm{Gegen-}$ baur's Vorschlag in der schematischen Fig. 30 nur eine Linie zu ziehen, welche die Richtung des Hauptstrahles andeutet, dann kann durch vier weitere Hilfslinien dic strahlige Reihenstellung aller Extremitiitenknochen gezeigt werden. Auf diese Weise wird 
durch die Zeichnung der Eindruck erweekt, als seien die an 'Zahl geringen Knnochen der Hebelgliedmalie reihenweise geordnet; und man kann nummehr das ganz anders geformte und als bewegliches Hebelsystem wirksame Skelett der Gliedmaßen aus dem bei den Lungenfischen angetroffenen biserialen Zustande ableiten durch die Vorstellung, dass die Knorpelreihe der einen Seite gänzlich zu Grunde ging, dass die Strahlen der anderen Seite stark reduziert, nur zum Teile erhalten und mit ihren Enden weiter auseinander geschoben wurden, indess das Basalstiick der Stammreihe als Oberarmknochen, humerus, bezw. als Oberschenkelknochen, femur, mïchtig entfaltet worden sei. Dann würden die Phalangenknochen cines Fingers den Endstiicken der Stammreihe entsprechen. Gegenbaur hielt 1870 dafür, dass die Speiche des Vorderarmes und die Knochen des Daumens so aufzufassen sind, später bezeichnete er das Ellenbogenbein, und den fünften Finger als Ausläufer des Hauptstrables, und heute getraut er sich nicht zu entscheiden, ob der Hauptstamm ganz erhalten sei und seitlich die wenigen (vier) Strahlen trage, oder ob vom Hauptstanıme nur das kräftiger entfaltete Basalstiick vorhanden und mit fünf in die Finger auslaufenden Strahlen besetzt sei.

Obwohl die Idee bereits $1870^{1}$ ) veröffentlicht wurde, ist man seither nicht weiter gekommen. Zum Beweise will ich einige Abschnitte aus modernen Lehrbüchern vorlesen, zugleich ausdrücklich bemerkend, dass ich Stellen aus Büchern heranziehe, deren Verfasser Anhänger der Descendenztheorie sind. Ich rïcke die Darstellung Haeckel's an den ersten Platz, damit Sie durch die nachfolgenden Äußerungen anderer Forscher lernen kömnen, wie sehr der Laie durch die Lektüre seiner. Schriften über den wirklichen Stand einer zoologischen Frage getäuscht werden kann. In der systematischen Phylogenie, einem dreibündigen Werke, das sich ansschlieblich an Fachgelehrte wendet und Laien nicht verständlich ist, heilit es mit einer iiberraschenden Bestimmtheit ${ }^{2}$ ), gleich als wïre der Vorgang selbst beobachtet:

..Aus den polydaktylen Flossen der Fische und Dipneusten (Lungevfische) entwickelte sich spätestens während der Karbonzeit der pentadaktyle (fünftingerige) Fuss der Amphibien und vererbte sich ron dieser Stammgruppe der Quadrupeden (rierfiißigen Tiere) anf sämtliche Amnioten (d. h. Reptilien, Vögel und Säugetiere). Die bedeutenden Teränderungen der Funktion, welche dabei die paarigen Gliedmaken erlitten, wirkten auf alle Teile ihrer Struktur zurück. Aus dem einfachen Hebel der platten Fischflosse wude der gegliederte

1) C. Gegenbaur, Jenaische Zeitschr. Y, p. 433.

$\left.{ }^{2}\right)$ E. Haeckel, Systematische Phylogenie. Berlin 1895. III. Bl., p. 91. 
Hebclapparat des Gangfußes, für welchen ein höherer Grad von Festigkeit, Gelenkigkeit und Beweglichkeit unerlässlich war. Indem die Dipneusten (Lungenfische) das Wasser verließen und ihre Ruderflossen zum Fortschieben anf dem festen Lande benutzten, trat in erster Linie eine transversale Gliederung der freien Extremität ein, sowie eine festere Verbindung mit dem Rumpfskelett; lie biegsamen Knorpelstäbe verwandelten sich in feste Knochen; an ihren Verbindungsstellen bildeten sich Gelenke aus. - - Schon bei den ältesten Amphibien, deren fossile Reste wir kennen, den karbonisehen Stegocephalen, tritt uns die Pentanomie, der typische Skelettbau des pentadaktylen Fußes, in derjenigen charakteristisehen Ausbildung entgegen, welche er auch noch bei heutigen Amphibien besitzt, und deren unverwischbare Grundziige sich von diesen auf sämtliche Amnioten vererbt haben."

Beachten Sie, dass $\mathrm{H}$ a eckel hier wohl von den alten Zeugnissen fiir das Torkommen der fuinffingerigen Fiiße, aber nieht ron $Z$ wischenformen zwischen der Fischflosse und dem FingerfuB redet.

In dem jüngst erschienenen, für die große Masse der gebildeten Laien bestimmten Buche „Die Welträtsel" berichtes: Haeckel1) wie folgt:

"Der bedeutendste rergleichende Anatom der Gegenwart, Carl Gegenbaur, zeigte in seinen, Untersuchungen zur vergleichenden Anatomie der Wirbeltiere' (1864), wie diese charakteristische ,fünfzehige Beinform' der landbewohnenden Tetrapoden urspriinglich (erst in der Steinkohlenperiode) ans der vielstrahligen, Flosse" (Brustflosse oder Bauchflosse) der älteren wasserbewohnenden Fische entstanden war."

Gegenbaur ${ }^{2}$ ) selbst hatte aber das Ergelnis seiner Untersuchungen etwas anders bezeichnet:

„Es ist also das Extremitäten-(Gliedmaßen-)skelett der höheren Wirbeltiere nur in seinen allgemeinsten Einrichtungen mit jenem der Selachier (Haifische), und damit auch der iibrigen Fische vergleichbar, und so bestimmt es aus den im Laufe dieser Abhandlung hervorgehobenen Thatsachen hervorgeht, dass das Metapterygium der auch in das Skelett der Vorderextremität der höheren Tiere iibergehende Abschnitt der Brustflosse der Fische ist, so wenig begrindbar ist eine Ausführung der Vergleichung der einzelnen Stiicke mit einander. Wir

1) E. Haeckel, die Welträtsel. Bonn 1899, p. 35. Zeile 21.

2) C. Gegenbaur, Untersuchungen zur vergleichenden Anatomie der Wirbeltiere. II. Heft 1865, pag. 169. 
haben selbst bei den Selachiern (Haifischen) solch bedentende Verschiedenheit im Flossenbau gefunden, dass nur wenige Stiicke in allen gleichmäßig nachgewiesen werden konnten, die bei weitem größere Mehrzahl dagegen keine Vergleiche zuließen. Das Armskelett der höheren Wirbeltiere verhält sich nicht anders zum Flossenkelette der Selachier etc., als die Flossenskelette der Selachier etc. unter sich. Auch bei diesen fand die Vergleichung nur eine Homologie der Einrichtung des Ganzen, nicht der einzelnen Teile. Es fehlen also die Nachweise der speziellen Homologien, weil die Übergangsformen uns abgehen, nicht nur die ron den Fischen zu den höheren Wirbeltieren, sondern anch jene, welche unter den Selachiern einen unmittelbaren Zusammenhang herstellen könnten."

Acht Jahre später erklärt Gegenbaur ${ }^{1}$ ), dass seine Untersuchungen in der „A ufstellung einer Grundform des Gliedmaßenskelettes der Wirbeltiere und der stufenweise verfolgbaren Ableitbarkeit aller bis dahin bekannten Formzustände desselben ihren Abschluss fanden." Bei manch anderer Gelegenheit hat der Begründer der Theorie das Hypothetische und Ungeniigende seines Versuches scharf gekennzeichnet: Ebenso rorsichtig drïckt er sich im ersten Bande seines kürzlich erschienenen Handbuches der vergleichenden Anatomie ${ }^{2}$ ) aus :

„Eine weite Kluft trennt die Organisation der Flosse von jener, welcher wir ron den Amphibien an im Armskelette begegnen." - - In den nächsten 15 Zeilen wird der Gedanke ausfiihrlicher besprochen. _ _ ,Eine Reihe ron Übereinstimmungen lässt das Skelett der Gliedmaßen der höheren Wirbeltiere mit jenem der niederen verknüpfen, wie es zuerst durch mich geschehen ist. Wenn wir nicht ron einem einzelnen gebildeten Zustande ausgehen, wie er da und dort verschiedenartig ausgebildet ist, sondern aus der Summe der Organisation das Gemeinsame aufsuchen, so gelangen wir zur Erkenntnis jenes Zusammenhanges. Fiir das Flossenskelett hat sich das Archipterggium als mannigfachen Zuständen zu Grunde liegend ergeben. - - Sollte das Archipteryginm auch in der Gliedmaße der höheren Wirbeltiere vorhanden sein? Wir finden ein Knorpelstiick als Stamm, welches mit Radien (Seitenstrahlen) besetzt ist, die sich wie der Stamm in Abschnitte gliedern."

1) C. Gegenbanr, Über das Archipterygium. Jenaische Zeitschrift VII, 1873, pag. 131 .

2) C. Gegenbaur, Vergl. Anatomie der Wirbeltiere. I. Bd. Leipzig 1898. pag. 519. 
Gegenba u legt dam seine Ansicht dar, dass die Gliedmaken entsprechend ihrer neuen Funktion ais lokomotorische Werkzeuge sich zu dinem Hebelsystem gestalteten. Der Oberarm erscheint ihm als der zuerst selbständig gewordene.

Manche Befunde bei Amphibien erinnern ihn an die Lungenfische, doch vorsichtig setzt er hinzu, "wenn wir anch die Amphibien nicht ron Dipnoem in derselben Organisation, wie sie ihre noch lebenden Terwandten besitzen, abzuleiten vermögen. - „Ob dieser Glieslmakenbefund bereits bei den nächsten Vorfahren der Amphibien bestand, ist ums umbekannt."

Andere Fachgenossen nahmen Gegenbaur's Ansicht mit geringem Beifall auf. Ch. S. Winot ${ }^{1}$ ) schreibt:

.Die morphologische Bedentung der Wirbeltierextremitäten ist lange Zeit Gegenstand der Diskussion und Spekulation gewesen, und die Lösung, welche die Frage angenblicklich erfahren hat, ist mehr eine theoretische als eine positive. - - Gegenbaur hat über die Entstehung der Extremitïten eine Hypothese anfgestellt, für welche seine Alhandlung sehr wenig Beweismaterial liefert."

.Diese Theorie, welcher sich $H$ uxley angeschlossen hat, erregte seiner Zeit großes Aufsehen, wurde aber widerlegt durch die Beobachtungen ron Balfour über die Entwickelung der Flossen bei Scyllium."

„Auf Grund ${ }^{2}$ ) unserer Kemntnisse von der Entwickelung und der Morphologie der Flossen können wir, wenigstens gegenwärtig, Gegenbaur's Auffasung nicht anerkennen."

"Unter diesen Umständen ${ }^{3}$ ) scheint mir die Gegen ba ur"sche Theorie nur noch historisches Interesse zu besitzen."

J. Kollmann, Professor der Anatomie in Basel berichtet ${ }^{4}$ :

„Die Frage, anf welche Weise ans der Brust- und Banchflosse der Fische die fünfstrahligen Extremitäten der höheren Wirbeltiere entstanden seien, beschäftigt die Embryologie seit .Tahren. Auf Grund weitgehender Untersuchungen wird angenommen, dass in der formenreichen Gruppe der Urselachier (Lrhaifische) derjenige Fisch zu suchen sei, den die Natur einst durch verschiedene $/$ wischenstufen auf die Höhe eines

1) Ch. S. Minot, Lchrbuch der Entwicklungsgeschichte des Menschen, Leipzig 1894, pag. 453, 454.

2) Minot 1. c. p. 456 .

3) Minot l. c. p. 454 .

t) J. Kollmann, Lehrbuch der Entwicklungsgeschichte des Menschen. Jena 1898, p. 287. 
Lrmolches gehoben habe. - - - Aber alle Anstrengungen, den Weg zu finden, auf dem sich diese Umwandlungen vollzogen, sind bisher fruchtlos gewesen."

R. Wiedersheim, Professor der Anatomie in Freiburg i. Br., sagt, das Gleiche mit etwas anderen Worten $^{1}$ ):

..So leicht sich anch das Flossenskelett sämtlicher Hauptgruppen der Fische anf einen Grundtypus zuriickfïhren lässt, so schwierig scheint von hier aus die Ankniipfung an die Extremitäten der Amphibien. Zwischen beiden scheint eine tiefe, auf die verschiedenen Lebensbedingungen zuriickzuführende Kluft zu existieren und eine sichere Antwort auf die Frage: wie ist aus der nur für das Wasser eingerichteten Flosse die Gliedmaße eines luftatmenden, für die Bewegung auf dem Lande bestimmten Wirbeltieres, eines Urlurches entstanden? - ist rorderhand nicht möglich. Ob die Lösung dieses kardinalen Problems in befriedigender Weise durch künftige paläontologische Forschungen zu erwarten steht, muss die Zukunft lehren."

Es wäre überflüssig, den eben vorgeführten Urteilen einen langen Epilog anzufügen. Sie kennen jetzt die Belege dafür, dass eine Haeckel sehr einleuchtende stammesgeschichtliche Vermutung andere Fachgelehrte nicht befriedigt. Gegenbaur erhebt nicht den Anspruch, das Problem gelöst zu haben. Weil der Vorgang selbst jenseits der Beobachtung liegt, rersuchte er die Möglichkeit einer Lösung anzubahnen, indem er die verschiedenartige Anordnung der Skelettelemente subjektiv so beurteilte, dass alle Extremitäten der Wirbeltiere auf ein Schema zurückgeführt, d. h. einem morphologischen Lagerungstypus unterworfen scheinen. Da seine Denkweise von wenigen adoptiert wurde, ist das Problem heute nicht gelöst

Je mehr die Forschung vertieft wird, um so geringer erscheint die Aussicht auf einstmalige Antwort. Bei der Betrachtung der Fig. 17, wird der Unbefangene sicher sagen, es gehöre die bestimmte Absicht, unter allen Umständen die Ähnlichkeit mit der Fischflosse aufzuspiiren, dazu, um die Strahlen in der ron Gegenbaur bezeichneten Weise zu erkennen. Fünf strahlige Reihen sind sicher vorhauden, sie werden durch die Knochenglieder der Finger und deren Mittelknochen gebildet, oberhalb derselben kann ich keine strahlige Ordnung wahrnehmen. Mir erscheint rielmehr die Lagerung der iibrigen Teile des Arm- oder Fußskelettes fundamental abweichend vom Typus der Fischflosse. Im Oberarm, also der dem Rumpfe

1) R. Wiedersheim, Grundriss der vergleich. Anatomie. 4. Aufl. Jena 1898, pag. 128. 
benachbarten Zone liegt ein einziger Knnochen, daran schließt ein Knochenpar, Speiche und Elle des Unterarmes, damn folgen zwei Querreihen der Handwurzel, die eine aus drei Stücken, die nächste aus vier bis fünf Stücken bestehend und erst jenseits dieser zehn Stïcke, deren Zahl auf jeder vom Rumpfe weiter entfernten Zone in einfacher Proportion: 1, 2, 3, 5 zunimmt, beginnt die Strahlenstellung.

Wollen Sie trotz alle dem die strahlige Ordnung sämtlicher Stücke des Extremitätenskelettes im Sinne Gegenbaur's behaupten, so thun Sie den Thatsachen einen theoretischen Zwang an, der in denselben nicht begrindet ist. Es bleibt daher dem persönlichen Ermessen jedermanns überlassen, der ihm zusagenden Ansicht beizupflichten. Die Sprache der Thatsachen ist nicht so eindeutig, dass sie uns zwänge, einhelliger Meinung zu sein. Das ist sehr häufig das Resultat der sogenannten stammesgeschichtlichen Forschung, sie beseitigt nicht, sundern vergrößert den Gegensatz der subjektiren Urteile. Mir freilich will es scheinen, als sei die Sprache der Thatsachen in diesem Falle bestimmt und schlagend, indem sie uns unter allen Umständen verbieten, den Gedanken eines genetischen Zusammenhanges bei derartig verschieden gebauten Werkzeugen des Tierkörpers zu hegen, wie es Flosse und Fingerfüße sind.

Aber auch angenommen, die Gegenbaur'sche Zusammenfassung wäre begründet, so würden wir immer noch im Dunkeln tappen bezüglich der Frage, in welcher Weise die große Zahl der Flossenstiicke im Laufe vieler Generationen reduziert, wie die straffe Bandverknüpfung derselben gelockert, wie die einzelnen dicht geschmiegten Strahlen allmählich weiter aus einander gespreizt, und wie der höhere und geringere Grad der gelenkigen Verbindung unter ihnen erzeugt wurde. Mit anderen Worten, wenn Gegenbaur's und Haeckel's Meinung richtig wäre, so könnte dieselbe nicht als Lösung der Frage gelten, sondern wäre nur der Ausgangspunkt fiir neue Spezialuntersuchungen, welche endlich die Gewissheit iiber den thatsächlichen Prozess der Extremitätenentwickelung fördern könnten.

Das spezielle Beispiel erläutert, mit welchen Schwierigkeiten der Versuch verbunden ist, innerlialb eines geschlossenen Organisationstypus exakte Anhaltspunkte für die phylogenetische Umwandlung eines Organes zu finden. Heute können wir nur sagen, dass eine plausible Vorstellung über die Entwickelung des Flossenskelettes der Fische in die fünffingerige Gliedmaße der höheren Wirbeltiere nicht existiert.

Beiläufig möchte ich das eben crläuterte Problem benutzen, um Ihnen die sonderbare Methodik mancher popularisierender Schriftsteller der Descendenztheorie zu erläutern. Dieselben glauben nämlich, 
dem Laienpublikum dio ungenügende Art der Begründung ihrer Lieblingstheorie nicht offenbaren zu sollen und sprechen mit auffallender Bestimmtheit davon, dass hervorragende Gelehrte den Beweis für theoretische Ansichten geliefert hätten, welche in der That bis hente leere Vermutungen geblieben sind. So ist Carus Sterne, dor in weiten Kr reisen hochgeschätzte Verfasser von "Werden und Vergehen", für folgende Sätze ${ }^{1}$ ) verantwortlich:

„Gegenbaur hat gezeigt, dass sich in der halbgefiederten Flosse der meisten jetzt lebenden Urfische alle Knochen der Amphibiengliedmaßen finden und hat durch stärkere Schraffierung derselben im Brustflossenskelette des Selachiers die Elemente der Amphibienhand hervorgehoben."

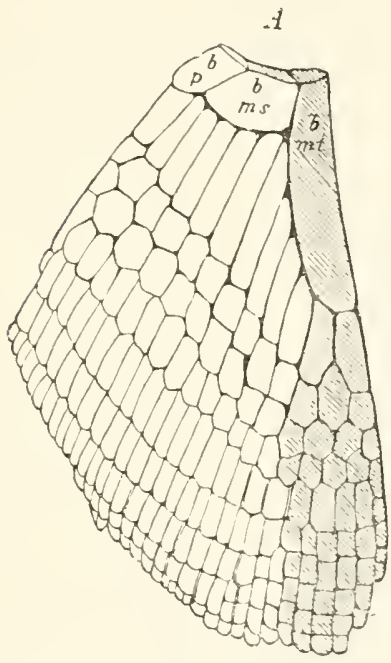

Fi.. 31 .

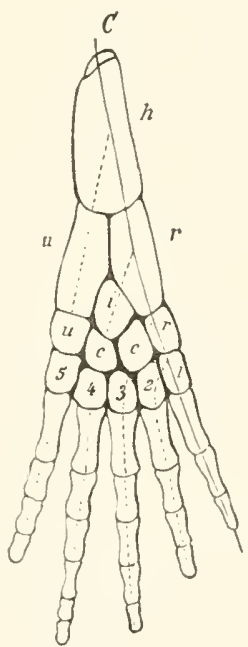

Fig. 32.

Fig. 31. Brustflossenskelett eines jüngeren Urfisches mit Schraffierung der daraus abgeleiteten $\mathrm{Hand}$. $b$ Die drei Easalsticke der Flosse. Nach Gegenbaur.

Fig. 32. Handskelett eines Amplibium. $h$ Oberarm (humerus), $r$ Speiche (radius), u Ellenbein (ulna), $v i c u$ Handwurzelknochen der ersten Reihe, $1-5$ Handwurzelknochen der zweiten Reihe. Nach Gegenbaur.

Figuren und Erklärung sind dem Buche: "Werden uud Vergehen" von Carus Sterne entnommen.

Carus Sterne hat die obenstehenden Figuren 31 und 32 Welche ich photographisch kopieren ließ, zur Erläuterung seiner Angaben beigefiigt. Wenn Sie die ron mir citierten Stellen aus Gegenbaur's Werken vergleichen, werden Sic einschen, dass derselbe sich von solch kühnen Behauptungen weit entfernt gehalten und die Fig. 31 nicht gezeichnet hat.

1) Carus Sterne, Werden u. Vergehen 3. Auf. Berlin 1886, p. 401. 


\section{Fünftes Kapitel.}

\section{Das „Paradepferd“ der Descendenztheorie.}

Zuletzt habe ich Sie einen Einblick gewinnen lassen, dass im Lager der Descendenz-Theoretiker selbst große Unklarheit herrscht über die Art und Weise, wie sich aus einer Fischflosse die fünffingerige Hand der iibrigen Wirbeltiere habe entwickeln können. Ich sage ausdriicklich: habe entwickeln können, da wir sehr weit von der Beantwortung der Frage entfernt sind. Denn Zwischenformen sind nicht gefunden und die bisher zum Ersatz des Mangels an positiven Thatsachen aufgestellte Theorie hat sich keines großen Beifalls zu erfreuen. Es besteht also sowohl nach meinem Urteile, als auch nach dem Urteile der Descendenztheoretiker selbst eine bis jetzt durch keine bekannten Zwischenglieder auszufüllende Khuft zwischen den niederen Wirbeltieren, den Fischen, die man als Urformen und Vorfahren zu denken gezwungen ist und den höheren Gruppen der Wirbeltiere: Amphibien, Reptilien, Vögel und Säugetiere. Da ich hier nicht bloß meine Privatansichten, sondern den gegenwärtigen, in der zoologischen Wissenschaft herrschenden Zustand der Unklarbeit objektiv schildern will, habe ich mich neulich der umständlichen Vorlesung einiger Stellen ans drei Werken bedient, deren Verfasser alle Anhänger der Descendenz-Theorie sind. Sie konnten daraus lernen, dass die Freunde dieser Lehre sich in verlegenes Schweigen hiillen müssen, sobald Sie für die ausserordentlich wichtige Entwickelung der Gliedmassen die Demonstration der Übergänge verlangen. Höchstens Ha eck el ergreift das Wort, um mit überraschender Bestimmtheit einen Prozess zu schildern, fïr dessen thatsächliches Vorkommen niemand einen anderen Beweis als die logische Denkmöglichkeit vorzulegen im stande ist. Man kann dabei nur die Biegsamkeit unserer Sprache bewundern, deren Ausdrucksmittel es gestatten, unsere absolute Unkenntnis ïber die Umwandlung der Fischflosse in die fünffingerige Hand der höheren IVirbeltiere so täuschend zu verbergen, dass der Fernstehende nichts davon merkt. Ich dagegen sage, was nuitzt mir die ganze Abstammungslehre, wenn sie mich im speziellen Fall vollkommen im Stich lässt, wenn sie mir keine 
exakten Beweisgründe für einen Vorgang vorführen kann, der mir aus logischen Grïnden durchaus notwendig erscheint. Wie kann ich meinen zweifelnden Verstand zwingen, die Richtigkeit einer Theoric anzunehmen, welche mir in so wichtigen Fragen keine ïberzeugenden Thatsachen als sicheren Auhalt giebt. So zwingend der Schluss erscheinen mag: wenn eine Entwickelung der Wirbeltiere auf Erden stattfand, so muss diesclbe von den Fischen ausgegangen sein; rom Standpunkt des nüchternen Forschers ist der Schluss als vollkommen in der Luft stehend zu betrachton, bis die Beweise vorgelegt sind, dass die theoretische Folgerung mit den thatsächlichen Ereignissen wirklich übereinstimmt.

Einen gleich ungünstigen Zustand des Beweismateriales der Abstammungslehre rerrät die Betrachtung der Pferdegeschichte. Sie werden das mit Verwunderung hören, da die meisten von ihnen in populären Schriften gelesen haben, dass das Pferd und seine Sippe unzweifelhafte Belege sciner stammesgeschichtlichen Genealogie hinterlassen hat. Wenn ich hier das gerade Gegenteil einor landläufigon Meinung vortrage, so stehe ich, wenigstens soweit sich die Stellungnahme meiner Fachkollegen nach der wissenschaftlichen Litteratur beurteilen lässt, mit moiner kritischen Auffassung zicmlich allein. Hätte ich nicht selbst eine Zeit durchlebt, während welcher ich überzongter und energischer Vertreter der Abstammungslehre gewesen bin, würde ich nicht begreifen, wie es kommen kann. dass so viele meiner Fachkollegen fest ant die beweisende Klarheit der paläontologischen Urkunde in der Pferdegeschichte schwören. Aber so weiß ich aus eigener Erfahrung, dass der Anhänger dieser Theorie durch leidenschaftliche Begeisterung für den schönen Gcdanken derartig fasziniert wird, dass er, ohne es zu wissen und zu wollen, viele unbequeme, den Beweisgang störende Thatsachen übersieht oder als unbedentend einschätzt. Ich will hier, um Missverständnissen vorzubengen, ansdrücklich honstatieren, wie rollkommen fern es mir liegt, meinen der älteren Ansicht anhängenden Fachkollegen irgendwie persönlich zu nahe zu treten. Nein, ich erkenne die Tüchtigkeit, die ausgezeichnete Begabung und die glänzenden Leistungen meiner theoretischen Gegner, auch diejenigen Hacckels neidlos und unbedingt an; ich behaupte nur, sie sind das Opfer einer Täuschung geworden, indem sie die Richtigkeit ihrer Lieblingsmeinung in vielen Fragen anerkannten, beror die notwendige Prïfung mit der erforderlichen Schärfe ausgefïhrt war.

Nun will ich zur Begründmng meines Urteiles fortschreiten. Durch den Besitz eines einzigen Fingers an Arm und Bein steht das Pferd, Equus caballus L., samt seinen wenigen Terwandten, den Eseln und Zebras, ganz vereinsamt in der heutigen Tierwelt 
da, wie etra der Strauß unter den Vögeln. Die ältere Systematik drïckte das Verhältnis durch die Bildung einer besonderen Gruppe der Einhufor aus. Aber die patäontologischen Funde haben dazu beigetragen, diese systematische Gruppe in ungeahnter Weise zu erweitern, so dass heuto die Zahl ihrer Glieder recht grol geworden ist und die Gruppe selbst wegen der Mannigfaltigkeit der zugehörigen Arten als Ordnung der Unpaarhufer, Perissodactyla, ein-, droi- und fünfzehige Tiere umfasst. Dadurch erhielt die Gruppe größeren IVert für die Descendenztheorie. Noch am Beginn der sicbziger Jahre sprach man nur vom Übergange fossiler pferdeähnlicher Arten des Paläotheriums durch Anchitherium und Hipparion in das hentige Pferd. ${ }^{1}$ ) Auch Haeckel hebt in den älteren Auflagen der "Natürlichen Schöpfungsgeschichte“ und der ":Anthropogenie" die Pferdereihe nicht besonders hervor. Nachdem aber die amerikanischen Paläontologen Leidy, Cope und Marsh ihre interessanten Funde von fossilen Pferderesten in Nordamerika veröffentlicht und $\mathrm{Huxley}$ diesolben alsbald in populären Vorträgen zu New York besprochen hatte, steigerte sich die Bedeutung der Pferdegruppe: die fossilen Reste dersolben schienen die ehemalige Entstehung dieser Sippe zu bezengen und eine Ansicht zu unterstützen, welche E. Haeckel ${ }^{2}$ ) vor kurzem folgendermaßen formuliert:

„Die bedeutungsvolle phyletische Entwicklungsreihe der Pferde ist jetzt von den ältesten eocaenen Condylarthren (Phenacodus) bis zum heutigen Equus durch die ganze Reihe der tertiären und quartären Formationen hindurch so vollständig bekannt, dafs sie mit vollem Rechte als das imposante "Paradepferd der Descendenzthorie" gilt, als eines der wichtigsten und vollkommensten Beispiele von paläontologisch bewiesener allmählicher Umbildung. - - Nachdem schon frïher die wichtigsten Stufen dieser phyletischen Stufenleiter aus dem Tertiärgebirge von Europa bekannt geworden waren, sind sie nenerdings in liickenloser Vollständigkeit und iiberraschender Reichhaltigkeit in den verschiedenen Tertiärschichten von Nordamerika gefunden worden."

Diese Auffassung wird in den meisten Lehrbiichern durch die beistehende Abbildung (Fig. 33) erläutert, welche in der Mitte der siebziger Jahre von dem amerikanischen Paläontologen O. C. Marsh für die von Th. Huxley in New York gehaltenen Vorträge ge-

1) Vergl. Oscar Schmidt, Descendenzlehre und Darwinismus. Internationale wissenschaftliche Bibliothek. 2. Bd. 1873, p. 255.

$\left.{ }^{2}\right)$ E. Haeckel, Systematische Phylogenie. III. Bd., p. 549. 


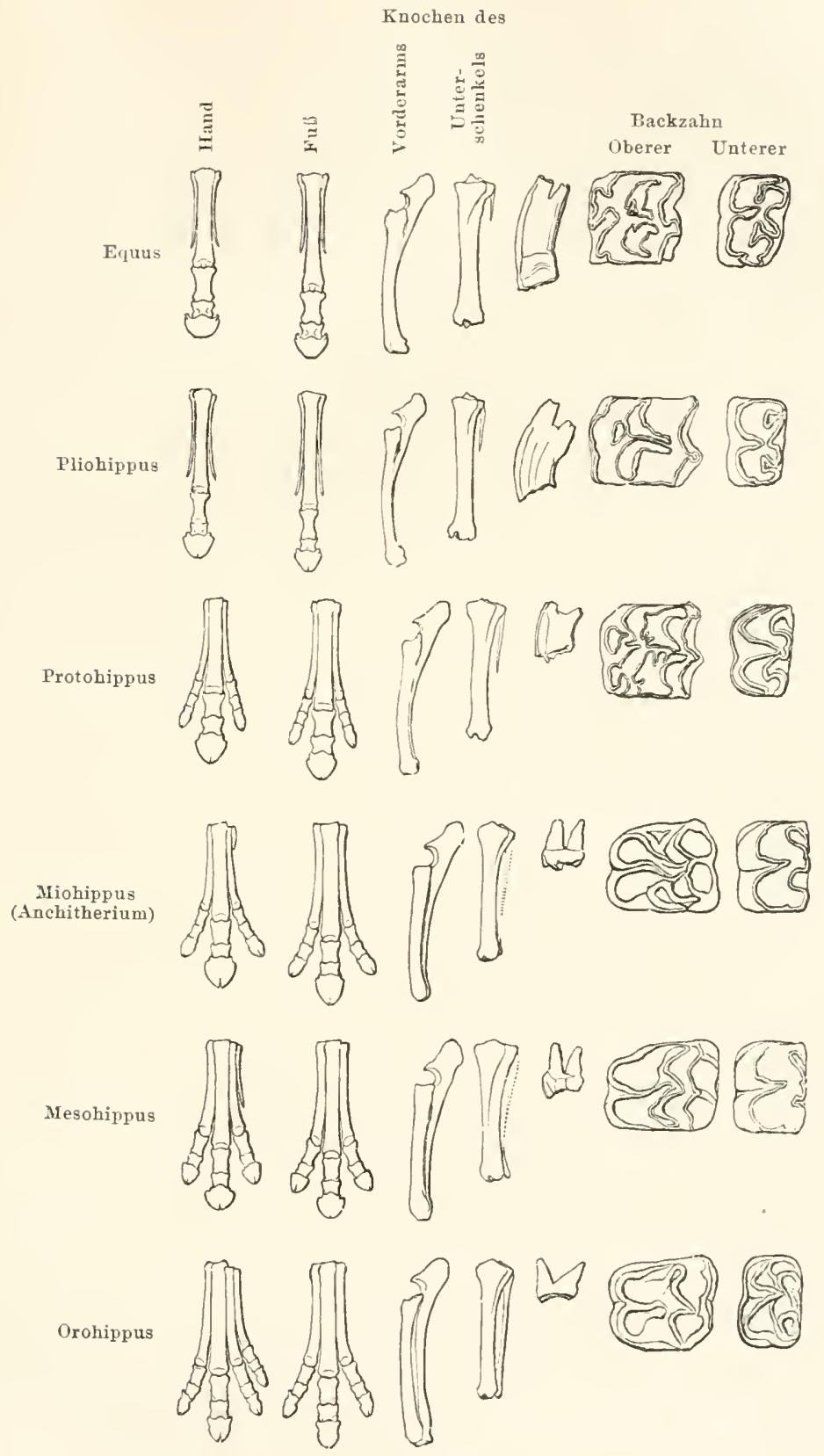

Fig. 33.

Genealogie des Pferdes. Nach Marsh, Polydactyle Horses. Amer. Journ. 1879. (Cliché aus Zittels Paläozoologie IV. Bd. p. 261.)

Fle ischmann, Descendenztheorie. 
zeichnet und später von Marsh ${ }^{1}$ ) selbst publiziert worden ist. Huxley hatte sie in der gedruckten Ausgabe seiner Vorträge und Reden reproduzieren lassen und seitdem ist sie in riele das gleiche Thema behandelnde Schriften iibergegangen.

Wer die Figur 33 unbefangen ansieht und durch die erklärende Beischrift erfährt, dass hier die stammesgeschichtliche Reihe der Pferde übersichtlich zusammengefasst sei, mufs die Beweisführung für schlagend halten. Die einzelnen Figuren sind in horizontalen Zeilen so geordnet, dass unten die älteren Reste, oben die jüngeren Fundstücke und die Skeletteile des jetzt lelıenden Pferdes stehen. Auf diese Weise werden wichtige Zïge des Hand- und Fufsskelettes, des Unterarmes und Unterschenkels, sowie der Zähne ron verschiedenen als Pferde hezeichneten Tierarten dargestellt, deren Reste vor 30 Jahren bekanut geworden sind. In den älteren Ablagerungen wurden mehrfingerige Pferde gefunden, während dreifingerige Arten in neueren Schichten auftreten und die jetzt lebenden Pferde nur je einen Finger an Hand und Fuls besitzen.

In der untersten Zeile, welche sich auf den etwas mehr als fuchsgroßen Vorläufer des Pferdestammes, Orohippus bezieht, zeigt die Hand vier, der Fuß drei Zehen; beiden fehlt der Daumen und dem Fuße überdies noch der fünfte Finger. Der Mittelknochen und die Glieder des dritten Fingers sind an Hand und Fufs stärker, als die gleichwertigen Stiicke des zweiten und vierten Fingers; die Stiicke des fünften Fingers der Hand sind kürzer und zarter als diejenigen aller ïbrigen Finger. Bei dem schafgroßen Mesohippus und dem Miohippus, beide in Ablagerungen des Miocän's gefunden, treten die Mittelknochen des zweiten und vierten Fingers gegen den starken Mittelknochen des dritten Fingers zuriick und sind auch etwas verkïrzt. An der Hand hängen noch Reste des fünften Mittelknochens, besonders klein bei Miohippus.

Bei Protohippus, von welchem einige Arten die Grölse des Esels erreichten, fällt die mächtige Entwicklung des dritten Mittelknochens und die schwache Ausbildung des zweiten und vierten Mittelknochens auf, welche kurze, den Boden nicht mehr berührende Afterzehen tragen. An Pliohippus und Equus werden die Fingerglieder des zweiten und vierten Fingers vermisst und die zugehörigen Mittelknochen hängen neben dem großen Mittelknochen des kräftigen dritten Fingers als diinne, unten spitz zulaufende sog. Griffelbeine, die nicht einmal bis zum unteren Rande des dritten Mittelknochens reichen. Hier ist jede Spur des fünften Fingers und des zugehörigen Mittelknochens verschwunden.

1) American Journal of Science, III. ser, 1879, vol. 17, p. 505. 
Die Figur 33 lehrt also, dass bei vielen ron den Paläontologen als Pferde angesprochenen, ausgestorbenen Tierarten der erste und fünfte Finger zum Schwunde kommt, dass der zweite und rierte Finger immer schmäler und deren Fingerglieder immer kleiner und iiber den Erdboden zurückgezogen werden, während beim jetzt lebenden Pferde die beiden Seitenfinger ganz rückgehildet und deren Mittelknochen als unnuitze Reste, als sog. Griffelheine, erhalten sind.

Auf Grund der in Fig. 33 sichtbaren Formenstufen der Gliedmafsenbildung haben die Anbänger der Descendenztheorie die bisher besprochenen und mehrere nicht genannte fossile Pferdearten in eine stammesgeschichtliche Reihe geordnet und gewähnt, dadurch die Richtigkeit ihrer Lieblingsmeinung iiber jeden Zweifel erhoben zu haben. Aber die Aufgabe war nicht so einfach, als es schien. Terschiedene Forscher äusserten abweichende Ansichten iiber die genealogische Verknüpfung der fossilen Formen und beschenkten uns mit einer grösseren Auswahl ron Stammbaumentwürfen, ron welchen ich nur einige herausgreifen will. Zunächst Haeckel's Stammreihe aus der natürlichen Schöpfungsgeschichte, 8. Auflage, p. 669, der dem Torschlage von Marsh folgt, aber die Reihe um etliche von M arsh eingeschobene Zwischenformen kiirzte.

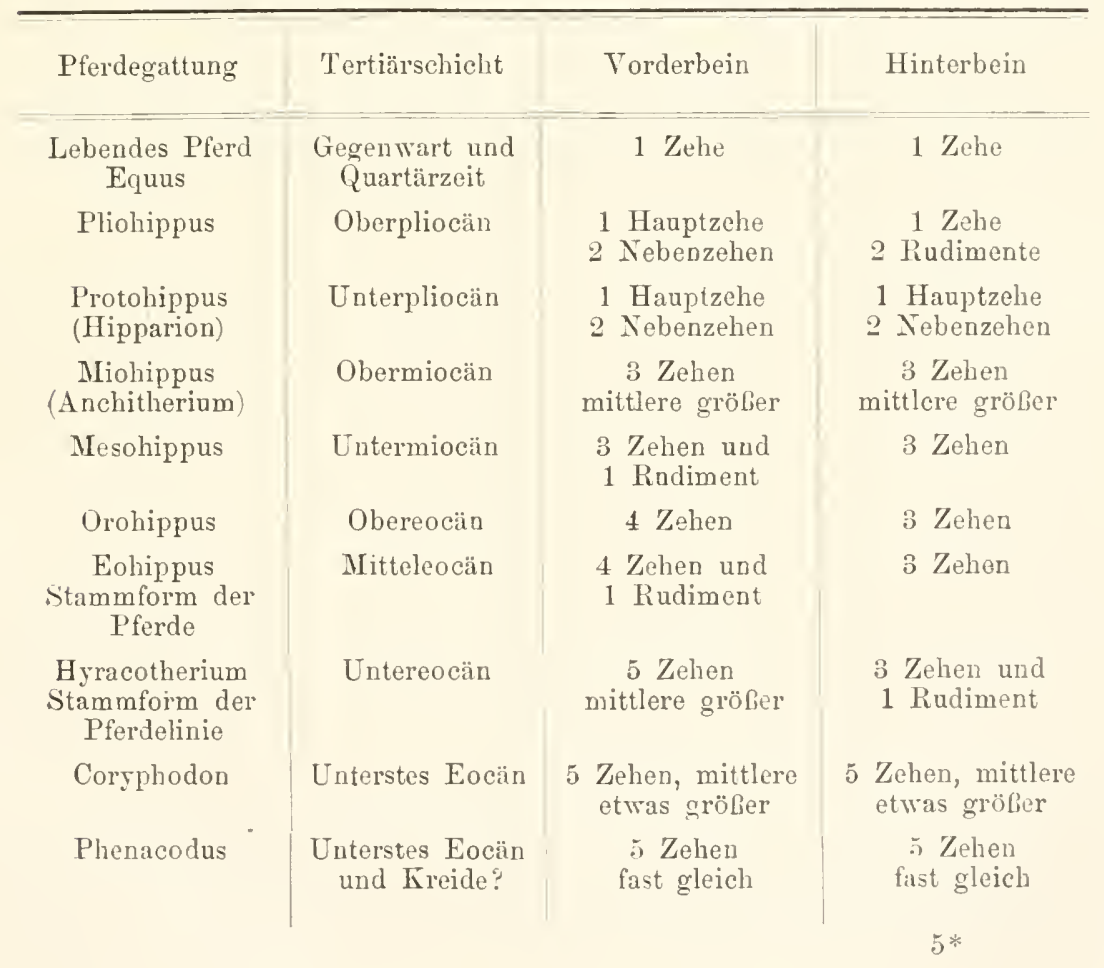


Anderen Gelehrten erschien der Vorschlag zu einfach, besonders die amerikanischen Paläontologen Cope und Wortmann, denen sich Oscar Schmidt und Carl Vogt anschlossen, meinten die jetzige Gattung Pferd sei nicht von einer einzigen Stammart - monophyletisch entstanden, sondern seine Vorfahrenreihe lasse sich in zwei vollständig getrennten Stammlinien - diphyletisch zu eiufachen Urformen verfolgen, die in Europa und Amerika verschiedenartige Zwischenformen gezeugt hätten. Zur Erläuterung setze ich den Cope'scheu Entwurf bei:

Amerika
Equus
Hippidium
Protohippus
Anchitherium
Mesohippus
Palaeotherium

Europa

Equus

Hipparion

Anchitherium

Paloplotherium

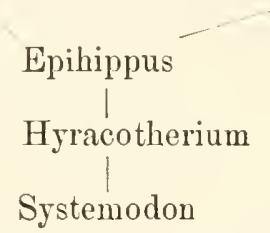

Neuerdings hat E. Haeckel1) einen verbesserten Stammbaum der Pferde veröffentlicht, indem er sich vollständig den von Max Schlosser ${ }^{2}$ ) im Jahre 1889 geäußerten Ansichten anschloss.

Hippidium Equus

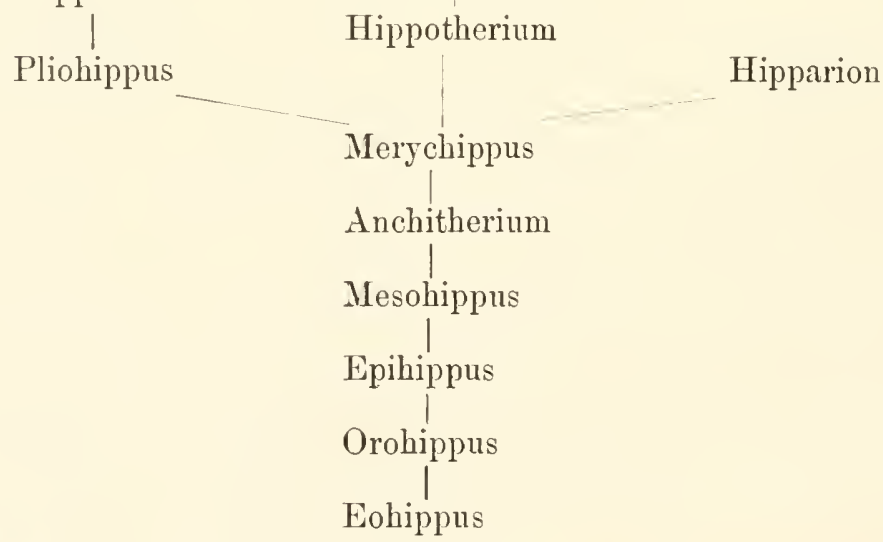

1) Systemat. Phylogenie III, pag. 548.

2) M. Schlosser, Beiträge zur Kenntnis der Stammesgeschichte der Huftiere etc. Morpholog. Jahrbuch, Bd. 12, pag. 30 . 
Wer das Fußskelett der Pferdeformen vergleicht, wird die Berechtigung der Stammbäume nicht bestreiten wollen. Das Arrangement der Abbildungen von Marsh ist so einleuchtend, dass man sich der Mühe überhoben dünkt, nach anderen Beweisgründen zu fragen. Sicher sind auch viele Fachgelehrte durch die Älnlichkeit der Fußbildung fuir die phylogenetische Deutung der Pferdereste gewonnen worden. Und doch ist eine weitere Prüfung sehr notwendig, weil neben den übereinstimmenden Charakteren des Extremitïtenskeletts eine Menge von Unterschieden besteht. Denn wenn einer bei der Ausarbeitung eines Stammbaumes nur die Gliedmaßen im Auge hat, wie es gegenwärtig bei Ihnen allen der Fall ist, so kann er mannigfache Fehler begehen. Ich will sie an einem analogen, nicht ganz zutreffenden Beispiele erläutern, wobei ich weit entfernt bin zu behaupten, die Paläontologen seien in gleich große Irrtümer verfallen, wie ich sie jetzt ans didaktischen Gründen begehe :

Ich kanu ohne Anstand die Gliedmaßen der Säugetiere in eine Reihe ordnen, welche einer Entwickelungsfolge gleichsicht. An die menschliche Hand mit ihren fünf dentlichen Fingern (Fig. 18) schließe ich die Hundehand, (Eig. 19) deren Daumen schwach entwickelt ist, dann folgt die Hand des Schweines (Fig. 21). ohne Daumen, mit schwachem zweiten und fünften Finger und stärkerem dritten und vierten Finger. die Hand des Kameles (Fig. 20) zühlt nur zwei Finger; das Pferd schlielit die Reihe mit einem einzigen Finger. Wenn ich nun behaupte, das sei eine unleugbare Umbildungsreihe, eine Serie von natïrlichen Objekten, welche die Vereinfachung des Handskelettes während der stammesgeschichtlichen Entwickelung der Säugetiere offenbare, so lege ich dem Umstande, dass sich fünf-, vier-, drei-, zwei-, und einfingerige Hände natïrlich in der Reihenfolge der Ordnungszahlen neben einander stellen lassen einen allzu hohen Wert bei; denn durch diese Iröglichleit bequemer Ordnung werden andere Unterschiede des Körpers nicht aufgehoben, und man braucht kein Fachmann zu sein, um den ron mir begangenen Fehler zu durchschanen. Sobald Sie nur die Namen der Tiere hören: Mensch, Hund. Schwein, Kamel, Pferd, treten Ihnen Allen die specifischen Züge der ganzen Körpergestalt dieser Arten so lebhaft vor die Augen, dass Sie sagen werden, meine eben gebildete Reihe gestatte wohl in bequemer Weise die Einsicht in die Modifikationen der Handbildung, nimmer mehr aber kömne sie als Beweis für einen stammesgeschichtlichen Zusammenhang der ausgewählten Arten gelten.

Würden Sie sich nun getrauen, das direkte Gegenteil über die Hand- und Fußreihe der fossilen Pferdearten auszusagen und würden Sie bestreiten, dass das paläontologische Material, welches Sic nur durch 
Beschreibung und wenige Abbildungen kemnen, uns zu ähnlichen Fehlern verführen kömnte? Muss nicht die Frage viel schwieriger rrscheinen, da dem Zuhörer durch seine eigene Unkenntnis des Aussehens und dor Beschaffenheit ausgestorbener Tiere die Möglichkeit kritischer Pruifung benommen ist?

So wenig ich Thmen eine klare Vorstellung von dem Aussehen des Barramunda geben konnte, indem ich Ihneu die skelettierte Flosse desselben (Fig. 29) zeigte, so wenig wird jemand, der nur die Marsh'sche Tabelle der Pferdegeschichte gesehen hat, von einer Kenntnis der Pferdeahnen sprechen dürfen. Wir miissen also weiter fragen. wie andere Teile dersolben beschaffen waren und wie die vollständigen Tiere aussahen. Der Paläontologe von Fach wird dadurch nicht in Verlegenheit gebracht, weil er eine möglichst vollständige Beschreibung der fossilen Reste geben will. Unsere Aufgabe wird es nun sein, die von der Paläontologie geförderten Resultate zu verfolgen. Dahei müssen wir immer im Simne behalten, dass unser Urteil sich rertieft, je melır Körperteile von fossilen Pferden wir genau kennen lernen.

Auf die Schilderung der Weichteile und aller physiologischen Torgänge müssen wir leider von vornherein verzichten, weil die

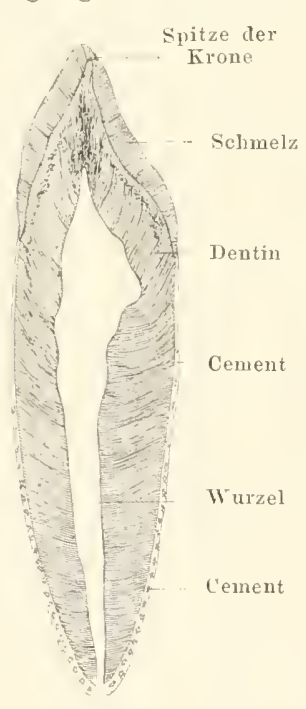

Fig. 34 .

Läingschliff durch den Eckzahin des Menschen. versteinerte Urkunde bloß Reste von Hartgebilden, vou Knochen und Zühneı, iiberliefert. Wir wollen darum die zahlreich gefundenen Zähne der fossilen Pferdearten etwas genauer betrachten. Hier treten uns große Unterschiede entgegren; ich kann nur einige derselben namhaft machen, indem ich ihre Aufmerksamkeit auf die Eigenschaften der Backzähne leite und Schneide- wie Eckzäihne vernachlässige.

Die Backzähne der heutigen Pferde weichen ron dem unter den Säugetieren weit verbreiteten Typus der schmelzhöckerigen Zähne bedentend ab. Gewöhnlich sind die zwei Bestandteile jedes Zahnes, das Zahnbein - Dentin und der Schmelz - Email auf einander gelagert, wie z. B. am Schneidezahn (Fig. 34) eines Menschen. Der Dentinkern des Zahnes trägt auf der in die Mundhöhle ragenden Krone einen Ueberzug von Schmelz, während der schmelzlose Dentinteil als sog.

Wurzel in einer Kieferhöhle befestigt ist. Die grole Mehrzahl der älteren Pferde besitzt wurzelige schmelzhöckerige Back- 
zähne, deren schmelzüberdeckte Krone eine breite Kautläclıe bildet. Die Kaufläche des Dentinkernes ist in kleine Erhabenheiten oder Höcker ansgezogen und die Schmelzlage überzieht dieselben in genau entsprechender Weise gewellt und vorgebuchtet (Fig. 36, A).

Unsere heute lebenden Pferde dagegen besitzen schmelzfaltige Backzähne, d. h. die Schmelzdecke der Kaufläche buchtet sich mittels tiefer sackartiger Falten in den Dentinkern ein, so dass eine gemischte Lagerung der harten Zahnsubstanzen entsteht. Der Dentinkern selbst ist sehr hoch prismatisch; der Schmelz umhiillt denselben gleich einem prismatischen Futterale und treibt ron der Kaufläche, welche der Grundfläche des Prismas zu vergleichen ist, hohle Einstiilpungen in das Dentin. Die letzteren sind am fertigen Zahn mit einer dritten Hartsubstanz, dem Cemente, ausgefüllt, das auch die SchmelzauBenfläche des prismatischen Zahnes belegt. Durch die Kauthätigkeit wird die Kaufläche der Zähne abgerieben und es treten dann die drei

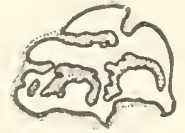

Fig. 35 .

Querschliff diurch den Backzahu des heutigen $\mathrm{Pf} \in \mathrm{rdes}$.

Sehmelz schwarz, bentin weib, Cement punktiert. $d$

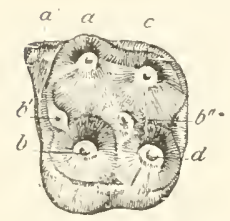

Hrracotherinm leporinum (Owen). Zweiter oberer Backzalin ${ }_{1}$.

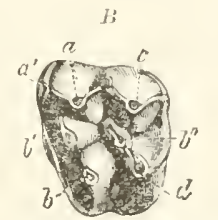

Pachrnolophus siderolithicus (Pictet). Oberer Backzahn?.

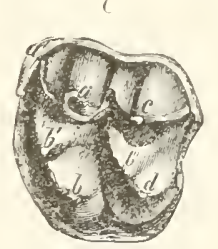

Propalacotherium argentonicum (Gerv.) (j)erer Backiahn ${ }^{1}$.

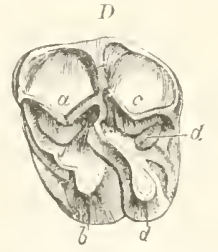

Anchitherium aurelianense ( $\mathrm{Cu}$. $)$ Oberer Backzahn ${ }^{1 /}, 1$.

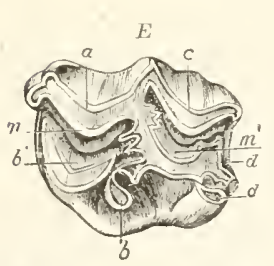

Merychippus mirabilis (Leidy). Oberer Milchbackzahn ${ }^{1}$.

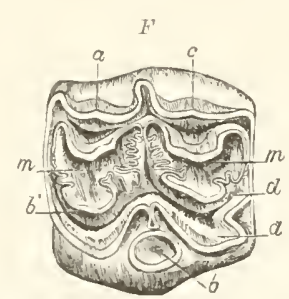

Hipparion gracile (Kaup). Oberer Backzahn ${ }^{1}$.

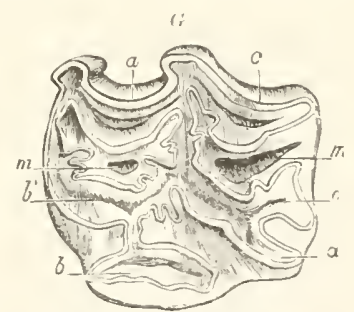

Fius caballus (Lin.) Oberer Backzahn ${ }^{1}$.

$$
\text { Fig. 36, A-G. }
$$

Obere Backzähne verschiedener Pfex dearten. A-D Ansichten der schmelzhöckerigen Kaufläche. E-G Ansicht der schmelzfaltigen Kaufläche. a, $c$ Aussenlïcker, b, $\gtrsim$ Innenhöcker, $\mho^{\prime}, Z^{\prime \prime} Z$ wischenhöcker, $a^{\prime}$ accessorisches Aussenhöckerchen, $d^{\prime}$ accessorisches Innenhöckerchen, $m, m^{4}$ Marken.

Die Figuren sind Zittel's Paläozoologie, Ir. Band, S. 234 entnommen. 
den Zahn aufbauenden Substanzen: Cement, Schmelz, Dentin teils als Felder, sog. Thäler, teils als gewundene Schmelzbänder deutlich hervor. (Fig. 35.)

Im Gegensatze zum modernen Pferde sind die Zähne vieler fossilen, als Pferde gedenteten Arten nicht prismatis sh, sondem kurz, wurzelig und schmelzhöckerig. Meist ragen vier niedrige, rundliche Höcker nebst zwei Zwischenhöckern über die Kanfläche (Fig. 36, A). Bei den ältesten Arten (Fig. 36, B, C) sind die Höcker getrennt und nur die Zwischenhöcker mit den Innenhöckern durch schwache Grate verbunden, bei etwas jüngeren Arten (Fig. 36, D) erscheinen die Höcker nicht mehr rundlich, sondern mit kantigen, sie ungefähr halbierenden Kielen versehen, und bei neueren Arten (Fig. 36, E, F, G) finden sich an Stelle der getrennten Höcker gerade oder gebogene Leisten oder J oche, zwischen welchen vertiefte Stellen der Kaufläche, die sogenannten Marken, liegen. Zühne von dem Typus der heutigen Pferde werden erst bei Arten des unteren Pliocäns (Fig. 36, E) beobachtet. Die Zähne von Hipparion besitzen prismatische Gestalt und sind von einer dicken Cementschicht

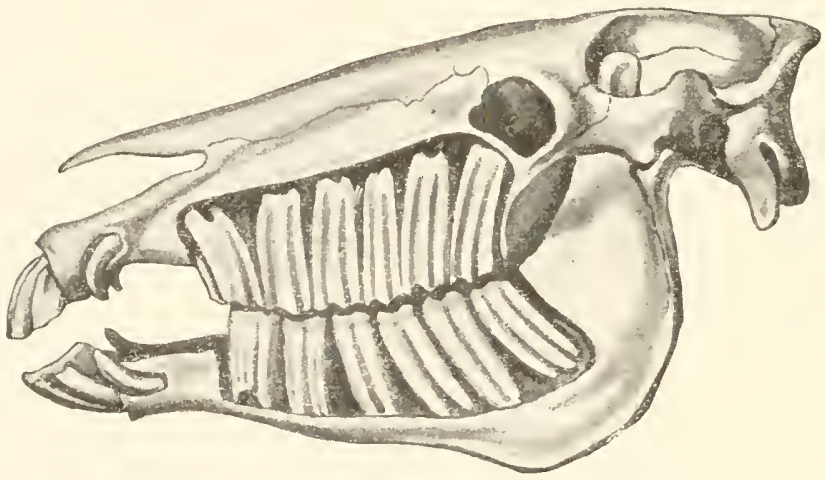

Fig. 37.

Schädel des heutigen Pferdes, Equus caballus. Die Backzähne sind blob gelegt.

umhüllt, welche an Zühnen der älteren geologischen Zonen ïberhaupt nicht vorkommt. Die Zähne von Equus selbst sind nicht wurzelig, sondern ragen als hohe vierseitige Säulen tief in die Kieferknochen hinein, wie die Figur 37 erläutert. Während ferner die vorderen Backzähne der meisten fossilen Arten, Hyracotherium, Eohippus, Orotherium, Palaeotherium, kleiner sind als die hinteren, indem die Zahnkrone vom ersten, kleinsten bis zum letzten Backzahn an Größe zunimmt, rerhält sich das Gebiß des jetzigen Pferdes und etlicher weniger fossiler Arten umgekehrt: cine vorderen Backzähne haben die gröliten Kauflïchen, die hinteren 
kleinere und schmälere. Bei Mesohippus und Anchitherium kommen die vorderen Backzähne den hinteren an Größe gleich.

Der allgemeinen Formähnlichleit in der Ausbildung der Füße gesellen sich also recht bedentende Unterschiede der Bezahnung. Alle Arten bis zum oberen Niocän. Eohippus, Orohippus, Mesohippus, Niolippus, Anchitherium (Fig. 38, A), besitzen mehrwurzelige Backzïhne, Protohippus und Pliohippus, Hipparion (Fig. 38, B) und Equus (Fig. $38, \mathrm{C})$ haben aber prismatische Backzähne mit reichlichem Cementbelage. Die prismatischen Backzähne des Protohippus und Pliohippus sind wesentlich niedriger, die Backzähne ${ }^{1}$ ) ron Hipparion ungeführ halb so hoch als diejenigen ron Equus selbst. Da ich nicht tiefer in das verwickelte Detail

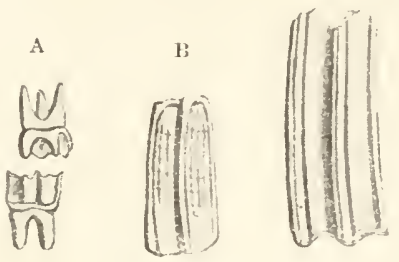

Fig. 38 .

A Mehrwurzelige Backzähne rou Anchitherium. B Prismatischer Backzahnron Hipparion. CPrismatischer Backzahn von Equ us. Nach Kowalewsky. '+ nat. Grösse. der Bezahnung bei den fossilen Pferden eingehen darf, kann ich nur lakonisch bemerken, dass niemand zu schildern rermag, wie die prismatischen Zähne durch Umbildung der mehrwurzeligen entstanden sind.

Die Unterschiede der Zähne stehen mit anderen Differenzen des anatomischen Baues in Zusammenhang. Wie Kowalewsky zuerst ausführlich begründete, ist die Schädelform wesentlich ron der Beschaffenheit der Zähne abhängig. Wurzeln in den Kieferknochen kleine niedere Zähne. so wird nicht soviel Raum beansprucht, als wenn hohe säulenförmige Backzähne dort Platz finden sollen (Fig. 37). Deshalb sind die Oberkieferbeine viel mächtiger bei Arten mit prismatischen Backzähnen. Die Größe der Oberkiefer modifiziert wieder das Aussehen des ganzen Schädels, indem sie bei mächtiger Entfaltung dazu beitragen, den Antlitzteil des Schädels recht massig gegenüber dem Hirnschüdel zu gestalten. Die Abbildungen etlicher Pferdeschädel (Fig. 39-43) illustrieren die Unterschiede. Bei den älteren Arten (Fig. 41-43) mit niedrigen Wurzelzähnen ist der Gesichtsteil klein, der Jochbogen steht weit ab und die Augenhöhlen sind nicht geschlossen, wïhrend beim Pferde (Fig. 39) das gerade Gegenteil gilt. Wenn auch der Knochenschädel des Hipparion eine gewisse Ähnlichkeit mit dem Pferdeschädel zeigt, so weicht der Schädelbau der älteren Arten, welche als Vorfahren bezeichnet werden, von Auchitherium (Fig. 41),

1) Ich habe die VerhäItnisse durch die guten Abbildungen ron Zittel und Kowalewsky illustriert. Der Tergleich mit den Figuren in der Marsh'schen Tabelle wird Ihnen zeigen, dass letztere die Natur nicht treffend wiedergeben. 


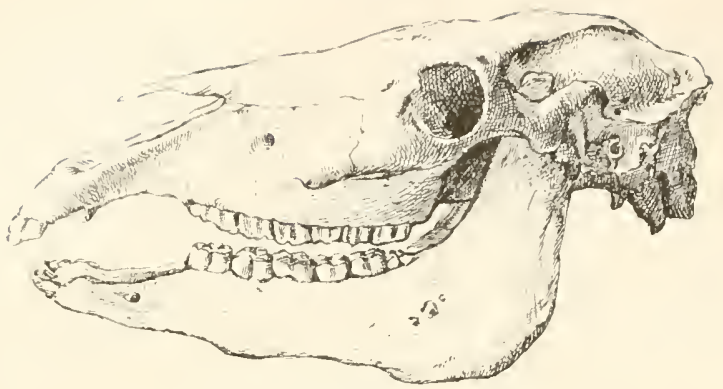

Fig. 39.

Sehital des Pferdes, Equuk caballus.

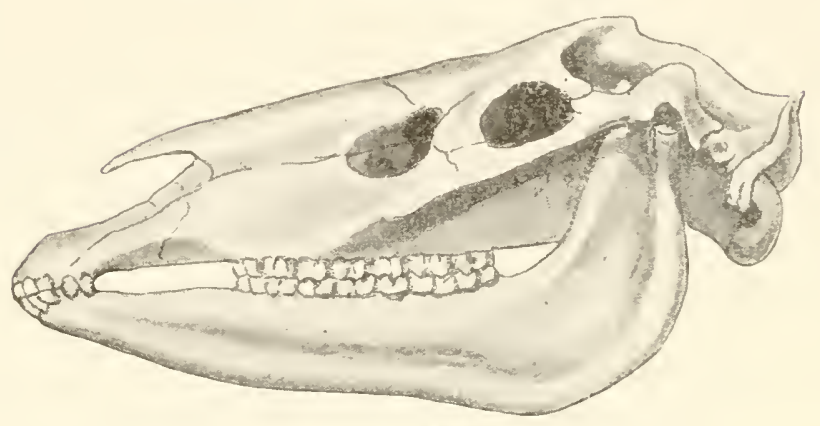

Fig. 40.

Schädel vou Hippariom. Xach kowalewsky.

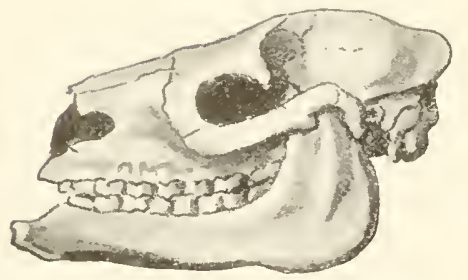

Fig. 41.

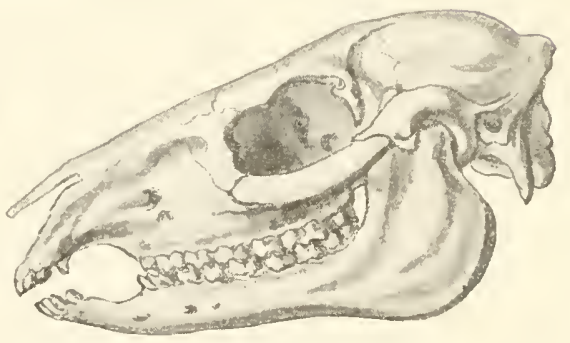

Fig. 42.

Fig. 41. Schädel von Anchitherium. Nach Kowalewsky. - Fig. 42. Schädel von Iesohippus Bairdi. Nach Scott.

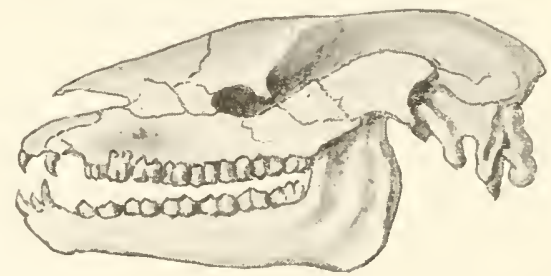

Fig. 43 .

schälel vur Palaeotherium. Xacls Kowalewsky. 
Mesohippus, (Fig. 42), Palacotherimm (Fig. 43) doch so bedentend von dem Pferdetypus ab, dass man sich schwer vorstellen kann, in welcher Weise die hochgradige Umbildung der Schädelplastik erfolgte. Schlosser hob schon 1889 hervor, dass der Schädel des Anchitherium (Fig, 41) mehr dem des Palaeotherium gleicht, als dem jezt lebenden Pferde, während Anchitherium im Bau der Gliedmassen grosse Ähnlichkeit mit dem Pferde zeigt. Der Schädel des im Haeckel'schen Stammbaumentwurfe vorhergehenden Mesohippus, dessen ganzes Skelett neuerdings durch soott1) sehr genau bekaunt gemacht wurde, weicht in noch höherem Maße daron ab, und für Epihippus, Orohippus und Eohippus ist sicher keine größere Ähnlichkeit mit dem hentigen Pferde zu vermuten.

Auch im Skelette fallen bei genauerem Studium bedeutende Dirergenzen auf, besonders an den Vorderarmknochen und den Unterschenkelknochen, welche bei eimigen Arten wohl getremnt, bei anderen verschmolzen sind.

Die hier nur kurz besprochenen Unterschiede sind ziemlich bedeutend und haben die Paläontologen reranlasst, die fossilen als Ahnen des Pferdes gedeuteten Tierarten in drei gesonderten Familien, die Hracotherinae, Palaeotherinae und Equinae zu verteilen. Ich gebe ihre Charakteristik nach Zittel's Handbuch der Paläontologie ${ }^{2}$ :

1. Familie der Hyracotherinae:

Augenlı̈hlen hinten offen.

Elle und Speiche getrennt, ron nahezu gleicher Stärke.

VorderfuB vier, Hinterfuß drei Zehen.

Backzähne sehr niedrig, die vorleren sind einfacher als die hinteren. Hyracotherium, Eohippus, Orohippus, Epihippus.

2. Familie der Palaeotherinae:

Augenhöhlen hinten weit offen oder unvollständig knöchern begrenzt. Elle und Speiche getrennt.

Backzähne mehrwurzelig, ohne oder mit schwach entwickeltem Cemente.

Zwei oder drei der vorderen Backzähne in der Regel den hinteren gleich.

Vorder- und Hinterfüße dreizehig, die Seitenzeben vorn und hinten den Boden erreichend.

Palaeotherium, Mesohippus, Anchitherium.

3. Familie der Equinae:

Augenhöhlen hinten rollständig knöchern geschlossen.

Elle und Speiche verschmolzen.

I) W. Scott, osteology of Mesohippus, Journal of Morphology T. 1891.

$\left.{ }^{2}\right)$ C. Zittel, Paläozoologie IV. Bd. S. 239, 245, 252. 
Backzïhne mit reichlichın Cemente.

Die vorderen Backzälne den hinteren gleich.

Merychippus, Hipparion, Protohippus, Hippidium, Equus.

Durch solche thatsïchlichen Feststellungen wird unser Urteil über den beweisenden Wert der Marsh'sclen Abbildungen und der phylogenetischen Stammbäume etwas modifiziert. Gedruckt sind die Namen der Vorfahren des Pferdes einfach auf den Tabellen abzulesen und wirken wie ein vollgiltiger Beweis. Wenn man aber alle bekannten Eigenschaften der ausgestorbeuen Formen erwägt, so stellen sich dieselben als Tiere dar, welche im Aufbaue der Hände und FüBe wohl eine gewisse Ähnlichkeit mit dem modernen Pferde besitzen, in vielen anderen Punkten jedoch ron ihm abweichen. Es sind also die älteren Arten aus der Familie der Hyracotherinae und der Palaeotherinae überlaupt auszuschlicßen und nur die jüngere Familie der Equinae als wahre Pferde anfunfassen. Schon Coper) hat hervorgehoben, dass in der Organisation der Familie der Paläotherinae ein tiefer Kontrast mit den eigentlichen Pferden liege.

Wie haben sich nun die Equinae aus den äIteren Formen entwickelt? Als rermittelndes Glied wird Merychippus genannt. Auf diese Gattung, welche zu Ende der siebziger Jahre in Amerika entdeckt wurde, legt $\mathrm{Haeckel}$ mit Schlosser ein Hauptgewicht. Während eines Aufenthaltes in Amerika bei Marsh hatte letzterer Gelegenheit, die Reste von Merychippus genau zu studieren. Er bezeichnete sie als die wichtigste Übergangsform²) zur Organisation der modernen Pferde; das Gebiss ist bereits pferdeartig, besitzt Cement und ebene Kauflächen, doch ist die Zahnkrone recht niedrig. In einer Anmerkung fügt er hinzu, diese Züihne seien das Frappanteste, das er je an Uebergangsformen gesehen hat. Wemn Sie aber fragen, wie Merychippus ausgesehen habe, so kann nur geantwortet werden, dass die Zähne nach dem Typus des Pferdes gebaut waren. Fragen sie nach der Beschaffenheit der Gliedmaßen, des Skelettes, des Schädels, so bleibt die Auskunft rersagt. Von Merychippus sind nichts als Zähne bekannt.

In diesem, wie in manch' anderem Falle wird der stammesgeschichtliche Zusammenhang behauptet, weil zwischen isoliert gefundenen Zühnen eine gewisse Formenverwandtschaft auffällt. Die amerikanischen Palïontologen haben ïberhaupt bei den Untersuchungen nach der Stammesverwandtschaft der Pferde das Hauptgewicht früher so ansschlieBlich auf die Zähne gelegt, dass man glauben kömnte. die Tiere hätten gar keine andieren Organe besessen.

1) American Naturalist rol. 21b, 1887, p. 1067.

2) M. Schlosser, Morph. Jahrbuch 1887, p. 14, 15. 
Der wissenschaftliche Name ..Merychippus" hat also in diesem Falle eine ganz andere Bedeutung, als der von irgend einem lebenden Tiere, z. B. Equus caballus, das Pferd. Während der letztere im Geiste des Keuners hunderte ron wohlbekannten Eigenschaften bedeutet, bezeichnet das Wort „Merychippus" ein Tier, von welchen einzig und allein die Zahnreihen bekannt sind.

Der genealogische Nachweis droht an einer neuen Schwierigkeit zu scheitern. Wir kennen jetzt eine Anzahl älterer Arten, die in ihrer Organisation wesentlich von den heutigen Pferden abweichen, z. B. Hyracotherium, Eohippus, Orohippus, Mesohippus, Anchitherium und eine Gruppe anderer Arten, welche unzweifelhaft wahre Pferde sind, nämlich Hipparion, Protohippus, Pliohippus, Hippidium. Das Terbindungsglied beider Gruppen soll Merychippus sein, ein Tier, das abgesehen von seinen Backzähnen vorderhand nur durch seinen lateinischen Namen bekannt ist. Obgleich der Name ohne weiteres in die klaffende Lücke der Stammreihe eingerückt werden und Laien über unsere Unkenntnis hinwegtäuschen kann, lässt sich doch der thatsächliche Mangel wirklicher Zwischenglieder nicht verschleiern, deren Studium uns vielleicht gestatten würde, die Transmutation der Tnpaarhufer ans den Familien der Palaeotherinae und Hyracotherinae an den Skeletten direkt abzulesen.

In der Pferdegeschichte klafft also an entscheidender St elle, genau so, wie zwischen der Fischflosse und der fünffingerigen Hand eines höheren Wirbeltieres eine bis heute nicht aus gefüllte Lücke.

Die Vergleichung der Gliedmaßen hilft darïber nicht hinweg; denn sie belehrt uns nur, dass der bei der anfänglichen Betrachtung des einfingerigen Pferdefußes jedem auftauchende Gedanke, derselbe falle ganz aus dem Rahmen der sonst bei Säugetieren herrschenden Fußbildung, falsch ist, da die vereinfachte Pferdehand sich als Spezialfall der Säugerhandbildung erweist. So leicht nun alle Gliedmaßen der Pferdereihe übersichtlich geordnet, und so einfach die Rückbildung der vier übrigen Finger sich verfolgen lässt, so ist doch dadurch die Stammesgeschichte nicht als ein wirklicher Prozess erwiesen; denn Hand- und Fußskelett sind nur Abschnitte des Tierkörpers, die niemals als sichere Indikatoren einer an sämtlichen uibrigen Organen erfolgenden Umbildung gelten dürfen. Die Dreizehigkeit einer fossilen Tierart allein ist noch kein schlagender Beweis, dafs sie eine direkte Vorfahrenform des Pferdes sei, mag sie auch von den Paläontologen durch Composita des Wortes Hippus benannt sein.

Wer die Stammesverwandtschaft rerschiedener im zoologischen Systeme einander nahe gerïckter Tierarten aufweisen will, darf 
elen nicht blok rin einziges Merkmal, nicht die Beschaffenheit eines Bruchstiickes hetrachten. sondern soll den ganzen Körper samt all seinen T'eilen in Erwägung ziehen. Dann sprechen aber die oben berichteten 'Thatsachen gegen direkte Verwandtschaft und in manchen Fällen gesellt sich dazu die Schwierigkeit, dafs viele fossile Pferdearten nur teilweise bekannt sind. Infolgedessen wissen wir gar nicht, wie manche sog. Stammväter des heutigen Pferdes ansgesehen haben. Wir besitzen wohl paläontologische Beweise für das Torkommen zahlreicher Pferdearten, aher dieselben reichen nicht aus, uns eine anschauliche Vorstellung von der Körperbeschaffenheit derselben zu geben. Wäre das Skelett der in den stammesgeschichtlichen Tabellen aufgefuilurten fossilen Pferdearten so bekannt, wie das der jetzt lebenden Tiere, dann wäre freilich die Sache anders; man wiirde wenigstens das Ḱnochengeriiste der verstorbenen Arten rollständig studieren und vergleichen können.

Vielleicht wïrden sich aber neue Übelstände geltend machen. Ich rermute es nach der alten Erfahrung, dafs sich die vollständig bekannten Skelette jetzt lehender Arten schwer, richtiger gesagt, niemals in eine phylogenetische Reihe ordnen lassen und der Anlänger der Entwicklungstheorie uns entschuldigend erklärt, die verkniipfenden Mittelformen seien wohl früher rorhanden gewesen, jedoch vor langer Zeit ausgestorben und ihre Reste bisher nicht gefunden worden.

Um nur ein Beispiel anzugeben, will ich Sie an die Faultiere erinnern. In Sïdamerika leben zwei Arten, welche sich durch ihre Fingerzahl so unterscheiden, dafs sie als dreizehiges und zweizehiges Faultier bezeichnet werden. Der Name rïckt uns die Vermutung nahe, ob nicht die zweizehige Art infolge stärkerer Reduktion der Finger aus der dreizehigen Art entstanden sei. Das zoologische Studium deckt dagegen die Unmöglichkeit des Gedankens anf. Die beiden Arten weichen außerordentlich stark von einander ab und können nicht direkte rerwandtschaftliche Beziehungen gehabt haben. Man hat sie darum seit langer Zeit in zwei gesonderte Gattungen gestellt, das dreizehige Faultier, Bradypus tridactylus Wied., mit 9 Halswirbeln in die Gattung Bradypus, das zweizehige Faultier, Choloepus didactylus mit 7 Halswirbeln in die Gattung Choloepus.

Glïcklicherweise ist die Thätigkeit der Paläontologen nicht so beschränkt, wie es nach den vorhergehenden Sätzen scheinen möchte. Günstige Funde lassen auch für die versteinerten Reste neben manchen Ähnlichkeiten tief greifende und höchst interessante Unterschiede nachweisen. Ihre Kahl wïrde sich nach meinem Urteil sicher sehr bedeutend vermehren, wenn wir jemals in die glïckliche 
Lage versetzt werden könnten, die Weichteile der ausgestorbenen Arten zu prüfen. Da aber der gesetzte Fall ein Irrealis ist, so müssen wir uns mit den Unterschieden begnügen. die an den versteinerten Stücken des Tierkörpers deutlich geschrieben stehen, zugleich im Sinne haltend, dass dieselben sicherlich mu einen kleinen Abschnitt aus einer ungeheuren Menge ron Unterschieden darstellen.

Die eingehende Analyse der ron Jahr zu Jahr vollständiger bekannt werdenden Skelettreste einiger fossiler Pferdearten hat bereits den Anlass gegeben, dieselben aus der direkten Ahnenreihe des Pferdes zu entfermen. Als einlenchtendes Beispiel hebe ich zunächst das Hipparion hervor. Es ist noch keine lange Frist verstrichen, als allgemein das Hipparion als wichtigste Zwischenform geschildert und die pferdeähnliche Gestalt seines Schädels, seiner Fiile und seines Gebisses betont wurde. Heute spricht man weniger davon, weil die einleuchtende Darstellung ron A. Weithofer ${ }^{1}$ ) die Unmöglichkeit erhellte, die dem heutigen Pferde zukommende Eigenart des Skelettes in den Verhältnissen des Hipparionskelettes gleichsam als Torstufen zu erkennen. Hipparion wird darum, wie der Stammbanm auf Seite 68 zeigt, von Weithofer und Haeckel als Seitenzweig angesehen.

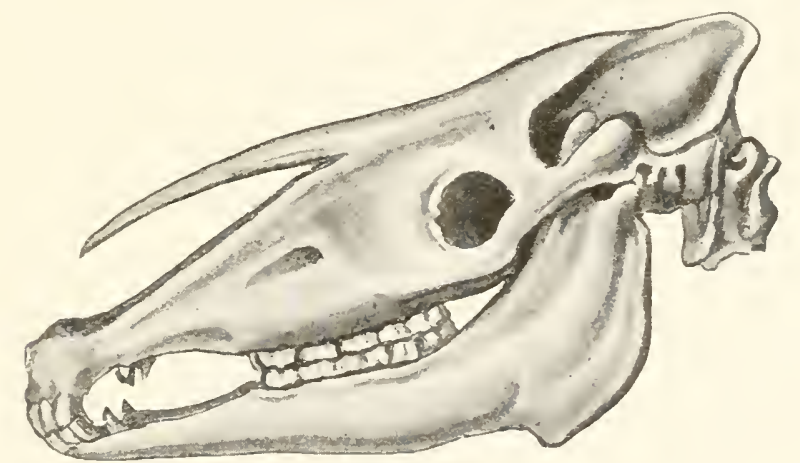

Fig. 44.

Schädel ron Hippidium neogaeum. Nach Durmeister.

Von den zeitlich nahestehenden Formen fällt Hippidinm ebenfalls aus der direkten Reihe. Hippidium ist eine Pferdeart Südamerikas, deren Körperbau den Zebras, ja selbst dem Esel ähnlicher war als den echten Pferden: durch die größere Zierlichkeit des Rumpfes, welche ganz der des Esels entspricht, durch die verhältnis-

1) A. Weithofer, Beiträge zur Kenntnis der Fauna von Pikermi. Beiträge zur Paläontologie Österreich-Ungarns, Bd. VI., 1888, S. 273-280, ferner M. Parlow, Etudes sur l'histoire paléontologique des Ongulés. Bull. Soc. Imp. des Naturalistes Moscou 1887, 1888, 1890. 
mäßig kurzen Gliedmaßen und einen absolut größeren Kopf (Fig. 44). Die Nasenhöhlen sind nicht soweit nach vorn knöchern geschlossen als beim Pferde, deshalb haben die Nasenbeine lange freie Spitzen. Die dicken, stark gekrïmmten, Backzähne besitzen kürzere Zahnkörper und die Kauflächen eine ganz andere '/eichnung als die von Equus.

Nit Anchitherium, um damit zu den älteren Formen überzugehen, verhält es sich nicht anders. Sein sehr wohl bekanntes Skelett unterscheidet sich so wesentlich vom Pferde, dass Schlosser es überhaupt nicht als direkten Vorfahren bezeichnet.

Für Mesohippus hebt Scott die mannigfachen Unterschiede des Skelettbanes gegenüber den neueren Arten hervor.

Gehen wir endlich bis zu Phenacodus zurück, dessen vollständige Skelette 1882 gefunden wurden, so erhellt die beistehende Abbildung (Fig. 45) die grossen Unterschiede vom heutigen Pferde,

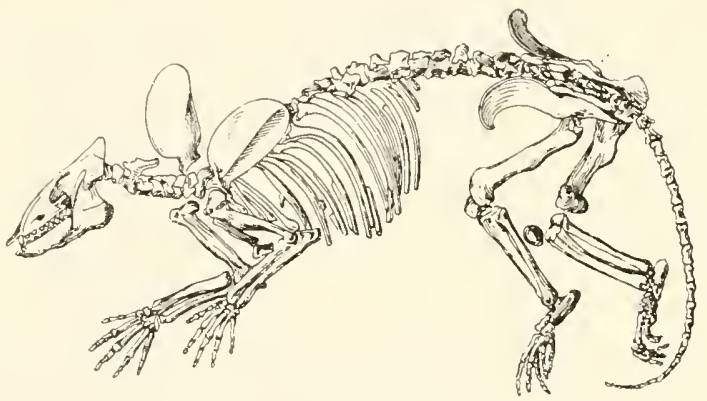

Fig. 45 .

Phenacodus primaevus. Nach Cope.

überhaupt von sämtlichen fossilen Equinen. Das kleine Tier besitzt fünf dentliche Finger an Hand und Fuß, welche nur darin mit dem Pferde übereinstimmen, dass der Mittelfinger etwas stärker ausgebildet ist, als die iibrigen Finger.

Schlosser äußerte vermutungsweise die Meinung ${ }^{1}$ ), „die Stammform der Pferde haben wir wohl in Phenacodus puercensis Cope aus dem Puercobed zu suchen. Es ist derselbe zwar noch nicht vollständig bekannt, doch genïgt sein Gebiss allen Anforderungen, die man an die Stammform der Pferde zu stellen berechtigt ist."

Er fährt fort:

„Von einem der älteren Phenacodus, bei welchem vermutlich wohl die erste und fünfte Zehe noch kräftiger entwickelt waren, stammt wahrscheinlich der erste echte Equine, das Hyracotherium, ab, doch erhielten sich zugleich auch noch mehrere Phenacodus-

1) 1. c. p. 11 . 
formen. - Fast möchte ich den verhältnismäßig hochbeinigen und zugleich im Zahnbau noch primitiveren Phenacodus Vortmani für den Vorläufer der Equiden, den plumperen Phenacodus primaevus dagegen für den Ahnen der Paläotherien ansehen."

Auf Grund neuerer Studien glaubt aber Matthew ${ }^{1}$ ), dass Phenacodus puercenis Cope, welcher heute Euprotogonia puercensis Cope genannt wird, nicht ein direkter Vorfahre von Hyracotherium sei.

Eine weitere Schwierigkeit für den genealogischen Nachweis der Pferdeahnen scheint mir die Thatsache zu bereiten, dass die Arten der modernen Pferdegattung gleichzeitig mit anderen Arten in den Sivalikschichten Ostindiens, d. h. Ablagerungen des obersten Miocän, und im oberen Pliocän von Italien und Algier gefunden wurden. Es kamen also die Individuen der als Stammräter betrachteten Arten, sowie die Individuen der darans entsprossenen Arten gleichzeitig mit einander vor. Die beistehende Tabelle aus Zittel's Handbuch gestattet eine bequeme Übersicht der einschlägigen Thatsachen.

\begin{tabular}{|c|c|c|}
\hline Jetzt & $\begin{array}{c}\text { Europa, Nordafrika } \\
\text { Equus }\end{array}$ & $\begin{array}{c}\text { Nordamerika } \\
\text { Equus von Europa } \\
\text { eingeführt }\end{array}$ \\
\hline $\begin{array}{l}\text { Pleistocän } \\
\text { Diluvium }\end{array}$ & Equus & \multirow{2}{*}{$\begin{array}{l}\text { Equus } \\
\text { Pliohippus } \\
\text { Protohippus } \\
\text { Hipparion } \\
\text { Merychippus }\end{array}$} \\
\hline Pliocän & $\begin{array}{c}\text { Equus } \\
\text { Hipparion }\end{array}$ & \\
\hline Oberes Miocän & Hipparion & $\begin{array}{l}\text { Hipparion, Miohippas } \\
\text { (Anchitherium) }\end{array}$ \\
\hline Mittleres Miocän & Anchitherium & Miohippus \\
\hline Unteres Miocän & & Mesohippus \\
\hline Oberes Eocän & Palaeotherium & Epihipp us \\
\hline Mittleres Eocän & $\begin{array}{l}\text { Palaeotherium } \\
\text { Pachynolophus }\end{array}$ & $\begin{array}{l}\text { Epihippus, Helohippus } \\
\text { Pachynolophus }\end{array}$ \\
\hline Unteres Eocän & $\begin{array}{l}\text { Pachynolophus } \\
\text { Hyracotherium }\end{array}$ & $\begin{array}{l}\text { Hyracotherium } \\
\text { Eohippus }\end{array}$ \\
\hline
\end{tabular}

1) Matthew, a rèvision of the Puerco Fauna. Bulletin of Amer. Mus. o wat. hist. vol. IX, 1897, pag. 309.

Fleischmann, Descendenztheorie. 
Die paläontologische Urkunde zeigt also nicht eine so klare Folgereihe der fossilen Reste, wie man sie für den Beweis der Stammesentwickelung eigentlich notwendig hat.

Das gemischte Torkommen verschiedener Pferdearten erinnert. an den gegenwärtigen Zustand, da auch heutzutage mehrere durch Pan und Wohnort wohl aus einander zu haltende Pferdearten neben dem Edelpferde leben. Das sind

Equus hemionus Pallas, Dschiggetai I Steppen von

Equus onager Schreb., Kulan, Wildesel f Centralasien

Equus taeniopus Heuglin, Steppenesel, Afrika

Equus asinus L., Esel

Equus zebra L., Zebra

Equus quagga Gmel., Quagga

Equus Burchellii Gray, Tigerpferd.

Wie heute dem Zoologen acht gleichzeitige Pferdearten bekannt sind, lehren die paläontologischen Funde, dass auch früher mehrere Arten die Länder der Erde bewohnten. Die Arten selbst unterscheiden sich durch viele Merkmale der äußeren Erscheinung und des ganzen anatomischen Banes. Was die FüBe anlangot, so waren die Differenzen friiher größer. Im Pliocän und Pleistocän lebten drei- und einfingerige Arten neben einander, hente nur einfingerige Arten. Aber das gemeinsame Torkommen eines systematischen Merkmales bei den letzteren ist mit recht vielen und auffïlligen Unterschieden des ganzen Habitus gepaart. Dies hat die Descendenztheoretiker auch abgeschreckt, eine bestimmte Meinung ïber die Verwandtschaft und die phylogenetische Entstehung der Zebras und Esel aus den fossil erhaltenen Arten zu äußern.

Nach der Besprechung so rieler Liicken der exakten Beobachtung muss ich endlich einen weiteren für die klare Anschaulichkeit der Pferdegeschichte sehr bedenklichen Mangel an den Pranger stellen. Die scheinbare Bestimmtheit aller Stammbaumentwiirfe verliert nämlich an exaktem Werte, sobald man erführt, dass die so einleuchtend iiber und seitlich aneinander gereihten Namen des Pferdestammbaumes, z. B. Eo-, Oro-, Meso-, Miohippus etc. wissenschaftliche Gattungsnamen bedeuten, welche zur Bezeichnung einer größeren oder geringeren Zahl von Einzelarten dienen. Das kann natïrlich der dem speziellen Arbeitsgebiete ferner stehende Laie nicht wissen und wenn er es erfährt, zunächst auch gar nicht ermessen, was es besagt; das heisst nicht mehr und nicht weniger, als dass die Worte: Eo-, Oro-, Meso-, Mio-hippus genau den gleichen Sinn haben, wie der Ausdruck: die Gattung Katze, Felis, welcher den Hörer auffordert, an sämtliche Katzenarten zu denken, oder ihm 
etwas, sämtlichen Katzenarten Gemeinsames mitteilt. Wenn ich z. B. ron der Gattung Bär, d. h. lateinisch von dem Genus Ursus oder auch kurzweg Ursus rede, so unfasst der Ausdruck die Gesamtheit folgender Arten : Eisbär, brauner Bär, syrischer Bär, Kragenbår, Grislybär, Bartbär, malayischer Bär, Lippenbär, Höhlenbär.

In der gleichen Weise dienen die paläontologischen Namen: Eo-, Oro-, Meso-, Miohippus etc. nicht der Bezeichnung für eine ganz bestimmte Pferdeart, sondern sie nennen je eine Gattung fossiler Tierarten, welche wegen ihrer gemeinsamen Eigenschaften in eine weitere Gruppe zusammengezogen wurden. Der paläontologische Terminus Protohippus ohne weiteren Beisatz bezeichnet folgende Arten:

Protohippus perditus Leidy.

Protohippus profectus Oope.

Protohippus labrosus Cope.

Protohippus placidus Leidy.

Protohippus medius Cope.

Protohippus sejunctus Cope.

Im Verkehr mit den Fachgenossen kiuzt man die umständliche Aufzählung sämtlicher Arten eines Gattungsbegriffes durch die Angabe des Gattungsnamens zur allgemeinen Bequemlichkeit ab, weil man weiss, dass der Gelehrte Bedeutung und Inhalt der Abbreviatur kennt. Der Laie kann jedoch zu schwerem Irrtum durch die ilım nicht so geläufige Methode geführt werden. Deshalb will ich Ihnen die Arten mehrerer im Stammbaum eine wichtige Rolle spielender Gattungen ïbersichtlich zusammenschreiben. ${ }^{1}$ ) Equus bedeutet außer den oben genannten lebenden Arten noch folgende fossile Arten:

Equus sivalensis Falc. et Cautl.

Equus namadicus Falc. et Cautl.

Equus Stenonis Cocchi.

Equus caballus fossilis Cuv.

Equus hemionus fossilis.

Equus excelsus Leidy.

Equus crenidens Cope.

Equus major Dekay.

Equus fraternus Leidy.

Equus occidentalis Leidy.

Equus curridens Owen.

1) Ich folge dabei meist den Angaben Zittel's und dem neuen Verzeichnisse von Matthew. 
Equus argentinus Burm.

Equus andium Wagn.

Equus rectidens Gerv. Amegh.

I) Liattung Merychippus bedeutet:

Merychippus insignis Leidy.

Merychippus mirabilis Leidy.

Zur Gattung Mesohippus gehören nach Matthew:

Mesolippus (Anchitherium) bairdi, Leidy.

Mesohippus intermedius O. et. W.

Mesohippus copei O. et. W.

Mesohippus gracilis Marsh.

Mesohippus celer Marsh.

Mesohippus westoni Cope.

Mesohippus praestans Cope.

Mesohippus equiceps Cope.

Mesohippus brachylophus Cope.

Mesohippus longicristis Cope.

Mesohippus condoni Leidy.

Die Gattung Epihippus umfasst die Arten:

Epihippus Uintensis Marsh.

Epihippus gracilis Marsh.

Die Gattung Orohippus umfasst die Arten:

Orohippus major Marsh.

Orohippus silvaticus Leidy.

Orohippus nintanus Marsh.

Orohippus agilis Marsh.

Ton der Gattung Hipparion sind ungefähr 20 Arten, ron der Gattung Pliohippus 3 Arten, von der Gattung Hippidium vier Arten bekannt.

Schriebe ich also den Stammbaum des Pferdes so anf, dass die eigentliche Bedentung der wissenschaftlichen Gattungsnamen nicht rernachlässigt ist, so miisste ich an Stelle der wenigen Worte des iibersichtlichen Haeckel'schen Entwurfes (S. 68) die Zahl der unter ilnen subsumierten Arten einzeichnen. Sobald Sie sich die Operation im Geiste ausgeführt denken, sehen Sie ein, dass ein wirklicher, den allerbescheidensten Anforderungen der Genealogie geniigender Stammbaum der Pferdegruppe nicht existiert. Denn der stammesgeschichtliche Forscher soll uns bei der Terfolgung des Pferdestammes in frühere geologische Perioden bestimm te Tierarten als Stammeltern, nicht eine Unsumme ron Tierarten nennen und dem Entscheide, welche derselben genealogisch am wichtigsten ist, nicht aus dem Trege gehen. 
Dazu gesellen sich weitere Mängel. Ich kann Ihnen nicht mit positiver Bestimmtheit sagen, ob die Zahl der oben angeführten Arten mehierer paläontologischer Gattungsbegriffe sicher steht. Die Beschreibung und die Nomenklatur fossiler Funde ist zum Teil so unsicher und ungenügend, dass leicht möglich ein und dieselbe Art unter zwei oder meh lateinischen Namen figuriert. Cope ${ }^{1}$ ) tadelt z. B. dass Marsh der Entwickelungsreihe der Pferde zwei Formen, Hyracotherium und Hippidium zugefïgt, aber beiden neue Namen gegeben habe, dem Hyracotherium den Namen Eohippus, dem Hippidium den Namen Pliohippus, ferner dass Marsh zwei neue Stufen als Orohippus und Miohippus aufgestellt habe, die nicht genügend charakterisiert werden konnten, um sie wieder zu erkennen. So geht es noch in vielen anderen Fällen. Das erheischt für die Zukunft eine umständliche kritische Untersuchung und eine genaue Nachprïung des fossilen Materiales, damit die unsagbar rerwirrte und widerspruchsrolle Nomenklatur sowie die systematische Einteilung der rersteinerten Reste ausgestorbener Pferdearten endlich geklärt werde. Da die Mehrzabl der natürlichen Funde in amerikanischen Museen liegt, ist es hier in Deutschland nicht möglich, zu einem abschließenden Urteile zu gelangen, und das Studium der einschlägigen Abhandlungen steigert nur die Schwierigkeit klarer Einsicht.

Die Notlage des exakten Forschers wächst durch die beklagenswerte Ungenauigkeit mancher Paläontologen und Geologen, welche in der Sucht, einige neue Arten zu beschreiben, manchmal ungenügend bestimmte Bruchstiicke als Reste einer neuen Tierart beschreiben, anstatt zu warten, bis ein gliicklicher Zufall reichlicheres Material in die Hand des Untersuchers spielt. Da in der fossilisierten Urkunde der Säugetiere die Menge der gut erhaltenen Zahnreste diejenige aller anderen Skelettteile überwiegt, bildet das rergleichende Studium derselben die wichtigste Grundlage für die Diagnostik, Systematik und Spekulation der Paläontologen. Wenn nun z. B. ein Forscher irgend einen noch unbekannten hinteren Backzahn findet und ihn durch den lateinischen Doppelnamen bezeichnet ${ }^{2}$ ), der im zoologischen Systeme gewöhnlich für vollständige, wohlbekannte oder wenigstens jederzeit anatomisch zu erforschende Tiere gilt, während ein anderer Paläontolog an einer weit entfernten Fundstelle einen gleichfalls noch unbekannten rorderen Backzahn der gleichen ausgestorbenen Art findet, und ihn mit einem andern lateinischen Doppelnamen

1) Cope, American Naturalist vol. 21 b, 1887, p. 1074.

2) Leidy z. B. begründete Hypohippus anf die wohlerhaltene Krone eines Backzahns, Anchippus auf einen Backzahn, Parahippus auf drei obere und einen unteren Backzahn. 
belegt, so figurieren im Systeme zwei rerschiedene Namen und werden von Jedem, der die Originalabhandlungen eingehend zu priifen keine Zeit oder Lust hat. als Beweis für das Vorkommen zweier getrennter Arten betrachtet, bis endlich cler glückliche Fund einer voliständigen Zahnreihe und die kritische Revision der frïheren Beschreibungen die Widersprïche löst. Ohne direkten Augenschein ist es darum nicht möglich, den Wert der Fossilien wach der Beschreibung richtig einzuschätzen. Jedenfalls bestehen heute noch so riele Widerspriiche, dass man die versteinerten Pferdereste als rollgiltige Zeugnisse der Stammesgeschichte nicht anrufen darf, bevor nicht sämtliche Funde von tüchtigen Forschern kritisch verglichen und nebst guten Figuren klar beschrieben sind.

Die Abstammung des Pferdes ist also nicht mit der einer exakten Beweisführung geziemenden Präzision festgestellt und es wird noch lange Arbeit erfordern, um die eingehende Kenntnis der fossilen Arten zu erlangen. Welch seltsamer Kontrast besteht hier zwischen den nüchternen Thatsachen und der frohen Hoffnung der Descendenztheoretiker, deren populärem Apostel Carus Sterne ich zum Schlusse noch das Wort geben will:

"Wir müssen auf die Abstammung des Pferdes ron mehrzehigen Ahnen etwas genaner eingehen, weil dieses Beispiel das Lehrreichste für die nenere Auffassung des Lebens ist, was es geben kann. In Amerika, wo selbst das Pferd bei Ankunft der Europäer vollkommen ausgestorben und unbekannt war, sind seine Verwandten in allen Epochen der Tertiärzeit so häufig gewesen, dass massenhafte Überreste dieser Tiere gefunden wurden, die eine rollständige, fast liickenlose Entwickelungsreihe darstellen, so dass man diesen Erdteil als die eigentliche Heimat des Pferdegeschlechtes betrachten muB." - Dann folgt eine Schilderung der oben kritisierten Stammesgeschichte rom fuchsgroßen Eohippus bis zum hentigen Pferde. "Wenn wir einen Blick auf die Tafel ron O. C. Marsh (Fig. 33) werfen, so sehen wir mit einem Blicke, wie sich diese Umwandlung rollzogen hat. - - _ Eine ebenso deutliche und in ihrer Bewegung klar verständliche Entwickelungsfolge bieten die Zähne der vorweltlichen Pferdearten. Ihre Länge und ihr Schmelzleistenbau hat sich mit der Zeit dahin verbessert, dass sie immer rollkommener die Aufgabe erfiillten, einem so lebendigen und der Kraftentfaltung bediurftigen Organismus die Nahrung zu rerschaffen. Auch in anderen anf der Tafel nicht dargestellten Eigentiimlichkeiten lässt sich ein ebenso allmählicher Fortschritt konstatieren. So hat MI r rsh in bezug auf das Gehirn nachweisen können, dass bei den Pferden

1) Carus Sterne, Werden und Vergehen, Berlin 1880, pag. 420, 422, 423. 
eine stetige Erweiterung der Gehirnhöhlung seit der Eocänzeit stattgefunden hat, so dass auch in dieser Richtung Eohippus, Orohippus, Nesohippus und Pliohippus bis zum Equus eine regelmäBige Reihe bilden, in der clas Gehirn in einem bedeutend stärkeren Verhältnisse als der Körper an Größe zugenommen hat. - - - So haben wir die Entwickelung des Pferdes ans ihm höchst unähnlichen. tapirähnlichen, fünfzehigen Urtieren in einer fast lïckenlosen Reihe verfolgen können; wie es eben nur bei einem Geschlechte möglich war und erwartet werden konnte, dessen Arten während einer sehr langen Epoche beständig in großen Schwärmen rorhanden waren, und rermöge ihrer Geschwindigkeit ungeheure Länderstrecken be völkern konnten. Aber ein solches Beispiel genügt, um die Herrschaft des Gesetzes darzuthun und uns eine Ahnung zu erwecken, wie andere Tiergattungen in entsprechender Weise sich langsam ron verwandten Formen abgezweigt und schliesslich zu röllig isolierten Typen geworden sind." 


\section{Sechstes Kapitel.}

\section{Die Stammesgeschichte der Vögel. Der Urgreifvogel.}

Die Vertiefung in die anatomischen Untersuchungen iiber die fossilen Pferde hat uns bezuiglich aller wichtigen Ereignisse der Stammesgeschichte dieser Gruppe die heute bestehende Unklarheit und fïr eine Frage, welche den Descendenztheoretiker hauptsächlich auf die paläontologische Unterstiitzung anweist, den unzureichenden Erkenntniswert der versteinerten Bruchstïcke vor Augen gefiihrt. Die gleiche Erfahrung ist anch in anderen Fällen gemacht worden, wo man ein unerwartetes fossiles Fundstiick als die Lösung aller Rätsel betrachtete, um allmählich zur bescheidenen Resignation zuriickzukehren.

Die Stammesgeschichte der Vögel bietet dafür ganz unzweifelhafte Belege. Bei der Ahnenprobe derselben sind Säugetiere und Fische eo ipso ausgeschlossen, so bleiben als niedere Torfahren nur die Lurche und Reptilien. Da die letzteren mehr Nerkmale mit den Vögeln gemeinsam haben, muss bei ihnen der Anschluss gesucht werden, aber sogleich erheben sich bedentende Schwierigkeiten. Die Vorfahren der gefiederten und leicht beschwingten Wirbeltiere müssen unter allen Umständen eine Körperbeschaffenheit besitzen, welche viele Anklänge an die Organisation der heutigen Tögel zeigt. Wir sollen also bei den Eidechsen, Schlangen, Krokodilen, Schildkröten und den ausgestorbenen Reptilien, Dinosauriern, Pterosauriern anatomische Ähnlichkeiten mit diesen nachweisen.

Die einlenchtende Forderung jst jedoch schwer zu erfiillen, weil der Togelkörper viele ihm ausschließlich eigentïmliche Besonderheiten besitzt und sich dadurch von allen uibrigen Wirbeltieren weit entfernt. Sein Skelett (Fig. 46) ist durch die Verkiimmerung des aufwärts gekriimmten Schwanzabschnittes und die starre Terwachsung der Becken- und Leudenwirbel, sowie eines großen Teiles der Brustwirbel gekennzeichnet. Das breite Brustbein trïgt einen hohen Kamm und ist knöchern mit den 
Rippen rerbunden. Der Schädel besitzt schnabelartig verlängerte /wischen-, Ober- und Unterkieferknochen. Die meisten Skelettteile sind lufthohl, denn Anhänge der Lungen, fünf Paar Luft-

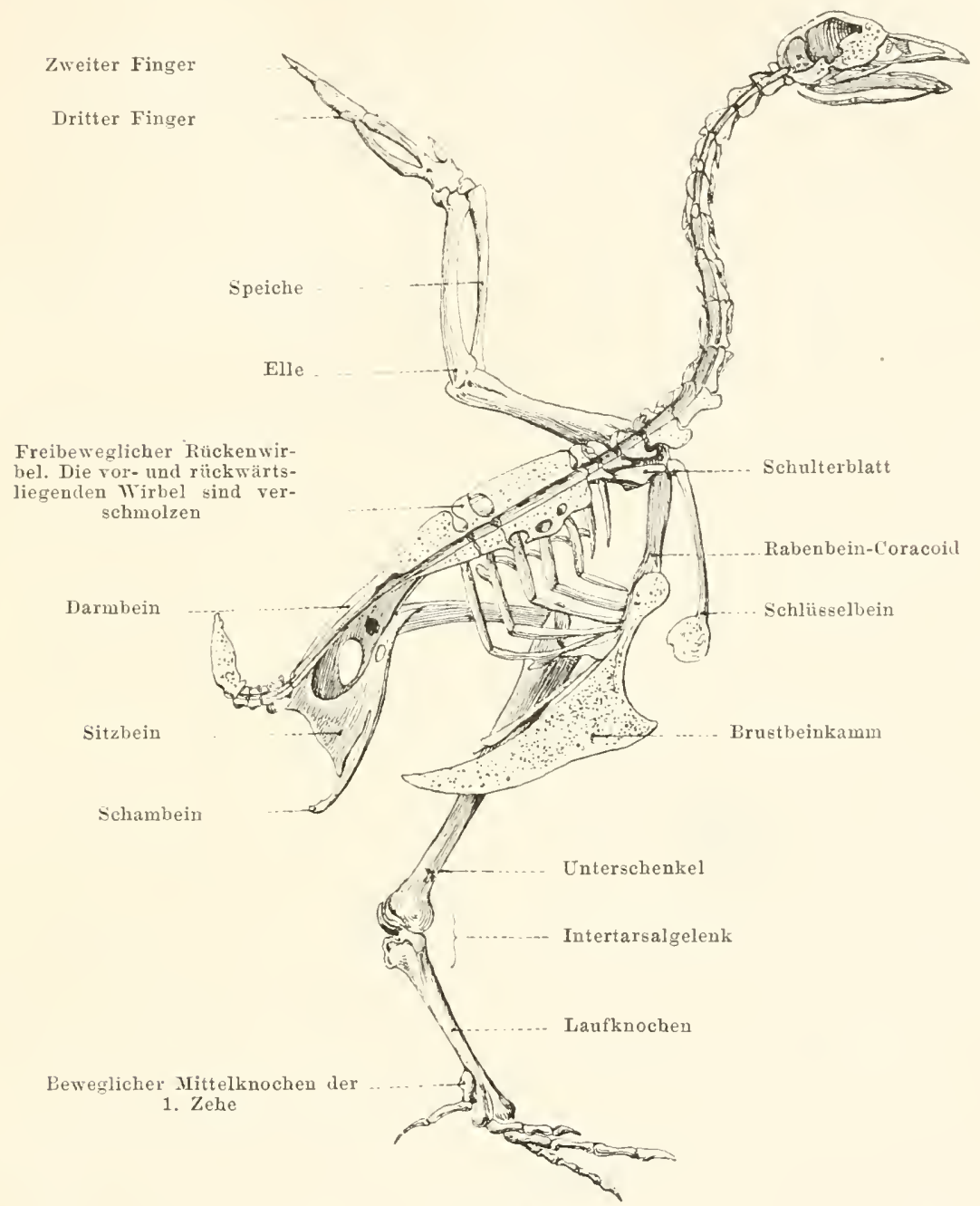

Fig. 46.

Linke Hälfte des skelettes vom Huhn. Nach Jilne Marshall und Hurst.

säcke, hängen teils in die Leibeshöhle, teils dringen sie zwischen die Muskeln unter die Haut und in die Knochen oft bis zu den äußersten Zehenspitzen ein. Der Mangel der Zähne wird durch den muskelkräftigen, mit einer derben Membran ausgekleideten Kau- 
magen ersetzt. I)ie Angen sind enorm groß wie bei keinem anderen gleich großen Wirbeltiere. Sie legen kalkschalige Eier und sorgen brütend für deren Entwickelung. Das Flugvermögen wird ihnen durch eine ganz eigenartige Einrichtung gesichert. Ich könnte eine Masse ron anderen Eigenschaften anführen, welche erhärten, wie scharf die Tögel von den anderen Wirbeltieren geschieden sind, wenn ich nicht fürchten müsste, ihre Geduld zu erschöpfen.

$W_{0}^{r}$ lassen sich nun bei Reptilien Anläufe zu solcher Spezialisierung, die vorbereitenden Einrichtungen zur Entwickelung des Flugvermögens wahrnehmen? Man könnte an andere Flieger, an die Fledermäuse, an die fossil erhaltenen Flugeidechsen, die Pterosaurier, denken. Allein die genanere Betrachtung der anatomischen Thatsachen verbietet den Ausbau der Idee. Denn in beiden Fällen sind die Flugwerkzeuge nach rerschiedenem Typus gebaut. Obwohl sie stets einen seitlichen, lappenartigen Auswuchs an der Vorderregion des Rumpfes bilden, werden sie ron rerschiedenen Skeletteilen gestiitzt und ron anders gelagerten Muskeln bewegt.

Bei den Fledermäusen sind alle Teile des Armes stark gestreckt. Die langen Oberarm- und Unterarmknochen ziehen am

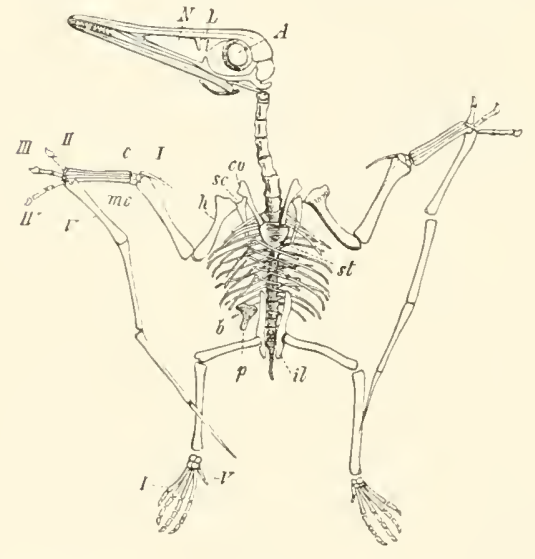

Fig. 47.

Pterodactylus spectabilis. Aus dem lithographischen Schiefer von Solenhofen. A Augenhöhle, $b$ Bauchrippen, $c$ Handwurzel, co Coracoid des Schultergürtels, $h$ Oberarm, il Darmbein, $m c$ Hittelhand, $N$ Kasenhöhle, st Brustbein. Torderrand der Flughaut, während die kolossal langen Mittelknochen und Phalangenglieder in die Flughaut einstrahlen.

Bei den Pierosauriern (Fig. 47) sind nur die Knochen des fünften Fingers stabförmig gestreckt und dienen der rom Rumpfe herüberwachsenden Flugmembran als Haftfläche. während die iibrigen vier Finger kurz, bekrallt und frei beweglich zum Aufhängen des ruhenden Tieres dienten. Bei den Vögeln (Fig. 46) dagegen sind die Finger, wie die ganze Hand schwach gebildet, nur der Oberarm, Elle und Speiche langgestreckt und die zwischen

Rumpf und Arm ausgespannte Flughaut winzig klein, indem die große Oberfläche des Luftruders durch die Schwingen des Federkleides geschaffen wird. Durch diese Merkmale ist die Eigentiimlichkeit des Togelkörpers scharf bestimmt, und unsere kurze Betrachtung zeigt 
zur Geniige, dass die Togelklasse nicht rou anderen Flugtieren abzuleiten ist. Trotzden muss der Descendenztheoretiker ähnliche, rielleicht nur etwas einfachere Flugeinrichtungen bei den Ahnen rermuten.

Da es mir hier versagt ist, alle wichtigen Eigenschaften der Togelorganisation zu besprechen, will ich mich auf das Beispiel des Arm- und Beinskelettes beschränken. Sie sind nach dem

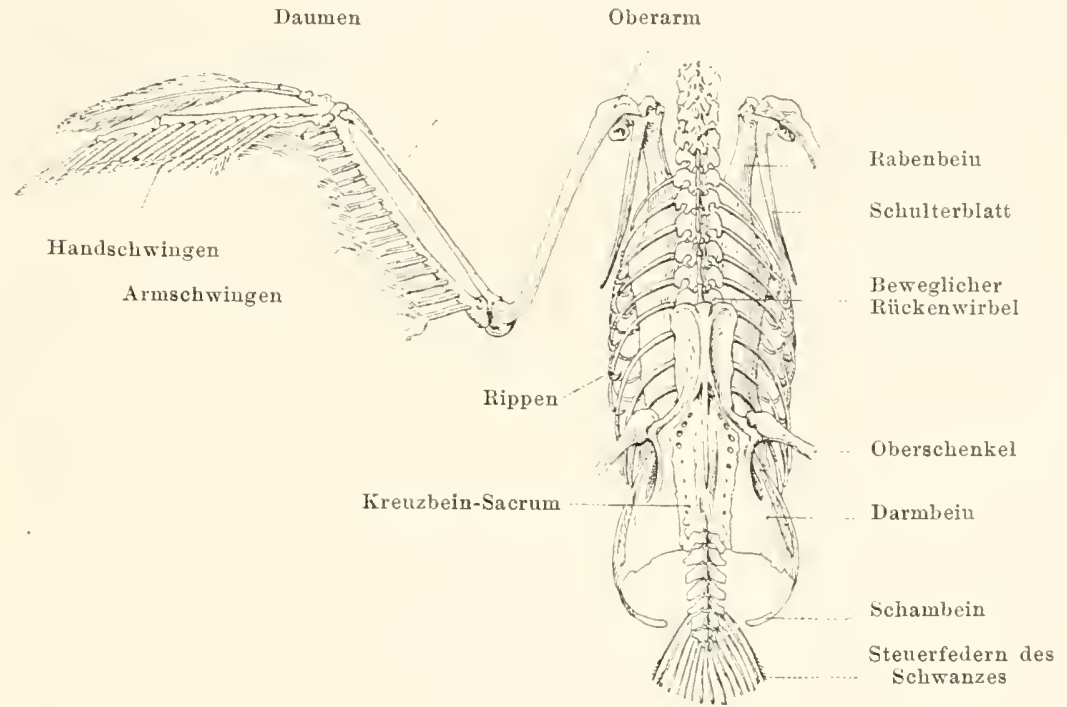

Fig. 48 .

Rumpfskelett ron Vulpanser tadorna, Fuchsente. Rückenansicht.

friher geschilderten Typus der Wirbeltiere angelegt und tragen dazu noch ganz besonderes, nirgends wiederkehrendes Gepräge.

Der Oberarmknochen ist sehr lang, bei guten Fliegern gilt das Gleiche auch für die beiden Unterarmknochen. Die Elle ist immer stärker als die Speiche. Der Hand fehlen zwei Finger nebst den zugehörigen Mittelknochen. Es ist noch nicht ausgemacht, ob die drei übrigen Finger dem ersten, zweiten, dritten oder dem zweiten, dritten, vierten Finger entsprechen. C. Gegenbaur huldigt der erstgenamnten Deutung, während R. Wiedersheim ${ }^{1}$ ) die zweite Möglichkeit vertritt. Hier löst sich die Alternative also nicht so befriedigend, wie bei Pferden und Wiederkäuern. Die drei Finger sind mit Federn bedeckt und erfiillen keine Funktion als Greifwerkzeuge.

1) R. Wiedersheim, Grundriß der vergl. Anatomie der Wirbeltiere. 4. Aufl. Jena 1898, p. 136. 
Besonders merkwiirdig erseheint die Terwachsung der Skelettteile in Handwurzel und Mittelhand: Während der Embryonalzeit verschmelzen nämlich die Knochen der zweiten Handwurzelreihe (Fig. 50, 51 punktiert). Die Mittellnochen des zweiten und dritten Fingers (ich folge jetzt der 'Zählung Gegenhaur's) verwachsen am rorderen und hinteren Rande, meist sehließt sich ihnen der Mittelknochen des Daumens an. Indem nun die verschmolzenen Elemente der zweiten Wurzehreihe und die verwachsenen Mittelknochen mit einander verschmelzen, entsteht an Stelle der halben Handwurzel und Mittelhand eine breite, ron einer schmalen Spalte durchzogene Knochenplatte, an deren oberem Ende sich zwei Knö̈chelchen der ersten Handwurzelreihe (Ulnare und Radiale) als Briicke zum Unterarm einschieben. Ton Phalangen sind nur kïmmerliche Reste als Anhängsel des bei guten Fliegern oft die Länge des Vorderarmes bedeutend iibertreffen-

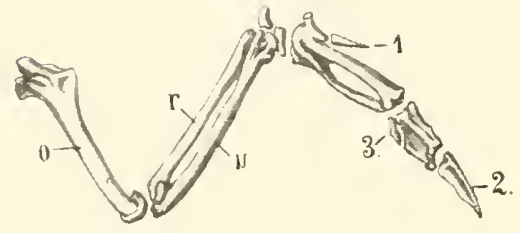

Fig. 49.

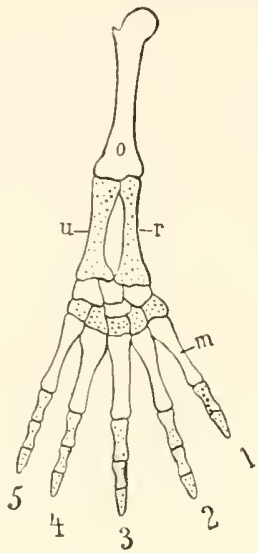

Fig. 50.

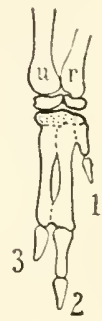

Fig. 51.

Fig. 49. Rechter Arm der Taube, Aubenseite. Nach Vogt und Young. o Oberarm, $r$ Speiche, $u$ Elle, 1, 2, 3 Finger.

Fig. 50. Schematische Skizzedes GliedmaBenskelettes der Wirbeltiere: $m$ Mittelhandknochen, o Oberarm, $r$ Speiche, $u$ Elle, zweite Handwurzelreibe punktiert.

Fig. 51. Schematische Skizze der Knochen der Vogelhand. $r$. Speiche, $u$ Elle, 1, 2, 3 Fingerglieder, die punktierte Zone deutet die mit den Mittelknochen rerschmolzenen Stücke der zweiten Handwurzelreihe an. Die Grenzen der Mittelkuochen siud durch Punktierung angedeutet.

den Komplexes der Mittelknoehen nachzuweisen: je eine Phalange des ersten und dritten Fingers, zwei Phalangen des zweiten Fingers. Sie werden begierig sein, zu erfahren, wie sich diese Umbildung des Handskelettes vollzogen hat; allein ich vermag keinen Aufschluss zu geben. Niemand weiß, bei welchen Vorfahren die Umbildung der typischen Vorderextremität zur spezifischen Vogelstilistik eingeleitet wurde. Andere Tiere, welche keine Vögel sind und einen einigermassen ähnlichen Bau des Armskelettes besitzen, sind nicht bekannt.

Das Fußskelett der Vögel sieht ebenso sonderbar aus. An einem gut montierten Skelette (Fig. 46) werden Sie vergebens die 
normalen Bestandteile des Fußes suchen. Wenn Sie auch leicht die Phalangen der vier oder drei Zehen erkennen, so vermissen Sie sämtliche Knochen der beiden Fußwurzelreihen und sehen zwischen dem kräftigen Schienbeine und den inneren Phalangen der Zehen einen einzigen Ḱnochenstab, den sog. Laufknochen eingeschaltet. Für die Klasse der Vögel gilt also anscheinend das früher an den Extremitäten der Säuger beobachtete Gesetz nicht, dass die Modifikation des Hand- und Fußskelettes zu ähnlichem Endresultate fiihrt. Und doch macht die genauere Analyse klar, dass am Fuße der Vögel die homologen Verwachsungen erfolgen, wie an der Hand, nämlich Verschmelzung der Fußwurzelreihen und der Mittelfußknochen.

Die Zehenzahl ist dagegen weniger stark beschränkt. Der fünfte Finger fehlt immer, nur ein Rudiment des zugehörigen fünften Mittelfußknochens erscheint. Von den übrigen vier Fingern ist manchmal der Daumen unterdrückt. Der Oberschenkelknochen ist verhältnismäßig kurz. Das Schienbein in jedem Falle kräftig, das Wadenbein zart und häufig ein ganz unbedeutendes Anhängsel. Während des Eilebens (Fig. 52) verschmelzen die Elemente sowohl der ersten wie der zweiten Fußwurzelreihe in zwei gesonderte Stücke, die erste Reihe als oberes, die zweite Reihe als unteres Tarsusstück. Die vier ron rornherein stark gestreckten Mittelkuochen verwachsen samt dem unbedeutenden Reste des fünften Mittelknochens zu einem einzigen, lang gestreckten Mittelstab, wobei ihre unteren Gelenkköpfe für die anstehenden Zehenphalangen getreunt bleiben. Indem später der Mittelstab mit dem unteren Tarsusstück verschmilzt, wird aus typisch zehn Fußskelettelementen der „L a ufknochen" gebildet; (Fig. 52) das obere Tarsusstück verlötet mit dem Schienbein untrennbar. Die Fußbewegungen erfolgen dann in einem zwischen den beiden Tarsalstücken liegenden Gelenke, dem

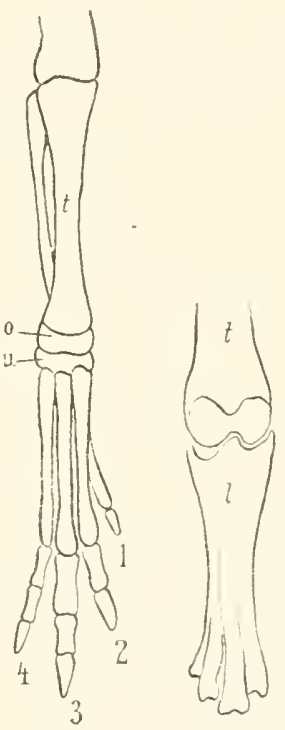

Fig. 52

Links: Fusskelet t eines H ühnchens rom 9. Brut tage. $t$ Unterschenkel, 0 Oberes, $u$ Unteres Tarsusstück, 1, 2, 3, 4 Zehen.

Reclits: Laufknochen (l) einer jnngen Taube. $t$ Unterschenkel, die Mittelknochen sind mit eiuander und dem unteren Tarsusstück bereits verschmolzen, aber ihre Grenzen uoch sichtbar. Nach Gegenbaur. sog. "Intertarsalgelenke", (Fig. 46) während bei Säugetieren die Beugung des Fußes im Gelenke zwischen Schienbein und der ersten Fußwurzelreihe geschieht.

Obgleich eine ähnliche Verwachsung der beiden Wurzelreihen 
am Fuße der Fidechsen beobachtet wird, muss der Gedanke an eine stammesgeschichtliche Beziehung der Vögel zu den niedrig gestellten Kriechtieren abgelehnt werden, weil die anderen Elemente der hinteren Extremität zu wenig Vogelähnlichkeit offenbaren.

Auch die Stellung der in so sonderbarer Kombination verlöteten Mittelknochen des Vogelfußes weicht von der sonst gewohnten Norm weit ab, weil sie mehr oder weniger steil in die Höhe gerichtet werden, dass der Laufknochen fast senkrecht gegen die inneren Zehenphalangen abgebogen steht und die Körperlast durch Vermittlung des Laufes nur auf die Zehen gestützt wird (Fig. 46). Die jetzt lebenden Reptilien dagegen schmiegen die Mittel- und Wurzelregion des Fußes direkt dem Erdboden an als sog. Sohlengänger - plantigrade Tiere.

Sie stellen jetzt natïrlich die Frage, ob sich nicht Beispiele bei anderen Tieren finden, dass die Mittelknochen cinigermaßen "iiber

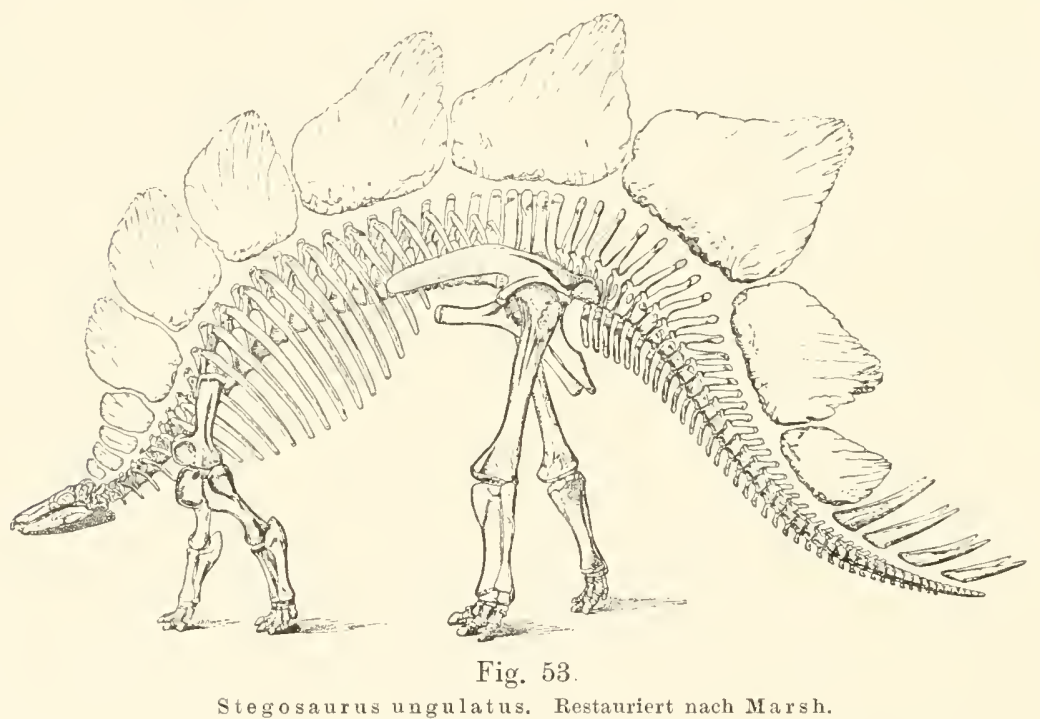

den Boden erhoben sind und vielleicht Neigung zeigen, mit einander zu verlöten? Solche Formen müssen ja als verknüpfende Glieder in der Stammesreihe der Vögel einstmals gelebt haben. Die Paläontologie hat die gewünschten Beispiele in Resten einer total ansgestorbenen Reptiliengruppe der Lindwïrmer, Dinosauria, ausgegraben, von denen manche sogar noch plantigrad waren. Viele Dinosaurierarten haben sich zu ungeheuren Riesen entwickelt, z. B. der Sohlengänger Stegosaurus im oberen Jura von Colorado, dessen Körperlänge $120 \mathrm{FuB}$ betrug (Fig. 53) und Iguanodon von nahezu 
10 Meter Länge (Fig. 54). Siebzehn vollständige Skelette der letzteren Art sind in Benissart bei Mons in Belgien gefunden und im Museum zu Brüssel aufgestellt worden. Sie rufen unser Interesse wach, weil wir daran bequem die Charaktere der sehr merkwïrdigen Untergruppe der Dinosaurier, der sog. Ornithopoden oder vogelfüßigen Drachen studieren können.

Die vordere $\mathrm{Ex}_{\mathrm{x}}$ tremitait bietet wenig hierher gehörige Eigenschaften, sie ist reptilienähnlich ohne Tendenz zum Vogeltypus. Die hinteren Gliedmaßen aber erimnern einigermaßen an den Vogelfuß. Die kräftigen Mittelknochen des zwei-

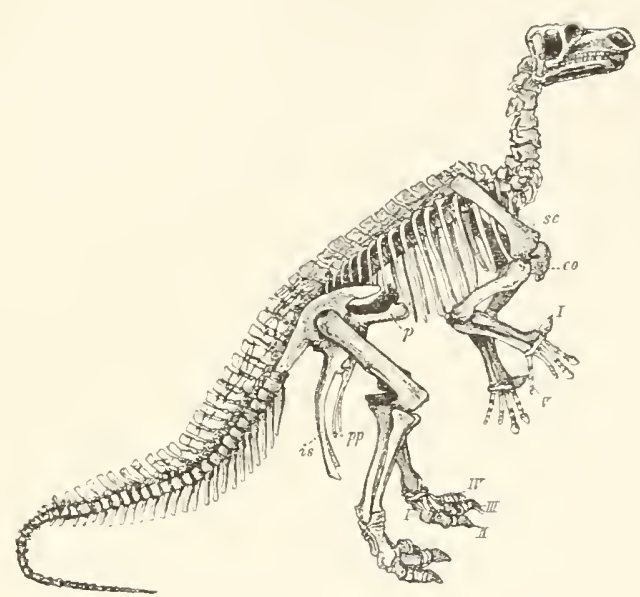

Fig. 54.

Iguanodon benissartensis. Das Sitzbein (is) und las Schambein $(p p)$ in vogelähnlicher Weise schwanzwärts verlängert. $I-V$ Finger, Zehen. ten, dritten, vierten Fingers sind aufgerichtet und nur die Zehenglieder liegen dem Boden an. Es steht also der Fuß etwa so, wie wenn wir auf den Zehen gehen und durch starke Muskelarbeit den Mittelfuß aufwärts ziehen. Andere Arten der Ornithopoden lebten auch als Zehengänger und man hatte in den siebenziger Jahren bald eine Reihe von Dinosaurierfüßen gesammelt, welche die stufenweise Abkehr rom Erdboden bis zu der bei Vögeln erreichten extremen Art klar

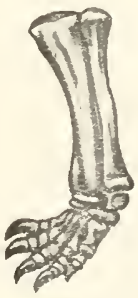

Fig. 5๊.

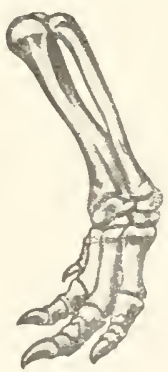

Fig. 56.

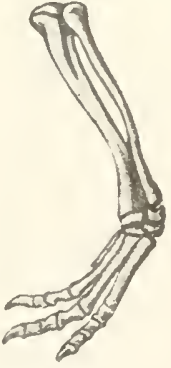

Fig. 57.

Fig. 55. FuB von Morosaurus grandis. Nach Marsh. Fig. 56. Fub von Camptonotus dispar. Nach Marsh. Fig. 57. Fub von Laosaurusaltus, Nach Marsh.

zu legen schienen (Fig. 55-57). Der ausgezeichnete englische Anatom, Th. Huxley glaubte sich darum berechtigt, die Dinosaurier als Vogelahnen anzusprechen, und längere Zeit haben andere Forscher ihm beigestimmt. Ich selbst hielt die Ansicht früher für ganz plausibel. 
Die Dinosauria stimmen noch in anderen Punkten ihres Kiörperbaues mit den Vögeln iiberein. Bei letzteren sind die Knochen nicht markhaltig wie bei den Säugern, sondern lufthohl. Sie brauchen nur den Oberschenkel einer Taube zu zerbrechen, um die Lufthöhle zul beobachten und wenn Sie genauer zusehen, finden Sie auch das Loch, durch welches die große Lufthöhle zugänglich ist. Bei den Dinosauriern gewahren wir dasselbe: die Beckenknochen, die Extremitätenknochen, der Oberschenkel, der Oberarm, Unterarm, die Wirbelkörper selbst, sind lufthohl. Diese Eigenschaft steigerte die Wahrseheinlichkeit der Verwandtschaft der Dinosaurier mit den Vögeln.

Dazu gesellen sich Eigentïmlichkeiten des Beckens, das bei allen Wirbeltieren aus 3 paarigen Teilen: dem Scham-, Sitz- und Darmbeine besteht. Das Becken der Dinosaurier ist ausgesucht vogelähnlich. Das Darmbein weit nach vorne verlängert, die Schamund Sitzbeine stabförmig nach rückwärts ausgezogen. Bei den Vögeln fallen ähnliche Charaktere auf (Fig. 46, 48), nur ist ihr Darmbein breiter und mit einer größeren Zahl $(6-15)$ von Wirbeln verschmolzen. Schambein und Sitzbein stoßen nicht in der ventralen Mittellinie zusammen.

Drei Merkmale, nämlich die Hinterfüße, die Lufträume der Skelettknochen und die Form des Beckens bezeugen also eine gewisse Formähnlichkeit der Dinosaurier mit den Vögeln und galten in den siebziger Jahren als zwingender Beweis dafür, dass direkte Blutsbande zwischen beiden Gruppen beständen. Aber seit jener Zeit haben auch die Descendenztheoretiker eingesehen, dass sie ihre Lehre nicht auf einzelne Organsysteme stïtzen dürfen. Sind die Dinosaurier wirklich die Stammväter der Vögel, so müssen sie in einer viel größeren Zahl von anatomischen Eigenschaften Übereinstimmung mit ihnen zeigen.

Die einfache Betrachtung der beiden Figuren 53, 54 führt Ihnen ungesucht mannigfache Unterschiede vor. Der Kopf ist winzig klein und ermangelt des Schnabels; die Wirbelsäule zeigt wesentliche Unterschiede von den Vögeln. Aus solchen und anderen Gründen hat die anatomische Forschung allmählich die Verwandtschaft der Dinosaurier mit den Vögeln abgelehnt. W'egen der beschränkten Zeit kann ich Ihnen leider nicht die Motivierung der neuen Auffassung im Detail entrollen. Dass es aber so ist, beweist ein Aussehnitt aus dem sehönen Buch ${ }^{1}$ ) des Professor Koken in Tübingen, welcher ein Anhänger der Abstammungslehre ist. Im vorhergehenden Abschnitte spricht Koken von der Ähn-

1) E. Koken, Die Vorwelt und ihre Entwicklungsgeschichte, Leipzig 1898, p. 393, Zeile 8. - p. 272, Seite 19. 
lichkeit der Dinosaurier mit den Vögeln, die Punkte verfolgend, die ich eben mit anderen Worten behandelt habe und führt dann fort:

„Aber alles das (nämlich die vogelähnlichen Charaktere der ornithopoden Dinosaurier) kann nicht darüber hinwegtäuschen, dass in anderen Teilen des Skelettes, besonders auch im Bau des Schädels, der inneren Schädelkapsel sowohl, wie der Deckknochen sich eine prinzipielle Verschiedenheit rom Vogeltypus offenbart, welche man nur im ersten Verfolge einer begeistert aufgenommenen Idee iibersehen und offenbaren Anpassungserscheinungen unterordnen konnte. Selbst die rogelähnlichsten Dinosaurier sind es nur in den eimzelnen Teiłen, während übrigens nur die allgemeinsten, bei allen Sauropsiden nachweisbaren Homologien zum Ausdrucke kommen. Die Ahnen der Vögel sind noch nicht entdeckt." -

„So treiben die Entdeckungen der Neuzeit die Konvergenzpunkte auch nahe verwandter Stämme in immer entlegenere Vergangenheit zurück. Was ist aus den Stammbäumen geworden, die man in der ersten Zeit des Darwinismus als bewiesene Thatsachen in die Welt sandte?"

Wir können die Vögel nicht bloß mit ausgestorbenen, sondern auch mit jetzt lebenden Reptilien vergleichen und finden dabei

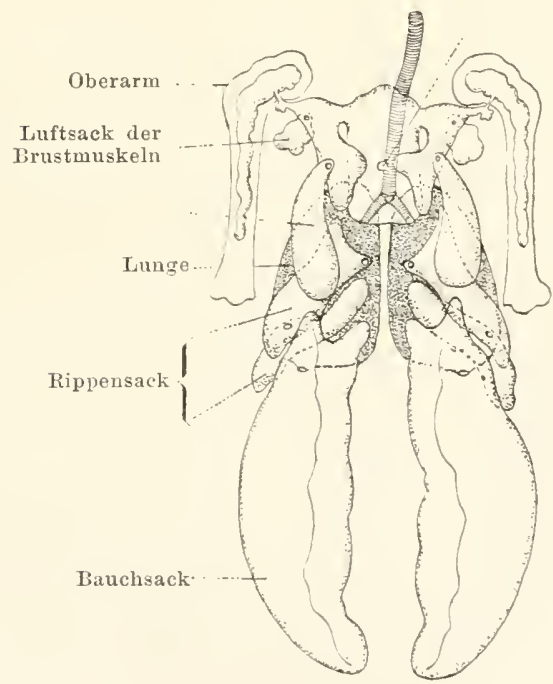

Fig. 58.

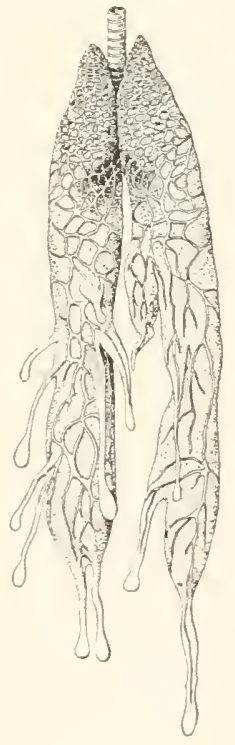

Fig. 59.

Fig. 58. Lungen und Luftsäcke einer jungen Taube. Schematisch nach Heider.

Fig. 59. I ungen des Cbamäleons mit engen Luftsäcken. 
manche Ähnlichkeit, z. B. zeigt der Magen des Krokodiles maunigfache Anklänge an den in 2 Abschnitte, einen Drüsen- und Muskelmagen, zerfallenden Vogelmagen. Das Chamaeleon (Fig. 59) und andere Reptilien besitzen an ihrer Lunge Luftsïcke, welche in die Leibeshöhle hängen, wie bei den Vögeln (Fig. 58). Aber die vercinzelte $\ddot{A} h n l i c h k e i t$ eines Organes hat keinen anatomischen Forscher

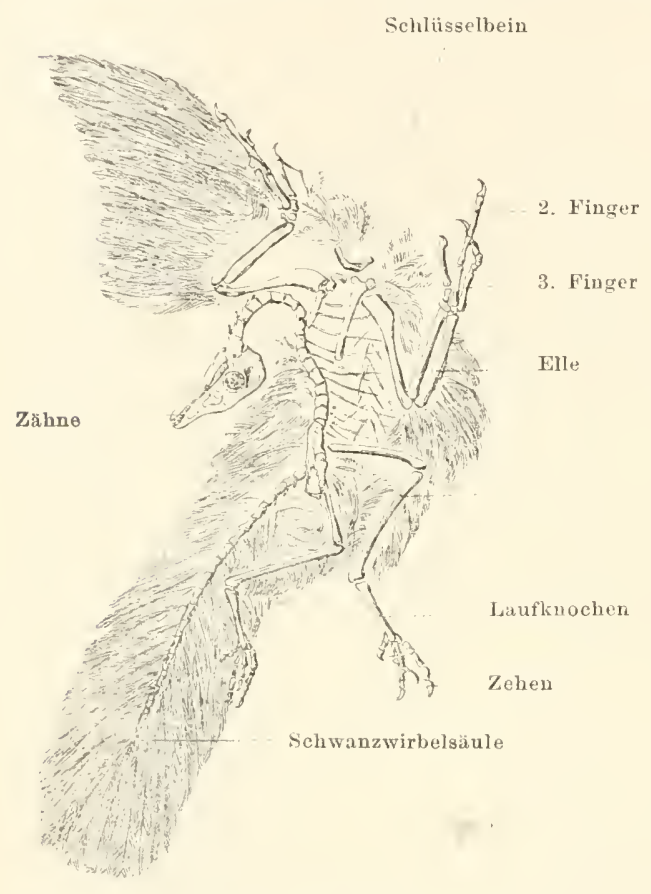

Fig. 60 .

Archaeopteryx lithographica. bestimmt, die Krokodile oder Chamaeleone als Stammeltern der Vögel zu betrachten, da die zugleich herrschenden Unterschiede zu angenfällig sind und man mit der Tertiefung der Diskussion immer mehr gezwnngen wird, durch Prüfung der gesamten Organisation die Flïgel der stammesgeschichtlichen Phantasie zu beschneiden

In dem Neere von Zweifeln, welche mein Bericht bei Ihnen erweckt hat, mögen manchem die Mitteilungen der ïberzengten Descendenztheoretiker über den fossilen Urgreif, Archaeo. pteryx lithographica, als Hoffnungsanker erscheinen. Wäre es nicht so, würde man die Zuversicht der Ausdrucksweise nicht verstehen, welche die Beschreibung von Carus Sterue ${ }^{1}$ ) atmet:

„Zwischen den Reptilien und den Vögeln, deren nahe Blutsverwandtschaft denkende Zoologen lïngst erkannt hatten, ist die vorhandene Liicke durch nenere Fnnde in unverhoffter Weise ausgefuillt worden. Nachdem man kurz vorher in jurassischen Schichten die ersten Vogelfedern gefunden hatte, entdeckte der Arzt und Petrefaktensammler Häberlein 1861 im Solenhofer Schiefer die Archaeopteryx lithographica. Die

1) Carus Sterne, Werden und Vergehen, Berlin 1880, p. 378. 
Gegner der damals eben ans Licht getretenen Darwin'schen Theorie empfanden diesen Fund als eine harte Niederlage; man sprach von einer Fälschung, einem Kunstprodukt, und als diese Deutung durch die genaneste Untersuchung widerlegt wurde, suchte man die Bedentung des Fundes in jeder Weise herabzusetzen. Indessen trug er die Beweise seiner Echtheit und Wichtigkeit in nur zu deutlichen und für die Entwickelungslehre lautes Zeuguis ablegenden Kennzeichen an sich." - -

Die Phantasie eines bildenden Künstlers hätte nicht leicht ein noch mehr bizarres Wesen erfinden können! Das im lithographischen Schiefer deutlich erhaltene Federkleid dient als Ausweis seiner Vogelnatur, aber der Besitz der langen, ans einer großen Zahl von Wirbeln gereihten Knochenstiitze des Schwanzes gemahnt direkt an Eidechsen, da die Schwanzwirbel der heutigen Vögel ganz kurz sind und zum Teil (4-9 Wirbel) mit der verlöteten Masse der Beckenwirbel (Sacrum) verschmelzen, zum Teil frei bleiben (6 Wirbel), teils wieder zusammenschmelzen. Gegen die Eidechseuähnlichkeit spricht hinwieder der Besatz des langen Schwanzes mit zweizeilig gereihten Federn. In den Kieferknochen wurzeln spitze, reptiliengleiche Zähne, während Hornscheiden die Schnabelknochen der heutigen Vögel umhiillen und Zahnanlagen nicht einmal in der frühesten Embryonalzeit entstehen. Das Brustbein, das mit Ausnahme der straußartigen Laufvögel bei allen Vogelarten einen kräftigen Mittelkamm trigt (Fig. 61), ist bei Archaeopteryx als flache Platte der Brustwand eingebettet. An der Hand ragen drei bekrallte Finger, gleich dem Befunde bei Pterosauriern, über die Haut. Unsere Vögel aber haben die Reste der Finger unbeweglich zwischen den Handschwingen verborgen. Kurzum alle Regeln der Syste-

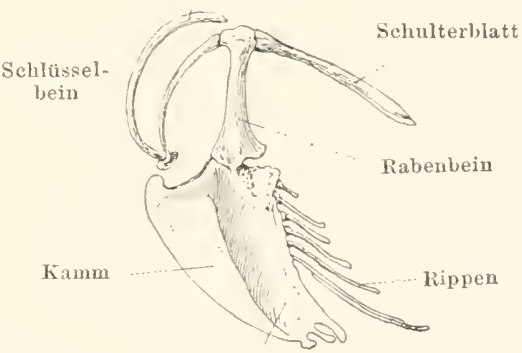

Brustbeinplatte

Fig. 61 .

Brustbein und Schultergürtel von Larus marinus, Mantelmöve. matik wurden iiber den Haufen geworfen, als der Vogel der Jurazeit bekannt ward. Der damals gehegte Gedanke, ihu als Schaltform zwischen die Reptilien und Vögel einzureihen, hat indessen die genaue anatomische Prüfung nicht ertragen.

Zunächst ist die Vogelähnlichkeit der Hand (Fig. 60) zu prïfen. Sie zeigt zwar eine ähnliche Redultion der Fingerzahl, indem drei Finger 
deutlich sind, der vierte und fünfte Finger fehlt; jedoch die drei vorhandenen Finger sind lang, tragen Krallen, wie die der Reptilien, ragen über die Flügel vor und konnten mittels kräftiger Phalangen zum Anklammern dienen.

Die zugehörigen drei Mittelknochen sind wohl getrennt und verraten keine Neigung, so wie bei allen jetzt lebenden Vügeln zu einer einfachen, von einer schmalen Spalte durchbrochenen Platte zu verschmelzen. Trotz des glïcklichen Fundes zweier Exemplare von Archaeopteryx fehlen darum noch immer Handformen, welche die Geschichte der reduzierten Vogelhand erhellen.

An den hinteren Gliedmaßen der Vögel ist der Laufknochen eine Bildung ganz besonderer Art. Sehnsiichtig wünscht der Freund der Abstammungslehre, möchte doch Archaeopteryx eine Vorstufe seiner Entstehung enthüllen. Leider wird auch diese Hoffnung zerstört. Der versteinerte Abdruck weist einen typischen Laufknochen (Fig. 60) mit wahrer Verschmelzung der Mittelfußstïcke auf. Er zeigt also nur, wie alt die typische Form des Vogelfußes ist und beleuchtet die Schwierigkeit des Problemes, anstatt es entsprechend den Wüuschen derer, welche die Palïontologie als wichtigste Bundesgenossin der stammesgeschichtlichen Forschung preisen, endgültig aufzuklären.

Die Sprache der fossilen Urkunde enttäuscht ferner unsere Neugier über die Entstehung des Federkleides, welche umsomehr eine bestimmte Antwort heischt, als die Haut der Reptilien mit Hornschuppen bedeckt ist und die Federn ein ausschließliches Besitztum der Vögel darstellen. Archaeopteryx war umzweifelhaft in ein Federkleid eingehiillt, dessen vollkommene Ausbildung uns nichts über die früheren Phasen eines wahrscheinlich unrollkommenen Dunengefieders der Greifabnen schließen lässt. Der Gegensatz in der Struktur der Körperdecke zwisehen Reptilien und Vögeln ist so groß, dass nicht einmal eine theoretische Vorstellung zu Gebote steht, wie man sich die erste Entstehung der Federn denken könnte, etwa wie Gegenbaur eine Vermutung bezüglich der Umwandlung des Archipterygiums in die Hebelextremität der vierfuißigen Wirbeltiere ausgesprochen hat. Ich weiß wohl, dass jüngst C. Maurer ${ }^{1}$ ) eine subjektive Vermutung in einer schönen Arbeit veröffentlichte, glaube aber nicht, dass seine Meinung, die Haare und Federn hätten sich aus den Hautsinnesorganen niederer Wirbeltiere zu besonderen Schutzzwecken entwickelt, des allgemeinen Beifalles teilhaftig geworden ist.

1) F. Maurer, die Epidermis und ihre Abkömmlinge. Leipzig 1895. 
Ebensowenig kann jemaud angeben, wie sich die Verschweißung der sonst durch Näte scharf getrennten Schädelknochen bei den Vorfahren der Archaeopteryx vollzog, noch wie die Verlängerung der Schnabelknochen, deren Federgelenk und die elegante Gleitvorrichtung der Kiefergaumenknochen an der Schädelbasis entstanden sei, wann sich der bei Archaeopteryx noch fehlende Knochenkamm auf dem Brustbein erhob und bei welchèn Arten die Zähne des Schädels riickgebildet wurden.

Wenn nun die Archaeopteryx über die Ahnen der Vögel recht wenig Aufschluss giebt, so stuitzen ihre gut erhaltenen Skeletteile nicht einmal die Annahme, dass sie selbst zu der dem Luftleben noch besser angepassten Organisation hentiger Vögel fortgeschritten sei. Viele Merkmale rerbieten direkt eine solche Vermutung: zunächst der breite Federsaum am langen Eidechsenschwanze, dessen Einzelfedern zweizeilig gereiht sind, während sie bei den lebenden Arten in fächerartiger Ordnung von den letzten verkümmerten Schwanzwirbeln getragen werden, dann der Mangel des Brustbeinkammes und die Form der Wirbel. Letztere stoßen bei allen heutigen Vögeln mit sattelförmigen Gelenkflächen an einander, bei Archaeopteryx ist die vordere und hintere Wand des Wirbelkörpers konisch ausgehöhlt ungefähr so, wic bei vielen fossilen Reptilien, den Lurchen und den Fischen, (sog, biconcave, amphicöle Wirbel).

Aus dieser kurzen Übersicht. welche Sie nach den Abhandlungen von $R$. Owen und W. Dames lejcht vervollständigen können, geht unleugbar hervor; dass die Archaeopteryx neben vielen wahren Vogelcharakteren, z. B. dem Federkleide, der Fußbildung, andere innerhalb der jetzt lebenden Vogelklasse nicht rorkommende Eigenschaften besitzt, z. B. die lange Schwanzwirbelsäule, das flache Brustbein, die biconkaven Wirbel, und infolgedessen nicht ein vermittelndes Übergangsglied sein kann. Die Freunde der Abstammungslehre haben darum ihre Bedeutung auf cin geringeres Мaß zurückgeschraubt; sie gilt ihnen jetzt als ein Seitenzweig der eigentlichen d. h. von keinem Menschen jemals gesehenen Stammeltern unserer Vögel. Die Auffassung ist nicht mehr neu. In einem großartigen Werke iiber die Anatomie der Vögel führte Max F ürbring e $\left.{ }^{1}{ }^{1}\right) 1888$ folgendes aus:

„Die jurassischen Archaeopterygidae treten durch eine Summe von Merkmalen. namentlich aber durch den langen eidechsenähnlichen Schwanz und die an die Verhältnisse bei Reptilien eriunernde Hand mit ihren gesonderten Mittelhandknochen und ihren drei gut ansgebildeten, bekrallen

1) M. Fürbringer, Untersuchungen zur Morphologie u. Systematik der Vögel, Amsterdam 1888, p. 1539. 
Fingern allen anderen bekannten Vögeln als tiefste und zugleich weit ron ihnen entfernte Vogelfamilie gegeniiber. Damit soll indessen keineswegs behauptet werden, dass sie einen ganz und gar alseits ron den anderen Vügeln liegenden Entwicklungsgang eingesehlagen hätten; die bisher bekannten Thatsachen machen r's viel wahrscheinlicher, dass hier ein recht friihes und primitives phylogentetisches Stadium vorliegt, welches sich in der Nähe desjenigen der jurassischen Torfahren der noch lebenden Flugvögel hefindet. Wie groß diese Nähe war, welche spezielleren Relationen mit den Ahnen dieser oder jener Ordnmng der anderen Tögel bestanden, wird mit einiger Aussicht anf Erfolg erst dann zu rentilieren sein, wenn durch nene gliickliche Funde die Osteologie (d. h. das Knochengeriiste) der Archacopteryx noch genauer bekannt geworden. Zur Zeit hindert namentlich die mangelhafte Ḱenntnis des Schädels, Brustbeines und Coracoiles jede grïndlichere Vergleichung."

Der Mïrchener Paläontologe K. Zittel begruindete kurz darauf seine Ansicht, daß Archaeopteryx ein echter Vogel und keine Zwischenform sei, mit folgenden Worten ${ }^{1}$ ):

„A. Wagner; der nur eine rohe, von Oppel ans dem Gedächtnisse ausgeführte Skizze gesehen hatte, erklärte die Archaeopteryx für ein mit Vogelfedern versehenes Reptil, Giebel hielt das Londoner Skelett anfünglich für ein Artefakt. während Owen darin einen echten Togel erkannte. Anch Huxley stellte Archaeopteryx zu den Tögeln und schlielit sich der Ansicht Haeckel's an, welcher 1866 fïr Archaeopteryx eine besondere Unterklasse der Tögel (Saururae) errichtet hatte. Das jetzt in Berlin befindliche Skelett reranlasste C. Vogt zu einer Abhandlung, worin er Archaeopteryx fuir eine Schaltfor'm zwischen Reptil nnd Togel erklärte, bei dem jedoch die Reptilienmerkmale im Bau des Kiopfes. Halses, Rumpfes, Brustgiirtels und der Vorderextremitäten überwiegen. Ähnliche Ansichten vertreten Dollo, Wiedersheim und Reichenow, während Seeley, Marsh, Dames, Fiirbringer u. a. in Archaeopteryx einen echten und typischen Togel, allerdings mit absonderlichen, zım Teil embryonalen Merkmalen erkennen."

..Das entscheidende Kennzeichen besteht ohne Zweifel in der Befiederung, die in keiner anderen Tierklasse rorkommt; dieselbe bedingt aber auch Warmblitigkeit und somit rogelartige Beschaffenheit des Herzens und Blntumlanfes. Der Schädel ist trotz seiner Bezahnung, ebenso wie das Gehirn,

$\left.{ }^{1}\right)$ K. A. Zittel, Palaeozoologie III. Bd. Mürıchen 1887-1890, S. 823-824. 
nach dem Togeltypus gebaut und auch die Torderextremität und der Brustgiirtel sind ungeachtet einer gewissen Ähnlichkeit mit Eidechsen doch im Wesentlichen, wie aus den genauen Beschreibungen ron Owen, Seeley und Dames herrorgeht, rogelartig. Nicht minder erweist sich Archaeopteryx durch die Hinterbeine als echter Vogel. Nur die aus amphicölen Wirbeln zusammengesetzte Wirbelsäule, die Rippen, das nur aus $5-6$ Wirbeln bestehende Sacrum und der lange - Schwanz wirden, wenn isoliert gefunden, eher ein Reptil als einen Vogel rermuten lassen. Immerhin haben aber die Untersuchungen ron Owen, Parker und M arshall gezeigt, dass bei zahlreichen jungen Tögeln eine ebenso große, ja sogar noch grölere Zahl ron Schwanzirbeln rorkommen als bei Archaeopteryx."

„Seeley, Dames, Furbringer u. a. betrachten wohl mit Recht Archaeopteryx nicht als Schaltypus zwischen Reptilien und Tögeln, sondern als einen echten Vogel, dem allerdings noch eine Anzahl embryonaler Merkmale anhaften. Dames legt namentlich auf die Entwicklung echter Schwungfedern großes Gewicht, und hält Archaeopteryx geradezu für einen Torläuer der Kielrögel. Die meisten anderen Systematiker (Hnxley, Fiirbringer, Menzbier) folgen Haeckel und stellen die Saururae als selbständige Unterklasse den iibrigen Vögeln gegeniiber."

Küzlich hat W. Dames') anf Grund neuer Untersuchung des Berliner Fundstücks die Archaeopteryx yanz bestimmt als wahren Vogel angesprochen:

"Auch die neu aufgedeckten oder doch vollständiger bekannt gewordenen Skeletteile der Archaeopteryx bilden nach meinem Dafürhalten ohne Ausnahme eine weitere Stiitze der in meiner friheren Abhandlung rertreteuen Auffassung, dass Archaeopteryx keine Übergangs-oder /wischenform zwischen den Klassen der Reptilien und Tögel mehr ist, sonderu in der Reihe der Vögel schon weit ab ron der Stelle, wo beide Äste der Sauropsiden sich trennten. ihren Platz tinden muss."

Haeckel²) kann sich dem Gewichte der anatomischen Grïnde, welche gegen die Auffassung sprechen, dab Archaeopterrx das lang ersehnte Bindeglied sei, nicht rerschliessen. Nur driickt er das Terhältuis in der ihm eigentiimlichen Stilisierung ans, indem

1) W. Dames, Über Brustbein, Schulter- und Beckengürtel der Archacopteryx. Sitz.-Ber. Akad. d. Wiss. Berlin, math. naturw. Milteil. 1897, p. 492.

2) E. Haeckul, System. Phylogene, Berlin 1895, III. Bd., p. 409. 
or die in Wirklichkeit bestehende grosse Kluft zwischen der Archaeopteryx und den Reptilien durch hypothetische Geschöpfe seiner Phantasie ausfuillt:

"Jedenfalls ist der Ausbildung der Archaeopteryx eine lange Reihe von Vorstufen vorausgegangen, welche die stufenweise Verwandlung der Reptilienahnen in die ersten fliegenden Tögel allmählieh vermittelten. Wir bezeichnen diese hypothetische älteste Stammgruppe der Tögel, von der uns fossile Reste zur Zeit noch nicht bekannt sind, als Stammvögel, Tocornithes."

Sie haben nunmehr die Urteile kompetenter Forscher vernommen und erkennen durch deren Dissonanz zu den populären, in tendenziösem Sinne gefärbten Referaten, (vergl. S. 98, Carus Sterne) dass die wissenschaftlich vertiefende Arbeit der letzten Jahrzehnte das Problem nur noch verwickelter erscheinen lässt, als man in der Freude der ersten Entdeckung für möglich hielt. Hente kann iiberhaupt niemand sagen, wie der einseitig modificierte Vogelkörper entstanden sei, und von einer Stannmesgeschichte wagen selbst die am meisten fanatischen Apostel der Entwickelungslehre kaum mehr zu reden. Um dem Verdachte zu begegnen, als wollte ich Ihnen meine Privatansicht als wissenschaftliches Gemeingut vortragen, füge ich einen Abschnitt aus Zittel's') Paläozoologie ein:

„Für eine Stammesgeschichte der Vögel liegt, wie aus dem Vorhergehenden ersichtlich, nur dürftiges Material vor. Immerhin weisen aber die fossilen Funde aus Jura und Kreide noch mit größerer Bestimmtheit, als die lebenden Vögel, auf eine Stammesverwandtschaft von Reptilien und Vögeln hin.

Nach den bahnbrechenden Untersuchungen iiber die Dinosaurier durch Huxley waren viele Autoren eine Zeit lang geneigt, in den Dinosauriern und speziell den Theropoden und Orthopoden die Vorläufer der Vögel zu suchen. (Wiedersheim, Bauer, Hörnes, Menzbier). Andere (Seeley, Owen) glaubten sie eher von Pterosauriern ableiten zu dürfen, oder entschieden sich für eine diphyletische Abstammung aus beiden Ordnungen (d. h. teils von Pterosauriern, teils von Dinosauriern) (Wiedersheim, Cope, Mivart). Die Übereinstimmung im Bau des Skelettes zwischen Dinosauriern, Pterosauriern und Vögeln beruht jedoch vielfach nur auf Anpassungsanalogie und gewisse osteologische Ähnlichkeiten wie die des Schambeines der Vögel und des Postpubis der Orthopoden wurden in ihrer morphologischen Bedeutung beträchtlich überschätzt, so dass man nach

1) K. Zittel, Palaeozoologie, München 1887-1830. III. Bd., p. 861. 
dem gegenwärtigen Stand unseres Wissens nur der von Marsh, Dames, Vetter, Parker, Eiirbringer, Pavlow und Mehnert befürworteten Ansicht beipflichten kann, wonach die Abstammung der Vögel aus einer bestimmten Ordnung der Reptilien unzulässig erscheint."

Somit bleiben als letzte Zuflucht für die nach meiner Meinung auf den Absterbeetat zu setzende Phylogenie die hypothetischen Tocornithes, welche Fürbringer in anmutiger Weise mit Worten gemalt hat. Dann aber lesen sie nicht mehr eine exakte Darstellung von positiven Beobachtungen, sondern folgen einem ernsten Naturforscher, welcher sich auf dem Gebiete des Romanes versucht und die von Jules Verne gewiesenen Bahnen einschlägt. Fürbringer freilich ist so ehrlich, das vorher selbst zu betonen. Aus der stilistischen Fassung anderer Autoren klingt der gleiche Vorbehalt für den Laien nicht so verständlich heraus.

Das anatomische Studium der recenten Vogelarten hat keine besseren Anhaltspunkte geliefert. Es sind jetzt 11000 Arten derselben bekannt; obgleich sie noch nicht so genau durchforscht sind, wie man eigentlich wünschen sollte, so liegen doch viele Arbeiten darïber vor und Fürbringer's monumentales Werk bedeutet einen markanten Fortschritt. Aber auch ihm gelang es nicht, die verwandtschaftlichen Beziehungen der jetzigen Gruppen anders als durch allgemeine Charakteristik zu erhellen. Die Ausrede, neue paläontologische Funde wiirden Aufklärung bringen, richtet sich hier von selbst. Lehren 11000 jetzt lebende Arten nichts über ihre Stammesgeschichte und wenig über ihre Verwandtschaft, wie werden dann versteinerte Bruchstiicke besseren Einblick gewähren, da die fossilen Reste durch die geringe Erhaltung aller wichtigen Weichteile immer von höchst problematischem Werte bleiben werden. 


\section{Siebentes Kapitel.}

\section{Die Wurzeln des Sïugetierstammes.}

Das Studium der versteinerten tierischen Reste, der „Denkmünzen der Schöpfung", wje Haeckel poetisch sagt, berichtigt die landläufige Vorstellung, welche den heute beobachteten Zustand der Tierwelt als unveränderlichen seit ungeheuren Zeitperioden ansieht. Bizarre Tiere, von der ïberschwenglichen Phantasie der Küinstler kaum geahnt, und riesenhafte Ungetüme von schrecklichem Aussehen verdrängen die uns vertraute Fauna, sobald wir in älteren geologischen Gesteinsschichten forschen. Aber anstatt uns die Vorfahrengeschichte der heutigen Arten zu erhellen, stellen sie bei genauerem Zusehen das Denken der Descendenztheoretiker vor nene Probleme, welche vorderhand gar keine Hoffnung einer kiinftigen Lösung erwecken. Die Kritik des Paradepferdes und die zuletzt citierten Urteile iber den Wert der Archaeopteryx haben Ihnen das genugsam bewiesen.

Hente wollen wir einmal eine andere Frage besprechen, für welche versteinerte Reste kaum in Betracht kommen. Da ich unsere Aufgabe zunächst möglichst einfach begrenzen will, halte ich mich noch innerhalb des geschlossenen Stilkreises der Wirbeltiere, welche durch so viele Punkte ihrer Organisation übereinstimmen und ihre systematische Zusammengehörigkeit, nach der Ausdrucksweise der Abstammungsfanatiker, ihre „Blutsverwandtschaft" jedermann offenbaren. Ich wähle daher heute die Stammesgeschichte der Säuget i e re oder Mammalia als Thema und suche Ihnen daran zu zeigen, wie die Descendenztheoretiker ein phylogenetisches Problem mit Hilfe der vergleichend anatomischen Untersuchung jetzt lebender Arten lösen wollen.

Bei der Ahnenprobe der Säugetiere müssen natiirlich die höher organisierten Glieder, wie Mensch und Affe, Raubtiere, Huftiere und die im Neere lebenden Wale aulser Betracht bleiben und ein-

fachere Formen als Ausgang dienen. Als solche sind die Beuteltiere, Marsupialia, lind die Kloakentiere, Monotremata, bekannt. 
Ehe die letzteren entdeckt und ehe die Beuteltiere anatomisch genau durchforscht waren, glaubten viele die Beutler als Stammeltern aller höheren durch die Entwickelung mittels eines embryonalen Mutterkuchens ausgezeichneten Säugetiere betrachten zu dürfen. Noch vor zehn Jahren wurde der phylogenetische Ahnenwert der Beutler ganz ernsthaft in diesem Sinne erörtert. Unterdessen sind jedoch so viele trennende anatomische Einzelheiten bekannt geworden, dass wohl nur wenige die Beutler als direkte Vorfahren bezeichnen wollen. Sie werden jetzt als ein seitlich stehender, eigenartig differenzierter Ast des $\mathrm{Stam} \mathrm{mb}$ a umes angesehen, und ich brauche keine Zeit aufzuwenden, Ihnen den Bau der Gruppe genau zu schildern.

So bleiben nur die Kloakentiere zur Eruierung der Vorfahrenreihe. In dieser Ordnung werden drei lebende Arten aus Süd - und Ostaustralien und Tasmanien vereinigt: das Schnabeltier, Ornithorhynchus paradoxus Blumenb., mit haarigem Felle, der stachelige Ameisenigel. Echidna hystrix Cur. mit Stachelkleid, der langhaarige Ameisenigel, Echidna setosa Cur., dessen Haarkleid mit spärlichen Stacheln durchsetzt ist. Ich will die Ordnung mit kurzen Worten charakterisieren: Kloakentiere sind Säugetiere. deren Weibchen Milchdriisen besitzen und mit dem Sekrete derselben ihre Jungen säugen, zugleich aber besitzen sie eine Kloake und legen Eier. Wenn ich danu für den zoologisch ungeschulten Zuhörer beifüge, dass der Besitz eines durch den After zugängigen Raumes, der Kloake, in welchen die Ausführwege der Harn- und Geschlechtsorgane, sowie die Harnblase einmünden. eine nie fehlende Eigentümlichkeit der Vögel und Reptilien ist, dann werden Sie sofort geneigt sein, das Vorkommen dieses Merkmales als sicheres Anzeichen dafür anzusehen, dass die drei Kloakentierarten Zwischenformen zwischen den Mammalien und niederen Wirbeltieren sind. Die Descendenztheoretiker haben in der That diese abseits stehenden Tiere als Urformen gedeutet, wie folgendes Citat aus Hackel's ${ }^{1}$ ) Schöpfungsgeschichte bezeugt: „Die beiden seltsamen Tiere, welche man in der Ordnung der Schnabeltiere zusammenfasst, sind offenbar die letzten überlebenden Reste einer vormals formenreichen Tiergruppe, welche in der älteren Sekundärzeit allein die Säugetierklasse vertrat, und aus der sich erst später, wahrscheinlich in der Trias oder Juraperiode die zweite Unterklasse, die Beuteltiere, entwickelte." -

„Jedenfalls müssen dem Auftreten der Beuteltiere zahlreiche, mit entwickeltem Gebiss und mit einer Kloake versehene Schnabeltiere vorausgegangen sein."

\footnotetext{
1) E. Haeckel, Natürl. Schöpfungsgesclichte. 8. Anfl. 1889, p. 650.651.
} 
Falls Sie dieser Ansicht beipflichtoton, wiirden Sie den gleichen Fehler begehen, welchen ich schon bei der Darstellung der Pferdegeschichte riigte, indem Sie ein einziges Merkmal zu hoch anschlagen; denn der phylogenetische Forscher darf nicht ein oder wenige Organsysteme betrachten, sondern muss die Prüfung auf den ganzen Organismus ausdehnen. Nachdem er aber den Bau der Kloakentiere sowohl mit den Sängern, wie mit den Reptilien und Vögeln verglichen hat, wird er der Deutung Haeckel's schroff widersprechen.

- Jedenfalls erweckt der sonderbare Bau des Schnabeltieres das lebhafte Interesse aller Beschauer. Nach ihrer Entdeckung, am Beginn des Jahrhunderts klang die Beschreibung desselben so überraschend, dass die Meinung geäulsert wurde, das Tier existiere überhaupt nicht, ein Schwindler habe das Fell eines Maulwurfes und einen Entenschnabel zusammengenäht, um die wissenschaftliche Welt zu dupieren. Als die Skeptiker iiber ihre Zweifel beruhigt waren, galt anderen der rundliche Kopf des Schnabeltieres, dessen Schnauze sich in einen mit fester Hornscheide überzogenen, entenähnlichen Schnabel verlängert, sowie der Besitz der Kloake als Beweis der Zwischenstellung desselben zwischen Vögeln und Säugetieren. Auch diese Auffassung ist längst verlassen, weil oberflächliche anatomische Kenntnisse ausreichen, die Unmöglichkeit derselben einzusehen. Will man überhaupt der Entstehung der Säugetiere aus niedereu Formen nachspüren, so kann man die Ahnen nur bei Reptilien suchen und in dieser Richtung bewegen sich alle neueren Arbeiten. Da aber weder anatomische noch paläontologische Zwischenformen gefunden wurden, so muss die anatomische Prüfung iiber die Stichhaltigkeit der Vermutung entscheiden.

Eine große Zahl von Forschern - um nur neuere zu nennen Howes, Seeley, Parker, van Bemmelen, Sixta haben am Brustbeine, am Schultergürtel und am Schädel von Ornithorhynehus auffallende Anklänge an Eidechsen oder Saurier gesehen. Da aber bei Echidna die Sauriereharaktere weniger leicht wahrgenommen werden, will ich aussehliefslich das Schnabeltier besprechen.

Der Schädel desselben erinnert lebbaft an den Vogelschädel, weil er eine einheitliche Knochenkapsel darstellt und Knochennähte vermissen lässt. Während nämlich bei den meisten Wirbeltieren, z. B. den Säugern, Reptilien und Fischen, die einzelnen den Schädel aufbauenden Knochentafeln zeitlebens mit zackigen Grenzrändern zusammenstoßen, werden sie bei den Vögeln in frïher Jugendzeit mit einander verschweifst. Das Schnabeltier folgt der letzteren Regel. Die Schädelhöhle bleibt klein, die niedrigen Kiefer sind lang, schnabelartig gestreckt. 
Drehen wir den Schädel des Schnabeltieres um, so erinnert das Verhalten der Knochen der Unterseite an die Regel der Säugetiere. Die Fliigel- und Gaumenbeine, Pterygoidea und Palatina sind fest mit der Schädelbasis verwachsen - nieht frei und beweglich, wie bei Vögeln und Reptilien. Ferner fällt uns auf, dass der Unterkiefer direkt an Schädel einlenkt. Bei Reptilien und Vögeln wird dazwischen ein besonderer Knochen, das Quadratbein eingeschaltet, das, dem Schädel selbst beweglieh angefügt, das Unterkiefergelenk trägt. Bei den Sängern aber wird das gleiche Verhalten nicht beobachtet; der Gelenkkopf des Unterkiefers passt direkt in eine Grube des Schläfenbeines, und so ist es auch beim Schnabeltiere.

Ein weiterer Unterschied wird durch die besondere Art der Gelenkverbindung zwischen dem Hinterhaupte und dem ersten Halswirbel geboten. Bei Vögeln und Reptilien sitzt übereinstimmend der Schädel mit einem einzigen unter dem großen Sehädelloch liegenden Gelenkhöcker dem ersten Halswirbel beweglich auf bei den Säugetieren vermitteln zwei rechts und links stehende Gelenkhöeker die bewegliche Verbindung zwischen Schädel und Wirbelsäule; der Schnabeltierschädel besitzt nun zwei große Gelenkhöcker zur Seite des großen Schädelloches.

Sie sehen also, der Schädel des Schnabeltieres trägt zugleich manche den Reptilien und Vögeln und andere den Säugetieren zuneigende Merkmale.

Die bei Reptilien, Vögeln und Säugetieren verbreiteten Rippen der Halswirbelsäule sind an Ornithorhynchus etwas stärker ausgeprägt, als bei den übrigen Säugern und erinnern uns an die bei den Reptilien herrschende Regel.

Das Brustbein der Reptilien (Fig. 62) ist eine flache Knorpeloder Knochenplatte, das der Säugetiere (Fig. 63) aber besteht aus einer vorderen, größeren Platte, dem sog. Griffe, Manubrium, dann mehreren oft verwachsenden Stiicken, deren Gesamtheit die Klinge des Brustbeines bildet, endlich der hinteren Spitze des Brustbeines. Dem Brustbeingriff ruht das unpaare knöcherne Episternum auf sowohl bei den Reptilien als vielen Säugetieren, wenngleich recht rudimentär bei letzteren. Das Brustbein von Ornithorhynchus (Fig. 64) schließt mehr an die Süngetiere an.

Von den drei Knochen des Schultergürtels: dem Schulterblatte, Schlïsselbeine, Rabenbeine, ist das Rabenbein der Reptilien und Vögel (Fig. 61) stark ausgebildet, den Säugern fehlt es bis auf kümmerliche Reste. Beim Schnabeltiere (Fig. 64) dagegen ist es als ein Paar schmaler, säulenartiger Knochen entwickelt, welche auf dem Brustbeine ruhen und mit dem Schulterblatte verwachsen. Nanche andere 
Ähnlichkeiten, die ich hier nicht ausfïhrlich erörtern will, veranlassten den neuesten Bearbeiter Sixta ${ }^{1}$ ) zu der Bemerkung:

„Selbst ein erfahrener Zoologe könnte den Schultergïrtel eines Ornithorhynchus aus dem Skelette herausgenommen für den Schulter-

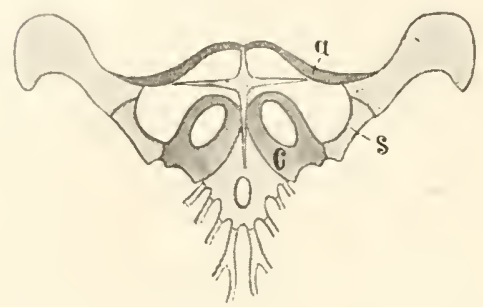

Fig. 62.

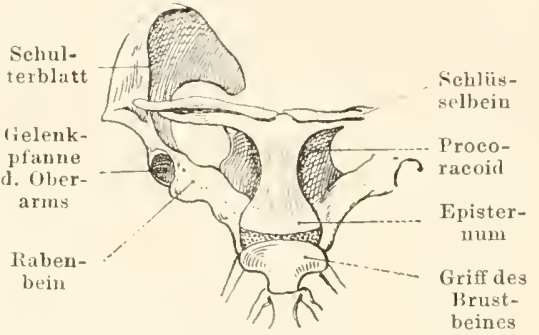

Fig. 64.

Fig. 62. Brustbein und Schultergürtel vou Lacerta agilis, Zauneidechse. Nach Gegenbaur. $\iota$ Schlüsselbein, $c$ Rabenbein, $s$ Schulterblatt.

Fig. 64. Sehultergürtel von Ornithorhyuchus paradoxus.

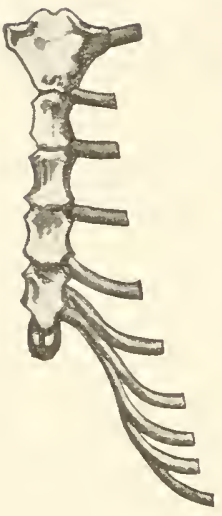

Fig. 63.

Brustbein des Mensehen. Oberes Stiick - Handgriff, die nächsten vier Stïcke bilden den Körper, an ihm hängt d. kurze Schwertfortsatz.

gürtel einer Eidechse, nicht für jenen eines Säugetieres halten."

Das Skelett der Gliedmaßen ist, wenn ich von dem Hornsporn am Fuße der Männchen absehe, nach dem Typus der Mammalien geformt. Die einzelnen Extremitätenknochen haben mehr Ähnlichkeit mit denen der Säuger als der Reptilien.

Den Reptilienanklängen etlicher Organe stehen tiefgreifende Unterschiede gegenïber. Ornithorhynchus und Echidna sind behaart ${ }^{2}$ ) und tragen in der Haut Schweiß- und Talgdriisen eingebettet, wie die wahren Säugetiere. Damit ist eine tiefe $\mathrm{Kluft}$ zwischen den Kloakentieren und den Reptilien gekennzeichnet; denn der Schuppenhant der Reptilien fehlt fast jegliches Drüsengebilde und Organe, die sich auch nur im entferntesten mit den Säugerhaaren vergleichen ließen, sind nicht gefunden. Ja es fehlt sogar eine plausible hypothetische Vorstellung, welche Vorstufen die Haare iiberliaupt hätten durchlaufen können, bis sie als schützendes Kleid iiber die Hautoberfläche der unbekannten Ahnen der Süngetiere verbreitet wurden.

l) V. Sixta, Zoolog. Anzeiger, 22. Bd. 1899, p. 335.

2) Die Stacheln ron Echidna und anderen Säugetieren z. B. Igel, Stachelschwein sind nur große, dicke Haare. 
Von dem Besitze der Haare oder Federn hängt die Gleichmäßigkeit der Körpertemperatur ab. Bei den Reptilien wechselt die Höhe der Körperwärme, d. h. sie sinkt und steigt mit der Temperatur der Umgebung. Bci den Säugern hält sie einen bestimmten gleichmäßigen Stand, unabhängig von den klimatischen Schwankungen der Luftwärme. Die Schnabeltiere erweisen sich hierin wieder als wahre Säugetiere, nur steht ihre Körperwärme auffallend niedriger $\left(25-28^{\circ} \mathrm{C}\right.$.), als die der ïbrigen Säuger $\left(37^{\circ} \mathrm{C}\right.$.).

Milchdriisen und Zitzen zum Säugen der Jungen fehlen den Reptilien. Die Kloakentiere ermangehn der Zitzen, aber in der Bauchhaut der Weibchen (Fig. 65.) kommen große Haufen von Milchdrïsen vor, die aufeinem kreisförmigen, siebartig durchbrochenen Milchfelde des Brutbeutels münden. Die Jungen saugen die dort zusammenrieselnde Milch ohne Schwierigkeit anf ${ }^{1}$ ), obgleich die besondere Anordnung der Drüsenausführgänge auf der Spitze einer warzigen Hauterhebung, der Zitze, welche alle anderen säugenden Wirbeltiere auszeichnet, hier unterbleibt.

Der muskulösen Bauchwand betten sich zwei auf dem vorderen Rande des Beckens fußende, schmale und schräg kopfwärts divergierende

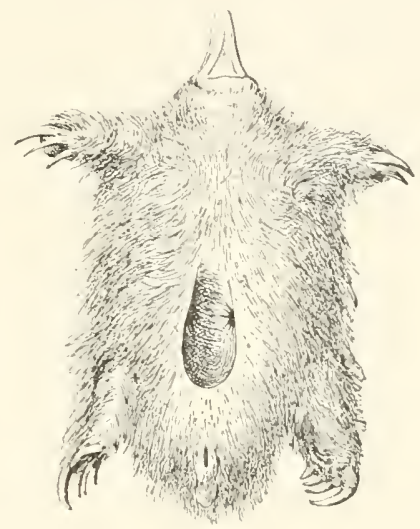

Fig. 65.

Unterseitedes brïteuden Weib. chens von Eehidna hystrix mit dem Brutbeutel. Nach Hacke. Kuochen, die sog. Beutelknochen ein, nur bei Kloaken- und Beuteltieren. Sie werden sowohl bei Reptilien als bei den wahren placentalen Säugern vermisst.

Der ïußere Gehörgang fehlt den Reptilien und das Trommelfell liegt meist an der Seitenwand des Kopfes, zwar nicht immer sichtbar, wie bei den Eidechsen, aber doch sehr nahe der Körperobertläche. Schnabeltier und Ameisenigel tragen das Trommelfell etwas tiefer geschoben. Ihr Labyrinthorgan erimnert wieder an die Reptilien, weil die Schnecke fast gerade ist, wïhrend sie bei den Säugern mehr oder weniger zahlreiche, spiralige Windungen beschreibt. Die Gehörknöchelchen zeigen wohl eine niedere Entwickelungsstufe, aber besitzen den dreigliederigen Stil der Süuger: Der Hammer ist sehr lang, der Amboss klein, der Steigbiigel säulenförmig, während die Reptilien nur ein Gehörknöchelchen besitzen, die, sog. Columella.

1) Zoolog. Anzeiger, 1899, Bd. 22. S. 241. 
Besonders auffallend ist das Verhalten der Eileiter, der paarigen, rechts und links von der Wirbelsäule ziehenden Ausführwege für die Eizellen, welche bei Amphibien, Reptilien, Vögeln und den Kloakentieren bis zur Mündung in den Endabsehnitt des Enddarmes getrennt bleiben, bei den Säugetieren aber die Neigung zu verschmelzen zeigen und in geringerem Grade (Beuteltierc) oder in höherem Grade (placentale Säugetiere) zu einem unpaaren Endstücke, der Scheide, Vagina, verwachsen. Der gesonderte Verlauf und die vollkommen getrennte Mündung der Eileiter in die Kloake ist als scharf trennendes anatomisches Merkmal anzusehen, durch welches die Kloakentiere weit ab von den Säugern rücken.

Endlich wird die Kloake, welche der systematischen Gruppe den Namen gegeben hat, als ganz besonders wichtiges Moment für die direkten stammesgeschichtlichen Beziehungen zu den Reptilien angeführt, weil die schulgemäße Systematik die Diagnose der drei Wirbeltierklassen: Amphibien, Reptilien, Vögel gegeniiber den Säugern nach der Anwesenheit der Kloake entscheidet. So gefasst ist der Wortlaut der Diagnose direkt falsch. Die Säugetiere besitzen ebenso gut wie alle ïber den Fischen stehenden Wirbeltierarten eine Kloake, sie treten den anderen nur dadureh gegenüber, dass die Kloake keine ständige, sondern eine vorübergehende Einrichtung bildet.
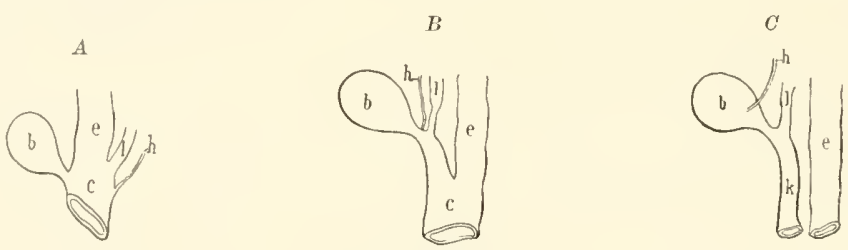

Fiv. 66.

Schematische Skizzen des Schicksales der Kloake. A Embryonaler Zustand, $B$ Befund bei dell Kloakentieren, $C$ Befund bei den höheren Säugetieren. $b$ Harnblase, $e$ Enddarm, $c$ Kloake, $h$ Haruleiter, $k$ Urogenitalkanal, $l$ Eileiter.

In frïher Embryonalzeit besitzt der Körper des Mensehen und sämtlicher Sängetiere iiberhaupt eine deutliche Kloake, (Fig. 66, A) d. h. einen gemeinsamen an den After reichenden Endabschnitt des Enddarmes, in welchen die Ausfïhrgänge der Harn- und Geschlechtsorgane, sowie die Harnblase einmïnden, so dass Kot, Harn und Gesehleehtsprodukte erst in die Kloake gelangen und von hier durch den After ausgestoßen werden. Eine später, jedoch während der Embryonalzeit einwachsende Falte spaltet den Kloakenraum in zwei dorsoventral über einander ziehende Räume (Fig. 66, B); der dorsale Abschnitt erscheint einfach als Fortsetzung des Enddarmes, der ventrale T'eil, sog. Urogenitalkanal, enthält die Miindung 
der Harublase und der Geschlechtsgänge. Dabei wird auch der After (Fig. 66, C) selbst in zwei, jenen Räumen zugehörige Mündungen gespalten.

Ton den, aus der Teilung der ursprünglich einfachen Aftergrube entstandenen, Mündungen stellt die dorsale Öffnung den Fäkalafter zur Entleerung der unbrauchbaren Speisereste aus dem Darme, die rentrale Urogenitalöffnung die Ausgangspforte für den Harn und die Geschlechtsprodukte dar.

Der Urogenitalkanal samt seiner besonderen Mündnng erfährt bei den placentalen Sängetieren recht bedeutende Umbildungen und zwar nach verschiedener Richtung für die männlichen und für die weiblichen Individuen. Ich will indessen das Resultat dieser Vorgänge nicht speziell beschreibeu, da ich zu weit von dem eigentlichen Zwecke unserer Betrachtung abgeführt würde. Halten Sie nur fest, dass die embryonale Kloake der Säugetiere in zwei Räume geschieden wird und dass der Urogenitalkanal stets unterhalb (ventral) des Enddarmes liegt.

Der Kloake der Amphibien, Reptilien und Vögel bleiben ähnliche Differenzierungen fremd. Die uns am meisten interessierende Kloake der Reptilien erscheint als eine einfache, quer gedrückte, Fortsetzung des Enddarmes, welche durch einen einfachen Afterspalt nach außen mündet. Ist eine Harnblase vorhanden - sie bildet sich nämlich bei den Eidechsen, Schlangen und Tögeln frühzeitig zurück - so hängt dieselbe an der unteren ventralen Wand der Kloake, die Geschlechtsgänge dagegen miinden an der dorsalen Wand, also gerade gegenüber der Harnblasenöffnung ein. Meine ganz gedrängte Darstellung hat Sie den fundamentalen Gegensatz der Kloakenbildung bei Säugern und Reptilien erkennen lassen. Bei den ersteren münden Harnblase und die Geschlechtsgänge dicht neben einander in das ventrale Teilstïck der Kloake, den sog. Urogenitalkanal, bei den Reptilien sind die Öffnungen auf die dorsale und rentrale Wand verteilt; der aus dem vorigen Jahrhundert stammende, schlechte Ausdruck: "Kloake" ruft also ein Missverständnis hervor, welches auf.. die phylogenetische Spekulation seinen Schatten wirft und eine Ähnlichkeit vortäuscht, wo keine zu finden ist.

Sie fragen nunmehr, welchem Typus der Kloakenbildung Schnabeltiere und Ameisenigel zuneigen. Die Autwort lautet: unzweifelhaft den Säugetieren. Denn der Endabschnitt des Enddarmes der Kloakentiere (Fig. 66, B) wird unvollständig in zwei Räume, den Urogenitalkanal und einen oberen Kotraun geschieden. Beide münden aber nicht mit getrennten Öffnungen an der Hautsondern besitzen noch ein kurzes gemeinsames Endstiick, so dass Kot, 
Harn und Geschlechtsprodukte durch ein und dasselbe Loch, den After, nach außen gelangen. Die unvollstïndige Scheidung des embryonalen Kloakenabschnittes kann einen wesentlichen Kontrast zwischen Kloakentieren und den iibrigen S̈̈ugetieren nicht bedingen, weil auch hei Beuteltieren und gewissen Arten der Nagetiere der Trogenitalkanal in eine seichte Kloakenaftergrube miindet. Also ist der Kloake der Schnabeltiere wirklich der Säugetiertypus zuzuerkennen, und ein wesentlicher Gegensatz gegen den Reptilientypus darin zu sehen, dass die Geschlechtsgänge ventral, nicht dorsal in den unvollständig abgespaltenen Urogenitalkanal einmünden, während bei den meisten Reptilien die Geschlechtsgänge und Harnleiter an cler dorsalen Wand der überhaupt nicht geteilten Kloake miinden.

Nun habe ich mir aber doch eine Übertreibung zu schulden kommen lassen, indem ich für die Kloakenbildung die typische Ïbereinstimmung sämtlicher Säugetiere, die Ḱloakentiere eingeschlossen, und die Unterschiede gegen die Reptilien zu sehr hervorhob: dem die Schildkröten nehmen unter den Reptilien wieder eine Sonderstellung ein und erinnern direkt an die Sängetiere. Ihre Kloake (Fig. 66, B) ist ebenfalls in einen ventralen Urogenitalkanal und einen dorsalen Kotraum unvollständig gespalten und Harnblase wie Geschlechtsgänge münden in den Urogenitalkanal. ${ }^{1)}$ Anstatt sich zu vereinfachen, kompliziert sich der phylogenetischen Forschung dadurch das Problem, weil die Schildkröten durch ihre gesamte Organisation die Annahme widerlegen, sie könnten die Stammeltern der Schnabeltiere sein. Die anatomische Kritik hat uns nur gelehrt, dass die Bildung des Urogenitalkanales heute nicht mehr als ein den Sängetieren allein eigentïmliches Merkmal gelten darf, da sie auch bei den Schildkröten rorkommt.

Ganz besonders schwer fällt für die Reptilienähnlichkeit der Kloakentiere die Thatsache ins Gewicht, dass sie große, mit ansehnlichem Nahrungsdotter ausgestattete, ron einer pergamentenen Schale umbüllte Eier ablegen, deren erste Entwickelung durch partielle Furchung, wie bei Reptilien und Vögeln erfolgt, während die Eier sämtlicher Säugetiere winzig kleine Eizellen sind, nicht abgelegt werden und im Eileiter selbst ihre Entwickelung bis zum geburtsreifen $\int$ ungen durchlaufen. Das Eierlegen ist daher ein wahres Reptilienmerkmal, welches sich in keiner Weise abschwächen lässt.

Damit habe ich die wichtigsten Züge der Organisation der untersten Säugerordnung rorgefuihrt, welche die stammesgeschichtliche Spekulation zur Ableitung der Säugetiere von den Reptilien

1) F. von Möller, Uber das Urogenitalsystem einiger Schildkröten. Zeitschr. für wissensch. Zoologie, Bd. 65 . 
rerwendet. Nach meiner Meinung sprechen dieselben weder für noch gegen die phylogenetische Rolle der Kloakentiere. Wir haben eine Anzahl ron Eigenschaften kennen gelernt, die die Kloakentiere mit den Säugern teilen, und andere, welche ihnen mit den Reptilien gemeinsam sind. Fïr die Frage, ob sie wirklich Übergangsarten zu den Reptilien seien, müssen wir die übereinstimmenden und trennenden Merkmale abwägen. und da muss ich sagen, die Säugetiermerkmale erscheinen mir so zahlreich, dass das Gewicht der Reptilien- und Togelähnlichkeit stark zuriicksinkt. Es würde ungemein viel Phantasie erfordern, wenn man sich vorstellen sollte, irgend ein Reptil, eine eidechsenähnliche Art hätte alle Organe seines Körpers so lange umgebildet, bis es eine dem heute lebenden Schnabeltier einigermaßen rergleichbare Organisation erreicht habe. Ich gestehe freimütig, es ist mir total unmöglich, solch einen Terwandlungsvorgang ohne die mnterstiitzende Beobachtung der vermittelnden Stufen mir in Gedanken vorzustellen. Da tauchen tausende von Fragen iiber das Detail der stammesgeschichtlichen Umbildung grober oder feinster anatomischer Einrichtungen auf und nirgends sehe ich die Möglichkeit, durch eine Spezialuntersuchung die quälenden $\mathrm{Zweifel}$ zu beseitigen.

Um die vorhergehenden Betrachtungen für die phylogenetische Spekulation kurz zusammenzufassen, ist nach dem Stile der Säugetiere bei den Kloakentieren gebildet:

Das Relief der Schädelbasis,

die zwei Gelenkhöcker am Hinterhauptsbein,

das gegliederte Brustbein,

das Skelett der Gliedmaßen,

die Behaarung der Haut,

die Schweiß-, Talg- und Milchdriisen,

die Bentelknochen,

die Kloake,

die konstante, aber niedrige Bluttemperatur.

Dagegen werden folgende Ähnlichkeiten mit den niederen Wirbeltieren, besonders den Reptilien, beobachtet:

der vogelähnliche Schädel mit den dünnen, nahtlos verwachsenen Knochen und der schnabelförmigen Verlängerung der Kieferbeine,

die deutliche Ausbildung des Rabenbeines,

die freien Halsrippen,

der Mangel des Kammes am Schulterblatt,

der getrenute Verlauf der Eileiter,

die pergamentschaligen Eier,

die nicht gewundene Labyrinthschnecke. 
Bei der Reflexion ïber die systematisehen Merkmale der Kloakentiere können wir entweder das Hauptgewicht auf die Reptilienähnlichkeit legen oder die Stilgemeinschaft mit den Säugern hervorheben. Im ersteren Falle wird uns die Übereinstimmung mit den Reptilien bedeutungsvoll erseheinen, weil wir die Säugermerkmale geringer schätzen. Dagegen lässt sich aber einwenden, dass die Behaarung des Körpers, das Vorkommen der Schweiß-, Talg- und Milehdrüsen in der Haut, die konstante Bluttemperatur ete. so sehr charakteristisch für die Säugetiere ist und in gar keiner anderen Gruppe der Wirbeltiere erscheint, dass wir ein mit denselben ausgeriistetes Tier nur zu den Säugern, aber nicht zu den Reptilien, Vögeln oder Amphibien stellen dürfen.

Wegen der großen Zahl der Merkmale, welche das Schnabeltier mit den Säugetieren gemein hat, ist es nach dem allgemeinen Urteil in die systematische Gruppe der Säugetiere einzureihen. Freilich besitzen die Kloakentiere so merkwïrdige Eigenschaften, dass sich niemand vorstellen kann, wie die Umbildung ihres Körpers ein höheres placentales Säugetier geschaffen hat. Wenn nun einer diesen Gegensatz besonders betonen will, so kann er die bisherige Klasse der Säugetiere auflösen und die Schnabeltiere als eine etwas abweichende Unterklasse den übrigen Säugetieren zur Seite stellen. Dadurch wiirde aber nichts für unsere stammesgeschichtliche Einsicht gewonnen. Es wird höchstens der anatomische Gregensatz zwisehen den beiden Gruppen einen schärferen formalen Ausdruck erhalten.

Unser etwas tiefer eindringendes Studium der sonderbaren Säugetiergruppe hat eben einen Übelstand aller menschlichen Systematik empfinden lassen, welcher dem Fachmann wohl bekannt ist, hingegen dem Laien weniger zum Bewusstsein kommt. Das ist die Unmöglichkeit, scharfe Grenzen zwischen den kleinen oder großen systematischen Gruppen zu ziehen.

Sie lernen einmal während der Jugendzeit die Einteilung des Tierreiches oder eines anderen wissenschaftlich erforschten Gebietes in Kategorien verschiedenen Umfangs und müssen sich, weil die Zeit zu ansgiebiger Gründlichkeit nie ausreicht, mit der Kenntnisnahme einiger auffallender Trennungsmerkmale begnïgen. Wenige beniitzen die durch den Unterricht, sei es auf der Schule oder auf der Universitït, gesehaffene Basis, $11 \mathrm{~m}$ selbständig weiter zu studieren. Den meisten wird die oberflächliche Orientierung geniigen.

Dann erscheinen aber dem weniger kenntnisreichen Verstande die friher gelernten Gruppen, sowie deren Merkmale als sichere, nicht anzuzweifelnde Größen, und wir alle hegen die falsche Vorstellung, als seien die systematischen Reiche so scharf geschieden, 
wie etwa die Grundstïcke zweier Nachbarn vertragsmäßig abgegrenzt werden können. Die Praxis des Lebens und der Wissenschaft belehrt uns allmählich rom Gegenteil. Wir sehen ein, wie Sie jetzt an einem bestimmten zoologischen Beispiel dazu Gelegenheit hatten, dass die Grenzen des Systemes logischer Ordunng der Thatsachen nicht scharf sind, dass manche Formen sich nicht in unser Schema einreihen lassen und wegen der Mischung ihrer Charaktere die Gïltigkeit des Systemes selbst erschuittern. Im Gerichtssaale kämpft der Jurist mit der schweren Aufgabe, die große Maunigfaltigkeit menschlicher Beziehungen nach den Paragraphen der Gesetze zu ordnen und im Studierzimmer bemüht sich der Gelehrte, die Umgrenzung d. i. die Definition der wissenschaftlichen systematischen Gruppen der Reichhaltigkeit und dem Flusse des Naturgeschehens anzupassen. Einzelne Fälle werden leicht einregistriert, andere hinwieder spotten aller Tersuche und als Resultat mühsamer Arbeit bescheiden wir uns endlich mit der Erkenntnis, dass in Wirklichkeit Fälle vorkommen, welche sich unserem Bestreben nach systematischer Ordnung nur dann unterwerfen werden, wenn wir uns entschließen, den Gruppenbegriffen selbst eine gewisse Dehnbarkeit, einen gewissen Grad ron Unbestimmtheit zu belassen, dass also - auf das zoologische System exemplifiziert - isolierte Tierarten auf Erden leben ohne engeren Zusammenhang mit den ïbrigen Gliedern der Säugetiergruppe, die neben vielen allgemeinen Ähnlichkeiten eine ausreichende Zahl eigenartiger Charakterzüge zeigen.

Die Freunde der phylogenetischen Spekulation lieben es, solche Arten, welche die Merkmale zweier grosser systematischer Gruppen gemischt besitzen, kurzweg „Bindeglieder" zu nennen. Gegen die Bezeichnung ist nichts einzuwenden, solange jeder sich darüber klar bleibt, das sie ein tropischer Ausdruck ist, welcher kein reelles, durch Blutsbande und stammesgeschichtliche Erolution erzeugtes Band andentet. Wenn aber einer durch das Wort "Bindeglied" in der phantatischen Vorstellung bestärkt wird, muss gegen den Gebrauch desselben energisch protestiert werden.

Nach der eben gegebenen Darstellung kann die Existenz der Schnabeltiere und Ameisenigel niemals beweisen, dass die Säugetiere von reptilienähnlichen Ahnen entsprossen sind; sie bietet uns nur die Gelegenheit, den schwankenden Umfang und die schwierige Umgrenzung der systematischen, ja der menschlichen Begriffe überhaupt einzusehen.

Gegen mein niichternes Urteil lasse ich auch die verführerische Erwägung mancher Autoren nicht gelten, die Kloakentiere (sowie die Lungenfische und Rädertiere) müssten Zwischenformen sein, sonst könnte man sie nur als Ausnahmen und Abweichungen des 
allgemeinen 'Typus betrachten, ohne einen Grund für ihr Vorkommen angeben zu können; demn ich frage, kann ich ïberhaupt einen stichhaltigen Grund dafiir anzeigen, dass es z. B. einen Jöwen oder eine Schlange giebt, dass etwa 11000 Vogelarten, etwa 3000 Süngetierarten vorkommen? Kann ich einen stichhaltigen Grund finden, warum die Fähigkeit des Fliegens in drei Klassen der Wirbeltiere, bei den Fledermäusen. bei den Vögeln, bei den Pterosauriern, und anlBerdem bei den Insekten beobachtet wird? Wer wagt es zu erklären, weshalb uns so mannigfache Beispiele einer gewissen Ähnlichkeit der ̈̈ıßeren Erscheinung von systematisch weit entfernten Tierarten anffällt, wie z. B. zwischen

der Känguruhratte, Hypsiprymnus murinus Illig. und

der Springmaus, Dipus aegypticus Hempr. und

dem Springhasen, Pedetes caffer Illig.

oder

dem Flugbentler, Petaurus taguanoides Desm. und

dem Flughörnchen, Pteromys vulgaris Wagn.

odler zwischen

dem Igel, Erinacens europaeus L. und

dem Greifstachler, Cercolabes prehensilis Brdt.

oder

zwischen rielen Schlangen und der Blindschleiche, Anguis fragilis L. und

dem Seheltopusik, Pseudopus apus Pall.

Es ist überflüssig, die Reihe der Beispiele zu verlängern. Alle zeigen sie, dass in verschiedenen Gruppen des Tierreichs ähnliche Merkmale beobachtet werden, deren Vorkommen wir als interessante Thatsachen besprechen könuen, ohne über den Grund desselben etwas auszusagen.

Mit der Frage nach der stammesgeschichtlichen Bedeutung dee Schnabeltieres befinden wir uns in der gleichen Lage. Infolgedessen hat jeder, der dieselben als Zeugen einer phyletischen Umbildung von den Reptilien zu den Säugetieren anspricht, eine Menge von unglaubwiirdigen Vermutungen als Stützen seiner Meinung notwendig. Hiefiir bietet Haeckel's Phylogenie ${ }^{1}$ ) wieder drastische Belege:

„Die Ordnung der Promammalien oder Ursäugetiere haben wir für die älteste Gruppe dieser Klasse aufgestellt. Dazu rechnen wir zunächst die gemeinsame hypothetische Stammform der Säugetierklasse, die wir als Architherium bezeichnen;

1) E. Haeckel, Systematische Phylogenie, Berlin 1895. III. Bd., p. 473, 423, $473,478$. 
weiterhin aber auch eine Anzahl von niedersten Monotremen (Gabeltieren), welehe den Übergang von diesem Arehitherium zu den iibrigen Ordnungen der Monotremen einerseits, zu den Prodidelphien, den Stammformen der Beuteltiere andererseits vermittelten. Durch eine lange Reihe von unbekannten Übergangsformen (Sauromammalien oder Hypotherien) wird diese Stammgruppe während der Triasperiode mit den Urreptilienahnen der Säugetiere verknüpft gewesen sein. Die letzteren werden p. 422, wie folgt, besehrieben:

„Diese wichtige Übergangsgruppe (nämlich die Hypotherien) wird schon gegen Ende der Palaeolith-Aera (in der Permzeit) und im Beginne der Mesolith-Aera (in der Triasperiode) dureh viele konnektente (verknïpfende) Formen vertreten gewesen sein; welche von den spärliehen, uns bekannten fossilen Resten dieser Übergangszeit etwa zu derselben gehören, lässt sieh wegen Unkenntnis ihres Weichkörpers und ihrer Entwickelungsgesehichte nicht ermitteln." -

„Wenn wir an folgender Ahnenreihe für die Säugetiere festhalten: 1. Progonamphibien (Stegocephalen) 2. Proreptilien (Toeosaurier) 3. Sauromammalien (Hypotherien) 4. Promammalien (Arehitherien), so miissen wir doch gestehen, dass wir die Kontinuität dieser Stammfolge nur in den allgemeinen Hauptpunkten begriinden kömen, dass uns aber zu einer speziellen Fixierung einzelner Stufen die palaeontologisehe Begründung noeh fehlt." -

"Wir nehmen an, dass die ältesten Formen der triassischen Ursäuger kleine, terrestrisehe (auf dem Lande lebende) Tiere von Größe und Habitus einer Eidechse oder Salamanders waren." -

Die heute lebenden Filoakentiere sind nieht die direkten Repräsentanten der Übergangsformen, demn Haeckel sagt ausdrücklich: „Die Sehnabeltiere bekunden durch ihren gesamten Körperbau, dass sie eine alte Spezialistengruppe darstellen, welche sich frühzeitig rom Stamme der älteren Monotremen abgezweigt und durch Anpassung an eigentiimliche Lebensweise vom Untergange gerettet hat."

Fragen Sie aber nach der Beschaffenheit der Ursäugetiere, bezw. nach den fossilen Resten, welche diese hinterlassen haben, so lautet die Antwort ganz ungenügend. Vorderhand sind die Deseendenztheoretiker nur im stande. Ihnen Zähne von merkwïrdigem Baue, sog. Multituberculatenzähne, deren Krone sehr viele dielitgedrängte, spitze Höcker besitzt, aus den Jura- und Kreidesehichten vorzulegen und den Mangel anderer Skeletteile durch die kïhne 
Behauptung zu ersetzen, dass die Besitzer dieser Zïhne gerade mit allen denjenigen Eigenschaften begabt gewesen waren, welche die phylogenetische Phantasie für die Wurzelglieder des Säugetierstammes träumt. Deshalb wendet sich Zittel') gegen diese leere Annahme:

„Huxley betrachtet die lebenden Monotremata als stark spezialisierte Abkömmlinge einer erloschenen Unterklasse primitiver Säugetiere, für welche die Bezeichnung Prototheria vorgeschlagen wurde. Cope und Lydekker glauben in den mesozoischen und tertiären Multituberculata (Allotheria) fossile Vertreter dieser hypothetischen Prototheria finden zu können, doch ist das vorhandene paläontologische Material noch keineswegs genügend für eine bestimmte Beantwortung dieser Frage."

Übrigens teilen nicht alle Phylogenetiker die Meinung, dass die Kloakentiere die Reste einer von den Reptilien zu den Säugern vermittelnden Übergangsgruppe seien. Manche ${ }^{2}$ ) werden durch die oben kurz zusammengefassten Mischcharaktere bestimmt, die sonderbaren Gesellen als ganz abseits sowohl von den Beuteltieren als den übrigen Säugetieren zu stellen und sie als eine isolierte Seitenlinie aufzufassen, welche mit den Ahnen der anderen Süuger überhaupt keine Blutsverwandtschaft besitzen, und frühzeitig d. h. schon zu Ende der paläozoischen Zeit von unbekannten Promammalien d. h. Vorsängetieren einen eigenen Formentwickelungsgang eingeschlagen haben.

Diese Ansicht ist nach meinem Urteil nichts weiter als eine Übersetzung der oben auf Seite 117 gemachten Bemerkungen in die Stilistik phylogenetischer Aufsätze.

1) Zittel Paläozoologie IV. Bd. p. 70.

2) Vergl. H. F. Osborn, the origin of Mammals. Americ. Jour. of, sc. vol. VII. 1899, p. 92. 


\section{Achtes Kapitel.}

\section{Die Entstehung der lungenatmenden Wirbeltiere.}

Wie der Vogel für den Flug prädisponiert erscheint, sind die Fische durch die Körpergestalt und die Flossenform in die Wasserflut gebannt. Obgleich einige Arten z. B. die Labyrinthfische das nasse Element verlassen, versagt ihnen doch die gesamte Organisation, die Erdfeste zum dauernden Wohnorte zu wählen.

Wenn nun die Descendenzlehre die Annahme erheischt und wegen des Vorkommens vou sogenannten Kiemenspalten bei den Embryonen aller Wirbeltiere, auch des Menschen, sogar als sicher hinstellt, dass Fische die Stammväter sümtlicher Amphibien, Reptilien, Vögel und Säugetiere gewresen seien, so müssen wir sehr tiefgreifende Veränderungen der Gestalt und physiologischen Bedeutung aller Körperorgane bei den hypothetischen, zunächst nur durch das theoretische Denken geschaffenen und gleich dem Antäns durch die Berührung mit der Mutter Erde zu nener Entwickelungskraft gekommenen Urahnen der vierfüßigen Wirbeltiere erwarten, durch welche den spät geborenen Enkeln die Unabhängigkeit, zum Teile sogar die direkte Feindschaft gegen das Wasser im langsamen Prozesse der Naturzüchtung erworben wurde. Leider hat niemand dem Vorgange, welcher in die paläozoische Zeit zu datieren wäre, beigewohnt und niemand kann für die Wirbeltiere die Metamorphose der wasserbewohnenden Vorstufen in luftatmende Tiere mit der für die Insekten, deren Jugendstadien im Wasser leben, gewohnten Sicherheit schildern. Deshalb wandte sich die Spekulation hilfesuchend dem Studium einer ganz sonderbaren Fischgruppe, den Lungenfischen oder Dipnoern zu.

Nachdem zu den wenigen in der Mitte des Jahrhunderts bekannten lebenden Vertretern einer ehemals zahlreichen Sippe, nämlich dem afrikanischen Schlammfische, Protopterus annectens Owen, und dem amerikanischen Caramuru oder Schuppenmolchfisch, Lepidosiren paradoxa Fitz. (1837 von Natterer beschrieben) noch der Barramunda, Ceratodus Forsteri Krefft, in den Flüssen von Queensland 1870 entdeckt war, glaubte die Descendenztheorie diese Fische als Bindeglieder $\mathrm{zwischen}$ den lungenatmenden 
Amphibien (d. h. Frösche und Molche) und den kiemenatmenden Fischen betrachten zn dürfen.

Die sonderbaren Einrichtungen ihrer Organisation veranlassten dieses Urteil. Das Herz der drei Arten erimnert dureh den Besitz von zwei Vorhöfen (die übrigen Fische besitzen nur einen Herzvorhof) an die Verhältnisse der höheren Wirbeltiere; die sonst blind geschlossenen Nasengruben sind hier in die Mundhöhle durchgebrochen und ihre Schwimmblase, mit atmosphärischer Luft regelmäßig gefüllt und entleert, dient als Luftatemorgan, während die Kiemen unscheinbar sind.

Im Bane der Atemorgane besteht ja ein tiefgreifender Gegensatz zwischen den höheren Wirbeltieren (Amphibien, Reptilien, Vögeln, Säugetieren) und den Fischen. Bei den ersteren wachsen die Lungen als parige, zunächst einfach sackförmige Aus-

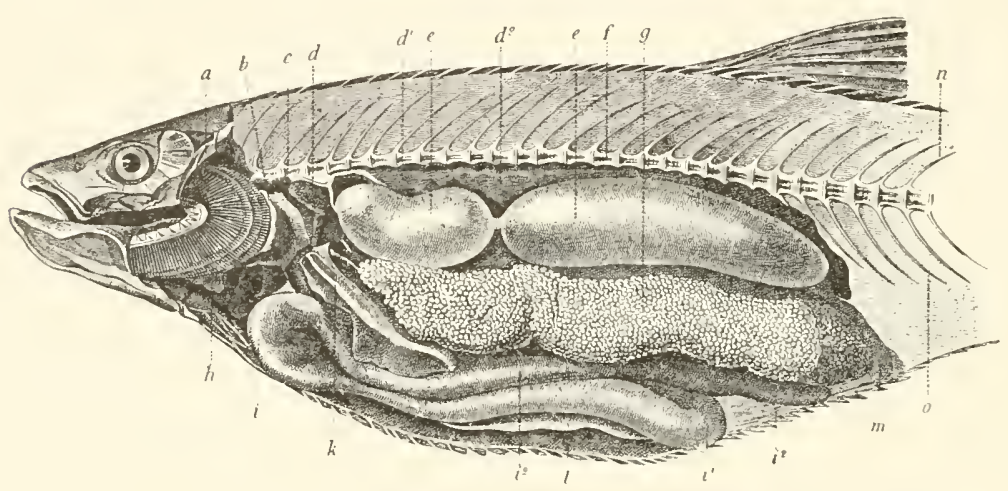

Fig. 67.

1)ie inneren Organe von Squalius cephalus, Döbel. Nach Vogt.

$a$ Kiemen, $b$ Schultergürtel, $c$ Gaumenbogen, $d, d,{ }^{1} d^{2}$ Uniere, $c$, $e^{1}$ Sehwimmblase, $f$ Wirbelsäule, $g$ Eierstock, $h$ Herz, $i$, ${ }^{1}, i^{*}$ Darmschlingen, $k$ Magen, voll der Leber bedeckt, $n$ obere, o untere Bogeu der Schwanzwirbelsäule.

stülpungen aus der ventralen Wand des Vorderarmes und entfalten sich zu großen, oft schwammigen, reich mit Blutgefäßen durchsponnenen Organen, deren Luftventilation überall durch das anı Boden des Vorderdarmes befestigte Kinorpelgeriiste des Kehllkopfes gesichert wird.

Bei den Fischen (Fig. 67) dagegen vollzieht sich die Atmung mit Hilfe der Kiemen und der den Lungen einigermaßen vergleichbare Anhang des Darmes, die Schwimmblase, ist doch recht verschieden von der Lunge. Denn sie entsteht als eine umpare Ausstülpung an der dorsalen Wand des Vorderdarmes und liegt als weite mit Gas erfüllte Blase unterhalb der Wirbelsäule. Trotzdem diese bei vielen Fischarten mittels eines engen Ganges, des sogenannten Schwimm- 
blasenganges, mit dem Darme verbunden bleibt, ist es unmöglich, dass die vom Fische etwa geschluckte Luft in die Blasenhöhle gelangt. Die Schwimmblase kann also nicht mit Luft gefüllt werden, ihr Gasinhalt wird vielmehr von den Blutgefäßen der Wand selbst abgeschieden. Deshalb ist sie auch kein Atemorgan, sondern hydrostatischen Zwecken dienstbar, indem ihre Volumänderung den Fischen gestattet, höhere oder tiefere Wasserschichten aufzusuchen.

Die Lungenfische folgen einer anderen Regel, da ihre Schwimmblase mit Luft regelmäßig gefüllt wird, und das reich entfaltete Gefäßnetz der Schwimmblasenwand den Sauerstoff derselben absorbiert und Kohlensäure dagegen abgiebt. Infolgedessen spielt hier die Schwimmblase die Rolle eines Atemorganes oder wie man sich auch fälschlicher Weise ausdrückt, sie ,stellt eine Lunge vor." Im einzelnen herrschen bei den drei Lungenfischarten recht abweichende Befunde. Die Schwimmblase ist unpaar bei Ceratodus, sie wird als paariger Sack angetroffen bei Protopterus und Lepidosiren. Ihr Ausführgang entspringt von der dorsalen Wand des Vorderdarmes bei Ceratodus, er mündet als kurzer und weiter Kanal an der Ventralwand des Vorderdarmes bei Protopterus.

Immer erscheinen die Kiemen der Lungenfische wenig kräftig, der Tergleich derselben mit den mächtigen Kiemenplatten bei Haiund Knochenfischen legt den Gedanken ihrer minderwertigen Bedeutung für das Atemgeschäft der Tiere nahe. So erscheinen die mit doppelten Atemorganen von verschiedenem anatomischen Typus versehenen Lungenfische als merkwürdige, in die heutige Fauna nicht mehr hereinpassende Tiere und wurden ron der descendenztheoretischen Schule als willkommene Zwischenformen, als Bindeglieder zwischen den kiemen-atmenden Fischen und den Lungenatmern begrüßt, umsomehr, als ja auch die Larven der lungenatmenden Amphibien eine Zeit durchleben, da sie sowohl äußere Kiemen als wahre Lungen besitzen, bis die Kiemen endlich schrumpfen, und als Atemwerkzeuge nur die Lungen erhalten bleiben.

E. $\left.\mathrm{Hacckel}{ }^{1}\right)$ hält mit dogmatischer Starrheit an dem Gedanken noch heute fest:

„Sowohl in morphologischer und systematischer, als in phylogenetischer und physiologischer Beziehung bilden die Lurchfische als "Doppelatmer" ein 'sehr interessantes und wichtiges $\mathrm{Zw}$ is chenglied zwischen der niederen Stufe der wasseratmenden Fische und der höheren Stufe der luftatmenden Lurche. Sie haben von den älteren Fischen (Selachiern) den größten Teil der Organisation geerbt, unterscheiden sich aber von ihnen scharf

1) E. Haeckel, Systematische Phylogenie III. Berlin 1885, p. 258, 267, 269. 
dureh die Lungenatmung und die damit verknüpfte Teilung der Herzvorkammer. In diesem bedeutungsvollen Fortschritte der Organisation stimmen die Lurchfische mit ihren Descendenten (Abkömmlingen), den terrestrischen A mphibien überein; sie besitzen aber noch nicht die fünfzehigen Gangfüße der letzteren, sondern haben die schwimmende Lebensweise und die Fischflossen beibehalten. Die ältere Auffassung der Lurchfische, nach welcher

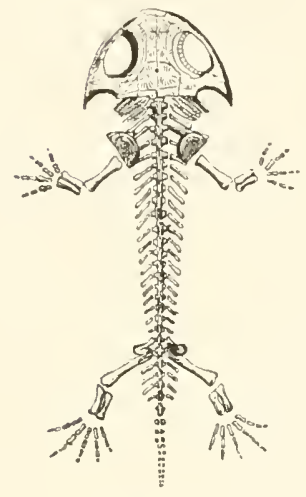

Fig. 68.

Branchiosaurus am blystoma. Larve eines Stegocephalen, restauriert. Nach Credner. sie zu den Amphibien gehören, ist ebenso einseitig und unbaltbar als die neuere, nach der sie unter die Fische versetzt werden. In Wirklichkeit bilden sie eine Intermediärklasse zwischen beiden."

„Die ganze Klasse der Amphibien ist monophyletisch, da alle Angehörigen derselben sich von der gemeinsamen Stammgruppe der carbonischen Stegocephalen (Fig. 68) ableiten lassen, der Ursprung dieser alten Stammgruppe ist bei den Palädipneusten, Urlungenfischen, zu suchen."

„Die Organisation des Weichkörpers der Amphibien im ganzen schließt sich unmittelbar an diejenige der Lungenfische an, und auch viele einzelne Bildungsverhältnisse sind von diesen Vorfahren direkt durch Vererbung übertragen."

So verführerisch Haeckel's Darstellung auch klingen mag, den wirklichen Vorgang der Schöpfung lungenatmender Tiere hat sie der Natur sicher nicht abgelauscht. Ich habe eben wieder einmal absichtlich den Fehler begangen, Thre Gedanken mit einem einzigen Organe einer Tiergruppe zu beschäftigen, während wir der Thatsache gewärtig sein sollten, dass die Natur einen vollständigen Fischorganismus in ein lungenatmendes Lebewesen umzubilden hatte. Schon neulich habe ich Ihnen das Extremitätenskelett der Flosse von Ceratodus (Fig. 29) vorgeführt nebst dem Urteile verschiedener Anatomen, welche es als unmöglich erklärten, daraus die Gliedmaßen der Vicrfiißer - sei es auch bloß durch eine theoretische Vorstellung - abzuleiten. Heute bitte ich Sie, die beistehenden Abbildungen der Gestalt von Ceratodus und Lepidosiren (Fig. 69, 70) anzusehen und selbst zu versuchen, ob Sie sich die Umformung derselben in ein einfaches salamanderähnliches Geschöpf lebhaft ausmalen können. Ich bin nicht dazu im stande und die seither erschienenen Untersuchungen anderer Organe haben auch anderen Zoologen keine zwingenden Beweise für die Haeckel- 
schen Behauptungen geliefert. Da eine Klärung der Ansichten bereits eingetreten ist, glaube ich mich der Darlegung speziellen Detailes überhoben und verlese sogleich einige Bücherstellen. L. Dollo ${ }^{1}$ ) fasste das Resultat seiner Studien in folgende Thesen zusammen:

3. Man lässt allgemein mit E. Haeckel, Professor an der Universität Jena, die Behauptung gelten, dass gewisse fossile Dipneusten die direkten Vorfahren der Batrachier sind.

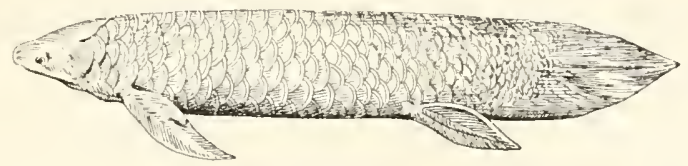

Fig. 69.

Ceratodus miolepis.

4. Aber - in Übereinstimmung mit der Ansicht ron J. E. V. Bo as, Professor an der Veterinärschule in Kopenhagen, E. D. Cope, Professor an der Universität in Philadelphia und J. S. Kingsley, Professor am Tufts College - bin ich der Meinung, dass sich die Behauptung nicht halten lässt.

8. Ich glaube also, dass die Batrachier nicht von den Dipneusten abstammen."

Mollier2) gewann durch das Studium der Litteratur folgende Meinung: „In letzter Zeit gewinnt die Ansicht an Boden, dass den Dipnoern in der Ahnenreihe von den Fischen zu den Amphibien

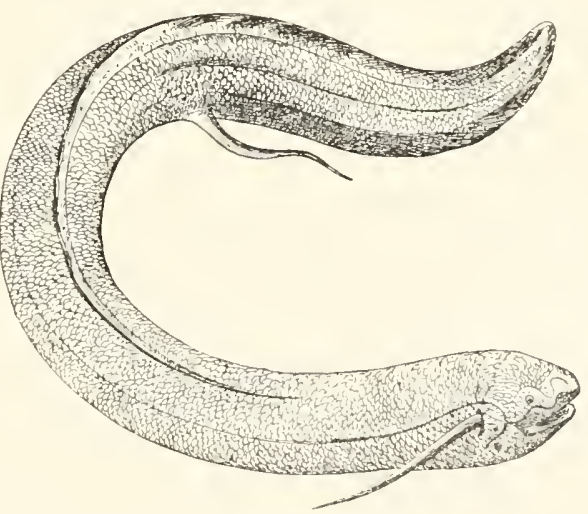

Fig. 70 .

Lepidosiren paradoxa. nicht der wichtige Platz zukomme, den man ihnen nach der Entdeckung des Ceratodus allgemein zugewiesen hatte, sondern dass die Stegocephalen in gerader Linie ron den Crossopterygieru abzuleiten sind. Schon früher haben Boas, Pollard

1) Louis Dollo, Sur la phylogenie des Dipneustes. Bulletin de la Sociètè belg. de Geologie. Tom IX. 1895.

$\left.{ }^{2}\right)$ S. Mollier, Die paarigen Extremitäten der Wirbeltiere. Anatom. Hefte. I. Abt. 8. Bd. 1. Heft. 1897. 
und Rabl diese Ansicht geäußert, und neuerdings sind es vor allem Baur und Dollo, die auf Grund ihrer vergleichend anatomischen Studien diese Auffassung energisch rertreten."

Wenn dic hente lebenden Arten die stammesgeschichtliche Spekulation nicht unterstiitzeu, so bleibt noch die palaeontologische Urkinde nachzuschlagen. Dort finden wir als fossile Verwandte die Ctenodipterini und Crossopterygier.

Was lässt sich nun iiber deren Organisation aussagen? Leider reeht wenig; abgeseheu von einigen Gattungen, die vollständige, aber meist zusammengequetschte Abdriicke des Skelettes und Schuppenkleides (Fig. 71) hinterlassen hat, kennen wir von den anderen nicht viel mehr als Schuppen, vereinzelte Knoehen und wohlerhaltene Zähne, sind also nicht in der Lage, die allereinfachsten Fragen eines wissbegierigen Schïlers, nach den allgemeinen Ziigen

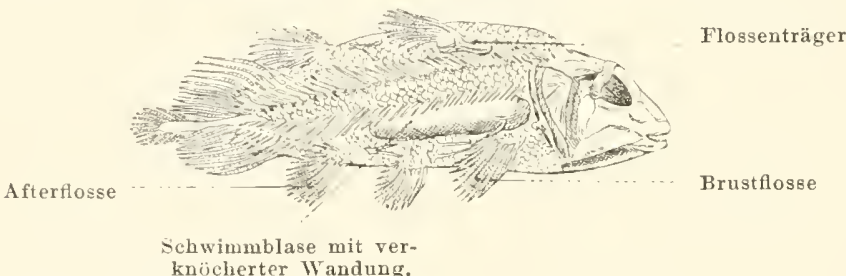

Fig. 71.

Undina penicillata. Fossiler Rest eines Crossopterygiers aus dem oberen Jura.

der Organisation jener Torfahren, welche die niedersten lungenatmenden Tiere, wie Frösche und Salamander gezeugt haben, zu beantworten.

Da die beiden Figuren 69, 70 wobl beweisen, dass bei der Umbildung eines Lungenfisches in das erste Amphibium recht ausgiebige Teränderungen erfolgen mussten, die Sie dureh das Studium der anatomischen Spezialabhandlungen in ihrer ganzen Größe erst richtig schätzen lernen, so werden Sie einsehen, dass $\mathrm{Ha}$ eckel nebst seinen Anhängern die ganze Frage etwas zu optimistisch behandelt hat.

Fragen wir schließlich, um anch die letzte Klasse der Wirbeltiere wenigstens kursorisch zu berühren, nach der Stammesgeschichte der Reptilien, d. h. nach der Entstehung der Krokodile, Schildkröten, Eidechsen, Schlangen, Ichthyosaurier, Pterosaurier, Dinosaurier, so bleibt man uns die Rechenschaft schuldig.

Die jetzt lebenden Gruppen (von den fossilen kann es nur vermutungsweise angenommen werden) zeigen zwar während der 
embryonalen Stufen im rergänglichen Besitze der Kiementaschen des Torderdarmes eine gewisse Verwandtschaft mit der nächst niederen Wirbeltierklasse, den Amphilien. Die genanere Priifung lehrt jedoch das Unbegrïndete des Anschlusses kennen. Ich will die Sachlage mit den Worten eines hervorragenden Tertreters der phylogenetischen Auffassung, C. Gegenbanr's1), charakterisieren:

"Wenn bei den amnioten Wirbeltieren (Reptilien, Tögeln, Säugetieren) an der Wand der Kopfdarmhöhle Spaltenbildung erscheint, die wir durch die Tergleichung mit den Anamnia (Amphibien, Fische) als Kiemenspalten betrachten, so sehließen wir darans, dass die Amnioten Zustände der Anamnia als Vorfahren besessen haben müssen. Mittels Kiemen atmende Tiere waren die Stammeltern der Amnioten, denn nur von solehen konnte jene Einrichtung ererbt sein. Gehen wir weiter in der näheren Bestimmung des Anschlusses, so bieten uns die Amphibien in dem bisweilen nur vorübergehend auftretenden Kiemenbesitze nähere Beziehungen zu den Amnioten als etwa die Fische dar; auch in der Ausbildung neuer Atmungsorgane, der Lungen, für welche bei Fischen wir Vorbilder besitzen, die des direkten Anschlusses entbehren. Wir folgern daraus, dass den Amphibien ähnliche Einrichtungen im phyletischen (stammesgeschichtlichen) Entwickelungsgange der Amnioten (Reptilien, Vögel, Säugetiere) bestanden haben werden. Ein weiterer Schritt der Vergleichung, ein Suchen nach den Stammformen bei einzehnen Abteilungen der lebenden Amphibien führt uns zu Hindernissen. Jedes genanere Eindringen deckt uns Verschiedenheiten auf, und die Priifung der Gesamtorganisation der Vergleichsobjekte lehrt die Unmöglichkeit der Ableitung der Amnioten von jenen. So entsteht uns die Einsicht von der Unvollständigkeit auch der phylogenetischen Zeugnisse."

Selbst Haeckel's Vorstellungskraft steht dem Probleme machtlos gegenuiber, denn er getrant sich nur ein „ideales Bild“ von der ältesten Stammgruppe ${ }^{2}$ ) aller höheren Wirbeltiere, den sog. Proreptilien oder Urreptilien zu entwerfen.

Jetzt habe ich mit Ihnen kurz, nicht eingehend die Fragen durchgesprochen, von welchen Vorfahren sich die vier Klassen der Wirbeltiere: die Säuger, die Vögel, die Reptilien, die Amphibien entwickelt haben könnten. An allen Beispielen lionnte

1) C. Gegenbaur, Vergleich. Anatomie der Wirbeltiere. I. Bd. Leipzig 1898 , p. 20.

2) Vergl. E. Haeckel, Systematische Phylogenie. III. Bd., p. 303 u. p. 282. 
ich zeigen, dass trotz eingehender anatomischer Untersuchungen der letzten Epoche die im Jahre 1859 von der Descendenztheorie hinter diese Gruppen gesetzten Fragezeichen bestehen geblieben sind. Niemand weilß einen klaren Aufschluss iiber die Stammeltern derselben zu geben; ja die anatomische Prïfung hat sogar erwiesen, dass vorderhand nicht einmal Anhaltspunkte für die Lösung der Frage gefunden sind. Die Kluft zwischen den systematischen Gruppen der Wirbeltiere gähnt groß und gewaltig. Dabei habe ich mich mit verhältnismäßig einfachen Fragen beschäftigt, weil ich innerhalb eines Organisationskreises geblieben bin, wo alle Glieder wirklich durch eine große Zahl von gemeinsamen, anatomischen Eigensehaften ausgezeichnet sind. Sehwieriger wird die Aufgabe, wenn die Descendenztheorie die fundamentalen Differenzen zwischen den Organisationstypen selbst ausfüllen soll. Bei der weiteren Diskussion des Problemes, ob die Typen des Tierreiches durch direkte Umbildung zu erklären sind, werden wir zu gleichen Resultaten gelangen. Das heißt mit anderen Worten: die Erwartungen, welche die Abstammungslehre vor 40 Jahren erweckte, sind bisher durch positive Resultate der phylogenetischen Erkenntnis nicht erfuillt worden. Also bin ich wohl berechtigt, von dem Zusammenbruch der Hoffnung, die Beweise für die Abstammung der Tiere jemals aufzufinden, zu sprechen. Wie sehr mich auch die Sehnsucht erfüllen mag, dem Abstammungsgedauken beizupflichten, inmer fehlen noch die exakten Beweisgrïnde und alle Bindeglieder zwischen den kleinen und großen Abteilungen des Tierreiches, welche meinen zweifelnden Verstand zwingen könnten, ein Anhänger zu werden. Aus diesem Grunde hat nach meiner Meinung die Abstammungslehre gar keine Berechtigung in der Naturwissenschaft.

Der Vorzug der letzteren besteht doch gerade darin, eine sichere Kenntnis der Thatsachen und eine den thatsächlichen Verhältnissen genau entsprechende Eingliederung derselben in das wissenschaftliche System zu vermitteln, dass jeder Zweifler gezwungen wird, die Richtigkeit einer vielgepriiften Lehre anzuerkennen, indem man ihm die einzelnen Beweisglieder vorführt und zeigt, er vermöge gar keine andere Meinung darüber zu hegen als diejenige, welche hervorragende Fachmänner auf Grund eingehendster Sachstudien geäußert haben. Das Hypothesengebäude der Stammesgeschichte bietet dagegen keine Thatsachen, sondern nur denkbare Möglichkeiten. Niemand auf der ganzen Welt vermag bestimmte Arten von Säugern, Vögeln, Reptilien, Fischen zu nennen, welche die jetzt bekannten Gruppen wirklich in derselben einleuchtenden Weise verknüpften, wie sich eine Puppe als notwendiges Glied zwischen das Raupen- und Schmetterlingsstadium einfügt. 
Mau kann die Sachlage auf verschiedene Weise darstellen und die Kürze der Untersuchungszeit, die seit der Publikation der Theorie Darwin's verstrichen ist, als Ursache dafür anführen, dass noch nicht alles genau geprüft wurde. Alle Anhänger der Descendenztheorie gestehen ja die großen Lücken der Beweisführung unbedingt zu. Sie fügen ermunternd an, bei der großen Arbeitslust der jetzt lebenden Generation und dem regen Interesse, welches die Allgemeinheit dem Studium stammesgeschichtlicher Fragen entgegenbringt, dürfe man die Hoffnung hegen, dass die heute bestehenden Unklarheiten in Zukunft beseitigt würden. Man kann den gleichen Gedanken auch recht dramatisch ausdrücken und seinen Zuhörern sagen: Ich werde den Triumph nicht mehr erleben, aber wenn ich längst im Grabe modere, werden Sie die Zeugen ungeahnten Fortschrittes sein und den Sieg des Menschengeistes iiber das nur widerwillige Auskunft spendende Untersuchungsmaterial feiern.

Aber wie geschickt man diesen Appell auch vorträgt, um eine momentane Wirkung bei der großen Masse zu erzielen, die Sätzo sind nach meinem Urteile doch nur unsichere Wechsel auf die

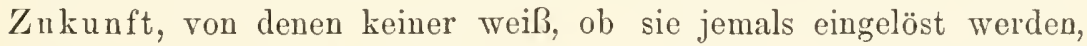
oder ob sie unbezahlt verfallen. Es verbirgt sich in ihnen ein durch Wohllaut bestechender Euphemismus für einen jetzt offenkundig bestehenden' Mangel der exacten Beweisgriinde zu gunsten der Descendenztheorie.

Ich persönlich neige der anderen Ausdrucksweise zu. Da man Übergangsglieder zwischen den Gruppen der Wirbeltiere nicht gefunden hat, so sage ich offen und ehrlich, sie sind uns nicht bekaunt. Mein geheimer Wunsch, sie möchten einstens gefunden werden, hilft bei dieser Sachlage gar nichts; wir haben sie eben vorderhand noch nicht. Infolgedessen fehlen gerade die wichtigsten Thatsachen, die als schlagende Beweise für die Richtigkeit der Abstammungslehre wirken könnten. In solchem Falle scheint es mir eines nüchtern denkenden Mannes würdiger zu sein, die ganze Theorie, welcher gerade für die springenden Punkte die Beweise fehlen, beiseite zu werfen. Alle innere Begeisterung für die Schönheit des Abstammungsgedankens, die ich genau so empfinde wie Sie und viele hundert andere Menschen, hilft uns über die rauhe Wirklichkeit nicht hinweg. Wir entbehren der unumstöBlichen Mittel, um jedermann zu zwingen, ihn für richtig zu halten.

Sehen Sie, meine Herren, das sind verschiedene Ausdrucksweisen fïr ein und denselben Thatbestand. Soweit ich die Menschen kenne, wird stets die größere Zahl derselben jener Darstellung zujubeln, welche Iücken der wissenschaftlichen Erkenntnis durch elegante Worte verschleiert, indem sie ihrer theoretischen Überzengung zuliebe 
die Thatsachen so färbt und auswählt, dass sie wie Beweise ausschauen. Wenige aber werden dem nüchternen Raisonnement beiptlichten, dass, weil keine exakten Beweisgründe gegeben sind, lieber die ganze Theorie fallen muss, als dass man sich noch länger in umnützen Spekulationen bewegt.

Da wir heute zu einer längeren Pause uns trennen, darf ich vielleicht einige persönliche Bemerkungen hinzufügen. Es ist mir von vielen Seiten sehr verdacht worden, dass ich mir die Mühe genommen habe, Sie über den gegenwärtigen Zustand der Abstammungslehre aufzuklären. Meine Kritiker behaupten sogar, ich sei von der Partei des Rückschrittes gedungen und spreche eigentlich gegen meine innere Überzeugung, wenn ich den Nangel zwingender Beweisgriinde in descendenztheoretischen Fragen Ihnen darlege.

Wo Sie solche Verdächtigungen meiner ehrlichen Absicht hören, dürfen Sie energisch widersprechen und dieselben als gänzlich unzutreffend bezeichnen. Ich habe die Vorlesungen angekündigt weder aus persönlicher Eitelkeit, weil ich eine eigene Theorie an die Stelle der unhaltbar gewordenen Lehre setzen möchte, noch aus krankhaftem Ehrgeiz, um von mir reden zu machen, sondern ich habe meine Einladung an Sie ergehen lassen, weil ich den jungen Männern, welche in den nächst folgenden Jahrzehnten ihre Wirksamkeit im dentschen Vaterlande entfalten sollen, einen guten Dienst zu erweisen glaubte, indem ich sie über den gegenwärtigen Zustand einer die Welt so stark erregenden wissenschaftlichen Frage sachlich unterrichte. Während der bisherigen Stunden haben Sie oft genug aus meinem Munde gehört, dass ich Sie nicht in meinen Privatansichten schulen will. Ich betrachte $\epsilon$ vielmehr als meine Aufgabe, das Resultat der zoologischen Forschungen während der letzten 40 .Jahre als objektiver Historiker in bündiger Form zusammen zu fassen und daraus das allgemeine Wertresultat der Epoche abzuleiten. Als solches erscheint mir und manchem anderen die Erkenntnis, dass für die Entwickelung weder der kleineren systematischen Gruppen, noch der großen Organisationstypen zwingende Beweise zur Zeit vorliegen, und nach dem gegenwärtigen Stand unseres Wissens scheint mir eine Verstärkung der Beweismittel in nächster Zukunft auch nicht zu erwarten zu sein. Unsere Lehrer und die älteren unserer 'Zeitgenossen sind deshalb nach meinem Urteil einer wohl entschuldbaren Täuschung zum Opfer gefallen und haben einen Zustand der Wissenschaft hinterlassen, der uns mit jedem Tage dringlicher in die Notwendigkeit versetzt, eine scharfe Grenze zwischen theoretischen 
Folgerungen und wirklich beobachteten Vorgängen zu zichen. Dadurch wird in den nächstfolgenden Jahren die Descendenzlehre aus der wissenschaftlichen Diskussion hinausgedrängt, und es wird dem Kreise der Laien offenbar werden, dass die sichere Bestimmtheit, mit welcher die Descendenztheoretiker ihre Ansichten aussprechen, nicht auf einem ebenso sicheren Fundamente klar gesehener Thatsachen begriindet ist, als man bisher nach einseitigen Berichten annehmen musste. Das wird dia unabweisliche Kionsequenz der bisherigen Entwickelung der zoologischen Wissenschaft sein, und sie wird von manchem Manne recht schwer empfunden werden. Dass aber das Ansehen der Naturwissenschaft wirklich geschädigt wird, weil ich einen dem Eingeweihten unzweifelhaft erkennbaren Zustand bereits heute vor Ihnen öffentlich schildere, und dass ich deshalb ein Verbrechen gegen die Wissenschaft und die hiesige Universitait begehe, wenn ich ehrlich meine auf langjährigen und gründlichen Studien beruhenden Ansichten vortrage, das kann ich nicht verstehen. Denn ich lebe trotz des Widerspruchs meiner Freunde und Feinde in der unerschiitterlichen Hoffnung, dass das ehrliche Streben nach exakter Erkenntnis niemals Unheil bringen und noch weniger die Wissenschaft zu schädigen vermag. Bin ich mit meinem Denken auf einen Irrweg geraten, so wird die wissenschaftliche Entwickelung der nächsten Jahre mir Unrecht geben und Sie werden meine Worte vergessen müssen. Steckt aber neben manchem Irrtume auch wahre Erkenutuis in meiner Darstellung, so haben Sie an dieser Stätte früher als anderswo künftiges Geschehen andeuten hören und sind in objektiver Weise darauf vorbereitet worden! 


\section{Neuntes Kapitel.}

\section{Die Stammesgeschichte der Arthropoden.}

An der Wende des Jahrhunderts offenbart sich die Schwäche der Abstammungslehre und zugleich der Zusammenbruch aller Hoffnungen, sie als bewiesen betrachten zu dürfen. Vier Jahrzehnte haben nicht hingereicht, eine vollgültige, nach naturwissenschaftlicher Anschauung zwingende Beweisführung für die Richtigkeit der Theorie zu schaffen. Die Anhänger der Lehre befinden sich in der gleichen Lage wie im Jahre 1860, wo Darwin's Werk die Suche nach den Übergängen angeregt hatte, welche die Umwandlung der durch so scharfe Grenzen geschiedenen Organisationstypen des Tierreiches erk]ären könnten. Wir stellen hente die gleiche Rätselfrage; aber keiner der jetzt lebenden Zoologen ist im stande, uns eine bestimmte Antwort zu erteilen. Freilich können Sie von den Anhängern scheinbare Antworten vernehmen, allein diese sind nur Ausfliichte, schöne Redensarten und müssen verstummen, sobald ich eine anschauliche Vorstellung von der Beschaffenheit der Vorfahren erhalten will. Ich mag die fünf Klassen der Wirbeltiere aufschreiben, wie ich will: entweder systematisch in horizontalen Zeilen unter einander:

Säugetiere,
Vögel,
Reptilien,
Amphibien,
Fische,

oder in Form eines Stammbaumes,

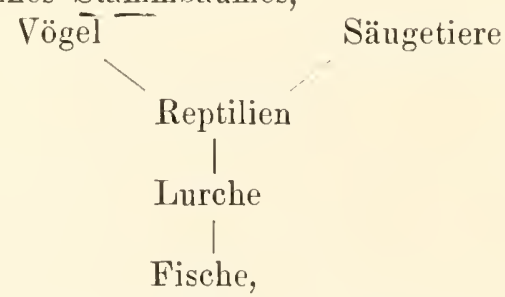

niemand kann mir eine klare Eeschreibung der Vorfahren entwerfen. Solange aber für die Umwandlungstheorie nicht einleuchtende 
Thatsachen demonstriert werden, ist sie ein wertloses Wahngebilde, welches die ihm gezollte Bewunderung nicht verdient. Damit stelle ich keine unbillige Forderung, sondern verlange nur, was jeder ernst denkende Mann wünschen wird, nämlich Überzeugung durch den Augenschein anstatt des Glaubens an theoretische Wahrscheinlichkeiten. Die Vorgänge in der Natur sind ja so geartet, dass man des Selbstsehens nicht entraten kann, will man sie richtig begreifen.

Durch theoretische Schliusse sind anatomische Thatsachen noch außerordentlich selten vorhergesagt worden, höchstens die allgemeinen Prinzipien derselben, niemals das spezielle Detail. Wer aus eigener Anschauung den verschlungenen Entwickelungsweg der Natur kennt, wer weiß, welch sonderbare Pfade sie einschlägt, um zu einem bestimmten Formziel zu gelangen, wer durch das Studium der Geschichte seiner Wissenschaft weifs, welche unsägliche Mühe die Feststellung des exakten Thatbestandes machte, und wie gleichzeitig durch die genaue Erkenntnis der Thatsachen viele vorher als richtig angesehene Lehrmeinungen über den Haufen geworfen wurden, der ist nicht geneigt, die theoretischen Folgerungen der Descendenzschule ohue positiven Beweis hinzunehmen. Wer hätte vor 200 Jahren geglaubt, dass es möglich wäre, in den verschiedenen Formen der Wirbeltiergliedmaßen einen gemeinsamen Grundtypus zu erkenuen? Wer hätte theoretisch den Bau der Archäopteryx konstruiert, der Vögel- und Reptilienmerkmale in kurioser Weise mischt? Niemand hat vorher prophezeit, dass die wahren Backzähne dem Milchgebisse zugehören, und der feinere Bau der Nieren, der Leber, des Gehirns, die Kernteilungsvorgänge mussten mühselig durch Beobachtung ergrïndet werden. Wie viele Theorien sind über den Bau, die Bedeutung, die Funktion des Nervensystems aufgestellt worden, welch scharfsinnige physiologische Abhandlungen sind darïber geschrieben worden! Die exakten Untersuchungen eines folgenden Jahrzehntes haben sie alle in Trümmer zerbrochen.

Diese Beispiele sollen Sie daran erinnern, dass es schwer, dass es meist geradezu unmöglich ist, das natürliche Geschehen ohne direkte Beobachtung im Studierzimmer durch die kombinierende Thätigkeit des Verstandes auszuklügeln. Da die Mangelhaftigkeit der theoretischen Schlussfolgerung für das zoologisch anatomische Gebiet so offen zu Tage liegt, sollte es den Freunden der Descendenztheorie nur angenehm sein, wenn sie durch den Widerspruch veranlasst werden, gute Beobachtungsgründe für ihre Meinung beizubringen. Freilich ist die Beweisführung während der letzten vier Zehntel des Jahrhunderts schwieriger geworden, als man anfangs träumte. Damals genïgte die vergleichende Betrachtung 
eines einzelnen Organsystems, eines Bruchstiiekes des Tierkörpers, um die Umbildung zu erweisen; jetzt wissen wir, dass die Methode falsch, ja, dass sie unwissenschaftlich war, weil sie der Gründliehkeit enthehrt. Indem wir jetzt alle Organe vergleichend betrachten und zusehen, ob die Gesamtheit derselben oder wenigstens ihre Mehrzahl für die denknotwendig erachtete Verwandtschaft mit benachbarten Tierklassen sprechen, werden unserem beweglichen Geiste Zügel angelegt. Wenn einer nach Betrachtung eines Organes den stammesgeschichtlichen Zusammenhang behaupten möchte, erhebt die total verschiedene Ausbildung eines anderen Organes ein kräftiges Veto. Um das Beispiel der Wirbeltiere festzuhalten: die Vögel lassen sich nicht bei den bekannten Reptilien anschließen. Keine der Reptilienarten ist als direkte Vorfahrenform der Säugetiere erkannt. Wir wissen nicht, wie sich die Reptilien von Amphibien herausgebildet haben. Es ist nicht klar, wie die Amphibien durch Umbildung von Fischen entstanden sind.

Wenn der Descendenztheoretiker trotz des negativen Ergebnisses der Forschung an der Abstammungslehre festhalten will und weiter nach den Vorfahren sucht, so wird er zu der Schlussfolgerung gedrängt, dass die jetzt lebenden Tiere nicht von den heute lebenden niederen Arten oder von anderen Arten, deren Bruchstiicke versteinert erhalten sind, abstammen, sondern dass als Urräter der fünf Wirbeltiergruppen Tiere von einfachem Körperbau, von anderer Organisation als die heute lebenden oder bereits ausgestorbenen Formen gelten sollen. Aber mit dieser Annalme hat der Descendenztheoretiker zugleich das exakte Gebiet vollkommen verlassen. Ich kann zu meinem Privatvergnügen mir den Kopf zerbrechen ïber das, was ich nicht sehen und beobachten kann, über die Beschaffenheit eines fremden Landes oder einer fremden Stadt, aber als Naturforscher ist es mir untersagt, uiber das, was ich nicht gosehen habe, eine bestimmte Angabe zu machen. Meine Thätigkeit bört auf, sobald mir die Möglichkeit der Beobachtung fehlt. Theoretische Kombinationen, von Gelehrten ausgesprochen, besitzen leider keinen größeren Wert, als die Vermutungen eines beliebigen I saien, mag auch der Name des Naturforsehers, welcher die Vermutung äußert, mit grossem Glanz und Ruhm umwoben sein.

Das Lancettfischehen, Amphioxus lanceolatus Rud., und die Manteltiere, Tunicata, welche als die wirbellosen Stammeltern der Wirbeltiere friiher eifrig studiert wurden, werde ich hier gar nicht behandeln, weil das Verständnis dieser auf ganz schwachen Füßen stehenden Verwandtschaft zu viel anatomische Kenntnisse fordert.

Wir wendeu uns daher gleich zur Betrachtung der Stammes- 
geschichte der Gliedertiere, Articulata. Die Gruppe umfasst sämtliche Insekten, die Käfer, Schmetterlinge, Heuschrecken, Fliegen, Wanzen, Bienen, Wespen, die Spinnen, Tausendfiißler, Krebse und die gegliederten Würmer. Ich darf den großen Organisationskreis kursorisch behandeln, weil die Anhänger der Descendenztheorie selbst keine klare Vorstellung iiber deren verwandtschaftlichen Beziehungen hegen. Das geht ans wenigen Worten Haeckel's') herror:

„Die beispiellose Mannigfaltigkeit der Speziesbildnng, durch welche die Gliedertiere alle anderen Tiere weit iibertreffen, hat in diesem Stamme schon seit langer Zeit zu einem höchst detaillierten Studium der Systematik geführt. Seitdem uns die Descendenztheorie in dem.,natiurlichen System" der organischen Formen ihren wahren Stammbaum aufzusuchen gelehrt hat, ist auch das systematische Studium der Artikulaten durch die Anwendung der phylogenetischen Methode auf eine höhere wissenschaftliche Stufe erhoben worden. Zugleich haben sich in nenester Zeit auf Grund der großen Bereicherung der phylogenetischen Urkunden unsere Ansichten ïber die verwickelten Terwandtschafts-Beziehungen der größeren und kleineren Gruppen wesentlich geklärt. Sowohl die großen Fortschritte in der vergleichenden Anatomie und Ontogenie der Gliedertiere, als auch namentlich die wichtigen Entdeckungen ihrer Paläontologie haben in neuester Zeit unser Verständnis dieses formenreichsten Tierstammes und seiner historischen Entwickelung wesentlich gefördert. Dennoch sind wir auch heute noch ron einer allgemeinen Anerkennung der wichtigsten Verwandtschafts-Beziehungen weit entfernt; das zeigt schon der Umstand, dass selbst die besten neueren Lehrbiicher die Arthropodengruppe als einheitlichen ,Typus* beibehalten und ron ihren Anneliden-Ahnen gänzlich trennen, dass die natiirliche Einheit der Tracheaten-Gruppe aufgelöst und die Arachniden mit den Merostomen verknüpft werden, dass die fundamentalen Beziehungen der Archanneliden (- als gemeinsame Stammgruppe aller Artikulaten! -) und der Trilobiten (- als gemeinsame Stammgruppe aller Crustaceen! -) oft gänzlich rerkannt werden. Wir halten es daher fuir wichtig, diejenige Ansicht ron der phyletischen Verzweigung des Artikulatenstammes, zu welcher wir durch die gleichmäßige Berücksichtigung aller drei phylogenetischen Urkunden gelangt sind, in folgenden Sätzen kurz zusammenzufassen. - - "

1) Haeckel, Systematische Phylogenie II, 1896, pag. 598. 
Die schönrednerische Färbung des Textes wird Ihnen nicht verbergen, dass Haeckel's Ansicht ron wenigen seiner Kollegen geteilt wird, sonst würde er sich nicht so dogmatisch ausdrücken.

Unter allen gegliederten Tieren sind die Gliederwürmer, deren Arten meist im Meere leben, die einfachsten. (Der Regenwurm

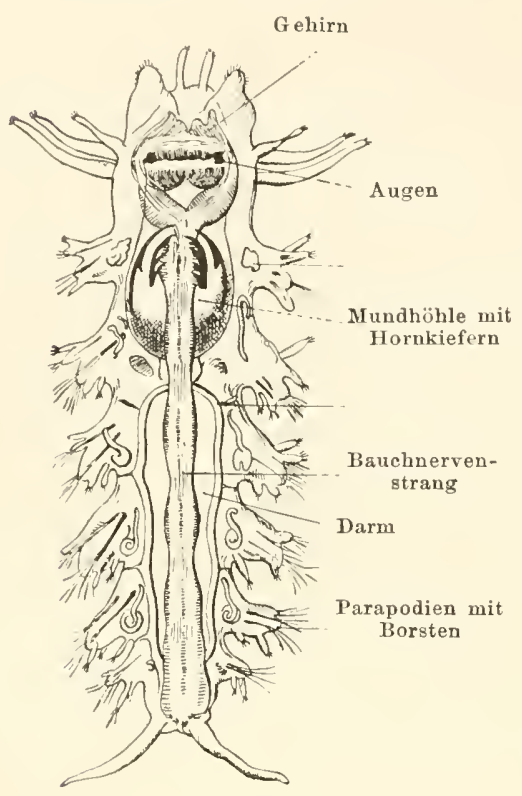

Fig. 72.

Bau einesjungen Gliederwurmes, Nereis. Nach Ed. Mayer. und der Blutegel sind Thwen bekannte Vertreter der Gruppe). Die stammesgeschichtliche Spekulation muss daher sie als die Stammeltern aller höheren Arten der Krebse und Insekten oder wenigstens als diesen Stammeltern nahe stehend betrachten. Der lange schlauchförmige Körper der Gliederwïrmer (Fig. 72) stimmt in der Gliederung mit den iibrigen Gruppen, in dem äußere, gleich weiten Abstand haltende Ringfurchen der Haut cylindrische Bezirke abgrenzen, die Segmente genannt werden. Die Hant aller Gliedertiere hält die segmentale Gliederung auch nach dem Tode des Individuums fest, weil sie mit der Fähigkeit begabt ist, eine erhärtende Substanz, das Chitin, als einen äußeren Panzer, ein gegliedertes Chitinskelett, abzuscheiden. Die Insekten und Krebse sind mit einem festeren Hautskelett gegiirtet, der Gliederwurm mit einem zarten Chitinhäutchen.

Der segmentalen Gliederung ist immer das Nervensystem unterworfen. Ob Sie einen Blutegel, einen Flusskrebs, einen Käfer präparieren, überall finden Sie am Boden der Leibeshöhle in bestimmtem, segmentalem Abstande kleine paarige, aus Nervenzellen und Nerrenfasern gewebte Ganglienknoten, die durch quer verlaufende Nervenstränge paarweise und durch längs ziehende Nerven segmentweise verknüpft, in ihrer Gesamtheit ein strickleiterartiges Nervensystem bilden. Dasselbe unterscheidet sich grundsätzlich ron dem nervösen Centralorgan der Wirbeltiere (Fig. 2), das die Gestalt eines Rohres (Riickenmark) innehält und zu vorderen Gehirnblasen erweitert wird. 
Oberhalb und unterhalb der Mundhöhle findet man meist zwei Paare größerer Ganglienknoten, die oberen und unteren Schlundganglien, die durch Quer- und Längsnerven zu dem, den Darm umschließenden, Schlundringe rereinigt werden.

Damit sind die wesentlichen gemeinschaftlichen Merkmale erschöpft, denn die Gliederwiirmer entbehren gegliederter Beine, gleich denen der Insekten und Krebse, welche selbst wieder durch die Zahl der Beinpaare getrennt werden. Die Insekten tragen an der Brust drei Beinpaare neben einigen frühzeitig verkümmernden Beinanlagen des Hinterleibes, die Krebse verfügen über einen ungeheuren Reichtum derselben; bei den größeren Krebsen, Gruppe der Malacostraca, ist ihre Zahl auf 36 fixiert.

Die Gliedmaßen sind stets in bewegliche Stiicke gegliedert, doch besteht wieder ein fundamentaler Gegensatz zwischen dem Bau der Insekten- und Krebsbeine. Den Ringelwürmern fehlen die

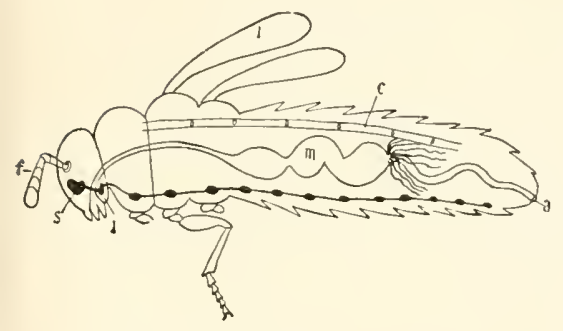

Fig. 73.

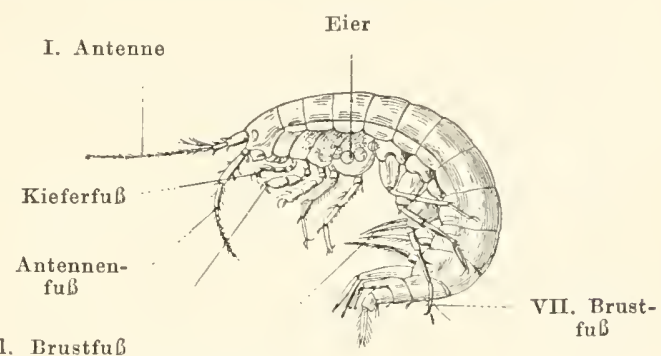

I. Hinterleibs fuß

Fig. 74 .

Fig. 73. Schematische Skizze des Bauplanes der Insekten. a After, c Herz, $f$ Fühler, $i$ Unteres Schlundganglion, $l$ Flügel, $m$ Magen, $s$ Oberes Schlundganglion. Strickleiternervensystem und Ganglienknoten schwarz.

Fig. 74. Gammarus neglectus, ein Wasserflohkrebs. Nach Sars, um die Gliederung des Körpers und die zahlreichen Fïße zu zeigen.

gegliederten Beine, die im Süßwasser und in der Erde rorkommenden Arten haben überhaupt keine beinähnlichen Körperanhänge. Die Gruppe der meerbewohnenden Gliederwürmer, Chaetopoda, dagegen ist durch kleine, nicht gegliederte und je ein Bündel chitinöser Borsten tragender Höckerchen (Fig. 72), die sog. Parapodien, Fußstummelchen, charakterisiert. Die übrigen Organe: der Darm, die Exkretions-, Geschlechts-, Sinnesorgane, das Blutgefäßsystem, die Scheidung der Leibeshöhle in Kammern weichen fundamental von den Einrichtungen bei Insekten und Krebsen ab. Der dadurch gebotene Gegensatz, welchen Sie in jedem Lehrbuche der Zoologie nachlesen können, hat weitere phylogenetische Spekulationen verhindert und erspart mir eingehende Schilderung. Man könnte die Sachlage 
etwa so kennzeichnen: die Descendenztheoretiker vermuten und wïnschen die Stammesverwandtschaft der Gliederfüßer mit den Gliederwürmern. Gefunden haben sie die notwendigen Übergangsformen jedoch noch nicht.

Man hoffte nun in den sechziger Jahren, dass die Larven der Insekten und Krebse besseren Aufschluss iiber das Dunkel der Stammesgeschichte bieten könnten. In der That gewann es auch den Anschein, als hätte Fritz Müller 1864 durch eine kleine ansprechende Schrift: „Für Darwin“ den rechten W'eg betreten, als er

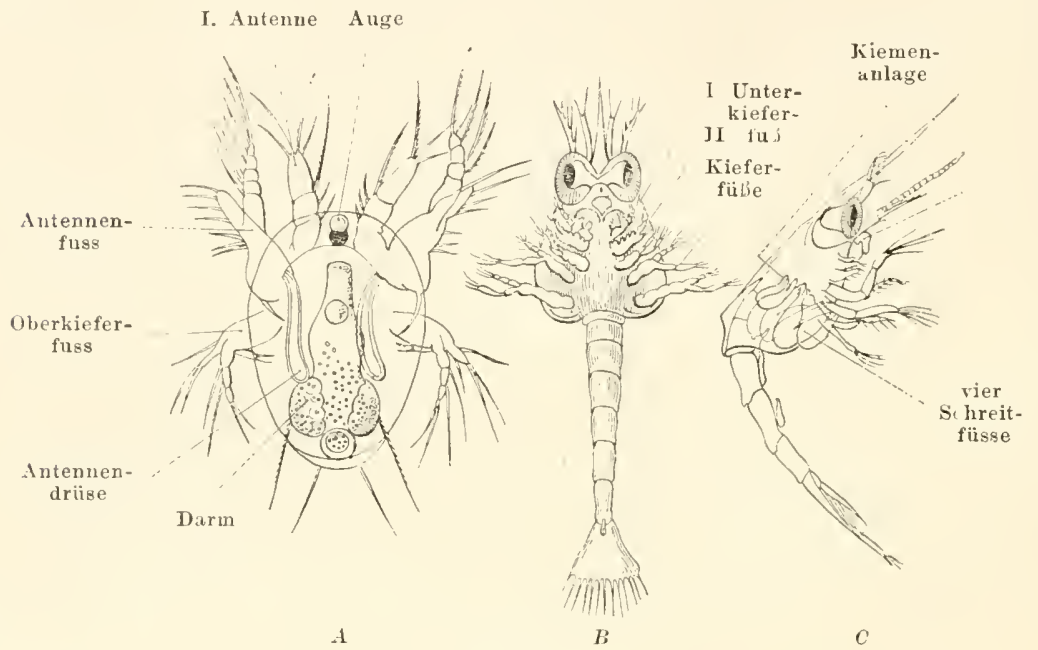

Fig. 75 .

Krebslarven. A Nauplius von Cyclops, einem kleinen Sübwasserruderkrebs. Nach Claus. $B$ Altere Larve von Hippolyte, sng. Zoëa, an welcher Brust und Hinterleib bereits entwickelt sind. 'Altere Zoëa von Eupagurus bernhardus, Einsiedlerkrebs, nach S ars, an welcher die Schreitfüle erscheinen.

den Tersuch wagte, die Larven der Krebse (Fig. 75) für Rückschlïsse auf die Urform, ron welcher der Krebsstamm sich abgezweigt hat, theoretisch zu behandeln. Unzweifelhaft sind auch die Larven der Insekten und Krebse sehr interessant, weil die Jugendstadien von später recht komplizierten Lebewesen einen außerordentlich einfachen Aufbau des Körpers zeigen. Sie brauchen nur an den Unterschied zwischen der Schmetterlingsraupe und dem fertigen Schmetterlinge zu denken. Die Fig. 75, A bildet die einfache Larve der Krebse ab. Meist kriecht aus den Krebseiern solch' eine kleine Larve, der sog. Nauplius, hervor, von den geschlechtsreifen Eltern dadurch unterschieden, dass sie keine Gliederung besitzt, und das freischwimmende, selbständig lebende Kopfstiick des allmählich durch Bildung der Brust- und Schwanzregion (Fig. 75, B, C) sich vervollständigenden Leibes darstellt. 
Fritz Mïller's Versucl. die Naupliusform als Ahnenbild der Krebse anzusehen, hat mehrere Jahrzehnte lang die wissenschaftliche Welt beherrscht und eine ungeheure Zahl ron Spezialuntersuchungen angeregt. Hente darf er als endgiiltig widerlegt gelten.

Noch weniger sind die Hoffnungen der Darwinianer durch das Studium der Insektenlarren gerechtfertigt worden, deren madenähnliche Gestalt (Fig. 76) den Tergleich mit einem Wurm direkt herausfordert oder nach der Ausdrucksweise der phylogenetischen Schriften die Vermutung ihrer Verwandtschaft mit den Wïrmern zur positiven Gewissheit steigert. Damit Sie uicht etwa glauben, ich wollte Sie in meinen Privatansichteu schulen, hebe ich aus zwei modernen Lehrbïchern, deren Terfasser rou der Möglichkeit stammesgeschichtlicher Forschung ehrlich iiberzengt sind, einige Stellen herror:

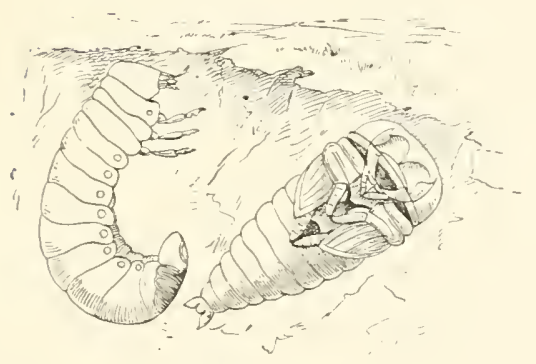

Fig. 76.

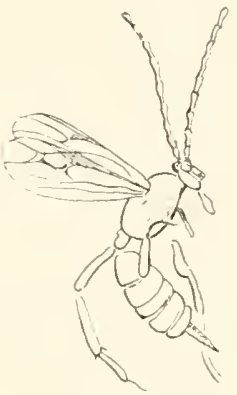

Fig. 77.

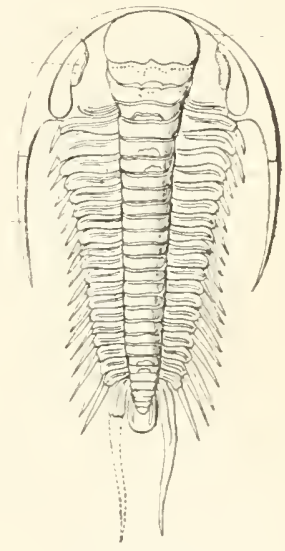

Fig. 78 .

Fig. 76. Larve und Puppe des Hirschschröters, Lucanus cervus, in der Erde. Fig. 77. Ichneumonites bellus, eine fossile Schlupfwespe des Miocins. Nach Heer. Fig. 78. Paradoxides bohemicus, ein Trilobite des Cambriums.

„Man hat frïher allgemein die Stammform der Krebse ${ }^{1}$ ) für ein naupliusähnliches Tier erklärt und angenommen, dass sich aus dieser Stammform die hente lebenden Krebse phylogenetisch in ähnlicher Weise entwickelt haben, wie sie heutzutage ontogenetisch (in der inviduellen Keimesgeschichte) noch durch eine Reihe von Metamorphosen aus dem Nauplius herrorgehen. Diese Ansicht halten wir für unrichtig und zwar aus allgemeinen wie aus speziellen Griinden." (Dies wird ausführlich erläutert.)

1) A. Lang, Lehrbuch der vergl. Anatomie der wirbe'losen Tiere, Jena $1 \varepsilon 94$, p. $420,421$. 
.Der Nauplins ist eine typische Krebslarve; die Torfahren der Krebse besaßen noch keine typische Nanplinslarve, noch weniger stammen sie ron einer napliusähnlichen Stammform ab."

"Es ergiel,t sich aus diesen Betrachtungen ${ }^{1}$ ), dass wir die Metamorphose der Insekten nur in beschränktem Maße nach der phyletischen (stammesgeschichtlichen) Richtung verwerten können. Vor allem muss man im Ange behalten, dass die aus dem Ei kommenden Larven bereits die typische Gliederung des Insektenkörpers aufweisen, dass also in keinem einzigen Falle Ahnenformen in den Larven zur Reproduktion kommen, welche den ältesten Insektenformen vorhergingen. Alles was uns die Insektenlarven lehren können, wird sich daher nur im Rahmen dieser Klasse bewegen können."

Die palaeontologische Urkunde ist unseren Zwecken nicht günstig. Sie giebt wohl die Abdriicke der äußeren Körperform, der Fliigel und Beine, wieder (Fig. 77) und schließt zugleich das genaue Studium einzelner Teile aus. So hat ihre Reichhaltigkeit (Zittel schätzte die Zahl der beschriebenen fossilen Insektenarten auf 2600 Arten) für unsere Zweke keinen Wert. Die fossilen Krebse, besonders die silurischen Trilobiten weichen von den recenten Gruppen so weit ab, dass die Aufgabe, zwischen beiden anatomische Beziehungen nachzuweisen, unsagbar schwer ist (Fig. 78).

Nachdem wichtige Zeugnisse der Stammesgeschichte absolut versagen, bleibt noch die Priifung der heute lebenden Glieder der großen Organisatiousgruppe ïbrig. Wiellerum zog eine erst in neuerer Zeit entdeckte Tierart, Peripatus, die Hoffnungen der wissenschaftlichen Welt auf sich, bis derselbe Abschluss erfolgen wird, wie er uns bei der phylogenetischen Deutung der Imngenfische iiberrascht hat. Die wenigen hierher gehörigen Arten, Peripatus

(4.

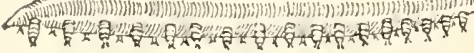

Fig. 79.

Peripatus capensis. Nach Moseley.

Edwardsi Blanch. und Peripatus capensis Gr. leben unter faulendem Holze in den tropischen Wiildern aller Erdteile und zeigen anatomische Merkmale der Insekten und Gliederwïrmer bunt zusammengewïrfelt, etwa wie das Schnabeltier eine Mischung von Charakteren der Sängetiere und Reptilien darstellt.

Peripatus weicht von allen Gliedertieren zunächst dadurch ab, dass sein Körper nicht gegliedert ist, also keine Segmentfurchen

1) E. Korschelt u. K. Heider, Lehrbuch der vergl. Entwicklungsgeschichte der wirbellosen Tiere. Jena 1890, p. 858. 
zeigt (Fig. 79). Nur der Torderabschnitt, der sog. Kopf, setzt sich rom schlauchförmigen Leibe dentlich als mnd trägt zwei schlank cylindrische, geringelte Anhänge, den Fiihlern (Antennen) der Insekten und Krebse rergleichbar. Zn beiden Seiten des nachfolgenden, nicht segmentierten Körpers stehen 14-42 Pare ron Höckern, die als Auswiichse der Leibeswand entstehen, mit Querreihen von Papillen besetzt sind und je zwei endständige Klamen tragen.

In der weiten Leibeshöhle liegen Luftatmungsorgane von besonderer Art. Sie verleihen dem Peripatus höheres Interesse, weil die Atemapparate der Insekten und Krebse in strenger Weise

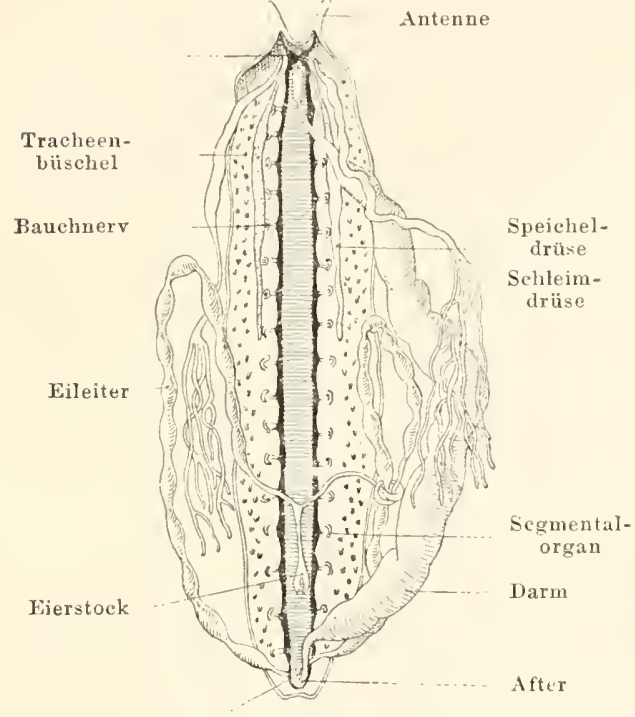

Geschlechtsöffuung

Fig. 80 .

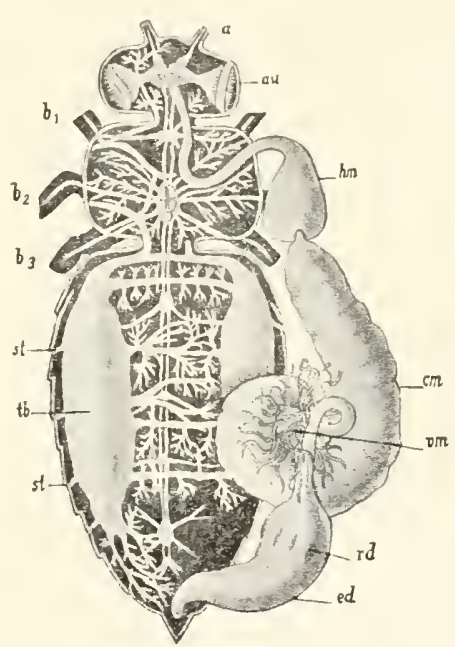

Fig. 81 .

Fig. 80. Die Eingewejde eines weiblichen Peripatus.

Fig. 81. Anatomie der Honigbiene. Nach Leuckart. a Fühler, an Ange, $b_{1} b_{2} b_{3}$ Beine, $\mathrm{cm}$ Chylusmagen, ed Enddarm, rl. Enddarmdrüsen, st stigmen, tb Haupttracheenstamm, vm MIalpighi'sche Gefäße. Das strickleiterförmige Nerrensystem zieht in der Mittellinie der Figur.

gesondert sind und es nicht möglich erscheint, beide direkt auseinander abzuleiten. Denn die Insekten sind luftatmende, die Krebse wasseratmende Wesen; die Insekten führen die Luft in Tracheenröhren des Körpers ein, die Krebse nehmen den Sauerstoff des Wassers mittels Kiemen anf, welche gleich Plättchen oder Fäden an den Beinen hängen (Fig. 75, C). Die Luftatemorgane der Insekten, ein System ron Hohlröhren oder Tracheen, durchziehen den Körper, wie die Blutgefäisse durch unsere Organe ziehen (Fig. 81). Von kleinen Offnungen an der seitlichen Körperwand, den sog. Stigmen, die mit reizenden Terschlussapparaten und Reinigungsvorliehrungen zur 
Abhaltnng des Staubes versehen sind, gehen weite Röhren ab und verzweigen sich, je tiefer sie vordringen, in sekundäre und tertiäre $\ddot{A s t e}$, in feincre Zwcige, bis sie in ein zierliches Maschennetz feinster Luftgefäße aufgelöst sind und damit alle Organe umspinnen. Erweiterude und pressende Bewegungen der Körperwand veranlassen die periodische Luftfïllung bezw. - entleerung des Tracheensystemes.

Bei Peripatus scheint eine Anfangsstufe der Tracheenatmung rorzuliegen. Denn seine Respirationsorgane sind Büschei ron 'Tracheemröhren, deren Zahl der Summe der Fusshöckerchen entspricht. Die Tracheen selbst sind kurz und umweben nicht dic Organe. Man kann also denken, man hätte einen anatomischen Zustand gefunden, der cinstmals vielen Urinsekten gemeinsam war, als diese die Wasseratmung aufgaben und mittelst blinder, ron der Körperwand eingebuchteter Hohlsäcke Luft zur Befriedigung des Sauerstoffbediirfnisses einzogen. Peripatus hätte die einfache Eimrichtung bewahrt, während die gesteigerte Lebensenergie anderer Gruppen der Urinsekten dic Vervollkommnnng zum reich rerzweigten Tracheennetzwerk herbeifuihrte.

Audere Eigenschaften zeigen die Exkretionsorgane, bestimmt zur Abscheidung und Ableitning der beim Stoffwechsel erzengten schädlichen Auswurfstoffe des Körpers. Bei Peripatus besitzen sie den Typus der Exkretionsorgane der Gliederwïmer, nämlich enge, zarte, vielfach geknäuelte Kanälchen von grolier, den Fulistummelchen entsprechender Zahl, welche an der Basis der FuBstummel ausmïnden. Solche Organe liommen wieder den Insekten nicht zu. Thre Exkretionsprodukte werden durch Malpighi'sche Gefäße des Darmes ausgeschieden, ein im Tierreich ganz einzig dastehendes Verhalten, da sonst der Harn durch getrennte Kanäle abgeleitet wird. Die Ahbildung (Fig. 81) illustriert die Verhältnisse der Honigbiene. An der Grenze zwischen Hitteldarm und Euddarm häugen die zahlreichen Exkretionskanäle. Sie miissen ihr Sekret in die Darmhöhle selbst entleeren, während dasselbe bei Gliederwürmern und Peripatus ans zahlreichen Exkretionsporen der seitlichen Körperwand träufelt. Bei den Krebsen liegen die gleichwertigen Orgaue sogar in der Kopfregion und münden an der Basis ron Kopffüßen.

Peripatus wiurde kraft dieser Eigenart zu den Gliederwürmern nähere Beziehungen haben und eine Etappe der Stammesgeschichte versimbildlichen, auf welcher die Bilkung der Atemorgane nach dem Insektentypus bereits eingeleitet war und die Entfernung der Gliederwurm-Exkretionsorgane noch nicht begonnen hatte, nur schade, dass sich bei den Insekten gar keine Spuren des ehemaligen Besitzes der gleichen Organe finden. 
Das Nerrensystem von Peripatus fällt gar nicht in den morphologischen Typus der Gliedertiere. Auf dem Boden der Leibeshöhle ziehen zwei weit ron einander abstehende Längsnerrenstränge ohne regelmäBig eingestrente, segmentalen Abstand haltende, Ganglienknoten, nur durch feine Nerrenquerbriicken verkniipft. Da fiir Insekten und Krebse das Strickleiternerrensystem (Fig. 81) die Regel bildet und die einfachen Gliederwürmer, welche einer niederen stammesgeschichtlichen Stufe zugehören, die gleiche Auordnung verraten, so schafft der verschiedene Bau bei Peripatus neue Terlegenheit. Denn die Urahnen der Insekten müssen doch die Form des Nervensystemes, welche mit zäher Regelmäßigkeit bei sämtlichen Gliedertieren auftritt, besessen haben, um sie auf die Nachkommen zu iibertragen.

Die einfachste Gruppe unter den Tracheenatmern bilden die TausendfüBer oder Myriopoden (Fig. 60). Bei oberflächlicher Betrachtung einigermaßen dem Peripatus ähnlich scheiden sie sich scharf ron demselben, weil der Körper in zahlreiche Segmente (15-70, 100, 150 und mehr) gegliedert ist, deren jedes ein paar kurzer geglielerter Beine trägt. Dadurch treteu sie zugleich in einen anatomischen Gegensatz zu den Insekten und Spinnen. welche mittels drei oder vier Beinpaaren gehen. Ich will ron der Anfzählung weiterer Unterschiede absehen. Jedes Lehrbuch fiihrt dieselben an und ihr Gewicht ist so groß, dass die Descendenztheoretiker wieder recht gewagte An-

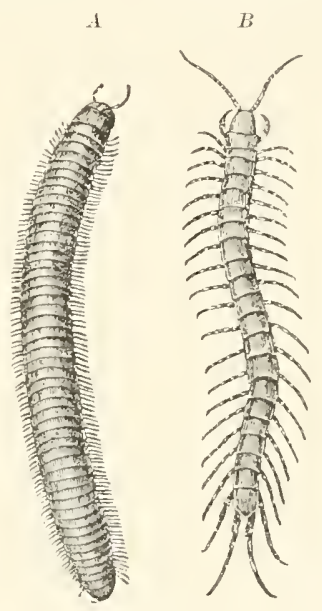

Fig. 82 .

Tausendfü $B$ er. A. Julus maximus, Tausendfuß. B. seolopendra morsitans, Bandassel. nahmen machen müssen, $u m$ ihre Lehre scheinbar zu begriuden. Haeckel l) urteilt iiber Peripatus:

..Natiolich ist dieser letzte moderne Überrest jener uralten Gruppe nicht als der unveränderte, Stammrater der Tracheaten' anzusehen; er wird sich aber ron diesem hypothetischen Stammvater nur wenig entfernen; und wir können uns leicht eine Reibe von Zwischenstufen vorstellen, welche von Protochaeten (den Crborstenwïmern) zu den ältesten Urluftrohrtieren hiniiberführten. Die Eutwickelung der letzteren aus den ersteren wird schon in der cambrischen Periode stattgefunden haben.*

1) System. Phylogenie. II. Bd., p. 669, 671. 
"Als gemeinsame Stammgruppe der Myriopoden müssen wir eine hypothetische Ordnung der Prochilopoden (d. h. UrtansendfüBer) annehmen, welche durch eine Reihe von Z/wisehenformen mit ihren Urluftrohrtier-Ahnen verbunden war. Gleich den letzteren wird dieselbe schon in cambrischer Zeit gelebt haben."

Die Krebse unterscheiden sich von den Tracheentieren und den Gliederwürmern so stark, dass Haeckel und andere Forscher die hypothetischen Stammgruppen der Krebse und der Tracheenatmer auf verschiedene Formen von Gliederwurm-A hnen zurïckführen müssen.

Als Ergebnis der sog. stammesgeschichtlichen Wissenschaft ist folgender Stammbaum zu betrachten, von dessen Ästen nur die durchschossen gedruekten Zweige wirklich bekannt sind.
Krebse
Spinnen
Insekten
Urkrebse
Tausendfüßer
Borstenwïrmer Peripatus Urtracheenatmer

\section{Urborsten würmer \\ Urgliederwürmer}

Sie sehen aus diesem Schema, welches lebhaft an den auf Venus und Aeneas zurückführenden Stammbaum des Kaisers Augustus erinnert, dass die Stammesverwandtschaft der Gliedertiere weit entfernt, bewiesen zu sein, hente noch ganz in der Luft steht. Die lebenden Gruppen sind durch anatomische und biologische Merkmale so scharf von einander geschieden, dass bloss der sehnliche Wunsch, von Verbindungsgliedern sprechen zu können, zur Bildung neuer Namen und einer absolut oberflächlichen Charakteristik der hypothetischen Eigensehaften jener Stammhalter Anlass giebt. Solch theoretisch konstruierte Tiere werden jedoch niemals lebensfähig, weil sie, wie Lseche treffend bemerkt, im Studierzimmer empfangen und geboren wurden. Die kritisehe Petrachtung der Anatomie von Peripatus hat gleich früheren Fällen - ich erinnere an Archaeopteryx, das Schnabeltier, die Lungenfische - dessen hohe Einschätzung als phylogenetisches Beweisstück zerstört. Er wird von den Descendenztheoretikern selber nur als ein Seitenast, nicht mehr als wirkliche Stammform betrachtet.

Die phylogenetische Spekulation ist eben in ein thatsachenleeres Gebiet verirrt und muss sich durch oberfläehliche Redensarten über das eigene Fiasko hinwegtänschen. Unzweifelhaft würde jeder Protest einlegen, wenn einer unserer Bekannten folgendes Verhalten 
an den Tag legen wollte. Er, der niemals im Gebirge gewesen war, machte eine Alpenreise, sagen wir nach Tirol und begniigte sich mit der Fusswanderung im Thal, er folgt also der Brennerstrasse nach Süden bis Bozen. Wenn dieser Mann nach seiner Rückkehr nicht bloss über die Gegend, die er zu Fuss durchwanderte, sondern auch über die Formen der Gipfel in den benachbarten Höhen der Stubaier, Zillerthaleralpen, Passeierberge und Dolomiten Angaben machte und uns die Schwierigkeiten oder Bequemlichkeiten dieses oder jenes Aufstieges zum Gipfel erläutern wollte, würde er bald Widerspruch erfahren, denn jedermann ist es selbstverständlich, dass man über die touristische Geographie einer Gegend nicht reden kann, wenn man sie nicht auf vielfachen Pfaden durchstreift und durch eigene Anschamug kemen gelernt hat. In einer ähnlichen Lage wie unser Fusswanderer befindet sich die Descendenztheorie. Sie bestrebt sich, detaillierte Angaben über Ereignisse und Vorgänge zu machen, die man nicht gesehen hat und nicht sehen kounte. Deshalb sind ihre Darlegnngen direkt abzuweisen; jemehr wir in die Einzelheiten eindringen, verliert die aus einer gewissen Entfernung recht schön erscheinende Theorie den Schein der Richtigkeit, umso größer erscheint die Schwierigkeit, ihre Anerkennung in nächster Zeit erwarten zu dürfen. Bei dem krampfhaften Suchen nach Zwischenformen ist der Peripatus zu dem Ansehen eines Stammvaters der Insekten gekommen, obgleich ihm eigentlich alle Eigenschaften mangeln, welche einem Stammrater zukommen müssten. Es fehlt die Gliederung des Kürpers, die gegliederten Beine, das gegliederte Nervensystem, und die Exkretionsorgane sind anders gebaut. Das einzige, was der Peripatus mit den Insekten anatomisch gemeinsam hat, ist die Thatsache, dass seine Atemorgane als Tracheen entwickelt sind, aber bei ihm sind es geschlossene Säcke, die büschelweise stehen, bei den Insekten reich verzweigte Röhren, die als zusammenhängendes Netzwerk erscheinen. Infolge dieser anatomischen Verschiedenheit zwischen Peripatus und Insekten muss die Descendenztheorie eine Menge ron ausgestorbenen und völlig unbekannten Zwischenformen anuehmen, damit die Behauptung aufrecht erhalten werden könne, der Peripatus sei als Torfahrenform der Insekten zu betrachten.

Was die Insekten selbst anlangt, so wissen wir über deren Entstehen nichts, trotz ihrer großen Zahl ${ }^{1}$ ): es giebt 220000 Arten, 93000 Arten Käfer, 30700 Arten Hautflügler; 44500 Arten Schmetterlinge, 24400 Arten Fliegen, 17000 Arten Wanzen. ITenn sich das ungeheure Material in stammesgeschichtlicher

1) A Günther, Numbers of Zoological species known in the Jears 1830 and 1881. Ann. nat. hist. 6. ser, rol. 17, 1896, p, 180. 
Richtung hätte verwerten lassen können, so hätte das anatomische Studium desselben, dessen Unvollständigkeit ich gern zugebe, doch immerhin einige Anlıaltspunkte für die Verwandtschaft liefern sollen, aber die letzten 40 Jahre haben gezeigt, dass die Grenzlinien zwischen den einzelnen Gruppen außerordentlich scharf sind, ja sie erscheinen bei tiefer eingehendem Studium noch schärfer, als wir sie vorher zu rermuten wagten. Wegen der ungünstigen Sachlage erwähnen auch die Anhänger der Descendenztheorie von der Stammesgeschichte dieser Gruppe sehr wenig. Wenn Sie die populären Schriften nachschlagen, so werden Sie iiber die Entstehung der Insekten nur einige Zeilen gedruckt finden, und die ausfuihrliche Darlegung eines stammesgeschichtlichen Zusammenhanges vermissen. 


\section{Zehntes Kapitel.}

\section{Die palaeontologische Entwicklung einer Süss- wasserschnecke.}

Da das stammesgeschichtliche Resultat für den Typus der Gliedertiere keine ausreichende Befriedigung gewährt, heben viele die „vollständige Einsicht in den Gang phylogenetischer Transformation" bei den Weichtieren, den Mollusken, hervor. Die Gehäuse derselben widerstehen der zersetzenden Wirkung der Fäulnis, der Atmosphärilien und des Wassers lange Zeit und werden versteinert in ungeheurer Zahl gefunden. Nach Zittel's Schätzung sind ungeführ 6000-7000 fossile Tintenfische, 10000 fossile Schnecken, mehr als 5000 fossile Muscheln bekannt, welchen als jetzt lebende Weichtiere ungefähr 140 Arten Tintenfische, 16100 Arten Schnecken, 5000 Arten Muscheln gegenüiber stehen. Das reichhaltige Material hat nach dem Erscheinen ron Darwin's Werke die Descendenztheoretiker hauptsächlich zu paläontologischen Studien angeregt in der Hoffnung, dadurch die Richtigkeit der Abstammungslehre zu demonstrieren. Ohne zunächst auf die Tintenfische und Muscheln genauer einzugehen, lenke ich Thre Aufmerksamkeit auf die fossilen Schnecken und nenne davon nur drei Beispiele:

Planorbis multiformis Hilgd. aus Steinheim (Württemberg), die Gattung Vivipara Lam. in Slavonien, Insel Kos, Ätolien, und Melanopsis Fer. in Nordsyrien, am Orontes, Griechenland.

F. Hilgendorf hat zuerst (1866) durch die paläontologische Untersuchung der Reste von Planorbis die allmähliche Gestaltveränderung der Organismen beweisen wollen. Wenige Jahre später hat der ausgezeichnete Wiener Paläontologe M. Neumayr ${ }^{1}$ ) in Verbindung mit C. M. Paul die Schalenreste der Gattung Vivipara, zu der die bei uns einheimische, lebendig gebärende

1) M. Neumayr u. C. M. Paul, Die Kongerien- uud Paludinenschichten Slavoniens und deren Fauna. Abhandl. d. K. K. Geolog. Reichsanstalt Wien, Bd. VII, Heft 3, 1875 . 
Sumpfschnecke, Paludina vivipara gehört, in weit ausgedehnten Schichten Slavoniens verfolgt. In neuester Zeit sind Schalenreste von Melanopsis aus Nordsyrien durch Blankenhorn') und aus Griechenland durch Oppenhei $\mathrm{m}^{2}$ ) beschrieben worden.

Alle diese Untersucher gehen von der Thatsache aus, dass in den über einander liegenden Schichten der Gesteinsrinde unseres Planeten auf verschiedenen, oft nahe benachbarten Horizonten Schalenreste von Schnecken gefunden werden, die sich teils durch die Größe und allgemeine Form, teils durch Skulpturen und Verzierungsvorsprünge wesentlich unterscheiden, und suchen durch das Studium der Lagerungsverhältuisse und das Aufspüren von Übergangsformen den Nachweis für die Umbildung der geologisch zusammengeworfenen Schalen zu erbringen, indem sie dieselben nicht bloss als räumlich benachbart, sondern anch als genetisch zusammengehörig, d. h. als Glieder einer blutsverwandten Sippe, einer phyletischen Umbildungsreihe betrachten.

Wer nun einen kurzen Bericht über solche Untersuchungen, noch dazu in populär-wissenschaftlichen Schriften liest, gewinnt leicht den Eindruck, als sei wirklich ein strikter Beweis geführt; wer jedoch tiefer in das schwierige Detail solcher Darlegungen eindringt, erkennt, dass die scheinbar beweisende Sprache der versteinerten Schneckenurkunde eigentlich nichts besagt.

M. Neuma y r und C. Paul ${ }^{3}$ ) betrachteten Süßwasserablagerungen in Slavonien von ungeheurer Mäclitigkeit als besonders günstig für eine descendenztheoretische Untersuchung, weil hier cine lange und ununterbrochene Schichtenreihe des oberen Miocäns liegt, welche unter gar nicht oder ganz unmerklich sich ändernden Bedingungen abgesetzt wurden. Die Schichten lassen sich in acht Horizonte einteilen, deren jeder verschiedene ans einander sich herausbildende Molluskenschalen aufweist. Neumayr konnte aus den zahlreichen dort gesammelten Versteinerungen vier anf den ersten Blick geradezu verblïffende Entwickelungsreihen von Schnecken der Gattung Vivipara Lam. und Melanopsis Fer. zusammenstellen. Wir wollen eine derselben betrachten ${ }^{3}$ ) (Fig. 83). "Auf den unteren Paludinenschichten tritt eine vollständig glatte Schalenform mit gerundeten Umgängen (Vivipara Neumayri) auf; allmählich flachen sich die Windungen ab und das Gehäuse nimmt eine kegelförmige Gestalt an (Vivip. Suessi), die Umgänge werden treppenförmig abgesetzt (Vivip. pannonica),

1) M. Blankenhorn, Zur Kenntnis der Süsswasserablagerungen und Mollusken Syriens. Palaeontographica, Bd. 44. 1897.

2) P. Oppenheim, Beiträge zur Kenntnis des Neogens in Griechenland. Zeitschrift d. deutsch. geolog. Gesellsch, 1891.

3) Neumayr u. C. Paul 1. c. S. 98. 
auf ihrer Mitte erscheint eine Einsenkung (Vivip. bifarcinata), diese Einsenkung wird tiefer, der obere Teil der Umgänge zeigt einen schmalen, wulstigen Kiel, ${ }^{1}$ ) der untere eine breite Aufbauchung (Vivip. stricturata), die untere Aufbauchung erhält ebenfalls einen stumpfen Kiel (Vivip. notha); nun werden beide Kiele scharf und rïcken bis auf die ersten Umgänge hinauf (Vivip. ornata), und endlich troten auf dem unteren Kiele zackige Knoten auf (Vivip. Hoernesi)." Diese Varietäten lagern in der Woise, dass Vivipara bifarcinata, stricturata, notha, ornata. Hoernesi jedc ein eigenes Niveau, eine über der anderen einnehmen, so dass die geologische Reihenfolge genan der Formentwickelung entspricht; sie orfüllen die mittleren und oberen Paludinenschichten während dio drei erston Formen, Tivipara Neumayri, Suessi und pannonica in dem großen, noch nicht weiter gogliederten Komplexe der unteren Paludinenschichten liegen.

Fiir Melanopsis der slavonischen Schichteu nimmt Neumayr die Abstanmung von einer glatten Urform an, aus welcher sich Formen mit stärker werdenden Rippen (d. h. senkrecht zur spiraligen Längsachse stehenden Wülsten der Schalenoberfläche) entwickelten, während in einer anderen Reihe die Rippen verschwinden und wieder glatte Formen auftreten.

Blankenhorn und Oppenheim
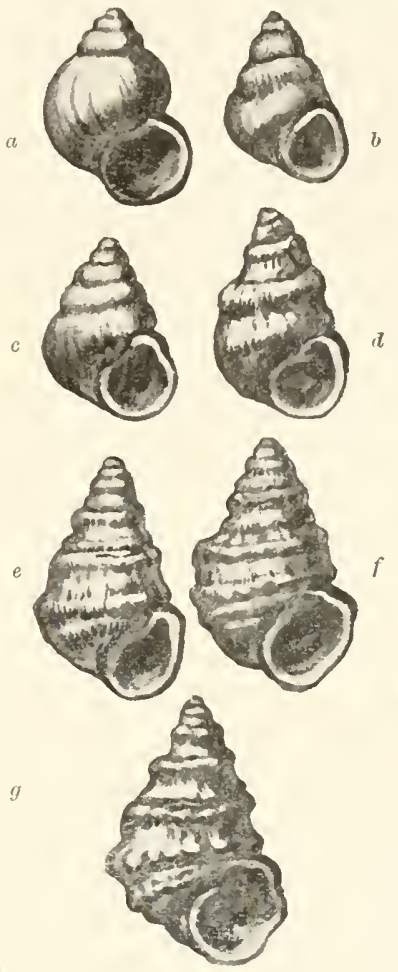

Fig. 83.

Entwicklungsreihe von Vivipara. Nach Neumayr.

$a$ V. Neumayri, $b$ r. Suessi, $c$ V. bifarcinata, $d V$. stricturata, $e \Gamma$. notha, $f \mathrm{~V}$. ornata, $g \mathrm{~V}$. Hoernesi. haben kürzlich andere Umbildungsreihen fiir die Gattung Melanopsis beschrieben. Aus längsgerippten Schalen bilden sich gekielte Formen, indem jeder obere und untere Rand der Längsrippe sich knotenartig verdickt und die benachbarten Knoten allmählich mit einander verschmelzen. So entsteht am oberen und unteren Rande jeder Schalenwindung ein Kiel, während die Längswïlste verschwinden.

Ich will aber auf diese Beispicle nicht näher eingehen, weil dieselben bisher nicht kritisch nachkontrolliert wurden. Neumayr's

1) Kiele sind spiralig an der Schale hinziehende Wülste. 
Ansicht wurde nur von seinem Schüler Penecke bestätigt, Blankenhorn und Oppenheim folgen gleichfalls der Neumayr'schen Denkrichtung.

Eine lebhaftere Diskussion aber hat sich um die Deutung der Schalen von Planorbis multiformis Hilgd. in den obermiocänen Süßwasserkalkschichten des Klosterberges von Steinheim bei Heidenheim an der Brenz ${ }^{1}$ ) entsponnen. Dieselben haber seit langer Zeit das Interesse der Geologen erweckt und sind, weil die Fundstätte so gïnstig liegt, vielfach durchforscht worden. Infolge dessen können wir diese Thatsachen als viel gepriiftes Material der Betrachtung zu Grunde legen.

Man kennt etwa 150 lebende, in der nördlichen gemäßigten Zone verbreitete Arten der Gattung Planorbis. Die größte derselben, die große Tellerschnecke, Planorbis corneus (Pfeiff.) lässt den Charakter der Schalenbildung bequem erkennen. Ihr Gehäuse ist in der Ebene spiralig eingerollt, also scheibenförmig mit vielen regelmäfig wachsenden, $d$. h. von der Spitze gegen die Mündung sich erweiternden Windungen. Hilgendorf hat nun in Steinheim Schalen gefunden, welche teilweise der Tellerschnecke recht ähnlich, d. h. scheibenförmig sind, teilweise eine hohe kegelförnige Gestalt besitzen und außerdem eine große Menge von Schalen mit gemischten Formcharakteren. Manche sind ganz flach, scheibenförmig und zeigen rundliche oder nur mit stumpfer Kante versehene Umgänge; andere sind scheibenförmig, aber die Umgänge tragen deutliche Kiele; eine dritte Gruppe ron Schalen neigt zu kegelförmiger Windung; eine vierte Gruppe hat die Schalenumgänge ïberhaupt nicht mehr in der Ebene liegend, sondern frei korkzieherartig in die Höhe geschoben. Der wissenschaftliche Name Planorbis multiformis Hilgd. dient also zur Bezeichnung einer ziemlich großen Mannigfaltigkeit von Schneckenschalen und bezieht sich nicht auf einen ganz bestimmten Formzustand wie etwa Planorbis corneus. Hilgendorf unterscheidet 19 Varietäten: denudatus, costatus, oxystomus, revertens, supremus, Steinheimensis, Kraussii, aequeumbilicatus, parvus, minutus, crescens, triquetrus, tenuis, pseudotenuis, discoideus, sulcatus, rotundatus, trochiformis, elegans.

Die sämtlichen Formen sind, wie Hilgendorf angiebt, in einer oberen Schicht durch einander gemengt, aber in tieferen unaufgewühlten Schichten liegen die verschiedenen Varietäten nach bestimmten Regeln verteilt und verlaufen nur in gewissen Horizonten durch Übergänge in einander. Die Mächtigkeit der beobachteten

${ }^{1}$ F. Hilgendorf, Planorbis multiformis im Steinheimer Süßwasserkalk. Ein Beispiel von GestaItveränderung im Laufe der Zeit. Monatsber. Akad. d. Wiss. Berlin 1866 p. 474. 
Schichten würde sich auf etwa 13 Meter belaufen, wenn sie an der nämlichen Stelle sämtlich entwickelt wären. In der gesamten Schichtenfolge verteilen sich die Varietäten in der Weise, dass einzelne Schichten als Schichtenfolgen durch das ausschlieBliche Vorkommen oder durch das Vorherrschen einzelner oder mehrerer Varietäten charakterisiert werden, welche sich innerhalb der Schichten konstant oder wenig variierend verhalten, zur Grenze gegen die folgende Schicht hin aber durch Übergänge zu den nachfolgenden Formen hinüberführen.

In der unteren Schicht sind von den 19 Tarietäten nur zwei vorhanden: Planorbis parvus und Steinheimensis, deren scheibenförmige Schalen rundliche Umgänge zeigen; nach und nach treten die anderen höher gewundenen und turmähnlicheren Formen auf und rergehen wieder, nur supremus behauptet zuletzt noch das Feld. In den dazwischen liegenden Schichten ist der Formenreichtum oft viel bedeutender, er geht bis zu sechs Varietäten in derselben Schicht.

Dieses Verhalten gestattete die ganze Ablagerung in zehn Zonen zu teilen und die Entwickelung der Varietäten des Planorbis multiformis dieser Zonen in Form eines Stammbaumes ${ }^{1}$ ) darzustellen:

crescens supremus

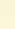

\section{crescens}

8 denudatus ।

costatus crescens

7

costatus minutus

6

costatus minutus

costatus minutus triquetrus

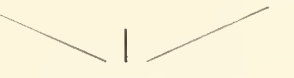

minutus

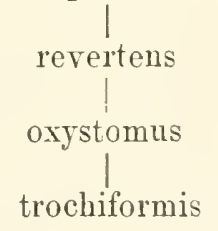

elegans pseudotenuis rotundatus | trochiformis is pseudotenuis

discoideus

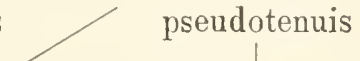
pseudotenuis

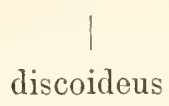

$$
\text { aequeumbilicatus }
$$

Steinheimensis

1) Hilgendorf 1. c. S. 476 . 
So übersichtlich der nebenstehende Stammbaum auch erscheinen mag, vor lebhaftem Widerspruche ist er nicht bewahrt geblieben. A. Hyatt1), der das gleiche Material in Steinheim studiert liat. weicht in mehreren Punkton von Hilgendorf ab. Trotzdom beide

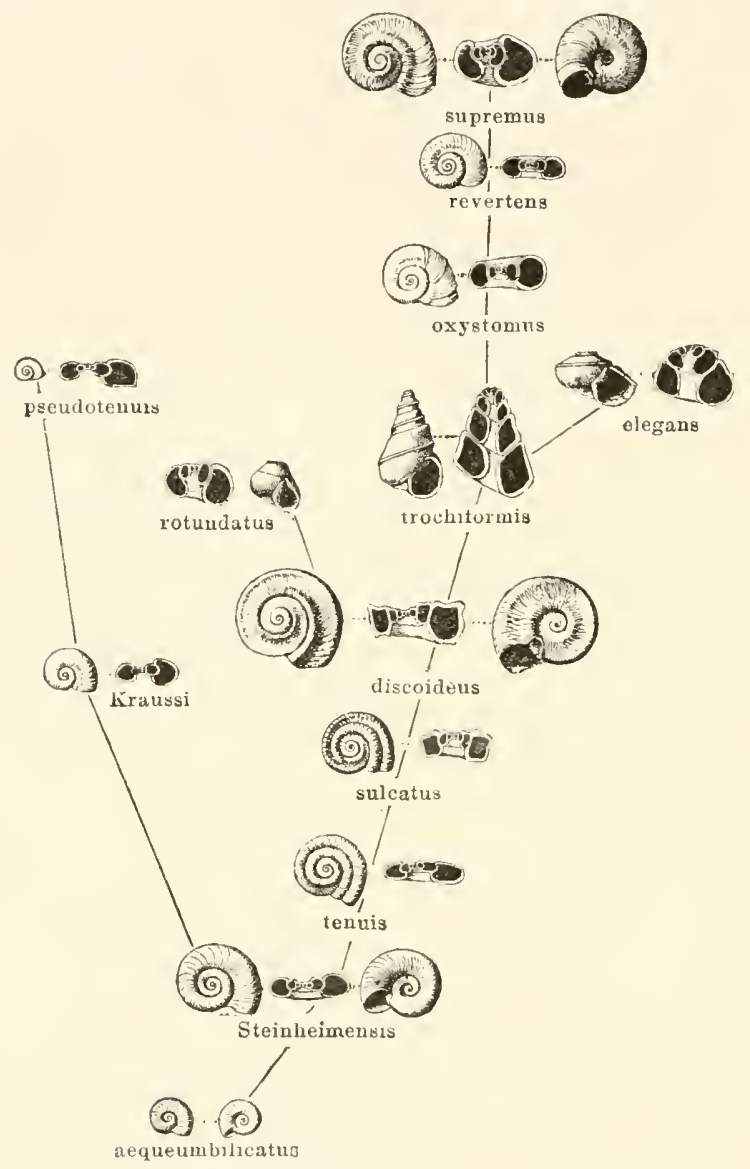

Fig. 84.

Stammba um der Planorbis multiformis. Nach Hilgendorf. Aus Zittel's Palaeozoologie.)

Anhänger der Descondenztheorie sind und darin übereinstimmen, dass sich alle Planorbisindividuen durch Umbildung einfachor Urformen entwickelt haben, denkt sich Hyatt einen ganz anderen Verlauf der Stammesgeschichte, den folgende Tabelle erläutert.

1) A. Hyatt, the genesis of the tertiary species of Planorbis at Steinheim. Anivers. Mem. Boston Society of nat. hist. 1880. 

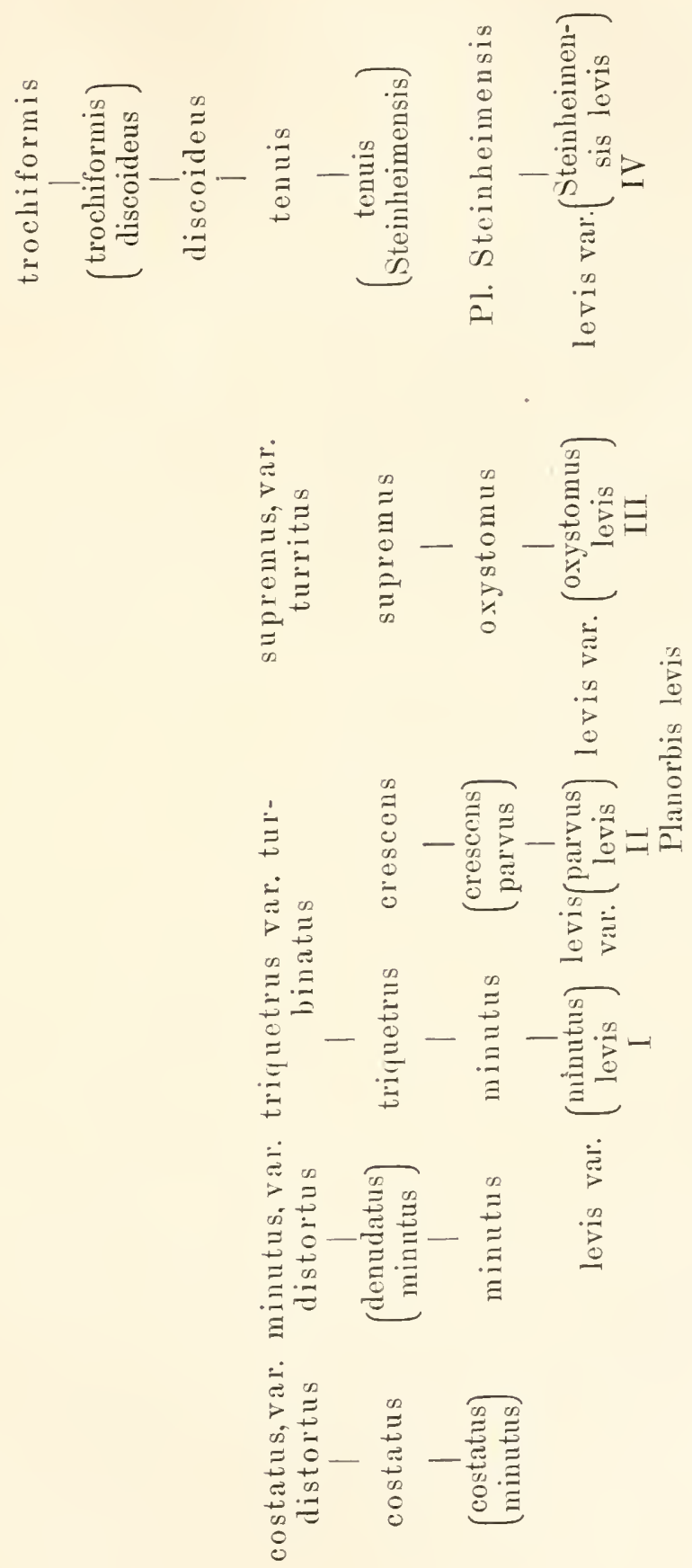
Hyatt sieht alle Formen als direkte Abkömmlinge von vier Varietäten einer Stammart, Planorbis levis an, welche vier Abarten bildete, beror sie in den See von Steinlieim einwanderte. Dieselben erzeugten dort erst vier parallele Entwickelungsreihen, deren letzte Ausläufer cinander ganz unähnlich wurden. Die Abweichungen der beiden Stammbaumentwürfe werden dadurch begreiflicher, dass Hilgendorf sellst mehrfach von der Sehwierigkeit spricht, die Formenreihe Planorbis parvus - minutus - crescens - costatus mit den beiden anderen Hauptästen zu verknïpfen. Er vermutet, sie geschehe vielleicht durch aequeumbilicatus.

Andere Forscher, Queenstedt, weil. Professor der Geologie in Tübingen und Fr. Sandberger, weil. Professor der Mineralogie und Geologie in Würzburg haben die gleichen Fundstätten zum Teil sehon vor Hilgendorf besucht und behaupten, dass Hilgendorfs Angaben über die reinliche Scheidung der einzelnen Planorbisformen in verschiedenen Schichten sich an den natïrlichen Aufschliissen der Steinlieimer San!gruben nicht so scharf erkennen lasse, wie sie in Worten präzisiert worden sei. Auch Hyatt stimmt ihrer Ansicht bei. Queenstedt nimmt sogar an, die Besitzer der Planorbisschalen hätten überhaupt nicht im hypothetischen Steinheimer See gelebt, die Schalen seien vielmehr in jene Gegend später zusammengeschwemint worden; so sei uns durch einen günstigen Zufall ein Komposthaufen fossiler Schneckenreste dort erhalten worden.

Die drei Forscher erheben also mehr oder wenig deutlich den Vorwurf gegen Hilgendorf, er habe cler Theorie zuliebe manche Thatsachen der geologischen Anordnung nicht so scharf hervorgehoben, als es eine naturwissenschaftliche Untersuchung erheische. Ihr. Widerspruch richtet sich auch gegen die schwer verständliche Angabe Hilgendort's über die im Laufe der Stammesentwickelung geschehene Rückkehr zur alten Schalenform, welche in der Reihe von Planorbis discoideus durch trochiformis, oxystomus zu revertens und supremus erfolgt sei. Da der sechsten, die kegelförmigen Planorbis trochiformis-Schalen bergenden Schicht die Oxystomus-Zone überlagert ist, sah sich Hilgendorf zu dem Schlusse gezwungen, dass die Trochiformis-Schnecken Nachkommen erzeugt hätten, welche unter Niederdrückung der Schalenspirale und Abrundung der Umgänge allmählich zu dem frïheren Schalentypus des Planorbis Steinbeimensis zurüekgekehrt seien und bezeichnet darum die auf oxystomus folgenden Schalen als revertens. Die Darstellung seiner Ausicht ${ }^{1}$ ), die im $W$ ortlaute zu studieren ist, zeigt zudem, wie schwer ihm der Nachweis dafür geworden ist und erscheint mir nicht

1) 1. c. p. $495-497$. 
zwingende Beweiskraft zu besitzen. Queensted t dagegen behauptet, er könne sich nicht davon ïberzeugen, dass die flachgewundenen Schalen der Hilgendorfschen Tarietät revertens der oberen Schichten eine wesentlich andere Gestalt besitzen als die Flachschalen ron Plauorbis Steinheimensis in den tiefsten Schichten. Jedenfalls sind die geologischen Lagerungsverhältnisse der Flachschalen nicht eindeutig, weil auch $\mathrm{H}_{y}$ att der Meinung Hilgendorf's nicht beipflichtet.

Queenstedt giebt ferner an, die mittlere Zone könne als Hauptmuschellager bezeichnet werden, denn man findet dort fiast alle ron Hilgendorf beschriebenen Formen bunt durch einander gewürfelt, wie es die beistehende Figur 85 zeigt. Diese Thatsache wird von Hilgendorf nicht direkt geleugnet, verschiedene Stellen seiner Arbeiten betreffen derartige Befunde, d. h. Schichten, wo die einzeluen von ihm unterschiedenen und in eine phylogenetische Reihe geordneten Varietäten wirr durch einander geworfen sind, so dass der

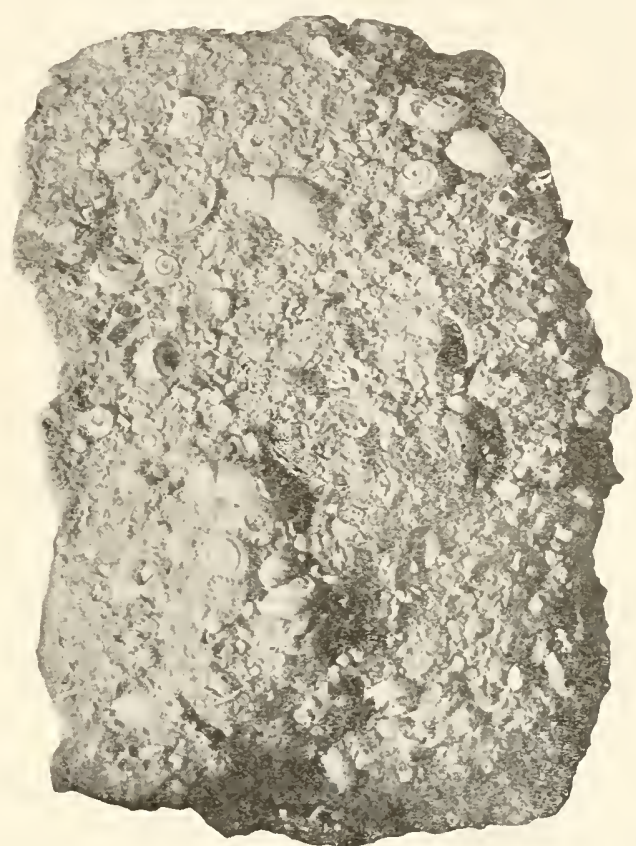

Fig. 85.

Gesteinsprobe aus den Kalkbänken von Stein. heim, enthaltend Schalen ron Carinifex multiformis, Lymnaeus socialis, Gyllia utricnlosa.

Beobachter fürchtet: ...alles müsse sich in endlose Verwirrung auflösen.“

An manchen Stellen der Gruben lüsst sich der Entwickelungsmodus nicht regelrecht entziffern, die klare Schichtung macht einem unerquicklichen Chaos Platz. Oft verhindert Grundwasser das saubere Abputzen und Studieren der Flächen, an anderen Stellen drängt Jurakalk oder Thon hervor, ohne dass man eine Planorbisschale bemerkt. Dann mïssen andere Gruben ergänzend eintreten, und der deutlichere Befund derselben die Liicken der anderen ergänzen. Sandberger ${ }^{1}$ ) betont gleichfalls, alle Formen bleiben

1) Fr. Sandberger, Die Land- und Süßwasserkonchylien der Vorwelt. Wiesbaden, C. W. Kreidel $1870-1875$. S. $630-648$. 
nicht auf die von Hilgendorf angegebenen Niveaus beschränkt, sondern finden sich, wenn auch zum Teil nur vereinzelt, in höheren oder tieferen Zonen wieder.

Diese kurze Skizze der Diskussion zeigt Ihnen den Widerspruch der Fachgelehrten und lehrt zugleich, dass die natürlichen Befunde nicht so eindentig und durchsichtig sind, wie der Laie nach einem schriftlichen Berichte anzunehmen geneigt ist. Zum Belege schiebe ich den summarischen Bericht eines hervorragenden Zoologen, des Professors A. Weismann in Freiburgein, gegeben kurz nach dem Erscheinen der Hilgendorf'schen Abhandlung ${ }^{1}$ ):

„Was Übergangsformen zwisehen vorwandten Spezies betrifft, so wird es Palaeontologen, denen ein sehr reiches Material zu Gebote steht, gewiss nicht schwer sein, solche in Menge aufzufinden. Eine speziell auf diesen Punkt gerichtete Arbeit ist neuerdings bekannt geworden. Sie bezieht sich auf eine im Steinheimer Süßwasserkalk zu Millionen vorkommende Schnecke der Gattung Planorbis. Hilgendorf unterscheidet von derselben 19 Varietäten, welche so wesentlich ron einander verschieden sind, dass man sie für Arten halten würde, hätte man sie einzeln vor sich, ohne die verbindenden Übergänge. Nun findet sich jede Varietït nur in einer ganz bestimmten Zone der Ablagerung und zwar liegen sie nach ihrer Verwandtschaft geordnet ïber einander, und die Hauptformen sind durch Übergänge verknüpft, die wiederum nur in den Grenzschichten der Zonen vorkommen.

Wir haben also hier die Entwicklungsgeschichte einer Art vor uns, die Umwandlung, die sie im Laufe vieler Jahrhunderte durchgemacht hat." ${ }^{2}$ )

Durch meinen Bericht ïber die Meinungsdifferenzen der Fachgelehrten haben Sie bereits erfahren, dass Weismann die Schichtenordnung der Planorbisschalen etwas ïberschätzt. Gerade in der

1) A. Weismann, Über die Berechtigung der Darwin'schen Theorie. Akademischer Vortrag, gehalten am 8. Juni 1868 in der Aula der Universität Freiburg. Leipzig, W. Engelmann 1868. p. 16.

2) In dem angezozenem Vortrage wurde der kurze Bericht über Hilgendorfs Untersuchungen benutzt, um darzulegen, daß Übergangsformen zwischen Arten vorhanden sind. Weismann sagte kurz vorher (p. 16 oben):"

„Obgleich offenbar nur ein kleiner Bruehteil der untergegangenen Tierwelt in fossilem Zustande sich erhalten konnte, und obgleich wiederum von diesem Bruchteil nur eir ganz kleiner Teil der Beobachtung offen steht, da man erst einen kleinen Teil des Festlandes und noch gar nichts vom Meeresgrund auf fossile Reste untersucht bat, so ist es dennoch jetzt bereits möglich, Übergangsformen in beiderlei Sinn nachzuweisen, und die Behauptung, daß dieselben fehlen, muß aufgegeben werden." 
Unklarheit der natürlichen Befunde ist die Schwierigkeit des ganzen Problemes begrïndet. Wenn Sie (Fig. 85) ein Probestück anschauen und die rerschicdenartigsten Schalenformen dicht neben einander sehen, so ist es unmöglich auszusagen, ob zwei dicht benachbarte, vielleicht einen halben Centimeter entfernte Flachschalen Eltern, Geschwister oder Vettern seien. Wer kann mit Bestimmtheit angeben, die beiden gleichschaligen Tiere hätten gleichzeitig gelebt? Wenn sich nun die Unterschiede benachbarter Formen steigern, d. h. wenn flach- und hochgewundene Schalen dicht beisammen liegen, wird es noch schwieriger, das genetische Verhältnis derselben zu erhellen. Die wissenschaftliche Pfljeht des Naturforschers würde vergessen, wollte einer behaupten, dass sie in blutsverwandtschaftlichem Verhältnisse stehen.

Es geht in diesem Falle, wie wenn wir uns kurz nach einer Utherschwemmung in das trocken gewordene Inundationsgebiet eines Flusses begeben und da und dort Haufen leerer Gehäuse von Wasserschnecken finden. Niemand wird es einfallen, mit Bestimmtheit zu behaupten, dass die Besitzer der zufällig angetroffenen Schalen in nächster Nähe der Fundstätte ihr Leben hinbrachten, und dass sie die Glieder einer eng verwandten Familie seien, weil wir alle aus Erfahrung wissen, in welch' kurioser Weise die Wasserfluten irgend welche Gegenstände an einer Stelle zufällig zusammenspülen.

In den Schichten der Gesteinskruste unseres Planeten findet der Palaeontologe die Reste der ausgestorbenen Arten, Skelettteile oder Schalen, wirr zerstreut und ist in noch schlimmerer Lage als der Untersuchungsrichter, welcher eine Leiche im unbewohnten Berglande findet und die Personalien, Heimat und Verwandtschaft des Ermordeten feststellen soll. Er ist nicht im stande zu sagen, ob das Tier, dessen leeres Gehäuse im Sande auffällt, an der betreffenden geologischen Fundstätte gelebt hat, ob sie durch Zufall, seien es nun Regengiisse oder Flussüberschwemmungen, an den Platz verschleppt wurde, oder ob sie bei der Eintrocknung eines Wasserbeckens nahe dem ursprünglichen Uferrande liegen blieb, wo sie nach Tausenden von Jahren der Mensch auflas. Aber da wir alle die Frage stellen und Antwort heischen, wird sie gegeben, wenngleich in limitierter Fassung und erscheint dann manchen als sicherer Entscheid.

Es ist wohl begreiflich, dass jeder nach dem etwas trockenen, rergleichenden Studium fossiler Stücke gewissermaßen zur Erholung sich Gedanken über die Lebensgeschichte der versteinerten Tierreste bildet. Er wird darüber eine gewisse Vermutung, seine subjektive Meinung aussprechen, über die sich reden lässt. Wenn je- 
dach solehe Termutungen gedruckt und von anderen mit der Arbeitsmethode der geologischen Wissenschaft weniger vertrauten Leuten gelesen werden, dam verwandelt sich nur allzu leicht die vermutungsweise ausgedrückte Ansicht in eine sicher stehende wissenschaftliche Lehre und wird rom Laien falsch bewertet.

Auch in unserem Ealle muss der Naturforscher das exakte Gebiet verlassen, wenn er Bildungsvorgänge der Planorbisschalen schildern will. An der Fundstelle sammelt er ans möglichst vielen Schichten, welche nach dem iibereinstimmenden Urteile aller Untersucher im Gelände' nicht so scharf geschieden sind, wie die kurze Beschreibung uns vermuten lässt, ein möglichst reiches, paläontologisches Material. Zu Hause werden die Schalen von der anhaftenden Erde gereinigt, isoliert, und der Inhalt jeder Lokalprobe möglichst genau sortiert, indem der Paläontologe die einzelnen Schalen genau vergleicht und nach ihrer Ähnlichkeit oder den Unterschieden zusammenlegt. So kommt man allmählich dazu, bestimmte Formentypen aus der natürlichen Mannigfaltigkeit hervorzuheben und sie auch durch die Nomenklatur zu kennzeichnen. Endlich gelingt es, das ganze Material in Reihen zu ordnen, welche die Umänderung einer Schalenform in eine andere, einer flachen in eine hoch gedrehte erläutern, etwa so, wie sich verschiedene Dreiecke derartig zusammenstellen lassen, dass ich an graphischen Figuren die Formverwandtschaft oder wie man lieber zu sagen pflegt, den Übergang eines stumpfwinkeligen Dreieckes in ein rechteckiges und spitzwinkeliges Dreieck zeigen kann.

Eine solche Reihe ist sicher keine stammesgeschichtliche Reihe, aber den Mangel der disekten Beobachtung des Geburtsvorganges und damit des unumstößlichen Beweises wirklicher Blutsverwandtschaft unter den Gliedern der Schalenformenreihe gleicht der Paläontologe durch ein "unbestrittenes Axiom" aus, welches Hilgendorf ${ }^{1}$ ) also formuliert:

"Formen, die mit anderen früher abgelagerten durch genügend fein abgestufte, in der Zwischenzeit erscheinende Übergangsexemplare in Zusammenhang gebracht werden können, dürfen als der früheren leibliche Nachkommen betrachtet werden."

Wenn auf diese Weise die Tielgestaltigkeit einer bestimmten Tierart einigermaßen iibersichtlich bearbeitet ist, zieht der Paläontologe die geologischen Beziehungen der Schalenvarietäten in Betracht. Er kehrt in das Gelände zurück, um zu prüfen, ob die theoretisch gewonnene Reihe trotz der bunt durch einander geworfenen Lagerung auch am Fundort sich wiederspiegelt und verfolgt die

1) F. Hilgendorf, Zur Streitfrage des Planorbis multiformis. Kosmos 1879. 
einzelnen Schalentypen ron unten nach oben durch die Schichtenreihe. Die abweichenden Behauptungen der Spezialforscher bezeugen, dass der Versuch in der Steinheimer Gegend und an anderen Lokalitäten nicht glatt geht, aber die Vorliebe für eine bestimmte Idee reranlasst riele, die hemmenden Thatsachen, obne es zu wissen und zu wollen, zu uibersehen. Wenn, wie Hilgendorf beklagend bemerkt, die klare Schichtung einem unerquicklichen Chaos Platz macht und lokale Verhältnisse das genaue Studium eines geologischen Aufschlusses rerbieten, hört die exakte Analyse auf. Der Wunsch wird der Tater des Gedankens. Wir sehen zu leicht das, was wir sehen wollen. und nicht das, was in der That rorhanden ist. Andere Untersucher (Hyatt, Queenstedt, Sandberger) fällen ein anderes subjektives Urteil, so entstehen Meinungsverschiedenheiten und paläontologische Stammbäume, die einander recht stark widersprechen. Sowohl iiber die Terbreitung der Schalenvarietäten in den einzelnen Schichten, als über die Formrerwandtschaft der isolierten Schalen entsteht der Streit, und der unlengbare Kontrast der Meinungen beweist, welche ungünstige Befunde die Paläontologen für die Untersuchung eines entwicklungsgeschichtlichen Torgangs rerwenden wollen.

Sobald man Hunderte und Tausende der Planorbisvarietäten in Formengruppen scheidet und diese wieder nach Formabstufungen in fortlaufende Reihen ordnet, wird der subjektive Entscheid des Gelehrten notwendig und damit die Wurzel alles Streites gegeben. Dem einen erscheinen manche Schalenvarietäten näher rerwandt als dem anderen. Er ordnet sie deshalb in eine sog. Entwickelungsreihe, welche sich mit dex einem anderen gefallenden Anordnung nicht deckt.

Indem Hilgendorf den Nachdruck auf die Verteilung der Schalenformen in rerschiedenen einander folgenden Zonen legte, ward er zu dem Glauben rerführt, dass eine hoch gewundene Form sich in eine flache, damenbrettartige Planorbisvarietït umgewandelt habe. Hyatt dagegen hat der Tergleichung der Schalenformen höheren Wert zuerkannt und die gemischte Lagerung rerschiedener Schneckenabarten als sekundäre Störungen betrachtet. Infolge dessen sind beider Stammbaumentwïrfe recht rerschieden ausgefallen. Hilgendorf glaubt 3 Hauptäste der Cmbildung erkannt zu haben, während Hyatt 4 Hauptreihen, ausgehend ron vier Tarietiiten der Planorbis levis, unterscheiclet und die Ruickbildung der hoch gewundenen trochiformis in supremus direkt ablehnt. Sie sehen also, dass verschiedene Forscher die „fein abgestuften Übergangsexemplare“ auf subjektir abweichende Art gedeutet haben, dass nicht die Thatsachen als solche uns zwingen, eine bestimmte Meinung zu hegen, 
sondern dass in der Ordnung fossiler Schneckenschalen lediglich das persönliche Ermessen des jeweiligen Untersuchers entscheidet. Ebenso steht es dem individuellen Urteile des Lesers der Abhandlungen frei, die eine oder andere Formenreihe vorzuziehen.

Dass die minutiöseste Analyse leerer Schneckenhäuser uns keinen Schritt dem hypothetischen stammesgeschichtlichen Vorgang näher führen wird, mag ein anderes Beispiel aus der vergleichenden Morphologie erläutern. Die Wirbelsäule der Säugetiere zeigt in ihren einzelnen Regionen (Hals-, Brust-, Lenden-, Becken-, Schwanzregion) recht beträchtliche Unterschiede iher reihenweise geordneten Elemente. Ohne eingehendes Studium möchte keiner ahnen, dass der

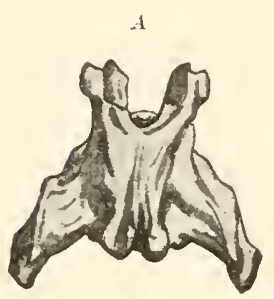

Fig. 86.

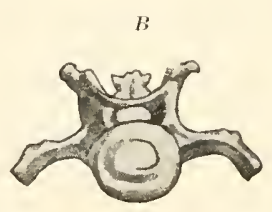

\begin{abstract}
然 $B$ Vorderseite.
\end{abstract}

Fig. 87. Zwölfter Schwanzwirbel des Leoparden. Nach Flower. A Rückenfläche. $B$ Vorderseite.

große Brustwirbel und irgend ein unscheinbares Knochenstiick der äußersten Schwanzspitze einem gemeinsamen Formtypus unterthan sind. Der Brustwirbel zeigt uiber einem großen eylindrischen Körper einen aufwärts geschlagenen oberen Bogen mit einem langen Dornfortsatze und zwei seitlichen, mehr oder weniger wagerecht stehenden Querfortsätzen. An einem der vorderen Schwanzwirbel (Fig. 86) fehlt der Dornfortsatz, während die (querfortsätze noch deutlich sind. Einer der letzten Schwanzwirbel stellt (Fig. 87) nichts als ein cylindrisches Knochenstäbchen dar. Wenu man aber sämtliche Glieder der zwischen beiden eingefügten Wirbelreihe vergleicht, so erkennt man die allmähliche Teränderung aller in der Brustregion mächtig entfalteten Formcharaktere und erhält das Verständnis für den alle Wirbel beherrschenden Stiltypus. In der Richtung von vorne nach hinten fortschreitend strecken sich die Wirbelkörper zu mehr und mehr cylindrisch erscheinender Gestalt, die oberen Bogen nehmen stufenweise an Größe ab und schwinden, die Querfortsätze schrumpfen bis auf kleine 
seitlich ragende Restchen ein. Schließlich schwinden auch die Reste aller Anhänge bis anf den cylindrisch gestreckten Körper des Wirbels.

Ich habe das Resultat der Wirbelvergleichung jetzt mit wenig Worten auf 6 Druckzeilen berichtet. Wollte ich die natürlichen Terhältnisse getren beschreiben, so wiirden viele Seiten gefiillt, und die stilistische Fassung derselben wïrde schrecklich eintönig, weil der Wortreichtum nuserer Sprache nicht hinreicht, die übereinstimmenden Eigenschaften ron 20- 40 Wirbeln mit verschiedenen Ausdrïcken zu schildern. Wir helfen mus gewöhnlich durch einen abkiirzenden Bericht und geben die einfache Formbeschleibung mittels Zeitwörtern der Bethätigung: die Wirbelkörper strecken sich, die Bogen nehmen an Größe ab, die ()nerfortsätze schrumpten zusammen. Der Fachgelehrte wird dadurch nicht irre gefiihrt, aber ein weniger tief eindringender Hörer köunte nach dem Wortlante vermuten. er lese die Beschreibung eines wirklichen Torganges, der unzweifelhaft ron Tertranen erweckenden Mïnnern der Wissenschaft beobachtet sei. Dieses Missverständnis spielt in alle Darstellungen der Descendenztheoretiker herein und lässt riele schlagende Beweise dort erblicken, wo keiner zu geben ist. Für die Wirbelsänle wird niemand behampten wollen, dass ein rorlerer Wirbel nach hinten gerutscht sei oder durch Fortptlanzung andere Wirbel gezengt babe, die nach hinten l'utschend durch die Eintlïsse der neuen ungewohnten Lage im Wirbeltierkörper ihre Eigenschaft allmählich rerändert hätten. Denn jeder kennt die straffe Terbindung aller Gliedstïcke der Wirbelsäule und wird nicht vermuten, dass es in graner Torzeit, damals als die Säugetiere entstanden sein sollen, in dieser Beziehung anders geresen sei. Nun könnte man dem Dilemma durch die Behauptung sich entziehen, dass die Torfahren der Säugetiere eine ans gleichartigen Wirbeln anfgebaute Wirbelsäule besessen hätten, deren Glieder durch den Einfluss der Lage in rorderen oder hinteren Regionen des Körpers allmählich verändert wurden. Damit gerät man aber in das Reich der Fabeln, denn eine so gleichartige Reihe der Wirbel, wie sie die Hypothese fordert. wird in der Natur schwerlich gefunden. Immer fallen Unterschiede der Glieder auf, gleichgiiltig, ob in höherem oder geringerem Grade. Wir vermögen also wohl den allgemeinen Bamplan innerhalb einer Reihe rerschiedenartiger Wirbel testzustellen. ohne dass das den Morphologen roll befriedigende Resultat uns dem historischen Torgange der stilistischen Modifikation näber führt. Wenn die Formähnlichkeit vieler Naturprodukte uns den Schluss nahe legt, dass die variierenden Formen durch mannigfache, anf ursprïnglich gleichartige Ausgangs- 
objekte wirkende Einflüsse entstanden seien, so darf derselbe in der Naturwissenschaft nur als Anregung für eine nene Untersuchung dienen, welche nicht eher rasten will, bis sie deu vermuteteu Prozess in all seinen Phasen durch Beobachtung wirklich wahrgenommen hat. Erfüllt sich die Hoffunng nicht, wie es in beiden hier besprochenen Fïllen geschieht, so bleilut der Schluss eine unbewiesene, wertlose Termutumg und kann nur dazu beitragen, unsere Unwissenheit in einer bestimmten Frage den Laien zu rerhiillen .

Die fossilen Molluskenschalen sprechen nicht dentlicher als die Stiicke der Wirbelsäule. Denn sie liegen als fertige Gebilde im Gestein und bieten uns bloß die Möglichkeit des Vergleiches. AnBerdem sind sie ein recht unginstiges Objekt für die Beweisversuche der Descendenztheoretiker. Die Formverwandtschaft der vielgestaltigen, Planorbis multiformis genannten Schueckenschalen lïsst sich nicht mit der wïnschenswerten Schärfe erweisen, weil die Gehäuse durchgehends sehr klein sind. Hyatt zeichnet sie bei 2, 4 und 8facher, Hilgendorf bei 3 facher, anf der dem Zittel'schen Handbuche entlehnten Figur 84 sind sie in anderthall)facher Vergrößerung abgebildet. Die flacheu Schalen haben einen Durchmesser ron 1-7 Millimeter, von den hoch gewundenen Tarietäten ist denudatus 2 Millimeter, trochiformis 8 Millimeter hoch. Die von Blankenhorn in Syrien gesammelten Schalen ron Melanopsis schwanken zwischen 7-30 Millimeter. Bei solch kleinschaligen Schnecken gerät der Morphologe in große Verlegenheit, scharfe Unterscheidungsmerkmale der Formgruppen aufzufinden und zwar nicht bloß bei fossilen Formen, sondern auch bei jetzt lebenden Familien z. B. Clansilia, deren Arten geringe Größe haben. Es mögen auf der ganzen Welt iiberhaupt nur einige Menschen im stande sein, Clausiliaarten vou einauder richtig zu unterscheiden. Das kann allein derjenige beuteilen, welcher sich selbst Stunden lang bemiiht hat, einen Haufen ron 100 irgendwo gesammelten liliputanischen Schneckenhäuschen aus einander zu klauben. Wie oft gerät man da in Zweifel: hat die Schale einen Kiel, der uns an der großen Schale so klar entgegenspringt. hat sie Höckerchen, Längsstreifen u. s. w.? Die gleiche Erfahrung bereitet die Praxis der mikroskopisch anatomischen Untersuchung. Je kleiner die Formen sind, um so schwieriger sind sie zu erkennen. Hat man sich freilich lange Zeit mit solchen Aufgaben beschäftigt, dann schärft sich das Auge und nimmt winzige Knickungen, Biegungen, Höckercheu etc. wahr, die ein anderer iibersehen müsste. So große Übung nun anch ein tüchtiger Molluskenkenner in der Formbeobachtung kleiner Kalkgehänse besitzen mag, die kleinen 
Schneckenschalen werden immer ein wenig giinstiges Objekt für die Beweistersuche zu gunsten der Abstanmungslehre bleiben, weil sie sich nicht scharf ron einander trennen lassen und weil unter den Spezialisten immer recht bedeutende Meinungsrerschiedenheiten bestehen. Bei den jetzt lebenden Formen lassen sich die Mängel der Formanalyse einigermaßen ausgleichen, weil wir in der gliicklichen Lage sind, die Gesamtanatomie, die Lebensweise und den Aufenthaltsort für die Diagnose anszunuitzen. Die Paläontologen dagegen sind dieser Unterstiitzung beraubt und auf die Analyse der versteinerten Formen angewiesen, mögen sie gut oder schlecht erhalten, mögen sie groß oder winzig klein sein.

Im letzteren Falle gelangen wir an die Grenzen unserer Beobachtungsgabe, aber statt den Mangel unserer Fïhigkeit offen einzugestehen, legen wir ihn der Natur bei und schreiben ihr eine umbegrenzte Umbildung zu, wo wir keine Schranken sehen, wo wir iı so und soviel Fällen nicht unterscheiden können, ob eine Schneckenschale der einen oder anderen Varietät zugerechnet werden miisse. In der Situation unangenehmer Ratlosigkeit schließen wir gewöhnlich einen Konpromiss und stellen nach bestem Gutdünken die Schalen zu der einen oder anderen Varietät. Wegen dieser Unsicherheit unseres Unterscheidungsvermögens herrscht in der Systematik noch lebhafter Streit und Widerspruch, und es giebt heute kein einwandfreies System der Schnecken überhaupt.

Ganz besonders schwierig ist das Einverständnis über die Ïbergangsformen zu erreichen. Was Hilgendorf als solche betrachtet, wird von anderen Forschern einer anderen Varietät zugerechnet. Wenn der Entscheid im engen Specialgebiet der Steinheimer Schnecken schon widersprechend ausfïllt, so ist er durchaus unmöglich, sobald man die Schneckenreste von längeren geologischen Perioden in dieser Hinsicht rerwerten will. M. Blankenhorn,1) welcher fest von der phylogenctischen Transformation der Mollusken ïberzeugt ist, drückt die Sachlage ganz richtig ans:

„Es giebt nirgends auf der Welt derartig vollständige, sich an einander reihende Aufschlïsse, die dazu nötig wären, um iiber die Fortentwickelung ron Süßwasserconchylien von der Tertiärzeit bis zur heutigen Form des betreffenden Landes ganz unanfechtbare Schliisse zuzulassen."

Für die Gattung Paludina erwachsen weitere Schwierigkeiten, weil ähnliche Entwickelungsreihen, wie sie Neumayr in Slavonien sammelte, von White in den Laramie-Schichten Amerikas beschrieben werden mit der gleichen Neigung, die Schale durch Kiel- und

1) M. Blankenhorn, Zur Kenntnis der Süßwasserablagerungen und Mollusken Syriens. Palaeontographica 44. Bd. p. 93. 
Knotenbildung zu verzieren. Infolge dessen driickt Oppenheim vorsichtig die Meinung aus, die im gleichen Sinue ab)indernden Paludinavarietäten können an verschiedenen Stellen der Erdoberfläche zu verschiedenen Zeiten von ganz verschiedenen Vorfahren polyphyletisch entstanden sein. Der in verschiedenen Ländern beobachteten allgemeinen Variationstendenz der Schneckenschalen muss, wie Oppenheim und Blankenhor'n denken, eine gemeinsame Ursache zu Grunde liegen. Aber sie genauer zu ergründen, ist bisher niemandem gelungen.

Wenn das richtig ist, so weil ich nicht, in welcher Weise die Stammesgeschichte für Tierarten geführt werden soll, die ursprïnglich an geographisch entfernten Stellen von wahrscheinlich etwas abwcichend geformten Ahnen entstanden sind und trotzdem übereinstimmende Gestalt im Kampfe ums Dasein erworben haben. Dann muss der stammesgeschichtlichen Bearbeitung jeder Art erst eine kritische Untersuchung vorangehen, ob die darunter zusammengefassten Individuen auch genetisch zusammengehören, was wir jetzt wegen der gemeinsamen Formcharaktere gewöhnlich annehmen.

Soll ich num meine Ansicht kundgeben, so will es mir bedünken, als handle es sich im Grunde nur um eine Frage der Nomenklatur. Der vergleichende Morpholog wird vor die Entscheidung gestellt, ob er Schalenreste, welche an einer Örtlichkeit, z. B. in Steinheim gemeinsam bei einander liegen, durchwegs als Planorbis multiformis bezeichnen soll, also ob er den verschiedenen auf der Figur 84 abgebildeten Formen einen gemeinsamen Namen geben und die zweifellos bestehenden Differenzen durch Beifïgung eines zweiten Wortes z. B. Planorbis multiformis - var. trochiformis ausdrücken soll, oder ob er die Unterschiede direkt durch anders lautende Worte hervorzuheben hat.

Die älteren Forscher Sandberger und Queenstedt haben das letatere gethan und die Schalenreste von Steinheim teils Paludina, teils Valvata, teils Carinifex genannt. Hilgendorf dagegen und Hyatt gaben all den so verschieden geformten Resten den Sammel-Namen Planorbis multiformis bezw. Planorbis levis.

Die durch einen Namen zusammengefassten Schalen sind außerordentlich vielgestaltig. Gemeinsam ist allen nur das runde, glatte, in einer Ebene aufgerollte Embryonalende und die schiefe, immer vollständige Mündung. Alle ïbrigen Eigenschaften (Zahl, Durchschnittsfigur und Dickenzunahme der Windungen, der Modus des Aufwindens und die aus diesen Faktoren zusammen sich ergebende Allgemeingestalt der Schale, Wandstärke, Skulptur, Bildung des Mundsanmes, Grösse) sind den bedeutendsten Schwankungen unterworfen und waren die Veranlassung, dass innerhalb der allgemeinen 
Bezeichungsgruppe wiederum 19 Form-Varietiten, in moderner Ausdrucksweise 19 stammesgeschichtliche Durchgangsstadien abgegrenzt wurden.

Durch einen solchen Modus der Nomenklatur wird aber vielen, den Thatsachen ferner stehenden Lesern nahe gelegt, die unter dem einfachen Namen Planorbis multiformis bezw. levis beschriebene Formenmannigfaltigkeit als Einheit aufzufassen und auf dieses Missverständnis weitere logische Operationen zu gründen.

Man kann ja darüber streiten, ob es im speziellen Falle rationell sei, flachen und hochgewundenen Schneckenschalen den gleichen Namen zu verleihen. Darüber jedoch wird ohne Zweifel keine Meinungsrerschiedenheit bestehen, dass der gleiche Name viele Leute die Schalen als weniger verschieden betrachten lässt, so wie friiher einmal der falsch gewählte Name: "Walfisch" tiichtige Männer vicler Generationen bestimmte, die im Wasser lebenden Süugetiere ohne weiteres für Fische zu halten und die in der äußeren Erscheinung beider Gruppen allein hervortretenden trennenden Merkmale gänzlich zu ignorieren. Die Geschichte aller beschreibenden Naturwissenschaften bietet dafiir zahlreiche Beispiele.

In der Gegenwart, wo das Denken sich langsam von dem unbedingten Einflusse der Abstammungsidee emancipiert, wird die Unterscheidung der abweichend geformten Schalen einer bestimmten Fundstätte durch anders klingende Namen wieder für nötig erachtet. Nach K. Miller ${ }^{1}$ ) enthalten die Stammbäume ron Hilgendorf und Hyatt die Vertreter nicht einer Art, sondern zweier verschiedener Gattungen Carinifex und Planorbis und dreier Untergattungen Grraulus, Dilatata, und Armiger, und Miller hat ebenso wenig wie Sandberger Übergänge zwischen diesen Gattungen gefunden. Miller bestreitet also Hilgendorf und Hyatt die Berechtigung, die meisten der bei Steinheim vorkommenden Schneckenschalen Varietäten von Planorbis zu nennen, weil die Verschiedenheit der Formengruppen zu groß sei und Übergänge zwischen ihnen nicht beobachtet werden. Folgende Tabelle giebt die Übersicht der Meinungsdifferenz der beiden Autoren.

Hilgendorf"s Varietïten

ron Planorbis multiformis

discoideus

sulcatus

trochiformis

elegans

rotundatus gehören nach Millers Meinung zu dem systematischen Begriffe:

1) Konr. Miller, Schneckenfauna des Steinheimer Obermiocäns. Jahresh. des Vereins f. vaterl. Naturkunde in Württemberg. 56. Jahrg. Stuttgart 1900. 
Hilgendorf's Tarietäten von Planorlis multiformis tenuis pseudotenuis

oxystomus

supremus

Steinheimensis

revertens

aerueumbilicatus crescens

triquetrus

minutus

denudatus

costatus

levis (Hyatt) gehören nach Millers Meinung zu dem systematischen Begriffe:

Carinifex tenuis

Carinifex oxystoma

Planorbis (Gyraulus) Steinheimensis Hilgd.

Planorbis (Gyraulus) Zietenii A. Br.

Planorbis (Armiger) costatus Klein.

Planorbis (Dilatata) Kraussii Miller.

Miller's neuer Vorschlag, welcher zugleich meine oben gemachten Bemerkungen iiber die subjektive Fürbung der Formengruppen von Planorbis bestätigt, ändert naturgemäß das Urteil jedes Nannes über die phylogenetische Bedeutung der Steinheimer Funde, denn sobald Sic hören, in Steinhein scien massenhaft Schalen von Carinifex, Gyraulus, Dilatata und Armiger gefunden worden und sich ferner crinnern (Fig. 85) wie kunterbunt die Schalen liegen, denken Sie gar nicht mehr daran, dlass dieselben durch Lmbildung aus einander entstanden sind, weil der Klang der Namen die Verschiedenheit der Schalen andeutet. Miller ${ }^{1}$ ) selbst resumiert:

„Die große Variabilität der Steinheimer Schnecken bleibt unbestritten und ist hochinteressant, aber der fragliche Stammbaum ist stratigraphisch nicht erweisbar, zoologisch und paläontologisch nicht annehmbar, da er nicht nur Arten und Unterarten, sondern zwei verschiedene Gattungen, deren eine in drei Untergattungen zerfüllt, in einander iibergehen lässt. (Dazu die Anmerkung: Wenn auch der Gattungsname des Carinifex oft wechselte (Paludina, Valvata, Poecilospira), so waren doch alle Autoren darin einig, dass multiformis nicht zu Planorbis gestellt werden dürfe. Hilgendorf und Hyatt mussten. um ihre Angaben annehmbar erscheinen zu lassen, vor allem diesen Gattungsnamen streichen und den Sammelnamen Planorbis einführen.) Und die Herausbildung dieser zwei Gattungen (Carinifex und Planorbis) und drei Untergattungen (Gyraulus,

1) 1. c., S. 388 . 
Dilatata und Armiger) soll in dem beschränkten Raume der Steinheimer Sandgrube und in der relativ kurzen Zcitspanne der Ablagerung dieser Schichten ror sich gegangen sein!

- Es ist deshalb nicht zu verwundern, wenn wir so wenig als Sandberger Übergänge zwischen diesen Gattungen und Untergattungen gefunden liaben; auch an den trefflichen Photographien des Hyattschen Werkes kann man sich von dem Nichtvorhandensein derselben leicht iiberzeugen, und es ist wohl kaum Zufall, weun in diesem Werke jeweils die entscheidenden Formen, welche den C̈bergang darstellen sollen, nur in der schmalen Seitenansicht und nicht in der Vollabbildung gegeben werden."

Wir wollen einmal von all diesen Bedenken ganz absehen und annehmen, die Folgerungen der Paläontologen seien wirklich richtig; die Entwickelung ron Planorbis, die Schmucksteigerung der Paludinen sei durch Neumayr, die Abänderung der Melanopsiden durch Oppenheim und Blankenhorn klar gelegt, so beweisen die wenigen Reihen toter Schneckenschalen doch nichts für die Abstammungslehre. Denn in den genannten Beispielen sind die Varietäten charakterisiert, teils durch das Auftreten ron Erhabenheiten auf der Schalenoberfläche, teils durch den verschiedenen Ausbildungsgrad einzelner Windungen, teils durch flache oder hoch aufstrebende Stellung der Gelıäusespirale, lauter Formerscheinungen, die wir bei vielen jetzt lebenden Mollusken wahmehmen. Sic brauchen nur eine gut geordnete Conchyliensammlung anzuschanen und besonders die Familie der das Meer bewohnenden Melaniiden ${ }^{1}$ ) zu verfolgen, dann sehen Sie hochgetürmte oder breite, niedergewundene Gehäuse, teils glatt, teils mit schmalen rippenartigen Erhöhungen, teils mit scharfen oder gekrönten Längskanten bedeckt und erfahren, dass der moderne Systematiker diese Besonderheiten beniitzt, um die Arten zu scheiden.

Infolge dessen muss sich der Zoologe, welchem die Formverschiedenheit der jetzt lebenden Arten wohl bekannt ist, von seinem Standpunkt sehr darüber wundern, dass man soviel Aufhebens davon macht, dass früher lebende Spezies die gleiche Erscheinung offenbaren. So weit ich urteilen kaun, lässt sich für die zahlreichen Arten oder Unterarten und Varietäten irgend einer recenten Schneckengattung kein direkter Beweis erbringen, dass die geographisch weit getrennten Formen durch Umbildung einer Stammform entstanden seien. Der Freund der Abstammungslehre rermag wohl sein sub-

1) M. von Linden, Unabhängige Entwicklungsgleichbeit bei Schneckengehäusen. Zeitschr. f, wissensch. Zoologie. Bd. 63. 
jektives Urteil in diesem Sinne abzugeben. In Wahrheit kann er bloss die Stiicke von verschiedenen Wohnorten vergleichen, die ähnlichen und abweichenden Formbesonderheiten beschreiben, aber keinen Schritt weiter gehen. Die morphologische Analyse fördert eben leider nur das Terständnis der fertigen oder der wachsenden Naturgebilde, Die geschichtliche Entstehung derselben wird durch sie nicht aufgehellt. weder während historischer Epochen noch während der geologischen Perioden, da ein naturhistorischer Prozess erlebt oder von einem verlässigen Augenzeugen uns berichtet werden muss, wenn er volle Glaubwürdigkeit besitzen soll.

Der hohe Grad der Variabilität kommt übrigens nicht nur den fossilen Arten, sondern auch den modernen Süßwasserschnecken, sowie den Schnecken des Brackwassers zu. Das bemerkt Op penheim ${ }^{1}$, und $\mathrm{O}$. B öttger ${ }^{2}$ ) betrachtet den Grund dieser auffallenden Variabilität als einen ganz allgemeinen, der sich wahrscheinlich über alle süßund Brackwasserbewohner aller Zeiten und aller Zonen erstrecken diirfte. Darum sind die Befunde bei Planorbis multiformis von Steinheim nichts Anßergewöhnliches und bereisen weniger die Blutsverwandtschaft der Schnecken, deren mannigfaltigen Schalen uns erhalten sind, als vielmehr die leichte Verïnderlichkeit der Schalenformen, d. h. mit anderen Worten: die Form des Gehäuses und die kleinen Skulpturbesonderheiten seiner Oberfläche sind nicht so pedantisch streng bestimmt, als wir es theoretisch anzunehmen pflegen. Sie brauchen nur hinauszugehen und hundert Stiick irgend einer gemeinen Schneckenart zu sammeln, so werden Sie das gleiche Resultat erhalten. Es besteht eben nicht die Regel, dass sämtliche gleichzeitig lebende Individuen oder die Individuen mehrerer Jahresgenerationen Schalen von absolut identischer Gestalt besitzen miissen. Viele Schwaukungen fallen bei näherer Betrachtung auf. Dieselben kömen verursacht sein durch verschiedene Wachstumsenergie der Einzeltiere, oder durch die Art und Masse der Nahrung oder durch klimatische Zustände, oder durch die Wärme und chemische Beschaffenheit des Wassers und durch viel andere Momente, deren ursächliche Verknüpfung wir heute noch nicht ahnen. Jedenfalls hindert die individuelle Variation den genetischen Nachweis eher, als dass sie ihn erleichtert.

Die Varibilität scheint häufiger zu sein bei den Tieren, welche ein änBeres Skelett besitzen, wie Schnecken, Muscheln, Krebse und Insekten. Allein das ist anch nur scheinbar, weil die Formbesonder-

1) Zeitschrift der deutschen geologischen Gesellschaft, 1891.

2) O. Böttger, Tertiärfauna von Pebas am oberen Marañon. Jahrbuch k. k. geolog. Reichsanstalt Wien 1878, 28. Bd. p. 485-504). 
heiten an der Oberfläche eines leicht zu erhaltenden Teiles des Tierkörpers liegen und deshalb mehr auffallen als bei inncren Skelettstücken. Die genane Untersuchung der letzteren bringt uns eine schier ebenso große Zahl der Formabweichungen zur Kenntnis.

Unn zum Schlıss zu gelangen, möchte ich Sie noch darauf hinweisen, dass die vergleichende Bearbeitung leerer Schneckenhäuser weder über die Organisation noch über die Entstehung der lebenden Tiere genügenden Aufschluss gewähren kann. Denn die Schalen sind eine Schutzhïlle des Weichkörpers, die als solche recht interessant und sehr wichtig für das Studium ist, aber sie ist eben nur ein Stïck und ersetzt uns nicht den Mangel aller übrigen Organe. Es ist also iiber die Schalenunter'suchungen genau das gleiche Urteil zu fällen, das ich frïher an anderen Beispielen, den Knochenteilen des Gliedmaßenskelettes und den von den Paläontologen mit so großer Vorliebe behandelten Zähnen, abgegeben habe: ein Stück des Körpers wird uns niemals den geschichtlichen Zusammenhang kleiner oder g rolier systematischer Gruppen beweisen. Ich stelle diese Behauptung nicht als meine Privatansicht auf und nicht, weil ich ein Gegner der Abstammungslehre bin: sie ist eine anatomische Erkenntuis, über die sich nicht streiten lässt. Niemand kann sich derselben entziehen. und E. Haeckel') spricht sie scharf genug aus:

.,Fossile Reste von Mollusken sind seit der kambrischen und silurischen Zeit durch alle Perioden der Erdgeschichte so massenhaft erhalten, in einer so großen Zahl von Arten und Individuen angehäuft, dass sie für die Geologie die größte Bedeutung besitzen. Viele Spezies (z. B. ron Cephalopoden) besitzen eine so ausgedehnte horizontale oder geographische Verbreitung und gleichzeitig cine so beschränkte rertikale oder geologische Verbreitung, dass sie höchst charakteristisch für einzelne Gebirgsschichten sind; sie werden daher in erster Linie zur Erkennung und Unterscheidung der ïber einander liegenden Formationen benutzt. So werden z. B. die einzelnen Horizonte der mesozoischen Sedimente vielfach durch besondere Ammonitenarten scharf bestimmt."

..Dieser anerkanuten und auBerordentlichen geologischen Wichtigkeit der versteinerten Weichtiere entspricht keines. wegs ihre phylogenetische Bedeutung. Es wiirde ein großer Irrtum sein, aus der ersteren auf die letztere zu schließen. Vielmehr ist die Paläontologie der Mollusken für die meisten allgemeinen Fragen ihrer Stammesgeschichte nur ron ganz untergeordnetem Wert; fïr diese sind vielmehr ver-

1) E. Haeckel, Systematische Phylogenie. II. Teil. Berlin 1896, S. 511. 
grcichende Anatomie und Ontogenie die Hauptquellen. Die wichtigsten Probleme der Molluskenphylogenie: der monopliyletische Ursprung und Ausbau des Stammes, die Entstehung und Terwandtschaft seiner Klassen und Ordnungen, die historisclie Differenzierung und Vervollkommnung ihrer Organisation etc. alle diese Hauptfragen werden nur durch die vergleichende Anatomie und Ontogenie der IVeichtiere aufgeklärt; ihre Paläontologie liefert dafiir gar keinen oder nur ganz geringfügige Beiträge. Dagegen ist die letztere von größtem Interesse für die spezielle Phylogenie vieler kleinerer Gruppen: Familien. Sektionen, Gattungen etc, auch die allmähliche Transmutation der Arten (z. B. bei den Ammoniten) lässt sich oft sehr schön durch die einzelnen Stufen hindurch verfolgen."

Auf S. 514 führt Haeckel fort, die Ursachen dieses Missrerhältnisses zwischen der geologischen und der phylogenetischen Bedentung der fossilen Molluskenmassen durch acht Thesen zu erklären. Fiir unsere Betrachtung wichtig hebe ich daraus nur These 5 und 6 hervor:

„5. Die allermeisten versteinerten Reste von Mollusken sind nur äußere Kalkschalen (Conchylien); uur selten und ausnahmsweise bleiben auch Abdriicke von Weichteilen oder von ganzen Tieren erhalten.

6. Die Kalkschalen der Mollusken sind zum größten Teile von sehr geringem morphologischen Werte und gestatten keinen sicheren Schluss auf die Organisation der Weichtiere, von denen sie ausgeschieden wurden. Schnecken von sehr verschiedenem Körperbau können ganz ähnliche oder kaum unterscheidbare Schalen bilden. Andererseits bilden oft nahe verwandte Schnecken ein sehr verschiedenes Kalkgehäuse, die einen bauen eine sehr entwickelte, die anderen eine rudimentäre, noch andere gar keine Schale. Dasselbe gilt teilweise auch von den Muscheln und den Kraken." 


\section{Elftes Kilpitel.}

\section{Das eigentliche phylogenetische Problem der Mollusken.}

Gewissermaßen als Gegengewicht gegen den kühnen Ikarusflug der menschlichen Phantasie auf dem wissenschattlich exakten Gebiete treten in unbestimmten Intervallen Männer auf deu Schauplatz des Lebens, welche ihre glünzenden Geistesgalou einer besouderen Idee weihen und deren Geltungsbereich auf viele Gebiete der Reflexion auszudehnen suchen. Dadurch werden sie gezwungen, die Konsequenzen des Gedankens nach allen Richtungen hin zu ziehen, seine Richtigkeit durch Erwägung der jeweils bekannten Thatsachen darzulegen, und die Berechtigung ihrer Meinung oder' das Gegenteil tritt offenkundig zutage. Dem Lebenswerke Haeckel's ist durch die Probe das traurige Los beschieden worden, dass der Mangel exakter Beweisgriunde sich nicht mehr verhiullen lässt. Alle bisher besprochenen Beispiele erläuterten den traurigen Zustand seiner Lehre. In der rorigen Stunde haben wir wiederum erkannt, dass die fossilen Schalen der Planorbis in Steinheim alles eher als die Blutsverwandtschaft ihrer einstigen Träger beweisen.

Noch ungünstiger gestaltet sich die Sache der Stammesgeschichte, wenn wir, des Grundsatzes bewusst bleibend, dass die Schale als ein Bruchstïck des Tieres nie volle Aufklärung über dessen historischen Werdegang giebt, den gesamten Bau des Weichkörpers berïcksichtigen. Denn so wenig, als der Aublick eines fremden Hauses uns den Charakter seiner Bewohner sicher erraten lässt, ersetzt das Studium leerer Schalen die zootomische Arbeit. Meinem Zwecke entsprechend werde ich nur die allgemein wichtigen Thatsachen hervorheben und das spezielle Detail zurückdrängen. Der Molluskentypus umfasst drei scharf geschiedene Unterkreise der Organisation, die Muscheln, Lamellibranchiata, die Schnecken, Gastropoda, die Tintenfische. Cephalopoda, deren wichtigste Merkmale durch die Figuren 88, 89, 90 erläutert werden.

Der Körper der M u scheln (Fig. 88) ist seitlich komprimiert und nach hinten mehr oder weniger lang ansgezogen. Die Seitenflächen des 
Körpers sind also breit, die ïbrigen, Vorder- und Hinter-, Riickenund Bauchflächen, schmale Streifen. An der schmalen Vorderseite liegt die Mundïffunng $(o)$, genau entgegengesetzt die Afteröffnung ( $($ ). Ohne weiteres kann man das Tier gar nicht wahrnehnen, weil dasselbe von den Mantellappen verdeckt ist, welche als zwei symmetrische, breite Falten an der rechten und linken Seite herabhängen und durch einen gebogenen freien Rand begrenzt werden. Da auf der gesamten Mantelfläche ein fest erhärtendes Sekret abgeschieden wird, liegen ihr die beiden Kappen der Muschelschalen auf. Wem ich die Schalen ablöse und den Hantel empor hebe, gewinne ich den Einblick in die weite. mit Wasser erfïllte Mantelhöhle

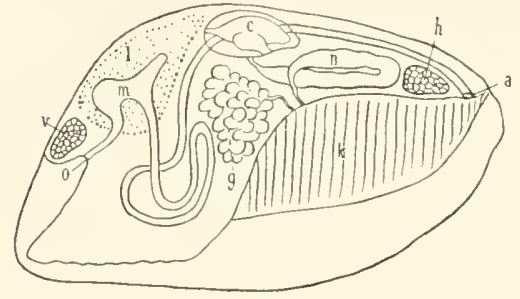

Fig. 88 .

Schematische Skizze der Organisation der Muscheln (die Schale ist eingezeichnet). $a$ After, $c$ Herz, $g$ Geschlechtskeimstätte, $h$ hintexer Schliebmuskel, $k$ Kieme, $l$ Leber, $m$ Magen, $n$ Niere, o Mund, $v$ vorderer Schliebmuskel. nnd sehe zunächst die Hälfte des Körpers, den sog. Eingeweidesack, zungenartig in die Höhle hereinragen. Die untere schmalkantige oder rundliche Randzone der Zunge wird ron starken Muskelmassen durchzogen und kann durch Blutschwellumg weit aus der Mantelhöhle als Kriechorgan, sog. FuB rorgestreckt werden. Oberhalb desselben wächst die Breitenausdehnung des Eingeweidesackes, um den Schlingen des Darmes und den Keimstätten $(g)$. d. h. Hoden oder Eierstöcken, Raum zu schaffen. Seitlich rom Eingeweidesack liängen in die Mantelhöhle je eine rechte und linke Doppelreihe von U-förmig geknickten Fäiden herab, welche durch Querbrïcken oft zu einer gitterförmigen $M$ Lembran. den Kiemenlamellen ( $\left.k_{i}\right)$, verwachsen sind. Von zahlreichen Bhnträumen durchzogen, nehmen sie aus dem fortdanernd in die Mantelhöhle eingefiihrten und wieder abgeleiteten Wasser Sanerstoff̈ auf und geben Kohlensäure ab. Die obere Hälfte des Körpers ist walzig gegen den After $(a)$ ausgezogen. Man kann also den Muschelleib ganz gut einer von den Mantellappen verhïllten, kurzstieligen Axt vergleichen. Oberhalb des Mundes am Torderende und unterhalb des Afters am Hinterende liegt je ein rundliches Büudel kurzer Muskelfasern, die sog. Schließmuskelı $(v, h)$, welche den Muskeluarben der Schalenklappen auhaften und dem Bediurfnisse des Tieres entsprechend deren gegenseitigen $\mathrm{Ab}$ stand regulieren. Der Darm wird hinter der Mundöffnung rasch zum Magen $(m)$ erweitert, zieht in mebrfachen Windungen durch den Eingeweidesack, steigt in die obere Stielhälfte empor und läuft, die am Rïcken liegende Herzkammer (c) meist durchquerend. ziemlich 
gerade gegen die Aftermuindung. Unterhall, des Herzens liegen die großen geränmigen Nierensäcke $(n)$.

Die Tintenfische (Fig. 89) rerhalten sich zu den Muscheln, wie ein Turm zu einer niedrigen schmalen Hiitte. Denn ihr Leib höht sich zuckerhutartig empor und der bei den Muscheln so bedentende Abstand zwischen Mund (o) und After $(a)$ ist hier ganz kurz. Vorderund Hinterfläche des Körpers sind breit, die Seitenflächen schmal und sanft gerundet. Beim Vergleich der Körperform gewinnt man also den Eindruck, als sei der Tintenfisch einem ron rorne und hinten wirkenden Drucke unterworfen gewesen, welcher die Leihesmasse zur Streckung in die Kegelgestalt zwang. Der größere Bezirk der Hautobertläche bildet ein als diitenförmige Kalkschale erstarrendes Sekret.

Die derbe Mantelfalte $(p)$ ist ganz hinterständig, verhältnismäßig recht klein, und zerfällt nicht in symmetrische Lappen. Sie ist dem Körper fest verwachsen, nur der untere Mantelrand steht frei. Der Mantel iiberspannt den breiten Schmalraum der Mantelhöhle, in welcher zwei gefiederte Kiemen - keine Längsreihen ron Kiemenfüden. sondern zweireihig gefiederte Kiemenblätter — symmetrisch ron der den After tragenden Breitwand

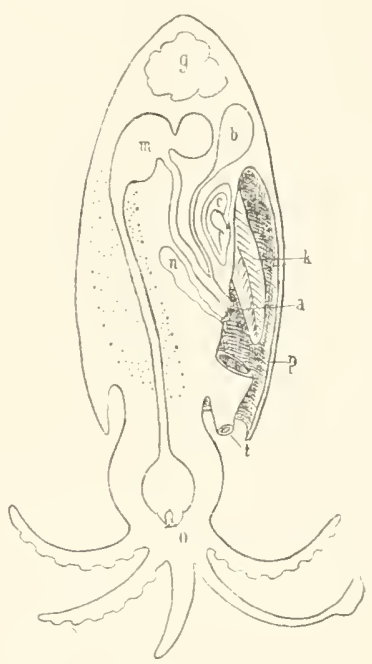

Fig. 89.

Schematische Skizze der Organisation der Tinten fische (die schale ist nicht eingezeichnet). Leber punktiert. a After, $\downarrow$ Tintenbeutel, c Herz, $g$ Geschlechtskeimstätte, $k$ Kieme, $m$ Magen, $n$ Niere, o Mund, $p$ Mantel, $t$ Trichter. des Körpers entspringen. Das Unterende des Tintenfisches schwillt rundlich an, sog. Kopf, und die dem Euße der Muscheln rergleichbare Zone ist in zehn bis acht bewegliche Lappen, die mit Saugnäpfen besetzten Arme, zerschlitzt. Zwischen der Hinterfläche des Kopfes und dem Mantelrande liegt ein trichterförmiger muskulöser Anhang, der Trichter $(t)$, welchem eine wichtige Bedeutung für das Schwimmrermögen der Tintenfische zukommt. Er ist ihrer Gruppe allein eigen. Dem Kopfe zind zwei hoch organisierte Augen eingebettet, wie sie in gleicher Tollkommenheit keine andere Molluskengruppe besitzt. In der Mundhöhle (o) liegen kräftige chitinöse Greifschnäbel und eine hornige Zahnreibeplatte. Der Darm steigt gegen den spitzeu Rückenpol des Tieres auf, erweitert sich zum komplizierten Magen $(m)$ und sendet einen rückläufigen Schenkel zum After ( $($ ), welcher sich in die Mantelhöhle 
zwischen den Kiemen offtnet. Nahe dem After mündet in den Enddarm der Ausfïhrkanal des Tintenbeutels $(b)$, eines nur den Tintenfischen eigenen Organes.

Ich branche andere spezifische Eigentiimlichkeiteu der Organisation, die Sie in jedem Lehrbnche rerzeichnet finden, gar nicht mehr zu beschreiben, weil die wenigen Thatsachen Sie in den Stand setzen, den kolossalen Unterschied zwischen den Muscheln und Tintenfischen zu benrteilen.

Die Schnecken (Fig. 90) lehren eine neue Stilvariante kennen. Ihr Körper ist niedrig und der muskulöse FuB bildet eine breite Kriechsohle. Beim Vergleich mit den Muscheln und Tintenfischen gewinnt man die Vorstellung, als habe in dieser Molluskenklasse eine Kompression in der Richtung einer die Bauch- und Rïckenseite verbindenden Geraden gewirkt. Sie wissen, dass der größere oberhalb der Kriechsohle liegende Teil des Schneckenkörpers spiralig gedreht ist, weil er im bekannten Schneckenhanse geborgen ist.

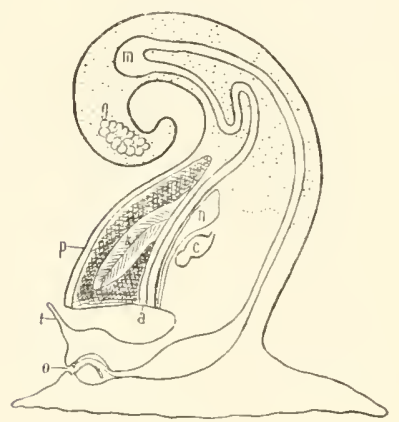

Fig. 90.

Schematische Skizze der Organisation der Schnecken (Vordcrkiemer). (Die Schale ist nicht einwezeichnet.) a After, $c$ Herz, $g$ Geschlechtskeimstätte, $k$ Kieme, Leber punktiert, $m$ Magen, $n$ Niere, o Mund, $p$ Mantel, $t$ Tentakel. Diese Spiralzone kann man als einen langkegeligen Auswuchs der hinteren Riickenpartie des Schneckenleibes auffassen, der schräg nach hinten und aufwärts zieht und in eine Spirale eingerollt wird. Nicht die leiseste Neigung zu ähnlicher Bildung wird bei den Muscheln und Tintenfischen beobachtet. Auch die Mantelhöhle nebst den Kiemen nimmt eine total andere Lage ein, als wir bisher fanden. Während dieselbe bei den Muscheln seitlich vom Körper sich mund- und afterwärts erstreckt, bei den Tintenfischen an der Afterwand allein steht, liegt die Mantelhöhle bei den Schnecken gerade entgegengesetzt oberhalb des Mundes und zwar asymmetrisch an der rechten Körperseite. Verglichen mit den

Tintenfischen scheint sie eine Drehung mach vorne erlitten zu haben. Die Kiemen $(k)$ sind gefiederte Platten. Sehr häufig birgt die Mantelhöhle nur eine einzige Kieme, oft auch ein ungleichnäßig entfaltetes Paar. Von der Mundhöhle (o), welche schwache hornige Kanwerkzenge besitzt, steigt der Darm fast bis zur Spitze des spiralig gerollteu Körperteiles empor, bildet dort einen sehr kleinen Magenraum $(m)$ und sendet einen rïckläufigen Schenkel zu dem oberhalb des Mundes asymmetrisch reehts liegenden After $(\alpha)$. Würde ich noch 
genauer auf den Bau der Schnecken eingehen, so würden Sie eine viel größere Zahl von unterscheidenden Merkmalen kennen lernen. Ich meine aber, die bisherige Schilderung und noch besser die Betrachtung der schematisehen Skizzen reicht aus, Sie von dem fundamentalen Gegensatze der drei Hauptsprossen des Molluskenstammes zu iberzengen. Gerade in diesem Falle kann die Beschreibung unmöglich das Formstudium guter anatomischer Präparate oder deren Surrogate, die Abbildungen, ersetzen, weil die der natürlichen Plastik gegenüber beschämende Ärmlichkeit der Sprache uns zwingt, die gleichen Ausdrïcke zur Bezeichnung von ganz verschieden geformten, tierischen Organen zu gebrauchen.

Die absonderliche Asymmetrie des Schneckenkörpers erscheint bei den das Meer bewohnenden, durch ihr schönes Gehäuse Ibnen bekannten, Schneckenarten der Vorderkiemer, Prosobranchia, und den Lungenschnecken (z. B. der Weimbergssehneeke) am schärfsten ausgeprägt. Sie bedingt einen scharfen Kontrast zu den beiden anderen Molluskenklassen, weil die Tintenfische und Muscheln gut bilateral symmetrisehe Tiere sind, deren für die Beurteilung des anotomischen Stiles wichtige Organe, hier die Mantelhöhle und die Kiemen, symmetrisch zur Mittelebene des Körpers liegen. Nun giebt es freilich Sehneckenarten, bei welehen die Kiemen symmetrisch am Hinterende des abgeflachten Körpers stehen und von einer symmetrisehen halbmondförmigen Nantelfalte iiberschirmt werden, bei welchen ferner der After genau entgegengesetzt rom Munde am Hinterende liegt und der spiralige Auswuchs des Körpers fehlt. Allein diese symmetrischen Schnecken sind kraft ihrer Organisation auch so seharf von den zwei anderen Klassen der Museheln und Tintenfische geschieden, dass der Mangel eines Merkmales, nämlich der Asymmetrie, keine Vereinfachıng schafft. Obgleich die morphologisehe Analyse den Triumph gefeiert hat, durch eine einfache Hilfsworstellung den Gegensatz zwischen symmetrischen und asymmetrischen Schnecken in einen gemeinsamen Formenbegriff zusammenzufassen, ist die historische Genese der Asymmetrie dadurch nicht erklärt worden. Mir erscheint es unnötig, diese Frage hier ausfiihrlicher zu besprechen, da jeder Interessent in den Lehrbüchern der vergleichenden Anatomie gute Darstellungen darïber findet. Meine Torlesung soll sich nur an die wichtigsten Punkte halten und darf auch da nicht zu sehr in die Breite gehen, wo meine eigene Neigung mich verführen möchte. Wir fahren daher in der Betrachtung der oberflächlichen Unterschiede fort und widmen noch den Kalkgehäusen der Mollusken einige Aufmerksamkeit.

Jeder Laie kennt die Untersehiede der Mnsehel- und Schnecken- 
schalen. Die Muscheln scheiden zwei meist symmetrische, oft auch asymmetrische, durch ein elastisches Schlossband zusammengehaltene Schalenklappen ab; die Schnecken tragen selten kegelförmige oder noch flachere Schalen, meistens ist ihr Gehäuse ein spiral hoch oder niedrig gewundener, gegen die Spitze verjüngter Kalkschlauch. In den beiden Klassen füllt der Weichkörper des Tieres den ganzen Schalenraum aus. Bei den Muscheln ist gewöhnlich das lebende Tier unter den Schalenklappen versteckt, bei den Schnecken kann der Kriechfuß vollständig in die Schale eingezogen werden. Anders ist es bei den Tintenfisehen. Der turmförmig erhöhte Leib derselben scheidet einen dütenförmigen Kalkschlauch als Schale ab, welche mit dem Wachstum des Individuums länger wird. Dabei kann sie entweder gerade gestreckt bleiben, wie bei den fossilen Belemniten, oder sich in verschiedenartige Spiralen zusammenrollen, wie bei den Ammoniten und Nautiliten. Der lebende Tintenfisch bewohnt niemals die ganze Schalenhöhle, sondern nur einen rorderen als Wohnkammer bezeichneten Abschnitt derselben. Der Längsschnitt durch das Perlenboot des indischen Oceans, Nau-

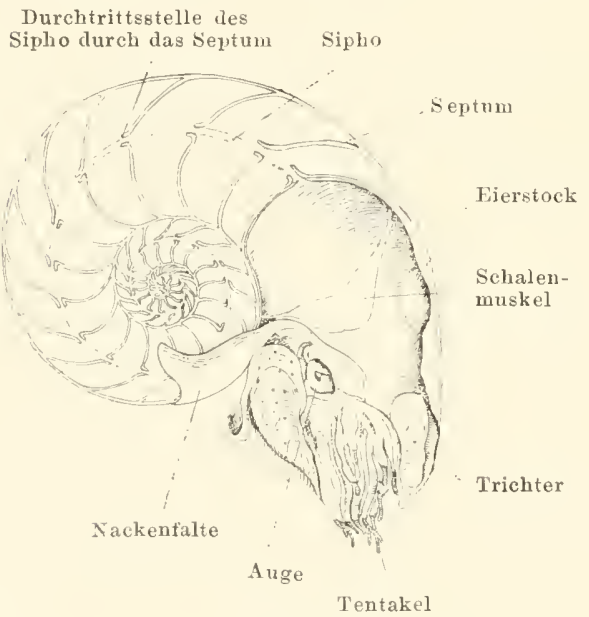

Fig. 91.

Nautilus pompilius, Perlboot, in der durchschnittenen Schale. tilus pompilius (Fig. 91), des einzigen, jetzt lebenden Tintenfisches, welcher eine typische Schale besitzt, illustriert die Thatsache. Der rom Tiere nicht beanspruchte Schalenraum ist durch Scheidewände, sog. Septa, in kleine gaserfüllte Kammern geteilt und sichert dadurch das Schwimmvermögen der beschalten Tintenfische. Mit dem Grössenwachstum des Tieres und der Schale werden immer neue Scheidewände eingeschoben und eine große Zahl von Gaskammern erzeugt. Der

Leib des Tintenfisches steht mittels eines sämtliche Scheidewände durchbohrenden, zarten Stranges, sog. Sipho, mit dem ältesten Teil der Schalenspitze in Verbindung.

Nachdem Sie durch meine oberflächliche Schilderung die Unterschiede der Molluskenklassen kennen gelernt haben, werden sie die Unmöglichkeit einer Antwort auf die Frage begreifen, wie die 
Tintenfische, Muscheln und Schnecken sich aus einer einfachen gemeinsamen Grundform hätten entwickeln können. Dringen wir in die innere Anatomie genauer ein, so würde die besondere Form-

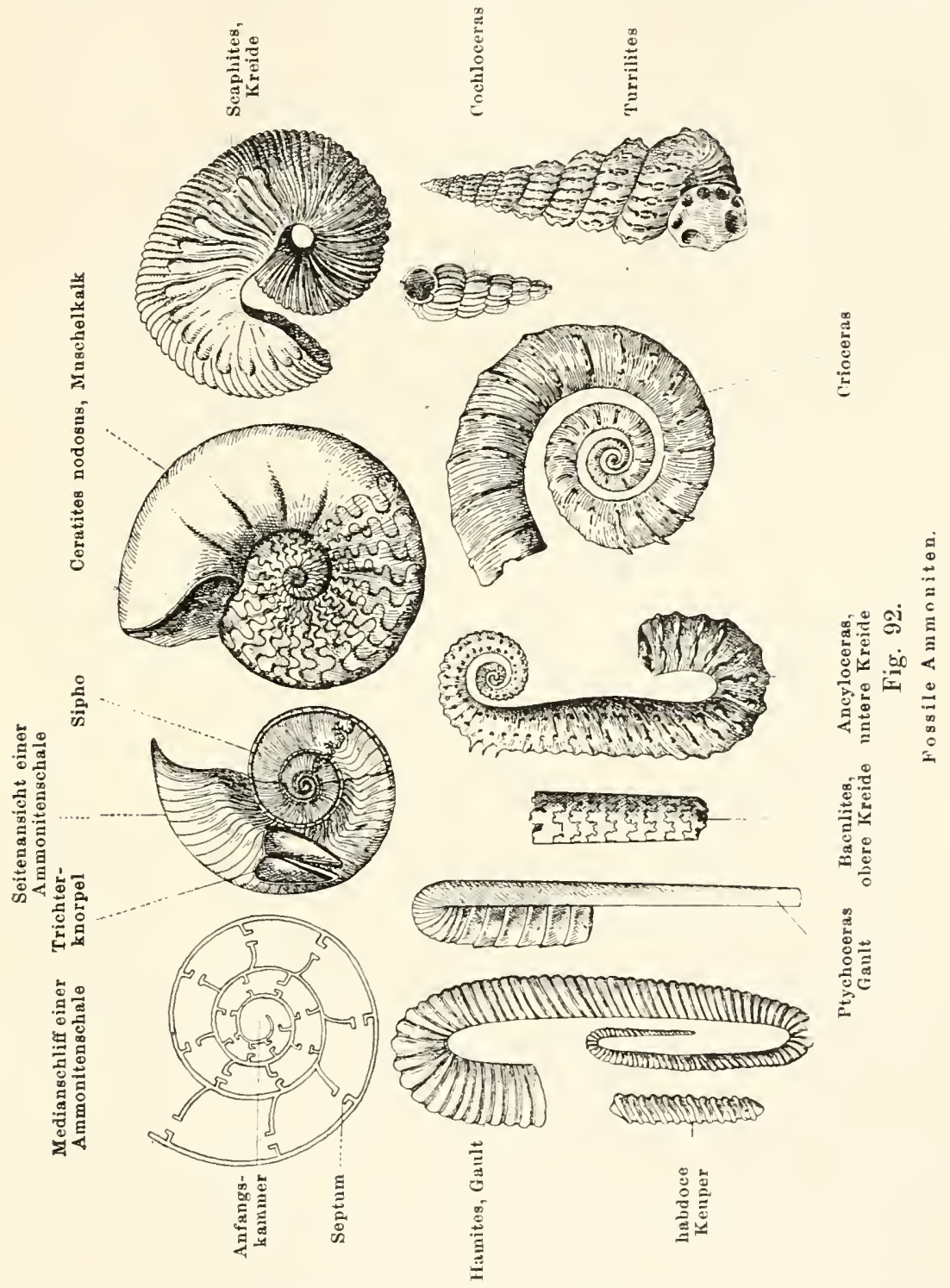

gestaltung jedes Körperteiles uns neue Rätselfragen vorlegen. Trotzdem es gelungen ist, gewisse allgemeine Merkmale des Körperbaues zu Gunsten der stilistischen Zusammenfassung der drei Klassen in 
dem Organisationstypus der. Mollusken aufzudecken, sind die anatomischen Verschiedenheiten der in einen gemeinsamen logischen Begriff eingeordneten Gruppen der Weichtiere ebenso groß, wie in anderen Abteilungen des zoologischen Systemes z. B. bei den Wirbeltieren und Gliedertieren. Auch hier fehlt jeder Anhalt, selbst nur eine plausible theoretische Vorstellung zu entwickeln, welche uns eine Möglichkeit denken ließe, wie die Stammgruppe der von der Descendenzschule wohl mit Namen genannten, fiktiven Urmollusken, Promollusca, sich in drei fundamental geschiedene Zweige spalten konnte. Meine Kritik zielt auf alle stammesgeschichtlichen Versuche über die Mollusken überhaupt; ihre Richtigkeit werde ich, um Ihre Geduld nicht allzusehr zu erschöpfen, am Beispiel der Tintenfische allein begründen, indem ich E. Haeckel ${ }^{1}$ ) sprechen lasse:

„Die systematischę Gruppierung der zahlreichen Cephalopoden-Formen und die damit verknüpfte Erkenntnis ihrer wahren Verwandtschafts-Bezichungen ist eine ebenso interessante und lehrreiche, als verwickelte und schwierige Aufgabe der Naturgeschichte. Einerseits besitzen wir in den gewaltigen Massen der fossilen Nautiliten, Ammoniten, Belemniten u. s. w. einen so kostbaren phylogenetischen Schatz, wie ihn die Palaeontologie in wenigen andern Tiergruppen darbietet; indem wir die Tausende von palaeozoischen und mesozoischen Spezies genau vergleichen und die allmähliche Umbildnng ilurer Schalen Schritt für Schritt durch die Schichtenreihe der Formationen verfolgen, gewinnen wir eine vollständige Einsicht in den Gang ihrer phylogenetischen Transformation, und damit zugleich einen glänzenden Beweis für die Wahrheit der Descendenz-Lehre. Anderseits erhalten wir aber durch das genaueste Studium dieser fossilen Schalen nicht den mindesten Aufschluß über die spezielle innere Organisation der Tiere, welche diese äußeren Cuticular-Schalen absonderten. Im Gegenteil belehrt uns die Vergleichung von Orthoceras und Belemnites, von Nautilus und Spirula, von Sepia und Argonauta, dass wir keinerlei sichere Schliisse aus der Schalenbildung allein auf den inneren Körperbau der betreffenden Tiere ziehen können."

Um die absolute Unkeuntnis der verbindenden Zwischenformen zu verschleiern, stellt Haeckel gerne die Behauptung auf, dieselben bätten wohl früher gelebt, seien aber nicht versteinert erhalten geblieben:

„Ferner ist noch zu berïcksichtigen, dass auch die Tausende von fossilen Cephalopoden-Arten, deren Schalen wir kennen, sicher

1) Haeckel, System. Phylogenie, II. Bd. 1896, p. 580-581,-582, 577. 
nur einen Bruchteil des formenreichen Stammes dieser höchstentwickelten Mollusken-Klasse bildeten. Wie jetzt, so haben gewiss auch in früheren Zeiten zahlreiche Cephalopoden gelebt. welche durch Riickbildung ihre Schale teilweise oder ganz eingebüßt hatten. Ferner haben sicher in palaeozoischer Zeit zahlreiche counectente (verbindende) $Z$ wischenformen zwischen den ältesten Cephalopoden (Archolenen) und ihren Promollusken-Ahnen existiert. Unter diesen werden sich Übergangsformen mit einer einfachen Kegelschale (gleich manchen Pteropoden) oder selbst mit einer einkammerigen, in symmetrischer Planospirale aufgerollten Schale (gleich Bellerophon) befunden haben."

.Daraus leiten wir weiter die Annahme ab, dass die ältesten (cambrischen und praecambrischen) Cephalopoden eine besondere dritte Ordnung der Klasse bildeten. Wir bezeichnen diese hypothetische Stammgrupe beider Ordnungen als Teutholenen und rechnen dazu die formenreiche Gruppe der palaeozoischen Orthoceraden. Wir miissen weiterhin annehmen, dass zwischen den ältesten (cambrischen) Tentholenen und deren praecambrischen Vorfahren, den Promollusken, eine lange lieihe von ausgestorbenen Übergangs-Formen existiert hat; denn nur durch diese $\mathrm{H}_{y}$ pothese ist die Entstehung der hoch differenzierten Cephalopoden-Form aus der typisch ähnlich organisierten, aber viel einfacher gebauten Amphineurenform erklärbar. Diejenige Gruppe; dieser Reihe, in welcher der typische Cephalopodenbau zuerst auftrat (die eigentliche Stammgruppe der Klasse) unterscheiden wir als Ordnung der Archolenen." (Die Gruppe wird von Haeckel nur zu Gunsten seiner Abstammungsspekulationen aufgestellt und enthält gar keinen irgend wie bekannten Vertreter.)

Wie mir scheint, mutet der Begründer der systematischen Phylogenie jedem ron uns eine fast den jesuitischen Sacrificio dell' intelletto erreichende Gläubigkeit an die bypothetischen Stammgeschlechter und großes Vertrauen auf die Richtigkeit der morphologischen Phantasie zu, wenn man solch verklausulierte Schilderungen für wissenschaftliche Ergebnisse der stammesgeschichtlichen Forschung betrachten soll. Sie hören aber zugleich aus dem Munde eines berufenen Vertreters, dass die landläufige Ansicht, der paläontologische Reichtum an Tintenfischen sei vou hervorragendem phylogenetischen Werte, nicht ganz zutrifft. Jeder Morpholog beklagt beim Studium der fossilen Ammoniten, Belemniten und Nautiliden traurig den Mangel jeglichen Anhaltes, welcher den Bau des Weichkörpers wenigstens in den allerrohesten Zïgen erkennen ließe. Ähnlich 
steht es mit den fossilen Resten der Muscheln und Schnecken, wie Sie in jedem Handbuche der Paläontologie lesen können. Ich übergehe darum den ausführlichen Nachweis und bespreche zum Schlusse die Entstehungsgeschichte des Molluskenstammes selbst.

Die Abstammungslehre wünscht sämtliche Klassen der Mollusken auf einfache Stammarten zuriickzuführen und gleicht darin einem Schiffbrüchigen, der vergebens nach Land ausguckt. Kein Mensch hat jemals die theoretisch so ausserordentlich wichtigen Tiere gesehen und niemand kann mir eine klare Beschreibung derselben geben. Haeckel, ${ }^{1}$ ) der doch in allen phylogenetischen Fragen die positivsten Behauptungen aufstellt, lässt sich sehr reserviert aus:

"Die gemeinsame ursprüngliche Stammform des Mollusken-Phylon, von welcher sich alle die mannigfaltigen Glieder ditses formreichen Stammes morphologisch und phylogenetisch ableiten lassen, besass nach unserer Ansicht ungefähr folgende Organisation":

Nun folgt die Beschreibung derselben, welche ich hier unterdrïcken kann. Haeckel2) fährt dann fort:

"Diese hypothetische Organisation der Promollusken, die sich aus der vergleichenden Anatomie und Ontogenie des ganzen Stammes - und insbesondere seiner älteren, primitiven Zweige - ergiebt, hat sich in keinem lebenden Vertreter desselben vollständig konserviert."

„Die Frage von der Entstehung und dem Ursprung des Weichtier-Stammes, sowie von der Verwandtschaft desselben mit den übrigen Tierstämmen ist in verschiedener Weise beantwortet worden. Nach unserer Ansicht besteht keine direkte Stammverwandtschaft der Mollusken zu folgenden Stämmen: Wirbeltieren, Tunicaten, Artikulaten, Echinodermen. Insbesondere können wir die Gründe für die Abstammung der Weichtiere von Anneliden oder ähnlichen "gegliederten Tieren" nicht auerkennen; wir finden in keinem echten Mollusk eine Spur von wahrer, motorischer Metamerie. Vielmehr können nach unserer Überzeugung als Vorfahren der Mollusken (oder als nächste Verwandte ihrer Ahnen) unter den heute lebenden Metazoen nur zwei Klassen in Betracht kommen: die Turbellarien als älteste und die Trochozoen als jüngere Verwandte."

Ich kann in dieser Fassung nur das verschleierte Eingeständnis der eigenen Unsicherheit erkennen. Sogar der Verfasser der natür-

1) E. Haeckel, System. Phylogenie, Berlin 1896. II. Bd., p. 506.

2) E. Haeckel, System. Phylogenie, Berlin 1896, II. Bd., p. 507-508. 
lichen Schöpfungsgeschichte vermag keine plausible Hypothese über die Abstammung der Mollusken vorzutragen. Mit anderen Worten: Die Hoffnung der Descendenztheorie, es ließen sich die blutsverwandtschaftlichen Reihen der Tierarten durch wissenschaftlich exakte Studien ergrïnden, ist schmählich getäuscht worden. Für meine eigene Ansicht kann ich die Bestïtigung aus dem Munde anderer Fachkollegen bringen. Aruold $\operatorname{Lang}^{1}$ ), ein ausgezeichneter Vertreter der phylogenetischen Richtung schreibt iiber die Phylogenie der Mollusken:

"Wir wollen uns hier kurz fassen. Direkte Ankniipfungspunkte des Molluskenstammes an andere Abteilungen des Tierreiches sind zur Zeit nicht bekannt. Über den Ursprung der Mollusken steht subjektiren Ansichten Thiir und Thor offen." Korschelt und Heider ${ }^{2}$ ) urteilten ein Jahr friiher:

„Über die Abstammung und Verwandtschaftsverhältnisse der Mollusken ist sehr viel geschrieben worden. Wir verzichten von vornherein auf eine Diskussion der verschiedenen, einander teilweise scharf gegentiberstehenden Auffassungen, da dieselbe unsere Ausführungen nu weit umfangreicher. aber nicht klarer machen wïrde."

Nachdem also vorderhand nicht der Funken eines Beweises dafür erbracht ist, dass die Mollusken ron anderen Typen abstammen. schlieBt das Resultat unserer Betrachtung in erfreulicher Harmonie an das kritische Ergebnis an. welches ich für die Wirbeltiere und Arthropoden erläuterte; die konsequente Durchführung einer rerlockenden Idee bezeugt deren absolnte Haltlosigkeit in der exakten Forschung, wo, wie Kant vor langer Zeit bemerkte, die scheinbare Denknotwendigkeit nicht die Existenznotwendigkeit eines Dinges bedentet.

1) A. Lang, Lehrbuch der vergleich. Anatomie, Jena 1894, p. 858.

$\left.{ }^{2}\right)$ E. Korschelt u. K. Heider, Juehrbuch der vergleich. Entwicklungsgeschichte der wirbellosen Tiere. Jena 1893, p. 1167. 


\section{Zwölftes Kapitel.}

\section{Die Entstehung der Stachelhäuter.}

Ebenso steht es mit einer anderen Gruppe der niederen Tiere, den Stachelhäutern oder Echinodermen, d. h. den Arten der Seesterne, Seeigel, Seewalzen und Haarsterne. Bereits bei einer früheren Gelegenheit (Seite 27, 28) habe ich Ihnen die dem systematischen Typus charakteristische Anordunng der wichtigen Organe in fünf radiale Zonen des kugeligen, walzigen oder platten Körpers vorgefiihrt und dabei betont, dass sie durch das fünfstrahlige Gepräge sich von allen bekannten Tieren unterscheiden, deren Teile fast immer zur rechten und linken Seite einer Hauptebene paarig symmetrisch liegen. Es sei nochmals auf die schematische Figur eines Seeigels

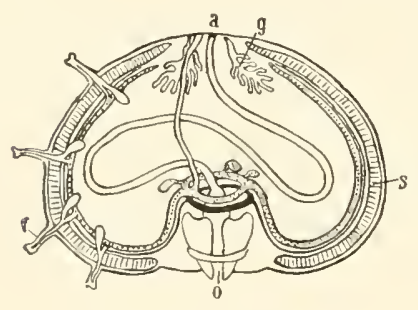

Fig. 93.

Schematische Skizze des Banplanes der Seeigel. a After, $f$ Wasserfüßchen, $g$ Geschlechtsorgan, o Mund, s Skelett, Wassergefäbe punktiert, Blutgefälring schwarz. verwiesen, wo wir in der Nähe des Mundes drei ringförmige Organsysteme mit fünf radialen Ästen erblicken: 1. den Ringkanal mit Wasser gefüllt, 2. den Nervenring und 3. das Ringgefäl3 des Blutes. Diese oberfächliche Angabe kennzeichnet schon zur Genüge die Sonderstellung der Echinodermen; in keiner anderen Abteilung sind Einrichtungen vorhanden, welche sich damit im entferntesten vergleichen ließen. Die Echinodermen bewegen sich auf eine ganz sonderbare Art mit Hilfe von Handschuhfingern vergleichbaren Auswüchsen der Körperwand (Fig. 11). In diese Auswüchse strahlen kleine Seitenzweige des Wassergefäßsystems hinein, sie vermögen die Füßchen so zu schwellen, dass ein Seestern oder Seeigel sich auf die Füßjchen stiitzt und teils mittels Anschwellung, teils mittels Abschwellung verschiedener Füßchengruppen auf der Unterlage weiter schiebt. In der Haut liegt ein mehr oder weniger mächtiges Kalkskelett (Fig. 12). Ich will Sie nicht weiter in die komplizierte Anatomie einführen und nur das eine noch bemerken, dass der Typus der 
heutigen Echinodermen vier stilistische Varianten aufweist: entweder erscheint er als sphärischer Hohlkörper mit Kalkstacheln besetzt Seeigel —, oder als langgestreckte walzige Seegurke - Holothurien -, oder als flache fünfzackige Scheibe, wie die Seesterne, oder die Körperscheibe ist kelchartig gekrümmt und ihr aboraler, d. h. dem Munde entgegengesetzter Pol, in einen langen Stil ausgezogen, die Arme lang cylindrisch - Haarsterne, Crinoiden. Außerdem sind die fossilen Reste von zwei gänzlich ausgestorbenen Gruppen der Cystideen und Blastoideen bekannt. Kein Anhänger der Descendenztheorie kann eine plausible Darstellung geben, wie die sechs Stilvarianten aus einer gemeinsamen Urform entstanden seien. Diese Sachlage spiegelt sich in Haeckels ${ }^{1}$ ) Bericht wieder:

„Zur Erklärung des Ursprungs und der Phylogenese der Echinodermen sind seit 30 Jahren mehrere, sehr weitauseinandergehende Theorien aufgestellt worden. Nachdem die ganz verfehlte Ableitung der pentaradialen Echinodermen von tetraradialen Nesseltieren (bald Medusen, bald Ctenophoren) aufgegeben war, kamen die übrigen Hypothesen in dem wichtigen Grundsatze überein, dass die uralte gemeinsame Stammform des ganzen Phylon ein „w wurmartiger Organismus", ein bilateraler Helminth gewesen sein müsse. Ferner einigten sich die meisten Theorien in dem zweiten wichtigen Grundsatze, dass die Entstehung der pentaradialen Echinodermen aus den bilateralen Helminthen durch Anpassung an festsitzende Lebensweise bewirkt sein müsse. Da eine andere physiologische Ursache für die Ausbildung der füntstrahligen Körperform nicht gefunden werden konnte, ist auch dieser zweite Grundsatz jetzt fast allgemein angenommen. Dagegen gehen noch heute die Hypothesen dariber weit auseinander, mit welchem Körperteile die älteste Dipleurula (oder vielmehr die entsprechenden Astrelminthen-Ahnen) sich festgesetzt haben, und durch wclche eigentïmlichen Umbildungen daraus das Astrozoon entstanden sei. Unter den verschiedenen, heute noch vertretenen Hypothesen halten wir diejenige für die richtige, welche (1888) als die Pentactaea-Theorie aufgestellt worden ist. Wenn sie auch nicht alle Rätsel der Astrogenese löst und nicht alle Seiten dieses verwickelten Problems richtig betrachtet, so enthält sie doch nach unserer Überzeugung den wertvollen Kompass, der zur vollen Lösung derselben führen wird."

Beachten Sie wohl, so resigniert schreibt ein überzeugter Apostel der Descendenztheorie! Ich spreche die gleiche Thatsache nur

1) E. Haeckel, Systematische Phylogenie, II. 1896, p. 355. 
mit anderen Worten und nüchtern aus: Es kann kein Mensch über die Entstehung der Echinodermen eine bestimmte Meinung äuliern. Zwei andere Zeugen. Korschelt und Heider ${ }^{1}$, beide warme Anhänger der Desccndenztheorie, sagen dasselbe noch bestimmter: "Alle Echinodermen besitzen einen radiüren Bau, die Larven hingegen sind von bilateral-symmetrischer Gestaltung, sowohl in Bezug auf ihre innere wie änßere Organisation. Wie auf ontogenetischem Wege (d. h. während der individuellen Keimesentwickelung) die radiäre aus der bilateralen Struktur hervorgeht, wurde an verschiedenen Beispielen gezeigt, doch thut sich nun die Frage auf, wie die Gestaltung der Echinodermen in phylogenetischer Hinsicht zu erklären ist. Um diese Frage zu lösen, wiirde es erst eine andere zu beantworten gelten, nämlich die, ob die verschiedenen Echinodermengruppen von einander herzuleiten und welche dann die höchst stehende, welche die niedrigste sei. In neuester Zeit hat man die Holothurien und speziell die füßcheulosen Holothurien (Synapta) als die am tiefsten stehenden Formen angesprochen. - - Diese Theorie leitet zwar die Echinodermen auf einfache Formen zurück, aber sie giebt keine Erklärung für die Entstehung der radiären Gestaltung."

"Eine andere Theorie ist die, welche die einzelnen Abteilungen von einander getrennt auf eine gemeinsame, als Pentactaea bezeichnete Stammform zurückführt (Semon). An dieser Theorie fällt die Schwierigkeit auf, dass die fünf Stämme, wenn sie eine solche getrennte Entwickelung genommen hätten, kaum eine so große Übereinstimmung in ihrer Organisation zeigen würden, als sie thatsächlich besitzen. Uns scheint es richtiger, die Stammformen der Echinodermen unter dem thatsächlich vorliegenden Material zu suchen, welches die Paläontologie bietet, wobei allerdings wieder die andere Schwierigkeit hervortritt, dass dieses Material nicht vollständig ist, indem zartere Formen nicht erhalten bleiben und dass es nur die äußere Gestaltung erkennen lässt."

„Mit der Frage, welcher Art wohl die bilateralen Vortahren der radiären Stammform gewesen sein mögen, stehen wir vollkommen in der Luft."

Arnold Lang ${ }^{2}$ ) muss ein ähnliches Urteil fällen:

"Kein Stamm steht in der Tierwelt so scharf abge-

1) E. Korschelt u. K. Heider, Lehrbuch der vergl. Entwicklungsgeschichte der wirbellosen Tiere. 1890, p. 305, 306.

2) A. Lang, Lehrbuch der vergleich. Anatomie der wirbellosen Tiere, Jena 1894, p. 1139. 
grenzt da, wie derjenige der Echinodermen. Alles in ihrer Organisation ist fremdartig, selbst der radiäre Ban ist fremdartig in so ferne er im Gegensatz zu demjenigen vieler Cölenterateu nur die Maske ist, hinter welcher sich eine uns noch unverständliche, komplizierte Asymmetrie verbirgt. Wir sind nicht im stande, irgend einen erwachsenen Vertreter der Echinodermen mit irgend einem erwachsenem Vertreter eines anderen Tierstammes von phylogenetischen Gesichtspunkten aus zu vergleichen.

Die Schwierigkeiten, die dem Versuche einer Rekonstruktion der Phylogenese der Stachelhäuter entgegenstehen, werden noch dadurch vermehrt, dass sich die typischen, charakteristischen Echinodermenlarven auf keinem Stadium der Entwickelung mit irgend welchen Larvenformen anderer uns bekannter Tierformen vergleichen lassen."

Dann folgt eine ausfïhrliche Darstellung der subjektiven Ansicht, welche A. Lang selbst über die Stammesgeschichte der Gruppe hegt. Sie klingt in folgende Sätze ${ }^{1}$ ) aus:

„In den vorstehenden phylogenetischen Betrachtungen haben wir vermieden, in das Einzelne zu gehen und haben auch ganz wichtige Fragen - - nicht beriicksichtigt. Sie können nur durch erneute, sowohl ausgedehnte als vertiefte und verfeinerte Untersuchungen weiter gefördert werden. Bei der Anwendung unserer Gesichtspunkte auf speziellere Fragen der Echinodermenmorphologie müssen wir in der Mehrzahl der Fälle erkennen, dass sie zur Erklärung nicht ausreichen, dass sie mit zahlreichen Thatsachen der Ontogenie und Anatomie sich zur Zeit nicht vereinbaren lassen. Die neueren Untersuchungen iiber Echinodermenmorphologie und die tastenden Versuche einer phylogenetischen Erlilärung, die ganz neue Gesichtspunkte bringen, berechtigen aber entschieden zu der Hoffnung, dass sich nach und nach manches interessante und wichtige Problem anf diesem Gebiet in befriedigenderer Weise wird lösen lassen."

Also mit anderen Worten: Die Organisation der Echinodermen ist so eigenartig, so scharf geschieden vom Aufbau des Tierkörpers in anderen systematischen Gruppen, dass wir uns keine Vorstellung bilden können, aus welcher Urform sie sich heraus gebildet haben.

Man begreift die in den oben angeführten Citaten sich anssprechende Resignation erst, wenn man die mannigfachen und widerspruchsvollen phylogenetischen Hypothesen iiber die Entstehung und Terwandtschaft der Echinodermen genaner studiert. Da dies hier

1) 1. c. p. 1147 . 
nicht am Platze ist, will ich Ihnen nur ein gedrängtes Resumé iiber die in dem letzten Jahrzehnt erschienenen Publikationen geben.

L. Cuénot behauptete 1891, dass keine der Echinodermenklassen von einer der anderen abstamme, jede besitze ihre eigene Urform, diese aber seien aus einander entstanden. Im gleichen Jahre leitete F. J. Bell alle Klassen von einem Urechinoderm ab. Biitschli dachte sich eine bilateral symmetrische hypothetische Urform und gab sich alle Nïhe, die Entstehung der fünfstrahligen Organisation aus ihr einleuchtend zu machen. H. Bury bestritt 1895 die Richtigkeit aller vorher geäußerten Hypothesen, um eine nene kriechende bilaterale Urform zu konstruieren, welche im Laufe der Stammesgeschichte radiär geworden sein soll. E. Haeckel erklärte 1896 sein Phantasiegebilde, die uralte Pentactaea als die Stammform sämtlicher Stachelhäıter; nur die ältesten paläozoischen Echinodermen sollen einer noch :ilteren bilateralen Form, welche Amphorea genannt wird, entsprossen sein. Vor kurzem hat der Freiburger Paläontologe G. Steinmann ${ }^{1}$ ) eine ganz sonderbare Ansicht ausgesprochen, welche ich mit seimen eigenen Worten vortragen will:

„Alle heutigen und die meisten fossilen Vertreter der Stachelhäuter zeichnen sich durch die regelmäßig fünfstrahlige Anordnung ihrer wichtigsten Organe aus. Dif anseheinend mathematisch gesetzmäßige Grundlage ihres Baues ist durchgängig auch schon beim jungen Tier ausgeprägt, welches sich aus einer zweiseitig gebauten Larve durch Metamorphose entwickelt. Aus diesem Verhalten war die Vorstellung entsprungen, dass dem gemeinsamen Torfahr aller Stachelhäuter, der seinerseits von zweiseitig gebauten Ahnen stamme, die regelmäßig fïnfstrahlige Anlage eigen gewesen, und dass diese auf alle Nachkommen als homologes Merkmal übertragen worden sei. Trotzdem nun fossile Repräsentanten der einzelnen Ordnungen in großer Zahl aus allen Zeiten, namentlich auch aus den ältesten Formationen bekannt waren, hatte doch die Paläontologie auch in diesem Falle in der Auffindung der gemeinsamen Stammform und der geforderten Übergangsformen zu den einzeluen Ordnungen versagt. Dagegen waren in den älteren Ablagerungen zahlreiche Vertreter einer ausgestorbenen Gruppe, der Beutelstrahler, Cystoidea, gefunden worden, die wegen der unvollkommenen oder gar nicht ausgeprägten Fïnfstrahligkeit im Gegensatz zu den Normalformen als aberranter und gänzlich erloschener Formenkomplex erschien. Neumayr konnte mun iiberzeugend darthun, dass in den Beutelstrahlern die Stammgruppe der haupt-

1) G. Steinmann, Die Erdgeschichtsforschung wälırend der letzten vier Jahrzehnte. Rede bei der Ubergabe des Prorektorates. Freiburg i. Br. 1899. S. 47 . 
sächlichsten heutigen Ordnungen gegeben sei, und dass der fünfstrahlige Bau sich innerhalb derselben mehrmals unabhängig herausgebildet habe."

An einer späteren Stelle der Rede kommt Steinmann nochmals darauf zurück. (S. 49)

..An dem Beispiele der Stachelhäuter konnte ein weiteres Ergebnis der historischen Methode anfgezeigt werden, die allmähliche und mehrfach wiederholte Herausbildung der mathematischen Gesetzmäßigkeit, welche jetzt den Bau der ganzen Klasse beherrscht. Wo derartige Gesetzmäßigkeiten, sei es in der Zahl und Lage der maßgebenden Organe, sei es in der regelmäßigen, z. B. kugelförmigen Gesamtgestalt in der Tier- und Pflanzenwelt auftreten, hat man sie mit Vorliebe für Merkmale genommen, die der betreffenden Gruppe von einem bestimmten Zeitpunkte ihrer Stammesgeschichte an durch einen einmaligen Torgang endgiltig aufgeprägt worden seien. Sie galten für etwas Ursprïngliches im" Gegensatz zu der unregelmäßigen oder ungesetzmäßigen Ausgestaltung, welche sich bei einzelnen Individuen oder bei größeren verwandten Formenkomplexen findet. Daher auch die Neigung. bei der Konstruktion von Stammbäumen von den regelmäßigsten Gestalten auszugehen und die abweichenden daron abzuleiten. Für manche Fälle soll die Möglichkeit eines solchen Vorganges nicht geleugnet werden, die am besten studierten Beispiele, so die Stachelhäuter, Steinkorallen u. a. sprechen für das Gegenteil."

Mich hat an dieser Darstellung zunächst das Referat über Neumayr's ${ }^{1}$ ) Ansichten ïberrascht, denn ich war durch die Lektiire des Buches dieses tüchtigen Gelehrten zu einer anderen Meinung gelangt und glaubte, Neumayr wolle die bekanuten Echinodermen ron regelmäßig fünfstrahligen Torfahren ableiten, sonst würde ich folgende Sätze seiner Darstellung nicht begreifen:

p. 487. ..Schon eine oberflächliche Betrachtung zeigt, dass die Aufstellung eines genauen Stammbaumes nicht möglich ist, und dass die paläontologischen Erfahrungen keinen Anhaltspunkt geben für die Aufstellung einer Hypothese iiber die Tierform, aus welcher die Echinodermen sich entwickelt haben. Allein wenn auch so weittragende Folgerungen ausgeschlossen sind, so liegen doch einige sehr wichtige Thatsachen für die Beurteilung der Frage vor, welche unter den verschiedenen Echinodermenformen. die wir kenneu, dem Grundtypus am nächsten steht."

p. 489. ..Es sind nur die Cystideen, welche als der Stammtypus der Echinodermen, beziehungsweise als die deuselben am nächsten stehende Abteilung betrachtet werden können. Nehmen wir eine

1) M. Neumayr, die Stämme des Tierreiches I. Bd. Wien. F. Tempsky. 1889. 
Form an mit zahlreichen unregelmäßig gelagerten Tafeln, aber mit regelmäßig fiinfzähligen Ambulacren, so stellt sie uns denjenigen Typus dar, aus welchem sich alle anderen durch einfache Entwickelung ohne Zuhilfenahme naturwidriger Vorgänge ideell entwickeln lassen. Agelacrinus ${ }^{1}$ ) könnte etwa als ein der Stammform nahe verwandter, aber durch Festwachsung der Unterseite modifizierter Typus betrachtet werden; da iiberdies jene urspringlichsten Vorkommnisse vermutlich mit Kelchporen versehen gewesen sein diirften, so kann etwa die Gattung Mesites ${ }^{2}$ ), wie wir sie oben kennen gelerut haben als eine dem Stammrater besonders nahe stehende Sippe betrachtet werden."

.. Wenn eine solche Form den Seesternen, Seeigeln, Crinoiden und Blastoiden gegeniiber als eine ursprüngliche betrachtet werden kann, so ist eine andere Frage, ob sie auch unter den Cystideen selbst dieselbe Rolle spielt. Es handelt sich dabei um die Frage, (1) die Formen mit fünf normal strahligen oder diejenigen mit unregelmäßigen Ambulacren als primitiver betrachtet werden miissen."

26 Keilen später bemerkt Neumayr (p. 491), die Frage sei noch nicht spruchreif und rerdiente, der Aufmerksamkeit späterer Forscher empfohlen zu werden.

Professor Steinmann war, nachdem ich ihm meine Bedenkeu mitgeteilt hatte, so liebenswürdig, mir zu schreiben, dass er durch die persönliche Bekanntschaft mit Neumayr wisse, dass derselbe während des Druckes der "Stämme des Tierreiches" seine Meinung änderte. Leider konnte Neumayr das nicht mehr aussprechen. In dem Nachtrage zum ersten Bande ${ }^{3}$ ) verleiht er nur dem Umstande Ansdruck, dass ,aller Wahrscheinlichkeit nach die Fünfzähligkeit des Echinodermenbaues sich erst innerhalb der Cystideen entwickelt."

Für unsere Betrachtung ist es übrigens irrelerant, ob Stejnmann mit Recht die Autorität Neumayr's anzieht. Uns interessiert mehr die Thatsache, dass durch Steinmann's Ideen das stammesgeschichtliche Problem eine neue Verwickelung erfährt. ${ }^{4}$ )

1) Agelacrinus gleicht einem auf eine Platte aufgewachsenen See- oder Schlangensterne. Die Platte selbst haftet auf einem anderen Körper und wird aus zahlreichen, ohne Regel geordneten, schuppenförmigen Stïeken gebildet.

2) Mesites ist eine Form mit ganz reiner Fünfzahl der Ambulaeren.

3) Neumayr, l. e. S. 582.

4) Um Missverständnissen zu begegnen, bemerke ich, dass sehon vor Steinmann andere Phylogenetiker die gesonderte, unabhängige Entstehung größerer oder kleinerer systematischer Gruppen behauptet haben. (Verg]. S. 120, 164.) Ich habe Steinmanns Ansichten nur wegen der Feierlichkeit und Öffentlichkeit der Äuferung herausgegriffen, um den ferner Stehenden die Konsequenzen zu läutern. Eise nmfassende Kritik aller phylogenetischen Versuche liegt nicht in meinem Plan und ist heute zomeist überflüssig. 
Bisher hatte man ziemlich allgemein angenommen, dass die in einer größeren systematischen Gruppe ob der vielen gemeinsamen Charaktere des Körperbaues vereinigten Artindividuen von einer einzigen Wurzel sich allmählich entwickelt haben, dass also alle Echinodermen, Reptilien, Vögel u. s. w. von einer Wurzelart stammen. Steinmann aber ist anderer Meinung. Er vertritt den Gedanken, dass, wie verschiedene Wege nach Rom führen, auch die Natur eine ähnliche Organisation auf verschiedenen Entwickelungswegen gezeitigt haben könne. Das klingt zunächst sehr überraschend, weil der dem zoologischen Erfahrungsschatze ferne stehende Laie die mannigfachen Differenzen zwischen den größeren Gruppen eines Organisationskreises nicht kennt und die pedantische Herrschaft eines ihm gerade bekannten anatomischen Baues für alle Einzelfälle vermutet. Erinnern Sie sich aber des fundamentalen Gegensatzes z. B. zwischen den drei Hauptformen der Mollusken, so werden Sie begreifen, dass ein tüchtiger Mann zu der Meinung kommen kann, dass die Muscheln, Schnecken und Tintenfische unabhängig entstanden seien. In dessen Denken gewinnen eben die wirklich bestehenden Unterschiede eine größere Gewalt als das Vorkommen gemeinsamer Merkmale. Er sagt sich, wenn wir auch die Muscheln, Tintenfische und Schnecken Mollusken oder Weichtiere nennen, so sind sie doch sehr von einander verschieden, dass ich mir unmöglich vorstellen kann, wie dieselben von einer einzigen Ahnenform entstanden seien. Andere ziehen sich gleich Haeckel aus der Verlegenheit, indem sie einige total unbekannte, ausgestorbene Verbindungsgruppen in solch einem Falle einschieben. Steinmann aber vertheidigt die Ansicht, die Verschiedenheit der heutigen Gruppen deute auf Verschiedenheit der Ahnen hin. Die soeben angestellte Erwägung mit etwas anderen Worten stilisierend sagt er: Die systematischen Gruppen des Tierreiches sind ohne Rïcksicht auf stammesgeschichtliche Gesichtspunkte früher unterschieden worden. Deshalb müsse, ehe sie als Gerüste für die Konstruktion der Stammbäume übernommen würden, erst geprüft werden, ob die ihre systematische Zusammengehörigkeit erzwingenden Merkmale vieler Arten auch in phylogenetischer Hinsicht verwertbar seien und wirklich für die monophyletische Abstammung sprechen. Wer einmal so weit fortgeschritten ist, neigt innerlich dem Prinzipe der Vielstämmigkeit lieber zu, umsomehr, als er dadurch eine bis jetzt nur zaghaft geäußerte Auffassung innerhalb der phylogenetischen Schule vertritt, welche von der bisher wenig angefochtenen Grundansicht der Descendenztheoretiker wesentlich abweicht. Denn bisher legte die allgemeine Verbreitung des typischen Organisationsplanes und seine unbedingte Herrschaft in allen Fällen, auch dort, wo starke Modifikationen desselben (ich erinnere an die vorderen Gliedmaßen der Wirbeltiere 
Seite 55) genaues Studium erforderten, bis er thatsächlich erkannt war, den Descendenztheoretikern den Gedanken nahe, dass der fünffingerige Fuß der Stammgruppe der Vierfußßer bereits eigen war, oder, $1 \mathrm{~m}$ einen ähnlichen Gedanken in der modernen, sog. historischen Fassung auszudriicken, dass die gemeinsamen typischen Merkmale einer Gruppe z. B. die fünstrahlige Ordnung der Seitenäste des Wasser-, Blutgefäß-, und Nervenringes etc. den Echinodermen zu einem bestimmten Zeitpunkte ihrer Stammesgeschichte durch einen einmaligen Vorgang endgiiltig aufgeprägt und auf sämtliche mannigfach divergierende Nachkommen vererbt wurden.

Ja sogar die entfernteste theoretische Möglichkeit, irgend ein gemeinsames Moment der Ähnlichkeit zwischen fundamental geschiedenen Organen, z. B. zwischen der Gliedmaße und Fischflosse anzuzeigen, hatte den Fanatikern der Abstammungslehre geniigt, die Blutsverwandtschaft als feststehend anzusehen. Auch Haeckel's Denken bevorzugt in den meisten Fällen die einwurzelige, monophyletische Abstammung.

Jetzt tritt Steinmann auf den Plan, ebenso wie die Mehrzahl der heutigen Gelehrten von der Richtigkeit der Abstammungsidee überzengt, und proklamiert das gerade Gegenteil oder mindestens die. Ungiiltigkeit der bisherigen Schlussfolgerung. in einigen Fällen. Ihḿ bezeugt der höhere oder geringere Grad anatomischer Übereinstimmung der Organe bei den Gliedern einer weiten Gruppe nicht unbedingt die Blutsverwandtschaft; er denkt, die einer Gruppe, z. B. den Echinodermen oder den Säugern, gemeinsameu Merkmale können eine bestimmte Kombination von anatomischen Eigenschaften darstellen, welche ron ganz verschiedenartigen Tiergeschlechtern zu verschiedenen Zeiten erworben wurde, etwa so, wie der Nestbau bei Vögeln und Ameisen, Bienen, Wespen oder die Fähigkeit der Tonerzeugung bei Vögelı und Grillen auftritt, oder wie die Wasseratmung während der Larvenzeit verschiedener, später luftatmender Tiere, der Amphibien, vieler Fliegen und anderer Insekten vorübergehend erscheint. So könnte die fünfstrahlige Ordnung wichtiger Körperorgane der Echinodermen mehrfach in verschiedenen Geschlechtern entstanden sein. Nach Steinmann, der sich damit einer von amerikanischen Paläontologen, z. B. Osborn, geänßerten Denkrichtung anschließt, könnten auch die systematisch wichtigen Eigenschaften der Säugetiere mehrmals und vielstämmig, d. h. in drei ganz verschiedenen Reptiliengruppen entstanden sein, indem eine noch unbekannte Reptiliengattung sich gesondert zu den Schnabeltieren, eine andere zu den Beuteltieren und eine dritte unabhängig zu den placentalen Säugern entwickelt hat. In anderen Gruppen mag das in ähnlicher Weise gegangen sein. 
Obwohl Steinmann seine Idee noch nicht weiter ausgeführt und am thatsächlichen Material die Notwendigkeit derselben erläutert hat, ist sie für unsere Betrachtungen deshalb wichtig, weil sie einen neuen-Zwiespalt im descendenztheoretischen Lager andentet, der zum rollständigen Bankerott führen wird. Die Rede Steinmann's zeigt, dass ein ehrlich iiberzeugter Anhänger des Abstammungsgedankens, ohne denselben selbst aufzuheben, die ganze bisherige Richtung der phylogenetischen Spekulation umwerfen kann. Das wäre nicht möglich, wenn die C̈berlegungen und Schlüsse derselben wirklich auf thatsächlichem Boden festen Halt gefunden hätten.

Im descendenztheoretischen Lager selbst werden also Zweifel dagegen laut, dàss die systematische Zusammenfassung der kleinen oder größeren Tiergruppen ohne weiteres als genetische Folgen der hypothetisch rermuteten Blutsrerwandtschaft betrachtet werden. Neue Untersuchungen sind anzustellen mit der ausgesprochenen Absicht, den systematischen Zusammenhang aufzulösen und einen scharfen Gegensatz zu der empirischen, d. h. im modernen Sinne reformierten, Lin néschen Systematik und der phylogenetischen Klassifikation zu statuieren. Es ist nun abzuwarten, ob man bei der von der ganzen Abstammungsschule beklagten Unvollständigkeit des positiven Thatsachenmaterials die polyphyletische Entwickelung einer großen systematischen Gruppe wird besser beweisen können, als die bisher gesuchte monophyletische Entstehung.

Die phylogenetischen Versuche an anderen Organisationsgruppen ebenso eingehend zú schildern, halte ich hier nicht mehr für nötig, da Sie an vier tierischen Typen die Unzuläuglichkeit der stammesgeschichtlichen Denkrichtung sehen konnten und die Vorfahrenreihe der übrigen nicht sicherer steht.

Über die Würmer urteilt Haeckell) selbst recht kleinlaut:

„Die morphologischen und phyletischen Verwandts chafts Beziehungen der fünfzehn Wurmtier-Klassen, welche wir auf die angefüihrten 4 Cladome rerteilt und in dem nachstehenden System zusammengestellt haben, sind sehr schwierig zu beurteilen; die Ansichten darüber gehen daher auch heute noch weit auseinander, mehr als in irgend einer anderen Gruppe des Tierreichs. Dieser Umstand ist nur zum Teil in irrtümlichen Ansichten und Urteilen der Systematiker begründet, zum anderen Teil aber in der Sache selbst. Denn wir müssen

1) E. Haeckel, System. Phylogenie 1I, p. 263. 
bedenken, dass die heute noch lebenden Vermalien-Klassen (Wurmklassen) nur die le tz ten grïnenden Zweige eines reich verzweigten Stammbaumes sind, dessen za h I r e i c h e Äs te zum größten Teil längst abgestorben sind; dieselben waren im Laufe vieler Jahr-Millionen durch Tausende von divergenten Zweigen vertreten, welche wegen Mangels harter Skeletteile uns keine Spur ihres Daseins hinterlassen konnten."

Auch die Schwämme stehen noch ganz isoliert. wie Haeckel's ${ }^{1}$ ) Worte beweisen:

"Die zahlreichen fossilen Schwämme, deren versteinerte Überreste wir genau kennen, und deren Struktur uns erst seit den letzten 20 Jahren näher bekannt geworden ist, bilden jedenfalls nur einen geringen Bruchteil von der reichen Spongien(Schwamm-) Fauna, welche seit der Archolith-Ära Millionen von

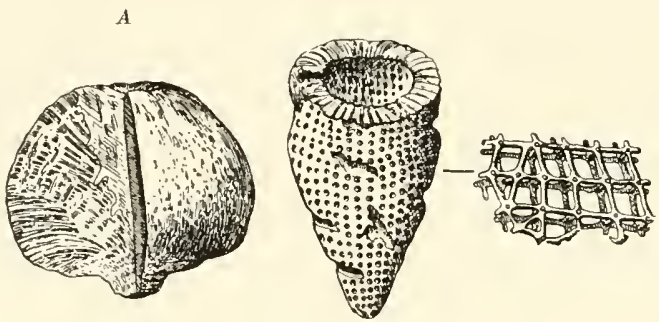

Fig. 94 .

Fossile Schwämme. A Aulocopium aurantium, unteres Silur und Diluvium, $B$ Craticularia paradoxa, rechts die Skelettelemente vergrößert, oberer Jura.

Jahren hindurch die Meere bevölkert hat. Denn erstens ist ein großer Teil dieser Tiere der Versteinerung nicht fähig, vor allen die zarten Asconaten mit ihrem dünnwandigen Röhrenleib; ferner die skelettlosen Malthospongien, welche keine Kieseloder Kalk-Skleriten (Fig. 95) bilden, endlich auch alle jene weichen Kiesel- und Kalkschwämme, deren Mineralspikeln leicht auseinanderfallen. Zweitens sind diese Mineralstïcke oft metalithisch verwandelt: ursprüngliche Kalknadeln sind gelöst und durch Kieselerde ersetzt; aber auch der umgekehrte Prozess ist nachgewiesen, an die Stelle von ursprünglichen Kieselnadeln ist Kalkerde getreten. Daher ist ihre Deutung oft zweifelhaft. Drittens lehrt auch hier wieder die auffallende Ungleichmäßigkeit in der Verteilung und Erhaltung der fossilen

1) E. Haeckel, System. Phylogenie JI, p. 75. 
Reste, wie liickenhaft die paläontologische Urkunde immer bleibt; so finden sich zahlreiche fossile Spongien (besonders Lithistiden und Hexaktinellen Fig. 94) schon im Silur, später im Carbon, dann massenhaft im Jura nnd der Kreide; aber die mächtigen, zwischen diesen Formationen abgelagerten Schichten des Devon, Perm nnd Trias enthalten teils gar keine, teils sehr unbedeutende und wertlose Reste ron fossilen. Spongien. Dazu kommt viertens noch, dass schon unter den ältesten fossilen Schwämmen die hoch entwickelten Formen mit stark differenzierten Kiesel-Nadeln (Fig. 95) (Lithistiden und Hexaktinelliden) vertreten sind. Daratus müssen wir

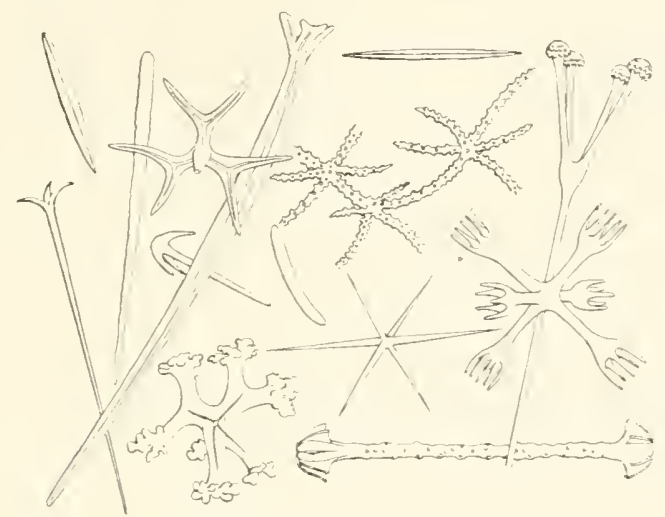

Fig. 95 .

Jieselskleriten oder Kieselnadeln ron $\mathrm{Sch}$ w $\mathrm{m}$ men.

schlieben. dass der ältere und interessantere Teil ihrer Stammesges'chichte in die frïhere Archolith- ̈̈ra, in die cambrische und präicambrische Zeit fällt."

.. Die Paläontologie der Spongien hat demnach für die großen allgemeinen Ziige ihrer Stammesgeschichte fast gar keinen Wert; ihre liickenreichen positiven Daten könneu nur auf die historische Entwickelung einiger kleinen Formengruppen ein unvollkommenes Licht werfen. Immerhin geht daraus das hohe Alter dieses ninrollkommensten MetazoenStammes positir hervor. Für die Erkenntuis der wichtigsten Phasen seiner Geschichte, die Entstehung und Fortbildung des Olynthus, die Geschichte aller Askonaten und aller skelettlosen Camaroten sind wir ganz allein auf die Urkunden der rergleichenden Anatomie und Ontogenie angewiesen." 
Als einfiahste Lebewesen erscheinen uns die L'rtiere. Protozoen, und zugleich als die Stammeltern sämtlicher höherer Typen, wenn wil deren Entwickelnng aus niedersten Formen iiberhaupt annehmen. Üher die Art, wie die Vervollkommnung der einzelligen Tiere zu einem vielzelligen Organismus erfolgte, können Sie nirgends positiven Aufschluss, ja nicht einmal eine allgemein acceptierte Hypothese hïren.

Wir diirfen das Studium der Organisationstypen und ihrer hypothetischen Stammesgeschichte um so mehr beschließen, als die Descendenztheoretiker sellist allmählich zu der Meinung kommen, dass die Entstehung der Typen iiberhaupt jenseits des exakten Gebietes sichtbarer Vorgänge liegt. Das geht unzweifelhaft aus der Kritik hervor, welche Haeckel1) an dem Wert des paläontologischen Materials iibt:

„Die zahlreichen versteinerten Reste und Abdrïcke, welche uns die Metazoen von der cambrischen Zeit bis zur Gegenwart hinterlassen haben, besitzen einen verschiedenen Wert für die Phylogenie. Wir können in dieser Beziehung drei Gruppen unterscheiden: [. Höchst wichtig für die Stammesgeschichte sind die massenhaft erhaltenen Petrefakten nur in den drei von den zehn Stämmen der Metazoen, nämlich 1) den Mollusken, 2) den Echinodermen und 3) den Vertebraten (von den Fischen aufwärts bis zum Menschen).

II. Zahlreiche und gut erhaltene fossile Reste, aber von geringerer oder gar keiner Bedeutung fii r die Erkenntnis der Phylogenie, haben uns ausserdem drei andere Stämme hinterlassen, nämlich: 1) die Spongien, 2) die Cnidarien (Hydropolypen, Korallen) und 3) die Articulaten (besonders die Crustaceen).

III. Von den vier ïbrigen Stämmen ist nur ein Teil der Termalien (die Bryozoen und Brachiopoden) durch sehr zahlreiche Versteinerungen bekannt, welche jedoch auch keiuen besonderen Wert für deren Stammesgeschichte besitzen; die grosse Mchrzahl der Vermalien bestand aus weichen und skelettlosen Tieren, die keine fossilen Reste hinterlassen konnten, und dasselhe gilt fïr die drei Stämme der Gastraeaden, Platoden und Tunicaten.

Hieraus geht hervor, dass die grosse Mehrzahl ter Tiere, welche seit Jahr-Millionen auf unserem Erdballe gelebt haben, keine fossilen Urkunden oder auch nur Spuren ihrer Existenz hinterlassen hat. Aber auch die positiven

1) E. Haeckel, System. Phylogenie II, p. 15. 
Daten. welche uns die bekannten Petrefacten der Minderzahl liefern, besitzen für deren Stammesgeschichte einen sehr ungleichen Wert; in dieser Beziehung sind folgende Unterschiede herrorzuheben: 1) die fossilen Spongien sind zwar zahlreich und gut konserviert, geben aber keine wichtigen Aufschliisse über die Organisation dieser niedersten Coelenterien, welche wir als "Gastraea-Cormen" auffassen. - 2) Die rersteinerten Cnidarien haben nur in einer Klasse dieses formenreichen Stammes ein bedeutendes historisches Interesse, in der Klasse der Korallen; die palaeozoischen Vertreter derselben (Tabulaten, Tetrakorallen) sind wesentlich rerschieden ron den mesozoischen Epigonen (Hexakorallen etc.); auch unter diesen läßt sich die historische Umbildung der Formen-Reihe teilweise verfolgen. Bei den übrigen fossilen Cnidarien (Hydropolypen) ist dies nicht der Fall. - 3) Die wohlerhaltenen Kalkschalen der Bryozoen und Brachiopoden, der einzigen versteinerten Glieder des Vermalien-Stammes sind zwar in palaeozoischen und mesozoischen Formationen massenhaft und durch mehrere tausend Arten vertreten; sie sind auch ron hohem geologischen Interesse, geben aber über die Organisation und Geschichte dieser Tiere wenig Auskunft. 4. Die Tersteinerungen von Articulaten, die wir kemnen (wenige Anneliden, zahlreiche Crustaceen und Tracheaten) bilden jedoch nur einen kleinen Bruchteil ron der ungeheuren Arten-'/ahl dieses formenreichsten Stammes; sie sind aber teilweise ron hohem phylogenetischen Interesse, besonders die Aspidonien (Trilobiten und Merostomen) auch die palaeozoischen und mesozoischen Insekten. - 5) Die fossilen Mollusken besitzen unter allen Versteinerungen die grösste Wichtigkeit für die Geologie, da sich Tausende von Arten wohlerhalten in allen Petrefacten fiihrenden Sedimenten, rom Cambrium bis zur Gegenwart finden; viele derselben dienen als wichtige „Leitmnscheln“ zur Charakteristik der einzelnen Schichten, indem sie eine ausgedehnte horizontale, aber nur beschränkte vertikale Terbreitung besitzen. Dies gilt ron allen drei Hauptgruppen der Weichtiere. von den Muscheln, den Schnecken und den Kraken. Tiel geringer ist der Wert der fossilen Mollusken-Schalen für die Phylogenie dieses Stammes; denn erstens ist deren äußere Form oft nicht charakteristisch für den inneren Körperbau und die systematische Stellung, und zweitens treten alle drei Hauptgruppen schon im Cambrium neben einander auf; ihre Entstehungsgeschichte fällt also in die prïcambrische Zeit. - 6) Die versteinerten Echinodermen dagegen, welche ebenfalls sehr zahl- 
reich in allen Sediment-Gebirgen rom Cambrium an sich finden, sind von höchster Wichtigkeit für die Phylogenie dieses Stammes; denn ihr vortrefflich erhaltenes Dermal-Skelett giebt uns unmittelhar die wichtigsten Aufschlüsse über ihre innere Organisation und systematische Verwandtschaft; auch sind von den acht Klassen dieses Stammes die drei ältesten (Amphorideen, Cystoideen, Blastoideen) nur aus palaeozoischen Schichten bekannt. - 7) Noch wichtiger endlich, und die bedeutungsvollsten aller Versteinerungen, sind die fossilen Vertebraten.

Schon aus dieser kurzen Übersicht der Hauptgruppen ergiebt sich die zweifellose Thatsache, dass die groBe Mchrzabl der ausgestorbenen Tier-Arten keine fossilen Reste hinterlassen hat; aher auch von der Minderzahl, deren Körper feste Skeletteile besaß und an sich der Versteinerung fähig war, blieben viele Arten (wahrscheinlich die meisten!) nicht erhalten, aus den gcologischen und biologischen Gründen, die wir früher bereits erörtert haben. Besonders ist noch hervorzuheben, dass uns die zahllosen Jugendformen, Embryonen und Larven der ausgestorbenen Metazoen wegen ihrer zarten Fonsistenz fast niemals fossil erlalten bleiben kounten; diese empfindliche Lücke ist um so mehr zu bedauern, als deren Kenntnis fuir die Phylogenie von lı̈chstem Werte sein würde“.

Ebenso umbefriedigend lautet das Urteil über die erste Entstehung der Tiere selbst. Einstimmig bekennen die Anhänger der Entwickelungstheorie, dass wir darïber ïberhaupt keine sichere Kenntnis erwerben werden. Ich will zunächst E. Haeckel') das Wort geben :

.:Der erste von den vier grossen Hauptabschnitten der organischen Erdgeschichte umfasst den ungeheuren Zeitraum vom Beginn des organischen Lebens bis zum Abschluss der cambrischen Ablagerungen; wir bezeichnen denselben als das archozoische Zeitalter oder die biogenetische Urzeit Häufig wird dieser Zeitranm auch heute noch als .. azoische Periode" den folgenden gegenübergestellt, hauptsächlich weil die mächtigen Sedimente desselben iiberaus arm an Versteinerungen sind; nur die oberen Abteilungen, die cambrischen Schichten, enthalten eine geringe Anzahl gut erbaltener Petrefacten. Wenn aber hieraus gefolgert wird, dass während der Bildung der unteren, verstcinerungslosen Schichten, der gewaltigen laurentinischen Formationen, noch kein organisches Leben existicrte, so ist dieser Schluss völlig irrtümlich. Der Mangel ron Petre-

1) E. Haeckel, System. Phylogenie I. 1894, p. 20. 
facten erklärt sich sehr einfach durch den metamorphischen (oder besser: metalithischen) Zustand, in welchem sich der größte Teil der archolithischen Gesteine befindet. Die zahlreichen versteinerten Reste von Protophyten und Protozoen, Aløen und I'irbellosen, welche diese krystallinischen Schiefer- und GneiBbildungen ursprüinglich einschlossen, sind durch die spätere Metalithose (d. h. Umänderung des Gesteincharakters) derselben völlig zerstört worden. Aber schon aus dem phylogenetischen Charakter der ältesten bekannten Petrefacten (aus dem untersten Cambrium) ergiebt sich, dass diesen relativ hoch organisierten Brachiopoden, Mollusken, Trilıbiten r. s. w. lange Reihen von niedern Ahnen vorausgegangen sein mïssen: Ahnenreihen, die zu ihrer phyletischen Ausbildung viele Millionen von Jahren bedurften."

Jch setze hinzu, Ahnenreihen, innerhalb welcher die Entstehung der Organisationstypen des Tierreiches geschehen sein mußte, aber Ahnenreihen, die nur theoretisch vermutet. uns vollkommen unbekannt und deshalb für die exakte Forschung ron keinem Belange sind.

E. Koken ${ }^{1}$ ) sprach früher die gleiche Ansicht ganz klar und deutlich aus:

.. Eine kurzs Zusammenfassung führt zu dem Resultate. dass Cölenteraten, Brachiopoden, Mollusken, Echinodermen, Krustentiere sicher, Anneliden und andere TWürmer höchst wahrscheinlich schon in der cambrischen Periode scharf geschieden existierten, ja diss sogar unter diesen grossen Gruppen viele der uns bekaunten Abteilungen niederen Ranges sich herausgebildet hatten. Wenn wir uns auf den Boden der Entwickelungslehre stellen und. ganz abgesehen ron der Frage nach der Entstehung des ersten Lebens, rerlangen, dass es eine Zeit gegeben habe, in welcher nur Protozoen (einzellige Urtiere) die Bevölkerung der Meere bildeten, so können wir diese ruhig ebensoweit vor den Beginn der cambrischen Ära setzen, wie die gesamte uachcambrische Zeitrechnung beträgt. Wir haben nicht eimmal das Recht, das Fehlen der Wirbeltiere als begründet hinzustellen. Die lebenden, niedrigsten Vertreter der Wirbeltiere sind nackt, haben weder eine Haut noch ein rerfestigtes Imnenskelett, dass es sich fossil erhalten konnte, und angesichts der neuerdings bekannt gewordenen Thatsache, dass schon im Untersilur von Petersburg Fischreste vorkommen, können wir den S. 82.

1) E. Koken, Die Vorwelt und ihre Entwicklungsgeschichte. Leipzig 1893. 
Satz aussprechen: Schon in den ältesten Zeiten, ans denen wir Urkunden in Gestalt von Fossilien besitzen, waren sämtliche großen Kreise der Tierwelt vertreten und zum Teil in mehrere Gruppen gespalten."

Die Darlegungen der Phylogenetiker besagen also, dass die siimtlidhen Typen des Tierreichs zu einer Zeit entstanden sind, aus welcher gar keine positive Kunde zu uns dringen kamn. Der Professor der Paliäontologie in Freiburg, Dr. Steinmann bekräftigte erst kiirzlich in seiner Prorelitoratsrede') die gleiche Ansiclit mit den kategorischen Worten:

.. Wir glauben bestimmt zu wissen, dass uns die ältesten Tertreter der Tiere und Pflanzen aller Art für immer unbekannt bleiben werden; ihre spuren wurden wobl iiberall infolge der hochgradigen Umwandlung, welche die ältesten Schichtgesteine erfahren haben, rollständig verwischt."

Deshalb ist es ganz ausgeschlossen, die Entstehung der 17 Organisationstypen des Tierreichs (vergl. S. 31) jemals zu erkennen. Der Descendenztheoretiker vergeudet seine Zeit in der Suche nach unmöglicher Einsicht!

1) Freiburg 1899, p. 33. 


\section{Dreizehntes Kapitel.}

\section{Das Licht der Entwicklungsgeschichte.}

Das haltlose Phantasiegebünde der Abstammungslehre hätte sein längst verdientes Schicksal schon früher gefunden, wenn nicht im Denken jedes Menschen die Neigung für Märchen-Erzählungen so stark lebendig wä:e. Der Märchenglaube aber wird um so unerschütterlicher, wenn der nicht fachmännisch geschulte Zuhörer einen scheinbaren Beweis für die Richtigkeit der Erzählnng in die Hand bekommt. Als solcher wirkt in unserem Falle die Behauptung voll den ausgestorbenen fossilen Resten, welche Übergangsformen zwischen den heute lebenden und durch so scharfe Grenzlinien der Organisation geschiedenen Gruppen des Tierreiches vortühren. Die Leichtgläubigkeit, welche die große Masse des Tolkes den stammesgeschichtlichen Berichten jederzeit entgegen bringt, erinnert mich lebhaft an eine Episode, welche Tain $\mathrm{e}^{1}$ ) berichtet: Unter der Regierung ron Ludwig XVI. glaubte das Tolk, dass die Tenerung kiinstlich sei. Eines Tags belauschte ein Offizier die Gespräche der Soldaten und hörte sie aus voller C̈berzeugung reden, dass die Prinzen und Höflinge das Mehl in die Seine werfen, um Paris aushungern zu lassen. Hierauf stellte der Offizier den Wachtmeister zur Rede, wie er eine solche Dummheit glauben könnte, und erhielt die Antwort: ".Es ist aber die Wahrheit, denn die Mehlsäcke waren mit blauen Schnïren zugebunden". Von diesem Argumente, das die Leute für unfehlbar hielten, waren sie durch nichts abzubringen. In unserem Falle treten teils die fossilen Funde, teils die jetzt lebenden sog. Zwischenformen an die Stelle der blauen Schnüre und gelten den Laien als ein ganz unerschiitterlicher Beweis der Abstammungslehre. Das ist ein ganz sonderbares Verhalten. Wenn bei anderen Gelegenheiten jemand eine Schilderung von dem giebt, was einmal gewesen ist, so glaubt man ihm nicht, bis er die Belege für die Richtigkeit seiner Erzählung bringt. Fängt aber der Anatom zu sprechen an, es können einmal Tiergeschlechter von ganz sonderbarer Gestalt gelebt und als Nachkommen irgend eine der jetzt

1) H. Taine, Geschichte des rorrevolutionären Frankreichs. I Bd. p. 384. 
verbreiteten Giruppen gezeugt haben, so lauschen ihm die Laien ohne zweifelnde Bedenken und reden sich schlieslich ein, es sei reine Wahrheit. Was sie nur als Vermutung aussprechen gehört laben. Diese Leichtgläubigkeit der großen Masse ist durch ihre Unkenntnis zu entschuldigen; denn sie werden durch die früheren Tollesungen eingesehen haben, welch umfassendes Wissen in Anatomie und Palïontologie erforderlich ist, um ein richtiges Urteil über den Wert oder den Unwert der Abstammungsbeweise zu fällen.

Derjenige aber, welcher dic Thatsachen kennt, befindet sich in einer noch viel schlimmeren Lage als der Laie. Er gebietet über ein thatsächliches Material, das iiber die Entstehung der Tiere keine Gewißheit verbreiten kann. Der Anatom hat immer nur fertige Tierkörper vor sich, er kann ihren Bau, ihre Formen studieren, er kann die Formeigenschaften jedes Organes genau feststellen, und dieselben bei den näher verwandten oder weiter cntfernten Arten vergleichen, deren Ähnlichkeiten oder Unterschiede auslesen, aber er ist und bleibt an das Material gebunden, das feststeht und sich nicht verändert. Was er in der \%eit eines kurzen Menschenlebens untersucht, besitzt ganz bestimmte Merkmale des allgemeinen anatomischen Aufbanes, welche wohl in engeren oder weiteren Grenzen schwanken, jedoch nicht in ganz newe Modifikationen verwandelt werden. Die anatomischen Thatsachen verleiten uns also nicht direkt, an eine Umwandlung der Tierwelt zu denken, sie führen uns im Gegenteil strenge Grenzen innerhalb einer scheinbar unbeschränkten Mannigfaltigkeit vor. Der Formtypus der Wirbeltiere ist durch viele Eigenschaften scharf von den ïbrigen wirbellosen Tieren, die Insekten wiederum von den Krebsen und GIiederwiirmern getremnt. Das Studium der Mollusken und Echinodermen bestïtigt die gleiche Thatsache und wïrde ich noch die anderen 14 großen Gruppen des Tierreiches mit Ihnen durchsprechen, so wïrden wir zum gleichen Resultate gelangen. Sie haben auch gehört, dass diese scharfen Grenzlinien der 'Tierkreise nicht bloß ron mir, sondern auch von den Anhängern der Descendenztheorie betont werden, da sie zu offenkundig dem exakten Forscher in die Augen springen. Wenn man nun imnerhalb eines Organisationstypus z. B. der Wirbeltiere Übergangsformen zwischen den fünf durch scharfe Grenzlinien des Körperbates geschiedenen Kilassen sucht, so erhält man wiederun kein befriedigendes Resultat; denn ich zeigte Ihnen frïher am Schnabeltier und den Lungenfischen, dass diese auf den ersten Blick für ' Wwischenstufen zu haltenden Wirbeltiere nimmermeh. vermittelnde Formen zwischen den Reptilien und Säugetieren, bezw. zwischen den Fischen und Amphibien sind. Wohin auch die anatomische Forschung bis jetzt geführt wurde, an den Übergängen 
zwischen den kleineren systematischen Gruppen und den gröleren, durch die Anordnung der wichtigsten Körperorgane geschiedenen Organisationskreisen des Tierreiches scheiterten die Hoffnungen der Descendenz-Theoretiker.

Ebenso verhält es sich mit den paläontologischen Beweisen Ha ckel's eigene Worte sagten Ihnen, dass die fossilen Reste, welche viele niedere Tiergruppen in unsagbarer Fülle hinterlassen haben, uns gar keinen Einblick in den Aufbau des Weichlïrpers ihrer Träger geben. Infolgedessen tappen wir beziglich der Umwaudlung der meisten Typen ganz im Dunkeln. Dieses Resultat wirkt umsomehr niederschlagend, als die Paläontologie vor 40 Jahren vou der Descendenztheorie als Bundesgenossin angerufen worden war in der Hoffnung, man brauche nu* die älteren Ablagerungen der Erdkruste zu durchsuchen, um dort die längst rom Schauplatze des Lebens abgetretenen Ausgangsformen, die einfachen Wurzeltriebe des jetzt so reich entfalteten Tierstammbaumes zu finden. Die Hoffnung hat sich als trügerisch erwiesen, weil in den ältesten Schichten nicht, wie man erwartete, die einfachsten Formen, sondern die Reste hoch organisierter Geschöpfe vorkommen.

An allen bisher besprochenen Beispielen konnte ich Ihuen klar legen, dass die bis jetzt bekannten fossilen Reste uns die grolien Liicken des hypothetischen Stammbaumes z. B. der Plerde, der Sängetiere, del Mollusken nicht auszufüllen vermögen. dass viele frïher als Zwischenformen beurteilte Funde z. B. die Archaeopteryx heute nicht mehr den hohen theoretischen Wert beanspruchen. Da also die Anatomie und Paläontologie uns vollkommen im Stiche lassen, wenden wir uns voll Neugier der dritten Gruppe von 'Thatsachen, welche die Abstammungslehre stïtzen sollen, nämlich der' Entwickelungsgeschichte der Tiere zu.

Hier tritt uns eine Umbildung des Tierkörpers entgegen, die man nicht für möglich hielt, solange die Larven- und Eientwicklung ausserhalb des Gebietes zoologischer Studien lag. Heute weiss jedermann, dass jegliches Lebewesen aus dem Ei heraustritt im unvollkommenen Zustand, klein, schwach und oft hiltlos auf die Brutpflege der Eltern angewiesen, dass es allmählich heranwächst und zur Selbständigkeit reift. Aus den Kinderschuhen tritt es in die Tugendzeit und in das Mannesalter ein, erfüllt die Geschäfte der Fortpflanzung, bis endlich der Körper im Greisenalter morsch zusammenbricht. Während all dieser Perioden des Lebens erleidet sein Leib gewaltige Veränderungen des äulieren Ansehens und des innelen Banes.

Ich branche blob etliche Beispiele kurz zu besprechen, damit Sie sehen, dass das Studium der Entwickelungsgeschichte jedermann 
zum Glauben verfiihren muk, die Transmutationshypothese sei eine richtige Anuahme der Naturfor'schung. Zugleich werden Sie begreifen, warum hervorragende Männer ihre ganze Arbeitskraft der Begriindung und V'erteidigung dieser nach meiner und neiner theoretischen Fremude unhaltbaren Ansicht gewidmet haben.

Wir steigen auf den Meeresgrund. Dort sitzen likeine pflanzenähnliche 'Jiere oder Polypen, schlauchförmige Gestalten,

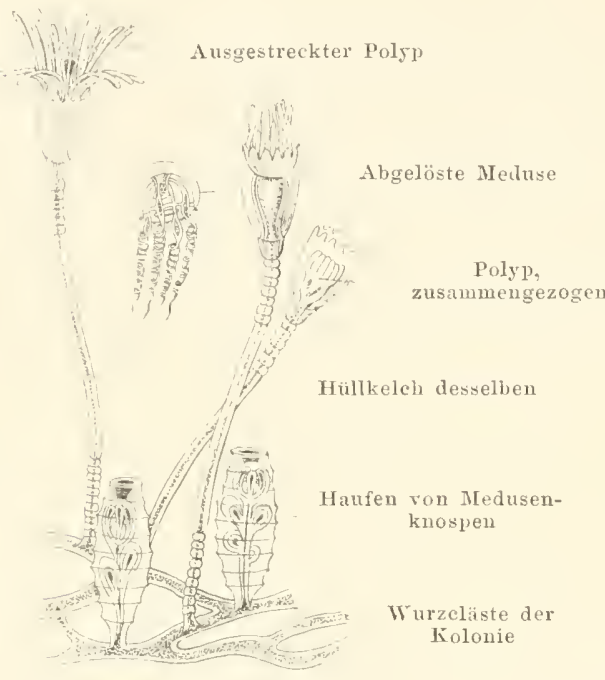

Fig. 96 .

stück einer Polypenkolonie von CampanuIaria Johustoui mit einem $\mathrm{Pol}$ festgewachsen, am andern liegt die Mund-Öffnung, die in die grolje Magenhöhle fuihrt. Die Mundöffnung ist von kleinen fingerartigen Fortsaitzen umstellt, welche sich schlangengleich bewegen können und stets bereit sind, nahe kommende Beute zu packen und in den Mund zu stopfen. Eine grosse Abteil ung derselben, die Hydroidpolypen, bilden strauchartige Kolonien von vielen Einzeltieren (Fig. 96). Zu bestimmten Zeiten wuchern an der Kolonie neue Tiere, indem sich eine rundliche Zone oder viele dichtbenachbarte Zonen

der Körperwand verdicken. Die verdickte Scheibe wird größer. endlich löst sich die Kinospe vom Leibe des Polypen ab und schwimmt als Meduse im Meerwasser herum. Die Meduse besitzt cine schirm- oder glockenähnliche Form (Fig. 96). Aus der Schirmhöhle hängt ein Stiel herunter, der an seinem freien mnteren Ende die Mundöffnung trägt. Von ihr steigt der Darm als enger Kanal im Mundstiel empor, $u m$ sich im Schirm selbst zur Magenhöhle zu erweitern. Von der Magrenhöhle ziehen radiüre Kanäle durch den Köörper gegen den Schirmrand in das Ringgefäß.

Die Medusen scheinen zunächst keine Ähnlichkeit mit Polypen zu besitzen. Hätten wir Zeit, so könnte ich nachweisen, dass eine Meduse als stilistische Modifikation des Polypensackes zu betrachten ist: aber das liegt heute aufer meinem Plan. Ich habe die Polypen nur herangezogen, weil man hier 
direkt die Entstchung eines ganz ander's aussehenden Tieres, der Meduse beobachten kann. Letztere sind die Geschlechtstiere der Polypen. An den radialen Kanälen oder an der Magenwand verschiedener Medusen entstehen nämlich Geschlechtszellen, Samenoder Eizellen, welche durch Platzen der Schirmwand ins Meer entleert werden. Dort kommen sie mit eimander in Berührung, und die Befruchtung erfolgt. Aus den Eiern gehen jedoch nicht Medusen, sondern Polypen hervor. Wir lernen also eine regelmäBige Abänderung der auf einander folgenden Generationen ron ganz gewaltigem Grade kennen.

Noch komplizierter ist die Entwicklungsgeschichte des Leberegels, Distomum hepaticum, eines kleinen flachen $W u ̈ r m c h e n s$ von Lanzettgestalt (Fig. 97), das in den Gallongängen der Schafleber lebt. Seine reifen Eier gelangen durch die Gallengänge in den Darmkanal, später mit dem Kot nach aussen und miissen ins $\mathbb{V}^{\top}$ asser gespiilt werden, damit aus ihnen birnförmige Larven (Fig. 98) ausschlüpfen, von zartem Bau, bedeckt mit feinen Flimmerhärchen, die Rudern gleich die Larte im Wasser herumtreiben, bis sie sich in eine Wasserschnecke, Lrmuaeus truncatulus, einbohrt.
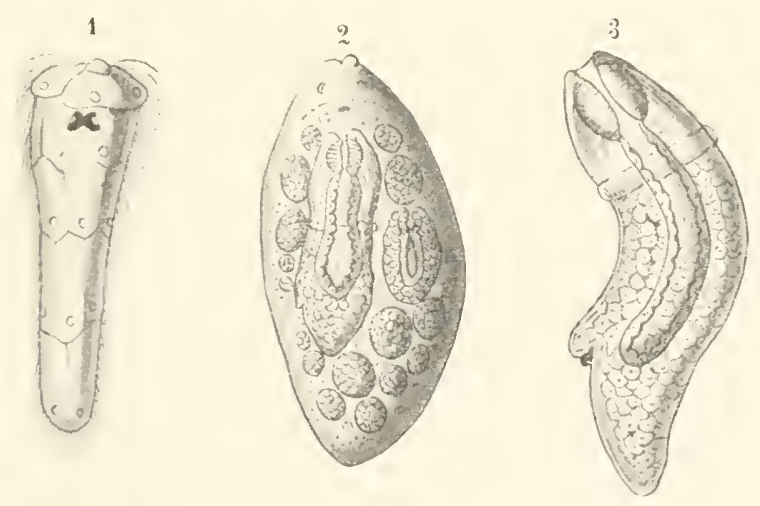

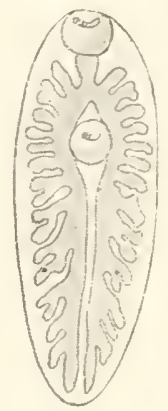

Fig. 97.

Junger Leberegel. Mit Mund-und Batch. saugnapf und zweischenkligem, verzweigten Darm.

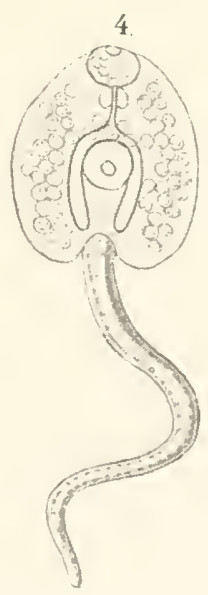

Fig. 98.

Fntwicklungs formen des Leberegels. 1 Flimmerlarve, 2 sporocyste, 3 Fiedie, 1 Cercarie.

Die Flimmerlarve nistet sich in der Leber ein, verliert dabei alle für das Wasserleben wichtigen Organe, die schwarzen Augen- 
flecke, die limmerhare u. s. w. und verwandelt sich in einen Sack, der Sporocyste (Fig. 98) genannt wird. An der Wand desselben beginut nun neues Keimen. Es lösen sich von derselben kleine Zellenballen los, die in die Sackhöhle hineinfallen, zuerst von rundlicher Gestalt, späiter länger auswachsend. Indem sich eine Mundöffnungr und im Innern der Darmkanal entwickelt, werden die Keimzellhaufen junge, länglich gestreckte Tiere, die wir Redien (Fig. 98) nennen. Die Redien bleiben in de's Schnecken wohnen und lassen in ihrem Imneren wiederum Ballen von der Wand knospen und in die Leibeshöhle fallen. Diese Ballen runden sich oval ab und am hinteren Rand wïchst ein kleiner, cylindrischer Fortsatz, der sogenannte Schwanz hervor. Im Innern des Körpers entwickelt sich der Darmkanal, als gabeliger Schlauch, wie ihn der geschlechtsreife Leberegel (Fig, 97) besitzt, die Saugnäpfe entstehen am vorderen Ende und am vorderen Drittel des Körpers. Die kleinen Tiere, Cercarien (Fig. 98) genannt, zeigen die meisten Organisationseigentimlichkeiten des Leberegels, unterscheiden sich aber durch den Ruderschwanz. Endlich brechen sie aus ihrem bisherigen Gefüngnisse in Schneckenleibe aus und schwirren im $\mathrm{W}$ asser mit Hilfe des Ruderschwanzes herum. Aber bald heften sie sich an eine Wasserpflanze fest, werfen den Ruderschwanz ab und scheiden ein Sekret aus, das als Kapsel erstart und sie vor dem Vertrocknen schiitzt. Ein Schat muss in rlie Nähe kommen, die Kapsel samt der Pflanze fressen, damit im Magen die Hïlle platzen und der junge Leberegel in die Gallengänge wanderu kaun.

Dieses Beispiel belenchtet den komplizierten Entwicklungsgang bei den Plattwiirmern. In anderen Gruppen des Tierreiches finden sich ähnliche Beispiele; ich hahe schon aufmerksam gemacht, dass alle Krebse nicht in der Gestalt aus dem Ei kriechen, wie sie Thnen bekannt sind, sondern dass die meisten Arten als .Nauplien" (Fig. 75) erseheinen. Das sind kleine orale Larren, welche drei Paare ron Anhängen besitzen, sehr wenig Ähnlichkeit mit einem fertig ans. gebildeten Krebs zeigen und nur dem Kopfe des kïnftigen Tieres entsprechen. Während sie frei im Wasser herumschwimmen, wachsen die fehlenden Körperteile langsam nach.

Gleiche Beispiele sind Ihnen besser bekannt ans der Abteilung der Insekten, ferner bei den Fröschen (Fig. 105). die das Ei als dem Wasselleben angepasste Kaulquappen verlassen, welche auf dem Lande elend zn Grunde gehen miissten. wenn sie ein Zufall dorthin brächte. Ku bestimuter Zeit büssen sie ihren Ruderschwanz ein, verlieren die änßeren Kiemen, welehe die Atmung im Wasser erlaubt hatten und wandeln sich in anscheinend ganz andere Tiere, die lungenatmenden Frösche. um. 
Der smmmarische Berieht über die tiefgreifenden Umbildungsrorgänge jugendlicher Tiere muss für heute genügen. Die meisten dieser Beispiele sind frühzeitig bekannt gewesen und haben das Nachdenken der Naturforscher mächtig angeregt. Zum Beginn unseres Jahrhunderts rerbreitete sich die Meinung, der Lmstand, dass jedes tierische und ptlanzliche Lebewesen nicht fertig ins Lehen trete, sondern nach der Geburt eine Reihe ron Veränderungen durchlaufe, künde ein tieferes Geheimuis der Natur an. Die Emständlichkeit des individuellen Entwickehngsganges so vieler Arten zeige die historische Folge welche die Natur bei der Schöpfung der Tierwelt eingeschlagen habe. Als erster Apostel dieser" Ansicht, die sicher schon ron älteren Forschern gehegt, aber nur nicht schriftlich niedergelegt wurde, tritt in' der Litteratur der Naturphilosoph Lorenz Oken ${ }^{1}$ ) in Jena hervor, dessen Auffassung durch folgende, seiner allgemeinen Naturgeschichte für alle Stände entnommenen Sätze beleuchtet werden soll:

..Ich bin durch meine physiologischen Untersuchungen schon ror einer Reihe ron Jahren auf die Ansicht gekommen. dass die Entwickelungszustände des Kïchelchens im Eie Ähnlichkeit haben mit den rerschiedenen Tierklassen, so dass es anfangs gleichsam nur die Organe der Infusorien besitze. dann allmählich die der Polypen. Quallen, Muscheln. Schnecken u. s. w. erhalte. Umgekehrt musste ich dann auch die Tierklassen als Entwickelungsstufen betrachten. welche denen des Küichelchens parallel gingen. Diese Ansicht von der Natur forderte die genaneste Tergleichung derjenigen Organe, welche in einer jeden höheren Tierklasse neu zu den anderen hinzukommen und ebenso diejenigen, welche im Küchelchen sich während des Briitens nach einander entwickeln. Ein rollkommener Parallelismus ist natïrlich nicht so leicht bei einem so schwierigen und noch lauge nicht hinlänglich beobachteten Gegenstande herzustellen. Zu beweisen aber, dass er wirklich rorhanden sei, ist in der That nicht schwer: dieses zeigt am deutlichsten die Terwandlnng der Insekten, welche nichts weiter ist, als eine Eutwickelung der Jungen, die auBerhalb dem Fi ror unseren Angen rorgeht und zwar so langsam. dass wir jeden embryonischen Zustand mit MuBe betrachten und mntersuchen können."

"Wenden wir uns nun zu denjenigen Insekten, bei welchen diese Zustände am grellsten hervortreten. so finden wir deren bei den Schmetterlingen drei. wämlich den Zustand der Raupe oder Larre. den der Puppe und den des rollkommenen Hliegenden Insekts. - - _ -

1) L. Oken, Allgemeine Naturgeschichte für alle Stände 1833. IV. Bd., p. 468. 
"Vergleichen wir diese drei Terwandlungszustände mit anderen Tieren. su kann es uns unmöglich entgehen, dass die Raupen die größte Ähnliehkrit mit den Wïrmern haben und zwar mit den Neerwiirmern, an denen man Fusswarzen und Borsten bemerkt.

Betrachten wir die Puppen, so ist die Ähnlichkeit mit der Schalenbedeckung der Krebse nicht zu rerkennen; nnd man kann nicht mmhin zu sagen, dass die Raupen ihre Wurmform abgelegt und die Krebsgestalt angezogen haben. Hier wäre mithin die sogenannte Verwandlung nichts anderes als pin Durchgang durch zwei Tierformen oder Tierklassen, nämlich durch die Wiirmer und die Krebse zu den vollkommenen Insekten."

Wer die Entwickelung der Tierwelt studiert, beobachtet gleich sonderbare Veränderungen bis zum Erreichen der definitiven Kö̈perform der Geschlechtsreife nicht bloß bei Tieren. welche frei lebende Larvenstadien besitzen, sondern auch bei den Tieren. denen unsere Sprachgewohnheit die direkte Entwickelung znerkennt. Wenn die Eier ron den Miittern gelegt werden, mögen sie nachher noch bebriitet oder sich selbst iiberlassen sein, so kriecht wohl aus dem Ei ein Individium, das dem elterlichen Organismus mehr oder weniger ähnlich ist, z. B. bei Fischen, Eidechsen, Schlangen und Tögeln. Sobald man aher das Schicksal des jungen Keimes imnerhalb der Eischale, d. h. ror dem Ausschlïpfen rerfolgt, gewahrt man eine Folge ron Veränderungen, welche sich den Erscheinungen der freien Metamorphose direkt an die Seite stellen lassen. Man wird daher den Thatsachen besser Rechnung tragen, wenn mandie allgemeine Regel so formuliert: Stark modellicrende Teränderungen des Kïrpers sind ein allgemeines Bildungsgesetz für sämtliche Tierarten. Ihm folgen nicht blok die dem Laien bekannten, der Metamorphose unterworfenen Tierarten, sondern fast sämtliche Eier mit sog. direkter Entwickelung. Die hochgradigen Formwandlungen der letzten Gruppe sind zu Beginn des Jahrhunderts nicht ordentlich bekannt gewesen, erst der emsige Fleiß der entrickelnngsgeschichtlichen Schnle hat dieselben und ganz besonders die auffallende Ähnlichkeit verschiedener. später recht anffillig geschiedener Tiergruppen während der ersten Entwickelungsstadien klar gestellt.

Diese Thatsachen hahen das Denken Darwin's ${ }^{1}$ ) so stark beeinflusst, dass er die Oken'sche Lebre in erneuter Fassung wiederholte:

$\left.{ }^{1}\right)$ Charles Darwin, Uber die Entstelung der Arten im Tier- und Pflanzenreiche. Stuttgart 1860, p. 452, 450, 453 . 
..Denn der Fmbryo ist das 'Tier in seinem weniger modifizierten Zustande und enthïllet uns insofern die Struktur seines Stammvaters. Zwei Tiergruppen mögen jetzt in Bau- und Lebensweise noch so rerschieden ron einander sein; wenn sie gleiche oder ähuliche Embryonalzustände durchlaufen, so diirfen wir uns iberzeugt halten, dass beide ron denselben oder von einander sehr ähnlichen Eltern abstammen und deshalb in entsprechendem Grade einander nahe verwandt sind. So verät l̈bereinstimmung in der Embryonalbildung gemeinsame Abstammung. Sie rerrät diese gemeinsame Abstammung. wie sehr auch die Organisation des Alten abgeändert und verhiillt worden sein mag."

„Die vorderen Gliedmaßen z. B.. welche der Stammart als Beine gedient, mögen infolge lange währender Modifikation bei einem Nachkommen zu den Diensten der Hand, bei einem anderen zu deuen des Ruders und bei einem dritten zu solchen des Fliigels angepasst worden sein: so werden nach den zwei Prinzipien, dass nämlich jede der successiven Modifikationen in einem späteren Alter entstand und sich auch erst in einem entsprechenden späteren Alter rererbte, die rorderen GliedmaBen in den Embryonen der rerschiedenen Nachkommen der Stammart einander noch sehr ähnlich sein; denn sie sind ron den Modifikationen nicht betroffen worden. Nun werden aber in jeder unserer neuen Arten die embryonischen Tordergliedmaßen sehr ron denen des reifen Tieres rerschieden sein, weil diese letzten erst in späterer Lebensperiode große Abänderung erfahren haben und in Hände, Rurler und Flïgel umgewandelt worden sind. Was immer für einen Finthuss lange fortgesetzter Gebranch und Übung einerseits und Nichtgebranch andererseits anf die Abäuderung eines Organes haben mag, so wird ein solcher Einfluss hauptsächlich das reife Tier betreffen, welches bereits zu seiner ganzen Thatkraft gelangt ist und sein Jeben seliber fristen muls: und die so entstandenen Wirknngen werden sich im entsprechenden reifen Alter vererben, daher riihrt es, dass das Junge durch die Folgen des Gebrauches und Nichtgebrauches nicht verändert wird oder nur wenige Abändernng erfïhrt."

"In gewissen Fällen mögen die auf einander folgenden Abänderungsstufen aus uns ganz unbekannten Griuden schon in sehr friiher Lebenszeit erfolgen orler jede solche Stufe in einer früheren Lebensperiode vererbt werden, als worin sie zuerst entstanden ist. In beiden Fällen wird das Junge oder der Embryo der reifen elterlichen Form rollkommen gleichen. — “

..So scheinen sich mir die Haupterscheinungen in der Embryologie, welche an naturgeschichtlicher Wichtigkeit keinen 
anderen nachstehen, aus dem Prinzipe zu erklären, dass geringe Modifikationen in der langen Reihe von Nachkommen eines alten Stanmvaters, wenn auch vielleicht in der friihesten Lebenszeit rines jeden veranlasst, doch keineswegs in sehr frihem Alter weiter vererbt worden sind. Die Embryologie gewinnt sehr an Interesse, wenn wir uns den Embryo als cin mehr oder weniger rerblichenes Bild der gemeinsamen stammform einer jeden großen Tierklasse vorstellen."

F. Haeckel1) galj dem unbestimmten Gedanken Darwins wenige Jahre später eine bestimmte dogmatisehe Fassung, nannte spine Stilisierung das biogenetische Grundgesetz und verstand es, demselben allgemeine Anerkennung zur verschaffen. Dasselbe besagt :

.. Die Ontogenesis oder die Entwickelung der organischen Individuen als die Reihe ron Formveränderungeu. welche jeder indiriduelle Organismus während der gesamten Zeit seiner indiriduellen Existenz durchläuft, ist ummittelbar bedingt durch die Phylogenesis oder die Entwickelung des organischen Stammes (Phylon), zu welchem derselbe gehört. Die Ontogenesis ist die kurze und schnelle Rekapitulation der Phylogenesis bedingt durch die physiologischen Funktionen der Vererbung und Anpassung. Das organische Individum wiederholt während des raschen und kurzen Lanfes seiner individuellen Entwickelung die wichtigsten ron denjenigen Formrerinderungen, welche seine Toreltern während des langsamen und langen Laufes ihrer paläontologischen Entwickelung nach den Gesetzen der Vererbung und Anpassung durchlanfen haben. Die vollstïndige und getrene Wiederholung der phyletischen Entwickelung durch die biontische (d. h. individuelle) Entwickelung wird verwischt und abgekürzt dureh sekundäre Zusammenziehung, indem die Ontogenese einen immer geraderen Weg einschlägt: daher ist die Wiederholung um so rollständiger, je länger die Reihe der successive durchlaufenen Jugendzustände ist. Die vollständige und getreue Wiedcrholung der phyletischen Entwickelung durch die biontische (individuelle) Entwickelung wird gefälscht und abgeändert dureh sekundäre Anpassung. indem sich das Bion (d. h. Individuum) wïhrend seiner individuellen Entwickelung neuen Verhältnissen anpasst: daher ist die Wiederholung um so getrener, je gleichartiger die Existenzbedingungen sind, unter denen sich das Bion (Individumm) und seine Torfahren entwickelt haben."

1) E. Hacckel, Generelle Morphologie der Organismen. Berlin 1866. II. Bd. p. 300 . 
Dieser Auffassung ist E. Haeckel während seines Lebens treu geblieben. Noch im Jabre 1896 schreibt er ${ }^{1}$ ):

„Die Ontogenie besitzt für die Phylogenie deshalh die höchste Bedeutung, weil zwischen diesen beiden Hanptzweigen der organischen Entwickelungsgeschichte ein unmittelbar enger Kansalnexus besteht."

An einer auteren Stelle ${ }^{2}$ ) ist das noch genaner erklärt:

.. Die Stammesgeschichte ist die wahre Ursache der Keimesgeschichte. Ohne die erstere wïrde die letrtere iuberhaupt nicht existieren. Derselbe findet seinen kiirzesten Ausdluck in nuserem biogenetischen Grundgesetze: die Keimesgeschichte ist ein Auszug der Stammesgeschichte oder schärfer gefasst, die Keimesentwickelung ist eine gedrängte und abgekïrzte Wiederholung der Stammesentwickelung. Diese Wiederholung ist umso rollstïndiger, je mehr durch beständige Tererbung die ursprüngliche Anszuşsentwickelung beibehalten wird. Hingegen ist die Wiederholung umso unvollständiger, je mehr durch wechselnde Anpassung die spälere Störungsentwickelnng eingefüht wurde."

Um den Sinn des biogenetischen Grundgesetres recht klarzulegen, fiihre ich die weitere Erlinterung Haeckel's ${ }^{3}$ ) an:

.Die gesetzmälige Reihentolge. in welcher bei den rerschitenen Tierstämmen die Organsysteme während der Ontogenese nach einander auftreten, gestattet uns nach dem biogenetischen Grundgesetze einen sicheren Schluss auf die historische Reihenfolge. in welcher sich die tierischen Organsysteme wïhrend des langeu und langsamen Laufes del organischen Erdgeschichte nach einander und ans einander entwickelt haben. Wir sehen also die Eigenschaften in derselben Reihe auf einander folgen, in der sie während der phylogenetischen Entwickelung erworben worden sind."

Haeckel fasst das biogenetische Grundgesetz dogmatisch und allgemein giltig. Er behauptet auch rom menschlichen Ei, dass dasselbe fast alle Organisationsstufen der niederen Tierwelt bis zu den Säugetieren während der Keimesentwickelung durchläuft. so dass der Keim eines Menschen oder eines anderen höheren Tieres sich zunächst als ein niedriges Lebewesen anlegt und in nachfolgenden Teränderungen auf höhere Organisationsstufen gehoben wird.

1) E. Haeckel, Systematische Phylogenie, I. Bd., p. 6.

2) E. Haeckel, Die Gasträatheorie, Jenaische Zeitschr. 1874 p. 5.

3) E. Haeckel, Die (iasträatheorie, Jenaische Zeitschrift 1874, p. 40. 
Das l,estätigen am besten seine „.Lehrsätze“ über die Entwicklungsgeschichte des Menschen ${ }^{1}$ ), deren „Wahrheit für jeden Anhänger des biogenetischen Grundgesetzes oder der Rekapitulationstheorie keines weiteren Beweises bedarf."

1. „Die einfache Beschaffenheit der menschlichen Eizelle leweist die einzellige Protisten-Natur der ältesten menschlichen Vorfahren."

2. ..Die Bildung der beiden primären Keimblätter beweist unsere Abstammung ron Gastrïaden."

3. „Das Stadium der scheihenförmigen Keimanlage mit Riickenmarksrohr, Darmrinne, Riickensaite und Mesodermlappen (sog. Chordula stadium) beweist, dass die Vorfahren des Meuschen wirbellose Prochordonier, d. h. Würmer, waren."

4. ,Das folgende Stadium, sog. Spondula oder Tertebrella, in welchem die Gliederung des Mesoderms in Urwirbel und Seitenplatten erfolgt, fiihrt den Beweis, dass der Mensch urspriinglich von Acranier'n abstammt."

5. „Die Keimform, welche der menschliche Embryo nach Terlauf ron 21 Tagen erlangt hat und welche eine Lïnge ron ungefähr $5 \mathrm{~mm}$. besitzt, ist ron besonderer Wichtigkeit: der Keim besitzt bereits die Anlage der drei primären Hirnblasen, der drei höheren Sinnesorgane, der Kiemenspalten und des Herzens; es fehlt aber noch jede Spur ron Gliedmaßen. Wir können daraus auf eine entsprechende Ahnenform aus der Klasse der Cyclostomen schließen."

6. „Die folgende Keimstufe zeigt bereits die fünf sekundären Hirnblasen, sowie zwei Paar Hossenförmige GliedmaBen; sie beweist die einstmalige Existenz einer Reihe von (silurischen) Ahnenformen aus der Klasse der Fische (Selachii)."

7. ,.Indem auf der folgenden Keimungsstufe die Lunge sich entwickelt, während die Kiemen noch persistieren, schließen wir auf eine entsprechende (devonische) Ahnenstufe ans der Klasse der Dipneusten (d. h. Lungenfische). "

8. "Nach Ablauf des ersten Monats beginnen sich beim mensehlichen Embryo die Kiemenspalten zu schlieben und die Anlagen der fünf Finger und Zehen an den beiden Gliedmaßenpaaren zu zeigen; der Keim entspricht auf dieser Bildungsstufe einer Reihe von (carbonischen) Ahnen aus der Amphibien-Klasse (Stegocephala)."

9. .. Die Bildung der Keimhällen (Amnion und Chorion) sowie das Hervorwachsen der Allantois und ihrer respirato-

1) E. Haeckel, Systematische Phylogenie. III. Bd. 1895, p. 619. 
rischen Blutgefäße verhält sich beim Nenschen genau so wie bei allen iibrigen Amnioten; und da wir für diese ganze Gruppe einen monophyletischen Ursprung annehmen müssen, so folgt daraus die einstmalige (permische) Existenz einer menschlichen Ahnenform aus dex Gruppe der Proreptilien."

10. .In der folgenden Keimungsstufe nimmt der menschliche Embryo bereits charakteristische Figentimlichkeiten der Säugetierklasse an; sie rekapituliert die Bildungsstufen der triassischen Monotremen-Ahnen."

"In den folgenden Stadien durchläuft der menschliche Embryo die Stufen der Beuteltiere, der Urplacentaltiere, der Halbaffen, der echten Affen und endlich der Menschenaffen!:

Das biogenetische Grundgesetz herrscht nach Haeckel im ganzen Tierreiche. Überall soll uns die Eientrickelung eine Reihe einfacher und höherer Organisationsstufen rorführen, und in mehr oder weniger deutlicher Weise den Ausbildungszustand längst vermoderter Yorfahren eines bestimmten Individuums rekapitulieren.

Der Beweis für seine Auffassung wird ron ihm durch viele Thatsachen zu führeu rersucht. Ganz besonderen Wert legt er ${ }^{1}$ ) auf die Erscheinung, dass alle tierischen Lebewesen von einer gemeinsamen Ausgangsform entstehen, d. h. dass sie sich mit nur sehr geringfügigen Ausnahmen ans einem sphärischen Eie entwickeln.

..Die fundamentale Thatsache. dass jedes vielzellige Tier am Beginne der individuellen Existenz nur durch eine einfache Zelle dargestellt wird. ist nur durch die Annahme erklärbar, dass dieser einzellige Keimeszustand die erbliche Wiederlolung einer entsprechenden einzelligen Ahnenform ist. Wir schließen daraus, dass die ältesten Ahnen jener hoch entwickelten Metaphyten einfache, einzellige Protophyten

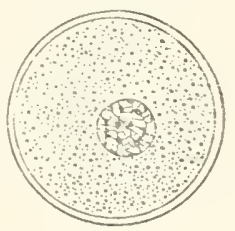

Fig. 99 .

Schematisches Bild der Eizelle. umgeben von der Eihaut. Im Inuern liegt der Keru mit seinem Nukleingegerüste. Der Plasmaleib ist punktiert.

aller Metazoen waren, ebenso wie die ältesten Vorfahre urspriinglich als einfache Protozoen lebten."

Die Eizellen tragen bei allen Tieren bestimmte Merkmale. Tm Innern ihres plasmatischen Körpers liegt der Eikern und die Oberflaiche des Eies wird von der mehr oder weniger dicken Eihaut bedeckt. Wenn Haeckel aus dieser Thatsache die unerhörte Folgerung zieht, die allgemeine $̈$ Änlichkeit der tierischen Eier beweise, dass in grauester Vorzeit alle Tierarten ron einzelligen 
Stammeltern gezengt worlen seien, so bildet er einen 'Trugschluss, indem er aus dem Fluss der Entwicklungserscheinungen die Merkmale eines einzigen Formstadiums herausgreift und alle anderen sonst noch in Betracht zu ziehenden Merkmale vergisst. Denn mögen anch alle Eizellen rou sphäriseher Gestalt sein, einen Plasmaleib, einen Korn und eine Eihant besitzen, die Thatsache ist dadureh nicht aus der Welt geschafft, dass die Eizellen selbst einen recht verschiedenen Ban anfweisen und dass eine Zelle zum sängetier, die andere Zelle zum Vogel, die dritte zu einem Krebs, eine antere zn einem Seeigel u. s. w. sich entwickelt, d. h. mit anderen Worten, dass tie eine gewisse Formähnliehkeit veratenden Mengen organischer Substanz, welche den Ansgangspunkt fiir die Entwickelung nener tierischer Individnen bilden, neben der gemeinsamen Eigensehaft, eine Eizelle zu sein, andere Verschiedenheiten in der Struktur des Plasmas, der Menge und Art des Dotters, nud besonders der ganz bestimmten Entwickelungsrichtung nach eiver hestimmten Endform hesitzen. Wir können das Schicksal der Eizelle beeinthussen, wir kïnnen sie in unnatiirliche Terhältnisse bringen und dadurch den normalen Gang ihrer Entwicklnug einigermaken stören, wir können die Eizelle töten oder zn krankhaften Missbildungen bestimmen, aber niemals ist es heobachtet worden, dass aus den Eiern einer sicher hestimmten Tierart ein ron den Eltern total abweichendes Lebewesen, d. h. dass ans dem Ei eines Togels eine Eidechse herrorkroch.

Haeckel vergisst, dass die scheinbar so einfachen Eizellen, welche ohne mancherlei Zwweifel allgemeine Ähnlichkeit zeigen, in jedem einzelnen Falle ron einem anderen Mutterboden herstammen und deshalh eine verschiedene chenische Zusammensetzung und eine rerschiedene Struktur besitzen. Die Eizelle des Säugetiers ist eben im Fierstock des Sängetieres, die Eizellen eines Vogels oder Krebses sind in ganz bestimmt begrenzten und wohl erkemnbaren Regionen des Vogel- oder Krebsleibes gebildet. Infolgedessen findet die Behauptung. dass die Eizelle selbst in dem ganzen Tierreiche ein gleichwertiges Produkt sei, anf eine gemeinsame Torfahrenform hinweise, keine Begriindnng in den thatsächlichen Verhältuissen.

Freilich wenn der Laie dranssen in der freien Natur kleine Eier von Thieren findet, ist er nicht im stande, zu sagen, von welcher Tierart sie abstammen, ferner werden ilım, mangels eingehenden Studiums die Unterschiede der Eizellen vieler Tiere nicht auffallen. Aber darin ist doch nicht der Beweis zu erblicken, dass die seinem Ange systematisch nicht unterscheidbaren Fier wirklich ein und dieselben Gebilde seien. Wir wïrden den Widerspruch jeder Eierhändlerin herausfordern, wenn wir ihr 
gegeniiber behaupten wollten. dass Hiihner-, Enten- und Taubeneier sich nicht unterscheiden lassen. weil das menschliche Auge blob geïbt sein muss, nm die feineren morphologischen Differenzen der Naturobjekte richtig zu beobachten. Deshalb sieht anch ein einfacher Handelsmann an seiner Tare feine Frkennungsmerkmale. welche hochgelehrten Männern oft gar nicht auffallen. Das Beispiel ist einfach gewählt, denn an den Eiern unserer Hausvögel springen die Unterschiede zu deutlich hervor. als dass man sie fiir identisch halten kïnnte. Das gleiche gilt aber auch für alle Eizellen iiberhampt.

Lm nu ein Beispiel anzuführen. will ich auf den Dotter der Eizellen rerweisen, welcher als Reservestoff für die Embryonalentwicklung oft zu großer Menge im Plasmaleibe des Eies aufgespeichert ist. Derselbe zeigt sehr wechselnde Lage,

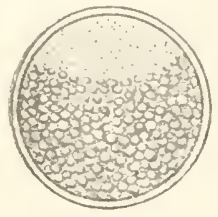

Fig. 100 .

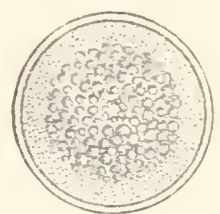

Fig. 101.

Fig. 100. Schematisches Bild eines Kno. cllenfischeies. Plasma punktiert, Dotter in Gestalt ron Trüpfchen.

Fig. 101. Schematisches Pild eines Insekteneies mit centraler Lagerung des Dotters. entweder erfüllt er die größere

Hältte des Eies und wird ron einer scheihenfömigen Kappe Plasmas hedeckt (Fig. 100) oder er liegt im Centrum, allseitig umhïllt rom Bildungsplasma (Fig. 101).

Die Behauptung Haeckels macht also den gleichen logischen Fehler, welchen ich begehe, wenu ich sagen wollte: alle Säugetiere werden geboren und von ihrer Mutter gesäugt, infolgedessen besitzen sie eine gemeinsame Mutter. Jedermann sieht den Fehler des Schlusses ein. Der Irrtum ist aber in beiden Fällen derselbe, indem wenige übereinstimmende Merkmale herausgegriffen wurden, um auf sie die vollständige Fleichheit der Eltern zu begründen, wälurend die zahlreichen Unterschiede rergessen werden.

Die Lehre unserer Betrachtung rerbietet es also, aus ciner Entwickelungsreihe ein einziges Formstadium hervorzuheben und die mehr oder weniger grosse Formähnlichkeit desselben bei verschiedenen Arten zu betonen. Wir diurfen nie außer Acht lassen, woher die Eier stammen, welchem Mutterboden sie entsprossen sind, welches Endergebnis die Entwickelung der Eizelle zeitigt. Weitere Ausführungen sind nach dieser Darlegung unnötig. Denn jedermann ist darïber unterrichtet. dass die Eizellen der Tiere und Pflanzen spezifisch verschieden sind, nur liegen die Unterschiede nicht so auf der Haud. wie bei dem Vergleiche ausgewachsener Tiere und man muss längere Zeit die Entwickelung verfolgen. um alle Unterschicde gewahr 

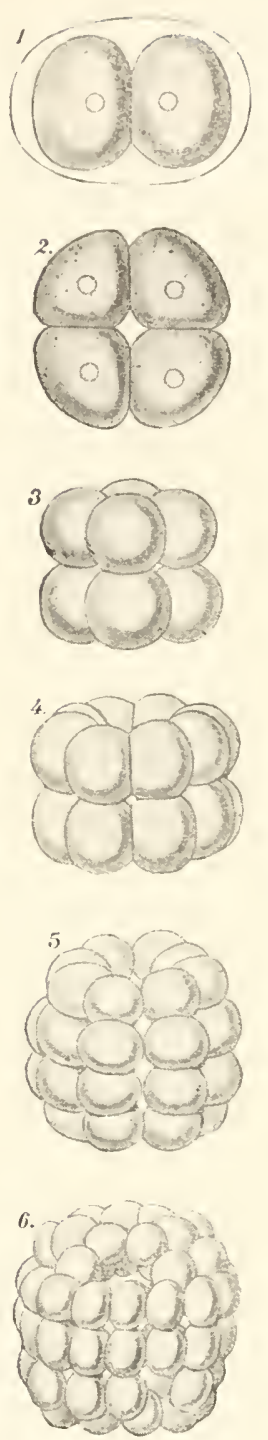

Fig. 102.

Eifurelung einer See. gurke, Holothuria tubulosa. Xach Selenka. 1, 3- 6 Seitenansicht, 2 P'olansicht, $1 \mathrm{Zw}$ wei Zellen, 2 Vier Zellen, 3 Acht, 4 Sechzehn Zellen, 5 Zweiunddreißig Zallen, $t ;$ Vierundsechzig \%ellen. zu werden. Aber bei Beriicksichtigung der an die befruchtete Eizelle anknüpfenden individuellen Gestaltung werden die spezifischen Besonderheiten nicht mehr vergessen werden können.

Wie sehr die voreingenommene Meinung das Urteil triiben kann, dafür bieten Haeckel's wissenschaftliche Arbeiten klare Beweise. Er hat in den siebziger und achtziger Jahren die ersten Entwicklungsvorgänge in verschiedenen Gruppen des Tierreichs sehr genau studiert und sich, da damals noch sehr wenig von jenen Vorgängen bekamnt war, zugleich das große Verdienst erworben, die ersten Schicksale der befruchteten Eizelle für eine große Zahl von Beispielen zum ersten Male aufzuhellen, jedoch ohne den Irrtum seiner oben (S. 211) citierten Behauptung einzusehen.

Nachdem die Eizelle jeglicher Tierart durch den Eintritt eines Samenfadens befruchtet ist, tritt die Teilung oder Furchung ein. Es entsteht ein Verein von Zellen aus welchem sich in ganz folgerichtiger Weise die einzelnen Organe aufbauen. Das Wesentliche dieser Vorgänge (Fig. 102) ist die Teilung der befruchteten Eizelle und die Bildung einer großen Zahl von Zellen. Zuerst schneidet eine Ebene die Eizelle in zwei Teile, eine zweite, zu ihr senkrechte Ebene, scheidet die zwei Furchungszellen in vier, eine dritte Ebene die vier Furchungszellen in acht Zellen, und so zerkliiften immer neue Furchungsakte den urspriinglich sphärischen Eileib in 2, 4, 8, 16, 32, 64, 128, 256 Zellen, bis die Zahl der Einzelzellen hinreicht, um
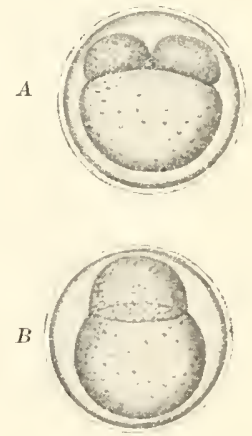

Fig. 103.

Zweifurchungstadien des Eieseines Knochenfisches. Der Eileib fült den von der Eihant umspannten Raum nicht ganz aus. Der in der Eizelle anfgespejcherte Dotter lässt di $\theta$ Fureluung nur an einem scheibentörmigen Teil des Eies auftreten. A. Zweiteilung, B. Endstadium der Furchung, in welchem ein sclueibenförmiger Haufen vou Zellen gebildet ist. 
den Modellierungsprozess des Embryos zu beginnen. Haeckel ${ }^{1}$ ) hatte sich früher um den Nachweis bemüht, dass „eine einzige
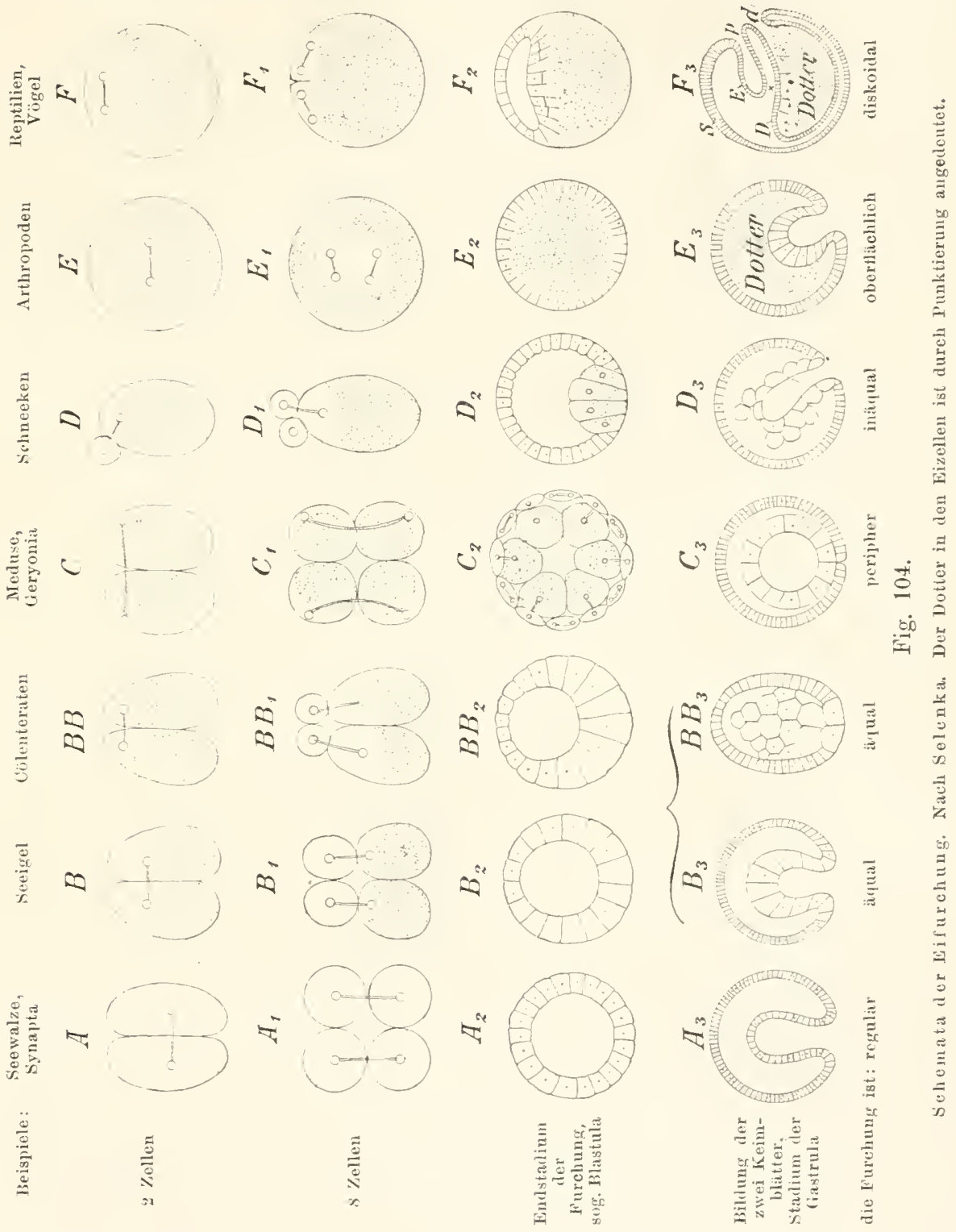

Form der Eifurchung als die ursprüngliche" und als "gemeinsamer

1) E. Haeckel, die Gastrula und die Eifurchnng der Tiere. Jenaische Zeitschrift, IX. Bd. 1875. S. 419, 420. 
Ausgangspunkt für die ïbrigen Formen der Furchung" betrachtet werden duirfe, und als bedentungsvoll hervorgehoben, dass bei ..den Angehörigen sämtlicher Tierstämme ganz dieselbe Form der ursprïnglichen Furchung anftritt." Aber diese Ansicht hat sich als unhalthar erwiesen; seitdem eine grosse Zahl von Einzelbeispielen genaner studiert worden ist, wissen wir vielmehr, dass der Furchungsprozess nicht die von Haeckel vermutete Einheit besitzt. Tergleichen Sie nur Figur 103, welche zwei Stadien aus der Entwicklung eines Knochenfisches illustriert, mit Figur 102, dann sehen Sie ein, dass die Eifurchung einer Seegurke und eines Fisches recht verschicdenartige Formcharaktere trïgt. Zur weiteren Thersicht füge ich eine schematische Tabelle (Fig. 104) meines hochverehrten Lehrers Selenka ein, welche besser als Worte die Mannigfaltigkeit der Furchung erläutert.

Bei den Reptilien und Vögeln wird die schwer mit Dotter belastete Eizelle ebenfalls nicht vollständig vom Furchungsprozesse exgriffen. Nur ein kleiner kappenförmiger Abschnitt derselben furcht sich, der ïbrige Teil bleibt ungegliedert. So entsteht zum Schlusse nicht eine kugelige Blase, sondern eine kleine urglasförmige Scheibe, die Keimscheibe.

Es wïrde zu sehr ins Detail führen, wenn ich die Unterschiede genaurer besprechen wollte. Darïber lautet auch das Urteil der entwickelungsgeschichtlichen Forscher einhellig, dass die Auffassung Haeckels cine falsche war. Der Furchungsprozess folgt im Tierreiche nicht einem einzigen Schema, und zeitigt nicht durchwegs iibereinstimmende Endresultate. Bei jeder einzelnen Art und jedem einzelnen Organisationstypus beginnt der Furchungsprozess an einem anderen Objekt, an einer verschiedenartig beschaffenen Eizelle und läuft in abweichender Weise ab. Wir haben nicht ein einheitliches Formgesetz erkannt, das die Entwickelung der Eizelle beherrscht. sondern einen Torgang, der graduell ausserordentlich verschieden ist. Wie die geschlechtsreife Form der Wirbeltiere, Gliedertiere, Insekten, Moliusken verschiedene Typen des tierischen Körperbaues darstellen, so zeigen ihre Eier uns rerschiedene Typen der Furchung. 
Tierzehntes Kiapitel.

\section{Die Ausnahmen des biogenetischen Grundgesetzes.}

Es ist eine unter den angehenden Jiugern der Wissmschaft weit rerbreitete Ansicht, dass die Theologen durch dogmatischorthodore Neigungen sich ror anderen Menschenkindern auszeichnen. welche freisinniger und toleranter zu sein wähnen. Soweit ich jedoch im stande bin. das menschliche Leben zu beurteilen, scheinen mix der Hang zur orthodoxen Meinung und der Zwang unter dogmatische Lehren Eigenschaften zu sein, die sich in der Brust jedes Menschen regen und anf jedem geistigen Arbeitsfelde breit machen. Auch in der Naturwissenschaft gewahren wir ihre spuren, trotzdem die Freiheit der Kritik. die unermiilliche Skepsis anf unserem Gebiete so laut proklamiert wird.

Die Subordination unter naturwissenschaftliche Dogmen folgt fiir riele Männer aus der Art und der Zeit des Studiums. Es unterliegt wohl keinem Zweifel, dass aller Lnterricht ein autoritatirdogmatischer sein muss. Denn jeder schüler und derjenige, welcher keine Zeit noch Lust hat, tiefer durch eigene Forschung einzudringen. muss den jeweiligen Stand der wissenschaftlichen Kenntnisse irgend piner Disciplin nach dem Tortrage seiner Lehrer annehmen und sich auf die rerbreiteten Lehrbiicher stïtzen. Fr lernt deren Inhalt zu einer Zeit, wo el selbst noch unfähig ist, die wirkliche Begrindung der Lehren zu ermessen. Obgleich allen die Möglichkeit einer späteren Priifung dessen, was sie im Hörsale erfahren haben, freisteht, so hat Thnen die eigene Beobachtung sicher schon gezeigt. wie wenige ron denen, welche jährlich die Universität rerlassen, wirklich in eine Prifung all der Fragen eintreten, die clas spezielle, eigene Arbeitsgebiet zu raten anfgiebt. Die Praxis und der Zwang des Berufes hindert die Tertiefung. So nehmen recht riele Jïnner die ron ihren Lehrern rorgetragenen Ansichten als richtio mit hinaus ins Leben und betrachten sie als sichere Wahrheit. Deshalb gilt die Autorität des herrorragenden Fachgelehrten hei 
den meisten wissenschaftlich gebildeten MIännern, nicht zum mindesten bei denjenigen, welche sich auf der Universität den naturwissenschaftlichen Studien gewidmet haben, und beherrscht lange Zeit das wissenschaftliche Denken der Gesamtheit, bis endlich bessere Beobachtungen den Bruch mit der falschen Lehre erheischen.

Was ich von der Autoritätsgläubigkeit sage, bezicht sich nur auf die große Masse der wissenschaftlich Gebildeten. Die selhstständig Denkenden und die Fachgelehrten sind dem Banne der Autorität weniger unterworfen, aber ich möchte nicht direkt behaupten, dass das Urteil eines jeden gauz frei rom Gehorsam gegen Autorität sei.

Die Naturwissenschaft unterscheidet sich also in dieser Hinsicht nicht fundamental ron anderen Wissenschaften: sie ist ein Menschenwerk und trägt den menschlichen Stempel an sich. Aber sie ist in gïnstigerer Lage gegeniiber anderen Wissenschaften, weil die Autorität leichter zerstört werden kann. Unsere Aufgabe ist es, die Erscheinungen in der Natur, die jedermann ror Augen liegen, scharf zu beobachten und klar zu beschreiben. Hat ein Fachgelehrter die Beschreibung eines Torganges nach bestem Ermessen gemacht, so kann niemand abgehalten werden, eine Nachprifung vorzunehmen und damit alte Irrtimer zu widerlegen. Die Gelegenheit dazu ist heute riel größer als in friiherer Zeit. Damals waren wenig Gelehrte am Werke, der litterarische Austausch zwischen deu Kulturnationen hat sich schwerfällig und miihselig vollzogen. Heute dagegen sind Hunderte ron Forschern thätig, in den wissenschaftlichen Instituten werden täglich neue Untersuchungen ansgefïhrt, die sich gegenseitig kritisieren, die Litteratur erscheint leicht und rasch, die Belanntgabe einer Beobachtung iiber die ganze Erdoberfläche ist in wenigen Tagen möglich. Deshalh ist die Kritik leichter und wird häufiger geiibt.

Aber wenn jemand, diese Mittel des wissenschaftlichen Fortschrittes benützend. gegen eine bisher gültige Lehrmeinung auftritt und sich bemiiht, die Fehler derselben darzulegen, so erhebt sich rasch der Widerspruch. Fragen Sie. wer ihn erhebt, so lantet die Antwort: Die Dogmatiker unter den Fachgelehrten. die in ihrer Meinung groß geworden sind und dieselbe während eines ganzen Lebens vertreten haben. Sie werfen die Antorität ihres Namens und ihrer unleugbaren Verdienste in die Wagschale, um die orthodoxen Ansichten einer ialteren Generation zu unterstiitzen. Der Streit der Meinung beginnt und währt so lange, bis endlich die alte Lehre abgethan und die neue an ihve Stelle gesetzt wird.

Durch diese Darlegung wollte ich Sie aufmerksam machen, dass die besondere Art unserer Studienobjekte und die exalite Methode 
der Beobachtung dic Naturforseher nicht mit besonderen Eigenschaften ausrüstet. Antoritüt und Dogma herrschen genau so wie in anderen Wissensgebieten, nur die Möglichkeit, eine falsche Autorität zu zerstören, ist auf unserem Gebiete größer. Auch in der Abstammungsfrage dominiert gegenwärtig der blinde Autoritätsglauben. Denn wie wenige der Anhänger haben die Beweisgrînde geprüft und sind im stande, über die Berechtigung derselben ein Urteil zu fällen! Aber die Lehre ist rerführerisch und man hält an ihr fest, weil sie am besten gefällt.

Die Bedeutung eines zoologischen Dogmas erlangte während der letzten Jahrzehnte F. Haeckel's biogenetisches Grundgesetz, welches besagt: die Entwickelung jedes Lehewesens wiederholt die wichtigsten Formreränderungen, welche die Voreltern während der langen Dauer ihrer Stammesgeschichte in graner Torzeit durchlaufen haben; sie giebt uns also ein Abbild der Umformung einfach gebauter Ahnen bis zur Erreichung der anatomischen Organisationsstufe der jetzt lebenden Arten. Einen Prozess, zu dessen Vollendung Millionen von Jahren erforderlich waren, führt die Entwickelungsgeschichte jedes einzelnen Individums dem Naturbeobachter in wenigen Stunden oder Tagen vor und giebt in einer gedrängten Rekapitulation die Übersicht der wichtigsten Formen, die von der gesamten Lebewelt seit ihrer Entstehung auf Erden durchlaufen worden sind.

Dieses sog. Gesetz übt einen starken verlockenden Zauber, da die Natur uns in der Metamorphose vieler Tiere beweisende Beispiele in Menge zu zeigen scheint. Die außerordentlich großen Unterschiede während der einander folgenden Altersstufen aller der Metamorphose unterworfenen Insekten erwecken in uns die Hoffuung, dass dieselbe wirklich einen sehr bequemen Einblick in die Vorfahrengeschichte eröffnen könnte. Ich habe Sie an die Insekten erinnnert, weil ihre Netamorphose am meisten bekannt ist. Diese Gruppe ist jedoch nicht allein durch die Metamorphose ausgezeichnet, dank der umfassenden Arbeit der entwickelungsgeschichtlichen Forscher wissen wir heute, dass die Metamorphose eine allgemeine Regel im Tierreiche ist, und dass jede Tierart während der Entwickelung aus dem Eizustande bis zur Geschlechtsreife ungeheuren Formwandlungen des Körpers folgen muss. Da nun in den letzten Jahrzehnten zahlreiche Beispiele der metamorphotischen Entwickelung aus allen Gruppen des Tierreiches bekannt geworden sind, haben die Anhänger der Abstammungslehre das biogenetische Gesetz gläubig hingenommen und ihm allmählich eine dogmatische Gültigkeit zugeschrieben, trotzdem sich in vielen Einzelfällen seine Wahrheit durch die realen Thatsachen nicht crhärten ließ.

Um ein einfaches Beispiel herzunehmen, wollen wir die Larven- 
formen der Insekten nach diesem Gesichtspunkt zunächst beurteilen. Sie wissen alle, dass aus den Eiern der Kïfer, Fliegen, Schmetterlinge u.s. w. kleine Larven ron scheinbar einfacher Organisation herauskriechen. Sie besitzon eine lïnglich gestreckte Gestalt, ihr Körper ist durch Ringfurchen in gürtelartige Segmente zcrfüllt, der Kopf ist nicht besonders groß, entbehrt der Fïlıler, oft auch der charakteristischen Facettenaugen, die Fliigel fehlen. die Beine sind sehr kurz. Auf den ersten Blick gewinnt dadurch die Lave eine gewisse Ähnlichkeit mit Wiirmern, und ein rasch urteilender Kopf könnte gleich Oken zu der Behauptung veranlasst werden, die jugendlichen Stadien der Insekten erschienen zuerst in der Form ihrer stammesgeschichtlichon Ahnen, der Gliederwïmer. Wenn wir aber genaner zuschen, dann bemerken wir eine Menge von Unterschieden gegenuiber den Gliederw ürmenn und finden die allerjüngste Larve wie ein typisches Insekt organisiert. Denn die für die ganze Klasse so charakteristischen Atemorgane, die Tracheen (Fig. 5), der Bau des Darmkanals mit den Malpighischen Gefäßen, die Form desHerzens. die Bildung des Kopfes und seiner Mundwerkzenge (Fig. 6), sowie die Anlage der Geschlechtsorgane (Fig. 7) tragen an der jüngsten Larve von Anfang an den Typus der Insekten, mit anderen Worten: der Raupenkörper ist genau nach dem Grundtypus des Schmetterlinges gebaut. Die Richtigkeit meiner Angaben keunt jeder, der sich, sei es auch nur als Sammler, mit Insekten eingehender beschäftigt hat. Die Merkmale der Kilasse sind an den jungen Larven so dentlich ansgepräigt, dass auch in dem Falle, wenn ein Sammler etwa Raupen begegnete, die er nie gesehen hat, er nicht lange im Kweifel bleiben wird, ol, er das Jugendstadim eines Schmetterlinges oder einen Turm vor sich habe. Die wissenschaftlichen Untersuchungen der letzten 40 Jahre haben auch für jeden unbefangenen Beurteiler klar gestellt, dass die jungen Larren nie und nimmer Bilder der Vorfahren geben können. Sie stchen rom ersten Momente ihres Lebens anf der Organisationsstufe des Insektes und werden in der folgenden Zeit nur hinsichtlich einzelner Organsysteme feiner modelliert. immer innerhalb des Rahmens des anatomischen Insektenstiles. Z/u Beginn der siebziger Jahre kounte der Engländer Lubbock in einem ammutend geschriebenen Büchlein den Tersuch wagen, die Insektenlarven nach dem biogenetischen Gesetze zu deuten. Heutzutage wird die Idee einfach ahgewiesen, wie das Citat aus Korschelt und Heider's Lehrbuch (p. 140) bezengt.

Mit den Larrenformen anderer Gruppen verbält es sich genau so. ». B. die Amphibien, d. h. die Frösche, Kröten (Fig. 105) und Salamander verlassen. wie Sie wissen, das Ei nicht in der fertigen Gestalt der Eltern, sondern als kleine rlem ansschlieBlichen Wasserleben ange- 
passte Kaulquappen, denen man eine gewisse Fischähnlichkeit nicht absprechen kaun. Sie besitzen einen breiten Ruderschwanz; seitlich an Kopfe stehen kleine, zierlich baumartig verzweigte Anhänge, reich von Blutgefäßen durehzogen. Das sind die für das Wasserleben notwendigen Atemorgane, die Hautkiemen. Ferner entbehren die Quappen lange Zeit sichtbarer Gliedmaßen. Diese drei Merkmale sprechen fuir die Fischähnlichkeit, besonders die Kiemenatmung, wolche erst am Schlusse der Larvenzeit durch Lungenatmung ersetzt wird: denn die Fische atmen zeitlebens durch Kiemen. Die eingehende anatomische Prifung zerstreut aber den Anschein der Ähn-

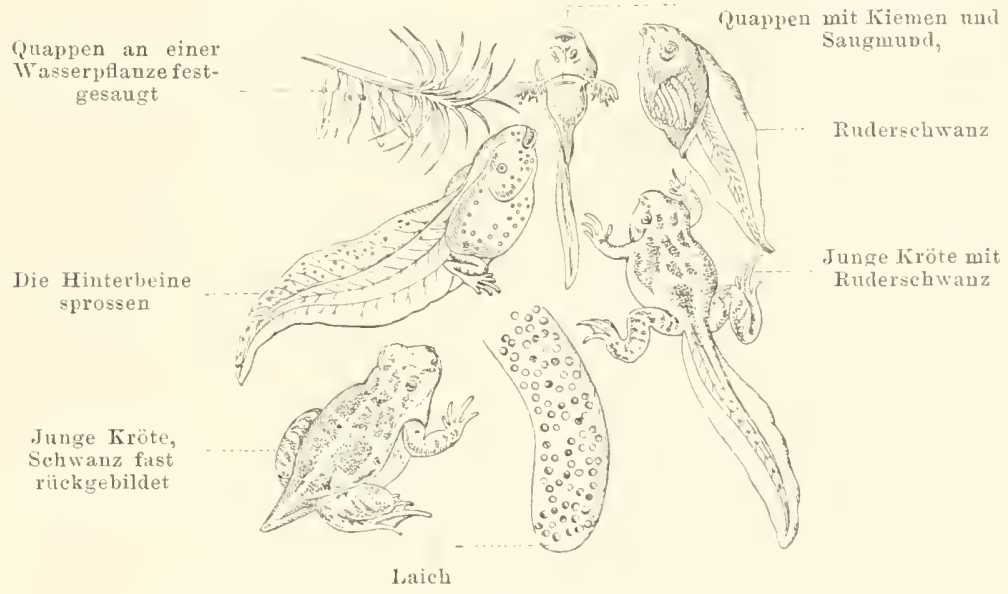

Fig. 105.

II et a morphose der Knobla u cliskröte, Pelobates fuscus.

lichkeit, weil die Kiemen der Fische und dic Kiemen der Amplibien ganz verschiedene Organe sind, welche an verschiedenen Stellen der Kopfregion liegen und nach abweichendem Typus gebildet sind. Bei den Fischen liegen die Kiemen als fïcherartig gefaltete Membranen in Seitentaschen des Vorderdarmes, also im Innern des Körpers verborgen, während sie bei den Larven der Amphibien als cylindrische, verzweigte Auswüchse anf der seitlichen Kiopfwand zwischen den äusseren Mïndungen der Schlundtaschen entstehen. Die Ähnlichkeit zwischen den Lurchlarven und Fischen wird also in bezug auf die Atemorgane durch den sprachlichen Ausdruck vorgetäuscht, indem ein und dasselbe Wort "Kieme" anatomisch total verschiedene Bildungen des Tierkörper's bezeichnet.

Je genauer man zusieht, um so größer wird das Gewicht der trennenden Eigenschaften, denn der fischgleiche Ruderschwanz der Quappen ist in anderer Weise aufgebaut als die Schwanz- 
region der Fische. Ferner besitzen die Quappen vordere und hintere Gliedmaßen naclı dem Typus der fünffingerigen Extremität, welche mit den Flossen der Fische überhaupt nicht vergleichbar sind. Bereits an der jüngsten kiemenatmenden Quappe sind die Lungen gebildet, welche den Fischen fehlen; ihr Herz zeigt immer den Typus der Amphibien und nicht den der Fische, der Darm erscheint ganz anders gebaut, desgleichen der Schädel n. s. w. Wenn später der lange Ruderschwanz eingeschmolzen wird, die Hautkiemen schrumpfen, die Gliedmaßen aus der Haut hervorwachsen, der Rumpf die Froschgestalt annimmt und die jungen Tiere endlich das nasse Element verlassen, um auf der feuchten Erde zu leben, treten Organisationseigentiimlichkeiten leicht sichthar vor die Augen des oberflïchlichen Beobachters, welche vom ersten Beginne des individuellen Larvenlebens vorhanden waren und dem Fachgelehrten wohl bekannt sind. Man kamn deshalb in dem Kanlquappenstadium keine Rekapitulation der Fischrorfahren erblicken. Um Ihnen die dem Laien etwas schwer rerstïndliche Sache klar zu machen, will ich ein drastisches Beispiel anziehen. Es verhalten sich die Amphibienlarven zu den Fischen genan so, wie der Schmetterling Callima paralecta aus Ostindien zu einem vertrockneten Blatte. Da Callima bunt gefürbt ist (die Vurderflïgel sind mit dunkelbramnen, gelb und blan gefürbten Schuppen bedeckt), so fällt sie durch das bunte Kleid fressgierigen Feinden auf und wird gerne vou Tögeln verfolgt. Sie rermag sich aber den Nachstellungen ihrer Feinde zu entziehen, indem sie sich unsichtbar macht. Der Schmetterling setzt sich auf einen Stamm nieder. schlägt nach der Art unserer Tagfalter die Flïgel nach anfwärts zusammen und gleicht nun durch die plötzlich sichthar gewordene Färbung und Zeichnung der unteren Fligelseite täuschend einem vertrockneten Blatte. Wenn Sie deuselben in der Nähe anschanen, so werden Sie durch die merkwürdige Ähnlichkeit überrascht sein. Es werden nicht nur die Vögel, sondern anch die Naturforscher getäuscht. Trotzdem wird es niemand einfallen, den Schmetterling als ein Blatt zu bezeichnen.

Ich habe das Beispiel gewähIt, um das Verhältnis der Larven der Amphibien zu den Fischen zu charakterisieren; denn in diesem Falle geht es ebenso wenig an, die allgemeine Ähnlichkeit jugendlicher Lurche mit der ganz anders organisierten Fischklasse als Beweis fuir die Wiederholung der ehemaligen Fischorganisation zu betrachten. Die Erinnerung an Fische wird in uns nur durch einige für das Wasserleben notwendige Formcharaktere der Kaulquappen wachgerufen, aleer das sind allgemeine Ähnlichkeiten ohne phylogenetischen Wert. Es fällt niemandem ein, einen Wal oder Delfin wegen 
ihrer wunderbaren Anpassung an das Wasserleben als direkten Abkömmling der Fische zu bezeichnen. Noch weniger ist der Gedanke für die Ente oder den Schwan gestattet. Das sind verschiedenartig gebaute Tiere, verschiedene Lebewesen, deren Aufenthalt ïbereinstinmt und die man deshalb in die unrichtig gebildete Gruppe der Wassertiere einreihen kanı.

Ob Sie die Naupliuslarven der Krebse oder die freischwimmenden Larven der Stachelhäuter oder die Larven der Frösche und Salamander prïfen, immer ergiebt sich dasselbe Resultat. Ich fuihre das nicht an vielen Beispielen ans, weil es zu langweilig wiirde. Wenn Sie irgend ein Lehrbuch der Entwickelungsgeschichte hernehmen, lesen Sie die unbestrittene Augabe gedrukt, dass die Larvenformen derjenigen Tiere, welche eine Metamorphose durchmachen, nie und nimmermehr sichere stammesgeschichtliche Rïckschliisse gestatten können.

Dabei ist es gleichgiultig, ob die Metamorphose an einem selbstständig lebenden Individunm, wie in den bisherigen Beispielen
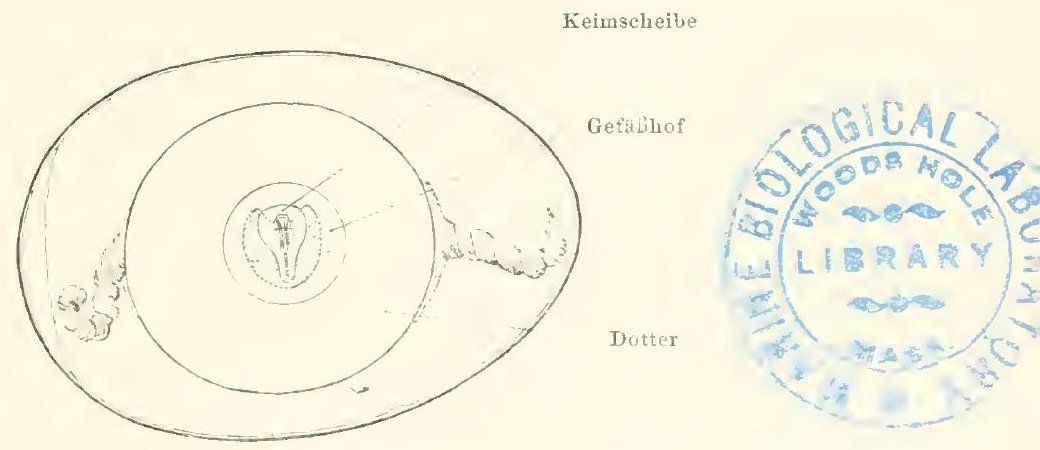

Fig. 106.

Hüln nere i, 46. Stunde der Bebrütung.

erfolgt, oder ob wir Tiere studieren, deren Verwandlung während des Eilebens d. h. vor der Geburt sich abspielt. Nach dem Gedankengange des biogenetischen Grundgesetzes sollen sich aus den Embryonalformen eines Keimes innerhalb der Eischale, z. B. eines Togels Rückschliisse auf die Torfahren der ganzen Klasse, auf Reptilien, Fische und sogar Würmer ziehen lassen.

Beobachten wir zunächst die Thatsachen. An einem frisch gelegten und kurz bebrütetrn Hühnereie (Fig. 106) sehen wir auf dem gelben Dotter innerhalb der Eiweißschichten eine kleine Scheibe, die Keimscheibe als erste Anlage des künftigen Togelindividums liegen. In den nächsten Bebrütungsstunden wächst die Scheibe, und es treten die primitiven Organanlagen auf. Da erscheinen jedoch nicht, wie man vielleicht erwarten kömute, die änßeren Formzüge des Leibes: der 
Kopf, die Beine, oder Federn, sondern zunächst werden die wichtigen inneren Organe, das Centralnervensystem, die Anlage der Wirbalsünle. die Leibeshöhle, das Herz. die Gefäße, der Darm gebildet und viel später enfolgt die Modellierung des Hautreliefs.

Die Keimscheibe setzt sich aus zwei flach streichenden Zellschichten zusammen, die untere Schicht, das innere Keimblatt oder Entoderm, berührt den gelben Dotter, darïber ist eine äuliere Zellschicht, das Ektoderm, gelagert. Früh erscheint auf der OberAäche der lieimscheibe (Fig, 107) eine kurze, seichte Pimne, die Primitivrinne;

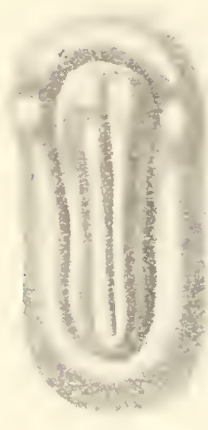

Fig 107.

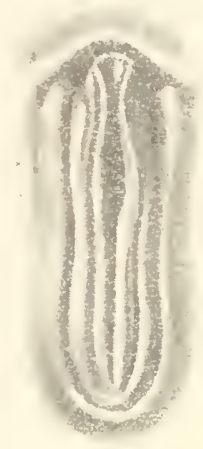

Fig. 108.

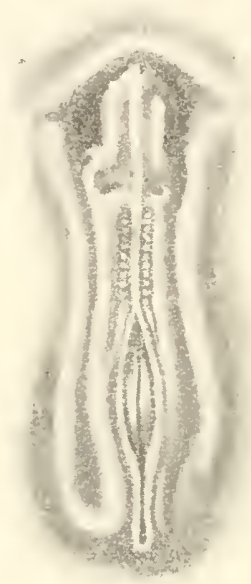

Fig. 109 .

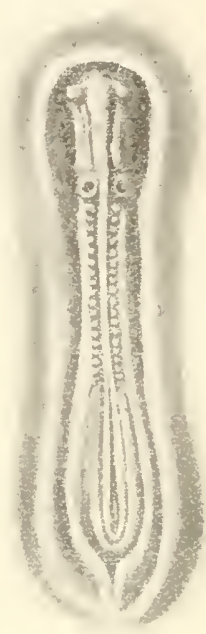

Fig. 110,

Fig. 107. Finbryonalanlage a s einemetwa 18 studen bebriteten Hubnerei. liickenansicht wach $\mathrm{H}$ is.

lig. 10s. Hïhnerembryo rom inde des ersten Bruttages. Rickenansicht nach His.

Fig. 109. Hüluerembryo an zweiten Eruttage. Rückenansicht nach His.

Fig. 110. Hähnerembryo $z$ wiscben dem zweiten und dritten Bruttage. Rïckenansicht nach $\mathrm{H}$ is.

sie deutet die Zone einer starken Produktion von Zellen an, welche sich als sog. mittlere Zellmassen, Mesoderm, zwischen die primären Keimblitter, das Elito- und Entoderm, einschieben und die Anlagen für den größten Teil der Körpersubstanz: die Muskeln, Knochen und Bindegewebe bilden. Die Primitivrimne bildet sich allmählich zurïick.

Bald nach dem Auftreten der Primitirrinne folgt vor ihr in der Richtung gegen das Kopfende der Keimanlage eine neue, viel weitere Rime (Fig. 108), rechts und links von vorspringenden Längsfalten begrenzt. Die Falten erheben sich gegen die Mittellinie, stoßen (Fig. 109) endlich zusammen und verwachsen $7 . n$ einem geschlossenen 
Rohre, das die Anlage des Centralnervensystems, des Rïckenmarkes und Gehirnes reprïsentiert. Indem sich sein Vorderende (Fig. 110) zu drei Blasen erweitert, wird die Anlage des Gehirnes sichtbar. Ungefähr gleichzeitig mit der Riickenmarksrinne ist unterhalb derselben im Entoderm ein ebenfalls in der Lüngsachse der Keimscheibe streichender Strang, die Chorda dorsalis, die erste Anlage der Wirbelsäule, entstanden.

Wenn Sie die Abbildung dieses Stadiums (Fig. 108), das in seiner allgemeinen Anlage auch den Typus der bei Süugetieren und dem Menschen spielenden V'orgänge illustriert, genauer betrachten, so sehen Sie ein, dass dasselbe mit einem Tiere, und sei es noch so einfach organisiert, überhaupt nicht zu vergleichen ist. Haeckel behauptet freilich, wir miissen darin die Rekapitulation der Wurmvorfahren der Wirbeltiere erkennen. (Vergleiche S. 210 These 3.) Ich liann jedoch seiner Auffassung ummöglich beipflichten, denn die eben oberflächlich beschriebene Embryonalscheibe ist ein unselbstïndiger, unfertiger, der weiteren Entwickelung bedürftiger Kieim, die flächenartig in der Ebene ausgebreitete Anlage des künftigen Vogelkörpers auf dem gelben Dotter des Eies. Sie wird sich später nach unten krümmen, die Randzonen der Keimscheiben werden mit einander verwachsen. Auf diese Weise wird die flache Anlage zum walzenförmigen Embryonalkörper (Fig. 111, 112) geschlossen. A uf der ron mir ins Auge gefassten Stufe entspricht sie keinem Tierkörper und giebt uns kein Recht, ihre Ähnlichkeit mit einem ausgebildeten Artindividum eines niedrigen Organisationstรpus, eben eines Wurmes, zu behaupten.

Dagegen spricht in schärfster Tonart das Torkommen des centralen Nervenrohres und der Chorda dorsalis, beides Organe, welche nur im Typus der Wirbeltiere erscheinen und in anderen Organisationskreisen niemals auftreten. Ihre Anwesenheit prägt dem jungen Hühnerkeime ganz bestimmt den Wrirbeltiercharakter auf und die Bedeutung dieser Kennzeichen wird nicht dadurch geschmälert, dass die anderen Merkmale der Wirbeltiere noch kaum kenntlich sind: die einfache Thatsache zerstreut Haeckel's dritte These (vergl. Seite 210) vollikommen in Nichtigkeit. Ton der Rekapitulation eines Wurmstadiums kann keine Rede sein, weil bei den Giliederwürmern niemals ein centrales Nervenrohr noch eine Chorda gebildet wird.

Wiirde das biogenetische Grundgesetz wirklich der in der Natur herrschenden Regel entsprechen, so künnte die junge Keimscheibe nur etwas iiber ihre Wirbeltierrorfahren aussagen, etwa ïber die Beschaffenheit der einfachsten Urfische, welche noch zum anatomischen Typus der Tertebraten gehört haben. Man kann sich 
jedoch schwer rorstellen, dass das scheibenförmige Stadium des keimenden Vogelleibes 'Zustände wiederspiegelt, welche früher während des freien selbständigen Lebens der Urahnen bestanden. Niemand wirl annehmen, dass der Weichkörper der Vorfahren nur das nervöse Centralrohr und die Chorda umsehloss und des Darmkanals, der Verdaungsdrüsen, des Herzens entbehrte.

Selbstredend behauptet Haeckel und seine Schule eine solche Ungereimtheit auch nicht. Ich will Sie nur anf die Widerspriche

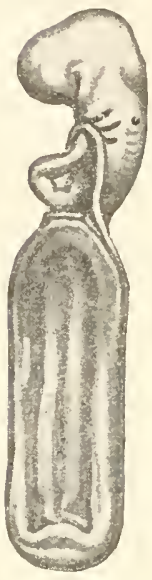

Fig. 111.

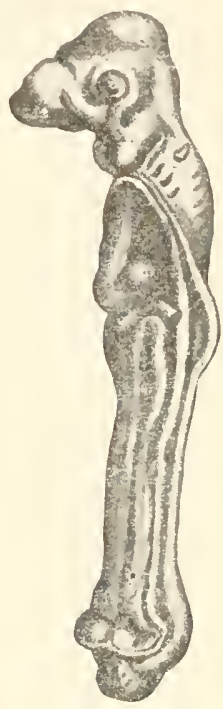

Fig. 112.
Fig. 111. Hühnerembryo am dritten Bruttage. Bauchansicht nach $\mathrm{His}$.

Fig. 112. Hithnerembryo am vierten Bruttage. Bauchansicht nach $\mathrm{His}$. aufmerksam machen, in welche wir verwickelt werden, wenn wir den Wortlaut des biogenetischen Grundgesetzes bedingungslos auf den speziellen Fall anwenden. Sie werdeu bald begreifen, dass die vielen Widerspriiche der exakten Thatsachen uns heutzutage bestimmen miissen, das ganze Gesetz als falsch aufzugeben.

Durch Krümmung nach der Bauchseite geht allmählich die flache Keimanlage in die Gestalt eines cylindrischen Körpers (Fig. 111, 112) ïber, an welchem Kopf-, Rumpf- und Schwanzregion und die Leibeshöhle erkennbar sind. Der Embryo hebt sich zugleich rom Dotter al, als ein immer selbständiger werdendes Gebilde, während die gelbe Dottermasse, nummehr von einer blutgefäßreichen Membran umschlossen, als cin Anhang desselben - Dottersack erscheint. Dabei wird der künftige Darmkanal zuerst als Rinne des Entodermes (Fig. 112) angelegt und zu einem blinden Rohr geschlossen. In der Kopfgegend gewinnen die Hirnblasen enorme Entfaltung.!

Das Verständnis des verwickelten Details würde eingehendes Studium erfordern; ich greife deshalb nur die Bildungsvorgänge des Darmes und die rasche Hirnentwickelung heraus, um daran das biogenetische Gesetz mit Thnen zu priifen, wobei ich bemerke, dass die rom Hühnchen abgebildeten Zustände in ähnlicher Weise auch bei Säugetieren und dem Menschen auftreten. Der Hiihnerembryo des vierten Bruttages (Fig. 112) ist noch nicht geschlossen und sein 
Darm stellt eine stark zusammengedriickte, etwas buchtig rerlaufende Rinne dar. Wenn die Ränder derselben rerwachsen, entsteht ein im Leibe eingeschlossenes Blindrohr einfachster Gestalt, das rom Kopfe bis zur Schwanzwurzel den Körper durchzieht. Mund und After fehlen. Bald senkt sich aber sowohl am Kopfe, wie nahe der Schwanzwurzel je eine kleine Tasche des äusseren Keimblattes, die Mund- und Afterbucht ein, wächst gegen das vordere und hintere Blindende des Darmrohres, lagert sich demselben an und indem hernach die trennenden Membranen reißen, wird die Darmhöhle durch ihre normalen Pforten, den Mund und After zugänglich. Zu jener Zeit ist der Darm ein ganz diinnwandiges, minimal enges Rohr ohne Muskelhülle für die peristaltischen Bewegungen, ohne Verdaungsdriisen.

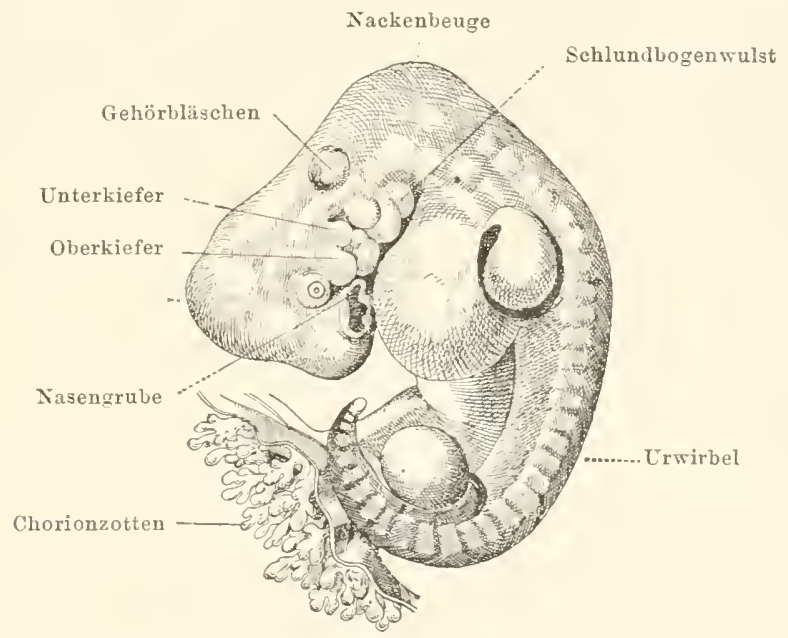

Fig. 113.

Menschlicher Embr so, ungefähr 4 Wochen alt. Nach His.

Können Sie sich um rorstellen, dass es Ahnen der höheren Wirbeltiere gegeben hat, welche des Nundes und Afters oder der anderen oben genannten Teile beraubt waren und mit dieser Organisation ein freies Leben führten? So wiirde ungeführ eine Konsequenz lauten, wenn die indiriduelle Keimesgeschichte dem biogenetischen Grundgesetze zuliebe wirkliche Torfahrenstadien wiederholen wïrde. Der Nonsens ist zu groß, als dass ich ihn ausführlich kritisieren sollte. Kein Anhänger des Haeckelschen Gesetzes hat ihn jemals ausgesprochen.

Beror ich darlege, auf welche Weise der Ausweg ans dem Dilemma versucht wurde, will ich andere Beispiele besprechen. Wenn Sie den Hïhnerembryo (Fig. 112) oder die Abbildungen 
irgend welcher Embryonen von Wirbeltieren, z. B. eines menschlichen Funloros der vierten Woche (Jig. 113) ansehen, fällt Ilnen anf, dass das Kopfonde derselben mächtig ausgebildet ist und durch scin Volumon in rinem schreienden Missverhältnis zu dem übrigen Körper steht. Noch an nengeborenen Sïngetieren und Menschen tritt die gleiche 'Thatsache herror". Sie ist dadureh verursacht, dass das Gehirn und Rïckenmark viel rascher ausgehildet werden als andere Organe und dureh ihr Tolumen die Masse der anderen litnge iibertreffen. bis allmählich die normalen Proportionen sichtbar werlen. Wollten wir im Sinne des Jiogenetischen Grundgesetzes dogmatisch urteilen, so mïssten wir folgeru, als Vorfahren existierten Tiere, ausgerüstet mit einem mächtigen Hirne und Riickenmark, während andere Organe, wie z. B. der Darm, die Bewegungsorgane u. s. w. muglaublich schwach entwickelt waren. Das ist jecloch wieder solch eine unfissluare Konsequenz, dass sie niemand ziehen mag.

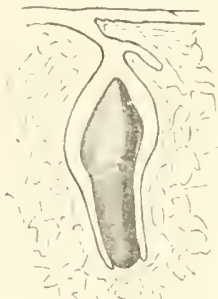

Fig. 114

Schematische Skizze einerim Kiefer verborgenen

Yahnanlage, welche vou dem Seltmelzorgane (weili) $u \mathrm{~m}$ liullt ist.

Ein anderes Beispiel! Sie wissen alle, diss die Zähne, die Zerkleinernngswerkzenge der Nahrung den nengeborenen Kindern fehlen. Sie liegen tief in den Kieferknochen verborgen, bedürfen langer Zeit, $u m$ in die II undhöhle durchzubrechen umı ihre Thätigkeit zu beginnen. Tor dem Durchbruche sind sie sogar ron einer besonderen Hülle, dem Schmelzorgane, gleich einer negatiren Formmatrize umschlossen. Müchten Sie durch das biogenetische Gesetz verleitet daraus schließen, es habe einstmals Tiere gegeben, welche echte Zähne besaßen, aber sie in ren Kieferkuochen verborgen hielten und sie nicht zum Ergreifen und zum Zerkanen der Nahrung rerwendeten? Sie wiirlen sicher alle eine derartige Dentung der stammesgeschichtlichen Urkunde verlachen.

Zu ähnlichen Unmöglichkeiten leitet die historische Deutung anderer Torgänge in der Embryonalentwicklung der höheren Wirbeltiere, welche ich wieder am Hiihnereie eharakterisieren will. Wenn in (lem ron Eiweiß und gelbem Dotter erfuillten Raum (Fig. 106) des kalkschaligen Togeleies ein kleines Kiichlein reifen soll, muss durch Resorption des Eiinhaltes Platz für den keimenden Embryo geschatfen werden. Zu diesem Zwecke wachsen zwei Schichten der Keimscheibe mit reichlichen BlutgefäBnetzen (Fig. 115) iiber den gelben Dotter als eine sackartige Hiille und führeu dessen langsam gelïste Masse in den Embryonalleib als Nährmaterial, zugleich wird anch das Eiweiß langsan resorbiert. Die abnehmende Dottermenge 
liegt also später in einem Dottersack und dieser steht durch den Dottergang mit dem Darm des Embryos in Verbindung.

Ausserdem hat sich ein besonderer, diinner Hïllsack, das Amnion (Fig. 115, 117) $\mathrm{nm}$ den Embryo selbst entwickelt und letzeren

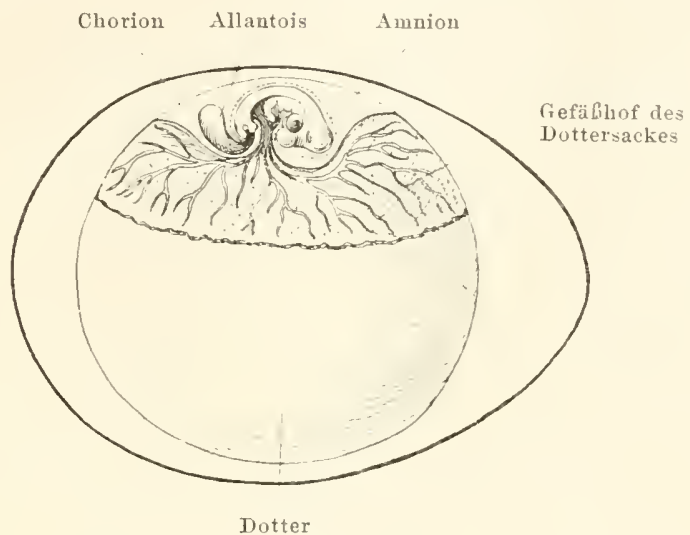

Fig. 115.

Hühnerei am Endedes fünften Bruttages. Tach Milne Marshall.

ganz umschlossen. Endlich ist an der rentralen Wand des Enddarmes eine blasenförmige Ausstiilpung, die Allantois (Fig. 135) entstanden, welche aus dem Körper in der Nabelgegend herauswächst. um sich außerhalb des Amnionsackes an die Eischale

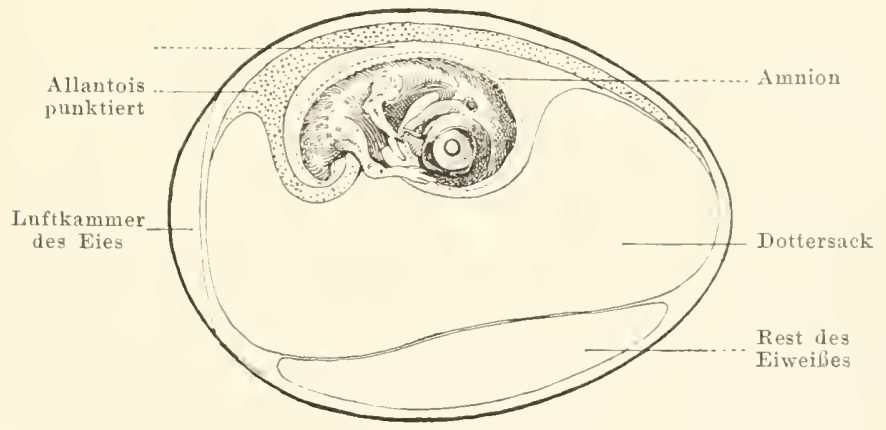

Fig. 116.

Hühnerei am Ende des nennten Bruttages.

anzulegen (Fig. 116) und als embryonales Atemorgan zu dienen. So wird der Embryo aller höheren Wirbeltiere, der Reptilien, Tögel und Säugetiere mit einer äußeren, sackförmigen Hülle, dem Amnion, und zwei Anhangssäcken, dem Dottersack und der Allantois versehen. 
Dieselben damern bis zum Verlassen der Eischale bezw. bis zur Geburt, wo sie zerrissen und abgeworfen werden. Die beiden niederen Klassen der Wirbeltiere, die Amphibien und Fische entwickeln sich ohne Eihiillen. Also bedingt deren regelmäßiges Torkommen bei den drei höheren Klassen ein recht bedentendes Trennungsmerkmal imerhalb des Typus der Wirbeltiere. Wiirden wir nun nach der Torschrift des biogenetischen Grundgesetzes in den embryonalen Hilfsorganen der Reptilien, Vöge] und Süugetiere die

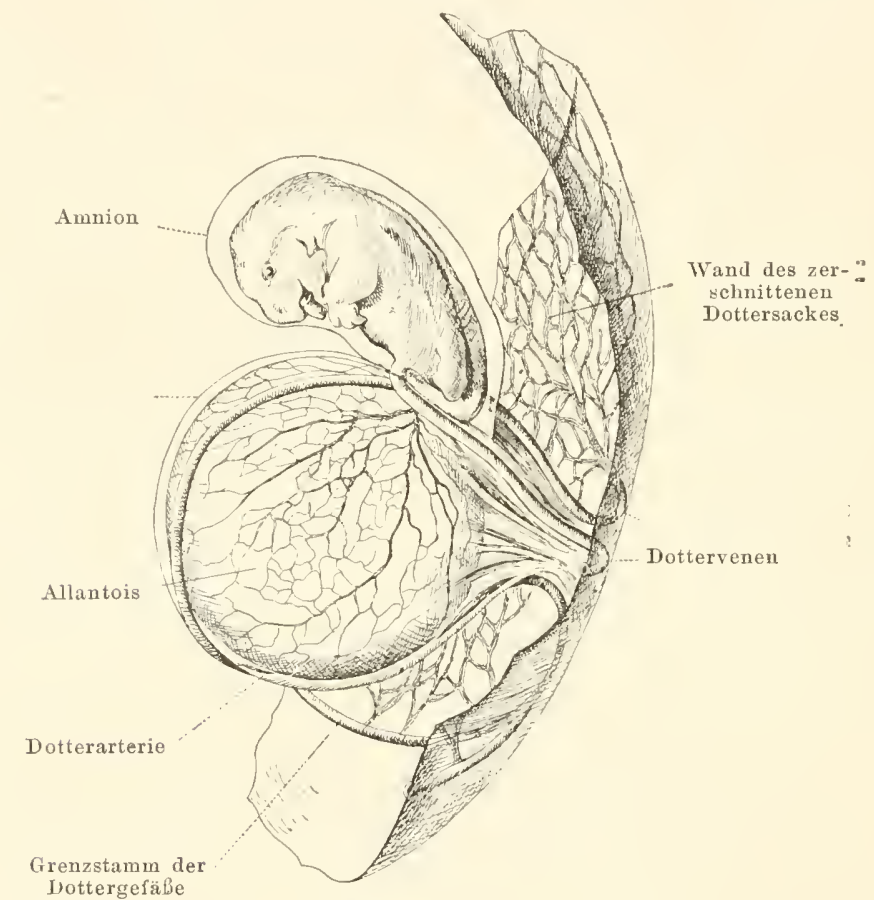

Fig. 117.

Embryo eines Opossums, Didelphys virginiana, mit den Eihäuten.

Wiederholung eines Besitztumes ihrer Vorfahren suchen, so kämen wir zu der Torstellung, die Ahnen seien während ihres Lebens in diimne Membrane gehiillt gewesen.

Ich habe Thnen mehrere dieser lächerlichen Konserpuenzen aus didaktischen Gründeu rorgeführt, um Ihnen klar zu machen, dass das biogenetische Grundgesetz nicht eine so durchgreifende Geltung besitzt, wie der Laie durch die lakonisch bestimmte Fassung desselben anzunehmen verleitet wird. Es wäre ganz ungehörig, wiirde ich nicht zugleich erklären, dass die Anhänger des biogenetischen Dogmas dieser Schwierigkeiten sich wohl bewusst waren 
und einen helfenden Answeg ersannen, um trotz des Widerspruches der Thatsachen ihre Verallgemeinerung aufrecht zu erhalten.

Haeckel') hat eine recht bestechende Ausrede gefunden, indem er sagt, mir sind die Fälle, in welchen das biogenetische Grundgesetz nicht ganz stimmen will, leicht erklärlich. Die Natur strebt danach, mit der Eientwickelung nicht allzu viel Zeit zu vertrödeln, sie will den indiriduellen Körper möglichst rasch rollenden und lässt sich keine Muße, die Vorfahrenstadien sämtlich zu rekapitulieren. So schlug sie im Laufe von Jahrmillionen einen immer mehr geraden Weg rom Eie zum fertigen Tiere ein, indem sie etliche Stadien aus der Trkunde der Torfahrenentwickelung strich und die Reihe der phylogenetischen Jugendzustände abkiurzte. Der ontogenetische Prozess erscheint infolge dessen gewöhnlich bedeutend einfacher, kiirzer und schneller als sein stammesgeschichtliches Torbild.

Er kann sich aber ron letzterem dadurch noch weiter entfernen, dass im Laufe der Zeit neue Prozesse eingeschoben werden (Metamorphose, Bildung von provisorischen Organen, Bildung ron Embryonalbiillen). Die neuen Charaktere wurden ron dem Organismus allmählich erworben und traten deshalb am Ende der entwickelungsgeschichtlichen Reihe hinzu. Dann zog sich die Reihe im Anfang zusammen, einzelne der ältesten Glieder schwanden röllig daraus, einzelne Zwischenstadien unterlagen einer mehr oder weniger weit gehenden Teränderung. Diese Neubildungen haben natiirlich gar keinen phylogenetischen Wert, sondern nur ganz beschränkte Bedeutung.

Die individuelle Keimesgeschichte führt uns also nicht eine klare, leicht rerständliche Urkunde ror. Wir sind nicht berechtigt. aus der stufenweisen Umbildung des Embryos unmittelbar auf die phylogenetische Umbildung einer entsprechenden Ahnenreihe zu schlielien, weil die Natur die Urkunde abkürzt und fälscht. Es bedarf rielmehr eines besonderen Studiums und scharfer Kritik, um die Fälschung ron den wahrheitsgetreuen Berichten zu scheiden.

Die Thatsachen zwangen also $\mathrm{H}$ aeckel, den Ausdruck .Rekapitulation der Stammesgeschichte" abzuschwächen in .. Auszug der Stammesgeschichte* und diese Bezeichnung wiederum einzuschränken durch den Zusatz: ,gedrängter und abgekürzter Auszug." Damit sinkt nach meinem Urteile das Grundgesetz auf die Stufe einer allgemeinen Phrase ohne wirklichen Inhalt herab. Demn wenn die entwickelungsgeschichtliche Crkunde nicht so rollständig ist, wie es der kurze Wortlant des biogenetischen

1) E. Haeckel, Die Gasträatheorie. Jenaische Zeitschr. 1874, p. 8. 
Gesetzes erwarten lïsst, wenn die Natur selbst, als Fälscherin ar heitend, viele Bildungsvorgäinge, die alte Verhältuisse wiederholen (sie wruden von Haeckel palingenetische Bildungen genannt), aus dem Flusse der Körperentwickelung jetzt lebender Arten gestrichen und nene den Fxistenzbedingungen der Embryonen besser förderliche cänogenetische Bildungen, wie z. B. die Embryonalhïllen der höheren Wirbeltiere eingeschoben hat, so steigern sich die Schwierigkeiten ins Ungemessene, um die gefailschte Urkunde zu entziffern und trotz der Inigen der Natur die Geschichte und das Aussehen längst rermoderter Ahnen richtig zu rekonstruieren.

Die Keimesentwickelung jeder lebenden Tierart stellt nach dieser Interpretation eine Mischung von palingenetischen und caenogenetischen Formen dar. \%. B. muter den Wrirbeltieren sind zwei KIassen, die Reptilien und die Tögel durch große. dotterreiche, pergament- oder kalkschalige Eier und die Bildung der Embryonahïillen (Fig. 106) während ker Eientwickelung ansgezeichnet. Die niedereu Klassen, die Amphibien und Fische, legen kleine Eier und entwickeln keine Hiillen. Infolgedessen mul der Descendenztheoretiker annehmen, die Eimerkmale der Reptilien und Tögel seien erst ron den Übergangsformen der Uramphibien zu dep Urreptilien (beide sind nie beobachtete Tiergruppen) erworben worden. Der nene Besitz aber hätte so störend anf die damals gïltige. uns wieder rollkommen mbekannte Entwickelung eingewirkt. dass die Natur gar nicht wusste, wie sie die wirklich palingenetischen Rekapitulationsstadien, welche teils die wirbellosen Ahnen. teils die Urfisch- und Uramphibienorganisation wiederspiegelten, dentlich ausbilden sollte. Mit raschem Entschlusse strich sie dieselben aus der damals gewohnten Entwickehungsreihe, schob die newen Embryonalhiillen ein und bruskierte die modernen Forscher, indem sie ihnen eine total cänogenetisch gefälschte Urkunde rorlegte.

Im gleichen Simne ist die beschlemnigte Entwickelung des Gehimes, der zeitweilige Mangel des Mundes und Afters, das lange Terweilen der Zähne in den Kieferknocheu zu deuten. Das sind alles cänogenetisch gefälschte Erscheinungen, nur dazn angethan, den descendenztheoretischen Eorscher in arge T'erlegenheit zu bringen.

Die bisherige Darstellung kennzeichnet eine Etappe in der Geschichte der phylogenetischen Forschung, welche ungefähr das .Tahr 1875 hegann und bis heute währt. In dieser Zeit suchte man die palingenetischen und cänogenetischen Vorgänge während der Eientwickelung immer deutlicher zu scheiden, mit Beriicksichtigung des Tmstandes, dass $H$ a eckel zwei Unterarten der cänogenetischen Fïlschung anfgestellt hatte, nämlich 
1. die Heterochronie der Entwickelung, d. h. die Organe können entweder früher oder später in der Keimesentwickelung auftreten, als es in der Stammesgeschichte der Fall war, z. B. das Gehirn, das Herz, die Angen;

2. die Heterotopie der Entwickelung, d. h. Organe können im Embryonalleibe eine andere Lage einnehmen, als sie im Körper der Urahnen besaßen.

Durch die eingehende Analyse vieler spezieller Beispiele wurde in den letztrergangenen zwei Jahrzehnten festgestellt, dass in der Eientwickelung sämtlicher Tiertypen riel mehr Heterochronien und Heterotopien, d. h. riel mehr cänogenetische Prozesse, als wahre Rekapitulation der früher herrschenden Zustände rorkommen. Deshalb messen manche Forscher der Entwickelungsgeschichte nicht mehr den großen, aufklärenden Wert bei, welchen ihr Haeckel und seine Schule frïher zugesprochen hatte. Ich will meine Behauptung durch einen Ausspruch ron C. Gegenban ${ }^{1}$ ) belegen:

... In der Ontogenese besitzt die rergleichende Anatomie eines der wichtigsten Hilfsmittel, insofern die Palingenese Zenguis bietet für die Torgeschichte der Organismen. Die Organe treten uns in jener in dem Sonderungsgange entgegen, und wir rermögen anch für mancbe uns nicht mehr lebend erhaltene Zustände Schliisse zu ziehen. Für die ans der Vergleichung ansgelildeter Organismen gewonnenen Erfahrungen bietet die Ontogenese nicht nur Bestätigung, sondern anch Ergänzung. Dieser Wert der Ontogenie ist jedoch kein alsoluter. Die mit der Palingenese rermischte Cänogenie in ihren mannigfachen Erscheinungen beschränkt jenen Wert und lässt ihn nur als relativen anerkennen. Bei der Verwertung der Ontogenese zu phylogenetischen Folgerungen bedarf es daher vor allem der kritischen Sichtung, der scharfen Sonderung der palingenetischen und der cänogenetischen Instanzen. Wer die Ontogenese mit allen ihren Erscheinungen für palingenetische Schliisse in Anspruch nimmt, gerät auf Irrwege, wie wir sie allerdings vielfach betreten finden. Die Notwendigkeit kritischen Verhaltens muss klar werden. sobald man der Thatsache Beachtung schenkt, dass selbst ein und dasselbe Organ nicht bloss bei ron eiuander entfernten Formen, sondern bei einander nächst rerwandten Gliedern kleinerer Abteilungen einen differenten Entwickelungsmodus besitzt. Jedes derselben rerweist scheinbar auf einen anderen zu Grunde

1) Carl Gegenbaur, Vergleichende Anatomie der Wirbeltiere. I. Bd., p. 17. Leipzig 1898. 
liegenden Zustand und doch kann nur ein einziger vorhanden gewesen sein! - - Ohne jenes kritische Verfahren liefert die Ontogenese nur ein verworrenes palingenetisches Bild."

Die Worte eines hervorragenden Meisters der anatomischen Forschung sagen Ihnen, mit welchen Schwierigkeiten die Dentung der entwickelungsgeschichtlichen Vorgänge im Sinne der Descendenztheorie zu kämpfen hat. Im Geiste eines anderen Mannes klingt die Ansicht in etwas anderer Fassung; deshalb füge ich noch die Meinung Steinmann's an, welcher die gleiche Überzeugung bestätigt;

„Es gibt ein biogenetisches Grundgesetz in dem beschränkten Sinne, dass manche Stufen der Stammesentwickelung in rohen Zügen auch noch ron den späten Nachkommen wiederholt werden, aber die Rekapitulation erweist sich als viel zu unvollständig und zu stark verschoben, als dass sie hei der Ermittelung der Stammbäume im Tordergrund stehen dürfte; ja sie kann, wie wir wissen, gerade den falschen Weg we isen."

Das biogenetische Grundgesetz besitzt also entgegen manch anderer Erkenntnis rom regelmäßigen Auftreten gemeinsamer Eigenschaften hei Naturvorgängen, welche man gewöhnlich Naturgesetz nennt, nicht die Eigenschaft, dass es in jedem speziellen Falle zutrifft. Es bedarf rielmehr für die meisten Fälle einer Reihe ron Ausnahmeklauseln und besonderen logischen Operationen, um seine Gültigkeit scheinbar aufrecht zu erhalten, kurz es kann nur durch einen Euphemismus „Grundgesetz“ der organischen Natur genannt werden.

1) Dr. Steinmann, Ein Facit aus den Fortschritten der Erdgeschichtsfurschung während der letzten vier Jahrzehnte, Prorelitoratsrede, Freiburg i. Br. 10. Mai 1899, p. 49 . 


\section{Fünfzehntes Kiapitel.}

\section{Der Zusammenbruch der Haeckel'schen Doctrin.}

Das Urteil ïber den theoretischen Wert der Entwickelungsgeschichte hat im nemzehnten Jahrhundert mannigfache Veränderungen erfahren. In der ersten Hälifte herrschten gerade entgegengesetzte Anschaunngen ron denen, welche heutzutage verbreitet sind. Zum Beweise dessen will ich Ihnen aus den Vorträgen über vergleichende Anatomie von Heinrich Rathke1), einem herrorragenden Forscher, dessen Urteil immer noch Bedeutung beanspruchen darf, eine Stelle vorlesen :

"Nachdem seit dem Anfange des siebzehnten Jahrhunderts mehrere Gelehrte bemiiht gewesen waren, durch anatomische Untersuchungen an erwachsenen Tieren eine Einsicht in den Bau derselben zu gewinnen, auch einige ron ihnen schon Forschungen ïber die Entwickelung der Tiere unternommen hatten, glaubte man vor einigen Decennien dahin gelangt zu sein, iiber die Verwandtschaftsverhältnisse und iiber die individuelle Entwickelung der Tiere auf sicherem Grunde folgende Ansichten aufstellen zu kömnen:

1. Alle Tierarten setzen eine einzige fortlaufende Reihe zusammen, in der jedes Glied körperlich etwas höher entwickelt ist als das zunächst vorhergehende.

2. Die ursprüingliche Form aller Tiere ist eine und dieselbe und aus dieser einen Grundform entwickeln sich alle, die höchsten wie die niedrigsten. Dieses aber geschieht, indem die höheren während ihrer individuellen Entwickelung ron ihrem ersten Entstehen bis zur vollendeten Ausbildung die bleibenden Formen aller niedriger stehenden durchlaufen, d. h. zu verschiedenen Zeiten ihres Lebens die bleibenden Formen der rerschiedenen tiefer stehenden Tierarten im wesentlichen auch an sich erkennen lassen. (Das ist die Anschauung, welche Haeckel das biogenetische Grundgesetz genannt hat.)

1) Heinr. Rathke, Torträge zur vergleich. Anatomie der Wirbeltiere. Leipzig 1862. p. 1. 
"Beide Ansichten haben aber völlig aufgegeben werden miissen - - - die zweite Ansicht ist durch v. Baer vollstïndig beseitigt worden. Überzengend hat derselbe insbesondere nachgewiesen:

1. Dass cin Tier bei seiner Entwickelung nicht aus einem der vier Grundtypen des Tierreiches in einen anderen iibergeht, sondern immer in den Grenzen des einen ron ihnen verbleibt, und

2. dass sich bei den verschiedenen Tieren, welche zu einer und derselben Gruppe gehören, während der Zeit ihrer Entwickelung zuerst der Grundtypus bemerkbar macht, nachher aber, während der Embryo einen immer höheren Grad der Ausbildung erlangt, sich aus diesem Grundtypus immer mehr untergeordnete Variationen desselben oder, mit anderen Worten, immer mehr spezielle Typen hervorbilden."

In scharfen Gegensatz dazu steilte sich die Meinung H a e ckels ${ }^{1}$ ), die ich nach einem seiner Aufsätze in der Jenaischen Zeitschrift citiere:

„Ziele und Trege der organischen Entwickelungsgeschichte werden nach meiner festen Überzeugung durch das biogenetische Grundgesetz endgiiltig festgestellt, dio Ziele klar enthiillt, die Wege bestimmt bezeichnet. Alle Arbeiten im Gebiete der Entwickelungsgeschichte, welche nicht bloß die empirische K'enntnis, sondern das kausale Verstïndnis der genetischen Phänomene anstreben, werden genötigt sein, dasselbe zu berücksichtigen, entweder bejahend oder verneinend. Die Gegner der Descendenztheorie werden notwendig das biogenetische Grundgesetz entschieden bekämpfen; His und Götte, sowie viele andere Gegner haben das auch bereits ganz folgerichtig gethan. Die Anhänger der Abstammungslehre werden umgekehrt in diesem wahren "Grundgesetze der organischen Entwickelung" den Schlïssel finden, mittelst dessen sie aus den offenkundigen Thatsachen der gegenwärtigen Keimesgeschichte unter gehöriger Beriicksichtigung der vergleichenden Anatomie die wichtigsten Schliisse auf die längst vergangene Stammesgeschichte ziehen köunen."

Die selbstbewusste Lobrede auf das sogemannte ..Grundgesetz" wurde vor 10-20 Jahren von einer großen Gemeinde unter den Naturforschem beifüllig aufgenommen. Unterdessen aber hat die nüchterne Kritik den schönen Schein wiederum zerstört, und ich konnte Ihnen viele Beispicle dafür anführen, dass die Thatsachen dieses Eigenlob nicht unterstiitzen. Doun die schroffe Fassung des

1) E. Haeckel, Ziele und Wege der heutigen Entwicklungsgeschichte. Jena 1875, p. 77. 
biogenetischen Grundgesetzes bereitet bei ihrer Anwendung auf den speziellen Fall recht große Schwierigkeiten und ist nicht als Ausdruck der Thatsachen, sondern als frommer W ${ }^{\top}$ unsch der Descendenztheoretiker anzusehen.

Zu gunsten desselbeu wurde früher geme die unleughare Thatsache angeführt, dass die sümtlichen Arten der Wirbeltiere oder eines anderen Organisationstypus, deren geschlechtsreife Tertreter nach den denkbar verschiedensten Formrichtungen ausgebildet sind, auf jungen embryonalen Stufen eine gewisse Ähnlichkeit offenbaren. Gemeinsame in der individuellen Keimesgeschichte jedes Wirbeltieres auftretende Formcharaktere, wie z. B. das Vorhandensein von seitlichen Taschen des Vorderdarmes, welche an der Haut mit kleinen Spalten, den Schlundspalten münden, boten der phylogenetischen Spekulation Anlass, dieselben als sichere Zeugnisse für die Blutsrerwandtschaft zu proklamieren, und allgemeiner Beifall wurde dieser Behauptung gespendet. Die Schlundspalten sind am Beginne des Jahrhunderts bei den Embryonen der Reptilien und Tögel entdeckt worden, später gelang der Nachweis des gleichen Vorkommens bei den Embryonen der Sängetiere und des Menschen. Als die nen reformierte Abstammungslehre in den sechziger Jahren das wissenschaftliche Denken auf beklagenswerte Irrwege führte, standen die Schlundspalten immer noch im Vordergrunde des allgemeinen Interesses, und alle Welt glaubte ein tieferes Verständnis der sonderbaren Einrichtung gewonnen zu haben dureh die descendenztheoretische Behauptung, dass die Schlundspalten ein alter, von den Fischen her ererbter Charakterzug seien; indem die Larven der Amphibien und die Embryonen der Reptilien, Tögel und Säuger solche Schlundspalten aufzeigen, wiederholen sie eine bei den Fischen bestchende Einrichtıng, und rekapitulieren das kiemenatmende Stadium der fischähnlichen Ahneu. Die Schlundspalten wurden also als eine palingenetische Bildung gedeutet, welche in der Keimesgeschichte der höheren Wirbeltiere getreu erhalten wäre.

Betrachten wir die Thatsachen selbst. Die Figur 118 zeigt Ihnen ein Stadium aus der Entwickelungsgeschichte eines Haifisches des Mittelmeeres, des Torpedo ocellata. An der Seitenwand des Kópfes fallen uns je fünf Schlundspalten auf. Das sind die äußeren Öffungen von paarigen Querkanälen, den Schlundtaschen, welehe vom Vorderdarme seitlich gegen die Haut ziehen und hinter der Mundhöhle Seitenwege bilden, auf denen alle durch den Mund in den Vorderdarm eingesogene Fliissigkeit ablaufen kann. Die Schlundtaschen entstehen am jungen Embryo als seitliche blinde Aussackungen des Vorderdarmes, wachsen gegen die Haut und brechen 
endlich an den Berührungsstellen in äußeren Spalten durch. Die Figur 119 zeigt Thnen das Vorkommen der Schlundtaschen am Vorderdarme beim Embryo eines Menschen. Die embryologischen Untersuchungen haben erwiesen, dass bei sümtlichen Wirbeltieren der Darmkanal frühzeitig die seitlichen Schlundtaschen gegen die Haut treibt. Thr Schicksal ist jedoch mannigfach verschieden. Entweder bleiben sie während des ganzen Lebens erhalten und spielen eine wichtige physiologische Rolle als Atemorgane -- das ist bei

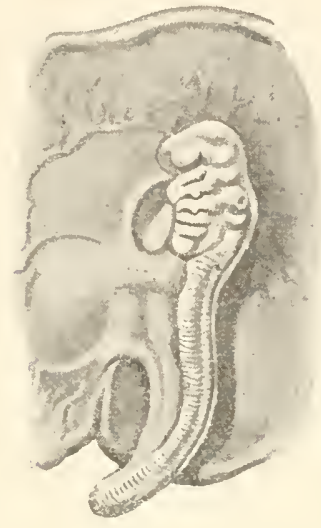

Fig. 118.

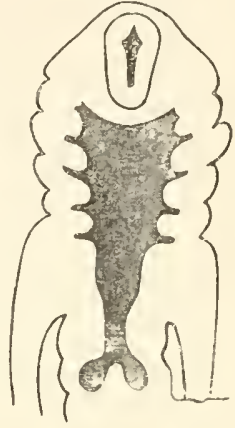

Fig. 119.

Fig. 118. Embryo des Zitterrochens, Torpedo ocellata. Nach Ziegler.

Fig. 119. Schnitt durch das Vorderende eines menschlichen Embryos, welcher viel jünger ist als das in Figur 113 abgebildete Stadium. Der Schnitt ist nngefäbr in der Richtung iles Nrklärungsstriches zum Worte: Schlundbogenwulst (Fig. 113) gefiihrt. Oben liegt der Querschnitt des Gehirns, darunter die Höble des Vorderdarmes mit den kleinen Schlundtaschen, hinten die Höhle der beiden L:angenanlagen.

den Fischen der Fall, oder sie bleiben unscheinbar, unterliegen bald einer Umbildung und schwinden meistens vor der Geschlechtsreife - das ist die Regel für die Amphibien, Reptilien, Vögel, Säugetiere.

Bei den Fischen erfahren die Schlundtaschen eine ungemein hohe Ausbildung zu mächtigen, halbmondförmigen Säcken, welche weit iiber die Seitenfläche des Vorderdarmes vorspringen. An ihrer Vorder- und Hinterwand entstehen die Wasseratemorgane, die Kiemenplatten, in Gestalt von feinen, dicht neben einander gelagerten Fächerfültchen, in denen reichliche Blutgefïßnetze entwickelt sind, so dass der Gasanstausch des Blutes an diesen Stellen sich leicht vollzieht. Um neue Wassermengen an die Kiemenplatten zu schaffen, machen die Fische fortwährend Atembewegungen (30-50 in der Minute) d. h. sie saugen mit dem Munde Wasser ein, leiten dasselbe in die Schlundtaschen und lassen es aus den Schlundspalten wieder abfließen. 
Die großen und zahlreichen Schlundtaschen beanspruchen am Kopfe vieler Fischarten einen so bedeutenden Raum, dass die Kopfregion von der Schnauze gegen die Brustflossen bedeutend anschwillt und z. B. bei den Karpfen wie ein nach hinten kegelartig verbreiterter Körperabschuitt ohne Grenze in den hohen Rumpf iibergeht. Die bei den Haifischen engen und niedrigen Schlundspalten der Haut dehnen sich bei den Knochenfischen ïber die ganze Seitenwand des Kopfes, langen säbelförmig gekrümmten Schlitzen gleichend. Außerhalb der Fischklasse wird eine ähnliche Entfaltung der Schlundtaschen nicht mehr beobachtet. Schon bei den Amphibien bleiben sie sehr klein und kurz, und dienen nicht mehr als Atemorgane. Sie erimnern sich ja von früher (S. 221), dass die Amphibienlarven mit Kiemen ganz anderer Struktur, mit den verzweigten, frei iiber die Kopfwand ragenden Hautkiemen (Fig. 121), begabt sind. Bei den Reptilien Vögeh und Süugetieren kommen

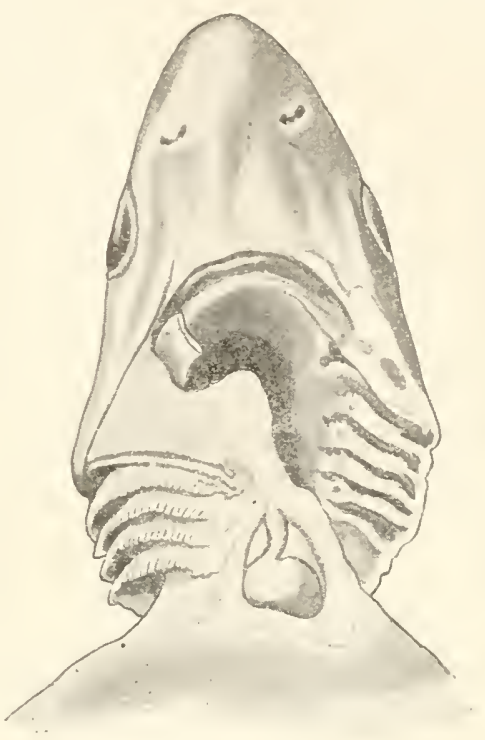

Fig. 120.

Kopfgegend des Dornhaies, Acanthias vulgaris. Aus der linken Kopfwand ist ein Keil ausgeschnitten, nm die sechs Schlundtaschen sichtbar zu machen, welche als dunkel schattierte Querräume gegen die Haut ziehen. An der rechten Kopfseite sind die gefalteten Kiemenplatten der fünf hinteren schlundtaschen freigelegt. die Schlundtaschen niemals aus der Kleinheit embryonaler Dimensionen heraus.

Die winzigen Täschchen werden bei allen lungenatmenden Wirbeltieren bald zurïckgebildet und die äußeren Schlundspalten schließen sich. Nur ein Paar, nämlich die erste Sehlundtasche dauert während des ganzen Lebens, doch gewinnt sie eine neue physiologische Bedeutung, dadurch dass sie vom Trommelfelle nach außen abgeschlossen und ihr die schallleitenden GehörKnöchelchen eingelagert werden. Sie wird später Paukenhöhle und Eustachi'sche Trompete genannt.

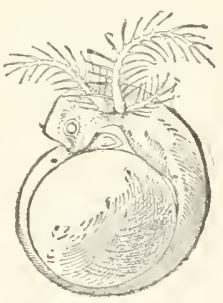

Fig. 121.

Embryo eines Amphibium, Epicrinm gIutinosum, mit ä u beren Kiemen. Nach Sarasin.

Somit beobachten wir in der Reihe der Wirbeltiere folgendes 
Schicksal der Schlundtaschen. Überall werden sie als winzig kleine Seitenrïume des Vorderdarmes angelegt, was wegen der niedlichen Verhältnisse des embryonalen Leibes wohl verständlich ist. Aber bald treten die Unterschiede ein; bei vier Klassen überschreiten sie niemals das minimale GröBenmak, bei den Fischen hingegen werden sie mïchtig entfaltet und mit Atemplatten begabt.

Vicle Descendenztheoretiker glaubten, die eben besproelienen Thatsachen bezeugen folgenden Verlauf der Stammesgeschichte: Einstmals war das Neer nur ron fischartigen Wirbeltieren bevölkert, deren Sehlundtasehen mäichtig ausgebildet wurden. Später entwickelten sich in einer noch gänzlich unbekannten Weise die lungenatmenden Wirbeltiere, zunächst von der Organisationshöhe der Lurche. Je mehr die Lungenatmung die Oberhand gewann, desto schwäeher wurden die Schlundtaschen nebst den Kiemen entwiekelt. Aber die Natur vermochte das allmählich iiberfiissige Organsystem nicht vollständig aus dem Körper zu entfernen, denn es war für Millionen und Milliarden früher verstorbener Arten zu wiehtigr gewesen und das pictätvolle Gesetz der Vererbung befahl, dass die Amphibicnlarven sogar ein im Wasser zu absolvierendes Jugendstadium, freilich mit cinem neuen Kiementypus bis auf den heutigen Tag beibehalten sollten. Während der Umbildung der Amphibien zu den Urreptilien, Vögeln und Sängern fand die Natur zum tiefsten Schmerze des Vererbungsgesetzes eine besondere Freude an der Fälschung der Entwickelungsgeschichte. Sie strich unverantwortlicher Weise das Wasserleben ganz aus dem individuellen Lebensrahmen der Arten, bildete auch keine Kiemenplatten mehr aus; in Anwandlung einer konservativen Laune behielt sic jedoch die winzigen Anlagen der Schlundtaschen bei, die jetzt keinen physiologischen Wert besitzen und höchstens den Zweck haben, die Stammesgeschichte skizzenhaft anzudeuten.

Dem schönen Romane, welchen ich mir in etwas satirischer Fürbung zu erzählen erlaubte, kann ich entgegen dem Urteile vieler tüchtiger Forscher keinen Wert zusprechen, weil die ganze Erzählung der Umbildung in der Luft steht. Thatsaehe ist nur, dass bei den Embryonen sämtlieher Wirbeltiere Seitentaschen des Schlundes zunächst in winziger Größse angelegt werden. Bei den Fischen wachsen sie zu mächtigen Säckchen heran, um als Atemorgane zu dienen, bei allen ïbrigen Arten bleiben sie klein und verkiimmern (ansgenommen das erste Paar). So grol3 auch die Eormähnlichkeit der Schlund taschen eines kleinen mensehlichen Embryos mit der entsprechenden Anlage eines Haifisches sein mag, jedenfalls gesellt sich ihr der Unterschied, dass die ersteren nicht, die letzteren wohl ins Große wachsen. Ich sehe da nicht ein, inwiefern man exakt beweisen 
könnte, dass die immer klein bleibenden und endlich verkümmernden Schlundtaschen der höheren Wirbeltiere einstmals die Fühigkeit besaßen, zu Kiementaschen auszumachsen!

Die nüchternen Thatsachen lehren uns für diese Frage bloB, dass die Kiemen der Fische wicht eine alleinstehende Einrichtung besonderer Art darstellen, sondern dass sie durch stärkere Ausgestaltung und feinere Modellierung einer allen Wirbeltieren zukommenden Taschenreihe entstehen. Mit anderen Worten: das entwickelungsgeschichtliche Studium hat die morphologische Übereinstimmung der Wirbeltiere für Organe nachgetriesen, welche früher ganz isoliert erschienen, wie wir in den ersten Stunden einmal das Flïgelskelett der Vögel als Modifikation des allgemeineu Typus des Extremitätenskelettes der höheren Wirbeltiere begreifen lernten.

Solcher allgemeiner Ähnlichkeiten der Wirbeltiere giebt es eine ganze Menge. Fische und Menschen sind charakterisiert durch den gemeinsamen Besitz des Rückenmarkes, der Gehirnblasen, des Hirnschädels, des gleichmäßig in Kammer und Torkammer geteilten Herzens, eines geschlossenen Blutgefäßsystemes mit typischer Lagerung der Hauptstïmme, durch den Besitz der Leber, der Bauchspeicheldrüse, den Ban der Seh- und Gehörorgane und durch die Bildung der Schlundtaschen. Jedes Lehrbuch hilft Ihnen, die große Zahl der gemeinsamen Merkmale aller cinem einheitlichen Organisationstypus zugehörigen Arten zu vervollständigen. Die gemeinsamen Grundzüge des Kö̈rperbaues treten frühzeitig während der individuellen Keimesgeschichte an dem winzig kleinen Körper der Embryonen auf. Sie scheinen in den kleinen Dimensionen einander in höherem Grade ähnlich, weil die Modellierung au kleinen Objekten stets geringfügiger ist als an monumentalen Größen und wenn Unähnlichkeiten trotzdem vorhanden sind. dieselben nicht so leicht gesehen werden. Die gemeinsamen anatomischen Eigenschaften entfalten sich aber rerschieden. Die Gehirnblasen z. B. erreichen ihr größtes Volumen in der Säugetiergruppe, während sie bei den Fischen unscheinbar bleiben und sich gerade umgekehrt wie die Schlundtaschen verhalten. Der Darmkanal der Fische ist kurz und in wenig Windungen gelegt, bei den Säugetieren wächst er zu einem langen, vielfach gewundenen und verschieden weiten Schlauch aus. Die Schwanzregion dient den Fischen als wichtiges Bewegungswerkzeug durch ihre kolossal entwickelte Muskulatur, während bei den Tögeln der Schwanz ganz verkümmert.

Diese Bcispiele sollen Ihnen nur erläutem, dass die allen Wirbeltieren gemeinsamen anatomischen Charaktere in verschiedeneu Klassen auf verschiedene Art entfaltet sind, ohne dass wir eineu 
stichhaltigen Grund dafür neunen kömnen. Das Vorkommen von Schlundtaschen und deren wechselnde Ausbildung bei den niederen und höheren Wirbeltieren gewährt uns darum nach meiner Ansicht ebenso wenig einen Einblick in die Stammesgeschichte als die Beobachtung der verschiedenen Abarten des Herzens, Gehirnes, Skelettes u. s. w.

Um noch ein anderes Organ zu besprechen, will ieh die zu großer theoretischer Bedeutung gelangte Chorda dorsalis hervorheben. Sie wissen meist nur, dass die Wirbeltiere als Stiitze ihres Körpers cine Wirbelsäule besitzen. Vom Anatomen erfahren Sie, dass durch die Reihe der Wirbel ein feiner Strang von weichlicher Konsistenz, die Rückensaite, Chorda dorsalis (Fig. 122), hindurchzieht.

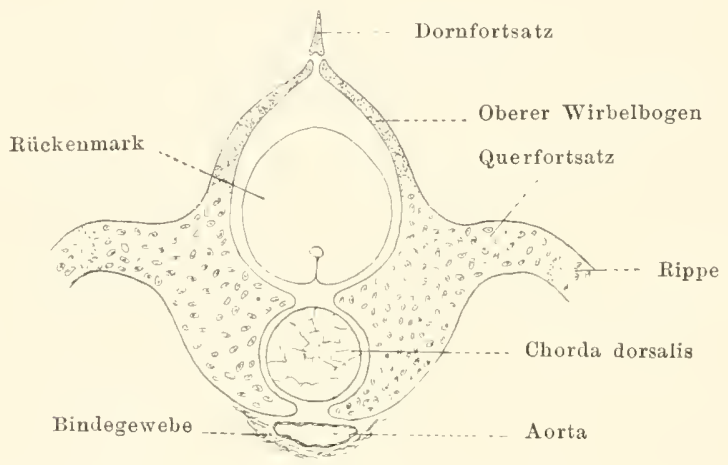

Fig. 122.

Querschnitt dureh die Gegend der Wirbelsäule eines jungen Karpfen. Nach Scheel.

Alle Wirbelkörper durchbohrend lässt sie sich von der Ḱopfregion bis zur Schwanzspitze verfolgen und tritt anßerordentlich frühe im Embryonalleben unterhalb des Rückenmarkrohres bei den Fischen, Amphibien, Reptilien, Vögeln und Sïugetieren auf.

Die Descendenztheoretiker führen das Vorkommen der Chorda gerue als einen Beweis für die Abstammung der höheren Wirbeltiere von den Fischen an, wiederum ohne Reeht; denn die Rüekensaite ist ein allen Wirbeltieren zukommender Besitz, der in verschiedenen Klassen verschiedengradig entfaltet wird. Bei den Fischen imponiert sie als mächtiger, durch die Wirbelkörper teilweise eingeschnürter Strang. Bei den höheren Wirbeltieren ist sie schon auf den jüngsten Stadien der Körperentwickelung schwach angelegt und erfährt keine Verstïrkung ihres Kalibers, ja allmählich schwindet sie bis auf unbedeutende Reste ohne lebenswichtige Bedeutung.

Besser als das anatomische Studium des ausgebildeten Tierkörpers enthüllt die Entwickelungsgeschichte das Vorkommen gemeinsamer 
Charaktere der Wirbeltiere. Es liegt jedoch kein zwingender Grund vor, den während der Embryonalzeit auffallenden Ähnlichkeiten, welche durch die Schlundtaschen, die Chorda etc. gekennzeichnet werden, einen größeren phylogenetischen Wert zuzusprechen als den zahlreichen während des ganzen Lebens dauernden gemeinsamen Eigenschaften. Auch die descendenztheoretische Schule kann für diese Bevorzugung keinen anderen Grund als die einfache Behauptung anfïhren und dem kritischen Blicke ihre Ohnmacht nicht verbergen.

Gegen meine niichterne Auffassung werden Sie leicht ablehnend gesinnt, sobald ein Anhänger der Entwickelungstheorie Thnen sagt, die Schlundtaschen und die Chorda dorsalis müssten als wichtige stammesgeschichtliche Zeugnisse gedeutet werden, soust könne man nicht einsehen, warum die nutzlosen Einrichtungen überhaupt bei den Embryonen der Reptilien, Tögel und Säugetiere rorkommen; die Frage heische notwendig eine Antwort und diese müsse im descendenztheoretischen Sinne gegeben werden. Nachdem ich schon bei einer früheren Gelegenheit (S. 118) Sie anf die Fehler hingewiesen habe, welche in der Schlussfolge rerborgen sind, möchte ich Sie heute nochmals ror dem rerführerischen Klange dieser gänzlich unlogischen Praktik warnen. Jedermann wird nach Kenutnisnahme der beiden eben besprochenen Beispiele für sich die Frage stellen, warum die Natur so streng an der Bildung der Chorda und Schlundtaschen festhält. Aber diese Frage darf hier nicht als Ausfluss des Causalitätsdranges unseres Denkens gelten, sondern als eine falsche, wenngleich durch den gewöhnlichen Sprachgebrauch entschuldbare Stilisierung für das Gefühl der Uberraschung, welches das embryonale Geschehen in uns erweckt.

Wir finden es sonderbar und auffallend, dass die Natur gerade so und nicht anders rerfährt, wir hätten einen riel einfacheren Modus der Entwickelung erwartet und bezeichnen unsere Terwunderung kurz durch den sprachlichen Ausdruck: warum wird die Chorda gebildet. warum treten die Schlundtaschen auf?" Wer genau iiber die reellen Thatsachen nachdenkt, wird allmählich einsehen, dass es für die als Frage stilisierten Gedanken überhanpt keine Antwort giebt.

Ein anderes Beispiel wird Ihnen rielleicht deutlicher sagen, was ich meine. Nehmen Sie an, wir hätten iiber den Bau des Menschen, ïber seine Fähigkeiten, seine kulturellen Fortschritte lange nachgedacht und die Überlegenheit unseres Wesens durch den Vergleich mit anderen Tieren recht empfunden, so freuen wir uns iiber die Torzïge unseres Geschlechtes und können diese Reihe ron Gedanken auch in die stilistische Fassung bringen: wie ist es möglich, dass gerade wir vor allen Geschöpfen der Erde so ausgezeichnet 
sind oder in anderer syntaktischer Form: warum besitzen wir Menschen die höchsten geistigen Figenschaften? Sie wissen alle, dass das eine sog. Frage ist (in Wirklichkeit ist sie ja nur ein in Frageform gekleideter Ausdruck der Terwunderung), welche das Nachdenken eimes ernsthaften Mannes nicht lohnt. Unsere menschliche Natur und die Eigenart aller individuellen Anlagen und Fähigkeiten muss der Denker als gegebene Thatsachen hinuchmen, ohne eine Ursache dafür zu ergrïnden. Warum ich fünf Finger habe, warum ich nur acht bis zehn Stunden des Tages marschieren kann u. s. w. kann ich nicht erklären. Ich kann nur konstatieren, dass es so ist, und dass viele glauben, interessanter zu sprechen, wenn sie die alltägliche Thatsache in das Gewand einer Frage kleiden. Die Descendenztheoretiker versuchen dieselbe Unmöglichkeit, indem sie sich den Anschein geben, als wollten sie wirklich nach der Ursache des Vorkommens der Chorda, der Schlundtaschen u. s. w. fragen.

In der Absicht, dem Laienpublikum das biogenetische Grundgesetz recht einleuchtend rorzutragen, liebt es Haeckel, die Angabe zu wiederholen. dass die Embryonen aller Wirbeltiere in den ersten Entwicklungsstadien einen sehr hohen Grad ron $\ddot{A} h n l i c h k e i t$ sowohl im äußeren Habitus, als auch im anatomischen Aufbaue offenbaren. Er setzt erklärend hinzu. das wäre nicht möglich, wenn nicht die Tiere blutsrerwandt wïren und kraft des Vererbungsgesetzes die gemeinsamen Formzïge ron ihren gemeinsamen Ahneu aufgeprägt erhalten hätten. In seinem letzten populäiren Werke, die ..Welträtsel $)^{1}{ }^{6}$ spricht er die Ansicht ganz bestimmt aus :

..Die wesentliche Übereinstimmung in der äußeren Körperform und dem inneren Bau, welche die Embryonen des Menschen und der iibrigen Vertebraten (Wirbeltiere) in dieser frithen Bildungsperiode zeigen, ist eine embryologische Thatsache ersteu Ranges.

"Wenn wir seben, dass in einem bestimmten Stadium die Keime des Menschen und des Affen, des Hundes und des Kaninchens, des Schweines und des Schafes zwar als höhere Wirbeltiere erkennbar, aber sonst nicht zu unterscheiden sind, so kann diese Thatsache eben nur durch gemeinsame Abstammung erklärt werden."

Jeder, der diesen Satz liest, muss glauben, dass wirklich eine unbeschreibliche Ähulichkeit zwischen den Wirbeltierembryonen bestiunde; ja, er wird die Angabe um so mehr für richtig halten, als sie ron dem Verfasser der natiirlichen Schöpfungsgeschichte seit

1) E. Haeckel, Die Welträtsel. Bonn 1899, p. 75. 
30 Jahren wiederholt wird. Ton wissenschaftlicher Seite wurde derselben aber gleich im ersten Momente ihrer Publikation sehr scharf opponiert. W. Hisl) hat ihre Unrichtigkeit schon im Jahre 1874 durch Wort und Bild gezeigt. Haeckel konnte damals blok in der frïher (S. 10) citierten, verlegenen Weise antworten.

Die Fortschritte der entwickelungsgeschichtlichen Forschung haben seither die Ansicht ron His bestätigt, die Beharptung Haeckel's aber als fehlerhaft erwiesen. Als Haeckel die Lehre ron der iiberraschenden Ähnlichkeit der Embryonen aussprach, war sein Irrtum zu entschuldigen; denn das Studium der Entwickelungsgeschichte steckte damals in den Kinderschuhen. Wenig Tierarten waren genauer untersucht, vou den meisten nur einzelne Entwicklungsstufen bekannt. Es konnte einem tiichtigen Nanne leicht das gleiche Missgeschick passieren, wie dem Meister der entwicklungsgeschichtlichen Untersuchung, K a r l Ernst von Baer²), welcher einst einige Embryonengliiser seiner Sammlung zu etikettieren rergaß und nach einem halben Jahre

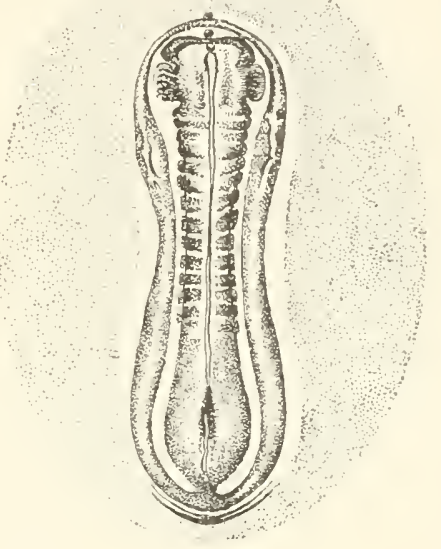

Fig. 123.

Keimanlage eines O possums, Didelphys virginiana. Nach Sel enka. nicht mehr unterscheiden konnte, ob er Embryonen ron Eidechsen, Tögeln odex Süugetieren aufgehoben hatte. Seit jener Zeit aber sind unsere Kenntnisse der embryonalen Formen an Umfing und Tiefe gewachsen und derartige Verwechselungen sind heute für den geübten Forscher ausgeschlossen. Ich glaube nicht, dass von sämtlichen Gelehrten, welche dem Studium der tierischen Entwickelungsgeschichte ihr Leben weihen, auch nur ein Einziger den oben citierten Satz Haeckel's unterschreibt. Durch die genaue Bearbeitung der Eientwicklung von zahlreichen Wirbeltieren ist eben die Erkenntnis gesichert worden, daß die spezifischen Merkmale der Tierarten an den allerjüngsten Embryonen mit derselben Dentlichkeit ansgeprägt sind, wie die Eier der Togelarten für den Kenner sich unterscheiden.

Ich bitte Sie zum Beweise den Embryo des Zitterrochens (Fig. 118) mit dem Huhnembryo (Fig. 112), ferner die Keim-

1) W. His, Unsere Körperform, Leipzig, F. C. W. Vogel 1871.

2) K. E. von Baer, Entwicklungsgeschichte der Tiere 1828. I. Teil. S. 221. 
scheibe des Opossums (Fig. 123) mit der Embryonalanlage des Hühnchens (Fig. 110) oder den Embryo eines Schweines (Fig. 124) mit dem menschlichen Embryo (Fig. 113) zu rergleichen.

Wer sich viel mit dem Sammeln und dem Studium ron Embryonen abgegeben hat, vermag schon an einer ganz winzig kleinen

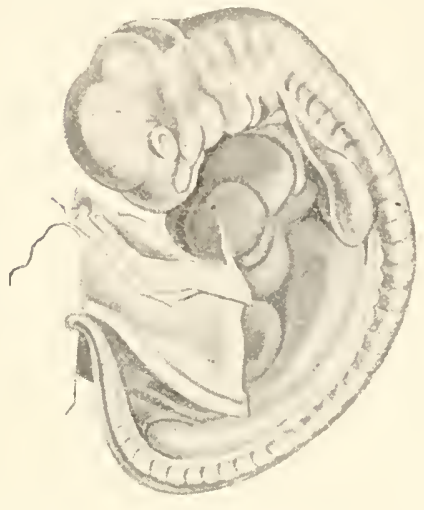

Fig. 124 .

Embryo des $\mathbb{S c b}$ weines, $21 \mathrm{Tage}$ alt. Nach Keibel. Keimscheibe sicherlich die Kilasse und die Gattung der Tiere zu bestimmen, zu welcher das Eistadium gehört. In vielen Spezialabhandlungen und in den neneren Lehrbüchern sind übrigens sehr viele Abhildungen der verschiedensten Embryonen enthalten, dass der Fernerstehende durch deren Betrachtung leicht eine Torstellung ron den spezifischen Unterschieden gewinnen kann. Es verlohnt darum nicht der Nühe, noch weitläufiger die Unhaltbarkeit der Haeckel'schen Angabe darzulegen.

Bei einem Manne, welcher die embryologische Litteratur mit so großer Aufmerksamkeit verfolgt, wie das Haeckel thut, ist auch nicht zu rermuten, dass er etwa selbst die Unterschiede der jungen Embryonalstadien übersehen könnte. Ich halte im Gegenteile dafür, er würde es als eine grobe Beleidigung bezeichnen, wollte einer etwa behampten, Haeckel sei nicht im stande, einen jungen menschlichen Keim vom Embryo eines Hundes, Schweines oder Togels zu unterscheiden - eine Aufgabe, welche jeder einigermaßen erfahrene Embryologe ohne Schwierigkeiten löst. Die Unterschiede waren schon vor 20 Jahren so allgemein bekannt, dass der Göttinger Anatom W. Krause ${ }^{1}$ ) arg bloBgestellt wurde, weil er 1875 einen ron einem ehemaligen Zuhörer unter falscher Bezeichnung eingesandten Hiihnerembryo kritiklos als ein friihes menschliches Entwickelungsstadium beschrieb.

Wollte ich jetzt freilich Sie vor die Aufgabe stellen,ein Dutzend von Säugetierembryonen artweise aus einander zu klauben, so würden Sie sich vergel)lich abmühen, weil Ihnen die Tertrantheit mit embryonalen Formen und die Übung des Blickes mangelt. Thre Unbehilflichkeit wird Sie jedoch nicht zu der Ansicht führen, dass die Unterschiede

1) W. His, Zur Kritik jüngerer menschlicher Embryonen, Sendschreiben an H. Prof. W. Krause in Göttingen. Archiv f. Anat. and Entwicklungsgesch. 1880. S. 407 . 
wirklich fehlen. Sie werden, wie ich denke, dem Urteile des Fachgelehrten vertrauen, welcher als Resultat eingehender Untersuchung mitteilt, dass die Natur den jiingsten tierischen Keimen ebenso scharfe, mit der weiteren Modellierung des Körpers sich steigerude Unterschiede aufgeprägt hat, wie es ron den Samenkörnern und Keimblättern der Pflanzen jedermann bekannt ist.

An skizzenhaften Beispielen habe ich Ihnen bisher die ron der wissenschaftlichen Welt rorgenommene Prüfung des biogenetischen Grundgesetzes zur Genüge erläutert, un zum Schlusse eilen zu dïrfen. Meine Beispiele waren zwar drastisch ausgewïhlt, aber sie illustrieren, wie mir scheint, klar die springenden Fragepunkte und sind dem Ungeübten einigermalien rerständlich. Denn Sie dürfen nicht rergessen, dass das eingehendste praktische Studium der Entwickelungsgesehichte für alle diejenigen notwendig ist, welche über den Wert des Haeckel'schen Dogmas ein maßgebendes Urteil füllen wollen. Meine Absicht zielte auch nicht dahin, Sie als Richter in dieser Frage aufzurufen, sondern ich wollte Sie den Gegensatz zwischen einer falschen Theorie und den nüchternen Thatsachen erkennen lassen.

Das rergleichende Studium zweier Ordnungen der Säugetiere, nämlich der Raubtiere und der Nagetiere hat mich vor neun Jahren zuerst daran zweifeln lassen, ob das biogenetische Grundgesetz wirklich der prägnante sprachliche Ausdruck für das Geschehen der Eientwickelung sei, nachdem ich zehn Jahre lang ein treuer Anhänger desselben gewesen war und jeden arg gescholten hatte, welcher dem sog. Gesetz nicht ebenso großen Glauben schenkte. Indem ich meine skeptischen Bedenken an den natïrlichen Thatsachen weiter prüfte, gelangte ich zu der Überzeugung, dass das Grundgesetz wohl einen verlockenden Klang, aberkeinen positiven Inhalt besitzt. Andere meiner Fachkollegen hat unabhängiges Nachdenken zu der gleichen Ansicht geführt. Ich zitiere zunächst zwei Männer, welche embryologische Studien zu dem Zwecke begannen, neue Thatsachen für die unbedingte Geltung des biogenetischen Gesetzes zu finden. Prof. Dr. A. Oppell) charakterisierte seinen Standpunkt im Jahre 1892 wie folgt:

„Er stand zu Beginn seiner Untersuchung über Vergleichung des Entwickelungsgrades der Organe zu verschiedenen Entwickelungszeiten bei Wirbeltieren auf dem Boden des biogenetischen Gesetzes und glaubte, dass ein solches in modifizierter Form Geltung habe. Während der Untersuchung fand er jedoch, dass das Gesetz nicht aufrecht erhalten werden könne,

1) Jahresbericht über die Fortschritte der Anatomie und Physiologie, herausgegeb. von Hermann und Schwalbe, 20. Bd. 1892. S. 683. 
da die Modifikationen schlieBlich dazu fülıren, dass das Gesetz nicht bestehe. Gestiitzt auf seine Untersuchungen kommt Verfasser zu dem Schlusse: Die Ontogenie ist nicht die Wiederholung der Phylogenie."

Prof. Dr. Fr. Keibel'1) in Freiburg hat das Studium der Entwickelung des Schweines benützt, um das biogenetische Gesetz zu prüfen. Er iiberzengte sich gleichfalls von dessen Unrichtigkeit:

"Die zeitlichen Verschiebungen (d. h. Heterochronie, vergl. S. 233) haben bei den Säugern eine solche Höhe erreicht, dass die Organe, welche sonst geeignet erscheinen mögen, die verschiedenen Stadien zu charakterisieren, durch einander geschoben sind. Bei Säugern kann man, wemn man den gegenseitigen Entwickelungsgrad der Organe im Organismus ins Auge faßt, von einer Wiederholung der Phylogenie in der Ontogenie durchaus nicht sprechen; das "biogenetische Grundgesetz" wird hier, wenn man so sagen darf, nul durch Ausnahmen bestätigt, d. h. mit einem Worte von einer Geltung des biogenetischen Grundgesetzes kann fuir die Säuger in der angedeuteten Hinsicht überhaupt nicht die Rede sein."

Nenerdings hat einer unserer ersten Anatomen, Oskar Hert$w_{i g^{2}}$ ) in Berlin, seine Wertschätzung des biogenetischen Gesetzes folgendermaßen formuliert:

„Die Theorie der Biogenesis macht an der von Haeckel gegebenen Fassung des biogenetischen Grundgesetzes einige Abänderungen und erlänternde Zusätze notwendig, durch welche sich der oben hervorgehobene Widerspruch beseitigen läßt. Wir müssen den Ausdruck: "Wiederholung von Formen ausgestorbener Vorfahren" fallen lassen und dafür setzen: Wiederholung von Formen, welche für die organische Entwickelung gesetzmäßig sind und vom Einfachen zum Komplizierteren fortschreiten. Wir müssen den Schwerpunkt darauf legen, dass in den embryonalen Formen ebenso wie in den ausgebildeten Tierformen allgemeine Gesetze der Entwickelung der organisierten Leibessubstanz zum Ausdruck kommen."

"Nehmen wir, um unsern Gedankengang klarer zu machen, die Eizelle. Indem jetzt die Entwickelung eines jeden Organismus mit ihr beginnt, wird keineswegs der alte Urzustand rekapituliert ans der Zeit, wo vielleicht nur einzellige Amöben

1) Fr. Keibel, Studien zur Entwicklungsgeschichte des Schweines. Morpholog. Arbeiten, herausgeg. von Schwalbe. Bd. III, 1893.

2) Oskar Hertwig, Dic Zelle u. die Gewebe. II. Buch. Jena 1898, p. 273. 
auf unserem Planeten existierten. Demn nach unserer Theorie ist die Eizelle zum Beispiel eines jetzt lebenden Süugetieres kein einfaches und indifferentes, bestimmungsloses Gebilde, als welches sie zuweilen hingestellt wird; wir erblicken in ihr ja das anßerordentlich komplizierte Endprodukt eines sehr langen historischen Entwickelungsprozesses, welchen die organisierte Substanz seit jener hypothetischen Epoche der Einzelligen durchgemacht hat."

,Wenn schon die Eier eines Süngetieres von denen eines Reptils und eines Amphibiums sehr wesentlich verschieden sind, weil sie ibrer ganzen Organisation nach nur die Anlagen für ein Süngetier, wie diese für ein Reptil oder ein Amphibium reprïsentieren, um wie viel mehr müssen sie verschicden sein ron jenen hypothetischen einzelligen Amöben, die noch keinen anderen Erwerb aufzuweisen hatten, als nur wieder Amöben ihrer Art zu erzeugen!: - - (Vergleiche dagegen Haeckels Auffassung, zitiert auf S. 211.)

,.Allerdings besteht in gewissem Sinne, wie anzuerkennen ist, eine Parellele zwischen der phylogenetischen und der ontogenetischen Entwickelung. Von dem Boden der allgemeinen Entwickelungshypothese aus, auf welchem wir stehen, werden Formzustände, welche in der Kette der Torfahren Endpunkte ihrer individnellen Entwickelung waren, von ihren Nachkommen jetzt als Embryonalstadien durchlaufen und so gewissermaßen rekapituliert. Auch sehen wir. dass cmbryonale Zustände höherer Tiergruppen mit den ausgebildeten Formen verwandter, aber im System tiefer stchender Tiergr'uppen mancherlei Vergleichspunkte darbieten."

"Indessen sind bei einem tieferen Eindringen in den Gegenstand über der zu Tage tretenden Ähnlichkeit auch nicht die sehr wesentlichen Verschiedenheiten zu iibersehen, welche in mehreren Bezichungen bestehen."

„Äußere und innere Faktoren wirken auf jede Stufe der Ontogenese wohl noch in höherem frade umgestaltend ein, als auf deu ausgebildeten Organismus. Jede kleinste Teränderung, welche auf diese Weise am Beginn der Ontogenese neu bewirkt worden ist, kann der Anstoß sein fïr immer augenfälligere Formwandlungen auf späteren Stufen."

..So können in der Ontogenese ganz neue Gestaltungen gewissermaßen neu eingeschoben werden (Cünogenese ron Haeckel), Gestaltungen, welche in der Vorfahrenkette als ausgebildete Zustände nicht existiert haben und ihrer Natur nach nicht haben existieren können." 
„Überhaupt ist bei der Vergleichung ontogenetischer mit vorausgegangenen phylogenetischen Entwickelungsstufen immer im Auge zu behalten, dass infolge der mannichfachsten Einwirkungen äußerer und innerer Faktoren das ontogenetische System in beständiger Voränderung begriffen ist, und zwar sich im allgemeinen in fortschreitender Richtung verändert, dass daher in Wirklichkeit ein späterer Zustand niemals mehr cinem vorausgegangenen entsprechen kann."

"Ontogenetische Stadien geben uns daher nur stark abgeänderte Abbilder von phylogenetischen Stadien, wie sie in der Vorzeit einmal existiert haben können, entsprechen ihnen aber nicht ihrem eigentlichen Inhalte nach."

„Dass gewisse Formzustände in der Entwickelung der Tiere mit so großer Konstanz und in prinzipiell übereinstimmender Weise wiederkehren, liegt hauptsïchlich daran, dass sie unter allen Verhältnissen die notwendigen Torbedingungen liefern, unter denen sich allein die folgende höhere Stufe der Ontogenese hervorbilden kann." - _ _ .So führt uns die Vergleichung der ontogenetischen Stadien der verschiedenen Tiere teils unter einander, teils mit den ausgebildeten Formen niederer Tiergruppen zur Erkenntnis allgemeiner Gesetze, von welchen der Entwickelungsprozeß der organischen Naterie beherrscht wird. Bestimmte Formen werden trotz aller beständig einwirkenden umändernden Faktoreı im Entwickelungsprozeß mit Zähigkeit festgehalten, weil nur durch ihre Vermittelung das komplizierte, Endstadium auf dem einfachsten Wege und in artgemäßer Weise erreicht werden kann."

Hertwigs Darstellung erscheint mir und manch anderem Manne, z. B. dem Prof. Keibel, als das verbliimte Eingeständnis, dass die Rekapitulationstheorie haltlos geworden ist. Da O. Hertwig ein Schüler und Freund von E. Haeckel ist, so ist es begreiflich, dass er, um den Redakteur des Gesetzes durch offene Terwerfung desselben nicht zu beleidigen. sich einer ängstlich rücksichtsvollen Ausdrucksweise zur Bekanntgabe seiner inneren Überzeugung bedient, dass die Formenreihe der Keimesgeschichte keine wirklichen Vorfahrenstadien wiederhole.

Da alle Wirbeltiere durch eine große Zahl gemeinsamer Merkmale eine gut geschlossene systematische Gruppe bilden, durchlaufen sie auch wïhrend des Aufbaues ihres Körpers gewisse übereinstimmende Entwickelungstufen, gleich wie ein Gebäude, mag es ein Palast oder eine Hütte sein, gewisse Stufen der Bauentwickelung passieren mußte: Zuerst die Aushebung und das Legen des Fundamentes, dann die Auhüufung des Rohmateriales, die Aufführung der 
Umfassungsmauern, das Einziehen des Gebälkes und die Aufsetzung des Dachstuhles. Ohne Bezug auf Ahnenformen folgen die Eistadien in formaler und physiologischer Correlation auf einander und bestätigen dadurch für die Embryonalzeit die Herrschaft gemeinsamer Stilregeln im Wirbeltierkreise. Jedenfalls sind es heutzutage nicht wenige Forscher, welche den Riickschluss aus den Embryonalformen auf die hypothetisch erdachte Vorfahrenreihe verpönen. Außer den eben genannten Namen haben noch Beard, Hensen, Emery, Driesch sich gegen die Giltigkeit des biogenetischen Grundgesetzes ausgesprochen. Die Zahl der offenen Gegner wird sich steigern, sobald der T'errorismus der phylogenetischen Schule noch mehr gebrochen ist. Fast vierzig Jahre sind verflossen und eine sehr große Zahl von Abhandlungen mußte geschrieben werden, bis das Resultat gezeitigt wurde, dass das natïrliche Geschehen in der Keimesentwickelung der Tiere nicht der Regel folgt, welche Ernst Haeckel sich einmal ausgedacht hatte, um seiner Privatansicht über die Welt und deren Entstehung die Herrschaft zu erringen.

Die Sachlage wendet sich für die Anhänger der Descendenztheorie böchst ungünstig! Woran soll nun die Stammesgeschichte abgelesen werden, wenn die Eientwickelung als aufklärende Urkunde versagt? Wir haben die verschiedenen Wege geprüft, auf welchen man die längst verschollenen Ahneureihen der heutigen Tierarten aufzuspüren hoffte, ohne ein positives Ergebnis zu finden. Das Studium der vergleichenden Anatomie hat die scharfen Grenzlinien zwischen den großen Organisationsgruppen des Tierreiches (der Wirbeltiere, Gliedertiere, Weichtiere, Stachelhänter. Pflanzentiere, Urtiere) aufgedeckt. In keinem Falle gelang es, die theoretisch geforderten Übergangsformen nachzuweisen. Als wir unsere Wünsche niedriger schraubten und innerhalb eines Typus die Zwischenstufen der Klassen suchten, hat das Beispiel der Wirbeltiere uns gezeigt, dass niemand sagen kann, wie sich die Fische in Amphibien und diese in Reptilien umgebildet haben. Niemand kann Rechenschaft geben, woher die Vögel, woher die Säugetiere stammen. Für andere Typen herrscht dieselbe Ungewißheit. Den Erkenntniswert der Paläontologie habe ich mit den eigenen Worten Haeckels und der Paläontologen beleuchtet. Die versteinerten Tierreste sind Trümmer ron Lebewesen und stumm ïber die nicht fossilisierten Körperteile. Heute haben Sie durch das Versagen des entwickelungsgeschichtlichen Zeugnisses eine neue Enttäuschung erfahren.

Damit ist die praktische Möglichkeit, etwas über die Urgeschichte des Tierreiches zu ergründen, vollständig erschöpft und die Hoffnung für alle Zukunft zerstört. Wir 
erhalten ein Resultat gerade umgekchrt von dem, was man erwarten sollte. Anstatt dass die Fachgelehrten im stande waren, eine rou Jahr zu Jahr wachsende Füille von Beweisen für die Richtigkeit der Abstammungslehre vorzuführen, ist der Mangel derselben und die Unmöglichkeit der Vervollständigung heute offenkundig. Diesen Zustand nenne ich den Zusammenbruch der Abstamnuugslehre, zunächst einen Zusammenbruch im Rahmen der engen Fachwissenschaft; denn ich denke nicht an die Tausende von Anhängern der Lehre unter den Gebildeten, an die Mediziner, Naturwissenschaftler, Juristen, Philologen, und Historiker, welche nicht in der Lage sind, sich durch eigene Anschaunng ein Urteil zu bilden. Ich spreche also nicht von einem Zusammenbruch der Lehre in den Kreisen derjenigen, welchen die Urteilsfähigkeit für diese Frage abgeht. Unter ihnen wird die Idee noch lange herrschen und viele Köpfe verwirren, da sie nicht gezwungen sind, die exakte Berechtigung eines schönen Märchens so streng zu prüfen wie der Fachgelehrte, welcher seine Wissenschaft auf genau beobachtete Thatsachen grïnden muss. Die Anzeichen mehren sich, daß man der leeren Spekulation allmählich überdrüssig wird. Vielleicht werden wir es noch erleben, daß die biologischen Forscher ron der aussichtslosen Arbeit sich ganz abwender und über die stammesgeschichtliche Spielerei der Gebildeten zur Tagesordnung übergehen. 


\section{Sechzehntes Kapitel.}

\section{Der Entwicklungsoedanke und die logischen Gesetze.}

Wenn ich bisher den Ideengang der Descendenztheorie als ein ernstlich diskutierbares Problem behandelt habe, so eutsprang mein Verhalten lediglich höflichen Rücksichten. Ich selbst betrachte den Entwickelungsgedanken für die Zoologie als verwerflich, als so fehlerhaft, dass ein auf ernste Arbeit gerichteter Sinn sich gar nicht mit ihm beschäftigen soll, weil er dadurch nur zu Wahngebilden und Phantastereien rerführt wird; denn moderne Stammesgeschichte besteht aus leeren, haltlosen Termutungen. Bis zu einem gewissen Grade deckt sich meine Ansicht mit Haeckels Auffassung, wenn man folgende Stellen ${ }^{1}$ ) aus seinen letzten Werken in's Auge fast.

„Zur Zeit sind die einzelnen Teile unserer Stammesgeschichte doch noch zu ungleichmäßigbearbeitet, und die Hypothesen der einzelnen Geschichtsforscher noch zu widerspruchsroll, um eine ausgefïhrte und einigermaßen abgerundete Darstellung derselben in Form eines Lehrbuches geben zu können. Tielmehr trägt mein ,.Entwurf"* noch durchweg den Charakter eines subjektiren Geschichtsbildes, welches in knappem Rahmen einen Überblick über das Gesamtgebiet der organischen Stammesgeschichte nach meiner persönlichen A uffassung geben soll."

„Selbstrerständlich ist und bleibt unsere Stammesgeschichte ein Hypothesen-Gebäude, gerade so wie ihre Schwester, die historische Geologie. Denn sie sucht eine zusammenhängende Einsicht in den Gang und die Ursachen von längst verflossenen Ereignissen zu gewinnen, deren unmittelbare Erforschung uns unmöglich ist. Weder Beobachtung noch Experiment rermögen uns direkte A ufschliisse über die zahllosen Umbildungsprozesse zu

1) E. Haeckel Systemat. Phylogenie. III. Bd, 1895. Vorwort, D. VIII. und I. Bd. 1894. Torwort, p. VI. 
gewähren, durch welche die heutigen Tier- und Pflanzenformen aus langen Ahnenreihen hervorgegangen sind. Nur ein kleiner Teil der Erzeugnisse, welche jene phylogenetischen 'Transformationen hervorgebracht haben, liegt uns in greifbarer Form ror Angen; der weitaus größere Teil bleibt uns für immer verschlossen. Denn die empirischen Urkunden unserer Stammesgeschichte werden immer in hohem Maße lïckenhaft bleiben, wie sehr sich auch im Einzelnen ihr Erkenntnisgebiet durch fortgesetzte Entdeckungen erweitern mag."

Leider lässt $\mathrm{H}$ aeckel das konsequente Festhalten an diesem bescheidenen und nicht zu beanstandenden Urteile über den Wert der Stammesgeschichte oft vermissen. Sobald er einen öffentlichen Vortrag1) hält oder populäre Schriften verfasst, äußert er sich in anderer Weise:

"Wir wissen nun bestimmt, dass die organische TVelt auf unserer Erde sich ebenso continuierlich entwickelt hat, wie es Lyell schon 1830 für den anorganischen Erdkörper selbst nachgewiesen hatte; wir wissen, dass die zahllosen verschiedenen Tier- und Pflanzenarten, welche im Laufe von Jahrmillionen unsern Planeten bevölkert haben, alle nur Z weige eines einzigen Stammbaumes sind; wir wissen, dass das Menschengeschlecht selbst nur einen der juingsten, höchsten und vollkommensten Sprossen am Stammbaume der Wirbeltiere bildet."

„An der sicheren Hand der drei großen empirischen Schöpfungsurkunden, der Paläontologie, der rergleichenden Anatomie und Ontogenie, fiihrt uns die Stammesgeschichte von den ältesten Metazoen, den einfachsten vielzelligen Tieren, Schritt für Schritt bis zum Menschen hinauf."

„Die Anthropogenie enthüllt die lange Kette ron Vertebratenahnen, welche der späten Entstehung des höchst entwickelten Menschensprosses rorangegangen sind."

..Die nnermessliche Bedentung des Lichtes, welches diese Aufschlüsse der Abstammungslehre anf das Gesamtgebiet der menschlichen Naturerkenntnis werfen, liegt klar vor aller Augen; sie werden jedes Jahr mehr ihren umgestaltenden Einfluss anf alle Wissensgebiete äußern, je mehr sich die Überzengung von ihrer unersehütterlichen Wahrheit Bahn bricht. Nur Unkundige oder beschränkte Geister können heute

1) E. Haeckel, Der Monismus als Band zwischen Religion u. Wissenschaft. Glaubensbekenntnis eines Naturforschers, vorgetragen am 9. Oktober 1892 in Altenburg. Bonn 1892, p. 18. 
noch an ihrer Wahrbeit zweifeln. Wenn ja noch hie und da ein älterer Naturforscher ihre Begründung bestreitet oder nach mangeluden Beweisen fragt, so beweist er damit nur, dass ihm die erstaunlichen Fortschritte der neneren Biologie und ror allem der Anthropogenie fremd geblieben sind."

Resigniertes Urteil über den wirklichen Wert der Stammesgeschichte und der Wunsch, seinem Lebenswerke unbedingte Anerkennung zu sichern, rermengen sich bei $\mathrm{Haeckel}^{1}$ ) auf sonderbare Art, dass er oft Gedanken, welche schroffe Gegensätze bedenten, in ein und demselben Atemzuge ausspricht:

"Wenn wir den heutigen Stand der Anthropogenie rom allgemeinsten Gesichtspunkt aus betrachten und alle empirischen Argumente derselben zusammenfassen, dann dürfen wir heute mit vollem Rechte sagen: die Abstammung des Mensehen von einer ausgestorbenen tertiären Primaten-Kette (Affenkette) ist keine rage Hypothese mehr, sondern sie ist eine historische Thatsache. Natürlich lässt sich diese Thatsache nicht exakt beweisen; wir können nicht alle die unzähligen, physikalischen und chemischen Prozesse nachweisen, welche im Laufe ron mehr als hundert Jahrmillionen allmählich rom einfachsten Honere und ron der einzelligen Urform bis zum Gorilla und zum Menschen hinauf geführt haben."

Ich kann Haeckels Terhalten nicht billigen, denn die zuerst citierten Stellen zeigen, dass er die Unzulänglichkeit der phylogenetischen Kombination in der nach exakten Prinzipien betriebenen zoologischen Wissenschaft ganz richtig beurteilt. Bei anderer Gelegenheit vergißt er aber anscheinend, dass die moderne Entwickelungsschule, wie früher einmal $\mathrm{Oken}$, das gesunde Terhältnis ron empirischer und spekulativer Betrachtung auf den Kopf gestellt hat, und trotzdem sie es in Worten stets ablengnet, rielleicht sich selbst ehrlich vortäuscht, an die Stelle der empirischen Erfahrung die theoretische Konstruktion geriickt hat. Indem sie die Liicken des zoologischen Systemes mit leblosen Phantasieprodukten zu gunsten der Abstammungslehre ausfüllte, wählte sie den rerkehrtesten Weg, die Blutsverwandtschaft der Tiere zu beweisen. Alle die Ahnen der Tiergeschlechter sind Fiktionen unbekannter Lebewesen und täuschen uns über die klaffenden Lücken unseres Wissens hinweg. Man kann über die Berechtigung solcher Fiktionen streiten,

1) E. Haeckel, Über unsere gegenwärtige Kenntnis vom Ursprunge des Menschen. Vortrag gehalten auf dem 4. internationalen Zoologen-Kongreß in Cambridge. Bonn 1898. 
riele der heutigen Forscher halten sie sogar für ein Zeichen hoher Wissenschaftlichkeit. Jedenfalls entspringen sie dem Bedürfnisse des menschlichen Geistes, welcher allzu gerne die unbekannten Glieder seiner Kenntnis rertuscht. Sie schaden auch dem selbstthätigen Fachgelehrten nicht viel. weil derselbe für jede kleine Spezialfrage das schier unbegrenzte Material von Einzelthatsachen und Deutungsversuchen keunt, deren historisches Resultat die Formulierung einer bestimmten hypothetischen Ansicht war. Sobald er den Widerspruch der Thatsachen gegen eine bisher giltige Hypothese gewahrt, wird er sie rasch aufgeben. Aber der Laie rerwechselt leicht eine schöne bestechende Hypothese mit wohlbekannten Thatsachen, nachdem gerade Haeckels rlogmatische Darstellung die Grenzen zwischen sicherer Erkenntnis und unsicherer Vermutung nach Möglichkeit unsicher gemacht haben. Dies ist um so mehr zu bedauern, als Haeckel kraft der Vorziige seiner Stellung als Unirersitätsprofessor mehr denn jeder andere berufen war, die Unklarheit des Denkens beim Publikum zu hekämpfen, sowie die Laien über die positiven und negativen Seiten der Wissenschaft zu unterrichten.

Die stammesgeschichtliche Schule hat nicht nur, wie ich bisher gezeigt habe, die Regeln der exakten Naturbeobachtung, sondern anch die logischen Denkgesetze in beklagenswerter Weise rernachlässigt. Wir wollen die Fehler zunächst durch eine geschichtliche Betrachtung aufdecken. In jedem denkenden Geiste regt sich einmal der Gedanke ron der Einheit der Natur im allgemeinen und der Lebewelt im besonderen: denn wir alle suchen den Zusammenhang im Getrennten, das Beharrende im Wechsel, das ewig Bleibende im Werden und Untergehen, die Einheit in der Mannigfaltigkeit. In unserer Frage wird die Einheit .Blutsverwandtschaft" oder „Stammesentwickelung aus einfachen Urformen“ genannt. Hat man den Gedanken einmal gefasst, so kehrt er beim geringsten Anlasse wieder und verdichtet sich allmählich zur unerschïtterlichen Überzeugung.

Ältere Forscher suchten deshalb ein einziges Urmodell für sämtliche Tiere und stellten sich das Tierreich als eine Stufenleiter vor, welche zur Krone der Schöpfung, dem Menschen, führt. Hente vergleicht man die Tierwelt nicht mit einer einfach geraden, sondern mit einer rerzweigten Leiter, d. h. einem Stammbaume. (Vergl. Seite 4.) Der Tergleich kann Menschen der verschiedensten Sinnesart gefallen. Im Mittelalter war er theologisch gefärbt, heute nach Änderung seines äußeren Aufputzes beanspruchen ihn die Freidenker als notwendiges Glied ihrer allgemeinen Vorstellungen rom Kosmos. 
Im vorigen Jahrhundert besaß der Entwickelungsgedanke rein theologische Bedeutung. Herder's Buch ${ }^{1}$ ) liefert dafür einleuchtenden Beleg. So sehr seine Ausdrucksweise mit den Schlagwörtern der modernen Entwickelungstheorie übereinzustimmen scheint, zeigt doch die genaue Prïfung seines Ideenganges, dass die Áhnlichkeit nur im Gleichklange der gebrauchten Worte, nicht aber in deren begrifflichem Inhalte besteht. Die Ausdruicke: ich sebe die Form der Organisation steigen - die mannigfaltigen Wesen folgen auf einander - die Natur schreitet ron großen Gestalten ins Zusammengesetztere, Kïnstliche, Feine fort, was kurzweg Progression der Schöpfung heißt - die Natur schritt immer höher, fand neue Proportionen oder die mehr poetische Fassung: die ahnlichkeit zweier Arten erscheint wie ein Reflex ron Lichtstrahlen, höhere Formen mit vielen Eigenschaften erseheinen als Kompendium der Züge vieler niederer Gattungen, und der Mensch ist geformt durch Zusammendrängung aller Gestalten (p. 104), welche lebhaft an die Rekapitulationstheorie erinnert, schließen bei Herder immer den Gedanken an den Schöpfer ein. Denn er nennt die ganze Welt ein Torratshaus göttlicher Erfindung, ein Hauptbild seiner Kunst und Weisheit (p. 59), und in der Einleitung spricht er von dem Wege Gottes in der Natur, von den Gedanken, die der Ewige uns in der Reihe seiner Werke thätlich niedergelegt hat. Die Annahme direkter Blutsverwandtschaft lag Herder ganz ferne.

Auch dem Philosophen Schelling erschien die Stufenfolge der Organismen nicht durch reelle Entwicklung entstanden. „Die Hoffnung ${ }^{2}$ ) mehrerer Naturforseher, den Ursprung aller Organisationen als successive und zwar als allmähliche Entwickelung ein und derselben ursprünglichen Organisation vorstellen zu können, verschwindet durch unsere Ansicht. “ - „Die Behauptung ${ }^{3}$ ), dass wirklich die verschiedenen Organisationen durch allmähliche Entwickelung aus einander sich gebildet haben, ist Mißverständnis einer Idee." Die theologische Deutung wird nicht mehr erwähnt. Doch denkt er immer noch an eine einfache Reihe. "Man wird versucht ${ }^{4}$ ), zu glauben, dass bei allen verschiedenen Gestaltungen der schöpferischen Natur ein gemeinschaftliches Ideal vorgeschwebt hat, dem das Produkt allmählich sich annähert. Die verschiedenen Formen, in die es sich begiebt, werden nur als verschiedene Stufen der Entwickelung einer und derselben Organisation erscheinen."

1) J. C. Herder, Ideen zur Philosophie der Geschichte der Menschheit. 3. Aufl. Leipzig 1828. I. Bd.

2) Schelling, sämtliche Werke. III. Bd. Erster Entwurf eines Systems der Naturphilosophie. 1857, p. 62.

3) Schelling, III. Bd., 1857, p. 63.

4) Schelling, III. Bd., p. 33.

Fleischmann, Descendenztheorie. 
Da im achtzehnten Jahrhundert das Tnteresse an physiologischen Untersuchungen die vergleichend anatomischen Ergebnisse in den Hintergrund drängte, dachten die Naturforscher und, von diesen beeinflusst, auch Schelling mehr iiber die Entwickelung der L ebens funktionen nach. Sie legten das Hauptgewicht auf die Übereinstimmung derselben, d. h. auf das gemeinsame Vorkommen der Reizbarkeit, Bewogung, Eruährung, Fortpflanzung bei allen Lebewesen, und nannten die Gemeinsamkeit der fundamentalen organischen Eigenschaften die Einheit der Natur oder kurzweg die Organisation. Die daneben herrschende Verschiedenheit der Tiergattungen und Tierarten wurde durch den Ausdruck berücksichtigt: innerhalb der Einheit der Organisation sei eine Verschiedenheit der Stufen zu beobachten, weil die organische Kraft auf den rerschiedenen Stufen der Erscheinungen gehemmt werde. „Die Kontinuität ${ }^{1}$ ) der organischen Natur wird nicht in den Übergängen der Gestalt und des organischen Baues, sondern in den Übergängen der Funktionen in einander gesucht." "Statt der Einheit des Produktes ${ }^{2}$ ) haben wir eine Einheit der Kraft der Hervorbringung durch die ganze organische Natur. Es ist nicht ein Produkt, aber doch eine Kraft, die wir nur auf verschiedenen Stufen der Erscheinung gehemmt erblicken. So wäre es Zeit, in der organischen Natur jene Stufenfolge aufzuzeigen und zu rechtfertigen, dass Sensibilität, Irritabilität, Bildungstrieb nur Zweige einer Kraft seien."

Schelling meint also eine Kontinuität aller Naturursachen, nicht cinen reellen Umbildungsprozess, und die Kontinuität ist ihm ein bloßer Gedanke, ein ideelles Terhältnis, ein kurzer sprachlicher Ausdruck dafïr, dass die Tierarten in eine aufsteigende Reihe geordnet werden können.

Hegel vertritt die gleiche Ansicht. „Die Natur ist als ein System von Stufen zu betrachten, deren eine aus der anderen notwendig hervorgeht und die nächste Wahrheit derjenigen ist, aus welcher sie resultiert: aber nicht so, dass die eine aus der anderen natïrlich erzeugt wurde, sondern in der inneren, den Grund der Natur ausmachenden Idee. Die Metamorphose kommt nur dem Begriffe als solchem zu, da dessen Veränderung allẹin Entwickelung ist". "Solcher nebuloser, im Grunde simnlicher (wir würden jetzt sagen: eine falsche Simnlichkeit erstrebender) Torstellungen, wie insbesondere das sogenamnte Hervorgehen z. B. der Pflanzen und

1) Schelling, III. Bd., p. 195. Anm.

2) Schelling, III. Bd., p. 207.

3) Hegel, Werke, VII. Abt. I. § 249. S. 32, 33, Zus. 33-36. 
Tiere aus dem Wasser, wie dann das Hervorgehen der entwickelteren Tierorganisationen aus den niedrigeren u. s. f. ist, muss sich die denkende Betrachtung entschlagen".

Die Naturforscher, welche in ihrer beschreibenden Arbeit den Gebrauch allgemeiner, umfassender Begriffe weniger üben und deshalb auch den Wert einer scharfen Definition der letzteren weniger schätzen, wurden durch den Doppelsinn des Wortes: „Entwickelung“ um die Wende des achtzehnten Jahrhunderts und noch späterhin auf Irrwege geleitet. Statt in der ihm von den Philosophen beigelegten Bedeutung fassten sie Entwickelung im naturwissenschaftlich exakten Sinne. Die Bedeutung: Stufenfolge wurde umgedreht in Umbildungsfolge und einer übereilten, dem ruhigen Historiker fast unverständlichen Spekulation Thür und Thor geöffnet.

Die Philosophen gebranchen das Wort Entwickelung zur Bezeichnung einer bestimmten Folgereihe von Begriffen d. h. einer logischen Ordnung oder Disposition derselben, wie anch einen Gedanken entwickeln heisst, die einzelnen logischen Glieder oder die einzelnen von ihm gemeinten objektiven Thatsachen in einer einfachen und deshalb leicht verständlichen Weise nach einander besprechen, um dadurch ihre allgemeine Zusammenfassung in das Kleid eines kurzen Satzes begreiflich zu machen. Die reihenweise Fïgung der Begriffsglieder nach dem Prinzipe, vom Einfachen zum Komplicierten fortzuschreiten, wird Entwickelung oder Evolution im Gegensatze zu Emanation, dem Hervorgehen des Niederen aus dem Höheren, genannt. Die Philosophen wollen mit Entwickelung nicht mehr und nicht reniger sagen, als dass die natürlichen Thatsachen bezw. die für die lebenden tierischen Individuen gebildeten Begriffe sich übersichtlich ordnen lassen. Sie sprechen das Resultat der Linnéschen Systematik nur mit anderen Worten aus; wir Zoologen reden von der systematischen Einteilung des Tierreiches, in welcher den einfachen Gruppen höhere folgen, die Philosophen nennen diese Anordnung "Entwickelung".

Dann kamen vicle Gelehrte, aber logisch nicht scharf definierende Männer, welche die ganz richtige und unbestreitbare Idee der Philosophen durch den naturwissenschaftlichen Schiller des Wortes Entwickelung auf das schwankende Gebiet unklarer Spekulation verschoben. Statt Entwickelung im Sinne der einfachen logischen Reihung der Begriffe setzten sie in ihrer Gedankenarbeit umbildende oder fortschreitende Entwickelung, wie sie dieselbe in der individuellen Keimesgeschichte und der Entwickelung bis zum geschlechtsreifen Stadium der Tiere beobachteten. So entstand als leitendes Prinzip für die zoologischen Studien der moderne Fortschrittswahn, dessen weitere Verbreitnng dadurch unterstützt 
wurde, dass man lange schon das Emporsteigen des Menschen zu einer höheren Stufe der Kultur, den Aufschwung der Wissenschaften, Kï̈nste und Gewerbe, kurz den Fortschritt aller menschlichen Thätigkeit mit spiessbürgerlicher Genugthuung gepriesen hatte.

Obwohl in den Naturwissenschaften eine dureh logisches Missrerständnis gewoinnene Vorstellung nicht lange die Herrschaft behauptet, weil das Gewicht der Thatsachen höher angeschlagen wird, als einleuchtende theoretische Kombinationen, hat der verführerische Reiz der Entwicklungslehre viele tüchtige Männer verhindert, die exakte Prüfung wirklich sachlich zu führen und die falsche Lehre blieb his heute in grossem Ansehen. Als sich später denen, welche den Irrtum verschuldet hatten oder von neuem begingen, die Unmöglichkeit des exakten Nachweises der Stammesentwicklung offenbarte, die ich in den vorhergehenden Stunden an speziellen Beispielen erläuterte, verfielen sie in den Fehler des Rationalismus des 17. Jahrbunderts.

Der Rationalismus ist das Gegenteil des Empirismus. Die Erfahrung spielt bei ihm eine untergeordnete Rolle und wird nur nachträglich zur Bestätigung der Spekulation herbeigezogen. Das natürliche Licht der Vernunft soll ohne thatsächliche Erfahrung uiber die natiirlichen Dinge Aufschluss geben. In einem gewissen Sinne ist jeder von uns Rationalist, sogar der nüchternste, allein auf die Sammlung von realen Thatsachen ausgehende Forscher, weil wir alle die Neigung haben, das, was wir nicht wissen, nach den Schliissen der Vernunft zu konstruieren. Manche sind sogar außer Stande, sich von der rationalistischen Grundlehre zu befreien, dass alle klare Gedankenkombination der menschlichen Vernunft wahr oder wenigstens möglich sein müsse.

Trotz ihrer Zugehörigkeit zur Zunft der exakten Naturforscher hegen Darwin, Haeckel, Huxley, Wallace und sämtliche Anhänger den gleichen Gedanken, wie Descartes, Spinoza und Leibniz, welche die Unfehlbarkeit der Vernunft lehrten. Sie vertraten die Abstammungslehre deshalb, weil wir uns nur die Alternative, entweder göttliche Schöpfung oder natürliche mechanische Entwickelung denken könnten und die Schöpfung als unwissenschaftliche Ansicht ablehnen müssen. Im Vertrauen auf diese ausgezeichnete Idee, der gar keine bessere an die Seite zu stellen sei, erkannten sie der Descendenz fast den Wert eines unfehlbaren Dogmas ${ }^{1}$ ) zu.

Der ganze uns bisher beschäftigende Streit dreht sich also eigentlich um die Berechtigung rationalistischen Denkens in der beschreibenden Naturwissenschaft, um die Frage, ob eine Idee durch

1) Vergleiche Weismann 1. c. p. 5-9. 
die einleuchtende Kraft ihrer Anschaulichkeit als begründet gelten, oder ob ihrer Anerkennung die Vorführung zwingender reeller Grundlagen vorangehen soll. Sie dürfen mit mir die Zuversicht teilen, dass gegeniiber allen rationalistischen Lehrmeinungen die nïchterne Empirie stets ihr Recht behaupten wird.

In jedem phylogenetischen Problem wuchert der Rationalismus in ïppiger Weise. Wer mir sagt, dic Thatsachen der vergleichenden Anatomie, Paläontologie und Entwickelungsgeschichte veranlassen meine Vernunft zu dem Gedanken, dass die Urlurchfische die Stammväter der Amphibien wurden, indem sich ihre vielstrahligen Fischflossen in fünfzehige Kriechfüße verwandelten, kann den bestimmten Vorgang gar nicht nachdenken. Er kennt nicht die einzelnen Phasen, welche notwendig gewesen sein könnten, um einen Fisch auf die Stufe des Uramphibiums zu heben. Wenn er sagt, ich kaun mir den Vorgang denken, so bedentet das eigentlich nur, ich wïnsche und hoffe, dass es so gewesen sei. Soll ich den Fachmann erst daran erinnern, wie viele Jahre eingehender Specialuntersuchung erforderlich waren, um die Umwandlung einer Raupe in den Schmetterling oder irgend eines anderen Larvenstadiums in das geschlechtsreife Tier zu verstehen und wirklich nachdenken zu lernen, welch grosse Missverständnisse zu beseitigen waren, ehe die Metamorphose irgend einer niederen Tierart exakt bekannt geworden ist? Dabei spreche ich ron Aufgaben, welche der Lösung dureh geduldige Analyse zugänglich sind, weil der Torgang an Tausenden ron jetzt lebenden Individuen spielt. Wie ganz unmöglich aber ist der Tersuch iiber die längst abgelaufene Tmwandlung der Tierarten eine Kenntnis zu erwerben, wo jede Gelegenheit des direkten Augenseheines mangelt!

Die rationalistische Neigung führte weiter zu der falschen Iionsequenz, dass die beschreibende Naturwissenschaft durch das Descendenzphantom in eine geschichtliche Wissenschaft umgebildet worden sei. Denn die leeren Phantastereien der Stammesgesehichte lassen sich mit der historischen Forschung gar nieht vergleichen. Wie Windelband kurz und richtig darlegte, ,sucht der Historiker irgend ein Gebilde der Vergangenheit in seiner ganzen indiriduellen A usprägung zu ideeller Gegenwärtigkeit neu zu beleben, er hat an demjenigen, was wirklich war, eine ähnliche Aufgabe zu erfïllen, wie der Künstler, der das Bildnis eines berühmten Mannes malt oder modelliert. Für die Historie ist trotz der kritischen Verarbeitung der Überlieferung die letzte Aufgabe, aus der Masse

1) Windelband, Geschichte und Naturwissenschaft. Rektoratsrede, Strafburg 1894. p. 31 . 
des Stoffes die wahre Gestalt des Vergangeneu zu lebensvoller Deutlichkeit herauszuarbeiten. Die Historie liefert Bilder von Menschen und Menschenleben, mit dem ganzen Reichtum ihrer eigenartigen Ausgestaltung, aufbewahrt in ihrer vollen individucllen Lebendigkeit."

Sie haben genug Gelegenheit gehabt, die Art der phylogenetischen Geschichtsschreibung kennen zu lernen und meine Aussetzungen über die mangelnde Anschaulichkeit ihrer sog. historischen Aufklärung zu hören, dass ich sie nicht nochmals von Neuem darzulegen brauche. In welchem Falle ist denn der stammesgeschichtliche Forscher im Stande gewesen, uns, gleich dem Historiker, die Entstehung der Vögel, der Säugetiere, der Insekten, der Mollusken, der Echinodermen u. s. w., in ihrem individuellen Verlaufe nacherleben zu lassen? Durch die Behauptung, die jetzt lebeuden Tierarten seien das Produkt eines stammesgeschichtlichen Processes, ist doch die beschreibende Zoologie der historischen Wissenschaft nicht euger verbunden worden. Die dramatische Wiederholung dieses Satzes vermochte wohl den unkritischen Sinn der großen Menge zu täuschen, aber zum Range einer positiven Thatsache ist er nicht aufgestiegen.

Wenn man ïberhaupt vom historischen Charakter der zoologischen Arbeit redon darf, so sind nur die ontogenetischen Darstellungen mit einigem Rechte als historische Berichte anzusehen, weil sie die an einer befruchteten Eizelle einander zeitlich folgenden Umbildungen samt allem kleinlichen Detail schildern. Die vergleichende Anatomie, die Paläontologie, ja selbst die vergleichende Entwickelungsgeschichte sind und bleiben jedoch zum Spotte der modernen rationalistischen Hoffnung beschreibende Wissenschaften, freilich beschreibende Wissenschaften, welche durch die Analyse der Einzelfälle gemeinsame Merkmale zur Aufstellung von Gattungsbegriffen ableiten.

Jede Beschreibung hat den Vergleich zur V'orbedingung. Auch auf der allerrohesten Stufe der Kindheit setzt der Gebrauch der alläglichen Worte die vergleichende Operation voraus, ob z. B. das Wort "Bein" der Bezeichnung des oinem menschlichen Beine so unähnlichen Vorderfußes der Katze oder des Pferdes dieneu darf. Niemand kann etwas ohne den fortwährenden Vergleich beschreiben. Die Vergleichung in der Zoologie wird von geistig reifen und gut begabten Männeru ausgeübt, infolge dessen steht sie höher als die simple Beschreibung eines Laien, aber nur dem Grade, nicht ihrem Wesen nach. Sie ist ferner in besonderer Richtung thätig, weil sie die Ähulichkeiten der verschiedenen Objekte mehr hervorhebt als die Unterschiede.

Durch den Vergleich wird zugleich eine Ordnung der Kennt- 
nisse geschaffen. Fr zeigt den Grad der Übereinstimmung mit anderen bereits bekannten Tierarten oder Organformen etc. an und ruft naturgemäß lie Zusammenfassung der verglichenen Objekte in Gruppen von geringerer oder größerer Konsonanz, der tierischen Individuen in Arten, Gattungen, Familien, Ordnungen, Klassen hervor. Bei der Aufstellnng der Gruppen kommt jedoch nicht der ganze Reichtum eigenartiger Ausgestaltung der Tierindividuen in Betracht, sondern nur einzelne ihrer Eigenschaften, denn ich kann z. B. ein Pferd, ein Nashorn und einen Tapir nur unter der Bedingung in die gemeinsame Gruppe der Unpaarhufer stellen, wenn ich die Unterschiede des änßeren Habitus der genannten Arten weniger betone und das Hauptgewicht anf die bei allen Arten beobachtete Eigenschaft lege, dass der Nittelfinger an Hand und Fuß immer kräftiger, als die übrigen Finger entfaltet ist, welche teils rorhanden, (z. B. beim Tapir), teils unscheinbar sind (z. B. beim hentigen Pferde). Schon der Artbegriff z. B. "Mensch" ignoriert die ungeheuren individuellen Verschiedenheiten der einzelnen Menschenkinder, welche Gegenstand eines besonderen, die ganze Lebenszeit erfordernden Studiums sind und durch die bloße Mitteilung des Artbegriffes uns nie bekannt werden. Im Gegenteile verleitet der Gebrauch des Artbegriffs unser Denken jederzeit, die individuellen Fälle desselben mehr gleichartig anzusehen, als sie in Wirklichkeit sind.

Die Gattungsbegriffe, sowie die noch weiteren Kategorien des Systems abstrahieren aus den Merkmalen der Artbegriffe eine beschränkte Zahl ron Eigenschaften. Infolgedessen sind sie nicht bloß dem Anfänger in irgend einer Wissenschaft wegen ihrer scheinbaren Leerheit schwer rerständlich, sondern es gehört auch die vertiefende Arbeit des Fachgelehrten dazu, um sie mit dem ganzen Reichtum ihrer natürlichen Anschaulichkeit zu erfüllen. Es ist ganz gleichgültig, ob ich auf zoologischem Gebiete oder dem einer anderen Wissenschaft exemplifiziere; die Thatsache ist jedem denkenden Menschen bekannt. Der Gattungsbegriff „Katze“ oder der Gattungsbegriff "gotische Hallenkirche“ ist arm an Inhalt für jedermann, der nicht sehr viele Katzenarten, d. s. Löwen, Tiger, Panther, Leopard, Serval, Luchs u. s. w. oder der nicht die wichtigsten in der gotischen Periode erbauten Kirchen Europas oftmals und eingehend studiert hat.

Am allerschwierigsten aber ist es, die allgemeinsten Begriffe z. B. Wirbeltier, Weichtier, Stachelhäuter oder Stilperiode des Rokoko mit anschaulichen Torstellungen zu erfüllen.

Sie werden jetzt einsehen, dass die naturwissenschaftliche, überhaupt die beschreibende Arbeit rom besonderen Indiriduellen zur 
Auffassung allgemeiner Ähnlichkeiten fortschreitet, indem sie eine Auswahl von Merkmalen zum Kwecke der größeren Abstraktion trifft. ,.In echt platonischem Sinne ${ }^{1}$ ) ]ässt sie das einzelne Sinnending in wesenlosem Scheine hinter sich und streht zur Erkenntnis der gesetzlichen Notwendigkeiten anf, die in zeitloser Unwandelbarkeit iiber allem Geschehen herrschen."

Aus der bunten Welt der reellen Mannigfaltigkeit baut das zoologische Denken ein System von Art- und Gattungsbegriffen auf, eine begriffliche Welt ron formalen Beziehungen. eine Auswahl ron topographischen und morphologischen Eigenschaften des Tierkörpers, leb- und empfindungslos, ohne Fleisch und Farbe, frei ron jedem Erdgeruche - ein Tierreich logischer Beziehungen.

Darum haben die Phänomenologen unrecht, welche meinen, die Natur darstellen zu können, ohne irgendwie ïber die Erfahrung hinauszugehen. Das System geht stets ïber die Erfahrung hinaus und stellt diese in ideeller Fassung dar, weil sie ein gedrängtes Bild der Beobachtung geben will, welches sehr riele Einzelerfahrungen umfasst und darum nicht die Erfahrung selhst ist. Unsere Begriffe sind aus einzelnen, in Ansehung der ungezählten Züge der lebenden Wesen verhältnismäßig wenigen Merkmalen anfgebant, sind also aus den natïrlichen Dingen abgeleitet und entsprechen nicht vollkommen der Wirklichkeit.

Deshalb geraten sie mit den Thatsachen fortwährend in Konflikt. Sie sind meist zu eng für die Mannigfaltigkeit der Thatsachen und zwingen uns, dort Grenzen zu ziehen, wo die Wirklichkeit eine Menge von Erscheinungen vorfühut, die sich schwer in den festen Rahmen eines bestimmten Gattungsbegriffes einreihen lassen.

Den Gattungsbegriffen als Produkten der menschlichen Verstandesthätigkeit haften die allen menschlichen Leistungen zukommenden Müngel an, sie genügen immer nu bis zu einem gewissen Grade und entbehren der absoluten Tollkommenheit. Ein nach den Regeln der neuesten Technik und mit der denkbar größten Sorgfalt hergestellter Wasserdamm bricht einmal unter dem mächtigen Andrange der Fluten; das schärfste Messer, aus dem vortrefflichsten Stahle in der Werkstätte eines tïchtigen Meisters gearbeitet, wird einmal stumpf; der edelste Trieb menschlichen Empfindens, die Mrtterliebe, kann ein Terbrechen veranlassen. Ebenso können Gattungshegriffe, welche in recht vielen Fïllen die klare Erkenntnis der natïrlichen Dinge unterstïtzen, bei anderen Gelegenheiten unser Denken auf Abwege leiten.

Die Welt ist mannigfaltiger, als unsere Begriffe zugeben wollen. Selbst die allgemeinsten Gattungsbegriffe, z. B. Togel, Fisch sind

1) Windelband, Rektoratsrede Straßburg 1894, p. 32. 
immer noch zu eng für den Umfang der natiirlichen Thatsachen und ihre schulmäßige Definition enthält wahrscheinlich zu keiner Zeit sämtliche wichtigen Merkmale der durch sie bezeichneten Objekte, weil immer nene Spezies entdeckt werden.

Solange die Archaeopteryx und die Lungenfische nicht bekannt waren, konnten die iibergeordneten Gattungsbegriffe als richtig und bestimmt gelten. Nachher wurde die Wissenschaft vor die Frage gestellt, wie sie die Definition der Begriffe: Togel und Fisch der Wirklichkeit anpassen wolle. Soll man die Archäopteryx nicht als Togel gelten lassen, weil sie einen eidechsenähnlichen, zweizeilig befiederten Schwanz besitzt, während sämtliche lebenden Togelarten das Merkmal einer verkümmerten Schwanzregion der Wirbelsäule und der fächerartigen Stellung der Schwanzfedern zeigen? Oder soll man den Begriff ., Togel" erweitern, indem man die Merkmale der Schwanzregion als weniger bedeutend hinstellt und die beiden Fälle: a) lange, b) verkürzte Schwanzwirbelsäule in die Definition mit einbezieht. In diesem und tausend ähnlich gelagerten Fällen (vergl. S. 117) retten wir uns durch einen Kompromiss. Wir ordnen die neven unerwarteten Thatsachen einem älteren durch die Gewöhnung lieb gewordenen Begriffe ein und nennen die Archäopteryx einen Togel, trotzdem sie viele typische Merkmale der ungeheuren Zahl der lebenden Vogelarten gar nicht aufweist. Damit ist in den Begriff ein Ausnahmefall aufgenommen worden, der in der kurzen Schuldefinition gar nicht beriicksichtigt wird und durch Erfahrung erst besonders gelernt werden muss, um den Degriff auch richtig zu denken. Wenn Sie ihre eigenen Begriffe durchprïfen, werden Sie zahllose Beispiele gleicher Art finden. Indem auf solche Weise der Inhalt und die Bedeutung der Begriffe geändert wird. treten leicht Missverständnisse auf dadurch, dass einer das Wort "Togel" im Sime der Definition vor Entdeckung des fiederschwänzigen Juravogels, ein anderer das Wort Togel im modernen zoologischen Sinne oder, dass ein und derselbe Kopf beide Bedeutungen promiscne gebraucht.

Die Schwankungen des von verschiedenen Männer'n einem bestimmten Wortklange beigemessenen Begriffsumfanges hat gewisse Annehmlichkeiten für die geistige Arbeit selbst und für den Unterricht im Gefolge. Man kann dem Schüler den Begriff des Vogels besser erläutern, wenn man einen jetzt lebenden Vogel als anschauliches Beispiel der Schilderung wählt. Man kann ferner die mannigfachen Übereinstimmungen zwischen den Vögeln und den Reptilien besser hervorheben, wenn man die Aufmerksamkeit mehr auf die Archäopteryx leitet.

Ich kann aber auch die Begrifłsmerkmale absichtlich veründern, um einem Anfünger das Wesen ron zwei durchaus verschiedenen 
Begriffen klar zu machen, z. B. der Begriffe: Affe und Mensch, indem ich sage: denken Sie sich den Schwanz des Affen verkümmert, seine gebeugte Haltung in den aufrechten Gang gewandelt, seinen Kehlkopf mit der Fähigkeit der Sprache begabt und sein Gehirn mit höheren geistigen Fähigkeiten ausgerüstet, so hat sich durch diese Änderung der Merkmale der Begriff Affe in den Begriff Mensch ungewandelt. Bei allen Fragen nach den Vermittelungsgliedern zwischen den größeren Abteilungen des Tierreiches gebraucht Haeckel die gleiche Methode (vergl. S. 55.) Die platte Flosse der Lungenfische entwickelt sich nach feiner Meinung zum Hebelapparat des Gangfußes, ,indem die Flossen zum Fortschieben auf dem festen Lande verwendet, transversal gegliedert, fester mit dem Rumpfskelette verbunden, die Knorpelstäbe in Knochen mit Gelenken verwandelt wurden." Aber auf diese Weise ist bloss der Begriff der Fischllosse in den Begriff der fünffingerigen Gliedmaße übergefühırt worden.

Jedermann weiß aus eigener Erfahrung, welch' ausgezeichnetes Mittel die abstrakte Vergleichung für den Unterricht bietet und wie sie die auffallenden Merkmale irgend eines Begriffes hervortreten läßt. Der mathematische Unterricht erläutert in gleicher Weise, wie der Begriff eines Zwölfeckes durch leichte Modifikation einiger Merkmale, d. h. durch die Vorstellung, die Seiten des Zwölfeckes seien vermehrt worden, bis ein Vieleck mit unbegrenzter Seiteuzahl entsteht, in den Begriff eines Kreises übergeführt werden kann. Kein Mensch meint hernach, dass ein Kreis gerade so einstmals phylogenetisch entstanden sei. Ich selbst wiederhole nur, was Hegel in dem obenstehenden Citate durch den Satz aussprach: "Die Teränderung des Begriffes allein ist Entwickelung", wenn ich behaupte, dic logische Umwandlung des Begriffes Affe in den Begriff Mensch ist keinstammesgeschichtlicher Prozess.

Die phylogenetische Schule ist leider in den fundamentalen Fehler verfallen, die an vielen logischen Begriffen leicht zu bewerkstelligende Metamorphose mit rationalistischer Sicherheit als einen reellen, an den natürlichen Objekten selbst verlaufenden Geschichtsvorgang zu betrachtcn und eine ganz abstrakte Operation, welche bloß an wesenlosen Gebilden unseres Geistes ausgeführt werden kann, mit der nüchternen Wirklichkeit zu verwechseln.

Als ich Sie in den vorhergehenden Kapiteln auf die mangelnde Anschaulichkeit der stammesgeschichtlichen Schilderungen hinwies, habe ich an speziellen Beispielen immer wieder diesen einen prinzipiellen Irrtum gegeißelt. Jetzt, wo er mit dïrren Worten aufgedeckt ist, lüßt sich kaum begreifen, wie Darwin, Haeckel und hundert andere die fundamentalen Regeln unseres Denkens und 
unserer Sprache, welche die Philosophen längst abgeleitet hatten, so arg vernachlässigen und trotzdem allgemeinen Beifall finden konnten. Indem Darwin lehrte, weil der Begriff der Art und alle höheren Gruppenbegriffe des zoologischen Systems schwankend seien, weil keiner der Naturforscher eine bestimmte und für jeden Fall gültige Definition des Begriffes der Art geben könne, müßten die Arten selbst in ständigem Flusse und niedere Ordnungen des Tierreiches in höhere ungebildet worden sein, hat er die Ursache der ihm auffallenden Unsicherheit missverstanden, welche teils im Wiederstande der objektiven Thatsachen gegen die logische Registrierung, teils in der Engheit unserer Begriffe und in der Beschränktheit der sprachlichen Ausdrucksmittel liegt. Durch modernen Anthropomorphismus hat er dann für eine nachteilige Konsequenz der zusammenfassenden Thätigkeit unseres Verstandes die natürlichen Objekte verantwortlich gemacht.

Die Begründung eines Begriffssystemes der zoologischen Thatsachen liegt in dem verschiedenen Grade von Ähnlichkeit, welchen die Naturobjekte offenbaren. Er gestattet uns, Reihen oder Gruppen konformer Dinge zu bilden und durch die ordnenden Begriffe, deren definierende Merkmale die Ähnlichkeit betonen, in dem logischen Abbilde die Zusammengehörigkeit verschiedener Arten unter einer Gattungs- oder Ordnungsgruppe schärfer auszudrücken, als sie in Wirklichkeit beobachtet wird. Die Gruppen selbst wieder können unter einander verglichen werden und einen höheren oder geringeren Grad von Ähnlichkeit besitzen, z. B. die Artgruppen der Katze, des Löwen, Tigers etc. Die Armut unserer Sprache veranlaßt uns, solche Gruppen nahestehend, benachbart oder verwandt zu nennen. Der Systematiker denkt dabei eine rein gedankliche Verwandtschaft, wie man auch in anderen wissenschaftlichen Gebieten z. B. Religionen rerwandt oder eine That dem Betruge verwandt nennt. Wir sprechen von verwandten Stilformen der Künstler, von verwandten Mineralien. Wenn wir bei Insekten und Vögeln Flügel beobachten, so sind das verwandte Einrichtungen für dio Flugbewegung, verwandt, weil sie zu demselben sprachlichen Begriffe: „Flügel" gehören. So giebt es auch eine Terwandtschaft der Tiere, ausgedrückt in dem natürlichen Systeme, d. h. einem System von Begriffen, welches mit breitester Berücksichtigung der natürlichen Thatsachen gebildet wurde und nicht bloß auf wenigen Merkmalen beruht, wie es zu jener Zeit war, als Linné den Plan desselben zum erstenmale auszuführen suchte.

Die Descendenzschule aber hat die formal logische Bedeutung des Wortes "verwandt" mit dem naturwissenschaftlichen Begriffe "blutsverwandt" oder "stammesverwandt" vertauscht und dort, wo es ihrem rationalistischen Denken gerade palite, ohne weiteres das 
die gedankliche Beziehung kemmeichnende Wort abgesetzt. So ist eine heillose Verwirung im Gerlankenleben vieler Menschen angerichtet worden. Wenn ich von der Verwandtschaft der Formen eines Krystallsystemes spreche, füllt es niemand ein, an die genetische Verwandtschaft zu denken. Wenn ich aber iiber systematisch verwandte Tiere, z. B. das Schnabeltier und die übrigen Säuger, rede, so wird bei den meisten die Erinnerung an das Faktum, dass jedes Lebewesen einen Kreis von Blutsverwandten besitzt zum Anlasse, an wahre Blutsverwandtschaft zu denken. Die unbegründete Verwechselung beider Begriffe geschieht so allgemein, dass es jedermann schwer fallen wird, sich ron dem Irrtum zn befreien. Ton Lamarck und Darwin begangen wird er, fürchte ich, noch lange das wissenschaftliche Denken in verderblicher Weise beeinflussen und durch seine ebenso fehlerhaften Konserpenzen den Fortschritt der W issenschaft aufhalten.

Bis heute ist die Stammesverwandtschaft aller systematischen Gruppen eine leere Redensart geblieben, denn das genealogische Register eines Kirchenbuches, aus welchem die Blutsverwandtschaft so vieler menschlicher Geschlechter mit positiver Sicherheit zu ersehen ist, wurde für das Tierreich niemals gefiihrt. Wenn wir von den Aufzeichnungen der Tierziichter absehen, sind für kein einziges Individuum der heute frei lebenden und meist durch Zufall gefangenen Tierarten, also z. B. für einen importierten Königstiger irgend einer Menagerie, dessen Schönheit und Eleganz unsere Bewunderung erregt, Vater und Großvater, Mutter und Großmutter, noch weniger die Geschwister und Schwäger bekannt. Noch ältere Ahnenreihen entziehen sich natürlich entsprechend der Zeitdistanz vom heutigen Tage ab unserer Kenntnis. In dieser Frage geraten exakte Wissenschaft und generalisierende Erfahrung in unangenehmen Widerstreit. Da man beobachtet, dass ein Pürchen des Königstigers die geschlechtliche Zeugung vollzieht und eine Zahl ron blutsverwandten Jungen hervorbringt, welche sich auf die gleiche Weise vermchren, so hindert kein Grund, die an den menschlichen Individuen alltäglich wahrgenommenen Erscheinungen der Entstehnng blutsverwandter Familien (im engeren Sinne) unverändert auf die Gattung Tiger und Tausende andere Tiergattungen zu iibertragen. Eine große Zahl der heute lebenden Tiger steht ebenso in Blutsbande, wie die Glieder irgend einer weit verzweigten Menschenfamilie. Wenn wir jedoch der jedem exakten Forscher auf genealogischem Gebiete auferlegten Verpflichtung nachkommen wollen, das verwandtschaftliche Verhältnis von etwa zwanzig wild gefangenen Tigern zueruieren, sind wir an die Grenzenderpositiven Wissenschaft gelangt. Soweit die Tiere unter unseren Angen gezeugt wer- 
den und aufwachsen, um neuerdings Nachkommen zu zeugen, kanu ihre Verwandtschaft festgestellt werden. Jenseits dieser Bedingung mangelt die Möglichkeit, die Verwandtschaft mit derjenigen positiven Genauigkeit zu verfolgen, welche die Stärke der beschreibenden Naturwissenschaft ausmacht. Ich will damit nicht sagen, dass die Ansicht von der Blutsverwandtschaft der Artindividuen unrichtig sei, sondern Thnen nur darlegen, dass solch eine einfache, uns selbstverständlich erscheinende Regel durch positive Beobachtung bloß an verhältnismäßig wenig Einzelfällen bewiesen werden kann.

Ein weiterer Schritt verdammt uns zu gänzlicher Entsagung. Ohne breite Darstellung weiß jedermann, dass es keinem Anhänger der Descendenztheorie gelungen ist, die Blutsverwandtschaft zweier systematisch verwandter Arten, z. B. der Pferdearten, mit derjenigen Gründlichkeit ${ }^{2}$ ) aufzuhellen, für welche der historisch genealogische Nachweis, z. B. der Verwandtschaft irgend eines europäischen Regentenhauses als Vorbild dient. Nicht einmal für die Haustiere haben Darwin und seine Nachfolger ein greifbares Resultat gefunden.

Weil der direkte Weg der Beobachtung verschlossen ist, hoffte die Descendenzschule auf einem Umwege ihr Ziel zu erreichen. Leider vergaß sie in ihrem rationalistischen Drange die Regeln der nüchternen Forschung von neuem. Blutsverwandtschaft der Artindividuen ist meist mit einer hochgradigen C̈bereinstimmung der Form und Thätigkeit aller Körperteile gepaart. Das Vorkommen der au zweiter Stelle genannten Merkmale kann daher als ein Anzeichen der Blutsbande für den praktischen Bedarf des Alltagslebens betrachtet werden, wo eine umständliche wissenschaftliche Untersuchung sich von selbst verbietet. Als aber die Descendenztheoretiker das in vielen Fällen ausreichende Erkenntnismittel für die schwierigsten Untersuchungen der Phylogenie verwendeten, indem sie jegliches Vorkommen von iibereinstimmenden Merkmalen bei systematisch weniger benachbarten Tierarten, z. B. den Arten der Dinosaurier und der Vögel als einen Beweis für die Blutsverwandtschaft deuteten, haben sie die Aufgabe der exakten Analyse treulos verlassen.

Ein einfaches Beispiel soll den Fehler ans Licht stellen. Jedermann kennt die Richtigkeit folgender Sätze:

Die Individuen ron sechs unter meiner Kontrolle gezeugten Würfen meiner Hauskatze sind blutsverwandt. Alle Individuen dieser Generationen besitzen Tausende gemeinsamer Eigenschaften, von welchen ich wegen der Einfachheit nur eine herausgreife. Alle

1) Vergl. O. Lorenz, Lehrbuch der Genealogie. Berlin 1898. 
besitzen je sechs Schneidezähne, je vier Eckzähne und je vierzehn Backenzïhne von ganz charakteristischer Form.

Die beiden Sïtze bilden Erfahrungen des Lebens, welche gesondert erworben werden und durch die Regelmäßigkeit der Beobachtung absolut sicher erscheinen. Ich kann nun die Umständlichkeit der Ausdrucksweise abkürzen durch die Fassung: Alle blutsverwandten Katzen besitzen sechs Schneidezähne etc.

Fiur tausend andere 'Tierarten ist die gleiche Erfahrung gesammelt. Es wäre allzı umständlich, einem Schüler die einschlägigen Erfahrungsthatsachen aus dem ganzen Tierreiche in so umständlicher Weise vorzuführen und z. B. zu lehren: Alle blutsverwandten Geier tragen scharfspitzige Krallen an den Fusszehen, alle blutsverwandten Rehe sind mit einem Geweih geschmückt. Wir kiirzen die sprachliche Mitteilung wieder ab durch deu Satz: Alle blutsverwandten Tiere besitzen gemeinsame anatomische Eigenschaften und gewinnen den Vorteil, unzählige auf Beobachtung gegrïndete Erfahrungsthatsachen durch sieben Worte auszusprechen. Ich kann dem Satze eine andere stilistische Fassung geben und die Definition bilden: Blutsrerwandt sind solche Tiere, welche gemeinsame anatomische Eigenschaften besitzen. Die Definition läßt sich nochmals stilistisch umformen: Wenn mehrere Tiere gemeinsame anatomische Eigenschaften besitzen, so mïssen sie blutsverwandt sein.

Mit der syntaktichen Umbidung beginnen die Missverständnisse. Wer diese Sätze von seinem Lehrer lernt, ohne späterhin iiber die historische Entstehung derselben nachzudenken, vergisst, dass sie streng genommen sich mur auf die wirklich beobachteten Fälle beziehen und keine Geltung für die nicht geprïften Spezialfälle beanspruchen. Dehnt er trotzdem ihre Gültigkeit auf noch unbekannte Erscheinungen ans, so verlässt er das sicher begründete empirische Gebiet und arbeitet mit einer bloßen Vermutung, mit einer uns allen gewiss sehr einleuchtenden Verallgemeinerung eines beschränkten Erfahrungssatzes.

So gerne wir auch in unserer Gedankenarbeit den Schritt vom Bekannten ins Unbekannte machen, dem niichternen Empiriker muß er so lange unbegründet und geringwertig gelten, bis seine thatsïchliche Wahrheit am Objekte selbst erwiesen ist. Weit entferut davon, eine sichere Gewähr zu bieten, legt der Schritt dem Naturforscher die Pflicht einer nenen Untersuchung anf. Nachdem er bei den Lungentischen und Amphibien einige gemeinsame Eigenschaften entdeckt hat, kann er das spezielle Beispiel in den allgemeinen Satz der Blutsverwandtschaft einfügen (wobei er die geringe Zahl der übereinstimmenden Merkmale der Lungenfische und Amphibien als nebensächlich und nicht gegen den Sinn des Satzes 
rerstoßend beurteilen muß, und in theoretischer Generalisation denken, die Arten beider systematischer Gruppen seien in der That blutsverwandt. Diese begriffliche Subsumption hat aber die Frage nicht gelöst, sie hat bloß eine nene Frage aufgeworfen, die jetzt durch direkte Beobachtung zum Entscheid zu bringen ist. Denu die bisherigen logischen Operationen haben nur die sprachli che Möglichkeit erwiesen, den Begriff blutsverwandt auf systematisch verwandte Tiergruppen anzuwenden, während der Naturforscher sich nicht mit dem Nachweis einiger, oftmals mit Blutsverwandtschaft gepaarter, anatomischer $\ddot{A} h n l i c h k e i t e n$ begnügen, sondern alle intimen Merkmale und sämtliche Phasen des blutbindenden Zeugungsprozesses durch sinnliche Beobachtung feststellen soll. Die griindliche Forschung unterscheidet sich ja gerade dadurch vom Raisonnement der Alltagsmenschen, dass sie in die Tiefe dringt und das breite Fundament für viele generalisierende Schlussfolgerungen schafft, welche ein kluger Kopf ohne gelehrten Apparat in einer Minute zieht.

Wie Sie durch die rorhergehende Analyse spezieller phylogenetischer Fragen gelernt haben, kann aber in den meisten Fällen, welche die Descendenzschule kurzweg durch logische, nach dem obigen Schema vollzogene Operationen gelöst erklärt, das Problem der Stammesrerwandtschaft mittels einer exakten Untersuchung gar nicht angepackt werden, weil niemand dem Zengungsrorgange früher verstorbener Tiergeschlechter beigewohnt hat. Obwohl die Darwinistisch gesinnten Jïnger der exakten Biologie sich durch das unrerbrüchliche Vertrauen auf die rationalistische Denkweise lange Jahrzehnte ïber die eben erläuterten Schwierigkeiten hinweggesetzt haben, glaube ich nicht, dass ihre Selbsttäuschung noch lange währen wird. Denn es gelingt stets nur für eine geraume

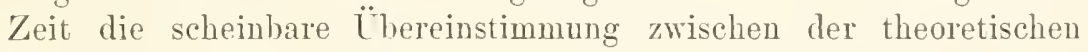
Kombination der abstrakten Begriffe und den Thatsachen aufrecht zu erhalten. Einmal revoltiert der mißhandelte Verstand gegen die falschen logischen Fesseln und erzwingt die Korrektur unhaltbarer Vorstellungen nach den unabänderlichen Thatsachen.

Wenn ich die rielen Irrtiimer der naturwissenschaftlichen Rationalistik bisher schonungslos aufdeckte, wollte ich ihr nicht jeglichen Wert absprechen, und noch weniger Sie verfiihren, dieselbe gänzlich zu rerabschieden. Abgesehen daron, dass mein Vorschlag niemals ausgefiihrt würde, glaube ich in meiner Darstellung gebïhrend betont zu haben, welche starke Neigung zum rationalistischen Denkeu allen Menschen ohne Unterschied inne wohnt. Operationen mit logischen Begriffen und unbedingtes Vertranen auf deren Resultate leben im reflektierenden Verstande als absolut notwendige 
Erscheinungen und können vom exakten Untersucher ebenso wenig als rom Philosophen entbehrt werdes. Lch wollte nur gegen eine allzu hohe Wertschätzung der rationalistischen Produkte protestieren. Wrie eine Cigarre nicht nährt, sondern dem Raucher einen angenehmen Anreiz bereitet, so regt das aus den jeweiligen Erfahrungssätzen auf die unbekannten Fälle generalisierende Denken neue Untersuchungen an, um zu priifen, ob das Resultat der begrifflichen Arbeit wirklich mit den noch nicht genau studierten Thatsachen iibereinstimmt.

Meine schroffe Ablehnung der Descendenztheorie ist also nicht Ausfluss der Abneigung gegen Hypothesen iiberhaupt. Wer auf wissenschaftlichem Gebiete thätig ist, hat ihren Wert so stark empfunden, dass er sie nicht verwerfen will. Ich opponiere blok gegen die jetzt allgemein rerbreitete Überschätzung ihrer Bedeutung. Eine ansehnliche Zahl der Gelehrten betrachtet sie als höchste Bliite der Wissenschaft, während ich sie als ein großes, wenn anch notwendiges $\ddot{U}$ bel erachte, das jeder in seinem Denken dulden muß, um Anregung zu neuen Arbeiten, oder wie man treffend sagt, um neue Ideen zu produzieren. Als mumgängliche Hilfsmittel der Forschung gehören sie in die Arbeitsstube des Gelehrten oder in die allerengste Fachdiskussion wissenschaftlicher Abhandlungen, nicht auf den Marktplatz des Lebens. Der nüchterne Forscher muß ferner verhüten, dass nicht die Hypothesen in seinem Denken iibermäßige Gewalt erlangen und ihm die objektive Prüfung theoretischer Kombinationen iiberfliissig erscheinen lassen, wie es den Anhängern der Descendenzlehre zum eigenen Schaden geschah. Denn im Gegensatz zum Laien und zum doktrinären Theoretiker, welch beide der logischen Methode zu viel vertrauen, soll der Naturforscher die Hypothese als ansgezeichnetes Hilfsmittel neben der sinnlichen Erfahrung gebranchen, welche unter allen Umständen höher steht und ihm den kritischen Maßstab fïr die Theorie liefert. Nach ihrer Aufstellung unterliegen die Hypothesen der Prüfung und werden achtlos bei Seite geworfen in dem Momente, da die sichere Beobachtung gemacht ist. Der Vorgang vollzieht sich täglich unter unseren Augen ohne viel Aufhebens; denn jede nene Entdeckung lehrt uns, was man frïher ungereimt gedacht hat. Nur wird nach Feststellung des wahren Verhältnisses aus menschlicher Eitelkeit nicht viel von dem frïheren theoretischen Irrtum geredet.

Die Descendenzhypothese wird das gleiche Schicksal erfahren, da sich ihre Unvereinbarkeit mit der einfachen Beobachtung deutlich zeigt. Zur Zeit ihres neuen Auftretens vor vierzig Jahren hat sie eine fördernde Wirkung auf den wissenschaftlichen Fortschritt geübt und eine große Zahl fähiger Köpfe angeregt, sich mit anatomischen, 
paläontologischen und entwickelungsgeschichtlichen Aufgaben zu beschäftigen. Aber unterdessen ist die Hypothese im Tergleich zu den mächtig anwachsenden, thatsächlichen Stoft' alt geworden und die Heißige Arbeit ihrer Anhänger zeigt dem niichternen Kritiker, dass es \%eit ist, lieselbe ad acta zu legen.

Am Schlusse unserer Betrachtungen werden Sie geriugere Befriedigung empfinden, als Sie am Anfange vielleicht erwartet hatten. Wir begannen unsere Arbeit mit einer scheinbar ganz einfachen Frage und enden mit einer ungeheuren Summe ron Problemen. Sie hahen es erlebt. wie die Fragen sich mehrten. je genauer wir die Untersuchung eindringen ließen. Mit der Zunahme unserer thatsächlichen Kenntnisse verlor die allgemeine Idee der tierischen Stammesgeschichte an Gewissheit. Endlich treiben wir nicht bloß auf einem Oceane von unbeantworteten Fragen, sondern haben zugleich das Licht verloren. Der Steuermann des Schiffes kann wohl seine Kenntnisse aufbieten und seine bei klarem Wetter zurerlässigen Instrumente herbeibolen, un den Kampf mit der Nebelmauer aufzunehmen; ob er aber Erfolg haben wird, ist zweifelhaft. Er kann uur seinem Empfinden, seinem auf unsichere Beobachtungen. Erwägungen. Voraussetzungen gegriindeten Urteile folgen und muss abwarten, ob ihn das Geschick in die rechte Straße oder auf Sand und Krlippen treiben wird.

Das ist der Zustand der modernen Zoolngie, nachdem sie an die Lösung der größten menschlichen Rätselfrage ging: woher stammen die Geschlechter der Tiere? Alle technischen Arbeitsmethoden, bis aufs äußerste angespannt. haben keine dufklärung gebracht. Was die Zukunft schenken wird, entzieht sich heute unserem Ermessen.

Viele ron Ihnen werden mir zürnen, dass ich kein anderes Resultat dargeboten habe. Dagegen ist zu bemerken, dass ich nur schildern kann, wie der moderne Stand der Zoologie beschaffen ist, wie die Licht- und Schattenseiten verteilt sind. Die momentane Lage der Wissenschaft kann ich weder ändern noch heeinflussen. Sie ist das Ergebnis einer anderthalb Jahrhunderte währenden Entwickelung der geistigen Arbeit und hat uns mit historischer Notwendigkeit die Grenzen der Forschung besser aufgezeigt, als unseren Vätern und Großvätern. Sie zwingt die Epigonen, bescheidenere Hoffnungen zu hegen.

Der Zusammenbruch aller descendenztheoretischen Beweisrersuche ist auch nicht geeignet, eine neue Hypothese an die Stelle der überlebten Fiktion zu setzen. Hätte ich das bealsichtigt, so 
würde ich nur statt eines haltlosen Phantasiegebäudes eiu anderes, ebenso haltloses Phantom haben aufrichten können, weil es sich um die Beantwortung einer Frage handelt, welche nach meiner Meinung jenseits des naturwissenschaftlichen Arbeitsgebietes liegt.

Wie ich mich durch diese Auffassung von vielen meiner nächsten Fachkollegen prinzipiell scheide, so dissentiere ich von ihnen in einem anderen Punkte, indem ich es als Gebot dringendster Notwendigkeit eracbte, den unbefriedigenden Zustand unserer Erkenntnis und die Schranken derselben öffentlich zu bekennen. Denn nach meiner Meinung haben diejenigen vollauf Unrecht, welche sagen, das Geständnis unserer Unwissenheit an der Wende des neunzehnten Jahrhunderts müsse den Wert der Wissenschaft und uns selbst in den Augen der Welt herabsetzen. Nur die Hochmütigen und Beschränkten sehen das Eingeständnis der uns mangelnden Allwissenheit als Bloßstellung an; der ernstlich vorwärts strebende Mann aber bedarf dieser Selbstkritik, um den Schwierigkeiten klaren Auges gegenüberzutreten und wirkliche Fortschritte zu machen.

Deshalb hielt ich es für meine Pflicht, Sie auf die geheimen Schwächen des Entwickelungsgedankens hinzuweisen, welche es verbieten, der Abstammungslehre beizupflichten; denn Sie treten bald in die Reihen der Nitarbeiter zur Aufsuchung der Wahrheit als wahre Kommilitonen ein. Ihnen wird es vielleicht beschieden sein, die Grenzen unseres Wissens da und dort ein kleines Stück weiter vorzuschieben. Sie werden gute Früichte ernten, wenn Sie aufrichtig und streng kritisch zu Werke geheu.

Über das bescheidene Resultat aller menschlichen Arbeit mag uns der Gedanke trösten, welchen Goethe kaum ein Jahr vor seinem Tode gegen Eckermann aussprach:

"Es geht doch nichts über die Freude, die uns das Studium der Natur gewährt. Ihre Geheimnisse sind von einer unergründlichen Tiefe; aber es ist uns Menschen erlaubt und gegeben, immer weitere Blicke hineinzuthun. Und gerade, dass sie am Ende doch unergründlich bleibt, hat für uns einen ewigen Reiz, immer wieder heranzugehen und immer wieder neue Einblicke und neue Entdeckungen zu versuchen." 





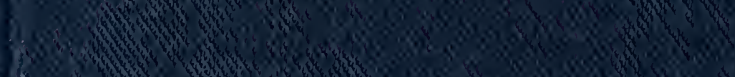

fommm mam

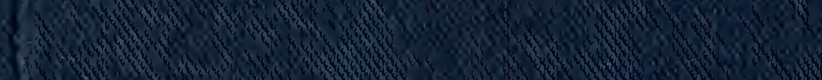

3.m.m. mh

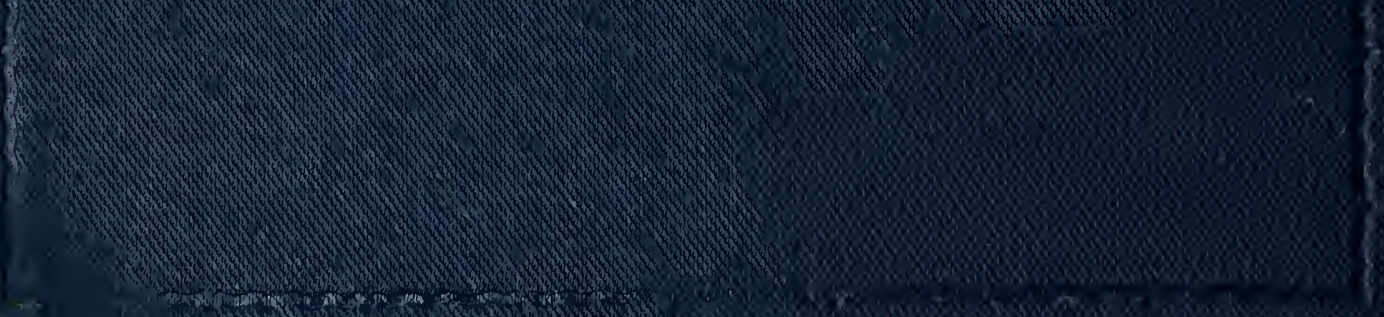

